University of Louisville

ThinkIR: The University of Louisville's Institutional Repository

Electronic Theses and Dissertations

$5-2017$

\title{
Urban governance reconsidered : assessing the roles of public-, private-, and third sector leaders in governing the modern city.
}

Benjamin Colby Leamon

University of Louisville

Follow this and additional works at: https://ir.library.louisville.edu/etd

Part of the Urban Studies Commons

\section{Recommended Citation}

Leamon, Benjamin Colby, "Urban governance reconsidered : assessing the roles of public-, private-, and third sector leaders in governing the modern city." (2017). Electronic Theses and Dissertations. Paper 2724.

https://doi.org/10.18297/etd/2724

This Doctoral Dissertation is brought to you for free and open access by ThinkIR: The University of Louisville's Institutional Repository. It has been accepted for inclusion in Electronic Theses and Dissertations by an authorized administrator of ThinkIR: The University of Louisville's Institutional Repository. This title appears here courtesy of the author, who has retained all other copyrights. For more information, please contact thinkir@louisville.edu. 


\title{
URBAN GOVERNANCE RECONSIDERED: ASSESSING THE ROLES OF PUBLIC-, PRIVATE-, AND THIRD SECTOR LEADERS IN GOVERNING THE MODERN CITY
}

\author{
By \\ Benjamin Colby Leamon \\ B.A., The University of Texas at Dallas, 2010 \\ M.S.S.W., The University of Louisville, 2012

\begin{abstract}
A Dissertation
Submitted to the Faculty of the

For the Degree of

Doctor of Philosophy

In Urban and Public Affairs

Department of Urban and Public Affairs

University of Louisville

Louisville, Kentucky
\end{abstract} \\ College of Arts and Sciences of the University of Louisville \\ In Partial Fulfillment of the Requirements
}

May 2017 

URBAN GOVERNANCE RECONSIDERED:

ASSESSING THE ROLES OF PUBLIC-, PRIVATE-, AND THIRD SECTOR LEADERS IN GOVERNING THE MODERN CITY

\author{
By
}

Benjamin Colby Leamon

B.A., The University of Texas at Dallas, 2010

M.S.S.W., The University of Louisville, 2012

A Dissertation Approved on

April 4th, 2017

by the following Dissertation Committee:

David L. Imbroscio, Committee Chair

D. Mark Austin

David M. Simpson

Rodger A. Payne 


\title{
DEDICATION
}

This dissertation is dedicated to the late

\author{
Jary Herrington
}

and

\section{Charles “Stasch" Wilkerson II}

who pushed me to take risks, aim high, and hammer away until I reached my goals. 


\section{ACKNOWLEDGEMENTS}

I would like to acknowledge my committee chair, Dr. David Imbroscio, for his patience and advice. I would also like to thank the other committee members, Dr. Mark Austin, Dr. David Simpson, and Dr. Rodger Payne, for their comments and encouragement along the way, and Dr. Timothy Weaver for his comments and advice on early drafts. I would also like to express thanks to Richard and Cheryl Gray for their advice and support, especially during the data collection phase of this dissertation. Also, many thanks to Ellen Johnston, for her comments on early drafts, and her endless support in this process. Further, I would like to thank my friends and family in Dallas, Texas: Mark Leamon, Lucas and Eric Gray, Tim and Sarah Carr, Julian Hernandez, and John Taylor. Finally, I would like to thank my friends and colleagues in Louisville, Kentucky: Charles Wilkerson III, Sam Rothgerber, Dan Sargent, Jeff Kendrick, Chad Frederick, Ian Mason, Yani Vozos, Patty Sarley, Juli Wagner, Stuart Neff, Kathy Meyer, Julie Onnembo, George Howe, and the entire Quills Coffee team, for keeping me caffeinated for the entirety of this journey. 


\title{
ABSTRACT \\ URBAN GOVERNANCE RECONSIDERED: ASSESSING THE ROLES OF PUBLIC-, PRIVATE-, AND THIRD SECTOR LEADERS IN GOVERNING THE MODERN CITY
}

\author{
Benjamin C. Leamon
}

May 13th, 2017

As central cities redefine themselves after decades of commercial abandonment, "urban renaissance" movements, white flight, and the gentrification of their central urban neighborhoods, are cities still governed by the political-business coalitions conceptualized by urban regime theorists, or have new players emerged? Further, as cities continue to evolve within the post-Fordist landscape, do extant theories of urban governance, themselves built upon decades-old observations, continue to provide adequate models for urban governance as it actually exists in cities today? This dissertation is a quantitative and qualitative examination of contemporary urban governance in the United States, and the roles of CDCs and anchor institutions in urban decision-making structures. Chapter One begins with a description of Dallas, Texas, and two of its central urban neighborhoods - Downtown Dallas, the city's CBD that is currently undergoing a conversion to mixed-use development; and North Oak Cliff, a former streetcar suburb that has suffered from a half-century of political and economic neglect, but has recently seen its fortunes dramatically improve. Chapter Two retells the interconnected histories of theories of urban governance, the socioeconomic impacts of Fordism, its crisis, and post-Fordism, and the evolution of Dallas from a regional industrial hub to a major commercial center, while highlighting a number of 
reasons why current conceptualizations of urban governance may no longer fit with actual urban governance. Chapter Three details this study's methods - first, the use of census data from 1980 to 2010, and second, a reputational analysis of 79 participants who showed themselves to be highly knowledgeable about Dallas' contemporary decision-making structure. Chapters Four, Five, and Six detail this study's key findings - first, that modern urban decision-making occurs within multiple interconnected levels (neighborhood and city); second, that the structure of urban decision-making is still critical in understanding the nature of which decisions get made (and which do not), as well as the range of responses for a given situation; third, that Dallas' third-sector organizations (e.g. CDCs and anchor institutions) have been largely unable to meaningfully involve themselves in the politics of decision-making; and finally, that under the right blend of economic- and political pressures, structures of urban governance can change from one type to another. In the Dallas case, the decline of its business coalition, and the court-ordered breakup of its at-large city council resulted in a new structure of governance, or better put, a non-structure, wherein multiple competing agendas and resource pools have taken over the larger political discourse, and have largely prevented a unified vision for Dallas from emerging. 


\section{TABLE OF CONTENTS}

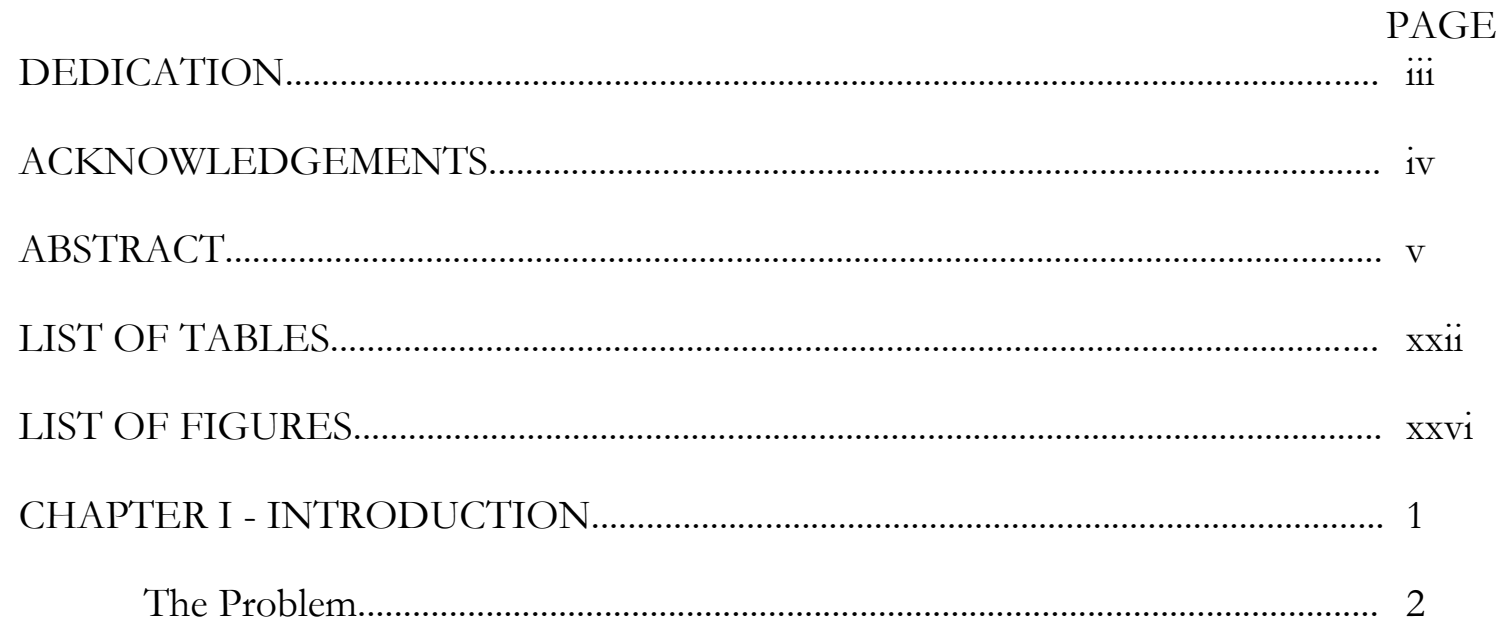

Post-Fordism and Cities after Urban Political Economy........................ 3

CDCs and Anchor Institutions as Unlikely, Emerging Partners in Urban Governance.................................................................................... 4

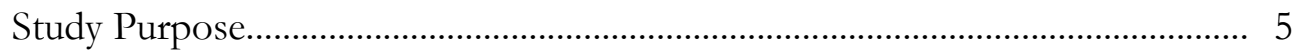

Why Dallas, and Why These Two Neighborhoods................................ 6

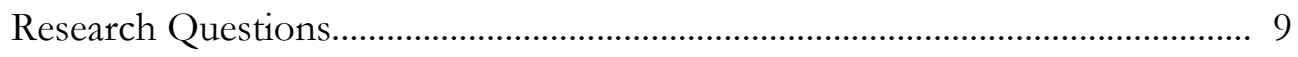

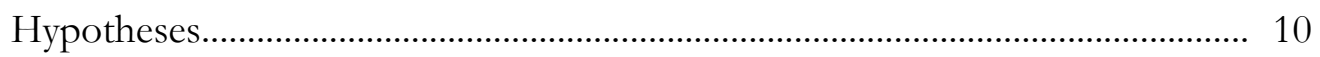

Hypothesis 1 ...................................................................................... 10

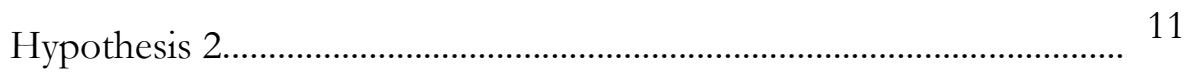

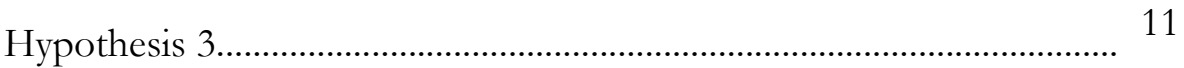

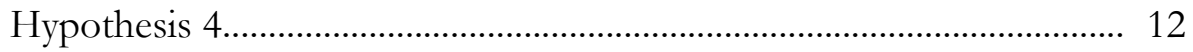

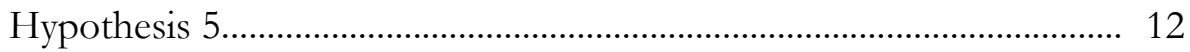

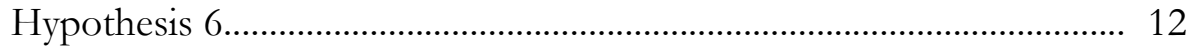




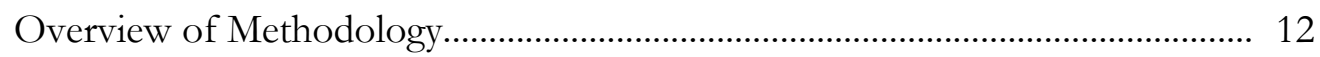

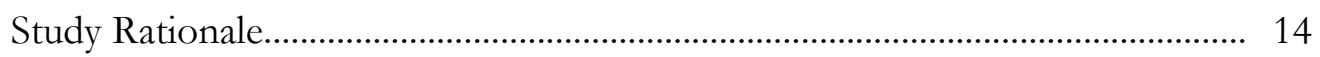

Organization of this Dissertation....................................................................... 16

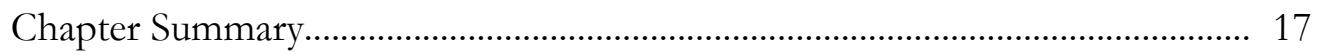

CHAPTER II - REVIEW OF EXTANT LITERATURE........................................... 18

Fordism, Community Power, and the Thometz Study of Dallas...................... 20

Fordism and Central Cities in the United States.................................... 20

Community Power: Urban Theory under Fordism................................ 21

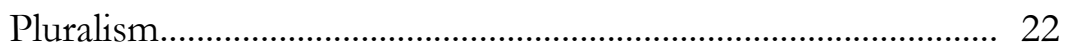

Elite Theory..................................................................... 23

Community Power, in Summary .............................................. 24

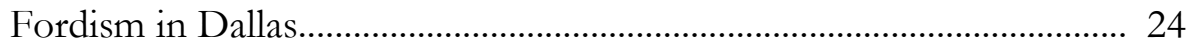

The Thometz Study: Urban Theory under Fordism in Dallas..................................................................................... 26

Fordism, Community Power, and the Thometz Study of Dallas, in Summary.............................................................................................. 27

The Fordist Crisis, Urban Political Economy, and the Elkin Study of Dallas.

The Fordist Crisis and Central Cities in the United States..................... 29

Urban Political Economy: Urban Theory under the Fordist Crisis....... 32

Growth Machine Theory.............................................................. 34

Critiques of Growth Machine Theory............................ 36

Urban Regime Analysis.............................................................. 37

Critiques of Urban Regime Analysis............................... 40

Urban Political Economy, in Summary..................................... 41 
The Fordist Crisis in Dallas.

The Elkin Study: Urban Theory Under the Fordist Crisis in Dallas.

The Fordist Crisis, Urban Political Economy, and the Elkin Study, in Summary.

Post-Fordism, Urban Political Economy, and the Need to Revisit

Dallas.

Post-Fordism and Central Cities in the United States.

Post-Fordist Economic Transitions. 50

Post-Fordist Demographic Transitions...................................... 51

Transitions in the Roles of CDCs and Anchor Institutions.... 53

CDCs: Moving Beyond Low-Income Housing............. 54

Anchor Institutions: Urban Development Without the Federal Bulldozer.

Transitions in the Roles of CDCs and Anchor Institutions, in Summary.....

Post-Fordism in Dallas..................................................................... 58

Economic Transitions.............................................................. 59

Political Transitions................................................................... 62

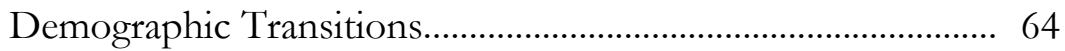

North Oak Cliff.............................................................. 65

Downtown Dallas.............................................................. 66

Post-Fordism, Urban Political Economy, and the Need to Revisit Dallas, in Summary................................................................................. 67

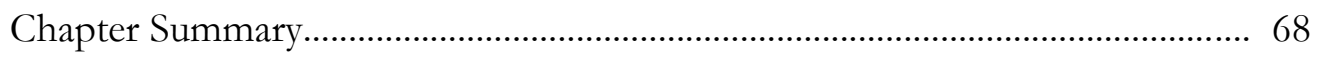

CHAPTER III - SETTING AND METHODOLOGY ................................................ 70

Research Questions and Hypotheses, Revisited................................................. 71 
Research Questions Revisited............................................................... 71

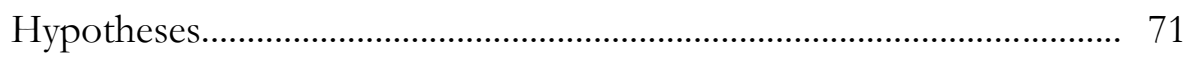

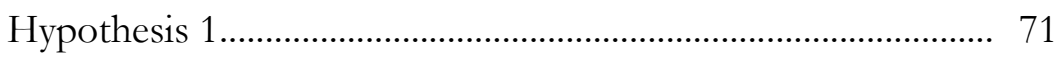

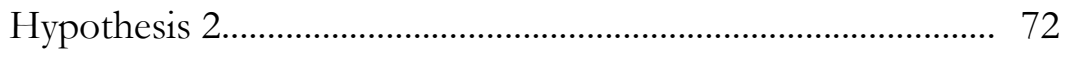

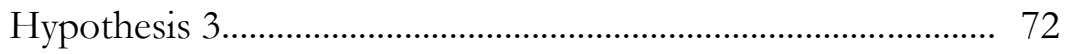

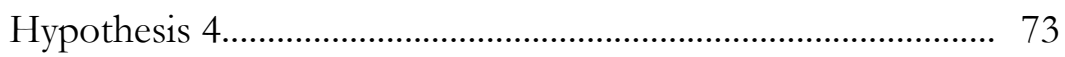

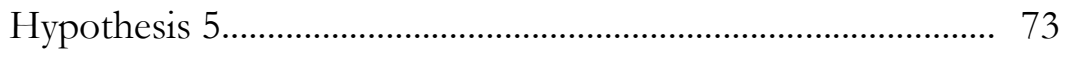

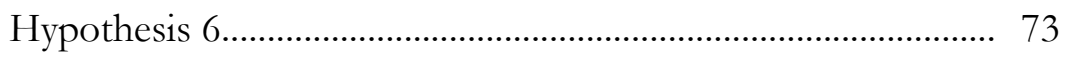

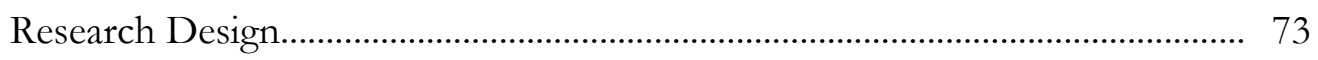

The Case Method........................................................................................ 74

Case Studies, Broadly............................................................ 74

Dallas as a Crucial Case........................................................... 76

A Note on Comparative Urban Research..................... 77

On the Appropriateness of the Case Method............................. 78

Network Analysis and the Reputational Method.................................. 78

Network Analysis....................................................................... 79

Reputational Method..................................................................... 79

Assumptions, Criticisms, and Methodological Challenges................................................................... 81

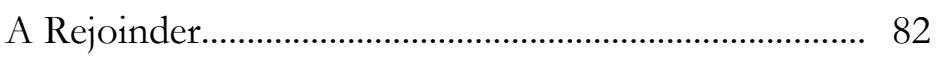

On the Appropriateness of the Reputational

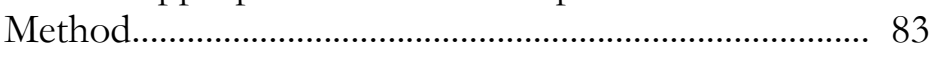

Secondary-Source Data Analysis............................................................ 84

On the Use and Appropriateness of Secondary-Source Data

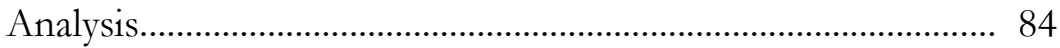


Concerns with using Secondary-Source Data................ 85

In Defense of Secondary-Source Analysis.................... 85

Study Focus Areas: Dallas and Two Central Urban Neighborhoods... 86

The City of Dallas, Texas............................................................... 86

North Oak Cliff....................................................................... 87

Downtown Dallas..................................................................... 88

Study Focus Areas, in Summary............................................... 89

Setting and Context of Data Collection............................................................ 90

Research Sample and Data Sources................................................................ 91

Quantitative Data Sources..................................................................... 91

Data Collected at Each Year......................................................... 91

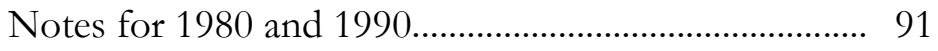

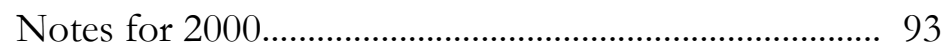

Notes for 2010 ................................................................. 93

Qualitative Data Sources......................................................................... 94

Target Population........................................................................ 94

Survey Sample........................................................................ 94

Identifying Public- and Private-Sector Participants..... 95

Identifying Third Sector Participants............................. 95

Supplementing Participant Lists..................................... 96

Initial Participant Pool and Final Participant Tally..................... 97

A Note on Participant Demographics........................... 97

A Note on Snowball Sampling and Diminishing

Returns............................................................................. 98

Ethical Considerations and IRB Statement........................................................ 98 


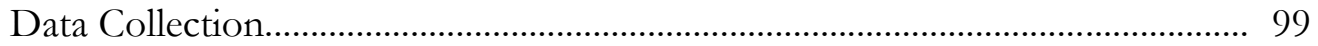

Quantitative Data Collection..................................................................... 99

Qualitative Data Collection........................................................................... 100

Survey Outline .................................................................... 100

Interview Outline..................................................................... 102

Data Processing and Analysis........................................................................... 103

Quantitative Data Processing and Analysis........................................... 103

Phase 1: Comparing Geographies over Time............................. 104

Phase 2: Comparing Data to Literature-Based

Expectations.......................................................................... 104

Qualitative Data Processing and Analysis................................................. 105

Phase 1: Establishing a Typology of Decision-Makers.............. 105

Phase 2: Conceptualizing Structures of Decision-Making......... 106

Assessing Internal and External Validity............................................................... 107

Assessing Internal Validity.............................................................. 108

Assessing External Validity....................................................................... 108

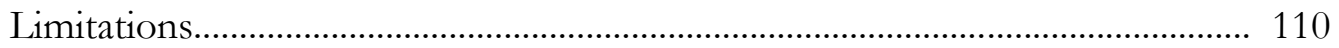

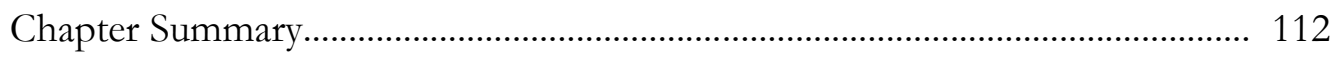

CHAPTER IV - PRESENTATION OF DATA.......................................................... 113

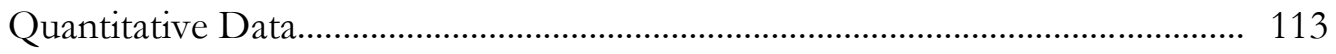

Dallas as a Whole...................................................................................... 114

Citywide Demographic Changes, 1980 to 2010......................... 114

Citywide Population......................................................... 114

Citywide Race and Hispanic or Latino Status................ 114

Citywide Economic Changes, 1980 to 2010.............................. 115 
Citywide Labor Force

Citywide Employment by Industry Cluster..................... 116

Citywide Median Household Income and Poverty....... 117

North Oak Cliff.

Neighborhood Demographic Changes, 1980 to 2010

Neighborhood Population.

Neighborhood Race and Hispanic or Latino Status..... 119

Neighborhood Economic Changes, 1980 to 2010..................... 120

Neighborhood Labor Force.

Neighborhood Employment by Industry Cluster....

Neighborhood Median Household Income and Poverty.

Downtown Dallas.

Neighborhood Demographic Changes, 1980 to 2010

Neighborhood Population.

Neighborhood Race and Hispanic or Latino Status..... 122

Neighborhood Economic Changes, 1980 to 2010....... 123

Neighborhood Labor Force.

Neighborhood Employment by Industry Cluster.

Neighborhood Median Household Income and Poverty.....

Quantitative Data, in Summary.....

Qualitative Data 126

Categorizing Decision-Makers 126

Formal Authorities 126 
First Tier Influentials

Second Tier Influentials......................................................... 127

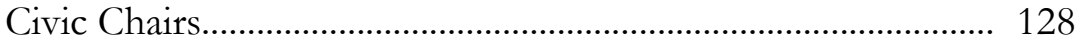

Anchor Captains................................................................. 128

Categorizing Decision-Makers, in Summary.............................. 128

Decision-Makers in Dallas as a Whole................................................... 129

Formal Authorities............................................................... 129

Dallas' City Council........................................................ 130

Dallas’ Mayor................................................................... 131

Appointed City Plan Commissioners............................... 131

Dallas’ City Manager......................................................... 132

Formal Authorities, in Summary..................................... 132

First Tier Influentials.............................................................. 133

Category Standout: John Wiley Price.............................. 134

First Tier Influentials, in Summary................................. 135

Second Tier Influentials................................................ 136

Ex-Formal Authorities..................................... 137

The Developer Class......................................... 138

Category Standout: Mary Suhm...................... 138

Second Tier Influentials, in Summary.............. 139

Civic Chairs...................................................................................... 139

Regional Civic Chairs.................................................... 140

Category Standout: Alice Murray................................... 141

Civic Chairs, in Summary............................................... 142 
Anchor Captains.

Category Standout: Gerald Turner.................................. 144

Anchor Captains, in Summary ........................................ 145

Decision-Makers in Dallas as a Whole, in Summary.................. 145

Decision-Makers in North Oak Cliff........................................................ 145

Formal Authorities.......................................................................... 146

City Staff and Political Appointees................................. 147

Category Standout: Councilmember Scott Griggs........ 149

Formal Authorities, in Summary .................................... 150

First Tier Influentials.............................................................. 150

Local Rentiers................................................................. 151

Category Standout: Jim Lake, Jr...................................... 152

First Tier Influentials, in Summary ................................. 152

Second Tier Influentials......................................................... 153

The Developer Class........................................................... 154

Category Standout: David Spence.................................. 155

Second Tier Influentials, in Summary............................ 155

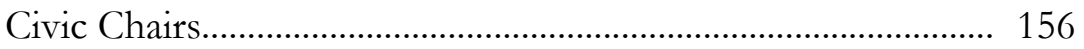

Category Standout: Pam Conley..................................... 157

Category Standout: Lisa Benskin.................................... 157

Category Standout: Jason Roberts.................................... 158

Civic Chairs, in Summary ................................................ 159

Anchor Captains............................................................................ 159

Anchor Captains, in Summary......................................... 161 


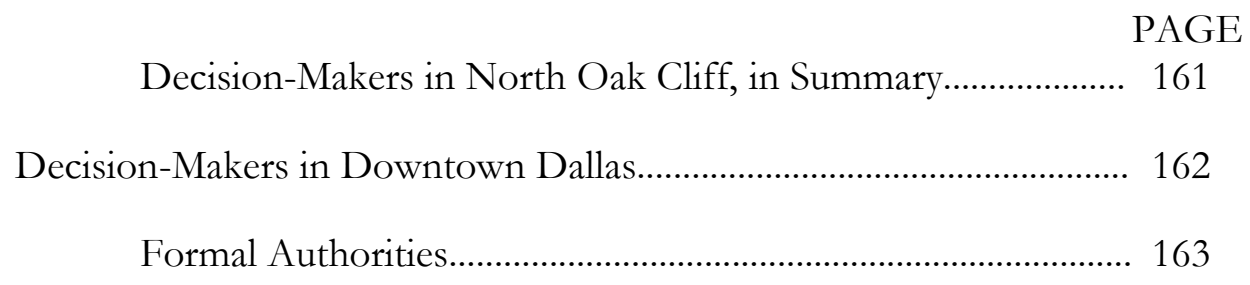

City Staff and Political Appointees................................. 163

Category Standout: Councilmember Philip Kingston.. 165

Formal Authorities, in Summary .................................. 166

First Tier Influentials............................................................. 167

The Old Guard................................................................... 168

Category Standout: Ray Hunt.......................................... 169

First Tier Influentials, in Summary................................. 169

Second Tier Influentials............................................................. 170

Category Standout: John Scovell.................................... 172

Second Tier Influentials, in Summary............................ 173

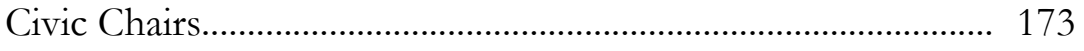

Civic Chairs, in Summary................................................ 176

Decision-Makers in Downtown Dallas, in Summary................. 176

Qualitative Data Summary................................................................ 177

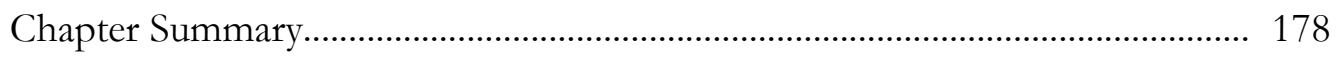

CHAPTER V - QUANTITATIVE ANALYSIS AND DISCUSSION........................ 179

First Research Question and Context Hypotheses Revisited............................. 179

First Research Question Revisited.......................................................... 179

Context Hypotheses Revisited............................................................. 180

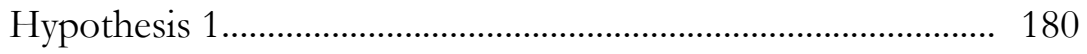

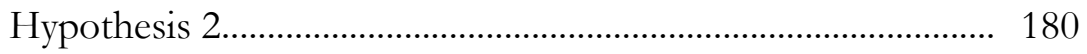


Evaluation of Hypotheses............................................................................. 181

Evaluation of Hypothesis 1..................................................................... 181

Evaluation of the Assumption of Dallas as an EconomicallyProsperous City ............................................................................. 182

Evaluation of Dallas as "Less White"........................................ 185

Evaluation of Dallas' Workforce as less Blue Collar and more Creative Class............................................................................. 187

Evaluation of Dallas as More Economically Polarized.............. 190

Evaluation of Hypothesis 2.................................................................. 192

Evaluation of North Oak Cliff as "More White"....................... 192

Evaluation of North Oak Cliff's Workforce as less Blue Collar and more Creative Class.............................................................. 194

Evaluation of North Oak Cliff as More Economically Polarized............................................................................... 195

Evaluation of Hypothesis 3................................................................ 198

Evaluation of Downtown Dallas as "More White"................... 198

Evaluation of Downtown Dallas' Workforce as less Blue Collar and more Creative Class....................................................... 200

Evaluation of Downtown Dallas as More Economically Polarized...................................................................................... 202

Discussion of Context Hypotheses...................................................................... 205

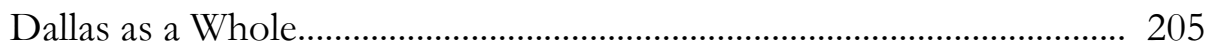

North Oak Cliff.................................................................................... 207

Downtown Dallas............................................................................. 209

The New Normal of Dallas Today vs. the Old Normals of Thometz 211 and Elkin..... 
Limitations, Revisited and Expanded............................................................ 213

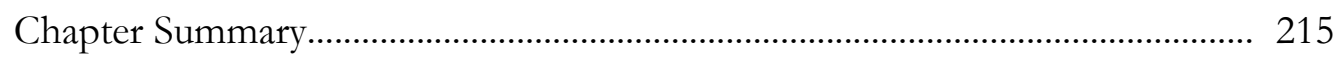

CHAPTER VI - QUALITATIVE ANALYSIS AND DISCUSSION.......................... 216

Second Research Question and Coalition Hypotheses Revisited........................ 216

Second and Third Research Questions Revisited................................... 216

Coalition Hypotheses Revisited............................................................ 217

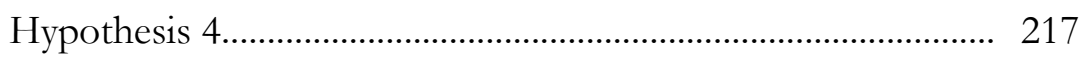

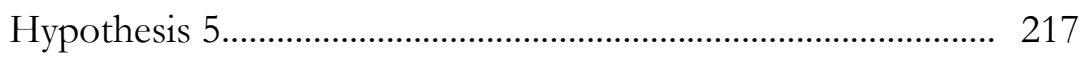

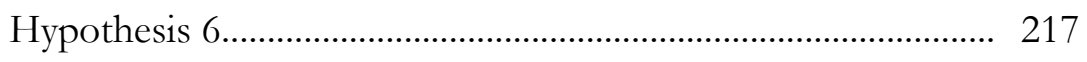

Evaluation of Coalition Hypotheses............................................................... 217

Evaluation of Hypothesis 4................................................................. 218

Citywide Decision-Makers............................................................... 218

Contemporary Distribution of Citywide Decision-Making

Power.................................................................................... 219

Dallas' Citywide Decision-Making Structure, Broadly.......................................................................... 223

Key Leaders, Past and Present........................................ 227

Top Level Leaders, Past and Present.............................. 230

Second Echelon Leaders, Past and Present.................. 231

Decision-Making Power and Nominations to Decision-

Making

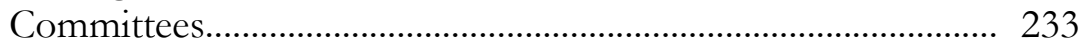

Familiarity and Shared Committee Service.................................. 236

Evaluation of Hypothesis 5..................................................................... 238 
Contemporary Distribution of Neighborhood Decision-

Making

Power...

North Oak Cliffs Decision-Making Structure, Broadly.....

Key Leaders and Top Level, Past and

Present.

Second Echelon Leaders, Past and Present.

Decision-Making Power and Nominations to Decision-

Familiarity and Shared Committee Service. 256

Evaluation of Hypothesis 6. 257

Downtown Dallas' Decision-Makers. 258

Contemporary Distribution of Neighborhood DecisionMaking

Power.

Downtown Dallas’ Decision-Making Structure, Broadly 262

Key Leaders and Top Level, Past and Present 263

Second Echelon Leaders, Past and Present. 267

Decision-Making Power and Nominations to DecisionMaking Committees

Familiarity and Shared Committee Service

Discussion of Coalition Hypotheses 272

Dallas as a Whole. 273

Analysis Methods Used. 273 
CDC and Anchor Institution Involvement in Decision-

Making......

The Structure and Nature of Decision-Making in Dallas as a

Whole 275

North Oak Cliff. 276

Analysis Methods Used............................................................. 276

CDC and Anchor Institution Involvement in DecisionMaking.... 276

The Structure and Nature of Decision-Making in North Oak Cliff. 277

Downtown Dallas 278

Analysis Methods Used. 279

CDC and Anchor Institution Involvement in DecisionMaking.

The Structure and Nature of Decision-Making in Downtown Dallas.

Equitable Economic Development in the Commercial Republic

Equitable Economic Development in a Subset of Other

Cities....

Equitable Economic Development, the Dallas Way 289

David Spence 290

Jason Roberts 291

Good Spaces and Better Blocks in Building a Local Economy

North Oak Cliff: Philadelphia and Cleveland Writ Small.

Dallas' Contemporary Governing Coalition. 295

Dallas' Decision-Making Structure as a Nonregime..... 300 
Discussion of Coalition Hypotheses, in Summary................................. 304

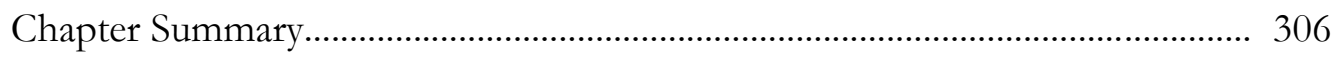

CHAPTER VII - CONCLUSIONS, LIMITATIONS RE-REVISITED, AND

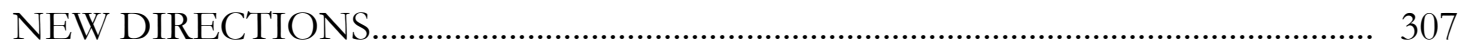

The Present Study in Review....................................................................... 308

Summary of Findings............................................................................. 310

Finding 1: the Interconnected Nature of Real-World Urban

Decision-

Making.

Finding 2: Structure still Matters in Urban Decision-Making.

Finding 3: CDCs and Anchor Institutions Have a Long Way Left to Go.

Finding 4: Under the Right Pressures, Governing Coalitions Can Transition

A Vision of Future Governance in the Commercial Republic............................. 316

Limitations, Re-Revisited and Expanded........................................................... 321

Recommendations for Future Research......................................................... 324

Chapter Summary....................................................................................... 326

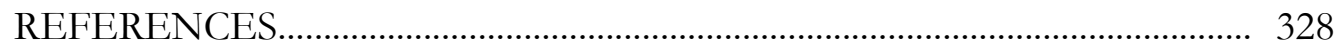

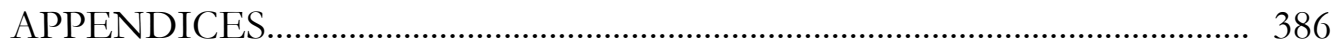

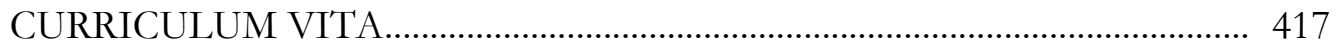




\section{LIST OF TABLES}

TABLE

PAGE

2.01 Community Power Keyword Search Results............................................... 33

2.02 Urban Political Economy Keyword Search Results..................................... 34

2.03 Typology of Governing Coalitions................................................................ 38

4.01 Citywide Population, 1980 - 2010 ............................................................. 114

4.02 Citywide Labor Force Size and Unemployment Rate, 1980 - 2010......... 116

4.03 Citywide MHI and Poverty Rate, 1980 - 2010........................................... 117

4.04 North Oak Cliff Population, 1980 - 2010................................................... 118

4.05 North Oak Cliff Labor Force Size and Unemployment Rate, 1980 2010 .

4.06 North Oak Cliff MHI and Poverty Rate, 1980 - 2010.............................. 121

4.07 Downtown Dallas Population, 1980 - 2010 ……………………................ 122

4.08 Downtown Dallas Workforce Size and Unemployment Rate, 1980 2010

4.09 Downtown Dallas MHI and Poverty Rate, 1980 - 2010........................... 125

4.10 Citywide Formal Authorities........................................................................... 130

4.11 Citywide First Tier Influentials........................................................................... 133

4.12 Citywide Second Tier Influentials................................................................... 137

$4.13 \quad$ Citywide Civic Chairs...................................................................................... 140

$4.14 \quad$ Citywide Anchor Captains................................................................................ 143

4.15 North Oak Cliff Formal Authorities............................................................. 146

4.16 North Oak Cliff First Tier Influentials........................................................... 150

4.17 North Oak Cliff Second Tier Influentials...................................................... 153 
4.18 North Oak Cliff Civic Chairs..................................................................... 156

4.19 North Oak Cliff Anchor Captains...................................................................... 159

4.20 Downtown Dallas Formal Authorities........................................................... 163

4.21 Downtown Dallas First Tier Influentials.................................................... 167

4.22 Downtown Dallas Second Tier Influentials................................................ 170

4.23 Downtown Dallas Civic Chairs...................................................................... 173

5.01 Citywide Population and Unemployment Rates, 1980 - 2010.................. 183

5.02 Citywide Population and Racial and Hispanic or Latino Status, 1980 -

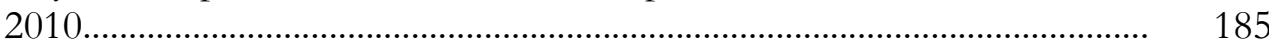

5.03 Race and Hispanic or Latino Status for Dallas and Surrounding MSA Counties, 2010.

5.04 Citywide Employment Percentages by Industry Cluster............................. 188

5.05 Citywide MHI and Poverty Rate, 1980 - 2010........................................... 190

5.06 North Oak Cliff Population and Racial and Hispanic or Latino Status, $1980-2010$

5.07 North Oak Cliff Population and Racial and Hispanic or Latino Status,

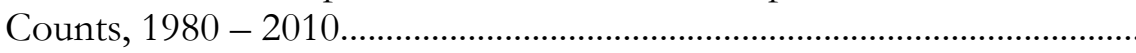

5.08 Citywide and North Oak Cliff Employment Percentages by Industry Cluster.

5.09 North Oak Cliff MHI and Poverty rate, 1980 - 2010............................... 195

5.10 Downtown Dallas Population and Racial and Hispanic or Latino Status, Percentages, $1980-2010$..

5.11 Downtown Dallas Population and Racial and Hispanic or Latino Status, Counts, $1980-2010$

5.12 Citywide and Downtown Dallas Employment Percentages by Industry Cluster.

5.13 Downtown Dallas MHI and Poverty Rate, 1980 - 2010........................... 202 
6.02 Power Ratings of Citywide Decision-Makers.............................................. 221

6.03 Citywide Decision-Maker Levels of Power.................................................. 222

6.04 Dallas City Council Divisions With Respect to Citywide Development......

6.05 Comparison between Citywide Decision-Making Committee Nominations and Decision-Maker Power Score.

6.06 Decision-Makers Selected to Serve on a Citywide Decision-Making Committee by Tier..

6.07 Citywide Decision-Maker Mean Familiarity Score by Tier.

6.08 Citywide Decision-Maker Mean Shared Board or Committee Service by Tier......

6.09 North Oak Cliff Decision-Makers

6.10 Power Ratings of North Oak Cliff Decision-Makers.

6.11 North Oak Cliff Decision-Maker Levels of Power

6.12 North Oak Cliff Participant-Identified Pro-Development Agenda Supporters.

6.13 North Oak Cliff Participant-Identified Progressive Development Agenda Supporters.

6.14 North Oak Cliff Participant-Identified Anti-Development Agenda Supporters

6.15 Comparison between North Oak Cliff Decision-Making Committee Nominations and Decision-Maker Power Score.

6.16 Decision-Makers Selected to Serve on a North Oak Cliff DecisionMaking Committee by Tier.

6.17 North Oak Cliff Mean Familiarity Score by Category and Tier................ 256

6.18 North Oak Cliff Mean Shared Committee Service by Tier........................ 257

6.19 Downtown Dallas Decision-Makers.......................................................... 258 
6.21 Downtown Dallas Decision-Maker Levels of Power.................................. 261

6.22 Downtown Dallas Participant-Identified Pro-Development Agenda Supporters.

6.23 Downtown Dallas Participant-Identified Progressive Development Agenda Supporters

6.24 Comparison between Downtown Dallas Decision-Making Committee Nominations and Decision-Maker Power Score.

6.25 Decision-Makers Selected to Serve on a Downtown Dallas DecisionMaking Committee by Tier..

6.26 Downtown Dallas Decision-Maker Mean Familiarity Score by Tier.......

6.27 Downtown Dallas Decision-Maker Mean Shared Committee Service by Tier 


\section{LIST OF FIGURES}

FIGURE PAGE

$2.01 \quad$ Chocolate Cities, Vanilla Suburbs Model......................... 53

$2.02 \quad$ New Donut Model.......................................... 53

3.01 Map of North Oak Cliff.................................. 88

$3.02 \quad$ Map of Downtown Dallas.................................... 89

4.01 Citywide Race and Hispanic or Latino Status, 1980 - 2010........... 115

4.02 Citywide Employment by Industry Cluster, 1980 - 2010.............. 117

4.03 North Oak Cliff Race and Hispanic or Latino Status, 1980 - 2010.... 119

4.04 North Oak Cliff Employment by Industry Cluster, 2000............ 121

4.05 North Oak Cliff Employment by Industry Cluster, 2010........... 121

4.06 Downtown Dallas Race and Hispanic or Latino Status, 1980 - 2010... 123

4.07 Downtown Dallas Employment by Industry Cluster, 2000........... 124

4.08 Downtown Dallas Employment by Industry Cluster, 2010.......... 124

6.01 The Structure of Citywide Decision-Making Power................ 233

6.02 The Structure of North Oak Cliff Decision-Making Power.......... 242

6.03 The Structure of Downtown Dallas Decision-Making Power......... 262

6.04 The Interconnected Decision-Making Structures of Dallas, North

Oak Cliff, and Downtown Dallas................................................................ 299 


\section{CHAPTER I}

\section{INTRODUCTION}

With respect to post-Fordist cities in the United States, who governs today? As central cities redefine themselves after decades of commercial abandonment, "urban renaissance" movements, white flight, and the gentrification of their central urban neighborhoods, are cities still governed by the political-business coalitions conceptualized by urban regime theorists, or have new players emerged?

Questioning long-standing conceptualizations of urban governance is not a new idea. As the $20^{\text {th }}$ century waned, urban scholars looked at the turbulence of the 1960 s, the construction (and subsequent dismantling) of the Great Society, the end of the Fordist crisis, and the rise of (some) cities within a truly global marketplace, and charged that the pressure politics of the community power paradigm could no longer conceptualize urban governance as it had become ${ }^{1}$. At the end of the $20^{\text {th }}$ century, urban theorists used observations of central U.S. cities to recast models of urban governance, first by painting cities as growth machines ${ }^{2}$, and later, by using a more generalized model of urban regimes and coalition governance ${ }^{3}$. Forty years after the start of this new, political economy paradigm, many cities look nothing like they did when growth machine theory and urban regime analysis were first conceptualized, so contemporary observations of central cities may, once again, yield new insight into their decision-making structures.

${ }^{1}$ DeLeon, 1992a, pp. 559-560; Harding, 2009, p. 34; MacLeod, 2011, p. 2630; Mossberger, 2009, p. 41; Peterson, 1981, pp. 27-29; Savitch \& Thomas, 1991. 238-239; Schragger, 2009, pp. 502-504

${ }^{2}$ Molotch, 1976; Logan \& Molotch, 2007

${ }^{3}$ Elkin, 1987a; Stone, 1989 
In the chapter sections that follow, this study will introduce the problem that it seeks to address within current conceptualizations of urban governance, resulting from changes within the demographic- and economic contexts of central cities, as well as the growing role of third sector organizations - specifically community development corporations (CDCs) and anchor institutions (i.e. urban universities and hospitals) - in urban policymaking and economic development projects. Then, it will set down a series of research questions and hypotheses for testing. Following this, it will outline methods that were used to test those hypotheses, through a mixed-methods analysis of Dallas, Texas. Next, it will offer a brief, logical argument to justify the study itself, as well as the significance of studying Dallas as a crucial case. Finally, it will present a brief roadmap for the remainder of the study.

\section{The Problem}

As noted above, in the decades since scholars first examined cities using the urban political economy perspective, cities in the United States have undergone another series of changes. First, while white flight allowed (some) residents to abandon central cities, a smaller, counter-migration of wealthier, highly educated whites moved back into gentrifying urban neighborhoods, at the cost of displacing people of color and people with lower incomes. Additionally, corporate disinvestment over that same period left many central cities all-but abandoned, and a subset of these are transitioning into mixed-use hubs of capital accumulation, culture, and entertainment ${ }^{4}$. At the same time, CDCs and anchor institutions expanded into urban economic development projects and urban policymaking - roles previously assumed by actors in governing coalitions. This integration has recently received some limited attention and speculation by academics ${ }^{5}$, but an in-depth examination of

${ }^{4}$ Judd \& Fainstein, 1999, pp. 261-272; Strom, 2008; Turner, 2002

${ }_{5}^{5}$ cf. Birch, Perry, \& Taylor, 2013; Democracy Collaborative, 2014; Harkavy et al., 2009; Kettl, 2000; Zuckerman et al., 2013 
whether this is actually occurring in cities, and what that involvement may portend, is largely absent in current scholarship.

This study proposes to, once again, revisit the nature of big city politics. In the following paragraphs, this study will first elaborate briefly on relevant post-Fordist contextual shifts in U.S. cities. Then, it will discuss the growing presence of CDCs and anchor institutions in roles once occupied by members of urban governing coalitions. Finally, it will argue that the confluence of these factors justifies further exploration, which the remainder of this study will attempt to undertake.

\section{Post-Fordism and Cities after Urban Political Economy}

Post-Fordism marked an (uneven) transition of the U.S. economy from its regional blue collar roots to a globalized, integrated economy built largely on globalized white-collar firms in finance, investment, and real estate (FIRE) sectors, supported by localized producer services $^{6}$. Although cities of the 1970s, 1980s, and early 1990s focused on attracting and retaining corporate capital, urban cores today focus on providing a host of amenities inter alia pedestrian-friendly streets, access to cultural amenities and entertainment, and unique housing options that are unavailable in the suburbs ${ }^{7}$. As urban cores shift from centers of capital production to centers of cultural consumption, the new values and preferences expressed by the voters, small business owners, and prominent organizations are fragmenting- and reducing the overall dominance of old guard economic elites on the governing coalitions ${ }^{8}$. Additionally, the firms that remain are connected to global capital

\footnotetext{
${ }^{6}$ T. Clark et al., 2002, p. 494; Giarratani \& Houston, 1989, pp. 549-552; Harkavy et al., 2009, p. 148; Harvey, 1989, pp. 179-184; Jessop, 1993, p. 68; Judd \& Simpson, 2003, pp. 1058-1059; Kantor et al., 2012, pp. 28-29; Savitch, 1988, pp. 19-21; Wolch \& Geiger, 1986 , p. 3 ${ }^{7}$ Clerval, 2006, pp. 6-7; Eisinger, 2000, pp. 316-317; Saito \& Truong, 2015, p. 268; Strom, 2008, pp. 37-38; Sumka, 2010, pp. 326-327

${ }^{8}$ T. Clark et al., 2002, pp. 493-497; Strom, 2008, pp. 37-38
} 
streams, and often show little (if any) interest in the politics of governing any particular place $^{9}$, leaving room for new actors to emerge.

An additional effect of this revitalization of urban cores can be seen in the racial composition of central urban neighborhoods. A traditional understanding of race and the urban/suburban divide suggests that, following decades of white flight, contemporary central cities urban cores are predominantly populated by people who identify as nonwhite, and often of low- and moderate incomes. Meanwhile, the suburbs and exurbs encircling these cities are often white, and comparatively more affluent ${ }^{10}$. This chocolate cities, vanilla suburbs model fails to adequately conceptualize the gentrification of urban cores, in which affluent whites migrate back into majority-minority central urban neighborhoods ${ }^{11}$, displacing both minority residents, and the businesses that serve them. These individuals and businesses often move into the inner-ring communities that were once populated by the first waves of white flight, creating a nonwhite ring of communities sandwiched between whitepopulated central urban neighborhoods and white-populated suburbs. The model that takes into account this new racial makeup of central cities is called the new donut ${ }^{2}$, and will be detailed in Chapter 2.

\section{CDCs and Anchor Institutions as Unlikely, Emerging Partners in Urban Governance}

While some scholars suggest that these new actors represent specialized

administrative units ${ }^{13}$, spatially-linked coalitions ${ }^{14}$, and regional governing bodies ${ }^{15}$, this study instead forwards that CDCs and anchor institutions, which are traditionally considered "ancillary" actors in governing coalitions, may have expanded to fill the power gap left

\footnotetext{
${ }^{9}$ MacLeod, 2011, pp. 2629-2630; Swyngedouw, 2011, p. 3

${ }^{10}$ Beauregard, 2010, pp. 11-23; Juday, 2015, pp. 3-4

${ }^{11}$ Florida, 2003, pp. 8-10; 2006, pp. 26-29

${ }^{12}$ Juday, 2015, pp. 3-4

${ }_{13}$ J. Smith, 2010, pp. 429-430

14 Pugalis \& Townsend, 2013 , p. 54

${ }^{15}$ Harrison \& Hoyler, 2013, pp. 2254-2256
} 
behind by hollowed-out public sector offices and fading business elites, potentially replacing value-neutral development with more equitable alternatives ${ }^{16}$. CDCs and anchor institutions have greatly expanded their roles within cities since the 1980s, attempting to fulfill their stated missions of service to their communities, and limited scholarly examination of these roles suggests that these organizations may be taking on greater roles in the politics of decision-making, and within governing coalitions ${ }^{17}$.

Looking first at CDCs, these nonprofit organizations have been charged with directing federal support into urban neighborhoods since the Great Society ${ }^{18}$, and have traditionally focused on providing low-income housing and administration of social welfare programs in economically-marginalized neighborhoods ${ }^{19}$. Since the 1980 s, many of these organizations have expanded into business enterprise development, commercial real estate, venture capitalism, community finance, and urban redevelopment ${ }^{20}$. Anchor institutions, for their part, have recently evolved into major economic engines in cities across the United States $^{21}$. Because they are geographically locked "anchored" in place, these institutions are principally self-interested in the local economy, and some have begun leveraging their status as major employers and purchasers in order to engage in more equitable economic development and investment in economically-marginalized neighborhoods ${ }^{22}$.

\section{Study Purpose}

Although CDCs and anchor institutions hold the potential to advance beyond "ancillary" status in the urban governing coalition, there is debate as to whether this occurs

\footnotetext{
${ }^{16}$ Robinson, 1996, pp. 1647, 1657-1659

17 T. Clark et al., 2002, pp. 495-496; De Socio, 2007, p. 340; Harkavy et al., 2009, p. 148

${ }^{18}$ Vidal \& D. Keating, 2004, pp. 126-127; Zdenek, 1987, pp. 112-114; Zielenbach, 2000, pp. 230-231

${ }^{19}$ Kettl, 2000, pp. 493-494; Vidal, 1992, pp. 61-62; Vidal \& D. Keating, 2004, pp. 132-134; Yin, 1998, pp. 139-143; Zdenek, 1987, pp. 115126

${ }^{20}$ Bruyn, 1987, pp. 5-6; Frisch \& Servon, 2006, pp. 90-91; Imbroscio, 1998, p. 239; Milward \& Provan, 2000, pp. 259-360; Romzek,

LeRoux, \& Blackmar, 2012, p. 442; Vidal, 1992, pp. 70-73; Yin, 1998, pp. 143-154; Zielenbach, 2000, pp. 231-234

21 Adams, 2003, p. 572; T. T. Ross, 2014, p. 2

22 Dubb \& Howard, 2012, pp. 4-9; Dubb, McKinley, \& Howard, 2013, pp. 1-2; Frisch \& Servon, 2006, pp. 89-91; Harkavy et al., 2009, pp. 148-149; T. T. Ross, 2014, pp. 10-14
} 
in actuality. While some CDCs have succeeded in creating social linkages with public- and private-sector actors, and can enmesh themselves within the decision-making process, research is somewhat inconclusive regarding whether they have actually done so in any meaningful way ${ }^{23}$. In addition, although urban hospitals and universities are significant drivers of urban economies, they are not often leveraged as policymaking assets because they are seen primarily as service providers, and some doubt the actual impact of their involvement in economic development projects ${ }^{24}$. If these organizations can be shown to play a significant role in policymaking, then it would suggest that current urban theory needs to be expanded, so that it can adequately describe this new, three-way (public-, private-, and third-sector) sharing of power.

The purpose of this exploratory study, then, is twofold: first, to evaluate the evolving urban context surrounding a contemporary governing coalition; and second, to evaluate the structure- and nature of decision-making in contemporary governing coalitions, especially with respect to the role of anchor institutions and CDCs, and the effects of those roles on economic development and social- and economic equity. In service of this purpose, this study will analyze the city of Dallas, Texas, a large, economically-thriving city in North Texas, as well as two of Dallas' central urban neighborhoods: North Oak Cliff and Downtown Dallas.

\section{Why Dallas, and Why These Two Neighborhoods?}

Previous studies of Dallas have identified myriad reasons why this city is particularly desirable for research into decision-making structures. Among these are Dallas' location far enough from major coastlines to avoid the particular cultural influences of those

\footnotetext{
23 J. Clark, 1992, pp. 153-154; Eisinger, 2000, pp. 328-331; Frisch \& Servon, 2006, pp. 96-97; Logan, Whaley, \& Crowder, 1997, pp. 607608; Najam, 2000, pp. 3-4; Robinson, 1996, p. 1648; Vidal \& D. Keating, 2004, pp. 126-127; Walcott, 1999, pp. 657-659; J. Yin, 1998, pp. $138-139$

${ }^{24}$ Adams, 2003, p. 579; Dubb \& Howard, 2012, pp. 14-15
} 
population groups, its (broadly) consistent pattern of growth and economic development, its diverse economy, and its self-contributing cultural life that creates (rather than imports) much of its art and music scene $e^{25}$. Further, the dynamics of the city's leadership as an entrepreneurial governing coalition are particularly salient; therefore, a study of Dallas provides a relatively straightforward setting for the study of these connections ${ }^{26}$. Building on this, Dallas' decision-making structure has, for decades, typified the developmental or entrepreneurial governing coalition, and so findings from this study may be generalized, at least in part, to other cities with similar decision-making structures - hardly a challenge, given that this type of governing coalition has long been considered the de facto arrangement of urban governance structures ${ }^{27}$. Further, as a large, economically-vibrant city in the United States, Dallas is an archetypical post-Fordist success story ${ }^{28}$, and so some subset of the results from this study may be generalizable to other, similar cities.

As this study of Dallas builds on two previous explorations of the city's leadership the first by Carol Estes Thometz, and the second by Stephen Elkin - it is important to (briefly) discuss the settings and contexts of each. Looking first at the Dallas featured in the 1963 Thometz study, the city could be characterized as being in a period of explosive growth and modernization. A tightly-knit business community largely commanded both long-term planning and day-to-day city operations, leading to significant public investment into private development, bolstered by cheap access to domestic- and international capital for real estate development projects ${ }^{29}$. Supported by both the public sector and the private, legendary developers demolished much of the city's urban core, replacing fine examples of art deco

\footnotetext{
25 Thometz, 1963, p. 7

${ }^{26}$ Elkin, 1987a, pp. 61-62

${ }^{27}$ De Socio, 2007, p. 349; Imbroscio, 2010, pp. 28-31; Kantor, Savitch, \& Haddock, 1997, pp. 353-368; M. Keating, 1991, p. 189; C. Stone, 1989, pp. 183-188; C. Stone, Orr, \& Imbroscio, 1991, pp. 229-236

${ }^{28}$ Dallas County Community College District, 2014, pp. 2-3; Editorial: New South Dallas, 2013; Graff, 2008, p. 46; Halkais, 2014; Schutze, 2014

${ }^{29}$ Grant, 1996, pp. 19-20, 21; Rice, 2007, p. 77; Sobel, 1989, p. 209
} 
construction with the high-rise office buildings that define a large percentage of Dallas' contemporary skyline ${ }^{30}$. Within this context, the Thometz study utilized participant interviews to uncover a three-tiered hierarchy among Dallas' leaders, in which senior businessmen operated at the highest echelons of decision-making, while younger, lessexperienced protégés worked on smaller projects, proving their worth through service, and advancing their careers alongside their roles as decision-makers ${ }^{31}$.

Roughly two decades later, the Dallas studied by Elkin (1987) had reached the peak of its boom times, but this growth came at a cost. At the time of the study, Dallas' business community was no longer as unified as it once was, owing first to fragmentation over how (or whether) to redevelop the city's limited remaining land ${ }^{32}$, and second, to the decline of locally-anchored businesses in favor of national- and international corporations whose executives had little (if any) particular interest in Dallas itself ${ }^{33}$. In addition, a court-mandated overhaul of Dallas' elections, in which its all-powerful city council went from at-large elections to a hybrid district-based / at-large system, had crippled the ability of the city's business community to control elections. Within this context, Elkin found that, although Dallas' business community continued to form alliances with political leaders, this politicalbusiness regime was no longer the pure entrepreneurial governing coalition that it was during the Thometz study ${ }^{34}$.

Returning to the present study, Dallas' history of development is a story of amnesiaby-design, wherein the city's powerful private-sector elites, ever-mindful of creating the image of the Dallas they wanted to see, paved over deep racial- and class divisions, and each

\footnotetext{
${ }^{30}$ D CEO, 2014; Graff, 2008, pp. 220-221; P. Hill, 1996, pp. 160-169; Rice, 2007, pp. 220-221

${ }^{31}$ Elkin, 1987b, pp. 35-36; Thometz, 1963, pp. 23-25, 48-49

${ }^{32}$ Elkin, 1987b, pp. 35-36

33 1987a, pp. $72-73$; 1987b, pp. 42-43

34 1987a, pp. $71-81$
} 
new project seems to further cement an enduring pattern of inequity ${ }^{35}$. Like in other postFordist cities, Dallas' pattern of development has not been even, and many of the city's historically low-income and majority-minority neighborhoods are not faring as well as the wealthier, whiter areas, excepting in cases of gentrification.

On the most positive end of Dallas' development spectrum is the neighborhood of Downtown Dallas; as the city's CBD, Downtown Dallas is the traditional hub of citywide economic activity, and it is also the home of several of Dallas' most identifiable landmarks, in addition to a dramatic transformation from being an abandoned corporate capital accumulator to becoming a vibrant, mixed-use urban hub. In contrast stands the neighborhood of North Oak Cliff, a neighborhood that, in the wake of white flight throughout the mid- $20^{\text {th }}$ century, has been occupied by people with low incomes and people of color. Like Downtown Dallas, North Oak Cliff has entered a period of revitalization, but unlike Downtown, much of this development has come at the cost of displacing long-time commercial- and residential occupants. So far, the displacement has been minimal, but residents (many of whom are renters or tenants, rather than owners) express concerns over ever-growing plans to redevelop ever-expanding tracts of land. By expanding its focus beyond the city level, and into these two neighborhoods, this study hopes to understand whether, or to what extent, neighborhood decision-making, and the actors who get involved, differ from decision-making and decision-makers at the citywide level.

\section{Research Questions}

Through its study of Dallas, this study aims to answer three primary research questions. First, how have the city's demographics and economy evolved in the decades since the city was studied by previous urban scholars? Second, to what extent (if any) are

\footnotetext{
${ }^{35}$ Phillips, 2006, pp. 3-5
} 
CDCs and anchor institutions active participants in Dallas' governing coalition? Finally, if these organizations are active participants in Dallas' governing coalition, what is the effect of that involvement on urban development and policymaking?

\section{Hypotheses}

To guide its attempts at addressing these questions, this study forwards six primary hypotheses. The first three of these hypotheses relate to the changing socioeconomic context of Dallas as a whole, as well as the neighborhoods of North Oak Cliff and Downtown Dallas, with regard to literature-based expectations of the demographic- and economic fortunes of central cities and their innermost urban neighborhoods. The second three of these hypotheses address the nature of governance in these same three geographies, and the effects of "who governs" on the decisions made in contemporary cities and neighborhoods. These hypotheses are as-follows:

\section{Hypothesis 1}

Consistent with expectations of modern, economically-prosperous cities in the globalized, post-Fordist paradigm and the chocolate cities, vanilla suburbs model, in the decades since the Elkin \& Thometz studies, Dallas' citywide socioeconomic context has changed in four primary ways:

- People identifying as "white alone" represent a smaller percentage of the population in 2010 (the most recent decennial census) than they did 1980 (the census immediately prior to the Elkin study).

- A smaller percentage of Dallas' workforce is employed in blue collar fields in 2010 than in 1980.

- A larger percentage of Dallas' workforce is employed in creative class fields in 2010 than in 1980.

- Dallas, as a whole, shows signs of greater economic polarization in 2010 than in 1980. 


\section{Hypothesis 2}

Consistent with expectations of literature surrounding gentrification of urban neighborhoods and the new donut model, within North Oak Cliff, recent urban redevelopment projects and neighborhood gentrification are associated with four primary changes in the neighborhood's respective socioeconomic context:

- People identifying as "white alone" represent a larger percentage of the neighborhood's population in 2010 than they did in 1980.

- A smaller percentage of the neighborhood's workforce is employed in blue collar fields in 2010 than in 1980.

- A larger percentage of the neighborhood's workforce is employed in creative class fields in 2010 than in 1980.

- The neighborhood shows signs of greater economic polarization in 2010 than in 1980.

\section{Hypothesis 3}

Consistent with expectations of literature surrounding gentrification of urban neighborhoods and the new donut model, within Downtown Dallas, recent urban redevelopment projects and neighborhood gentrification are associated with four primary changes in the neighborhood's respective socioeconomic context:

- People identifying as "white alone" represent a larger percentage of the neighborhood's population in 2010 than they did in 1980.

- A smaller percentage of the neighborhood's workforce is employed in blue collar fields in 2010 than in 1980.

- A larger percentage of the neighborhood's workforce is employed in creative class fields in 2010 than in 1980.

- The neighborhood shows signs of greater economic polarization in 2010 than in 1980. 


\section{Hypothesis 4}

In Dallas as a whole, representatives of anchor institutions and CDCs are primary (rather than ancillary) members of a citywide governing coalition, and this involvement portends a more equitable development paradigm than the value-neutral development seen in cities throughout the mid-late $20^{\text {th }}$ century.

\section{Hypothesis 5}

In North Oak Cliff, representatives of anchor institutions and CDCs in are primary (rather than ancillary) members, of a neighborhood governing coalition, and this involvement portends a more equitable development paradigm than the value-neutral development seen in cities throughout the mid-late $20^{\text {th }}$ century.

\section{Hypothesis 6}

In Downtown Dallas, representatives of anchor institutions and CDCs in are primary (rather than ancillary) members, of a neighborhood governing coalition, and this involvement portends a more equitable development paradigm than the value-neutral development seen in cities throughout the mid-late $20^{\text {th }}$ century.

\section{Overview of Methodology}

In studying the context surrounding contemporary urban governance, the structure of contemporary governing coalitions, and the hypothesized roles of CDCs and anchor institutions within these structures, this study utilizes a case analysis of a single city, as opposed to a more comparative research design. Although the results of case studies are limited by a lack of generalizability, their shortcomings do not preclude their usefulness as a basis for functional analysis of a phenomenon ${ }^{36}$. Further, this study argues for the use of

\footnotetext{
${ }^{36}$ Kennedy, 1979, pp. 670-671
} 
Dallas, Texas as a crucial case, or in other words, a "least-likely" scenario for changes to be found. The benefit of focusing on a least-likely scenario is that, if this study finds a transformation in the role of third-sector organizations in such a city, its results would be a powerful indicator of changes occurring elsewhere.

In considering this study's specific methods, recall that this study contains two components: first, a "context" component, and second, a "coalition" component; to address these, this study combines quantitative and qualitative methods. Looking first at examining changes in the demographic- and economic profiles of Dallas as a whole, North Oak Cliff, and Downtown Dallas, this study utilizes decennial census- and American Community Survey (ACS) records from 1980 to 2010, in order to understand how the city and a subset of its central neighborhoods have changed in the decades since Elkin's (1987) analysis of city governance.

Specifically, for each geography, this study will examine changes in racial makeup, labor force profiles using blue collar and creative class employment, and economic polarization using median household income and poverty rates. For Dallas as a whole, select data will be compared to its surrounding MSA, to compare actual demographic- and economic shifts to what would be expected from the chocolate cities, vanilla suburbs model of lower-income, majority-minority central cities surrounded by wealthier, whiter suburbs. For both North Oak Cliff and Downtown Dallas, data from these neighborhoods and Dallas as a whole will be compared to expectations from literature regarding the gentrification of central urban neighborhoods and the new donut model of affluent, gentrified, white enclaves within majority-minority, lower-income cities.

In addressing its "coalition" component, this study employs a reputational analysis of potentially influential actors in Dallas as a whole, as well as within its two focus 
neighborhoods of North Oak Cliff and Downtown Dallas. A previous reputational study of Dallas described the city's decision-making structure as being stratified into three tiers, with each being comprised almost exclusively of business executives and civic elites ${ }^{37}$. To determine whether (or to what extent) the previous reputational analysis' results remain valid, this study's 79 participants completed detailed surveys and interviews regarding the nature of decision-making in Dallas as a whole. To expand on previous studies of Dallas, participants were further divided into two groups, based on their self-reported area of expertise, and were asked to complete additional surveys and interview questions regarding either North Oak Cliff or Downtown Dallas.

Participant free-response survey items and interview responses were coded, and analyzed to determine whether decision-makers could be categorized into a typology; from this analysis, five typologies emerged, although the specific makeup of each, and the relative proportions of each differed within each geography. Participant survey results were also analyzed for various correlations using a series of Spearman's tests, comparing perceptions of power with participants' willingness to include any given actor on a critical decisionmaking team, as well as to uncover any effects of participant familiarity with particular actors. Additionally, for the city as a whole, and for each neighborhood, Duncan's New Multiple Range Test was used to establish the extent to which power is stratified within citywide- and neighborhood-level decision-making.

\section{Study Rationale}

Through its study of Dallas, this study aims to examine contemporary urban governance as it actually exists, in order to consider whether current conceptualizations of urban governance in theory remain valid, over a quarter-century after their inception.

\footnotetext{
${ }^{37}$ Thometz, 1963, pp. 47-49
} 
Specifically, this study aims to evaluate whether the roles of CDCs and anchor institutions are becoming driving forces in skewing many urban agendas away from value-free development, and toward more equitable models ${ }^{38}$, and further, that this increased involvement may portend a change in these organizations' respective positions within urban governing coalitions ${ }^{39}$.

To assess whether third-sector organizations have taken an impactful role in urban economic development, and whether this role (if it exists) portends the need to expand the governing coalition to include third-sector actors as core members, this study focused on Dallas, Texas. Throughout the city's history, Dallas' leaders have strived to make city policies favorable to businesses and growth, but a legacy of racism has focused this growth into white neighborhoods and Downtown Dallas, at the expense of majority-minority North Oak Cliff and other southern neighborhoods that continue to lag behind, but recently, have begun to gentrify as affluent whites migrate from Dallas' northern suburbs to its central neighborhoods $\mathrm{s}^{40}$.

While necessarily limited due to time and financial constraints, this study of Dallas offers at number of benefits to urban scholarship. First, the size of the city itself lends itself to offering a large participant pool, even when nonresponse is taken into account ${ }^{41}$. In addition, the city is currently engaged in a number of significant redevelopment projects ${ }^{42}$, the study of which may help uncover the presence- and nature of the city's governing coalition. Further, while the city has a long, documented history of pro-development coalition governance, it also shows signs of a growing third-sector involvement in a subset of

${ }^{38}$ Eisinger, 2000, pp. 328-331; Logan, Whaley, \& Crowder, 1997, pp. 607-608; Walcott, 1999, pp. 657-659

${ }^{39}$ Adams, 2014, pp. 9-10, 18-23; Alperovitz, 2011, pp. 100-101; Dubb \& Howard, 2012, pp. 4-9; Vidal, 1992, pp. 69-73

${ }^{40}$ Editorial: New South Dallas, 2013; Graff, 2008, p. 46; Schutze, 2014

${ }^{41}$ Dallas Convention \& Visitors Bureau, 2015

${ }^{42}$ Darling, 2012; Economic Research Associates, 2008; Hyde, 2008; Thompson, 2012 
economic development projects ${ }^{43}$. Finally, Dallas is a somewhat archetypical example of the pro-development governing coalition writ large; even if CDCs and anchor institutions are not found to be central members of its governing coalition, if successful examples of equitable economic development projects are found, either at the citywide level or in this project's two focus neighborhoods, then these could serve as inspiration for similar projects in other development-focused cities around the country.

\section{Organization of this Dissertation}

Over the summer of 2015, this study analyzed hundreds of census records to render an image of the changing demographic- and economic profiles of Dallas as a whole, as well as the neighborhoods of North Oak Cliff and Downtown Dallas. Additionally, its principle investigator conducted 79 surveys and interviews to develop an understanding of the structure and nature of decision-making in these three geographies. In Chapter 2, this study will outline relevant literature to undergird the present study, including changes in the greater urban context that challenge the accuracy of current urban political theory with respect to how it conceptualizes urban politics in practice. In Chapter 3, this study will describe the methods that this study used to understand contemporary urban governance in Dallas citywide, as well as in this study's two focus neighborhoods. In Chapter 4, this study will report data from its quantitative analysis of census and ACS data, as well as data from its qualitative analysis of participant surveys and interviews regarding the nature of contemporary urban governance. Chapters 5 and 6 will analyze these respective types of data with respect to this study's research hypotheses. Finally, in Chapter 7, this study will first summarize its key take-aways, and then it will suggest directions for future research.

\footnotetext{
${ }^{43}$ Appleton, 2013a; 2013b; City of Dallas Department of Sustainable Development and Construction, 2013, pp. 29-32; Economic Research Associates, 2008
} 


\section{Chapter Summary}

The purpose of this chapter is to introduce the reader to the present study, the background that led to its creation, its setting and methods, and its significance and rationale. In the preceding sections, this study introduced the problem of whether anchor institutions and CDCs are central actors in contemporary governing coalitions, and further, whether (or to what extent) that involvement portends more progressive urban policymaking and equitable alterative economic development programs. Next, it established a series of research questions and hypotheses for testing. Then, it outlined the quantitative and qualitative data sources and methods used to test those hypotheses. Following this, it provided a brief discussion of the rationale behind studying governing coalitions in Dallas and two of its central neighborhoods: North Oak Cliff and Downtown Dallas. Finally, it presented a brief roadmap for the chapters that follow. In Chapter 2, this study will expand on a number of these sections, especially those related to contemporary urban theory, the context of contemporary cities in the United States, and the evolving roles of CDCs and anchor institutions. 


\section{CHAPTER II}

\section{REVIEW OF EXTANT LITERATURE}

In writing about Dallas in the early 1960s, urban researcher Carol Estes Thometz noted that, 'in every community there are persons who 'run things,' who make decisions and take action in the citizens' behalf"76. The question, then, is not whether people govern, but "who governs?” Although bureaucrats are certainly a crucial component of governance, observation of urban governance in practice suggests that leaders of other organizations (e.g. churches, universities, labor unions, and chambers of commerce) have various roles to play in urban decision-making, and equally various motivations for playing those roles ${ }^{77}$. Urban political scientists often lack the luxury of truly experimental settings for their research into the "who" and "why" of participation in urban governance; as a result, they must look cities themselves to find answers to these questions.

Systematically observing active, complex urban environments is challenging in its own right, especially considering that cities are perpetually being reshaped by both internaland external social- and economic trends ${ }^{78}$. Thus, answers to the related questions of "who governs" and "to what end" (i.e. theories of urban governance) are anchored within an interlocking series of global-, national-, state-, and local economic- and social context; further, the studies of urban governance guided by those theories are also embedded within these contexts. Therefore, this study contends that as the urban context shifts, new studies

76 1963, p. 1

${ }_{77}^{7}$ Ricci, 1984, p. 4

78 Thomas \& Savitch, 1991, pp. 1-12 
must be conducted, in order to adapt urban governance from a theoretical perspective to urban governance in actuality.

This study aims to retest the tenets of the urban political economy, particularly urban regime analysis, in light of new developments in central cities in the United States, particularly the ongoing demographic- and economic changes resulting from post-Fordism and the globalization of capital flows, as well as the rise of CDCs and anchor institutions in urban policymaking. In retesting the tenets of contemporary urban theory, this study will also look to a city - Dallas, Texas - a city whose decision-making structure has been studied twice before, each under a different paradigm in urban political scholarship's understanding of who governs cities, and during two different economic paradigms - Fordism and early post-Fordism. Before doing this, however, this study will establish the presence of a lacuna within extant literature regarding contemporary urban governance - one that a welldesigned, exploratory study could begin to address.

In the sections that follow, this study will first explore the effects of Fordism on central cities in the United States, and then it will introduce pluralism and elite theory, which are competing theories under the community power perspective. Following this, it will describe Dallas under Fordism, and the 1963 Thometz community power study of the city's decisionmakers. Next, this study will describe the collapse of Fordism with respect to central cities in the United States, as well as the collapse of the community power debates, and the transition to the urban political economy perspective within relevant scholarship, including a discussion of both growth machine theory and urban regime analysis. Then, the present study will introduce the 1987 Elkin study of Dallas' governing coalition, and its findings. Subsequently, this study will introduce post-Fordism as an economic and social transformation, as well as the expansion of CDCs and anchor institutions into urban policymaking, and how these two factors justify 
a reconsideration of what Banfield (1965), and later Savitch and Thomas (1991) described as big city politics.

\section{Fordism, Community Power, and the Thometz Study of Dallas}

By the mid- $20^{\text {th }}$ century, central cities in the United States were transforming under the social- and economic effects of Fordism, with prewar construction being demolished to make way for urban renewal projects, highways, stadiums, and skyscrapers. Within this urban context, dozens (if not hundreds) of observations of central cities were conducted, and these observations led to two competing theories of urban governance: pluralism and elite theory, which are collectively referred to under the umbrella term of community power. In the paragraphs that follow, this study will first examine the greater urban context of postwar central cities in the United States. Then, it will discuss the two theories developed as a result of urban studies conducted within that context, concluding with a brief discussion on their similarities and the key, irreconcilable differences that engendered the community power debates. Next, this study will introduce the Thometz studies decision-making in Dallas, the results of which will be compared against the results of this study in Chapter 5.

\section{Fordism and Central Cities in the United States}

As a socioeconomic paradigm, Fordism can be described as a combined, co-evolving network of factors that, following World War II, defined over a decade of interactions between individuals, social modes of production, and the built environment ${ }^{79}$. At its most basic, Fordism is closely associated with the mass-production of commoditized consumer goods coupled with strong central state involvement in inducing demand for these goods through various national-level policies ${ }^{80}$. Critically for central cities in the United States, in

${ }^{79}$ Harvey, 1989, pp. 121-124; Jessop, 1993, p. 68

${ }^{80}$ Peck \& Tickell, 1994, pp. 289-291; Sabel, 1989, pp. 101-103 
the years following World War II, these policies and consumption patterns convinced a significant number of firms in related industries to co-agglomerate into regional manufacturing hubs, in order to take advantage of economies of scale and a generally reliable workforce $^{81}$. Responding to the centralization of well-paying, stable jobs in central cities, workers began a mass-migration from farms and small towns into the growing manufacturing hubs of cities like Cleveland, Pittsburgh, St. Louis, and Detroit. As a result, central cities across the United States grew at rates never seen before (or, in many cases, since $)^{82}$.

\section{Community Power: Urban Theory under Fordism.}

Following World War II, a new wave of perspectives on urban political science began to emerge. Beginning with Floyd Hunter's 1953 study of Atlanta (which also served as the starting point of the community power debates ${ }^{83}$ ), mid-century urban political scientists used empirical observations of postwar United States cities like New Haven and Atlanta, many of which were booming under the Fordist paradigm, to reject previous iterations of urban theory - notions which restricted (or, in some ways, ignored) the role of agency in communities. For these scholars, power was a property of people, rather than abstractions like the "hidden hand of the market;" thus, many focused instead on the study of power as a social phenomenon, and looked to individuals and groups as the unit of measure for understanding how community decisions are made ${ }^{84}$. In devising alternatives to the purely positivist urban theories of their predecessors, postwar urban scholars reformulated $18^{\text {th }}$ century republican- and populist conceptualizations of governance, and reconciled these

\footnotetext{
${ }^{81}$ Ellison \& Glaeser, 1997, pp. 917, 920-921

${ }^{82}$ Davis, 1965. p. 41; R. Hill, 1986, pp. 83-85

${ }^{83}$ Harding \& Blokland, 2014, pp. 32-33

${ }^{84} 2014$, p. 32
} 
with the political-economic reality of cities in the postwar United States ${ }^{85}$. What resulted from this process were two competing theories of urban governance: pluralism and elite theory.

Pluralism. Looking first at pluralism, this position was championed by scholars like Robert Dahl and Nelson Polsby, who argued that the urban decision-making process is best characterized by competition and compromise among various interest groups. In this model, the wide distribution of power among competing interest groups precludes coercion or dominance by any particular interest, and this dispersion forces groups to compromise and negotiate ${ }^{86}$. As a result, urban policies and projects were designed to ensure that most groups would be reasonably satisfied, at least as long as these groups maintain enough power to pressure the decision-making process ${ }^{87}$. Further, the nature of capitalist development and the democratization of governance actively create new roles for individuals and groups, whose right to equal treatment by public-sector actors frequently demands that the relationships among interests groups change and evolve $e^{88}$.

The end result of the pluralist model is that resource inequality among various stakeholders in the governing coalition ensures that no particular group has all of the resources necessary to govern, and as a result, cannot hold dominance over the entire system $^{89}$. However, as groups amass power and resources, some may seek to perpetuate injustices, increase their control over the decision-making process, or weaken the democratic process overall $^{90}$. It is, therefore, the responsibility of a strong, elected government to balance and regulate all of these competing interests, while respecting some degree of

${ }^{85}$ Joseph, 1981, p. 160; Schumpeter, 1950, pp. 250-268

${ }^{86}$ Frey, 1971, pp. 1081-1082; Tichy, Tushman, \& Fombrun, 1979, p. 511; Wyly, 2014, p. 3

${ }^{87}$ Alford \& Friedland, 1985, p. 157; Dahl, 1961, pp. 95-106, 139-1 1967, p. 24; Domhoff, 1978, pp. 1-2; Gilens \& Page, 2014, pp. 566-567; Kettl, 2000, p. 15; Manley, 1983, pp. 369-370; Wolfinger, 1973, p. 9

${ }^{88}$ Alford \& Friedland, 1985, pp. 156-157; Dahl, 1982, p. 21; Vogel, 1992, p. 108

89 Alford \& Friedland, 1985, p. 157; Dahl, 1961, pp. 95-100

${ }^{90}$ Dahl, 1982, pp. 1, 40-53 
autonomy, and using their counsel to ensure that policies adequately address the wants and needs of the electorate ${ }^{91}$.

Elite Theory. In repudiating the pluralist utopia, elite theorists like Lloyd Warner, Floyd Hunter, C. Wright Mills, and G. William Domhoff argued that, while a vigorously competitive governance structure in which citizens express their preferences through elections and interest groups vie for support of their agendas offers the governed their best opportunity for representation in the decision-making process $^{92}$, in reality, this doesn't happen. Instead, the differential distribution of resources allowed some interests, especially those of business leaders and wealthy elites, to exert dominance over the decision-making process, subverting pluralist pressure politics entirely ${ }^{93}$. In other words, the privileged position of an upper-crust of economic elites ensures a stability in which some elements of that structure are "more equal" than others ${ }^{94}$. From this inequality rises a relatively stable coalition of non-competing policy monopolies that support particular political interests ${ }^{95}$, and an urban governance structure that reflect a particular bias towards the upper class.

The end result of elite theory is that a small, interdependent network of public- and private sector actors are heavily involved in the politics of decision-making. Private sector actors support public goods and services as concessions to the general electorate ${ }^{96}$, and in exchange, economic elites are appointed to various positions of power, such as policyadvisory committees, issue-specific advocacy- and lobby groups, and are called upon to provide expert testimony to influence others in the decision-making process ${ }^{97}$. Further, urban policies and projects are deigned largely to support the agendas of these "power elite,"

${ }^{91}$ Dahl, 1961, pp. 90-94; 1982, pp. 49-52; Joseph, 1981, p. 160; Vogel, 1992, pp. 7-8

${ }^{92}$ Dahl, 1982, pp. 36-37; Schattschneider, 1960, pp. 140-141

${ }^{93}$ Bonjean, 1963, p. 672n3; Tichy, Tushman, \& Fombrun, 1979, p. 511; Wyly, 2014, pp. 2-3

${ }^{94}$ Baumgartner \& Jones, 1993, pp. 14-15; Gilens \& Page, 2014, pp. 565-566; Lindblom, 1977, p. 174

${ }^{95}$ Baumgartner \& Jones, 1993, p. 15

${ }^{96}$ Banfield, 1961, pp. 289-297; Schattschneider, 1960, pp. 40-42

${ }^{97}$ Domhoff, 1978, pp. 156-157; Schattschneider, 1960, pp. 31-35. 
and other concerns (e.g. public goods and services) are addressed primarily to ensure that voters keep "elite-friendly" political leaders in power".

Community Power, in summary. By the mid- $20^{\text {th }}$ century, central cities in the United States were booming under the Fordist paradigm, and to describe the decisionmaking processes that both responded to- and helped guide the individual expressions of Fordism in cities across the United States, then-contemporary urban scholars developed two competing theories of urban governance: pluralism and elite theory. Although each of these handles it differently, both theories center on how civic leaders mitigate the central tensions that result from the division of labor, and how they arrange land-use patterns within cities such that the effects of these patterns were the least likely to engender popular resistance to growth and development ${ }^{99}$. These conceptualizations were (and remain) wholly incompatible, and for decades, political scientists debated the relative merits of these different conceptualizations of urban governance structures, which led to a somewhat schizophrenic approach to the study of urban governance throughout the 1950s, 1960s, and early 1970 s (i.e. the community power debates) ${ }^{100}$.

\section{Fordism in Dallas}

While other cities, with federal support, rebuilt their urban cores as modern, industrial powerhouses, Dallas chose a different route, eschewing federal funds in favor of issuing municipal bonds ${ }^{101}$. The modern Dallas was founded in 1963, immediately following the assassination of President Kennedy ${ }^{102}$. Although ten years prior, Dallas' business leaders already felt that the commercial center of Dallas, with its architecture dating largely to the

\footnotetext{
98 Banfield, 1961, pp. 286-297; Domhoff, 1978, pp. 156-157; Gilens \& Page, 2014, pp. 566-567; Hunter, 1953, pp. 5-6, 175-177; Mills, 1956, pp. 278-280, 344-345; Schattschneider, 1960, pp. 40-42; Schumpeter, 1950, pp. 280-282; Walker, 1966, pp. 286-287

${ }_{99}$ Elkin, 2008, p. 13; Stone, Orr, \& Imbroscio, 1991, p. 222

${ }^{100}$ Ricci, 1984, pp. 271-275

101 Morgan, 2004, pp. 242-243

102 Graff, 2008, p. 294; Payne, 1994, pp. 325-326; Sobel, 1989, p. 65
} 
1920s, had become obsolete and too expensive to maintain, the Kennedy assassination energized city leaders (and more importantly, voters) to rebrand the city under a banner of growth and vibrancy, even if doing so meant making decisions in closed-door meetings and informal, off-the-record dealmaking sessions ${ }^{103}$. As noted in Chapter 1, the resulting period of explosive growth was encouraged by the support of political leaders who were largely hand-picked by the city's business elite ${ }^{104}$, and who invested millions of public dollars into private real estate investment. In addition, significant private investment - both domestic and international - flooded the real estate market, thanks to federal tax policies that allowed wealthy individuals to reduce their tax liabilities by investing in certain types of businesses, the most attractive of which was real estate development ${ }^{105}$. Supported by both the public sector and the private, legendary developers like Trammell Crow, Henry Miller, and Hank Dickerson spent the remainder of the 1960s and 1970s bulldozing the "old" Downtown Dallas, with its marble floors and brass fittings, and replacing it with the skyscrapers that comprise much of the city's current skyline $e^{106}$.

Dallas' growth was not spread evenly throughout the city, however. Following World War II, Dallas' leaders trumpeted the growth in the central city and northern neighborhoods ${ }^{107}$, while largely ignoring the minority-majority communities south of the Trinity River, even though the largest commercial corridor, located in what is today North Oak Cliff, was second only to Downtown Dallas in revenue generation throughout the 1940s and $1950 \mathrm{~s}^{108}$. However, public officials interested in re-election would largely ignore the actions of well-connected white supremacists who terrorized nonwhite neighborhoods in

\footnotetext{
${ }^{103}$ Rice, 2007, p. 220; Hanson, 2003, pp. 54-56

${ }^{104}$ Elkin, 1987a, pp. 65-70; Payne, 2010

${ }^{105}$ Grant, 1996, pp. 19-20, 21; Rice, 2007, p. 77; Sobel, 1989, p. 209

${ }^{106}$ D CEO, 2014; Graff, 2008, pp. 220-221; P. Hill, 1996, pp. 160-169; Rice, 2007, pp. 220-221

${ }^{107}$ Graff, 2008, p. 185

${ }^{108}$ Elliott, Summey, \& Kokel, 2009, pp. 47, 83
} 
southern Dallas. While privately, many within Dallas' governing coalition disapproved of racial violence, and its consequences for Dallas' image, the threat of political backlash ensured that there were no meaningful attempts to hold anyone accountable, as long as the problems stayed south of the Trinity River, and as long as the people responsible for those problems continued to support the development in northern Dallas. Thus, many of the same back-room deals that prepared Dallas to grow into a modern economic hub also resulted in the wholesale abandonment of Dallas' southern neighborhoods, both economically and politically $^{109}$.

The Thometz study: urban theory under Fordism in Dallas. In postwar Dallas' dynamic, though deeply troubled urban context, the Thometz study took shape. This study of the city's decision-making structure in the early 1960s, strongly aligned with the tenets of elite theory, and somewhat unsurprisingly, it found that Dallas' political and business leaders were tightly connected, and that leadership was highly stratified among three different echelons of decision-makers. At the top of this structure were seven key leaders, who represented Dallas' business elite, and who made the vast majority of decisions in the city only working with political leaders when public funding or approval was required. These leaders were informed- and assisted by several top level business executives, as well as dozens of younger, less-influential, second echelon business leaders, such as mid-level managers and "up and coming" young men ${ }^{110}$. The study also found that Dallas' men of power were interconnected through various civic organizations and trade associations, which acted as "stepping stones" for men looking to further their civic ambitions, and which allowed

\footnotetext{
${ }^{109}$ P. Hill, 1996, p. 169; Phillips, 2006, pp. 146-147
}

110 Thometz, 1963, pp. 48-49 
talented leaders to build the skills needed to eventually become top level and key leaders themselves ${ }^{111}$.

As Thometz notes in a section regarding study limitations, these findings are anchored in one particular point in time ${ }^{112}$, although they are corroborated by several other accounts of Dallas' leadership at that time ${ }^{113}$. By relying on a tightly-knit political-business leadership committee as the basis for a reputational analysis, the study was inherently limited by what these participants were willing to say, even with guarantees of anonymity ${ }^{114}$. This created a "blind spot" in the study's results; which neglected leadership in the southern (minority-majority) half of the city, which was already tipping into what would become decades of institutional neglect. As a result, people in southern Dallas who may have been involved in the city's leadership structure (whether any existed) were either not wellrepresented, or were not well-identified, and the study makes no mention of the leadership divisions over racism and racial violence perpetrated by some members of Dallas' decisionmaking structure. Further, the study was conducted during a time in which growth defined the city; as such, had it been performed during a less-dynamic period in Dallas' history of urban redevelopment, it seems possible that actors outside of the business community would have been more heavily represented in Dallas' decision-making structure.

\section{Fordism, Community Power, and the Thometz Study of Dallas, in Summary}

In the years immediately following World War II, central cities in the United States were trading in their $19^{\text {th }}$ and early $20^{\text {th }}$ century mid-rise CBDs for skyscrapers and convention centers, fueled by the Fordist boom and a rush to fill factories and office buildings with workers emigrating from the small, rural communities that dominated the

${ }^{111}$ Elkin, 1987b, pp. 35-36; Thometz, 1963, pp. 23-25, ch. 4

112 1963, pp. 96-97

113 cf. Elkin, 1987; Graff, 2008; Hanson, 2003; P. Hill, 1996; Payne, 1994; Rice, 2007

114 Thometz, 1963, pp. 96-97 
landscape of the United States until that point. Studying these cities, postwar urban scholars began to conceive of power as a social phenomenon, and looked to individuals and groups as the unit of measure for understanding how community decisions are made ${ }^{115}$. Resulting from these studies, two competing conceptualizations of urban decision-making: pluralism and elite theory totalized the study of community power, leading to an intractable series of community power debates that defined the study of urban political science for over a decade.

Within the above context, the Thometz study of Dallas found that the city's decision-making process was controlled by its business community, and more importantly, a stratified power-structure of business leaders whose wishes were made manifest by functionally subservient political leaders - only one of whom was even considered by the study to be a decision-maker at the citywide level, and who had previously been a leader in the city's business community ${ }^{116}$. As a result, Dallas represented what later scholarship would characterize as a "pure" political economy, wherein the primary purpose of city politics was to further economic development, where the connections between business leaders and political leaders were well-developed, and where citizens who rose to political prominence were all-but exclusively business leaders first ${ }^{117}$. Public officials in Thometz’ Dallas were voted for by the population, but the ballots were filled by those who were selected by the Dallas' leading business associations - the Citizens Charter Association and the Dallas Citizens Council ${ }^{118}$.

\section{The Fordist crisis, Urban Political Economy, and the Elkin Study of Dallas}

The postwar economic- and population boom that allowed central cities to grow so rapidly would not last, however, and neither would the community power debates. Social

\footnotetext{
${ }^{115}$ Harding \& Blokland, 2014, p. 32

116 Thometz, 1963, pp. 32-34

117 Elkin, 1987a, pp. 62-72; Payne, 1994, p. 296

118 Elkin, 1987a, pp. 65-69; P. Hill, 1996, pp. 163-173; Payne, 1994, pp. 128-129; 172-174
} 
upheaval and abandonment of central cities throughout the 1960s was followed by retrenchment and the "hollowing of the state" - a reassignment of responsibility for social services from public-sector actors to private- and third-sector alternatives - during the $1970 \mathrm{~s}$ and $1980 \mathrm{~s}^{119}$. The effects of the Fordist crisis, the wholesale rollback of federal support for central cities, and the emergence of a new, knowledge-based economy led some scholars to suggest that many of the generalizations made by community power theorists regarding the nature of urban governance had become increasingly obsolete ${ }^{120}$. In addressing these concerns, urban scholars at the end of the $20^{\text {th }}$ century attempted to recast models of urban governance within this new context of limited cities, Petersonian development agendas, and close relationships between powerful (but constrained) public- and private-sector leaders, first by painting cities as growth machines, and later, by using a more generalized model of urban regimes and coalition governance.

In the paragraphs that follow, this study will describe the Fordist crisis, and its effects on the context of cities in the United States. Then, it will connect these changes to calls among urban political scientists for a new conceptualization of urban power and decision-making, and the resulting urban political economy perspective. Finally, it will introduce the Elkin study of Dallas, which helped to cement urban political economy as the dominant urban theory at the end of the $20^{\text {th }}$ century.

\section{The Fordist Crisis and Central Cities in the United States}

By (at latest) the mid-1970s, the Fordist dream had become a nightmare for central cities, which found themselves in sharp decline ${ }^{121}$. Factors like high labor- and capital costs, slowing productivity, regulations seen as "hostile to business," and increased competition

\footnotetext{
${ }^{119}$ Fredericksen \& London, 2002, pp. 230-231; Jessop, 1993, pp. 8-10; Milward \& Provan, 2000, pp. 361-363

${ }^{120}$ Savitch \& Thomas, 1991, pp. 1-3

121 Alperovitz, 2011, p. 125; Guillén, 2001, pp. 237-238
} 
from Europe and Asia resulted in dramatic decreases in manufacturing profits ${ }^{122}$. In response, firms often slashed both employment- and wage levels in manufacturing firms ${ }^{123}$, and many manufacturers relocated to the comparatively lax regulatory environments in Sunbelt cities throughout the southern United States, while others took advantage of low shipping costs and international trade agreements to shift their production facilities to other nations entirely ${ }^{124}$.

What resulted - a period called the Fordist Crisis - was a rapid, totalizing midcentury exodus of industrial capital from older manufacturing cities in the United States, such as Cleveland, Pittsburgh, St. Louis, and San Francisco, which starkly reduced both employment- and wage levels in their primary industries ${ }^{125}$. As a result, not only could these cities no longer support full employment at the prevailing blue-collar wages that once were $\operatorname{common}^{126}$, the rapidly-growing ranks of long-term unemployed workers increasing the demands placed on cities to provide social services ${ }^{127}$. When workers could find employment, many opted to abandon central cities in favor of modern, consumptioncentered suburbs, located far from the collapsing property values, and perceived blight and degradation of urban cores $^{128}$.

With unemployment high and no end to the deindustrialization of the United States in sight, many cities underwent several years of social unrest, including massive, highly damaging riots that left many CBDs in flames. While some cities (e.g. Dallas, Atlanta)

\footnotetext{
122 Clarke, 2002, p. 33; Jessop, 1993, pp. 12-13; Judd \& Simpson, 2003, pp. 1056-1057; Harvey, 1989, pp. 179-184; Kantor et al., 2012, pp. 29-33; Préteceille, 1990, pp. 29-30; Rowthorn \& Coutts, 2004, pp. 767-769; Sassen, 2000, pp. 1-22; 71-75; Savitch, 1988, pp. 19-21; Strom, 2008, p. 39; Harvey, 1989, pp. 141-142; R. Hill, 1986, pp. 98-99; Jessop, 1994, pp. 256-257; Keil, 1988, pp. 276-277; Sabel, 1989, pp. 102103

123 Appelbaum \& Schettkat, 1999, p. 387-388; Logan \& Swanstrom, 1990, pp. 11-12; Storper, 1997a, pp. 4-5

124 Audirac, 2010, p. 70; Beauregard, 2003, p. 183-188; Schragger, 2009, pp. 483-484

125 Appelbaum \& Schettkat, 1999, p. 387-388; Logan \& Swanstrom, 1990, pp. 11-12; Storper, 1997a, pp. 4-5

${ }^{126}$ Harvey, 1989, pp. 142-146; Lipietz, 1997, pp. 3-4

${ }^{127}$ R. Hill, 1986, pp. 109-110

${ }^{128}$ Dreier, Mollenkopf, \& Swanstrom, 2004, pp. 13-14, 90-91, Judd \& Swanstrom, 1998, pp. 316-317; D. Keating, 2007, p. 1, Sternlieb, 1971, pp. 19-21; Stradling \& Stradling, 2008, pp. 530-531
} 
managed to avoid community conflict, by the mid-1960s, outbreaks of civil unrest in cities like Chicago, Cleveland, Detroit, and Philadelphia suggest that the relative utopia of the mid-20 $0^{\text {th }}$ century had largely unraveled, if it ever existed at all ${ }^{129}$ Under the Johnson administration, a number of federal attempts to alleviate extreme poverty and joblessness, as well as the riots that left parts of many central urban neighborhoods reduced to ash, were enacted $^{130}$. Before many of these programs could take effect, most were cut short by conservative rollbacks during the latter part of Johnson's administration, and were cut even deeper under both Nixon and Reagan; as a result, many cities were forced to divest themselves of many social service programs ${ }^{131}$, and mayors across the country opted instead to devote their dwindling tax dollars into programs designed to attract new businesses. These "beggar thy neighbor" practices of the 1970s and 1980s, seemed to confirm a belief that business elites had grown powerful to the point of being able to undercut political leaders in furtherance of their own agenda - a phenomenon that neither pluralism nor elite theory could readily explain ${ }^{132}$.

This Fordist crisis broadly refers to the apex of a demographic- and economic trend, primarily in mid-late $20^{\text {th }}$ century, wherein corporations and factories that traditionally filled urban cores opted to abandon them for new facilities, both in nearby suburbs and abroad ${ }^{133}$. Across the United States, waves of disinvestment left once-thriving central cities nearly abandoned ${ }^{134}$, while many of the remaining corporations and financial institutions engaged in international mergers, acquisitions, and consolidation efforts. As tax revenues declined and

\footnotetext{
${ }^{129}$ Ferman, 1991, p. 53; R. Hill, 1986, p. 96; Keating, Krumholz, \& Metzger, 1989, p. 122; Thomas, J.M., 1989, pp. 146-147; Thomas, J. C. \& Savtich, 1991a, pp. 1; 3-9

${ }^{130}$ Frug, 1984, pp. 33-34; Peterson, 1981, pp. 43-44

131 Clark, 2002, pp. 75-77; Jessop, 1994, pp. 264-265; Peck \& Tickell, 1994, pp. 293-294; Milward \& Provan, 2000, pp. 360-361

132 Joseph, 1981, pp. 161-162

${ }_{133}$ Clarke, 2002, p. 33; Jessop, 1993, pp. 12-13; Judd \& Simpson, 2003, pp. 1056-1057; Kantor et al., 2012, pp. 29-33; Préteceille, 1990, pp. 29-30; Rowthorn \& Coutts, 2004, pp. 767-769; Sassen, 2000, pp. 1-22; 71-75; Strom, 2008, p. 39; Baumgartner \& Jones, 1993, pp. 126, 142-144; S. Judd \& Swanstrom, 1998, pp. 236-239; Kaplan \& Cuciti, 1986, p. 11

134 Bluestone \& Harrison, 1982, pp. 25-48; Hackwork \& Smith, 2001, pp. 466-468; Sachdev, 1976, pp. 113-115; Sheets, Smith, \& Voytek, 1985, pp. 219-225
} 
demands for social services increased, the threat of financial insolvency loomed over many cities of the 1970 s and $1980 s^{135}$. In response, city leaders across the United States, with the blessing- and support of austerity-focused state- and national lawmakers ${ }^{136}$, contracted out responsibility for public services, and redirected the savings into neoliberal economic growth and development strategies ${ }^{137}$. The resulting policies and projects were supported in part through dependence on the federal funding ${ }^{138}$, especially the Urban Development Action Grant (UDAG) program, which awarded almost $\$ 5$ billion to thousands of economic development projects in hundreds of cities across the United States ${ }^{139}$. Although this funding stream would ultimately prove temporary, for a time, this funding, and the relationships between public officials and private-sector leaders that it engendered, resulted in a new model of urban governance: the development-focused, pro-business governing coalition ${ }^{140}$.

\section{Urban Political Economy: Urban Theory under the Fordist Crisis}

Roughly 25 years after they began, the community power debates (of which Thometz' Dallas study is a part) left urban political theory in disarray ${ }^{141}$. The radically different arguments, i.e. pluralism and elite theory, were well-established by the early $1960 \mathrm{~s}^{142}$, and what followed were hundreds of studies that found new examples of pluralistic tendencies and elite dominance, but that ultimately failed to result in definitive conclusions $^{143}$. Further, as scholars looked around at central United States cities in the 1980s, it became apparent that those who governed clearly had the ability to downplay (or even ignore) many interest groups entirely. The city of the 1980s, scholars argued, was governed

\footnotetext{
${ }_{135}$ Nyden \& Wiewel, 1991, p. ix; Peet \& Watts, 1993, p. 236; Sternlieb, 1971, pp. 16-21; Wolch \& Geiger, 1986, pp. 3-4

${ }^{136}$ Baumgartner \& Jones, 1993, pp. 126, 142-144; Judd \& Swanstrom, 1998, pp. 236-239; Kaplan \& Cuciti, 1986 , p. 11

${ }^{137}$ Harding, 2009, p. 34; Mossberger, 2009, p. 41; Schragger, 2009, pp. 502-504

${ }^{138}$ Judd \& Kopel, 1979, pp. 214-217; Judd \& Swanstrom, 1998, p. 328

139 Reed, 1989, pp. 93-94; Rich, 1992, p. 150

${ }^{140}$ Cox, 1997, p. 99; De Socio, 2007, pp. 340-341; Mossberger, 2009, p. 41

141 Polsby, 1980, p. xvii; Ricci, 1984, pp. 273-275

${ }^{142}$ Hunter, 1953, pp 6-7, 11; Mills, 1956, p. 22; Schattschneider, 1960, pp. 33-35, 140-141

${ }^{143}$ Dowding et al., 1995, pp. 265-271; Harding, 1996, pp. 637-639; 2009, p. 31; Polsby, 1980, pp. xi-xvii; Ricci, 1984, pp. 272-273;

Wolfinger, 1971
} 
by highly enmeshed groups of political- and economic elites, whose control over city politics was all-but complete, and who had the power to absorb oppositional groups into their structures, or to neutralize them entirely ${ }^{144}$. Responding to this, and to the changing urban context of cities since the start of the community power debates, a subset of scholars argued that, whether or not "community power" had ever actually existed, it had been replaced by highly enmeshed, informal coalitions of political- and economic elites, who merged their extensive, but limited resources in order to achieve their own particular goals, subordinate competing agendas and circumvent pressure politics ${ }^{145}$.

As a result of exhaustion from the community power debates, and new observations about urban governance under the crisis of Fordism, many urban scholars drifted away from the study of community power, as well as the methods employed in its study ${ }^{146}$. To illustrate this point, table 2.01 outlines the results of a brief archival search for scholarly work regarding community power, including published books and articles in peer-reviewed journals ${ }^{\mathrm{i}}$.

Table 2.01: Community Power Keywordii Search Results

\begin{tabular}{|c|c|c|c|c|c|c|}
\hline & $\mathbf{1 9 5 0 - 1 9 5 9}$ & $\mathbf{1 9 6 0 - 1 9 6 9}$ & $\mathbf{1 9 7 0 - 1 9 7 9}$ & $\mathbf{1 9 8 0 - 1 9 8 9}$ & $\mathbf{1 9 9 0 - 1 9 9 9}$ & $\mathbf{2 0 0 0 - 2 0 0 9}$ \\
\hline Publications & 390 & 2,419 & 4,679 & 3,971 & 3,532 & 2,309 \\
\hline
\end{tabular}

Though they are far-from comprehensive, these data suggest that scholarly interest in the community power debates peaked between 1970 and 1979.

As scholarly interest shifted, two new theories emerged: growth machine theory and the urban regime analysis. Both of these are parts of a new perspective on urban governance: urban political economy, which emerged as an attempt to reconcile the divergent truths of

\footnotetext{
144 DeLeon, 1992a, pp. 559-560; Harding, 2009, p. 34; Mossberger, 2009, p. 41; Peterson, 1981, pp. 27-29; Savitch \& Thomas, 1991, pp. 238-239; Schragger, 2009, pp. 502-504

${ }^{145}$ Harding, 1996, p. 640; Jonas \& Wilson, 1999, p. 3-4; Molotch, 1976, pp. 309-310; Mossberger, 2009, pp. 41-42; Saito \& Truong, 2015 , pp. 267-268; C. Stone, 1989, p. 6; 2005, pp. 324-325; Vogel, 1992, pp. $12-13$

146 Dowding et al., 1995, p. 265; Harding, 1996, p. 638
} 
elite theory and pluralism, while also overcoming the weaknesses inherent in $\operatorname{each}^{147}$. These both offered a fresh perspective on decision-making, using informal interviews and archival research of particular cities to suggest the interconnected nature of urban governance from a systemic, behavioral perspective, and as future sections will suggest, quickly grew to dominate the study of urban politics. Data in table 2.02 corroborate this, and suggest that research interest in contemporary urban theory - including growth machine theory and urban regime analysis, began to grow in the 1970s, and expanded most rapidly after 1980.

\begin{tabular}{|c|c|c|c|c|c|c|}
\hline & $1950-1959$ & $1960-1969$ & $1970-1979$ & $1980-1989$ & $1090-1090$ & 2000 2000 \\
\hline Publications & 41 & 98 & 434 & 3,012 & 4,488 & 9,280 \\
\hline
\end{tabular}

As with data regarding the numbers of articles and books related to community power, these data are certainly not intended to be exhaustive. Nonetheless, these data suggest that starting in the 1970s, urban scholars reflected on the state of their field, and on the nature of cities at the close of the $21^{\text {st }}$ century. In the paragraphs that follow, this study will unpack these new conceptualizations of urban decision-making, first for growth machine theory, and then for urban regime analysis.

Growth machine theory. First published about by Harvey Molotch in 1976, growth machine theory attempted to undercut all sides of the community power debates by focusing on the motives of economic actors within the governing coalition, as well as the actions they take in order to change the socially-constructed meanings and values of place within the city $^{148}$. At the core of the growth machine are place-based elites, whose control over the political decision-makers is all-but absolute, and who direct the policymaking process in order to maximize rental incomes and property values within the city, with all other concerns being of secondary importance ${ }^{149}$. Growth machine theorists argue that all places carry with

\footnotetext{
147 Vogel, 1992, pp. 12-13

148 Jonas \& Wilson, 1999, p. 4; Molotch, 1976, pp. 309-310

${ }^{149}$ Jonas \& Wilson, 1999, p. 3; Logan, Whaley, \& Crowder, 1997, pp. 604-605; Molotch, 1976, p. 313; 1993, pp. 31-33
} 
them two socially-constructed values - their use-value and their exchange-value. For landowners, the value in a parcel of land is in what the land could be worth if sold or rented; this is the place's exchange-value. For renters, who do not own the land, the value in a place is in how it is utilized or consumed - this is place's use-value ${ }^{150}$. For any given place, these two values necessarily contradict, and the resulting tension is the fundamental conflict of growth machine theory ${ }^{151}$.

Growth machine theorists also argue that landowners (or rentiers), by having their fortunes bound to local real estate values, universally support urban growth agendas ${ }^{152}$, and join with other influential actors ${ }^{153}$ to combine deep wells of financial resources, control over land-use regulations, tax abatement policies, and major media outlets to relentlessly pursue its growth agenda. These actors gain public support for their projects by establishing a discourse in which the city's troubles, whatever they happen to be, can only be solved through new, publicly-financed development projects ${ }^{154}$, that the costs of such development will be unproblematic, and its benefits will be widely-spread ${ }^{155}$. Further, growth machine members manipulate voters' fears of "losing out" to competing cities (domestically and abroad), proffering that alternatives to development will be highly detrimental to the city's well-being ${ }^{156}$. Individuals and organizations critical of the growth agenda are often discredited, and in some cases, actively excluded from the discourse through media shut-

\footnotetext{
${ }^{150}$ Logan \& Molotch, 2007, p. 2

151 Jonas \& Wilson, 1999, pp. 5-6; Logan, Whaley, \& Crowder, 1997, p. 607

${ }^{152}$ Harding, 2009, pp. 34-35; Logan \& Molotch, 2007, pp. 50-51; p. 62; Jonas \& Wilson, 1999, pp. 5-6

153 e.g. political elites, local media outlets, construction companies, real estate developers, and regional banks

154 Elkin, 1987aa, p. 55; MacLeod \& Goodwin, 1999, p. 701; Jonas \& Wilson, 1999, pp. 5-9; Logan \& Molotch, 2007, p. 115; Molotch, 1993, pp. 34-37; Wilson \& Wouters, 2003, pp. 123-125

155 Bast, 1998; Coates \& Humphreys, 2000, pp. 15-16; Cox \& Mair, 1988, pp. 319-320; R. Keating, 1999, pp. 3-7; Okner, 1974, pp. 325-348;

Troutman, 2004, p. 612; Zaretsky, 2001, p. 1

156 Zimmerman, 2008, pp. 230-231
} 
outs $^{157}$. As a result, growth machines are incredibly durable, regardless of opposition from anti-growth coalitions or changes in developmental regulations ${ }^{158}$.

Critiques of growth machine theory. While there are a number of critiques of growth machine theory, it is beyond the scope of this study to examine them all in detail; instead, this study will focus on two. To the first of these, scholars level that growth machine theory is somewhat conflicted with respect to what the growth machine actually is, and as a result, what the growth machine actually does. Logan \& Molotch, in their seminal work, define the growth machine - first with a narrow specification, and then with a broad one. To elaborate, the narrow definition of the growth machine refers only to the subset of elites who draw income from property rental ${ }^{159}$, while the authors' broad definition includes a wide variety of place-dependent organizations, such as local banks and media outlets ${ }^{160,161}$. By taking the narrow definition, growth machine theorists bind the growth machine and its members to a single-minded obsession with land-use and maximizing exchange value - a position that effectively wallpapers over conflicts among economic elites ${ }^{162}$. Meanwhile, the broadly-defined growth machine is engaged in perpetual conflict, both internally among its members, and externally with various renters over use-values for various places ${ }^{163}$. Building on this, a second critique suggests that growth machine theory too-narrowly defines exchange-value, limiting it to land values within cities themselves. Thus, growth machine theory ignores the exchange value of non-land assets ${ }^{164}$, and disregards the effects of greater socioeconomic forces ${ }^{165}$. Therefore, critics charge, the model cannot adequately account for

\footnotetext{
157 Delaney \& R. Eckstein, 2003; Logan \& Molotch, 2007, pp. 62-63; Troutman, 2004, pp. 614-618

${ }^{158}$ Jonas \& Wilson, 1999, pp. 7-8; Molotch, 1993, pp. 48-49

${ }^{159}$ Logan \& Molotch, 2007, pp. 29-31

160 e.g. public utilities and banks, as well as politicians, universities, cultural organizations, sports teams, organized labor, and small business owners

${ }^{161}$ Logan \& Molotch, 2007, pp. 64-72

162 Harding, 2009, pp. 35-36; Cox \& Mair, 1989, pp. 138; Valler, 1996, p. 386

${ }^{163}$ Logan \& Molotch, 2007, pp. 2, 13, 209-228

164 e.g. retail stock, equipment, machinery, and materials

165 Cox \& Mair, 1989, pp. 138-139; Harding \& Blokland, 2014, p. 110; MacLeod \& Goodwin, 1999, p. 701; Rodgers, 2009 , p. 14
} 
instances in which city leaders pursue agendas that may not directly induce development, such as education and service delivery ${ }^{166}$, nor can it account for why development slowed in many cities that took advantage of either private investment or federal funding to fuel urban development throughout the mid- $20^{\text {th }}$ century ${ }^{167}$.

Urban regime analysis. Although (largely) well-received by urban political scholarship, by the late 1980s, growth machine theory had been supplanted by a more generalized urban regime analysis ${ }^{168}$, which serves as the framework for contemporary urban theory ${ }^{169}$. Broadly speaking, urban regime analysis founds itself on the premise that the capacity to govern in the modern, complex urban environment emerges from informal relationships among partners within informal coalitions, and from their willingness- and ability to combine resources in order to govern the general electorate ${ }^{170}$. Critically, each partner possesses a resource that others lack, and as a result, urban regime advocates argue that the only path to successfully governing comes from partnerships with leaders who can marshal complementary resources ${ }^{171}$. Therefore, although political- and economic elites form the core of the governing coalition, they cannot effectively govern without additional support and legitimacy for their development-first agenda, support that comes from a wide range of ancillary coalition members ${ }^{172,173}$. By combining a broad range of resources to further particular policies and programs, the governing coalition possesses a structural power

\footnotetext{
${ }^{166}$ Harding \& Blokland, 2014, p. 110; M. Keating, 1991, pp. 187-189; Logan, Whaley, \& Crowder, 1997, p. 613

${ }_{167}$ Cox \& Mair, 1989, p. 140; Logan \& Molotch, 2007, pp. 11-12

${ }^{168}$ Harding, 1996, pp. 640-641; Imbroscio, 1998, p. 233; Lauria, 1997, p. 1

${ }^{169}$ Imbroscio, 2003, p. 271

170 Stone, 1993 , pp. 1-2

171 Molotch, 1993, p. 31-33; C. Stone \& Sanders, 1987, pp. 269-270

172 e.g. heads of community organizations and universities, community leaders, local experts, local media heads, leaders of construction companies, real estate developers, and executives of regional banks

${ }^{173}$ Elkin, 1987a, pp. 160-162; Harding, 2009, pp. 34-35; Jonas \& Wilson, 1999, pp. 5-6; Logan \& Molotch, 2007, pp. 62-74; C. Stone, 1989, pp. 234-242; Walcott, 1999, pp. 648-651
} 
to overcome objections to its goals that is far greater than that of any individual coalition member ${ }^{174}$.

The versatility of the regime model allows a variety of governing coalitions to exist; Stone himself identified four ${ }^{175}$ while subsequent authors have added additional typologies ${ }^{176}$. After consolidating over a decade of literature on regime typologies, Jill Clark constructed a six-type categorization scheme for urban regimes ${ }^{177}$, which table 2.03 summarizes; this table also includes a seventh coalition typology, the antiregime, which Clark merged into the demandside urban governing coalition, based on DeLeon's long-term studies of the evolving leadership structure of late- $20^{\text {th }}$ century San Francisco ${ }^{178}$. This study argues that it is still appropriate to include the antiregime, which is briefly summarized as one possible result of a collapsed (or otherwise failed) urban regime, and are composed of fragmented interest groups that fail to coalesce around a particular agenda, fail to establish ties with the business community, and fail to reconcile their various agendas with the political system ${ }^{179}$. Like the demand-side regime, the antiregime is successful at blocking unfavorable policies and development, but because it lacks the support of bureaucrats or organized institutions, it is unable to promote (or even to passively allow) beneficial urban policies or development projects $^{180}$.

\begin{tabular}{|c|c|}
\hline \multicolumn{2}{|r|}{ Table 2.03: Typology of Governing Coalitions } \\
\hline Coalition Type & Lead Actors \\
\hline Activist & $\begin{array}{l}\text { Minority-led electoral coalitions, engaged citizens, single-district councilmembers, neighborhood governments, } \\
\text { social justice or broker mayors, fiscal populists }\end{array}$ \\
\hline Caretaker & Caretaker mayors, anti-growth bureaucrats, fiscal populists, post-materialists \\
\hline Demand-Side & Neighborhood organizations, single-district councilmembers, minority mayors, post-materialists \\
\hline Entrepreneurial & Business-led coalitions, strong mayor, pro-growth bureaucrats \\
\hline Progressive & Minority-led electoral coalitions, single-district councilmembers, neighborhood governments, social justice mayors \\
\hline Stewardship & Group coalitions, engaged citizens, fiscal populists, "broker" mayors \\
\hline $\begin{array}{l}174 \text { T. Clark et al., } 20 \\
175 \text { Stone, } 1993 \text {, pp. } \\
176 \text { e.g. Burns \& The } \\
\text { \& Haddock, } 1997 \text {, } \\
177 \text { 2001, pp. 32, } 37 \\
178 \text { J. Clark, 2001, pr } \\
179 \text { DeLeon, 1992, p } \\
{ }^{180} \text { DeLeon, 1992, p }\end{array}$ & $\begin{array}{l}\text { p. 496; Logan \& Molotch, 2007, pp. 50-51, 62-63; MacLeod \& Goodwin, 1999, p. 702; C. Stone, 1993, pp. 3-5 } \\
\text { as, 2006, pp. 519-520; J. Clark, 2001, pp. 11-37; DeLeon, 1992a, p. 555; Imbroscio, } 2010 \text { pp. 28-31; Kantor, Savitch, } \\
\text { a54-368 } \\
9-31 \\
61 \\
561-562\end{array}$ \\
\hline
\end{tabular}


Notably, Table 2.03 should not be taken to suggest that coalition types are equally common; indeed, in practice, the pro-development, business-led entrepreneurial governing coalition (also represented by the growth machine model) is the de facto characterization of urban governance in the United States ${ }^{181}$, and the relatively privileged position of economic elites has resulted in a skewing of municipal agendas in favor of value-neutral economic development in many cities across the United States ${ }^{182}$. This coalition type is perpetuated in three primary ways. First, private-sector elites use their financial resources to underwrite reelection campaigns, and to support projects that keep their political allies in power $^{183}$. Because the tenures of these allies are limited by the constant need to be re-elected, political elites must continually appease their economic counterparts through business-friendly policy- and regulatory environments, tax incentives for economic development, and a general emphasis on economic development, often to the exclusion of social services, education, and infrastructure development ${ }^{184}$. Second, because the overall health and stability of the governing coalition is contingent upon cohesive internal cooperation, even in the case of conflicting interests ${ }^{185}$, members may selectively incentivized to "go along" with the development agenda in exchange for promises of coalition support for a future opportunity of their own, or in some cases, an immediate financial side-payment ${ }^{186}$. Finally, because governing coalitions must also mitigate external opposition, the aforementioned auxiliary members mobilize in order to create- and maintain a public discourse in support of the

\footnotetext{
${ }^{181}$ De Socio, 2007, p. 349; Imbroscio, 2010, pp. 28-31; Kantor, Savitch, \& Haddock, 1997, pp. 353-368; M. Keating, 1991, p. 189; C. Stone, 1989, pp. 183-188; C. Stone, Orr, \& Imbroscio, 1991, pp. 229-236

182 Elkin, 1987a, pp. 98-99; Kantor, Savitch, \& Haddock, 1993, p. 352, 369; C. Stone, 2005, pp. 317-381; Turner, 1992, pp. 3-4; Vogel, 1992, pp. 18-19

${ }^{183}$ Elkin, 1987a, p. 51; C. Stone, 1989, pp. 228-229

${ }^{184}$ Elkin, 1987a, p. 55; Jonas \& Wilson, 1999, pp. 3-6; Logan \& Molotch, 2007, p. 115; Logan, Whaley, \& Crowder, 1997, pp. 604-605;

MacLeod \& Goodwin, 1999, p. 701; Molotch, 1976, p. 313; 1993, p. 31-33

${ }^{185}$ De Socio, 2007, p. 340; Pierre, 2005, p. 447; C. Stone, 1993, p. 3; Walcott, 1999, p. 650

${ }^{186}$ Stoker \& Mossberger, 1994, p. 204; C. Stone, 1989, pp. 186-191
} 
coalition's agenda, silence and discredit dissenters, and lend legitimacy to the coalition's plans $^{187}$. As a result, entrepreneurial coalitions remain incredibly durable, even during times of sharp public criticism and private disagreement ${ }^{188}$.

Critiques of urban regime analysis. As is the case for growth machine theory, while there are a number of critiques of urban regime analysis, it is beyond the scope of this study to examine them all in detail; instead, this study will focus on three that are particularly germane to the present study. First, urban regime analysis fails to adequately embed the regimes themselves within the wider institutional context ${ }^{189}$, arguing that regime actors have - at best - a limited awareness of extra-local forces ${ }^{190}$. Corrections for this have been attempted by linking urban regime theory to regulation theory, but even here, urban regime theory continues to fail at any sort of sustained interrogation of economic trends, which weakens its value as a proscriptive theory ${ }^{191}$ or comparative one ${ }^{192}$. Additionally, urban regime analysis fails to address the consequences of particular types of governing coalitions; i.e., no one type is "better" or "worse" than another, with respect to addressing the specific needs of a given city. Moreover, the model cannot predict whether any particular governing coalition will be successful at actually governing an individual city, or whether that regime is vulnerable to replacement or collapse ${ }^{193}$. Finally, urban regime analysis takes on faith a distinct division of labor between public- and private-sectors, assuming that the traditional, profit-driven private sector dominates economic development ${ }^{194}$; whether this assumption was ever completely accurate is debatable, but as cities transition away from a myopic focus

\footnotetext{
187 Cox \& Mair, 1988, pp. 319-320; Delaney \& Eckstein, 2003; Jonas \& Wilson, 1999, pp. 6-9; Molotch, 1993, pp. 34-37

${ }^{188}$ Harding \& Blokland, 2014, pp. 101-102; Troutman, 2004, p. 612-618; Wilson \& Wouters, 2003, pp. 123-125

${ }^{189}$ Kantor, Savitch, \& Haddock, 1997, pp. 348-349; Lauria, 1997, pp. 4-5; MacLeod \& Goodwin, 1999, pp. 701-703

190 Stone, 1989 , p. $195 ; 1993$, pp. 9-10

${ }^{191}$ Imbroscio, 2010, pp. 34-36; Lauria, 1997, p. 8

192 Kantor, Savitch, \& Haddock, 1997, p. 349; Stoker \& Mossberger, 1994, pp. 195-196

${ }_{193}$ Harding \& Blokland, 2014, p. 113; C. Stone, 2005, pp. 331-332

${ }^{194}$ Cox, 1997, p. 109; Imbroscio, 1998, p. 236
} 
on business and capital generation, it may be that it is growing weaker. Taken together, these criticisms of urban regime analysis suggest that, as broader social- and economic forces change the urban context of cities, it is (at best) unclear whether urban regime analysis can adequately conceptualize the effects of these changes on real-world governing coalitions.

Urban Political Economy, in summary. In looking at United States cities in the mid-late $20^{\text {th }}$ century, urban scholars found that the pressure politics of community power, whether it ever actually existed, had been replaced by informal, highly enmeshed groups of political- and economic elites, whose control over city politics was all-but complete, and who combined their extensive, but limited resources in order to achieve their own particular goals, absorb oppositional groups into their structures, or to neutralize them entirely ${ }^{195}$. This merger of politics and economics - urban political economy - is composed primarily of two approaches, the narrower growth machine theory, and the broader urban regime analysis. Indeed, scholars have found hundreds of examples of urban regimes in cities across the United States, and even internationally, and the preponderance of available evidence strongly suggests that both the urban political economy approach broadly, and at least some variation of urban regime analysis has played a role in framing the scholarly observations of urban life and urban governance in cities across the world ${ }^{196}$.

\section{The Fordist crisis in Dallas}

During the formative, early years of urban regime analysis, Stephen Elkin used the city of Dallas, Texas to study the tight linkages between its political and business leaders. Like Thometz before him, Elkin cited the city's business growth (even in spite of national recession), and the strong links between Dallas' business community and its political leaders

\footnotetext{
195 DeLeon, 1992a, pp. 559-560; Harding, 1996, p. 640; 2009, p. 34; Jonas \& Wilson, 1999, p. 3-4; Molotch, 1976, pp. 309-310; Mossberger, 2009, pp. 41-42; Peterson, 1981, pp. 27-29; Saito \& Truong, 2015, pp. 267-268; Savitch \& Thomas, 1991, pp. 238-239; Schragger, 2009, pp. 502-504; C. Stone, 1989, p. 6; 2005, pp. 324-325; Vogel, 1992, pp. 12-13

${ }_{196}$ Harding \& Blokland, 2014, p. 113; Kantor, Savitch, \& Haddock, 1997, p. 352; Mossberger \& Stoker, 2001, p. 811; Walcott, 1999, p. 649
} 
as primary reasons for selecting it for study ${ }^{197}$. Indeed, while much of the United States stumbled economically during the Fordist crisis, Dallas' growth from the end of World War II until the mid-1970s was uninterrupted ${ }^{198}$, built on the backbone of a massive oil boom, defense contracts, and electronics.

Looking first at oil, manufacturing equipment for oilfields and refineries had been a steady part of Dallas' manufacturing base since the 1930s, but production orders ramped up alongside the automobile boom following the end of World War $\mathrm{II}^{199}$. In addition, throughout the war, and lasting until the end of the Cold War, over a quarter of the city's manufacturing employee were employed in producing military aircraft ${ }^{200}$. Finally, Dallas is also the home of Texas Instruments, first founded in the 1930s as a seismic services provider for the oil industry, but (with the support of Dallas' ruling elite) branched into transistor manufacturing in the 1950 s, eventually leading to the 1958 creation of the integrated circuit, and new manufacturing contracts for electronics and guided missiles using this new technology ${ }^{201}$. This convergence of high-growth industries within the city turned Dallas into an industrial hub so vibrant that in the mid-late 1950s, it had become the manufacturing hinge of the entire Southwest ${ }^{202}$. From the 1950s until the 1970s, the city's status as a regional manufacturing and trade hub was largely unchallenged, and helped attract a diverse combination of firms involved in wholesale and retail trade, banking and finance, and insurance ${ }^{203}$.

Of all of these industries, it was Dallas' ties to oil that would largely inoculate the entire region from the earliest effects of Fordism's collapse. The oil crisis brought on by the

\footnotetext{
197 Elkin, 1987a, p. 61; Morgan, 2004, pp. 116-117

198 Burrough, 2009, p. 356; Grant, 1996, pp. 18, 42-43

${ }^{199}$ Burrough, 2009, pp. 250-252, 267, 407-420; Lewis \& Stockton, 2010; Miller, 2013, p. 21; Payne, 1994, p. 274

${ }^{200}$ Hazel, 1997, pp. 45-47; McKnight, 1956, pp. 7-19; Miller, 2013, pp. 15-17

201 Miller, 2013, pp. 15-17; Payne, 1994, pp. 274-275

${ }^{202}$ McKnight, 1956, pp. 167-169; 1957, pp. 39-43; Miller, 2013, p. 17; Payne, 1994, p. 274

203 Thometz, 1963, pp. 10-11
} 
1973 Arab embargo caused Texas oil companies - many of which were headquartered in Dallas - to experience unprecedented growth and expansion. Prices per barrel of oil skyrocketed by over 2000\% between 1973 and 1980, and in that same period, land speculation drove real estate prices up over $900 \%{ }^{204}$. This boom would add over $\$ 367$ billion to Texas' overall economy between 1970 and 1986, and much of that investment was occurring in Dallas, where a city eager to remove itself from the shame of a slain president eagerly constructed a new skyline ${ }^{205}$, funded by a mixture of public financing and private debt from both domestic- and international sources ${ }^{206}$. For Dallas, the economic plight throughout the rest of the United States may as well have been occurring in another country entirely.

Not all of Dallas saw the benefits of the city's growth and prosperity, however. For decades, southern Dallas had been broadly ignored by both city leaders and the general public for decades, and garnered a reputation for commercial disinvestment, high crime, and poor school performance ${ }^{207}$. In reality, after many whites abandoned the neighborhood, people from African American and Hispanic communities moved in, creating a racially heterogenous region where wealth and poverty often lived within blocks of one another ${ }^{208}$. Minority-owned businesses replaced those formerly owned by whites, and while commercial corridors had changed by the late 1970s, limited commercial activity nonetheless remained, especially in- and near what would become known as North Oak Cliff ${ }^{209}$.

\footnotetext{
${ }^{204}$ Burrough, 2009, pp. 356-358; Grant, 1996, pp. 17-20

${ }^{205}$ Payne, 1994, pp. 322-333, 373-376

${ }^{206}$ Grant, 1996, pp. 16-18

207 Merwin, 1977; Simek, 2014; Young, 2014

${ }^{208}$ Blacks in Dallas, 2015; Merwin, 1977

${ }^{209}$ Elliott, Summey, \& Kokel, 2009, pp. 117-118; 2013, p. 59; Huang, 2014
} 
The Elkin study: urban theory under the Fordist crisis in Dallas. Writing in the mid-1980s, Stephen Elkin used a study of Dallas (the "commercial republic") to argue for the presence and dominance of business interests in a governance structure that characterized as an entrepreneurial governing coalition, in which a well-organized coalition of business leaders formed natural alliances with public officials, but were often at “arm's length" from the day-to-day running of the city, as opposed to the deep, almost-daily involvement of the business community in running the "pure" entrepreneurial coalition found in Dallas during the Thometz study. Elkin's study cites two primary reasons for this transition: first, the city's business community was no longer as unified as it once had been; and second, the city's political leadership was dramatically restructured, following a federal court order.

Looking first at the disunity among members of Dallas' business community, the Elkin study identified two causes, both of which were consequences of the city's success at inducing economic growth and development. First, by the late 1970s, Dallas had largely built itself out of undeveloped land ${ }^{210}$. In the past, Dallas' leaders simply authorized massive bond packages to induce redevelopment of the city's built environment, based on the needs of a unified business coalition. However, the city's success in attracting outside investment brought an influx of new corporations into the CBD, corporations whose heads often had little interest in the politics of governance, preferring instead to focus their energies on regional-, national-, and global concerns ${ }^{211}$.

Additionally, as the size of the business community grew, influential corporate executives were increasingly less-able to reconcile different agendas through side-payments

${ }^{210}$ Elkin, 1987 a, p. 71

211 1987a, pp. 72-73; 1987b, pp. 42-43 
or "go along to get along" dealmaking, leaving the business community fragmented and somewhat disorganized, and leading to tensions between developers who wanted to tear down the city and rebuild, and existing tenants who were largely happy with existing development $\mathrm{t}^{212}$. Further dividing the city's business community were the myriad redevelopment and infrastructure projects, such as the city's proposed light rail network, which were implemented at great (and uneven) costs to various stakeholders ${ }^{213}$. This fragmentation was most evident in the collapse of Dallas' Citizens Charter Association, which ceased operations following Dallas' first attempt at modern electoral reformation, concluding that it was no longer possible for the city's business community to act alone in guiding the city's growth and development ${ }^{214}$. It could also be seen, to a smaller (though just as important) extent, in the weakening of the Dallas Citizens Council, which remains influential in city politics, but no is no longer able to command elections ${ }^{215}$.

Shifting focus, in considering the restructuring of Dallas' elected leadership, in 1971, a lawsuit filed against the city contended that the at-large election system for city nearlyomnipotent councilmembers was in violation of the Voting Rights Act, because it rewarded candidates who were popular in areas with the highest voter turnout - in this case, the affluent, white-majority neighborhoods in north of the Trinity River ${ }^{216}$. Because those areas had higher voter turnout, plaintiffs argued, the system had the effect of diluting votes among Dallas' African-American and Hispanic populations ${ }^{217}$. The court case went on for four years, and in 1975, a federal judge ruled against Dallas, agreeing that the city's at-large council election system violated the Voting Rights Act $^{218}$. In response, the city council

\footnotetext{
2121987 b, pp. 35-36

213 1987a, p. 71; Graff, 2008, p. 227; Hill, 196, p. 171

${ }^{214}$ Elkin, 1987a, p. 78; Morgan, 2004, p. 112; Payne, 1994, pp. 355-362

215 Celeste, 2013; Elkin, 1987a, p. 72; Graff, 2008, p. 296; Payne, 1994, pp. 362-363; 2010

${ }^{216}$ Elkin, 1987b, pp. 35-36; Morgan, 2004, pp. 124-133; Payne, 1994, pp. 355-357

217 Morgan, 2004, pp. 130-131; Payne, 1994, p. 356

${ }^{218}$ Elkin, 1987b, pp. 40-43; Graff, 2008, p. 296; Morgan, 2004, pp. 135-137
} 
quickly replaced its existing at-large system with an "8-3" plan, in which eight

councilmembers were elected by districts in which they resided, while three more, including the mayor, would continue to be elected at-large. The council argued (and the federal judge agreed) that, while the eight district-based councilmembers would likely feel particular bias toward their own districts, the at-large councilmembers and mayor would be free to look after the needs of Dallas as a whole ${ }^{219}$.

Taking a broad approach to these changes, Elkin observed that their impacts were not as sweeping as one might have expected them to be. To begin, council members were only paid a small stipend for attending council meetings, so the position was still largely voluntary, and in addition, councilmembers rarely sought to build political coalitions, unless they intended to make politics a lifelong career. As a result, although the district-bound councilmembers paid some attention to local concerns, especially around election time, many continued to promote the pro-growth strategies of their predecessors ${ }^{220}$.

The study concluded that the ability of Dallas' business interests to continue seeing their needs often, though not always, addressed over those of the electorate was emblematic of a greater, societal failure to separate the political need to promote a healthy economy from "... how to contrive a happy environment for businessmen" ${ }^{221}$. Elkin argued that that public officials were induced to struggle and debate issues only when their audience demands struggle and debate; as long as business leaders and civic boosters composed that audience, then business inducement would remain at the core of public policy decisions ${ }^{222}$. Nonetheless, Elkin noted that even with a continued pro-business slant among Dallas' political leaders, the way in which citizens approached Dallas' bureaucracy had evolved since

${ }^{219}$ Jeffers, 2011; Morgan, 2004, pp. 132-138; Payne, 1994, pp. 357-359

${ }^{220}$ Elkin, 1987a, pp. 76-77; 1987b, pp. $42-43$

221 1987a, p. 144

222 19878a, p. 146 
the Thometz study. Specifically, Elkin found that citizens were increasingly drawn to interact with City Hall - not to further business interests or offer visions of the best way to bring vitality to Dallas - but instead to speak on behalf of their neighborhoods, or to demand public goods and services as bureaucratic clients ${ }^{223}$.

Improving upon the Thometz study, Elkin thoroughly wove racial tensions in Dallas into the narrative of the city's political- and economic evolution. Nonetheless, like the Thometz study before it, this study and its conclusions - are ultimately a product of an urban study conducted within the context of limited United States cities in the mid-to-late $20^{\text {th }}$ century. As a result, Elkin's “solutions" to the dominance of the entrepreneurial governing coalition are presented as national-level concerns, rather than local issues ${ }^{224}$. Additionally, because Elkin could only see Dallas through the constraining lens of a rigidlydefined public-private division of labor, he could not see alternative paths to a new decisionmaking structure - paths that utilize third-sector organizations and alternative economic development strategies, rather than national-level policy changes.

The Fordist crisis, urban political economy, and the Elkin study, in summary. While scholars abandoned the study of community power, both residents and firms were abandoning the communities themselves. Federal intervention strategies offered some hope of restoring cities, and the public-private partnerships that these strategies engendered portended a new kind of urban governance, the study of which would, in time, breathe new life into urban political theory ${ }^{225}$. This new perspective, urban political economy, succeeded in sidestepping many of the problems with both sides of the community power debates, and has been used to describe cities across the United States, as well as internationally. Using this

\footnotetext{
${ }^{223}$ Elkin, 1987a, pp. 71-78; Morgan, 2008, pp. 116-117

224 1987a, p. 146

225 Savitch \% Thomas, 1991, pp. 1-4
} 
perspective, the Elkin study of Dallas found the city's simple, political-business coalition had been replaced by a more complex model of interlocking relationships, internal discord among the business community, and political leaders who were (slightly) more inclined to serve their electorate, yet who still served within a system that was designed to ensure that business interests were ultimately given priority over other concerns ${ }^{226}$. Nonetheless, while urban scholars used these methods to study cities, the cities themselves were changing, in ways that progenitors like Elkin, Logan, Molotch, and Stone - like their predecessors - could not have imagined, and for which they could not have accounted in their studies and conclusions.

\section{Post-Fordism, Urban Political Economy, and the Need to Revisit Dallas}

In the decades since the Elkin study, the urban context has again shifted; first, the crisis of Fordism has given way to post-Fordism, a new socioeconomic paradigm that has reversed the economic- and population trajectories of many (though not all) cities in the United States; and second, third-sector organizations have expanded beyond their original missions and into public policy. As a result of these phenomena, the urban political economy approach, with its strict interpretation of the public/private division of labor, and its roots in the Fordist crisis, may need to be revisited. As the dominant theoretical model of urban governance, this study argues that it is imperative for urban political scholars to test the viability of what is now a (roughly) thirty year-old perspective. By re-examining Dallas, a city used previously to establish the validity of both the urban regime model broadly, and the city itself as an exemplar of the entrepreneurial governing coalition, the present study offers other urban scholars the opportunity to revisit urban regime analysis, and to consider (at the least) refining particular aspects of it. In the sections that follow, this study will first summarize

\footnotetext{
${ }^{226}$ Elkin, 1987b, pp. 35-36; Harding \& Blokland, 2014, p. 99
} 
particularly salient post-Fordist changes to United States cities throughout late $20^{\text {th }}$ and early $21^{\text {st }}$ centuries. Following this, it will focus on changes in Dallas following the Elkin study, especially those related to its business- and political leadership. Then, it will build a case for a fresh examination of the city's governing coalition.

\section{Post-Fordism and Central Cities in the United States}

As urban scholars of the late- $20^{\text {th }}$ and early $21^{\text {st }}$ centuries scoured cities across the United States $^{227}$ (and to some extent, abroad ${ }^{228}$ ) for evidence of urban regimes, cities themselves were undergoing significant economic and demographic reorganization, especially in- and immediately surrounding their respective CBDs. Against this backdrop, old ancillary members of governing coalitions - community development corporations (CDCs) and anchor institutions - began evolving their roles in economic development and policy decisions while, simultaneously, business leaders began exiting the politics of decisionmaking. This study argues that, while urban scholars publishing near the turn of the $21^{\text {st }}$ century identified several of these transitions, urban regime analysis - itself a product of research in the 1970s and early 1980s - failed to update itself with regard to these changes in the urban context. Importantly, this study does not fault earlier scholarship for failing to account for changes that had not yet happened, and instead argues that responsibility for advancing the collective understanding of contemporary urban governance falls to today's scholars.

Under the new paradigm of Post-Fordism, both economic resources and demographic trends have departed from their previous trajectories, and these changes have reshaped the built environments in central cities across the United States, and even in other

\footnotetext{
227 cf. T. Clark, 1994; DeLeon, 1992b, Elkin, 1987a; Lupsha, 1987; Pagano \& Bowman, 1995; C. Stone, 1989; Vogel, 1992; Whelan, 1987; 1994

228 cf. Davies, 2003, Harding, 1997; Kantor, Savitch, \& Haddock, 1997
} 
nations. In considering these economic changes, regionally-based, blue-collar manufacturing work has been largely (though not entirely) replaced by globalized flows of knowledgebased employment in technology and finance throughout the developed world. In considering demographic changes, the affluent (often white) employees of these technology and finance firms, as well as the ancillary businesses that support them (e.g. law, real estate development, advertising) often find themselves disillusioned with the suburban lifestyle, and are migrating back to central cities and adjacent neighborhoods. In response, former commercial cores have become high-end, mixed-use developments combining office space, luxury retail and housing, and cultural amenities like museums and art installations.

As new, competing interests flow into central cities, it may be that the older, "probusiness" decision-making bodies no longer hold as much influence over decisions being made in these areas, and further, there may be additional room for new actors with large resource pools, such as CDCs and anchor institutions, to find a role in policymaking, To better build this case, in the paragraphs that follow, this study will first discuss the economic and demographic transitions found in U.S. cities as a result of post-Fordism. Then, it will chronicle the expansion of third-sector organizations - particularly anchor institutions and CDCs - beyond their traditional roles and into urban policymaking.

Post-Fordist economic transitions. As an economic shift, post-Fordism can be summarized as a transition away from manufacturing as an economic engine, and into whitecollar firms in finance, investment, and real estate (FIRE) sectors, supported by localized producer services $^{229}$. Breakthroughs in transportation, communication, and information

\footnotetext{
${ }^{229}$ T. Clark et al., 2002, p. 494, 497; DeLeon, 1992, pp. 55; Giarratani \& Houston, 1989, pp. 549-552; Harvey, 1989, pp. 179-184; Jessop, 1993, p. 68; Judd \& Simpson, 2003, pp. 1058-1059; Kantor et al., 2012, pp. 28-29; Savitch, 1988, pp. 19-21
} 
technology ${ }^{230}$, combined with a number of trans-national trade agreements ${ }^{231,232}$, have rapidly accelerated the decline of urban fortunes within the Rust Belt ${ }^{233}$. However, they have also have sparked unmatched growth and prosperity in communities referred to as global cities ${ }^{234}$. From their positions as hubs in the global financial- and economic network, global cities have experienced significant employment gains and wealth generation, benefitting from the agglomeration of knowledge-based industries and innovation ${ }^{235}$.

Because firms can (and often do) find specializations in the global marketplace, there is a wealth of opportunity for global cities to be located all over the world, without necessarily engaging in direct competition with one another ${ }^{236}$. Each of these global cities becomes a significant agglomeration of highly specialized firms, and participates in the geographic restructuring of economic flows throughout the world ${ }^{237}$. In the post-Fordist economy, firms choose to locate in specific cities in order to harness local market knowledge, to convert that knowledge into profit, and to integrate that knowledge into their global enterprise ${ }^{238}$. As a result of these advantages, global cities are attractive to foreign investment - that is, investment in domestic businesses or the creation of new businesses in a city by international investors ${ }^{239}$. In this way, global cities like San Francisco and Boston have become international centers of knowledge production and economic power ${ }^{240}$. This prosperity comes at a cost, though, and is far-from uniform in its spatial distribution ${ }^{241}$. Although many cities have found prosperity in the new, global economy,

${ }^{230}$ Bluestone \& Harrison, 1986, pp. 41-42; Moretti, 2012, pp. 26-30

231 e.g. NAFTA, ASEAN

232 Audirac et al., 2012, pp. 231-232; Henderson et al., 2002, pp. 450-451

${ }^{233}$ Harvey, 1989, pp. 159-164; Rowthorn \& Coutts, 2004, pp. 767-769

234 Glaeser, 2011 pp. 34-40; Robinson, 2009, pp. 13-14; Sassen, 2000, pp. 21-24, 141-143Savitch, 2002, p. 20

235 Amin, 1999, pp. 370-371; Audirac at al., 2012, p. 230; Porter, 2000, pp. 22-23; Robinson, 2009, pp. 13-14

236 Sassen, 2000, p. 54

237 Amin, 1999, pp. 368-369; Beaverstock et al., 2000, p. 45; Sassen, 2000, pp. 21-30

${ }^{238}$ Ellison \& Glaeser, 1997 , pp. 890-891; Storper, 1990, p. 431; 1997, pp. 3-4

${ }^{239}$ Robinson, 2009, pp. 8-9; Sassen, 2000, pp. 12-18

${ }^{240}$ Glaeser, 2011, pp. 4-5; Kantor et al., 2012, pp. 23-27

${ }^{241}$ Brenner, 2012, p. 21; Harvey, 1989, pp. 147-159; Moretti, 2012, pp. 13-17 
there is simply not enough investment to go around ${ }^{242}$, which has created (or exacerbated) uneven economic development ${ }^{243}$. Indeed, by comparison, far more cities have been excluded from the post-Fordist economic boom than have been able to find a place within $\mathrm{it}^{244}$.In this new economic geography, the upper echelons of prosperity rest within global cities like San Francisco, New York City, London, Tokyo, and Dallas, while many other cities find themselves locked in a pattern of disinvestment and decline, bound to the fate of a shrinking manufacturing sector ${ }^{245}$. Additionally, and of concern with respect to entrepreneurial governing coalitions, because many firms in FIRE sectors are branches of globalized firms, private-sector leaders often have few - if any - particular ties to any given place ${ }^{246}$, and often do not become lasting members in pro-development governing coalitions ${ }^{247}$.

Post-Fordist demographic transitions. Contrary to the bleak predictions of “indifference and abandonment" regarding urban $\operatorname{cores}^{248}$, the paradigm shift that caused so much disinvestment and abandonment among central cities in the United States has also revived a subset of them, albeit no longer as centers of capital creation alone ${ }^{249}$. Beyond commercial investment, CBDs are also becoming home to a variety of cultural- and entertainment amenities such as, art galleries, university and hospital expansions, and upscale retail and dining, which in turn has attracted wealthier, residents to return to urban cores ${ }^{250}$. Finally, these younger, affluent professionals are also bringing with them a particular "leftliberal" ideology and political activism that may have implications for local elections,

\footnotetext{
242 Albecker, 2010, pp. 103-106; Storper, 1994, p. 197) or innovation (Harvey, 1994, pp. 362-363; Soja, 2010, pp. $47-49$

243 Robinson, 2009, pp. 18-19; Sassen, 2000, pp. 41-44

244 D. Smith \& Timberlake, 2002, p. 117

245 Audirac \& Alejandre, 2010, pp. 20-21; Ellison \& Glaeser, 2007, p. 51; Harvey, 1989, pp. 147-159; Sassen, 2000, pp. 136-137

${ }^{246}$ DeLeon, 1992a, p. 559; Hanson et al., 2010b, p. 63-70

${ }^{247}$ Giarratani \& Houston, 1989, p. 551; Hanson et al., 2010a, pp. 4-9; Harvey, 1989, pp. 159-164; Rowthorn \& Coutts, 2004, pp. 767-769;

Savitch \& Thomas, 1991

248 Sternlieb, 1971 , p. 15

${ }^{249}$ T. Clark et al., 2002, pp. 494-495; Strom, 2008, p. 37

${ }^{250}$ Clerval, 2006, pp. 6-7; Eisinger, 2000, pp. 316-317; Florida, 2006, pp. 26-29; Strom, 2008, pp. 37-38; Sumka, 2010, pp. 326-327
} 
especially in cities like Dallas and Atlanta whose decision-making structures are closely associated with the entrepreneurial-type governing coalition ${ }^{251}$.

Additionally, a subset of literature suggests that this changing demographic, unsurprisingly, carries with it a racial component. As Chapter 1 noted, a traditional reading of the racial composition of central cities across the United States ${ }^{252}$ describes the chocolate cities, vanilla suburbs model (shown in figure 2.01) of largely white suburbs surrounding predominantly African-American central cities, resulting from "white flight" throughout the mid- $20^{\text {th }}$ century, subsidized by federal policies, highway-building campaigns, and government-backed suburban mortgages ${ }^{253}$. While this model adequately describes cities in the wake of Fordist consumption patterns, it fails to account for the post-Fordist gentrification of many inner-city neighborhoods by white millennials and "urban pioneers." This "back to the city" counter-transition has the effect of pushing minority groups (and the businesses that serve them) out of the central city, and into the inner-ring communities that were once populated by the first waves of white flight ${ }^{254}$. Addressing the new reality of postFordist central cities, a new model - the new donut (shown in figure 2.02) ${ }^{255}$ - has emerged. In this model, white central neighborhoods are surrounded by majority-minority communities, which are themselves encircled by white outer-ring suburbs and exurbs.

${ }^{251}$ Hermann \& Leuthold, 2002, p. 2; Ley, 1994, p. 56

${ }^{252}$ S. Fainstein \& N. Fainstein, 1986, pp. 8-9; R. Hill, 1986, p. 91

${ }^{253}$ Dreier, 1993, p. 1377; Jackson, 1985, pp. 190-218

${ }^{254}$ Beauregard, 2010, pp. 11-23; Florida, 2003, pp. 8-10; Hartman, 2002, pp. 331-333; Imbroscio, 2004, p. 588; Lees, 2000, pp. 399-400;

Solnit \& Schwarzenberg, 2002, p. 14, 18-21; Zukin, 1987, pp. 133, 135-137

${ }^{255}$ Juday, 2015, pp. 3-4 


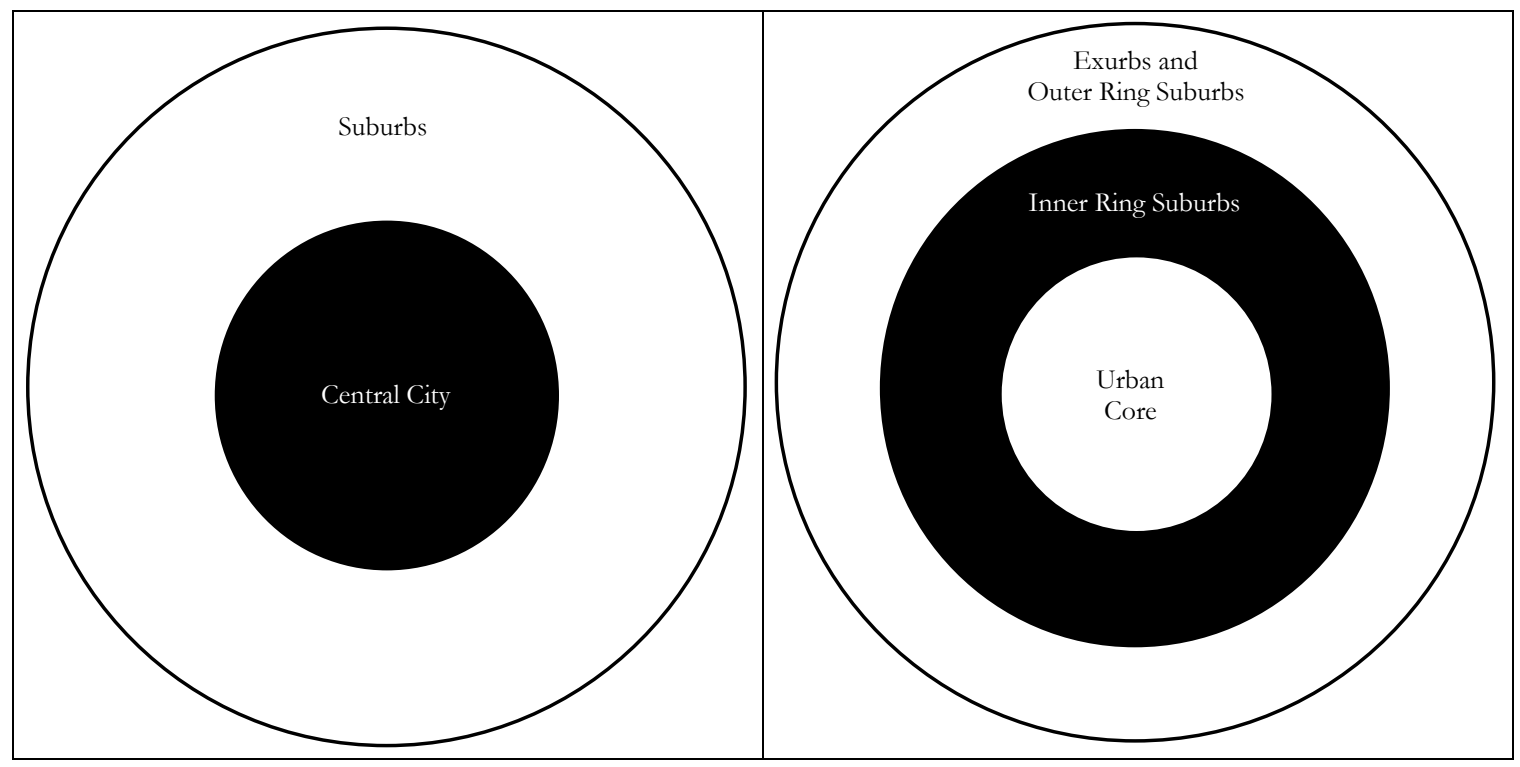

Transitions in the roles of CDCs and anchor institutions. As cities' economic-

and demographic profiles evolved under post-Fordism, so too did their rosters of actors willing to engage in the politics of decision-making. Indeed, while private-sector elites withdraw from governing coalitions, a subset of urban scholarship suggests that CDCs and anchor institutions are advancing their roles as coalition members ${ }^{256}$. In the paragraphs that follow, this study will first introduce the growing role of CDCs beyond their traditional involvement in low-income housing projects, and then, it will describe the efforts of urban anchor institutions to revitalize economically-marginalized communities without the use of the "federal bulldozer."

CDCs: moving beyond low-income housing. Most (though not all) community development corporations were founded during the height of the Great Society, as community action agencies (CAAs) charged with directing federal support into urban neighborhoods ${ }^{257}$. Even as small-government conservatives dismantled the Great Society, many cities greatly increased their reliance on the now-rebranded CDCs in order to address

256 T. Clark et al., 2002, pp. 495-496; De Socio, 2007, p. 340

${ }^{257}$ Vidal \& D. Keating, 2004, pp. 126-127; Zdenek, 1987, pp. 112-114; Zielenbach, 2000, pp. 230-231 
short-term, localist needs, such as low-income housing and social welfare provision in marginal neighborhoods ${ }^{258}$. Public-sector reliance on these organizations increased throughout the 1970s and 1980s, as federal policies cut cities off from federal development funds, while allowing CDCs to take advantage of the UDAG program, and later, the community development block grant (CDBG) that replaced it. Across the country, CDCs used these funds to accelerate expansion into projects like business enterprise development, commercial real estate, venture capitalism, community finance, and urban redevelopment ${ }^{259}$. Finally, since the 1990s, federal Empowerment Zone / Enterprise Community funds have been made available to CDCs, who are tasked with representing the needs of the communities being targeted by these federal programs ${ }^{260}$.

At the local level, CDCs draw cross-sector support through their boards of directors, which often contain representatives from state- and federal organizations, political and business leaders, private philanthropists, clergy, and neighborhood members, who combine their various resource pools in service of organizational projects ${ }^{261}$. Because of these connections, there is some evidence that CDCs have become a driving force in skewing many urban agendas away from value-neutral development and back toward environmentaland social equity concerns ${ }^{262}$. However, even with this support, CDCs are frequently undercapitalized, and lack the capacity to fully address growing needs in economically marginalized communities; these challenges often prevent all but the largest CDCs from

\footnotetext{
${ }^{258}$ Clavel, Pitt, \& Yin, 1997, pp. 447-450; Kettl, 2000, pp. 493-494; Vidal, 1992, pp. 61-62; Vidal \& D. Keating, 2004, pp. 132-134; Yin, 1998, pp. 139-143; Zdenek, 1987, pp. 115-126; Zielenbach, 2000, pp. 230-231

259 Adams, 2014, pp. 52-62; Clarke \& Gaile, 1992, pp. 188-189; Clavel, Pitt, \& Yin, 1997, p. 437; Frisch \& Servon, 2006, pp. 90-91; Imbroscio, 1998, p. 239; Milward \& Provan, 2000, pp. 259-360; Romzek, LeRoux, \& Blackmar, 2012, p. 442; Saito \& Truong, 2015, p. 270; Schill, 1996, pp. 753-754, 766-773; Vidal, 1992, pp. 70-73; Wolch \& Geiger, 1986, pp. 5-8; Yin, 1998, pp. 143-154; Zielenbach, 2000, pp. 231-234

${ }^{260}$ Clavel, Pitt, \& Yin, 1997, pp. 435-437; Gittell \& Wilder, 1999, pp. 341-342; Wallace, 1999, pp. 153-154

${ }^{261}$ Bruyn, 1987, pp. 17-18; Clavel, Pitt, \& Yin, 1997, pp. 432-433; Vidal, 1992, pp. 39-40; Vidal \& D. Keating, 2004, p. 125-126; Yin, 1998, pp. $137-138$

262 John Clark, 1992, pp. 153-154; Eisinger, 2000, pp. 328-331; Logan, Whaley, \& Crowder, 1997, pp. 607-608; Najam, 2000, pp. 3-4; Saito \& Truong, 2015, pp. 270-271; Walcott, 1999, pp. 657-659
} 
being as effective as various scholars suggest they could be ${ }^{263}$. Further, CDCs are often considered challenging to evaluate; as CDCs venture away from traditional "charitable" activities like housing and social services, their activities look increasingly like those of private developers, but their redistributive objectives encourage these organizations to develop in locations that traditional, for-profit developers would find undesirable, so it may be inaccurate to compare them to private-sector peers ${ }^{264}$. As a final complication, a CDC that is successful as an organization may not necessarily be benefitting its resident community $^{265}$.

One thread of scholarship outlines a number of challenges surrounding CDCs, including evaluating their effectiveness, connecting measures of organizational success to community improvement, and problems with organizational capacity. Alternatively, an additional thread highlights an expansion of CDCs into long-range planning and urban economic development, a connectedness to urban decision-makers, and the successful efforts of some CDCs in affecting urban policies. As a result, it may be that, in spite of their challenges, some subset of CDCs have achieved central positions within urban governing coalitions. If a well-designed study could find evidence of this, then those organizations could be studied to understand how they were able to grow beyond "ancillary status" within these coalitions, and the effects of this on urban economic development policies and projects.

Anchor institutions: urban development without the federal bulldozer. As organizations that are geographically-linked (or "anchored") to their surrounding cities, anchor institutions like universities and hospitals are uniquely situated to bring about positive

\footnotetext{
${ }_{263}$ Clavel, Pitt, \& Yin, 1997, pp. 437-438; Gittell \& Wilder, 1999, p. 343; Rubin, 1993, p. 434; Stoecker, 1997, pp. 2-3, 6-10; Wallace, 1999. P. 169 
improvements in their communities. The idea that anchor institutions can be catalysts for cities looking to solve complex urban problems reaches back to the late 1950s, though for much of the $20^{\text {th }}$ century, these organizations did not apply significant effort to advance beyond research and teaching ${ }^{266}$. Instead, throughout the 1960s, 1970s, and early 1980s, urban hospitals and universities used hundreds of millions of dollars in grants from the Ford Foundation and the U.S. Department of Health, Education, and Welfare to engage in destructive expansion projects that replaced economically-marginalized neighborhoods with new- and expanded facilities as part of grand development plans ${ }^{267}$. By the early 1990 s, decades of mounting losses in federal- and state funding, as well as significant public backlash regarding their untampered mid-century expansion projects ${ }^{268}$ forced anchor institutions to rethink their commitments to their missions, any many realized that that their missions could be better-served by improving the conditions in their surrounding communities $^{269}$.

In $21^{\text {st }}$-century cities across the United States, anchor institutions have become key players in local economies. Taken as a whole, urban universities and hospitals across the United States collectively represent over $\$ 1$ billion in payroll, and more than $\$ 1$ trillion in overall economic activity, and in the largest 20 American cities, frequently among the largest non-governmental employers. ${ }^{270}$ Additionally, because they are geographically anchored in place, these institutions are principally self-interested in the local economy, and are once again showing an interest in the vitality of their surrounding neighborhoods ${ }^{271}$. Increasingly, urban universities and hospitals are actively working to address economic inequity in

266 Alperovitz \& Howard, 2005, p. 142; Harkavy, 2009, pp. 147-149

${ }^{267}$ Bailey, 1959, pp. 291-292; Coffey \& Deirwechter, 2005, p. 81; Strom, 2008, pp. 122-127

268 Adams, 2003, pp. 573-576; Cummings et al., 2005, pp. 151-173; Coffey \& Deirwechter, 2005, pp. 81-82; Deitrick \& Soska, 2005, pp. 3335; Strom, 2008, pp. 119-121

${ }^{269}$ Alperovitz \& Howard, 2005, pp. 14-146; Cisneros, 1996, p. Deitrick \& Soska, 2005, pp. 38-39; Harkavy, 2009 , p. 149

270 Adams, 2003, pp. 572-573; Dubb, McKinley, \& Howard, 2013, p. 1; Misra, 2014, p. 2; T. T. Ross, 2014, pp. 2, 10-13

271 Adams, 2014, pp. 62-66; Dubb \& Howard, 2012, pp. 4-9 
economically-marginalized areas, leveraging their status as major employers and purchasers in order to engage in more equitable, value-driven economic development strategies in economically-marginalized neighborhoods that have historically been ill-served by valueneutral development ${ }^{272}$. However, at the city-, state-, and federal level, officials have largely failed to develop policies to utilize anchor institutions as partners in urban economic development, and it appears that current policies are ill-suited for the needs and capabilities of these organizations - in effect, public-sector decision-makers simply do not know how to work with economic development organizations outside of the private sector, and research on this appears to be slow in forthcoming. As a result, although anchor institutions are (arguably) critical for improving community infrastructure, supporting their efforts is often not seen as a priority by urban decision-makers ${ }^{273}$.

Transitions in the roles of CDCs and anchor institutions, in summary. As cities have grown within the post-Fordist, knowledge-based economy, urban anchor institutions, as centers of research and technological advancement, have become their economic centerpieces, directly injecting millions of dollars into local economies through purchasing and payroll. In limited cases, these organizations are leveraging this economic power to inject new life into economically-marginalized neighborhoods, but even in such cases, local policies usually fail to adequately support anchors' efforts, limiting their overall effectiveness in bringing about equitable economic development for cities' most concerning neighborhoods. As large employers and economic engines, these institutions are well-positioned to become central members of urban governing coalitions, but considering that urban policies have not adequately adapted to support their economic development projects in the same way that

\footnotetext{
272 Alperovitz \& Howard, 2005, pp. 151-153; Dubb, McKinley, \& Howard, 2013, pp. 1-2; Frisch \& Servon, 2006, pp. 89-91; Harkavy et al., 2009, pp. 148-149; T. T. Ross, 2014, pp. 10-14; Rubin, 1993, pp. 428-429; Zuckerman et al., 2013, pp. 41-57

273 Adams, 2003, pp. 573, 579-583; Harkavy, 2009, pp. 150-151
} 
these policies continue to benefit private-sector economic development projects, it would appear that they have not advanced beyond their traditional, ancillary positions. Like with CDCs, if a well-designed study could find evidence of anchor institutions operating as core members of a governing coalition, those organizations could be further examined in order to accomplish this, as well as the effects of this increased involvement with respect to urban economic development projects.

\section{Post-Fordism in Dallas}

Recall that the Elkin study found two key components that shifted Dallas' governing coalition away from the "pure" political economy found in the Thometz study: first, disunity within the business community; and second, the transition from a purely at-large city council to a mixed council of district-based and at-large members. Since the Elkin study, these components have only amplified. First, as the study was published, Dallas' economy was gutted by the Savings \& Loan Crisis and collapse of oil markets, only to be reborn in uneven, disruptive ways. Second, the lawsuit that forced the city to change its at-large councilmember elections to an "8-3" plan was again challenged under the Voting Rights Act, resulting in another restructure in 1994. Certainly, Elkin could not have foreseen these changes, just at Thometz could not have seen the changes that Elkin noted when arguing that the Thometz characterization of Dallas' decision-making structure was no longer accurate; nonetheless, this study argues that it is time for a new study to reevaluate Elkin's vision of a complex, business-dominated entrepreneurial governing coalition. In the sections that follow, this study will first examine Dallas' economic struggles and resurgence, then it will look at the city's political reconfiguration, and finally, it will broadly discuss the city's demographic changes. 
Economic transitions. Between 1981 and 1986, Dallas' seemingly-invincible economy, which had grown steadily since the end of World War $\mathrm{II}^{274}$, was crippled by a catastrophic decline in the oil market, as well the nearly-simultaneous Savings and Loan Crisis $^{275}$. The state as a whole, and Dallas in particular, had enriched itself over nearly a decade of oil speculation, funded on loans secured by extraction equipment, stock valuations, promises of future profit, and many loans were issued with little (if any) collateral, from recently-deregulated savings and loan institutions ${ }^{276}$. Eager to compete with these institutions, even traditional banks engaged in ever-riskier loan offerings, over-leveraging assets and over-investing in oil and land speculation ${ }^{277}$. The Saudi embargo on oil had brought incredible riches to the Texas economy, and to Dallas in particular, but the boom could not last. By the mid-1980s, utility companies diversified their fuel sources to include coal, natural gas, and nuclear power, while federal regulations forced fuel economy to rise in passenger vehicles; as a result of the reduced demand for oil, many resource extraction operations were forced into bankruptcy ${ }^{278}$.

As the owners of now-worthless oil drilling equipment and loans that would likely never be repaid (in full or in part), Dallas' banks could not continue operating. By 1992, 80\% of the region's savings and loans were insolvent, 506 banks had failed, and of the state's 10 largest banks, 9 had failed. Further, all of Dallas' locally-owned financial institutions and insurance firms - fully half of its economy - either abandoned the city or folded entirely ${ }^{279}$. For Dallas' other large industries - textiles, electronics, and defense equipment, the picture was similarly bleak. By 1988, surging competition from Asian manufacturing firms drove

\footnotetext{
${ }^{274}$ Grant, 1996, pp.19, 32-43

275 Grant, 1996, p. 20; Hazel, 1997, p. 61; Payne, 1994, pp. 398-399

${ }^{276}$ Burrough, 2009, pp. 356-358; Grant, 1996, pp. 19-21

277 Grant, 1996, pp. 49-50

278 Burrough, 2009, pp. 406-407

${ }^{279}$ Grant, 1996, pp. 2, 31, 216; Rice, 2007, pp. xviii-xix
} 
down the costs of computer chips, which in turn put many of Dallas' electronics manufacturing firms out of business, the giant Texas Instruments nearly included ${ }^{280}$. International pressure also impacted Dallas' textile manufacturers, as factory owners moved production to Mexico in the early-mid 1990s, lured by cheaper labor costs even before NAFTA further distorted the economics of U.S.-based manufacturing ${ }^{281}$. Indeed, for a brief moment in the late 1990s, the exodus of textile manufacturing to Mexico was so great that the country supplanted China as the largest clothing supplier to the U. ${ }^{282}$.

Finally, as the Cold War came to an end, defense spending cutbacks began hammering Dallas' beleaguered manufacturing sector. Between 1985 and 1989, defense spending in the United States was cut by roughly $20 \%$ in real terms ${ }^{283}$. For the Dallas area, which by 1988 was one of the largest recipients of DOD expenditures ${ }^{284}$, the effects were devastating, triggering thousands of layoffs throughout the industry, including layoffs of $82 \%$ of 'Texas Instruments' defense employees between 1990 and 1991, over 40\% of whom remained unemployed 9 months later ${ }^{285}$. Without oil revenues, and now without defense contract revenues, the last of Dallas' seemingly-endless capital streams dried up, and many firms throughout the city followed area banks into insolvency ${ }^{286}$. As a result of corporate bankruptcy and abandonment, by the early 1990s, 30\% of Dallas' CBD was vacant ${ }^{287}$, and many of its skyscrapers were so empty that they were referred to as "see-through" buildings $^{288}$.

\footnotetext{
${ }^{280}$ Borrus, 1997, pp. 1-2; Usborne, 1996

${ }^{281}$ Davis, 1993

${ }^{282}$ Gruben, 2006, p. 12

${ }^{283}$ Markusen, 1992, p. 392; Rundquist, Lee, \& Rhee, 1996, p. 277

284 Atkinson, 1993, pp. 108-109; U.S. Congress Office of Technology Assessment, 1992, p. 21

${ }^{285}$ U.S. Congress Office of Technology Assessment, 1992, pp. 96-99

${ }^{286}$ Grant, 1996, p. 20

${ }^{287}$ Grant, 1996, pp. 21-22

288 Burrough, 2009, pp. 433-434
} 
Eager to return to economic "boom times," civic first leaders looked to the business community for help; after all, when Dallas looked to rebrand itself after the Kennedy assassination, a group of civic-minded business elites stepped in to lead the charge. A quarter-century had passed since those leaders were in their prime; many were retiring (or dying), and had failed to groom their successors for positions in the governing coalition. The men and women who were rising to the highest echelons of business leadership often had little interest in the politics of development, and many remained divided over infrastructure projects and urban redevelopment plans ${ }^{289}$. Nonetheless, the remaining “old guard' successfully exploited divisions among the city councilmembers, and strong-armed the council and city manager into finding a new way forward for the city ${ }^{290}$. The result was that Dallas hired firms to market the city around the mythology surrounding its football team, as well as the popular Dallas soap opera. In addition, the council engaged in several rounds of urban redevelopment projects throughout Dallas' northern neighborhoods and central business district, although many of these projects fell far short of the grand ideas put forward by the "Dallas Plan," a 30-year development agenda approved by the city council in $1994^{291}$.

These efforts were highly successful, and since the mid-1990s, Dallas has seen economic growth, even as other parts of the nation decline $e^{292}$. In 2010, the city contained one of the highest agglomerations of Fortune 500 headquarters in the country ${ }^{293}$, and in addition, the once-abandoned skyscrapers that define Dallas' skyline are being converted into mixed-use units, adding thousands of new residential units to the area ${ }^{294}$. However, this

\footnotetext{
289 P. Hill, 1996, pp. 171-172

290 Morgan, 2004, pp. 236-239

${ }_{291}$ Graff, 2008, pp. 11-13; Morgan, 2004, p. 238; Payne, 1994, pp. 416-418

${ }^{292}$ Dallas County Community College District, 2014, pp. 2-3; Halkais, 2014

293 Dallas Convention \& Visitors Bureau, 2015; Fortune, 2014

${ }^{294}$ Dallas Convention \& Visitors Bureau, 2015
} 
development, which quite obviously favored the majority-white central- and northern sections of the city, engendered fierce political resistance from neighborhood groups in the city's southern half ${ }^{295}$. To quell social unrest, city leaders created a trust fund to improve access to credit for businesses and community organizations in the city's majority-nonwhite southern neighborhoods ${ }^{296}$, but it is unclear whether this fund has actually been used effectively, and the city has been accused of mishandling and misappropriating funds, while the area continues to suffer from decades of disinvestment and decline ${ }^{297}$.

Political transitions. While Dallas' economic transition has been relatively welldocumented by academia, its political transition is less well-documented, as its effects are more recent than many of the works that chronicle the city. The " $8-3$ " plan, identified by Elkin, was only a partial success for advocates of representative governance. As soon as it had been approved by the federal judge, the city had to determine how best to draw the eight council districts, but found it impossible to ensure adequate representation for the growing Hispanic and African-American populations, as well as changing demographics resulting from continued white flight ${ }^{298}$. Federal approval for Dallas' 8-3 proposal relied upon demographic data from the 1970 census, but by 1980, these data - and the raceconscious election districts derived from them - were already obsolete. In particular, between 1970 and 1980, the city's Hispanic population grew by 62\%, and its African American population by $25 \%$, while the white population fell by $9 \%$ over that same period; these changes would require that some of the white-majority council districts would need to be redrawn, or merged to become primarily African American, and somehow the city would also have to create a district for people identifying as Hispanic, without increasing total the

${ }^{295}$ Graff, 2008, pp. 202-203; P. Hill, 1996, pp. 169-171

${ }^{296}$ City of Dallas Office of Economic Development, 2010, p. 3

${ }^{297}$ Elliott, Summey, \& Kokel, 2009, p. 95; Morgan, 2004, pp. 245-246; Nunn, 2014; Schutze, 2014

${ }^{298}$ Morgan, 2004, p. 138 
number of districts - a feat that city staffers argued was impossible ${ }^{299}$. Further, political- and popular uproar over converting "white" districts into "black" districts under the 8-3

proposal engendered a variety of alternative proposals, including the creation of "quadrantbased" councilmembers to represent quarters of the city, and who would serve alongside district-based councilmembers, and the creation of at-large council seats elected by only half of the city ${ }^{300}$.

Ultimately, of the even reapportionment plans offered by the city manager's office, the city council would approve the quadrant-based 8-4-1 option for federal approval ${ }^{301}$. This move engendered fierce resistance from the city's African American community, with tensions reaching a breaking point during a council meeting when activists locked arms and sang We Shall Overcome at a 1989 council meeting concerning the plan ${ }^{302}$. By 1990, and before any elections could be held, the 8-3 system was ruled in violation of the Voting Rights Act, based on amendments made to the act after the 8-3 plan received initial approval ${ }^{303}$. In 1990, a federal judge ruled that the 8-4-1 system was also unacceptable, and the city's attempt to appeal to the Justice Department also met with defeat. Meanwhile, an alternative, 14-1 plan, in which 14 councilmembers would be elected by districts in which they resided, with the mayor elected at large, was defeated by Dallas voters; however, courts ordered the city to conduct its upcoming elections under the 14-1 plan, a plan that remains in-effect today ${ }^{304}$.

In the years following this transition, Dallas' city council is more racially diverse than ever before, with the city electing its first African-American mayor in 1995, and its first minority-majority city council in $1999^{305}$. In addition, under this new system, city

\footnotetext{
${ }^{299}$ Jeffers, 2011; Morgan, 2004, pp. 137-138

300 Jeffers, 2011; Morgan, 2004, p. 139

${ }^{301}$ Morgan, 2004, pp. 138-139

302 Jeffers, 2011

303 Morgan, 2004, p. 140

304 Jeffers, 2011; Morgan, 2004, pp. 124-150

${ }^{305}$ Jeffers, 2011; Morgan, 2004, p. 197
} 
councilmembers hoping for re-election are forced to evaluate- and address the demands of their districts, rather than the desires of business elites ${ }^{306}$. A side-effect is that council districts are often operated more like fiefdoms than parts of a greater whole, and with this approach, the opportunities for corruption are increased dramatically; indeed, since the inducement of the 14-1 system, at least three major corruption scandals have erupted, including the 2009 bribery and extortion conviction of the city's Mayor Pro Tem related to public housing contracts ${ }^{307}$. Absentee ballot fraud has also become a concern, peaking in 2001 when a judge disqualified absentee ballots and changed the outcome of a council election in southern Dallas ${ }^{308}$.

Demographic transitions. Unquestionably, Dallas has historically been a segregated city. Since (at least) the 1930s, city policies have reflected a city deeply divided both by the Trinity River (which splits the city into northern- and southern halves), and by race, with people identifying as White tending to cluster north of the river, and minorities, particularly people of Hispanic or Latino heritage and people identifying as Black or African American, confined to Oak Cliff, south of the Trinity ${ }^{309}$. Even as Dallas' economy has largely rebounded from the collapse of the oil market and the Savings \& Loan Crisis, not all of the city has found a way to thrive; indeed, much (though not all) of the city's southern half continues to suffer from decades of disinvestment and decline, resulting from white flight that followed racial violence and civil rights legislation in the 1960s, and the forced integration of Dallas' schools in $1971^{310}$. Although a comprehensive study of Dallas' demographic transitions since the mid-1980s is beyond the scope of this study, a significant

\footnotetext{
${ }^{306}$ Hazel, 1997, pp. 55-56; P. Hill, 1996, pp. 170-171

307 Jeffers, 2011; Schutze, 2009; Trahan, 2010

308 Morgan, 2004, pp. 192-193; Schutze, 2001

${ }^{309}$ Graff, 2008, pp. 157-164, 181

${ }^{310}$ Elliott, Summey, \& Kokel, 2009, p. 95
} 
portion of that story can be told through the rise, fall, and rebirth of these two central neighborhoods. The first of these, North Oak Cliff, is traditionally considered to be predominately-nonwhite, economically marginalized community, but in recent years has begun to rebound from decades of disinvestment, while the second, Downtown Dallas, is the traditional hub of the city's economic activity, the home of several of Dallas' most identifiable landmarks, and is currently undergoing a transformation from abandoned corporate capital accumulator to a vibrant, mixed-use urban hub.

North Oak Cliff. Recall that after whites abandoned the neighborhood, people from African American and Hispanic neighborhoods moved in to replace them, though often as renters rather than owners. Minority-owned businesses replaced those formerly owned by whites, and while commercial corridors had changed by the late 1970s, commercial activity nonetheless remained. Further, attracted by depressed home values, a subset of whites - the "urban pioneers" began to return to the area ${ }^{311}$, and beginning in the 1980s and early 1990s, developers like Jim Lake Jr. and David Spence began to redevelop portions of North Oak Cliff, primarily surrounding an area now known as the Bishop Arts District $^{312}$. In addition, the 2010 completion of a new bridge linking North Oak Cliff to Downtown Dallas has spurred additional development in the area; in-line with the new donut model, this has attracted wealthier, younger whites into the neighborhood ${ }^{313}$. While this revival of interest in North Oak Cliff is beginning to reverse decades of disinvestment, many fear the negative effects of gentrification - particularly the displacement of minority residents and businesses ${ }^{314}$.

${ }^{311}$ Elliott, Summey, \& Kokel, 2009, pp. 113, 117; Merwin, 1977

${ }^{312}$ Elliott, Summey, \& Kokel, 2009, pp. 117-118; 2013, p. 59; Huang, 2014

${ }^{313}$ D Magazine, 2016; Huang, 2014; Reitz, 2015

314 Grigsby, 2015; Nicholson, 2015; Prior \& Kemper, 2005, pp. 197-201 
Downtown Dallas. While North Oak Cliff is experiencing a (somewhat

controversial) revival, Downtown Dallas is experiencing a new birth - not as a center of pure capital accumulation, but as a center of both accumulation and consumption. Beginning at the dawn of the $21^{\text {st }}$ century, hundreds of apartment units, condominiums, and townhouses have been added each year, built on an edgier, urban aesthetic, and with the support of a Public Improvement District that reinvests levied fees into what has become, since the early 2000s, a white-majority neighborhood ${ }^{315}$. Since 2011 , this transformation has dramatically accelerated under Downtown Dallas 360, a comprehensive area redevelopment plan. This plan was (and still is) billed as a way to bring together public officials, city staff, private developers, and a nonprofit development corporation in order to both encourage- and guide redevelopment projects throughout the neighborhood ${ }^{316}$. Initial stages of the plan focused on infrastructure improvements ${ }^{317}$, while more recent stages emphasize attracting retail and dining option into areas surrounding a series of newly-built museums, urban parks, and outdoor art installations ${ }^{318}$. Early indicators suggest that the plan has been successful so far; in 2014, over 1.5 million square feet of office space were leased, renewed, or expanded in Downtown Dallas, and the number of real estate transactions reached a level unseen since the boom times of the 1980s. In addition, since 2011, the neighborhood has added over 4,600 new residences ${ }^{319}$.

\section{Post-Fordism, urban political economy, and the need to revisit Dallas, in}

summary. Contrary to the bleak outlooks of mid-late $20^{\text {th }}$ century urban scholars, the postFordist transition that caused so much disruption across the United States also revived a

315 Prior \& Kemper, 2005, pp. 199-207

316 Downtown Dallas Inc., 2015, p. B3; Grimes, 2010

${ }^{317}$ e.g. sidewalk repairs, bicycle lanes, improved lighting and crosswalks

318 Hall, 2015; Perez, 2014; Prior \& Kemper, 2005, p. 197

${ }^{319}$ Downtown Dallas Inc., 2015a, p. B4 
subset of these localities. This transition was much an economic shift as a social one, with locally-owned firms and manufacturing ceding ground to multinational organizations and a knowledge-based economy, while a subset of the affluent whites who abandoned cities during white flight return to reclaim urban neighborhoods for themselves. Within Dallas in particular, although the 1980s saw the collapse of its oil- and financial markets, which left the city's urban core significantly vacant, and its economy in shambles, by 2010, the city had largely rebounded, and its CBD had begun a revitalization process that continues today. As in many (if not all) central cities growing under the knowledge-based, economic aspects of the post-Fordist paradigm, the economic prosperity in Dallas is not uniform, and people of color living in economically-marginalized neighborhoods (primarily in southern Dallas) face threats of gentrification and displacement.

As cities transition in the early $21^{\text {st }}$ century, so too do the coalitions that lead them. While old guard leaders within governing coalitions remove themselves from the politics of decision-making, some cities are seeing a growth in the roles of anchor institutions and CDCs in governing coalitions. Although the involvement of CDCs and anchor institutions in Dallas' decision-making structure is unclear, literature already suggests a weakening of the “old guard," resulting in part from economic forces, but also from Dallas' dramatic, courtordered restructuring of its system of electing city leaders. As a result of these changes, four decades after the growth machine heralded in a new perspective on urban governance urban political economy - it may be time to revisit Dallas, and to once again reconsider big city politics.

\section{Chapter Summary}

Beginning in the late 1970s, but primarily in the 1980s and early 1990s, urban scholarship reflected the changes in the urban context since the late 1950s, and scholars 
suggested that the "community power" theories of urban governance could no longer adequately conceptualize urban governance in practice. Two models emerged to fill this then-void in the literature - growth machine theory and urban regime analysis - which conceptualized urban governance from a systemic, behavioral perspective, and as a result, quickly grew to dominate the study of urban politics.

Outside of the theoretical concerns regarding both of these theoretical perspectives, this study argues that, given the changes in the urban context beginning in the late $20^{\text {th }}$ century, especially the economic- and demographic transitions in United States cities, as well as a growing role of CDCs and anchor institutions, theories of contemporary urban governance may no longer be accurate in modeling the actualities of contemporary urban governance. Indeed, this study proffers that, as a result of continued changes in the urban context, primarily the effects of post-Fordism on urban cores, and the expansion of CDCs and anchor institutions into economic development, big city politics are again in transition, and the structural components of urban governance need to be revisited. A well-designed study, therefore, may be able to fill this emerging gap in the literature. In Chapter 3, this study will outline the methods it will use in order to again revisit the nature of urban governance.

\footnotetext{
i Author's note: Keyword searches were performed on March 18, 2016 using the WorldCat database, available through the University of Louisville (OCLC, 2016). The search was limited to books and journal articles, and the search examined both titles and abstracts (where available). Journals were selected from the 2014 SJR database, and included the 50 highest impact factor journals in the following SJRdefined categories: "political science and international relations," "public administration," "sociology and political science," and "urban studies," and were further limited to journals published in the United States, Canada, and Western Europe (Scimago Lab, 2016). From these 200 journals, 85 duplicate entries were removed; from these remaining 115 journals, the author deemed 16 unrelated (based on sample tables of contents from 2015), leaving 99 peer-reviewed journals to be searched.

ii Author's note: keywords included "biased pluralism," “community power," "decisional analysis," "decisional method," "elite theory,"

"elites," "influentials," "Madisonian pluralism," "pluralism," "power elite," "reputational analysis," and "reputational method."

iii Author's note: keywords included "growth machine," "growth coalition," "urban regime," "governing coalition," "growth machine theory,"

"urban regime theory," and "urban regime analysis."
} 


\section{CHAPTER III}

\section{SET'TING AND METHODOLOGY}

In the previous chapter, this study discussed the state of extant urban scholarship with respect to its research questions, and established the presence of a lacuna in the literature with respect to contemporary urban governance structures. In this chapter, this study will outline the setting of its data collection, and the methods it used to assess whether cities are still governed by the political-business coalitions conceptualized in the 1970 s and 1980s, or whether some subset of the third sector has achieved legitimacy as a primary, rather than ancillary, component of urban governance ${ }^{320}$.

In the sections that follow, this study will first revisit its research questions. Then, it will offer a series of hypotheses to be tested in order to answer those questions. Third, it will details the study design, arguing for its appropriateness in addressing the research questions. Fourth, it will describe the setting for this study, as well as the target population and research sample. Fifth, it will outline the data collection methods and instrumentation, including a note regarding the ethical considerations related to this study. Sixth, it will discuss how data are to be analyzed and processed - first for the descriptive data, and then for the surveys and interviews. Finally, it will offer an initial consideration of validity and limitations related to the findings.

\footnotetext{
${ }^{320}$ cf. Birch, Perry, \& Taylor, 2013; Democracy Collaborative, 2014; Harkavy et al., 2009; Kettl, 2000; Zuckerman et al., 2013
} 


\section{Research Questions and Hypotheses, Revisited}

The purpose of this section is to outline the research questions that this study attempts to answer, or at least begin to address, and to present a series of hypotheses to be tested. In the paragraphs that follow, this study will first list its overarching research questions, and following this, it will introduce the particular hypotheses to be tested.

\section{Research Questions Revisited}

This study aims to answer three primary research questions. First, how have Dallas' demographics and economy evolved in the decades since the city was studied by previous urban scholars? Second, to what extent (if any) are CDCs and anchor institutions active participants in Dallas' governing coalition? Finally, if these organizations are active participants in Dallas' governing coalition, what is the effect of that involvement on urban development and policymaking?

\section{Hypotheses Revisited}

As Chapter 1 noted, this study forwards six primary hypotheses. The first three of these relate the changing socioeconomic context of Dallas as a whole, as well as the neighborhoods of North Oak Cliff and Downtown Dallas, to expectations grounded in current literature regarding central cities and their urban neighborhoods. The second three of these hypotheses surround the nature of governance in these same three geographies, and the effects of "who governs" on the decisions made in contemporary cities and neighborhoods. These hypotheses are as-follows:

Hypothesis 1. Consistent with expectations of modern, economically-prosperous cities in the globalized, post-Fordist paradigm and the chocolate cities, vanilla suburbs model, in the decades since the Elkin \& Thometz studies, Dallas' citywide socioeconomic context has changed in four primary ways: 
- People identifying as "white alone" represent a smaller percentage of the population in 2010 (the most recent decennial census) than they did 1980 (the census immediately prior to the Elkin study).

- A smaller percentage of Dallas' workforce is employed in blue collar fields in 2010 than in 1980.

- A larger percentage of Dallas' workforce is employed in creative class fields in 2010 than in 1980.

- Dallas, as a whole, shows signs of greater economic polarization in 2010 than in 1980.

Hypothesis 2. Consistent with expectations of literature surrounding gentrification of urban neighborhoods and the new donut model, within North Oak Cliff, recent urban redevelopment projects and neighborhood gentrification are associated with four primary changes in the neighborhood's respective socioeconomic context:

- People identifying as "white alone" represent a larger percentage of the neighborhood's population in 2010 than they did in 1980.

- A smaller percentage of the neighborhood's workforce is employed in blue collar fields in 2010 than in 1980.

- A larger percentage of the neighborhood's workforce is employed in creative class fields in 2010 than in 1980.

- The neighborhood shows signs of greater economic polarization in 2010 than in 1980.

Hypothesis 3. Consistent with expectations of literature surrounding gentrification of urban neighborhoods and the new donut model, within Downtown Dallas, recent urban redevelopment projects and neighborhood gentrification are associated with four primary changes in the neighborhood's respective socioeconomic context:

- People identifying as "white alone" represent a larger percentage of the neighborhood's population in 2010 than they did in 1980.

- A smaller percentage of the neighborhood's workforce is employed in blue collar fields in 2010 than in 1980. 
- A larger percentage of the neighborhood's workforce is employed in creative class fields in 2010 than in 1980.

- The neighborhood shows signs of greater economic polarization in 2010 than in 1980 .

Hypothesis 4. In Dallas as a whole, representatives of anchor institutions and

CDCs are primary (rather than ancillary) members of a citywide governing coalition, and this involvement portends a more equitable development paradigm than the value-neutral development seen in cities throughout the mid-late $20^{\text {th }}$ century.

Hypothesis 5. In North Oak Cliff, representatives of anchor institutions and CDCs in are primary (rather than ancillary) members, of a neighborhood governing coalition, and this involvement portends a more equitable development paradigm than the value-neutral development seen in cities throughout the mid-late $20^{\text {th }}$ century.

Hypothesis 6. In Downtown Dallas, representatives of anchor institutions and CDCs in are primary (rather than ancillary) members, of a neighborhood governing coalition, and this involvement portends a more equitable development paradigm than the value-neutral development seen in cities throughout the mid-late $20^{\text {th }}$ century.

\section{Research Design}

Previous studies of informal urban governance structures suggest that governance emerges from interactions among people, whether those people are influential elites ${ }^{321}$ or competing interest groups ${ }^{322}$, and these interactions complex causalities, resource constraints, and an element of path dependency based on the outcomes and contexts of previous interactions ${ }^{323}$. In looking to current urban scholarship for recommended methodologies, it

\footnotetext{
321 cf. Elkin,1989; Hunter, 1953; C. Stone, 1989

322 cf. Dahl, 1961; Polsby, 1963; 1980; Wolfinger, 1960

323 George \& Bennett, 2006, pp. 258-259
} 
should be noted that seminal authors like Logan, Molotch, Elkin, and Stone all neglect to meaningfully endorse any particular methodology ${ }^{324}$, possibly to avoid having their work fall to the same fate as the community power studies to which their work owes a great deal.

These deep connections, however, offer some validity to the idea of using previous methods - those found in the community power debates - in a contemporary setting. To test its hypotheses, this study reproduced- and refined methods anchored in that literature: a single-shot reputational analysis of a particular city, supported by descriptive quantitative data drawn from decennial census- and American Community Survey (ACS) tables. In the sections and paragraphs that follow, this study will first elaborate upon the case method, including a note on comparative urban research, and why a case study is employed instead. Then, it will offer a broad explanation of network analysis, as well as a detailed description of the reputational method. Finally, it will consider the use of secondary-source analysis, particularly when using census data.

\section{The Case Method}

In addressing the nature of contemporary urban governance, this study utilizes a case analysis of a single city, as opposed to a more comparative research design. First, this section will broadly describe the case method, making note of its advantages and disadvantages, and then outline the use of Dallas as a crucial case for analysis. Next, it will present a brief discussion of comparative urban research as an alternative, arguing for the inappropriateness of a comparative model. Finally, it will offer a defense of using a case study in answering the research questions.

Case studies, broadly. As an alternative (or complement) to the comparative research methods, which takes a shallower look at a wide selection of cities, case studies

\footnotetext{
${ }^{324}$ Harding \& Blokland, 2014, pp. 115-116
} 
produce intensive examinations of particular locations ${ }^{325}$, and have been heavily used to investigate the variety of decision-making processes within cities, as well as the political and economic forces that make each one unique ${ }^{326}$. It is somewhat inaccurate to consider case studies as a unified block, and literature suggests that it is more appropriate to consider "case study" an umbrella term encompassing a wide typology of design methods ${ }^{327,328}$. Whatever the particular design, though, a well-chosen case study allows researchers to engage holistically with rare events that may not recur often enough for statistical analysis, enables the study of interactions within cases too rare for statistical analysis or comparative research ${ }^{329}$, and can be used to suggest the plausibility of a new position, especially when there is a general lack of secondary source data ${ }^{330}$. Finally, it is important to note that case studies generally require fewer financial resources to complete than comparative- or statistical methods, while offering a degree of depth and complexity that are often infeasible through these other designs ${ }^{331}$.

Certainly, case studies are not without their trade-offs. A primary concern with relying on the results of a single case is that doing so introduces the possibility that any conclusions drawn represent a deviant case, and as a result, are not representative of cases as a whole ${ }^{332}$. In addition, the looseness of the case study as a form of research can complicate attempts at generalization, as there are few widely-accepted guidelines for drawing inferences and assessing causation from the data. Further, because case studies highlight the particularities of any given case's context, these contextual differences weaken attempts at

\footnotetext{
325 Gerring, 2004, p. 341; Lijphart, 1971, p. 691; Yin, 1981, p. 59

${ }^{326}$ Kilburn, 2004, p. 633; Stake, 2005, pp. 443-444; Thomas, 2011, p. 512; Vogel, 1992, p. 26

${ }^{327}$ Stake, 2005, p. 443; Yin, 1981, pp. 58-59; 2014, pp. 15-17, 24

328 de Vaus, 2001, p. 219; Thomas, 2011, pp. 511, 515-516

${ }^{329}$ Bennett \& Elman, 2006, p. 259-264

${ }^{330}$ Eckstein, 1975, pp. 108-112; Eisenhardt, 1989, pp. 536-544; George \& Bennett, 2005, pp. 19-21; Lijphart, 1971, p. 691

${ }^{331}$ Eckstein, 1975, p. 95; Kennedy, 1979, p. 671; Lijphart, 1970, p. 691

332 Kennedy, 1979, pp. 664-665; Miles, 1979, p. 598; Yin, 2013, pp. 20-21
} 
generalization to the population as a whole ${ }^{333}$. Finally, case studies are often viewed as lacking rigor, with sloppy research and lack of systematic procedures allowing researchers to influence the direction of their findings and conclusions ${ }^{334}$. As a result, it can be challenging for a single case to either constitute the basis for new generalizations, or to fully discount existing ones ${ }^{335}$, and for these reasons, case studies have fallen out of favor in many fields, concurrent with the rise of more powerful statistical methods ${ }^{336}$.

Dallas as a crucial case. In studying the structure of contemporary governing coalitions, this study argues that Dallas is indeed a crucial case. While many Rust Belt municipalities have starved for new development, potentially rendering their governing coalitions more amenable to working with nontraditional organizations like CDCs and anchor institutions, Dallas has benefitted from its relative diversity of industries, as well as nearby resource extraction operations; indeed, the city's economy has largely thrived since the mid-1990s, even as the Great Recession plagued the rest of the nation ${ }^{337}$. As such, Dallas is argued to be a "least-likely" scenario for changes to be found. If a well-designed case study finds that there is a transformation in the role of third-sector organizations in Dallas, with respect to current theories of urban governance, this would be a powerful indicator of changes occurring elsewhere. By comparison, results from a "most-likely" case like Cleveland or Detroit may simply be explained by that aforementioned hunger for development, and it could be argued that the change in "who governs" is merely temporary, lasting only until economic fortunes improve ${ }^{338}$.

\footnotetext{
333 George \& Bennett, 2006, p. 266; Kennedy, 1979, p. 663; Thomas, 2011, p. 513

${ }^{334}$ Miles, 1979 , p. 590; Yin, 2013, pp. 19-20

335 T. Clark, Bonjean, \& Lineberry, 1971, p. 265; George \& Bennett, 2005, p. 25; 2006, p. 266; Kantor \& Savitch, 2005, p. 135; Kilburn,

2004, pp. 633-634; Mossberger \& Stoker, 2001, p. 811; Schutt, 2009, p. 243

336 George \& Bennett, 2005, p. 5

${ }^{337}$ Dallas County Community College District, 2014, pp. 2-3; Editorial: New South Dallas, 2013; Graff, 2008, p. 46; Halkias, 2014; Schutze, 2014

${ }^{338}$ Eckstein, 1975, pp. 115-120; George \& Bennett, 2005, pp. 120-121
} 
A note on comparative urban research. Comparative urban research is a popular trend in contemporary scholarship, which makes the use of a case study seem somewhat dated. Before defending the use of the case study, it is important to briefly discuss the comparative method, which allows scholars to assess causality of defining characteristics and trends within cities, by comparing them against one another within a uniform theoretical framework. There are a nearly limitless number of ways in which a comparative study can be designed, but in practical terms, most comparative designs tend to fall within a relatively narrow band of study types ${ }^{339}$ that share the primary goal of testing whether (or to what extent) an independent variable is causally linked to the dependent variables in the researcher's framework, and to develop empirically valid theories in the process ${ }^{340}$. Because comparative studies involve several cases that are intentionally selected based on researcheridentified characteristics, it is somewhat unlikely that any conclusions drawn come from outliers, as is possible with single-case studies ${ }^{341}$. Because of these strengths, comparative research has been used to greatly expand the scope of urban theory, and in some ways, the use of comparative methods helped revitalize urban research in the closing decades of the $20^{\text {th }}$ century $^{342}$.

With respect to varying approaches to urban research, "no concept can be comprehensive, much less perfect, and each has its relative merits and liabilities." 343 While comparative research offers a number of strengths, it can be hampered by political- and cultural differences among various cases, as well as in differences among cities in terms of how similar problems manifest themselves ${ }^{344}$. In addition, even when the differences among

\footnotetext{
${ }^{339}$ Lijphart, 1971, p. 691; Peters, 1998, pp. 31-34; Pierre, 2005, p. 454; Seawright \& Gerring, 2008, pp. $296-299$

340 Azarian, 2011, pp. 119-120; Lijphart, 1971, p. 683; Pierre, 2005, p. 454

341 George \& Bennett, 2006, p. 266; Miles, 1979, pp. 598-599; Yin, 1981, p. 62

342 Stoker \& Mossberger, 1994, pp. 195-196

${ }^{343}$ Kantor \& Savitch, 2005, p. 140

${ }^{344}$ Kantor \& Savitch, 2005, pp. 137-140; Lijphart, 1971, p. 687
} 
cities in a comparative study are minimized, the process of studying each city, and then comparing them comes at tremendous cost, both in terms of time and financial resources ${ }^{345}$ Finally, when comparing variables found over multiple cities, the city-specific context in which those data actually exist may be lost ${ }^{346}$. This study intended to address the research questions by building a complex narrative for the evolution of the city of Dallas, and as such, a comparative design was considered to be inappropriate.

On the appropriateness of the case method. Although the results of case studies are limited, and subjective opinions of the method vary, this does not suggest that they are without merit, as evidenced by their continuing popularity in urban research and theorybuilding $^{347}$. The shortcomings of case studies do not preclude their usefulness as a basis for functional analysis of a phenomenon, nor do they preclude the use of the method in exploring relevant attributes of the case itself $f^{348}$. These positions in mind, the use of a case study is appropriate for helping to foster a greater discussion about who governs cities today, and for suggesting the plausibility of the research findings which are detailed in later chapters.

\section{Network Analysis and the Reputational Method}

As part of its case study of Dallas, this study will employ a reputational analysis of the city's potentially influential individuals. Reputational analysis is an established (though historically controversial) method under the larger umbrella of network analysis. In the paragraphs that follow, this study will first briefly discuss network analysis as a cluster of related methods. Then, it will examine reputational analysis, including its assumptions,

\footnotetext{
${ }^{345}$ Eckstein, 1975, p. 95; George \& Bennett, 2005, pp. 21-23; Kilburn, 2004, pp. 633-634

${ }^{346}$ Miles, 1979 , p. 598

${ }^{347}$ Gerring, 2004, p. 341; Thomas, 2011, pp. 511-512

${ }^{348}$ Kennedy, 1979, pp. 670-671
} 
historical criticisms and conceptual shortcomings, before offering a rejoinder. Finally, it will offer a defense of a reputational analysis in answering the research questions.

Network analysis. Network analysis is not a single technique, but rather, a group of related techniques including reputational-, decisional- and positional analysis (among others) ${ }^{349}$, which vary with respect to the particular aspects of social networks (actors ${ }^{350}$, activities $^{351}$, or relations ${ }^{352}$ ) that they hold rigid, and which they allow to vary ${ }^{353}$. Generally speaking, each particular method operationalizes networks as interrelated sets of relationships among defined nodes or elements, which can represent range including (among others) individuals, organizations, and nations. Most commonly, network analysis methods attempt to explain and model the behavior of these people within their social networks, as well as to explain the network as a whole ${ }^{354}$, but many of these methods can also be used to examine individuals relative to their positions in organizations, or links between clusters of organizations $^{355}$. Further, network methods emphasize the importance of the structure of networks in shaping actions of individual actors, or in other words, the effects of how people are connected through their social environments, and how differing environmental contexts describe and explain various decisions and outcomes ${ }^{356}$. In short, network analysis attempts to evaluate the extent to which people know one another, and the extent to which the people they know also know one another ${ }^{357}$.

Reputational method. The reputational method (or reputational analysis) is a qualitative, narrative-driven method of network analysis, employed most commonly to

\footnotetext{
${ }^{349}$ Barnes, 1972, p. 3; Beekun \& Glick, 2001, p. 228; Burt \& Schott, 1989, pp. 186-188; Emirbayer \& Goodwin, 1994, p. 1414; J. C. Mitchell, 1969, p. 279

${ }^{350}$ cf. Hunter, 1953; Thometz, 1963

351 cf. Dahl, 1961

352 cf. Haas \& Drabeck, 1973

${ }^{353}$ Laumann, Marsden, \& Prensky, 1989, pp. 67-69

${ }_{354}$ Beekun \& Glick, 2001, p. 228; Doreian, 1989, p. 296; Laumann, 1979, p. 394; Laumann, Marsden, \& Prensky, 1989, p. 62; 67-68

355 Beekun \& Glick, 2001, pp. 228; 234; J. C. Mitchell, 1974, pp. 288-289; Mizruchi, 1994, pp. $333-334$

356 Borgatti et al., 2009, pp. 893-894; Doreian, 1989, pp. 296-298; Mizruchi, 1994, p. 335

${ }^{357}$ Mitchell, 1974 , pp. 288-290
} 
uncover the particular makeup of governing coalitions within given cities. This method focuses on the actors within a social network, using the reputation for influence in a community as a proxy for actual influence ${ }^{358}$.

Reputational studies of cities are generally conducted in two phases. In the first, the researcher identifies a core group of volunteers, such as bankers, real estate developers, and community leaders; these volunteers are asked to rank lengthy lists of citizens who, based on their positions in society, could reasonably be assumed to be influential people (commonly referred to in the literature as influentials or decision-makers) ${ }^{359}$. Then, a new set of lists (often containing 50-100 of the highest-rated names) are then presented to that same group of judges, who are then asked to "vote" for the 10-25 most influential people, based on their understanding of the city. The people with the highest votes are then invited to participate in the second phase of the study.

In the second phase of most reputational studies, the new group of participants are given similar lists of names to what the judges in the first phase were given, with similar instructions to rate the relative influence of individuals. In addition, participants are invited to add names that the list does not currently include. Researchers use these new names to expand the participant pool through snowball sampling. Eventually, the researchers cut off the snowball sampling, and use the results of the ranked lists to render an image the structure and actions within a social network ${ }^{360}$. This method, while not random, holds the advantage of being able to access hard-to-reach populations, as well as populations that are difficult to identify through traditional sampling methods ${ }^{361}$.

\footnotetext{
${ }^{358}$ Polsby, 1980, pp. 5-6; Walton, 1966, p. 434, Wolfinger, 1960, p. 636

${ }^{359}$ Abu-Laban, 1965, pp. 35-36; Bonjean \& Olson, 1964, pp. 283-287; Wyly, 2014, pp. 2-3

360 Agger \& Ostrom, 1956, pp. 81-82; Barth \& Abu-Laban, 1959, p. 71; Pfautz, 1962, p. 160; Schulze \& Blumberg, 1957, pp. 291-292;

Wolfinger, 1960, p. 637; Wyly, 2014, pp. 2-3

${ }^{361}$ Schutt, 2009, p. 174; Snow, Hutcheson, \& Prather, 1981, pp. 101-105
} 
Assumptions, criticisms, and methodological challenges. Reputational analysis

is built on three primary assumptions. First, the method assumes that power within a city is differentially distributed among members of a governing coalition, because the resources required to effectively govern a city are beyond the capacity of any particular actor or organization, regardless of their financial wealth or political clout ${ }^{362}$. Related to this, power rests within a relatively small group of actors willing and able to mobilize their resources in service of predetermined goals, with a reasonable likelihood of being able to attain them ${ }^{363}$. Finally, power cannot be measured directly, and instead, must be measured through a proxy variable; as such, a given actor's reputation for having power is assumed to be a valid standin $^{364}$.

The criticisms of reputational analysis generally fall into two broad categories: criticisms of its assumptions, and criticisms of its procedures and findings. To the first set of challenges critics assert that there is no reason to believe that power is either differentially distributed, or that it is an emergent property of interactions among various actors. Even if those assumptions can be supported, they do not necessarily suggest that influentials ever form into cohesive governing coalitions. Further, even if such a coalition exists, this does not presuppose dominance over the policymaking process. Finally, even if all of the previous assertions prove valid, they cannot be made a priori, which invalidates the reputational $\operatorname{method}^{365}$.

Looking at the method's procedures and findings, critics charge that the method offers little more than an ambiguous, static definition of power, and fails to recognize the

\footnotetext{
${ }^{362}$ C. Stone, 1993, pp. 1-2; Stone \& Sanders, 1987, pp. 269-270

${ }^{363}$ Hatt, 1950, p. 220; Molotch, 1993, p. 31-33

364 Abu-Laban, 1965, pp. 40-41; Agger, 1956, pp. 325-326; Bonjean, 1963, pp. 678-681

365 Abu-Laban, 1965, pp. 35-36; Dahl, 1958, pp. 465-466; Bonjean, 1963, pp. 672-681; Kaufman \& Jones, 1954, pp. 207-209; Polsby, 1959, pp. 800-803, 1960, p. 476-483; Thometz, 1963, pp. 17-20; Vogel, 1992, pp. 127-136; Wolfinger, 1960, pp. 638-40
} 
difference between generalized power and project- or agenda-specific power. As a result, the specific questions that reputational surveys use are generally imprecise, and results frequently confirm the positions of the authors. Finally, the roster of influential actors created by these surveys is merely a list of potential influentials, and cannot be assumed to contain all actual influentials ${ }^{366}$.

A rejoinder. These pluralist arguments appear to reflect a deep misunderstanding of the technique's ontological scholarship, as well as common-sense examinations of urban policymaking. To the suggestion that power is not differentially distributed, that there is indeed a distribution of power within cities has been supported by an overwhelming preponderance of evidence ${ }^{367}$, and dozens of studies are strongly suggestive of the presence of cohesive formal- and informal social-, legal, and business relationships among those who wield that power ${ }^{368}$. It is also inaccurate for critics to charge that reputational studies conceptualize power as a monolithic construct; instead, the majority of these studies suggest instead that, while some individual actors possess a degree of generalized influence, it is more common to see a broad range and typology of influential actors with dynamic, contextual scopes of influence that often reach beyond their particular fields or industries ${ }^{369}$. Finally, it is inaccurate for detractors to accuse reputational studies of presupposing the existence of governing coalitions. The reputational method itself does not assume the existence of a governing coalition of influentials; certainly doing this would indeed prejudge what has historically been a critical, fundamental question within urban political studies ${ }^{370}$.

\footnotetext{
366 Abu-Laban, 1965, pp. 39-42; Danzger, 1964, p. 708; Polsby, 1959, pp. 796-800; Wolfinger, 1960, pp. 640-642

${ }^{367}$ cf. DeLeon, 1992a; 1992b; Elkin, 1987a; Hunter, 1953; Kantor, Savitch, \& Haddock, 1997; C. Stone, 1989; Thometz, 1963, Vogel, 1992

368 Abu-Laban, 1965, pp. 37, 41-42; Bonjean, 1963, p. 676; Hunter, 1953, Ch. 4; Polsby, 1980, pp. 5-13, 20-21; Thometz, 1963, pp. 73-75

${ }^{369}$ Bonjean, 1963, pp. 678-681; D’Antonio \& Erickson, 1962, pp. 367-371; Freeman et al., 1963, pp. 797-798; Hunter, 1953, pp. 61-62;

Thometz, 1963, p. 19; Vogel, 1992, p. 17

${ }^{370}$ Rosenbaum, 1967, p. 99; Thometz, 1963, pp. 18-19
} 
Looking now to the criticisms of the method's procedures and results, it appears that many of these arguments are actually responses to poor applications of the technique, or result from cherry-picked meta-analyses of reputational surveys. For example, when noting that some reputational studies fail to differentiate between generalized and issue-specific influence, detractors accurately highlight a critical shortcoming those applications of the technique, which have been addressed in more rigorous studies ${ }^{371}$. In addition, the suggestion that the reputational method always finds a governing coalition ignores several studies whose results fail to support the presence of one ${ }^{372}$. Further, to the criticism that the reputation for influence is not a valid proxy for actual influence, during the 1950s and 1960s, scholars validated the method against decisional- and positional surveys, and found significant evidence that the reputation for power is a valid indicator of the extent to which an individual is actually involved in the policymaking process ${ }^{373}$. Finally, that the results of reputational studies are based on individual biases and imperfect knowledge is undeniable, and as a result, it is assumed that there are an unknowable number of "blind spots" in the results. However, all methods produce results that contain error, so it is (arguably) unreasonable to invalidate reputational analysis for that reason.

On the appropriateness of the reputational method. This study aimed to examine the structure of power in the city of Dallas, in order to consider fundamental questions about the nature of governing coalitions more broadly. In addition, it compared the Dallas of the early $21^{\text {st }}$ century with the Dallas of the mid- $20^{\text {th }}$, to understand how the city and its governing coalition have evolved over time and circumstances. In service of those goals, the reputational method held considerable appeal. First, the method is relatively

\footnotetext{
${ }^{371}$ D’Antonio \& Erickson, 1962, pp. 374-375; Danzger, 1964, pp. 708-716; Dick, 1960, p. 399; Thometz, 1963 , p. 18

372 Abu-Laban, 1965, p. 39; Bonjean, 1963, pp. 676-678; D’Antonio, Ehrlich, \& Erickson, 1962, p. 852

373 Abu-Laban, 1965, pp. 40-41; Agger, 1956, pp. 325-326; Bonjean, 1963, pp. 678-681
} 
straightforward, and can replicated across a number of communities of varying sizes ${ }^{374}$. In addition, the method contains a tremendous amount of face validity; that is, it addresses the research questions in a way that would (arguably) be substantiated by common-sense appraisals from informed observers of a community's affairs ${ }^{375}$. Finally, the previous study of Dallas utilized a reputational method, so in comparing the city's governing coalition today to how it existed in the past, choosing an alternative method would likely jeopardize this study's validity, as results would not easily compare to those of prior researchers. These positions in mind, the use of a reputational analysis was considered appropriate for analyzing the structure of urban governance in Dallas.

\section{Secondary-Source Data Analysis}

Finally, in addressing the nature of contemporary urban governance, decennial census- and ACS records from 1980 to 2010 are employed in order to trace the economicand demographic transformations in Dallas since the Elkin (1987) study. First, this section broadly discusses the use of census data in social sciences, including specific data used for this study. Next, it describes some of the concerns with secondary-source data, as they apply to this case. Finally, it presents a defense of the appropriateness using these secondarysource data in answering the research questions.

\section{On the use and appropriateness of secondary-source data analysis. Broadly}

speaking, the use of census data has taken on an expanded role in investigating the social world analysis, and its use is now widely accepted across the social sciences ${ }^{376}$. By federal law, the U.S. government conducts a decennial census, and since 1940, this census has included a census of housing as well, providing researchers with a valuable source of economic- and

\footnotetext{
374 cf. Barth \& Abu-Laban, 1959; Belknap \& Smuckler, 1956; T. Clark, Bonjean, \& Lineberry, 1971; French \& Aiken, 1968; Hunter, 1953; Pfautz, 1962; Thometz, 1963; Vidich \& Bensman, 1968; Vogel, 1992

375 Dick, 1960, p. 395; Hatt, 1950, pp. 220-222

376 Atkinson \& Brandolini, 2001, pp. 773-774; E. Smith, 2008, p. 334
} 
demographic information for a large section of the population ${ }^{377}$. These data are publicly available, are generally available at no additional cost to the researcher, are available at many geographic levels (e.g. tract-, city-, county-, and state-level), and are also available for multiple years. As a result, using census data allows inclusion of additional descriptive data than would have been feasible using direct surveys, in less time, for less money, and with data that are more readily comparable between different locations, such as among different areas within the same cities, or between one city and another ${ }^{378}$. This study utilizes decennial census data to examine demographic- and economic shifts between 1980 and 2010, as well as ACS data to supplement data from 2010 that have not yet been made available.

Concerns with using secondary-source data. The use of census data can be somewhat problematic, though, for a number of reasons. First, it is often the case that particular groups (e.g. people with low incomes, immigrants who are undocumented, people with outstanding warrants) are poorly represented ${ }^{379}$. Further, these data are not always reported at the level of specificity needed by the researcher, reported data may contain gaps and errors for which the researcher cannot easily correct, and some data may simply not be formatted or reported in a way that the researcher will find useful ${ }^{380}$. Finally, definitions often change from one reporting period to the next, and the researcher must ensure that they are aware of these changes, and that they can correct for them ${ }^{381}$.

In defense of secondary-source analysis. Although the use of census data is hardly free from perfection, it is a well-established method in exploratory research, with thousands of examples found across social sciences ${ }^{382}$. Decennial census data are considered

\footnotetext{
377 Schutt, 2009, p. 456 E. Smith, 2008, pp. 331-332

378 Coyer, 2005, p. 60; Johnson \& Turner, 2003, p. 317; Rew et al., 2000, p. 226; Schutt, 2009, pp. 455-457; E. Smith, 2008, pp. 331-334;

Windle, 2010, p. 323

${ }^{379}$ Coyer, 2005, p. 61; E. Smith, 2008, p. 329

380 Atkinson \& Brandolini, 2001, p. 786; Johnson \& Turner, 2003, pp. 316; Windle, 2010, p. 323

381 Atkinson \& Brandolini, 2001, pp. 785-791; Johnson \& Turner, 2003, pp. 316-317; Rew et al., 2000, p. 227; Schutt, 2009, p. 466-469

382 E. Smith, 2008, p. 333; Rew et al., 2000, p. 227; Schutt, 2009, pp. 454-455; Windle, 2010, p. 323
} 
"complete count" data, with participation mandated by federal law; as such, these data are effectively measures of the research population, or at least, are as close to the actual population as is feasible $e^{383}$. Looking at the problem of statistical error, the Census Bureau documents margins of error in the census files themselves, while also noting where error may have been introduced for the purpose of protecting confidentiality ${ }^{384}$. Finally, considering the problem of under-representation, tremendous effort is undertaken to include members of difficult-to-reach populations, beyond what is feasible for most researchers outside of the Census Bureau ${ }^{385}$. These positions in mind, the use of census- and ACS data for the purposes of suggesting economic- and demographic trends within Dallas was considered to be appropriate.

In the paragraphs that follow, this study will first briefly introduces Dallas, Texas, the site of the Thometz and Elkin studies, as well as this study's two focus neighborhoods: North Oak Cliff and Downtown Dallas. Then, it will detail the settings of the surveys and interviews themselves, so that future researchers can replicate the process, at least to the extent feasible when repeating studies in natural (rather than laboratory) settings.

\section{Study Focus Areas: Dallas and Two Central Urban Neighborhoods}

This study focuses on three geographic areas for its analysis: the City of Dallas as a whole, and two of its central urban neighborhoods: North Oak Cliff and Downtown Dallas. In the sections that follow, this study will briefly introduce each, in turn.

The City of Dallas, Texas. The City of Dallas is located in North Central Texas, and is the seat of Dallas County. The city was founded on the banks of the Trinity River, as a trading post located on a natural river crossing used by Native American tribes. Now,

\footnotetext{
383 Rives \& Serow, 1988, p. 15; Schutt, 2009, p. 456

384 Atkinson \& Brandolini, 2001, p. 787; E. Smith, 2008, p. 329; Schutt, 2009, p. 468; United States Census Bureau, 2012 ; 2015

385 cf. United States Census Bureau, 2015
} 
instead of traces, the city is crossed by four major Interstate highways: $20,30,35$, and 45 , as well as a number of rail lines, and is served by a major international airport ${ }^{386}$.

As Chapter 2 detailed, for nearly all of Dallas' postwar history, city policies have reflected the desires of city leaders to keep Dallas business-friendly, as well as deeply divided by race, with people identifying as White tending to cluster north of the Trinity River, and minorities, particularly people of Hispanic or Latino heritage and people identifying as Black or African American, confined to Oak Cliff, clustered to the south ${ }^{387}$. Chapter 2 recounted much of this history, at least with respect to the city's history of developmental politics and the differential developmental trajectories of its two halves. The effects of those histories and trajectories can be seen even today, in the neighborhoods of North Oak Cliff and Downtown Dallas, which are both revitalizing, but in strikingly different ways.

North Oak Cliff. Looking first at North Oak Cliff, recall that Chapter 2 recounted the political- and economic disinvestment through this once-vibrant commercial hub within southern Dallas. Much of southern Dallas has been broadly ignored by both city leaders and the general public for decades, and has garnered a reputation for commercial disinvestment, high crime, and poor school performance ${ }^{388}$. As Chapter 2 recounts, North Oak Cliff is becoming an exception to this, and is rapidly gentrifying through a mix of new construction and adaptive reuse of existing structures. As Chapters 4 and 5 will expand upon, these changes have divided opinions, with many newcomers praising the growth and revitalization, while a subset of existing residents, many of whom cannot afford to live in a Disneyfied version of the former streetcar suburb, and are unsure of where they will move when they are forced out of their rental houses and commercial pad sites. Finally, although the specific

${ }^{386}$ McElhaney \& Hazel, 2015

${ }^{387}$ Graff, 2008, pp. 157-164, 181

388 Merwin, 1977; Simek, 2014; Young, 2014 
boundaries of North Oak Cliff are somewhat fluid and subjective, a common definition bounds the neighborhood within Interstate Highway 30, Interstate Highway 35E, $12^{\text {th }}$ Street, and Hampton Road; these boundaries are reflected in figure 3.01 shows a map of North Oak Cliff $^{389}$.

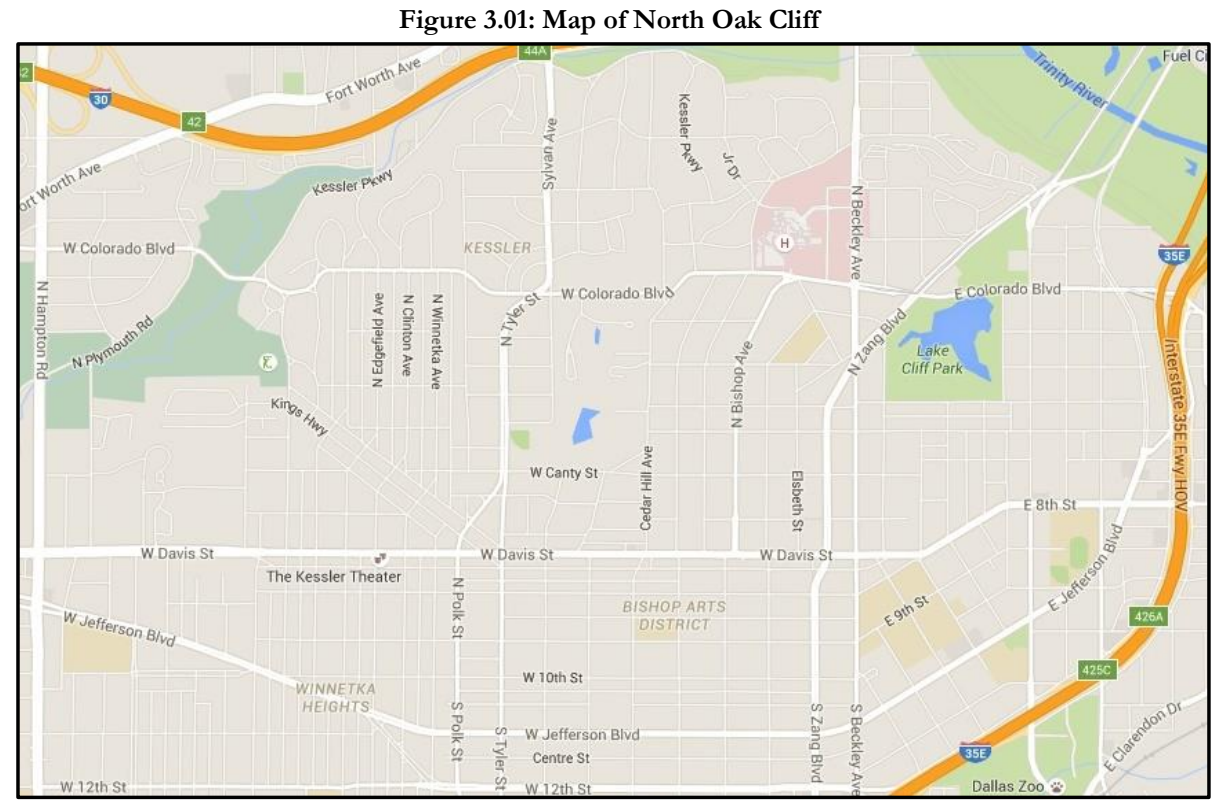

Downtown Dallas. The home of the city's skyline, Downtown Dallas is the city's visible face; as later chapters will note, many people believe this to be the heart of Dallas, and that its health (or decay) is representative of the rest of the city. As Chapter 2 noted, the Downtown Dallas skyline is largely a result of a publicly-funded push to move Dallas beyond the Kennedy assassination by bulldozing offices and warehouses from the early $20^{\text {th }}$ century and replacing them with convention centers, stadiums, and office buildings in a construction boom that lasted from the mid-1960s until the real estate, financial, and oil markets collapsed throughout the early-mid 1980s. After floundering for over a decade, starting in the mid-late 1990s, Downtown Dallas entered a second period of revitalization 
that continues today, under the Downtown Dallas 360 master plan. Rather than gentrifying an existing residential area, much of Downtown Dallas' real estate is being reclaimed from existing commercial properties, with offices being converted into upscale lofts; nonetheless, there is little room in the neighborhood for people with low- or moderate incomes. In terms of geographical boundaries, figure 3.02 shows a map of Downtown Dallas ${ }^{390}$, using Spur 366, State Highway 75 (Central Expressway), Interstate Highway 30, and Interstate Highway 35E as commonly-accepted neighborhood boundaries.

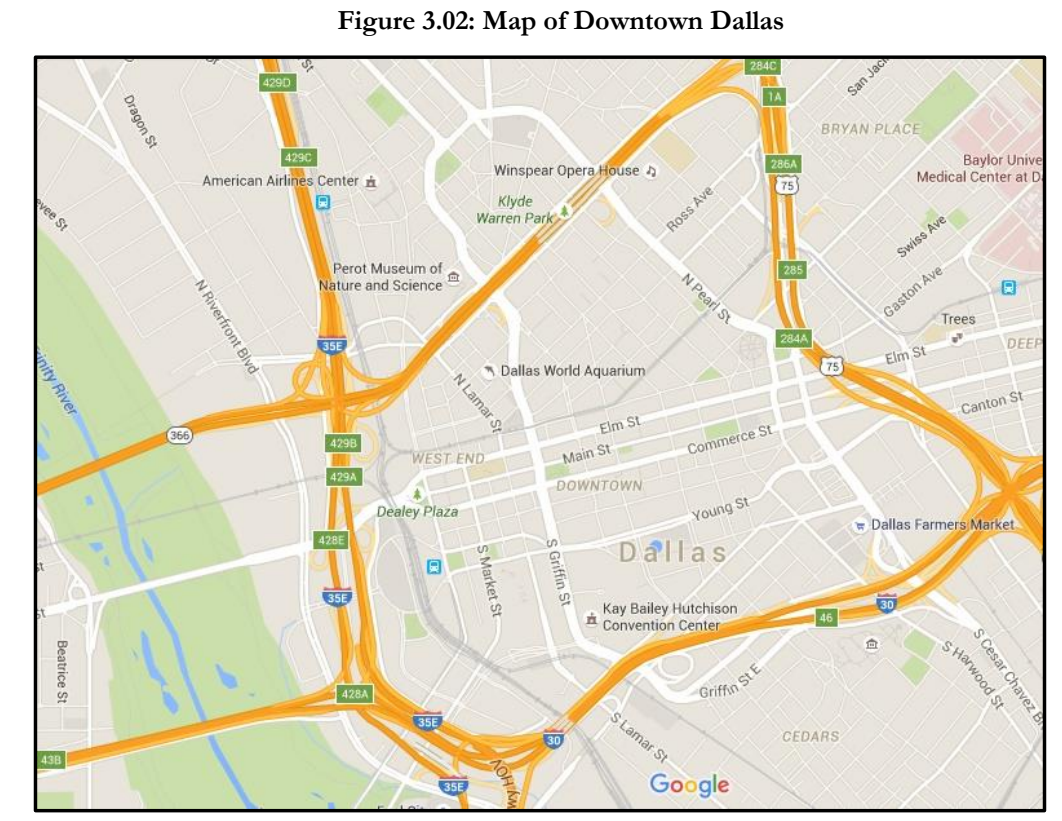

Study Focus Areas, in summary. Like other entrepreneurial governing coalitions, leadership in Dallas often seeks to solve its problems through growth and development. Indeed, as Chapter 2 describes, throughout the city's history, Dallas' leaders have strived to make city policies favorable to businesses and growth, although a legacy of racism has focused this growth into white neighborhoods like Downtown Dallas, often at the expense of majority-minority southern neighborhoods like North Oak Cliff. Although these neighborhoods continue to lag behind, recently, a subset of them have begun to gentrify as 
affluent whites migrate back to the city from Dallas' northern suburbs ${ }^{391}$. Although both Downtown Dallas and North Oak Cliff have experienced high vacancy rates and abandonment, the particular shape of that abandonment, as well as each neighborhood's respective paths to revitalization have been differentially affected by decisions made at the citywide level, neighborhood-level leaders (at least in North Oak Cliff) have also played a role. While the actions of past decision-makers are responsible for the current state of Dallas as a whole, as well as both North Oak Cliff and Downtown Dallas, from this point forward, this study will focus on the current decision-makers in these areas, as well as the effects of the decisions that they make - particularly with respect to equitable economic development.

\section{Setting and Context of Data Collection}

Looking first at quantitative data collection, records were collected and added to the dataset between April and June of 2015. For 1980 and 1990, data are not generally available in electronic format, so this phase of data collection was performed in the libraries of the University of Louisville and the University of Texas at Dallas using physical copies of Census Bureau publications. For 2000 and 2010, data are available through the American FactFinder website, which is produced and maintained by the Census Bureau.

For qualitative data collection, surveys and interviews were conducted over a fourweek period, beginning on June 3, 2015, and ending on July 2, 2015. To accommodate the participants, each was slotted into a two-hour window, with 3-4 interviews being conducted each weekday. Participants were invited to select the meeting slot and location, based on their availability. Of the 79 total participants, 43 chose to meet in their offices or nearby meeting rooms 31 elected to meet in coffee shops and cafes, 3 identified hotel conference rooms, and 2 chose to meet in locally-owned, independent businesses. While a more

\footnotetext{
${ }^{391}$ Editorial: New South Dallas, 2013; Graff, 2008, p. 46; Schutze, 2014
} 
rigorous experimental design would mandate the use of a specific, controlled meeting room, it was decided that because of the sensitive nature of the questions being asked of the participants, their preferences would be honored.

\section{Research Sample and Data Sources}

The purpose of this section is to outline the data sources used. First, it will list all data points selected for quantitative analysis of the city of Dallas, first for 1980, and then for 1990, 2000, and 2010. Then, it will describe the target population for the reputational analysis, as well as the sample of participants and how participants were identified and invited to participate. Finally, it will evaluate ethical considerations, and how confidentiality is protected.

\section{Quantitative Data Sources}

Data collected at each year. For all years ${ }^{\mathrm{iv}, \mathrm{v}, \mathrm{vi} \text {, vii }}$ this study uses the following data: population (all races combined), population (white alone), population (black or African American alone), population (American Indian or Alaskan native alone), population (Asian American, Pacific Islander, or native Hawaiian alone), population (other or mixed-race), population (nonwhite), and population (Hispanic, regardless of race). It also uses the following income and poverty data: median household income, poverty (all races combined), poverty (white alone), poverty (black or African American alone), poverty (American Indian or Alaskan native alone), poverty (Asian American, Pacific Islander, or native Hawaiian alone), poverty (other or mixed-race), poverty (nonwhite), and poverty (Hispanic, regardless of race), unemployment (all races combined), and employment by industry (manufacturing).

Notes for 1980 and 1990. It is important to note that in 1980 and 1990, definitions for a number of employment categories are not analogous to those listed in census files from 2000 onward. At the citywide level, these data are supplemented by data from the Texas 
Employment Commission. These data, while the best available, are less granular than those presented in the decennial census. For example, for 1980, data are presented for the Dallas/ Fort Worth standard metropolitan statistical area (SMSA) ${ }^{392}$, while in 1990, data are presented for the Dallas-Fort Worth primary metropolitan statistical area (PMSA). These terms were both deprecated in 2000 , replaced by the broader term "metropolitan statistical area" (MSA). The differences between an SMSA and a PMSA relate to how statistical areas are classified, with PMSAs being reserved for statistical areas with at least one county featuring a city of at least one million people, while SMSAs only require a county with a city of at least 50,000. Thus, as Dallas' population topped one million people in 1990, its statistical area became a PMSA; this change in nomenclature has no bearing on the data themselves. Nonetheless, it is critical to understand that these data are not limited to Dallas itself, and include its surrounding statistical area, which includes large cities such as Fort Worth and Arlington. This limitation will be revisited later in this study, but use of these data allow for comparisons over the entire period from 1980 to 2010 at the citywide level comparisons which would be unavailable using census data alone.

These caveats in mind, this study uses the following employment-related data: employment by industry (executive, administrative, and managerial), employment by industry (professional specialty occupations), employment by industry (technical and related support), employment by industry (sales), employment by industry (administrative support and clerical), employment by industry (private household), employment by industry (protective services), employment by industry (service occupations other than protective and private household), employment by industry (farming, forestry, and fishing), employment by industry (production, craft, and repair), employment by industry (machine operators,

\footnotetext{
${ }^{392}$ Ferguson \& Crockett, 1980;
} 
assemblers, and inspectors), employment by industry (transportation and material moving), employment by industry (handlers, equipment cleaners, helpers, and laborers), employment by industry (construction), employment by industry (manufacturing), employment by industry (transportation, communications, and utilities), employment by industry (wholesale and retail trade), employment by industry (finance, insurance, and real estate), employment by industry (professional and related services). Through analysis of relevant definitions, these categories (either alone or in combination) were found to be similar in scope to categories in census and ACS data, taking into account aforementioned limitations.

Notes for 2000. For 2000, this study uses the following employment-related data: employment by industry (agriculture, forestry, fishing and hunting, and mining), employment by industry (construction), employment by industry (wholesale trade), employment by industry (retail trade), employment by industry (transportation and warehousing, and utilities), employment by industry (information), employment by industry (professional, scientific, management, administrative, and waste management), employment by industry (arts, entertainment and recreation, and accommodation and food services), employment by industry (other services, except public administration), and employment by industry (public administration).

Notes for 2010. Finally, for 2010 this study also uses the following employment data: employment by industry (agriculture, forestry, fishing and hunting, and mining), employment by industry (construction), employment by industry (wholesale trade), employment by industry (retail trade), employment by industry (transportation and warehousing, and utilities), employment by industry (information), employment by industry (professional, scientific, management, administrative, and waste management), employment by industry (arts, entertainment and recreation, and accommodation and food services), 
employment by industry (other services, except public administration), and employment by industry (public administration). Of additional note, because of the comparatively recent nature of the 2010 decennial census, published records are incomplete. Where noted, this study uses ACS 5-year estimates, from the period of 2006 to 2010. While (arguably) less accurate than the decennial census, these data use incredibly complex modeling-and sampling techniques to remain a statistically valid representation of the population as a whole $\mathrm{w}^{393}$.

\section{Qualitative Data Sources}

Target population. The current conceptualization of urban governance is largely a product of studies conducted from the early 1970s to the mid- to late 1990s, which in turn owe a heavy debt to the community power studies of the 1950s and1960s ${ }^{394}$. These earlier studies suggested that the informal coalition of city leaders primarily include prominent businesspeople and leading politicians, but that a lower-tier of leadership exists on an asneeded basis, in order to help legitimize policies or development plans, with little overall input in the decisions being made; this larger group consists of heads of community organizations and universities, community leaders, local experts, local media, construction companies, real estate developers, and regional banks, as well as leaders from religious orders, social service organizations, and cultural institutions among ${ }^{395}$.

Survey sample. Because the exact makeup of Dallas' governing coalition is not known, it was decided to cast a wide net for potential participants. Using previous literature as a guide, this study identified political leaders at the city-, state-, and national level;

\footnotetext{
393 Alexander, 2002, pp. 363-364; Fay, 2005, p. 3016; A. Smith, 1998

${ }^{394}$ C. Stone, 1989 , p. $x i$

395 Abu-Laban, 1965, pp. 35-36; Bonjean \& Olson, 1964, pp. 283-287; T. Clark et al., 2002, p. 496; Elkin, 1987a, pp. 160-162; Harding, 2009, pp. 34-35; Jonas \& Wilson, 1999, pp. 5-6; Logan \& Molotch, 2007, pp. 51-57, 62-74; C. Stone, 1989, pp. 234-242; Walcott, 1999, pp. 648-651; Wyly, 2014, pp. 2-3
} 
executive leadership- and board members of large businesses in the city; administration and board members of the city's school district; members of the state board of education; county judges; executive leadership- and board membership of CDCs, universities, and hospitals; members of every chamber of commerce in Dallas County ${ }^{396}$, membership rosters of social clubs $^{397}$; leaders in local media (newspaper and television); retired mayors and city council members; pastors of large area churches; and neighborhood organization leaders.

Identifying public- and private sector participants. Identifying potential publicand private sector participants for this study was relatively straightforward. First, potential public sector participants were identified through newspaper articles in the Dallas Morning News - the city's newspaper of record - regarding development projects in south- and central Dallas, the Dallas City Council, the city's Office of Economic Development, the Dallas ISD organizational chart, and the Office of the Mayor. In addition, county judges, membership rosters from city-wide and neighborhood-level chambers of commerce, and state - and national legislators were added to the list, based on similar lists from previous studies. Potential private sector participants were identified through the Fortune 500 list of companies headquartered in Dallas, lists of the largest employers in Dallas, largest companies in, a listing of the largest real estate developers in the city, and a listing of the city's largest banks. For each of these organizations, key employees, executives, and boards of directors were identified through SEC filings and data found on corporate websites.

Identifying third sector participants. To identify potential participants from CDCs, this study used the Guidestar Online database of nonprofits headquartered in Dallas-

\footnotetext{
396 e.g. Greater Dallas Chamber of Commerce, the Dallas Black Chamber of Commerce, the East Dallas Chamber of Commerce, Oak Cliff Chamber of Commerce, among many others

397 i.e. Dallas Assembly, Dallas Citizens Council, Dallas Petroleum Club
} 
Fort Worth area, filtered by NTEE codes $^{398}$ to limit results to organizations involved in development, housing, and workforce development, as well as neighborhood organizations and community centers. From these filters, over 1,200 organizations with tax records from the past 5 years were identified. Using criteria for the IRS 990 form, which nonprofits file annually to renew their nonprofit status, the list was filtered to include organizations with at least $\$ 200,000$ in income, or over $\$ 500,000$ in assets. Finally, the list was reduced by eliminating trade unions, duplicate organizations, and professional societies, as well as organizations not headquartered in Dallas County. Executive management, key employees, and boards of directors were identified using organization websites and IRS 990 records from the Guidestar database, and were added to the list of potential participants. Anchor institution participant identification was considerably simpler; potential participants were found through hospital- and both public- and private university websites, to identify leadership, key employees, and members of boards of trustees.

Supplementing participant lists. Past reputational studies have used archival newspaper searches to add to their lists of potential influentials ${ }^{399}$. This study also utilized archival research, using newspaper articles regarding development in South- and Central Dallas from the Dallas Morning News (the city's newspaper of record), as well as two altnewspapers: the Dallas Observer and the Oak Cliff Advocate. The resulting list of possible influentials contained 7,727 names, including duplicates. Of these, 341 names appeared twice, 83 appeared three times, 15 appeared four times, and 3 appeared five times. Each time a name appeared was counted as a single "vote" for that person being an influential

\footnotetext{
398 Author's note: this study used the following NTEE codes: L20 (housing development, construction, management), L21 (public housing), L25 (housing rehabilitation), L40 (low-cost temporary housing, including youth hostels), S (community improvement, capacity building), T31 (community foundations)

${ }^{399}$ cf. Agger \& Ostrom, 1956, p. 84; Hunter, 1953, pp. 263-264; C. Stone, 1989, 258-260
} 
individual in Dallas' decision-making body, so, for example, a name appearing two times was given two "votes."

Initial participant pool and final participant tally. All names with at least three votes were used to fill the participant pool; this initial pool contained 101 names. Each person on the list was invited to participate in this study through a letter mailed to their office four weeks prior to the beginning of data collection, with a follow-up email sent two weeks prior ${ }^{400}$. Physical- and email addresses were collected through organizational websites. Out of the 101 names in the initial potential participant pool, 43 responded; through three rounds of snowball sampling, an additional 28 participants were recommended. These potential participants were contacted by phone, with an email follow-up three days later; from these, 19 additional participants were added to the sample. In addition, as surveys were analyzed, it became apparent that a final wave of interviews would need to be conducted. From the surveys, 31 additional people were invited by phone to participate in the study, with a follow-up email sent three days later. Out of these, 17 participants were added to the pool, for a total of 79 surveys and interviews.

A note on participant demographics. Of the 79 participants, 45 identified themselves as male, and 34 as female. Further, 41 participants identified themselves primarily as white, 19 as Asian-American, 16 as African-American, and 3 as another race or multiracial. Additionally, 13 participants identified themselves as Hispanic or Latino. Additionally, 2 were between 25 and 35 years of age, 8 were between 35 and 44, 28 were between 45 and 54, 35 were between 55 and 64, and 6 were 65 or older; the median age among all participants was 49.5. Finally, 75 participants identified themselves as having at least an undergraduate degree.

400 Author's note: a copy of the invitation appears in Appendix 5. 
A note on snowball sampling and diminishing returns. For the first two rounds

of surveys and interviews, participants greatly improved the reputational analysis by offering the names of several previously-unidentified participants, reinforcing existing lists of potentially influential actors, and providing valuable narrative to contextualize the results. This pattern declined sharply at the third round of sampling, and given the limited amount of time remaining for data collection in the field, it was decided to not engage in another round of snowball sampling. This is not to suggest that, had additional interviews been conducted, new insight would not have been gained, but given the limits of time and financial resources, it was deemed infeasible to continue.

\section{Ethical Considerations and IRB Statement}

The University of Louisville's IRB approved the study in April 2015, and the study is in full compliance with U.S. Department of Health and Human Services Code of Federal Regulations,45 CFR \ 46 (2009); a renewal was granted in April 2016. The IRB deemed the study to be one of minimal risk to participants, and that the probability and magnitude of harm or discomfort anticipated in the research was not greater than any ordinarily encountered in daily life, or during the performance of routine physical or psychological examinations or tests.

To protect anonymity, this study was granted approval to waive signed consent, and instead participants were given a letter stating that their participation in the study was equivalent to granting that consent, although they were free to withdraw that consent at any time, and doing so would carry no penalty; to date, no participant has withdrawn consent. Throughout the survey and interview, participants were reminded that their answers would be kept in confidence, and that no direct quotations would be used without permission. With respect to the snowball sampling interview question, participants were assured that their 
recommendation would be kept anonymous, and that additional participants would not be informed about who volunteered their information with prior consent; this proved to be a moot point, however, as all participants gave their consent to be identified as a source.

Completed surveys and interview notes were kept in possession of the data collector while in the field, and stored in a locked filing cabinet within a controlled-access office during the collection phase. After returning from the field, surveys and interview notes were stored in another locked filing cabinet within a controlled-access office. Only the data collector had access to these documents, which were shredded after being anonymized and converted to digital copy. Confidentiality of collected data was be maintained at all times, and identification of participants was not made available during or after the study.

\section{Data Collection}

The purpose of this section is to chronicle the data collection methods used by this study. In the paragraphs that follow, this study will document the methods used to collect quantitative data collection, using decennial census and limited ACS records. Then, it will chronicle the context and process for collecting the qualitative data, using surveys and interviews.

\section{Quantitative Data Collection}

For all years, both decennial- and ACS data are recorded from tables reporting data at the city level, using all tracts wholly- or partially within Dallas. In addition, for all years, tract data are aggregated at the neighborhood level by overlaying neighborhood maps ${ }^{401}$ provided by the Dallas Morning News and BC Workshop, a nonprofit urban research institute, atop decennial census tract maps ${ }^{402}$, and then approximating census tracts into

\footnotetext{
401 Schmidt, 2013; Wilonsky, 2012

${ }^{402}$ United States Census Bureau, 1980a; 1980b; 1990a; 1990b; 2000a; 2000b; 2010a; 2010b
} 
neighborhoods representing North Oak Cliff and Downtown Dallas. This process is repeated for 1980, 1990, 2000, and 2010, in order to capture any changes in census tract boundaries ${ }^{\text {viii }}$.

For 1980 and 1990, census data are not generally available in electronic format, so data were copied from physical publications of the Census of the Population and Housing for 1980 and 1990 into the study dataset - a series of Microsoft Excel tables. For 2000 and 2010, data are available through the American FactFinder website ${ }^{403}$, which is produced and maintained by the Census Bureau. Necessary data were downloaded in a Microsoft Excelcompatible format, and then copied the data into the study dataset. Finally, the study dataset was verified for accuracy against the source tables by two independent readers.

\section{Qualitative Data Collection}

Participants were asked to complete a paper survey, and also to participate in a brief interview session. First, this section details the survey itself, which was constructed based on the examples of older reputational analyses, including a previous study of Dallas, with modifications recommended by the dissertation committee ${ }^{404}$. Then, it discusses the interview questions used, which offered the participants the opportunity to contextualize their survey responses, offer deeper insight into both Dallas' development in recent years, and into its informal governance structure.

Survey outline. After a brief introduction, study participants were asked to complete a survey regarding how projects in Dallas come about, and who gets involved. First, participants were asked to provide informed consent, and gave them the opportunity to opt out of completing the survey. Once consent was given, the participants were asked to

\footnotetext{
403 i.e. http:/ / factfinder.census.gov

${ }^{404}$ French \& Aiken, 1968, pp. 263-269; Hunter, 1953, pp. 10-11; Thometz, 1963, pp. 115-117
} 
complete the survey of leadership and development in Dallas (a reproduction appears in Appendix 8); the five sections of the survey are detailed below.

In the first section, participants were presented with the master list of 101 influentials, and for each, was first asked to indicate how influential each person is with respect to policy decisions or development in Dallas as a whole, ranging from 1 (not very influential) to 4 (highly influential); participants were instructed to respond based on their own opinions, and were given an option to select “Don't Know / Not Sure." Then, for each of the 101 names, participants were asked to briefly elaborate on why they gave the rating that they did. Third, participants were asked to disclose whether they had served on a committee or project team with each of the 101 names. Finally, participants were asked to select which phrase ("Never heard of," "Know slightly," "Know well," or "Personal friend or relative") best described their relationship with each of the names listed. Participants were also invited to provide write-in names, in case the survey failed to identify someone who, in their opinion, was influential in city-wide projects.

In the second section, the survey asked participants to imagine that they were responsible for a project that would have an impact felt throughout the city, and that this project would require a decision made by a group of leaders - leaders whose opinions nearly everyone would accept. Using the lists from the previous section, as well as their own knowledge of Dallas' leaders, participants were asked to select up to 10 people for their team. For each of these names, participants were asked to disclose whether they had been on a committee or project team with that person in the past five years, and to describe (using the same phrases from above) their relationship with that person.

In the third- and fourth sections, participants were asked to imagine that they were responsible for a new project in, respectively, downtown Dallas and South Dallas / Oak 
Cliff, which would require a decision to be made by a group of leaders whose opinions nearly everyone would accept. Using the lists from the first section, as well as their own knowledge of Dallas' leaders, participants were asked to select up to 10 people for their team. For each of these names, participants were asked to disclose whether they had been on a committee or project team with that person in the past five years, and to describe (using the same phrases from above) their relationship with that person.

Finally, in the fifth section, the survey asked participants to record any concluding thoughts on the nature of decision-making in Dallas, such as their thoughts on how decisions are made, who makes them, or the types of people who get most heavily involved in Dallas' decision-making body - either for the city as a whole, or for projects in particular neighborhoods. Participants were also asked to list any names of people who might be willing to provide additional information that may be helpful for this study.

Interview outline. After completing the survey, participants engaged in a brief interview with the data collector; this interview ${ }^{405}$ contained four questions. These questions were intended to be kept brief, but participants often had much to say, and interviews frequently took up the majority of the meeting time. For each interview, the data collector kept detailed notes, labeled with the date and interview number; for example, the second interview on the date June 23, 2015 would be labeled "2015072302."

The first interview question asked participants about their subjective opinion about development in Dallas; specifically, which individuals and organizations (public-, private-, and third-sector) tend to get involved, and whether (and to what extent) residents of neighborhoods being developed are part of the development process. The second question asked participants to contrast development in Dallas' CBD, particularly the Downtown

\footnotetext{
405 A listing of interview questions appears in Appendix 9.
} 
Dallas 360 plan, with development in the Oak Cliff area, particularly with respect to the Bishop Arts District and Oak Cliff Gateway projects. These specific projects were chosen because, based on newspaper articles and discussions with local media reporters, these are largest and most visible of the developments in the respective areas. The third question asked participants to talk about the involvement of particular organizations in development, and was tailored based on previous answers. For example, participants frequently discussed the private sector's involvement in development, so this question was often modified to ask specifically about public- and third-sector organizations. The final question asked participants to discuss their individual involvement with development in these areas, and their individual experiences with the process. For participants who were most closely associated with projects in either the CBD or Oak Cliff, this question was tailored to their particular focus area, and for participants who were less-directly connected to one project, the question was kept intentionally broad.

\section{Data Processing and Analysis}

The purpose of this section is to outline methods that were used to process the data after collection. First, it will briefly sketch how quantitative data are to be processed and analyzed. Then, it will detail a two-phase analysis to be undertaken of the qualitative surveyand interview data.

\section{Quantitative Data Processing and Analysis}

Quantitative data were analyzed in two phases. During the first phase, a series of data tables and charts were created to show changes in racial- and economic profiles for Dallas as a whole, as well as for North Oak Cliff and Downtown Dallas. In the second phase, these data were compared to expected data based on literature regarding post-Fordist racial- and economic trends in central cities, as well as in central urban neighborhoods. In the 
paragraphs that follow, this study will introduce these quantitative data processing and analysis methods.

Phase 1: Comparing geographies over time. In the first round of quantitative analysis, economic and demographic census data were copied into a Microsoft Excel file; data from 1980 and 1990 were hand-copied, while data from 2000 and 2010 were available electronically, and were imported as .csv files, reducing the likelihood for transcription errors. Then, detailed tables and charts were constructed from this "master" file, the demographic- and economic profiles have changed over the 30-year period from 1980 to 2010, for Dallas as a whole, North Oak Cliff, and Downtown Dallas. These data first appear in Chapter 4, and also serve as the basis of further analysis in Chapter 5.

Phase 2: comparing data to literature-based expectations. In the second round of analysis, this study recast its quantitative data in the context of expectations based on literature regarding the effects of post-Fordism on cities overall, and within central urban neighborhoods. Recall that literature regarding post-Fordist shifts in central cities and urban neighborhoods suggests that, while wealthier whites largely abandoned central cities for suburban alternatives (conceptualized by the chocolate cities, vanilla suburbs model), a subset of them are "rediscovering" central urban neighborhoods (conceptualized by the new donut model and gentrification literature). To test whether, or to what extent, these two trends appear in Dallas citywide, North Oak Cliff, and Downtown Dallas, this study made three primary comparisons: first, between Dallas and its surrounding suburbs; second, between the neighborhoods of North Oak Cliff and Downtown Dallas; and third, between these neighborhoods and Dallas as a whole. These comparisons are featured in Chapter 5. 


\section{Qualitative Data Processing and Analysis}

Completed surveys and interview notes were also analyzed in two phases. During the first phase, completed surveys and interview notes were used to first create a typology of decision-makers within Dallas as a whole, North Oak Cliff, and Downtown Dallas; these typologies will be presented in Chapter 4. In the second phase, this study examined the presence- and nature of decision-making structures that comprise these various typologies, first for Dallas citywide, then for North Oak Cliff, and finally for Downtown Dallas. In the paragraphs that follow, this study will introduce these qualitative data processing and analysis methods.

Phase 1: Establishing a typology of decision-makers. Previous studies of Dallas found that the highest levels of decision-making were largely occupied by business executives and civic organizations ${ }^{406}$, supported by sympathetic public-sector officials through business-friendly legislation and public funding for private development, especially in Downtown Dallas. Recall that, in the decades following these studies, much of the commercial heart of Dallas had moved to its surrounding suburbs, and many of its locallyowned firms have been merged into national- and international corporations. Additionally, recall that in 1991 Dallas' city council underwent a dramatic restructure that distributed power from wealthy, white North Dallas into districts across the city. Finally, recall that Dallas' leadership was suspected of having failed to identify successors to retiring leaders, leaving the future of the entrepreneurial regime in a degree of doubt.

To the extent that business dominance of citywide decision-making was ever accurate, it may no longer be so today. Therefore, during the first phase of qualitative data analysis, this study analyzed coded participant responses, as well as characteristics of every

\footnotetext{
${ }^{406}$ Elkin, 1987a, pp. 67-71; Thometz, 1963, pp. 31-33
} 
actor nominated to serve on any participants' hypothetical decision-making team (even those that did not receive enough nominations to be included in further analysis). Because this study is also interested in decision-makers in North Oak Cliff and Downtown Dallas, it repeated this analysis for each of these neighborhoods. As a result of these three analyses, this study created a five-category typology of decision-makers in Dallas, which will be introduced in Chapter 4, and which will serve as a starting point for this study's examination of structures of decision-making in Dallas as a whole, as well as in two of its component neighborhoods.

Phase 2: Conceptualizing structures of decision-making. The previous reputational study of Dallas found that, at the citywide level, decision-making power was stratified among three levels, with a small cohort of key leaders at the top, a larger tier of top level leaders supporting them, and a still-larger pool of second echelon leaders below those ${ }^{407}$. To test whether, or to what extent, this remains an accurate depiction of the structure of citywide decision-making in Dallas, this study's participants were asked to rate their influence in the city on a scale from 1 to 4, with higher numbers indicating a greater level of generalized influence throughout the decision-making process. In addition, participants were asked to nominate up to 10 of these names to serve on hypothetical decision-making teams.

The previous reputational study of Dallas found that those individuals with the most nominations also tended to have the highest mean power scores. This result suggests two things: first, that participants' perceptions of an individual's degree of decision-making power are a valid indicator of their decision-making power in actuality; and second, that the reputational method is indeed a valid method for examining decision-making power. Building on these results, the previous study of Dallas also used a Duncan's New Multiple

\footnotetext{
${ }^{407}$ Thometz, 1963, pp. 56-57
} 
Range Test to establish a stratification of decision-makers within Dallas. Duncan's test compares mean scores within a given dataset, and determines when the differences between any two means are statistically significant; in effect, Duncan's test is a method that helps to establish whether subgroups exist within a larger dataset.

To allow its results to be compared with those from the previous reputational study of Dallas, this study will first replicated methods used in the Thometz study for Dallas as a whole ${ }^{408}$. Because the present study is also interested in the structure of decision-making in two of Dallas' component neighborhoods, it also replicated these analysis methods for both North Oak Cliff and Downtown Dallas. To contextualize these findings, this study also this study recast results from its statistical analyses in light of participant observations regarding decision-making in each respective geography, in order to understand the effects of the presence (or absence) of types of decision-makers on the kinds of decisions that are made, with respect to both urban policy and economic development projects. These results will appear in Chapter 5, and also serve as the basis for larger themes regarding the role (or lack thereof) of anchor institutions and CDCs in contemporary decision-making structures, as well as conclusions drawn in Chapter 6.

\section{Assessing Internal and External Validity}

No study, no matter how well-planned, is immune to concerns over the validity of its results; in the paragraphs that follow, this study will offer an initial foray into possible concerns over both internal- and external validity of the study's findings. First, it will outline the methods used to check for internal validity, or whether the results actually measure what this study claims they do. Then, it will discuss external validity, which establishes the extent to which whether findings are transferrable to other cities.

\footnotetext{
408 Thometz, 1963, pp. 44-46
} 


\section{Assessing Internal Validity}

Looking first at the quantitative data, of prime importance to this study is whether the data are free of error, to the extent that the study can control for it. Because decennial census- and ACS data contain some amount of error, but the primary-source data contained within their reports are generally unavailable, this source of error cannot be controlled for by this study. Transcription errors were identified and corrected by verifying data against the source material; after the data are copied from Census Bureau records, three readers (the researcher and two volunteer assistants) verified the inputted data against the source material, correcting as-needed. After the data were used to construct the charts and tables that appear throughout this work, these were also validated by volunteer readers.

This study's survey and interview data were validated by summarizing and discussing results with participants, so that each had ample opportunity to clarify or contextualize their responses. First, participants were given opportunities to clarify their statements at the end of each interview; additionally, participants were asked clarifying questions during natural pauses in their interviews, giving them the chance to revise previous statements. In order to preserve the confidentiality of the participants, outside readers were not allowed to read interview notes, though it should be noted that past reputational studies have validated this method against alternative techniques, and regularly found that these methods are able to identify individuals who are deeply involved in the policymaking process ${ }^{409}$.

\section{Assessing External Validity}

Although this study argues for Dallas as a crucial case, it also argues that the city is not so unique as to make results of this study inappropriate for comparison against other cities;

\footnotetext{
409 Abu-Laban, 1965, pp. 40-41; Agger, 1956, pp. 325-326; Bonjean, 1963, pp. 678-681; Danzger, 1964, pp, 708-709; D’Antonio, Ehrlich, \& Erickson, 1962, pp. 851-852; Freeman et al., 1963, pp. 797-798
} 
in short, although Dallas is argued to be a least-likely scenario for supporting the presence of third-sector actors in urban development, the city's context is still similar to that of other cities, and many aspects of the city's historical- and present contexts will sound familiar to urban scholars.

Like many cities, Dallas is divided by the lingering effects of white flight, with its (comparatively) newer, northern neighborhoods tending to be wealthier (and whiter) than those found to the south of the Trinity River. Unsurprisingly, these neighborhoods have been the primary recipients of development, job growth, and infrastructure improvements, while the predominately African-American and Hispanic portions of the city have fallen into decades of decline and neglect, leading one newspaper to declare Dallas "worst in the nation" for neighborhood inequality ${ }^{410}$. Additionally, the city, like many others, is locked in competition with its suburbs for new businesses and residents; while the Dallas region (known as the "DFW Metroplex") continues to grow, new development in Dallas is on sharp decline. Further, existing corporations have been vacating the city for lush corporate campuses in northern suburbs like Plano, Frisco, and Allen ${ }^{411}$.

Even as businesses continue to abandon the city, a counter-trend is for younger residents to move back - often finding highly affordable options those same neighborhoods that have been historically neglected ${ }^{412}$. As demand grows for smaller housing, in walkable neighborhoods, and with proximity to office buildings, these once-blighted areas are rapidly gentrifying, causing concern among existing residents ${ }^{413}$. As a result of these trends, the city is engaged in a number of development projects, both in its CBD and in inner-ring

${ }^{410}$ Darling, 2012; J. Mitchell, 2015; Schnurman, 2014

${ }^{411}$ Elkin, 1987a, p. 71; Graff, 2008, p. 227; D. Keating, 2007, p. 1; Stradling \& Stradling, 2008, pp. 530-531

${ }_{412}$ Juday, 2015, pp. 3-4

413 Appleton, 2013a; 2013b; Benning, 2014; Brown, 2014; Editorial: New South Dallas housing formula, 2013 
neighborhoods, ${ }^{414}$ and like other cities, Dallas' third sector seems to be involved in some of this development ${ }^{415}$.

Dallas' history of white flight and corporate abandonment, and its current trend of white return and rediscovery of the city are hardly unique, especially among cities that are prospering in the post-Fordist economy ${ }^{416}$. In addition, the city's response to these trends, and the presence of third-sector actors in the redevelopment of low-income areas, are largely similar to trends in other cities ${ }^{417}$. These positions in mind, this study argues that its results are likely to be transferable to other cities in the United States.

\section{Limitations}

Every study, no matter how well constructed, has limitations that shape the conclusions that can be drawn ${ }^{418}$. While Chapter 5 will offer an expansive discussion of study limitations, it is nonetheless useful to introduce a subset of these before presenting this study's results and their analyses. In the paragraphs that follow, this section will first introduce limitations related to the surveys and interviews. Then, it will introduce a number of additional limitations, not directly related to the surveys and interviews.

With respect to survey and interview limitations, because they were collected in a natural (rather than laboratory) setting, it is extremely difficult for future scholars to replicate the study in other settings. Further, the responses were limited by the time constraint on the meetings; participants may have truncated responses in order to fit within the time allotted, reducing their overall quality. Next, because a number of survey items restricted the range of

\footnotetext{
${ }^{414}$ Darling, 2012; Economic Research Associates (ERA), 2008; Hyde, 2008; OED, 2014e; Thompson, 2012

415 Appleton, 2013d; City of Dallas Department of Sustainable Development and Construction, 2013, pp. 29-32; ERA, 2008; OED, 2014e;

${ }^{416}$ Audretsch, 1998, pp. 27-28; Dreier, Mollenkopf, \& Swanstrom, 2004, pp. 13-14, 90-99; Florida, 2003, pp. 8-10; 2006, pp. 26-2; Judd \&

Swanstrom, 1998, pp. 316-317; Storper, 1997, pp. 6-7

${ }^{417}$ Bruyn, 1987, pp. 5-6; Milward \& Provan, 2000, pp. 259-360; Romzek, LeRoux, \& Blackmar, 2012, p. 442; Vidal, 1992, pp. 70-73;

Zielenbach, 2000, pp. 231-234; for a discussion of Dallas specifically, see City of Dallas Office of Economic Development, 2010; 2013;

2014a; 2014b; 2014c; 2014d

418 Schutt, 2009, p. 20
} 
possible responses, the results are narrower than they may have been, were the questions written to be open-ended. Additionally, the lack of cross-case comparative data case study limits the ability of this study to eliminate alternative explanations for the findings, including the possibility that Dallas is an extreme outlier. Also, the nonrandom nature of snowball sampling introduces the possibility that the study sample is not actually representative of the (arguably unknowable) population. Finally, because this study incorporates secondary-source data, any error present in the source data is inherited by this study.

With respect to other aspects of this study, secondary-source data (e.g. decennial census, ACS) may contain unknown errors in reporting and data collection; while every attempt to use corrected data was made, it is possible that some error remains. In addition, with particular respect to data regarding employment by industry, this study is limited by the availability and sourcing of data; when possible, the decennial census was utilized, but for two years (1980 and 1990), these data were unavailable, due to irreconcilable differences in data reporting. In these cases, non-census data were used, and while these data are reliablysourced from the Texas Employment Commission (TEC), a state agency, they present additional challenges, only some of which could be overcome. Differences in reporting between TEC datasets and those in census records were successfully reconciled, but this "translation" process introduces the possibility that a category was translated in error. In addition, TEC data are representative of the entire Dallas-Fort Worth (now Dallas-Fort Worth-Arlington) statistical area, and are not limited to Dallas itself. Third, TEC data are derived from employer reports (rather than employee self-reports), and this difference in methodology introduces a further source of error. Finally, these data preclude analysis at levels more granular than the statistical error, so for years 1980 and 1990, employment by industry cannot be ascertained for the North Oak Cliff and Downtown Dallas 
neighborhoods. For these reasons, discussions of employment by industry should be seen as a "rough estimate," based on data that are flawed beyond what should be expected from census data in particular, and secondary-source data more broadly.

\section{Chapter Summary}

As noted in its introduction, the purpose of this chapter is to outline the research setting and methods used to assess whether cities are still governed by the political-business coalitions conceptualized in the 1970s and 1980s, or whether some subset of the third sector has achieved legitimacy as a primary, rather than ancillary, component of urban governance. In the preceding sections, this study restated its research questions, and then offered a series of hypotheses to be tested in order to answer them. Third, it described the study design, and argued for its appropriateness. Fourth, it discussed the setting for this study, as well as the target population and sample. Fifth, it outlined the data collection methods and instrumentation implemented, including a summary of ethical considerations. Sixth, it detailed how data were analyzed and processed. Finally, it discussed validity and limitations related to this study's findings, which follow in the next chapter.

\footnotetext{
iv Author's note: a detailed listing of tables referenced for 1980 appears in Appendix 1.

v Author's note: a detailed listing of tables referenced for 1990 appears in Appendix 2.

vi Author's note: a detailed listing of tables referenced for 2000 appears in Appendix 3.

vii Author's note: a detailed listing of tables referenced for 2010 appears in Appendix 4.

viii Author's note: a detailed listing of changes to census tracts appears in Appendix 6; a listing of all tracts used appears in Appendix 7.
} 


\section{CHAPTER IV \\ PRESENTATION OF DATA}

The purpose of this chapter is to report data collected using the methods introduced in Chapter 3, in order to address this study's research questions and hypotheses. In the sections that follow, this study will first report quantitative data regarding select socioeconomic changes from 1980 to 2010, first for Dallas as a whole, then for the study's two focus neighborhoods: North Oak Cliff and Downtown Dallas. Then, it will detail participant responses to surveys and interviews regarding decision-making in Dallas as a whole, North Oak Cliff, and Downtown Dallas.

\section{Quantitative Data}

This study is primarily interested in the nature of governance, both formal and informal, in the City of Dallas, as well as within two of its neighborhoods - Downtown Dallas and North Oak Cliff. Before reporting qualitative data regarding the actors who govern, and the structure in which they operate, this study will report quantitative data regarding the economic- and social profiles of the people being governed. In the following sections, this study will present findings from census-based data collection; first, this study will first outline a brief demographic- and economic profile for Dallas as a whole, with data reported at 10-year intervals to coincide with decennial census reports. Then, it will repeat these data for each of the focus neighborhoods: North Oak Cliff and Downtown Dallas. 


\section{Dallas as a Whole}

This study hypothesized that Dallas as a whole has undergone demographic- and economic transitions consistent with the chocolate cities, vanilla suburbs model of cities. While evaluation of whether this is indeed the case will be held until Chapter 5, in the chapter sections that follow, this study will first present data documenting changes in Dallas' citywide demographic profile from 1980 to 2010, and then it will present data documenting changes in the citywide economic profile over that same period.

Citywide demographic changes, 1980 to 2010. In the following subsections, this study will report relevant changes in Dallas' demographics from 1980 to 2010. First, it will report trends in Dallas' population size, primarily to serve as an anchor for the data that follows. Then, it will report decennial changes in Dallas' demographics by race and Hispanic status.

Citywide population. Table 4.01 shows Dallas' citywide population changes from 1980 to 2010.

\begin{tabular}{|l|c|c|c|c|}
\hline \multicolumn{1}{|c|}{ Table 4.01: Citywide Population, $\mathbf{1 9 8 0}-\mathbf{2 0 1 0}$} \\
\hline Year & $\mathbf{1 9 8 0}$ & $\mathbf{1 9 9 0}$ & $\mathbf{2 0 0 0}$ & $\mathbf{2 0 1 0}$ \\
\hline Decenniation Gain (Loss) & 904,078 & $1,006,877$ & $1,188,580$ & $1,197,816$ \\
\hline
\end{tabular}

As the table shows, Dallas' overall population rose steadily from 1980 to 2000, with the city gaining over 250,000 residents between those years, even in spite of the Savings \& Loan Crisis that ruined Dallas' financial markets and sent its economy into a severe retraction. Equally striking is the lack of population growth between 2000 and $2010(0.008 \%$ growth effectively no change), suggesting a growth plateau.

Citywide race and Hispanic or Latino status. Within the context of the city's rapid growth and subsequent plateau, figure 4.01 shows the changing demographic profile of Dallas' population with respect to race and Hispanic origin. 
Figure 4.01: Citywide Race and Hispanic or Latino Status, 1980 - 2010

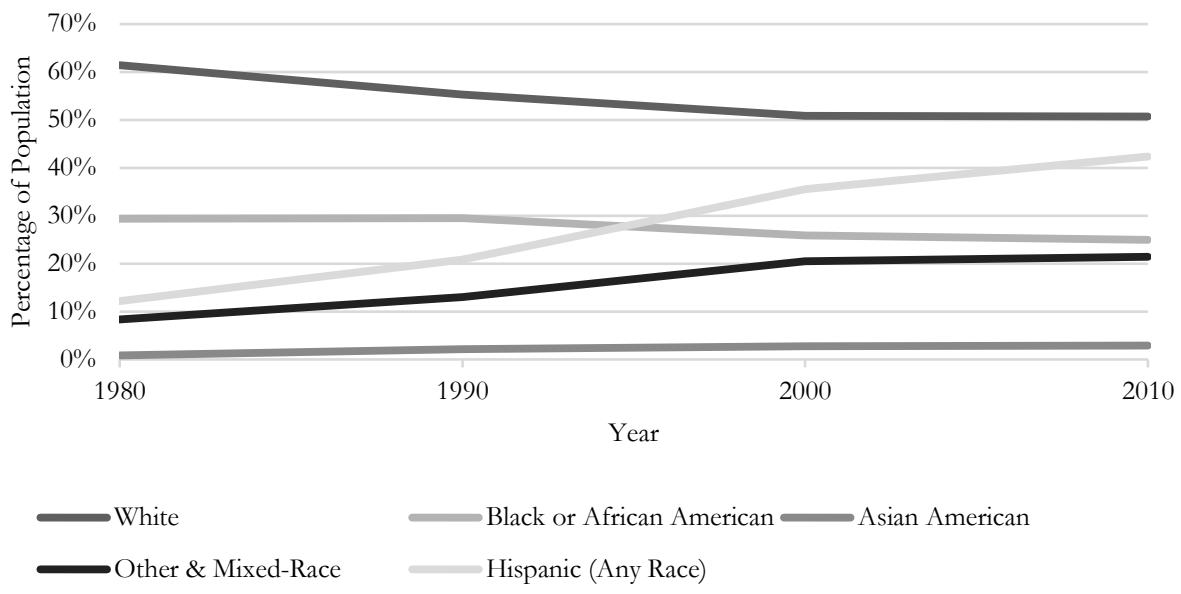

Data suggest that, since 1980, the proportion of the population represented by the largest two racial groups in Dallas tend to decline from one census to the next, with people identifying as "white alone" falling from $61.4 \%$ in 1980 to $50.7 \%$ in 2010, and people identifying as Black or African American falling (though less precipitously) from $29.4 \%$ in 1980 to $25.0 \%$ in 2010 . By contrast, the populations of people identifying as Asian American, and especially those identifying as "Other" or multiracial has increased. Finally, of particular note, the population identifying as Hispanic (of any race) increased nearly fourfold, from $12.2 \%$ in 1980 to $42.4 \%$ in 2010 .

Citywide economic changes, 1980 to 2010. In the following subsections, this study will report relevant changes in Dallas' economic context from 1980 to 2010. First, it will report basic data on workforce size and unemployment as an anchor for data to follow. Then, it will report employment by industry cluster, combining data reported by BLS industry code into the following categories: creative class $^{\mathrm{ix}}$, blue collar ${ }^{\mathrm{x}}$, services and trade ${ }^{\mathrm{xi}}$, and public administration ${ }^{x i i}$. Finally, it will report data related to median household income and poverty rates. 
Citywide labor force. Table 4.02 shows Dallas' workforce size and unemployment rate in from 1980 to 2010.

\begin{tabular}{lcccc} 
& Table 4.02: Citywide Labor Force Size and Unemployment Rate, $\mathbf{1 9 8 0}-\mathbf{2 0 1 0}$ \\
\hline \multicolumn{1}{c}{ Year } & $\mathbf{1 9 8 0}$ & $\mathbf{1 9 9 0}$ & $\mathbf{2 0 0 0}$ & $\mathbf{2 0 1 0}$ \\
Workforce Size & 481,224 & 552,303 & 588,385 & 610,562 \\
Decennial Gain (Loss) & $(\mathrm{x})$ & 71,079 & 36,082 & 22,177 \\
Unemployment Rate & $7.4 \%$ & $12.2 \%$ & $4.3 \%$ & $5.6 \%$ \\
Decennial Gain (Loss) & $(\mathrm{x})$ & 4.8 pts. & $(7.9$ pts.)
\end{tabular}

While the size of Dallas' workforce has increased at the 1990, 2000, and 2010 census, data suggest that the rate of gain at each census appears to be slowing, with the labor force gaining fewer new people at each census than at the census before. Data also show that, somewhat unsurprisingly, citywide unemployment increases between 1980 and 1990, as well as between 2000 and 2010; these periods both bookend financial downturns - the Savings \& Loan Crisis of the 1980 s $^{419}$, and the Great Recession from 2007 to $2009^{420}$.

Citywide employment by industry cluster ${ }^{421}$. Figure 4.02 shows the percentages of Dallas' citywide workforce employed in the creative class-, service sector-, blue collar-, and public administration fields from 1980 to 2010. As a reminder, data from 1980 and 1990 are representative of the statistical area; while not as precise as census data from 2000 and 2010, these data represent a "best estimate" from among available sources.

\footnotetext{
${ }^{419}$ Federal Deposit Insurance Company, 1987, pp. 166-169

${ }^{420}$ National Bureau of Economic Research, 2010

421 Author's note: as reported in Chapter 3, TEC data are used to estimate employment by industry at the citywide level for 1980 and 1990. Among their myriad flaws, these data are unavailable at the census tract level.
} 


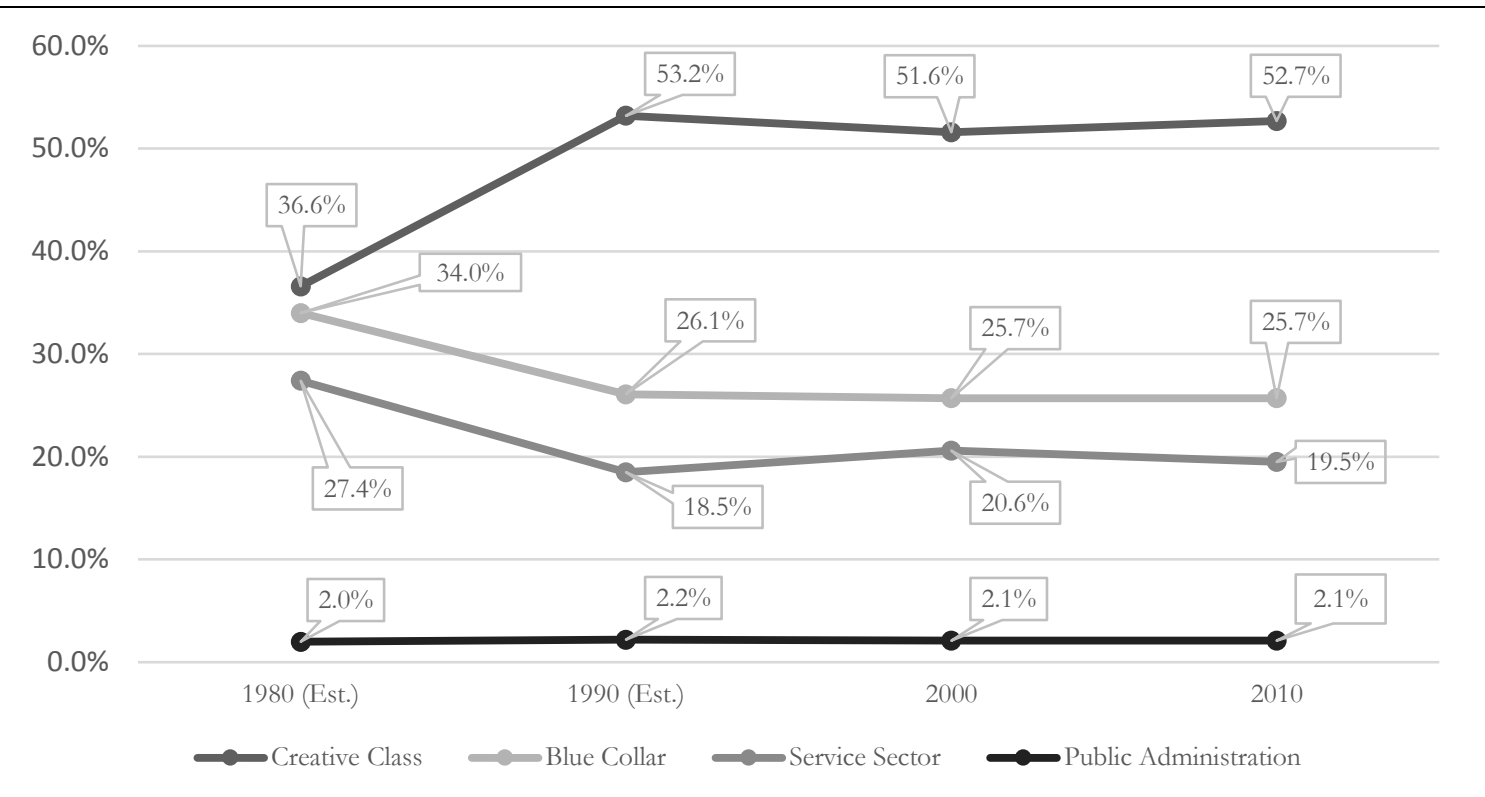

These data suggest that, between 1980 and 1990, there is a notable increase in the percentage of working Dallasites employed in creative class fields, while over that same period, there is a nearly-equal decrease in employment within blue collar and service sector fields. Since 1990, these three employment clusters have remained relatively stable, with slightly over half of working Dallasites being employed in creative class fields, roughly one-quarter of working Dallasites being employed in blue collar fields, and about one-fifth of working Dallasites being employed in service sector fields. Finally, at all four data collection points, about $2 \%$ of working Dallasites have been employed in public administration.

Citywide median household income and poverty. Table 4.03 shows data related to Dallas' citywide median household income (MHI) in 2015 inflation-adjusted dollars, as well as the citywide poverty rates, from 1980 to 2010, including basic trends in both.

\begin{tabular}{|c|c|c|c|c|}
\hline Year & 1980 & 1990 & 2000 & 2010 \\
\hline MHI in 2015 Dollars & $\$ 79,611$ & $\$ 50,461$ & $\$ 52,146$ & $\$ 45,616$ \\
\hline Decennial Gain (Loss) & (x) & $(\$ 29,150)$ & $\$ 1,685$ & $(\$ 6,530)$ \\
\hline Poverty Rate & $18.0 \%$ & $18.0 \%$ & $17.8 \%$ & $22.3 \%$ \\
\hline Decennial Gain (Loss) & $(\mathrm{x})$ & 0 pts. & (0.2 pts.) & 4.5 pts. \\
\hline
\end{tabular}


These data suggest that median household income in Dallas fell sharply from 1980 to 1990, holding relatively steady in 2000, and falling again in 2010, with median household incomes in 2010 holding at just over $57 \%$ of their 2015-adjusted level in 1980. Additionally, data show that the poverty rate held at roughly $18 \%$ between 1980 and 2000, but increased to over $22 \%$ in 2010 .

\section{North Oak Cliff}

This study hypothesized that the neighborhood of North Oak Cliff has undergone demographic- and economic transitions consistent with gentrification literature regarding central urban neighborhoods, and the new donut model of cities. As with data regarding Dallas as a whole, evaluation of whether any identified changes in North Oak Cliff are consistent with said literature will be held until Chapter 5. Nonetheless, in the chapter sections that follow, this study will first present data documenting changes in the neighborhood's demographic profile from 1980 to 2010, and then it will present data documenting changes in North Oak Cliff's economic profile over that same period.

Neighborhood demographic changes, 1980 to 2010. In the following subsections, this study will report relevant changes in North Oak Cliffs demographics from 1980 to 2010. First, it will report trends in population size, and then, it will report decennial changes in the neighborhood's demographics by race and Hispanic status.

Neighborhood population. Table 4.04 shows the population changes from 1980 to 2010 for North Oak Cliff.

\begin{tabular}{|l} 
Table 4.04: North Oak Cliff Population, 1980 - 2010 \\
\begin{tabular}{|l|c|c|c|c|}
\hline \multicolumn{1}{|c|}{ Year } & $\mathbf{1 9 8 0}$ & $\mathbf{1 9 9 0}$ & $\mathbf{2 0 0 0}$ & $\mathbf{2 0 1 0}$ \\
\hline Population & 17,713 & 17,544 & 19,617 & 15,055 \\
\hline Decennial Gain (Loss) & $(\mathrm{x})$ & $(169)$ & 2,073 & $(4,562)$ \\
\hline
\end{tabular}
\end{tabular}

Data suggest that, between 1980 and 2010, the neighborhood's population has declined, losing over 2,500 people, or $15 \%$ of its population. Data also suggest that these losses have 
been inconsistent, with an insignificant loss at the 1990 census, a significant gain of slightly over 2,000 people at the 2000 census, but then a loss of over twice that by the $2010-\mathrm{a}$ census-over-census loss of over $23 \%$.

Neighborhood race and Hispanic or Latino status. Within the growth and abandonment of the neighborhood, Figure 4.03 shows the changing demographic profile of North Oak Cliff's population with respect to race and Hispanic origin.

Figure 4.03: North Oak Cliff Race and Hispanic or Latino Status, 1980 - 2010

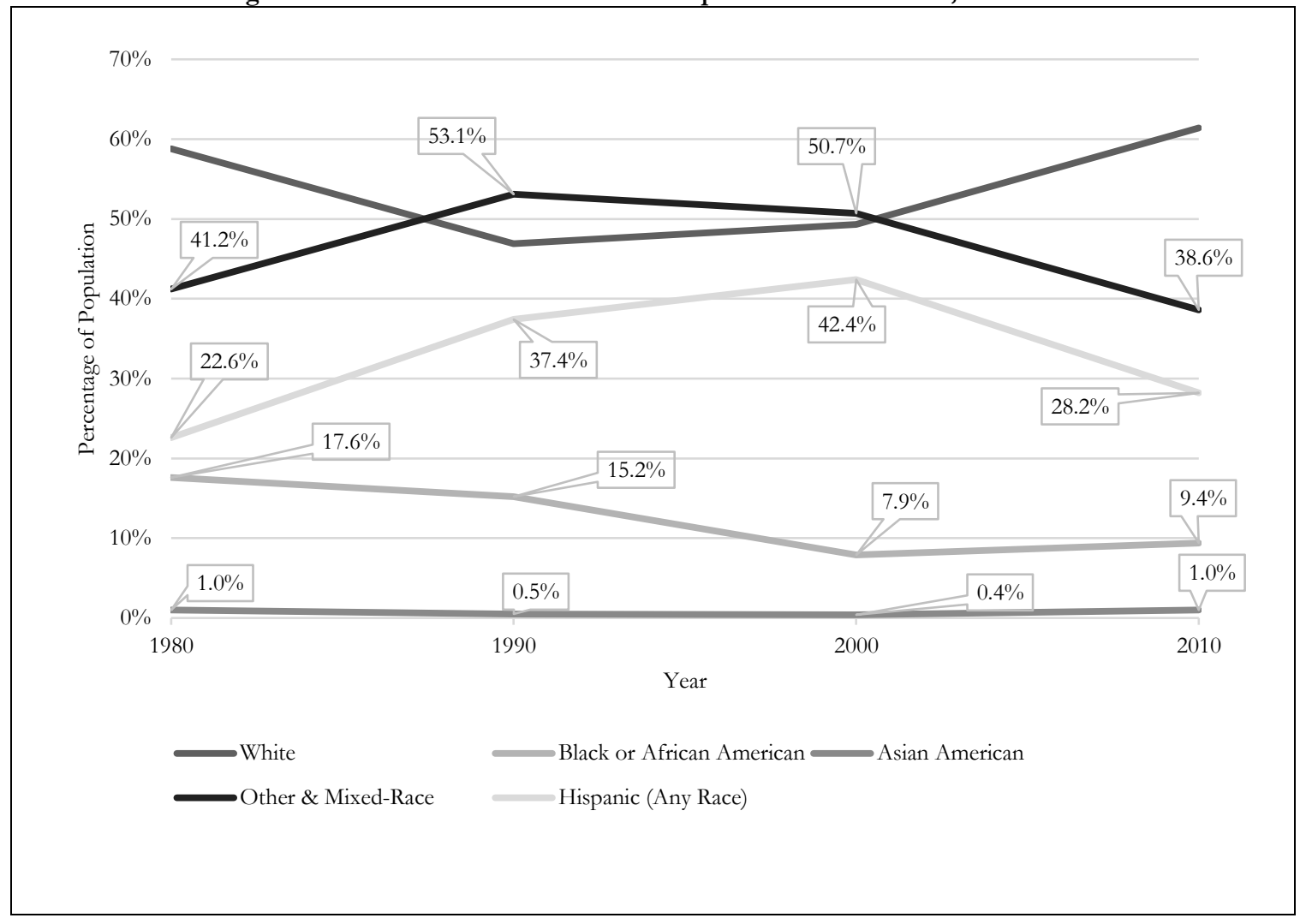

Anecdotally, people who live outside of the southern half of Dallas often assume the area to be "mostly black" ${ }^{422}$, although whether this was ever true for North Oak Cliff, data suggest that this hasn't been true since (at least) the 1980 census. At that time, North Oak Cliff was majority-white, but by 1990, the neighborhood became majority-minority. This trend reversed in 2000, and by 2010, people identifying as "white alone" had risen to their largest

\footnotetext{
422 cf. Merwin, 1977; Schutze, 2010, 2015a
} 
share of the population during the time period studied, at over $61 \%$. Meanwhile, people identifying as Black or African American have never held more than one-fifth of the area's population over that same period, and have not made up more than $10 \%$ of the population since 2000. Until the 2010 census, the trend in the percentage of North Oak Cliffs population identifying as Hispanic or Latino followed the growth found in Dallas as a whole, but by 2010, this trend had reversed, and the neighborhood's demographics returned to showing a white majority.

Neighborhood economic changes, 1980 to 2010. In the following subsections, this study will report relevant changes in the economic characteristics of North Oak Cliff from 1980 to 2010. First, it will report basic data on workforce size and unemployment. Then it will report employment by industry cluster. Finally, it will report data related to median household income and poverty rates.

Neighborhood labor force. Table 4.05 shows sizes of- and trends for North Oak Cliff's labor force and unemployment rates from 1980 to 2010.

\begin{tabular}{lcccc} 
& Table 4.05: North Oak Cliff Labor Force Size and Unemployment Rate, $\mathbf{1 9 8 0}-\mathbf{2 0 1 0}$ \\
\hline \multicolumn{1}{c}{ Year } & $\mathbf{1 9 8 0}$ & $\mathbf{1 9 9 0}$ & $\mathbf{2 0 0 0}$ & \\
Workforce Size & 8,580 & 7,852 & 8,559 & $\mathbf{2 0 1 0}$ \\
Decennial Gain (Loss) & $(\mathrm{x})$ & $(728)$ & 707 & 4,421 \\
Unemployment Rate & $5.3 \%$ & $6.6 \%$ & $4.4 \%$ & $(4,138)$ \\
Decennial Gain (Loss) & $(\mathrm{x})$ & 1.4 pts. & $(2.2$ pts.)
\end{tabular}

Data suggest that, from 1980 to 2000, the area's labor force remained relatively stable, with unemployment below the citywide average in 1980 and 1990, and only $0.1 \%$ higher in 2000 . Significantly, at the 2010 census the labor force dropped by over 4,000 workers, in a trend similar to the overall population loss in the neighborhood; at the same time, the unemployment rate increased to $0.5 \%$ over the citywide average.

Neighborhood employment by industry cluster. Figures 4.04 and 4.05 show the percentages of North Oak Cliff's workforce employed in the creative class-, service sector-, blue collar-, and public administration fields in, respectively, 2000 and 2010. 
Figure 4.04: North Oak Cliff

Employment by Industry Cluster, 2000

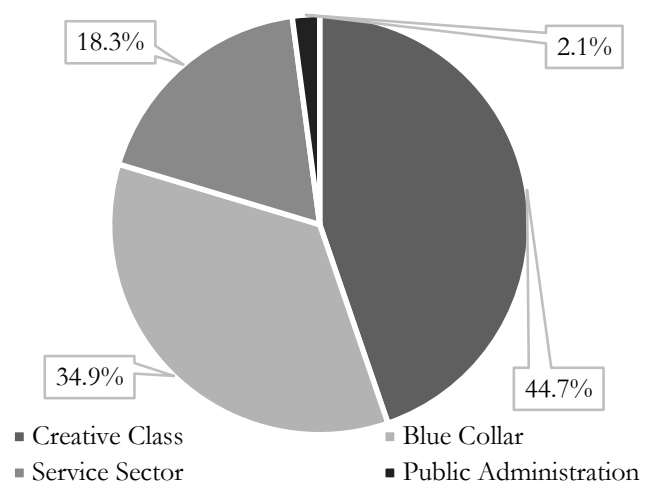

Figure 4.05: North Oak Cliff Employment by Industry Cluster, 2010

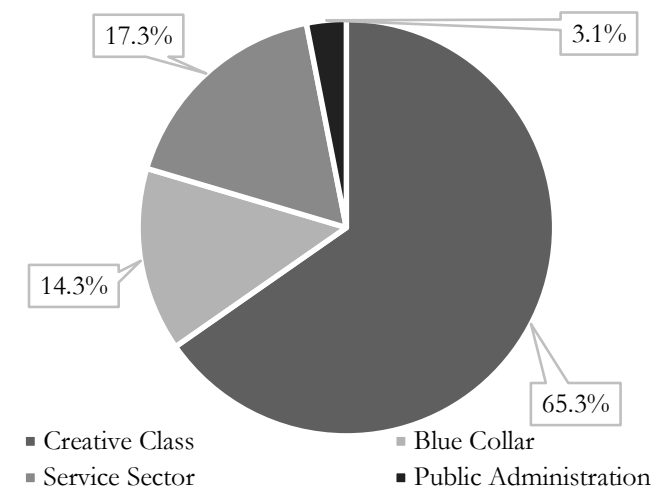

Although data are unavailable for 1980 and 1990, available data suggest a loss of 20 percentage points in blue collar employment between 2000 and 2010, and a gain of 20 points in creative class employment, which in 2010 holds a clear majority of the neighborhood's employment by industry cluster.

Neighborhood median household income and poverty. Table 4.06 shows the median household income (in 2015 inflation-adjusted dollars) (MHI) and poverty rate for North Oak Cliff, from 1980 to 2010.

Table 4.06: North Oak Cliff MHI and Poverty Rate, 1980 - 2010

\begin{tabular}{lcccc}
\hline \multicolumn{1}{c}{ Year } & $\mathbf{1 9 8 0}$ & $\mathbf{1 9 9 0}$ & $\mathbf{2 0 0 0}$ & $\mathbf{2 0 1 0}$ \\
\hline MHI in 2015 Dollars & $\$ 28,861$ & $\$ 25,617$ & $\$ 51,915$ & \\
\hline Decennial Gain (Loss) & $(\mathrm{x})$ & $(\$ 3,244)$ & $\$ 26,298$ & $(\$ 12,809)$ \\
Poverty Rate & $17.5 \%$ & $18.0 \%$ & $24.3 \%$ & $21.8 \%$ \\
Decennial Gain (Loss) & $(\mathrm{x})$ & 0.5 pts. & 6.3 pts. & $(2.5$ pts.)
\end{tabular}

Data suggest that, from 1980 to 1990, MHI decreased while the poverty rate increased. Of greater note is that, in 2000, neighborhood MHI increased to more than $200 \%$ of its 1990 level, while the neighborhood poverty shows an increase of over 135\% over that same period. Data also suggest that, in 2010, neighborhood MHI decreased to just over $75 \%$ of its 2000 level, while the neighborhood poverty rate also decreased, to just under $90 \%$ of its level in 2000. The implications of these dramatic changes in MHI and poverty rates, especially in 
the context of the neighborhood's gentrification, will be discussed in Chapter 5 .

\section{Downtown Dallas}

This study hypothesized that the neighborhood of Downtown Dallas, like that of North Oak Cliff, has undergone demographic- and economic transitions that are consistent with gentrification literature regarding central urban neighborhoods, and the new donut model of cities. While evaluation of data with respect to this hypothesis will be held until Chapter, in the chapter sections that follow, this study will first present data documenting changes in the neighborhood's demographic profile from 1980 to 2010, and then it will present data documenting changes in Downtown Dallas' economic profile over that same period.

Neighborhood demographic changes, 1980 to 2010. In the following subsections, this study will report relevant changes in Downtown Dallas' demographics from 1980 to 2010. As with North Oak Cliff and Dallas as a whole, this subsection will first present data on changes in population, and then on race and Hispanic status for people living in the neighborhood.

Neighborhood population. Table 4.07 shows the population changes from 1980 to 2010 for Downtown Dallas.

\begin{tabular}{|c|c|c|c|c|}
\hline Year & 1980 & 1990 & 2000 & 2010 \\
\hline Population & 2,828 & 3,444 & 2,198 & 9,262 \\
\hline Decennial Gain (Loss) & (x) & 616 & $(1,246)$ & 7,064 \\
\hline
\end{tabular}

Data suggest that the growth rates in Downtown Dallas vary widely, but of significant note is the significant decline from 1990 to 2000, just before a dramatic increase in 2010, wherein the neighborhood's population increased to nearly three times its 2000 level.

Neighborhood race and Hispanic or Latino status. Within the context of Downtown Dallas' growth and decline, Figure 4.06 shows the changing demographic profile of the neighborhood's population with respect to race and Hispanic origin. 


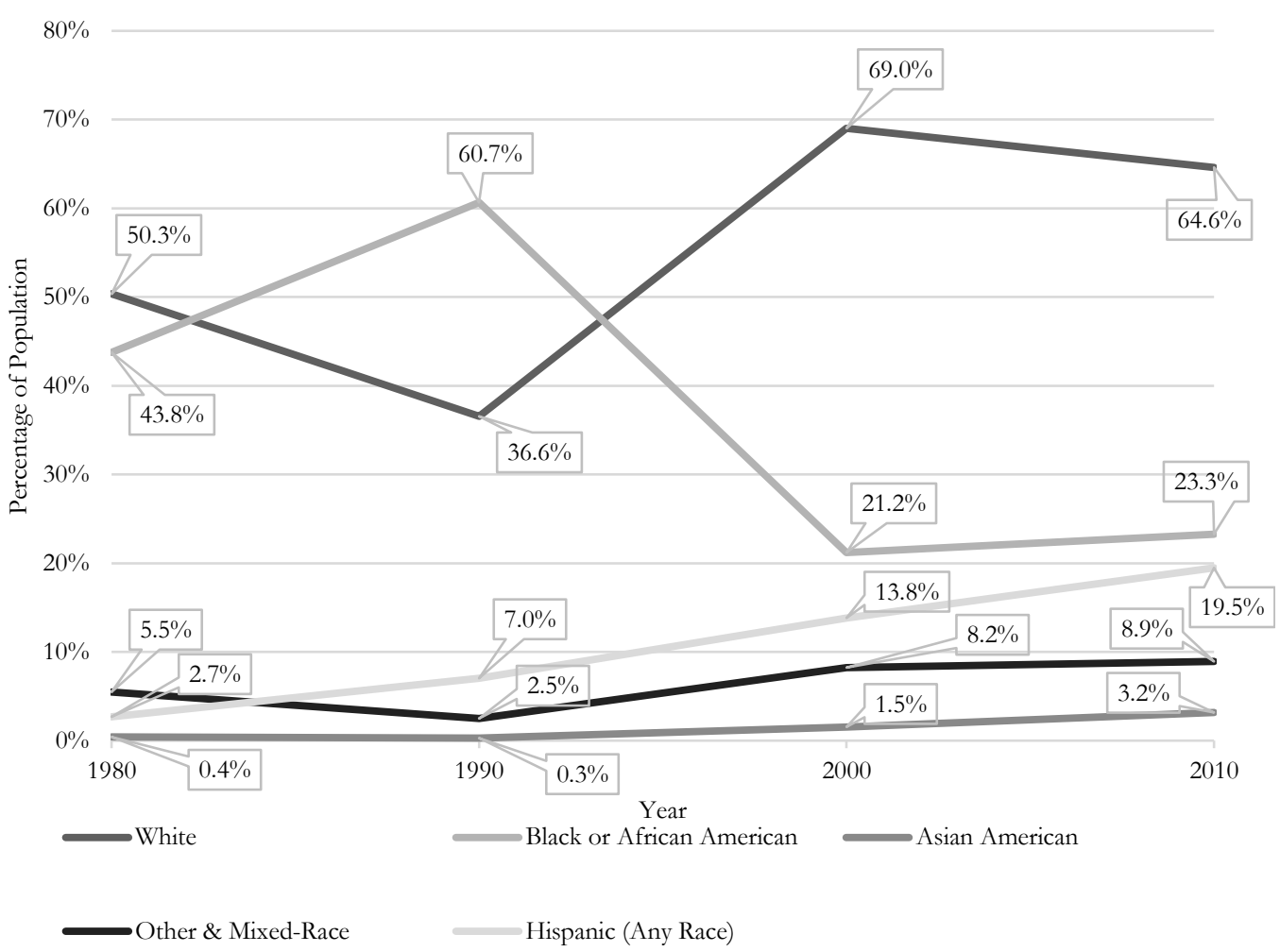

Data suggest a negative correlation between the percentages of neighborhood populations identifying as "white alone" and Black or African American, throughout the entire time period from 1980 to 2010, even as the neighborhood's population increases over that same period. Overall, the trend is one of growth for people identifying as "white alone," with this group making up a nearly two-thirds majority of the neighborhood's population at the 2010 census. Of additional note is that the growth pattern for the percentage of the population identifying as "other \& mixed-race" similar to - though less dramatic than - that for the population of people who identify as "white alone." Finally, much like in Dallas as a whole, the percentage of people identifying as Hispanic or Latino has grown at each census.

Neighborhood economic changes, 1980-2010. In the following subsections, this study will report relevant changes in the economic characteristics of Downtown Dallas from 
1980 to 2010. First, it will report basic data on workforce size and unemployment. Then, this study will report data regarding employment by industry cluster. Finally, it will report data related to $\mathrm{MHI}$ and poverty.

Neighborhood labor force. Table 4.08 shows sizes of- and trends within Downtown Dallas' labor force size and unemployment rates from 1980 to 2010.

\begin{tabular}{lcccc} 
& Table 4.08: Downtown Dallas Workforce Size and Unemployment Rate, $\mathbf{1 9 8 0}-\mathbf{2 0 1 0}$ \\
\hline Year & $\mathbf{1 9 8 0}$ & $\mathbf{1 9 9 0}$ & $\mathbf{2 0 0 0}$ & \\
Workforce Size & 582 & 273 & 1,157 & 2010 \\
Decennial Gain (Loss) & $(\mathrm{x})$ & -309 & 884 & 4,370 \\
Unemployment Rate & $6.7 \%$ & $5.5 \%$ & $5.4 \%$ & 3213 \\
Decennial Gain (Loss) & $(\mathrm{x})$ & $(1.2$ pts. & $(0.1$ pts.)
\end{tabular}

Data suggest that, while the size of the labor force residing in the neighborhood declined between 1980 and 1990, it has been growing ever since, with a large expansion between 2000 and 2010. Data for unemployment rates in 1980 and 1990 suggest a small decrease, but the unemployment rate has held relatively steady since then, growing, though at a much smaller rate than the expansion in the labor force overall.

Neighborhood employment by industry cluster. Figures 4.07 and 4.08 illustrate relevant characteristics of Downtown Dallas' labor force in both 2000 and 2010.

Figure 4.07: Downtown Dallas Employment by Industry Cluster, 2000

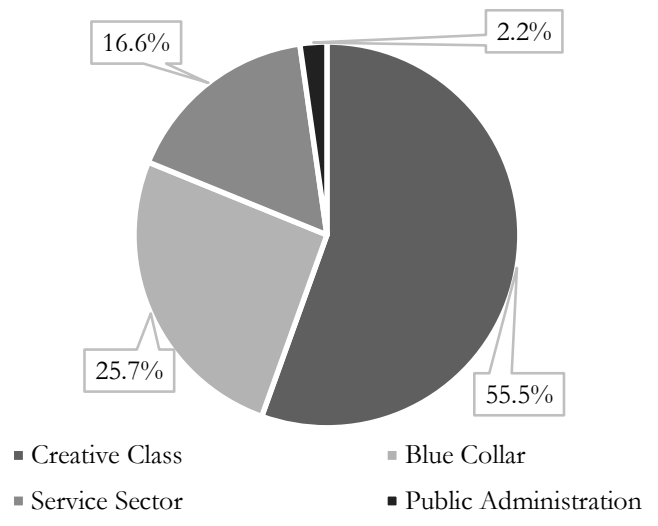

Figure 4.08: Downtown Dallas Employment by Industry Cluster, 2010

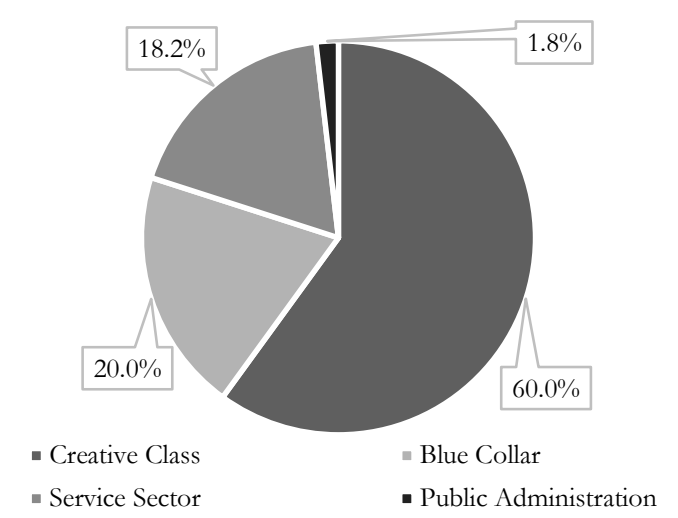

As with North Oak Cliff, while data for Downtown Dallas' employment profile are unavailable for 1980 and 1990, available data suggest that the majority of neighborhood 
residents are employed in creative class fields for both 2000 and 2010 . Between these two years, there is an increase in the percentages of residents employed in both creative class fields, and in services and trade, with subsequent decreases in blue collar employment and public administration, though blue collar employment saw the largest decrease of the two.

Neighborhood median household income and poverty. Table 4.09 shows

Downtown Dallas' MHI in 2015 inflation-adjusted dollars, the neighborhood's poverty rates, and basic trends in both, each for the period of 1980 to 2010 .

Table 4.09: Downtown Dallas MHI and Poverty Rate, 1980 - 2010

\begin{tabular}{rcccc} 
& Table 4.09: Downtown Dallas & $\mathbf{1 9 9}$ & $\mathbf{2 0 0 0}$ & $\mathbf{2 0 1 0}$ \\
\hline Year & $\mathbf{1 9 8 0}$ & $\$ 46,678$ & $\$ 78,897$ & $\$ 64,618$ \\
\hline MHI in 2015 Dollars & $\$ 38,324$ & $\$ 8,354$ & $\$ 32,219$ & $(\$ 14,279)$ \\
Pecennial Gain (Loss) & $(\mathrm{x})$ & $7.7 \%$ & $15.5 \%$ & $19.6 \%$ \\
Peverty Rate & $22.0 \%$ & $(14.3 \mathrm{pts})$. & $7.8 \mathrm{pts}$ & $4.1 \mathrm{pts}$
\end{tabular}

Data suggest that MHI more-than doubled from 1980 to 2000, with the majority of that increase occurring between 1990 and 2000, although there is a significant decrease at the 2010 census. Additionally, data suggest that, although the percentage of people living in poverty fell precipitously between 1980 and 1990, it has been rising ever since, with nearly one in five neighborhood residents living in poverty in 2010, only 2.4 percentage points lower than the 1980 high of $22.0 \%$. Finally, data suggest that the largest rise in poverty rate occurred between 1990 and 2000, the same years that bookend the largest MHI increase.

\section{Quantitative Data, in Summary}

In the preceding sections, this study presented various data regarding economic- and demographic transitions in Dallas as a whole, as well as in this study's focus neighborhoods. Although this study is primarily interested in the nature of Dallas' governance structure, these data are suggestive of (arguably) inescapable socioeconomic changes with which any governance structure, if it exists at all, must contend. This study makes several hypotheses regarding the significance of these data, and Chapter 5 will revisit them in order to address those hypotheses; before that, however, this study will report its qualitative findings. 


\section{Qualitative Data}

The previous reputational study of Dallas described three "classes" of leaders within the city's decision-making structure, and each class was comprised almost exclusively of business executives and wealthy elites ${ }^{423}$. To determine whether (or to what extent) the previous reputational analysis' results remain valid, and to expand on its findings, this study's 79 participants completed detailed surveys and interviews regarding the nature of decisionmaking in Dallas as a whole, as well as in two focus neighborhoods.

Previously, this study reported quantitative data regarding Dallas' demographic- and economic changes since 1980, and building on this, in the following sections, this study will report data from its qualitative data collection. First, it will describe the broad categories into which participants' responses were ordered. Then, it will summarize results from surveys and interviews; first, those regarding Dallas' citywide decision-makers, then for decision-makers in North Oak Cliff, and finally for decision-makers in Downtown Dallas.

\section{Categorizing Decision-Makers}

Through participant surveys and interviews, it quickly became clear that Dallas' decision-makers regularly fell into thematic categories. Whereas the Thometz study of Dallas proffered three categories of decision-makers: key leaders, top level, and second echelon ${ }^{424}$, this study categorizes participant-identified decision-makers into five categories: formal authorities, first tier influentials, second tier influentials, civic chairs, and anchor captains. In the sections that immediately follow, this study will broadly introduce each of these categories.

Formal authorities. Actors in this category consist of elected officials, members of council-appointed boards, committees, and commissions, and senior bureaucrats. As the

${ }^{423}$ Thometz, 1963 , pp. 47-49

424 1963, p. 46 
category title suggests, these actors are defined primarily by their formal authority to make decisions, and this authority is generally derived from a combination of Dallas' city charter, various ordinances and policies, and unwritten practices of professional deference and delegation. Participants universally acknowledged that these actors are the primary decisionmakers in Dallas, and that their authority is often difficult to meaningfully challenge.

First Tier Influentials. These actors have long-standing connections to the city, or at least to particular neighborhoods within it, as well as reputations for remaining active in the politics of decision-making, though this activity is normally indirect, through the use of intermediaries (or, as some participants called them, "proxies"). While these actors lack formal authority to make decisions, participants acknowledged that they have tremendous financial capital, real capital, and/or social capital, and use these resources to influence the agendas of those who do have that authority, in service of a broadly agreed-upon vision that normally consists of neoliberal urban development strategies and packages of publiclyfunded inducements for private development.

Second Tier Influentials. This category's actors are the most diverse, and can be divided into three particular subcategories. First, retired formal authorities, such as former mayors and city councilmembers, who remain active in the politics of development, often on behalf of private-sector employers. Second, retired first tier influentials who remain connected to Dallas' most elite social institutions, but are no longer deeply involved in the politics of decision-making. Finally, prominent leaders within Dallas' developer class, including executives within national- and global construction, real estate development-, investment-, and sales offices, as well as senior partners in real estate law firms. Participants suggested that actors in this category are regularly marshaled for support and advice on individual projects and policies by first tier influentials and formal authorities. 
Civic Chairs. Actors in this category are heads of civic organizations, and are charged with representing the interests of their constituents, so while they may have significant leeway in interpreting those interests, participants repeatedly called these actors "mouthpieces" for the organizations that they represent. Participants concurred that these actors are well-known for building (temporary) alliances among actors in other categories, either in support for- or opposition against particular issues, based on their organizational missions and agendas. Participants frequently proposed that these actors benefit from the social capital surrounding their organizations, and the support of their members, even when actors in other categories (and, in some cases, the general public) oppose their efforts on a particular project or policy decision.

Anchor Captains. Actors in this category are comprised of leaders within locallyanchored organizations and institutions, such as university presidents, departmental deans, and hospital directors. Like civic chairs, these actors are able to draw support from actors in other categories, as well as from outside of the decision-making process, but unique to these actors is that they are not necessarily linked to any particular geographic group or social class. Participants regularly noted that these actors benefit from a perception that their organizations are politically neutral, and their support generally brings tremendous public support for projects and policies.

Categorizing decision-makers, in summary. Expanding on previous research, this study uses themes from participant interviews to group participant-identified decisionmakers into five categories: formal authorities, first tier influentials, second tier influentials, civic chairs, and anchor captains. How these categories interact, and the particular constitution of each at the citywide- and neighborhood levels will be the focus of the remainder of this chapter. In the sections that follow, this study will report the makeup of these five categories; first, for 
Dallas as a whole; then, for North Oak Cliff; and finally, for Downtown Dallas.

\section{Decision-makers in Dallas as a whole.}

Recall that Chapter 2 recounted two previous studies of Dallas; the 1963 Thometz study identified a decision-making structure heavily populated by-, and biased towards the interests of high-ranking business leaders, and the 1987 Elkin study that agreed with Thometz, but also found that cracks were beginning to form in the city's entrepreneurial regime. In order to understand the structure and nature of Dallas' contemporary decision-making structure, and the extent to which anchor institutions and CDCs have found a more prominent role within it, this study asked participants knowledgeable about Dallas' decisionmaking process to identify- and describe actors who get involved in making citywide decisions, and to nominate 10 people to form a committee that would be responsible for making a decision that would affect the city as a whole.

With 79 participants, a maximum of 790 nominations were possible, and out of those possible nominations, 726 of those nominations, or $91.9 \%$, are represented by the 32 individual- or group actors who will be identified in the sections that follow. In reporting on these actors, this study will first detail Dallas' citywide formal authorities; next, it will introduce the city's its first tier influentials; third, its second tier influentials; fourth, its civic chairs; and finally, the citywide anchor captains.

Formal authorities. Table 4.10 shows summary statistics related to Dallas' citywide formal authorities, named by eight or more participants to a hypothetical committee responsible for making a decision that would affect Dallas as a whole, and that would need to be supported by a majority of the city. 
Table 4.10: Citywide Formal Authorities

\begin{tabular}{|c|c|c|c|c|c|c|c|}
\hline \multirow[t]{2}{*}{ Name } & \multirow[t]{2}{*}{$\begin{array}{c}\text { Primary or } \\
\text { Notable } \\
\text { Affiliation(s) }\end{array}$} & \multicolumn{2}{|c|}{$\begin{array}{l}\text { Decision-Making } \\
\text { Committee } \\
\text { Nominations }\end{array}$} & \multirow{2}{*}{$\begin{array}{l}\text { Mean } \\
\text { Power } \\
\text { Level } \\
(1-4)\end{array}$} & \multicolumn{2}{|c|}{$\begin{array}{l}\text { Recent Shared } \\
\text { Committee Service }\end{array}$} & \multirow{2}{*}{$\begin{array}{c}\text { Mean } \\
\text { Familiarity } \\
\text { Level } \\
(1-4)\end{array}$} \\
\hline & & \# & $\%$ & & \# & $\%$ & \\
\hline District-Based Councilmembers (14) & Dallas City Council & 79 & $100 \%$ & 4.00 & 44 & $56 \%$ & 2.93 \\
\hline Mike Rawlings & Mayor & 73 & $92 \%$ & 3.78 & 21 & $27 \%$ & 2.10 \\
\hline A.C. Gonzalez & City Manager & 64 & $81 \%$ & 3.78 & 15 & $19 \%$ & 2.38 \\
\hline Appointed Commissioners (15) & City Plan Commission & 26 & $33 \%$ & 3.51 & 17 & $22 \%$ & 2.11 \\
\hline \multirow{2}{*}{\multicolumn{2}{|c|}{$\begin{array}{l}\text { Mean Value (Actors in This Category) } \\
\text { Mean Value (Actors in All Categories) }\end{array}$}} & 61 & $77 \%$ & 3.77 & 24 & $31 \%$ & 2.38 \\
\hline & & 23 & $29 \%$ & 3.11 & 20 & $26 \%$ & 2.27 \\
\hline
\end{tabular}

At the citywide level, this category consists of two individual actors (i.e. the mayor and city manager), and two group actors ${ }^{425}$ (i.e. the Dallas City Council and the City Plan Commission, or $\mathrm{CPC}$ ). Compared to other categories, formal authorities have above-average numbers of nominations to decision-making committees, as well as above-average power ratings, shared committee service with participants in the past five years, and familiarity with participants. In the paragraphs that follow, this study will summarize participant thoughts on each actor in this category, and how they fit into the citywide decision-making process.

Dallas' City Council. The Dallas City Council's powers include setting citywide policies, approving annual budget- and capital improvement plans submitted by the city manager, establishing and managing tax rates, municipal services, and municipal ordinances, issuing municipal bonds, and creating municipal departments ${ }^{426}$. In explaining why the inclusion of at least one councilmember is critical for a citywide decision-making team, participants agreed that the city council is Dallas' primary decision-making body, and that successful policy- and project proposals must be written such that they will gain the approval of an eight-councilmember majority; as one participant put it:

Dallas is run by the eight-vote majority; those votes change from one issue to another, but every proposal is made to appeal to eight out of fifteen. A unanimous approval is the best possible outcome, but short of that, eight is the magic number.

\footnotetext{
${ }^{425}$ Author's note: at the citywide level, the city council and CPC were considered as group actors, rather than as individual actors, because participants often used generic titles ("a councilmember" or "someone on the CPC"), rather than giving specific names. Additionally, participants suggested that, in many cases, the specific actor within these groups was less important than having any actor within them, for purposes of supporting a decision that would affect Dallas as a whole.

${ }^{426}$ Dallas City Charter, 2015, pp. 9-18
} 
Dallas' Mayor. Dallas features a weak mayor form of government, and its mayor acts as an at-large $15^{\text {th }}$ councilmember, in addition to a number of administrative and ceremonial roles $^{427}$. When asked to elaborate on including Mayor Rawlings on their decision-making committees, participants often pointed out that Rawlings, like his predecessors, partners closely with actors like the ones found in Dallas' citywide first-and second tier influentials, as well as many citywide civic chairs, and most considered these partnerships particularly valuable in getting a citywide decision accepted by a majority of Dallasites, or at least, a majority of the individuals with the influence and resources to put up a significant challenge; describing this phenomenon, participants regularly admitted that:

For mayoral candidates, powerful endorsements and large contributions are a necessity; for the elite, endorsements and contributions are investments. In exchange for their support, Dallas' regents expect a certain degree of access to their candidates, so if you have the mayor's support on a project, it's a safe bet that you have the support of his masters, too.

Appointed City Plan Commissioners. Although fewer than one-third of participants named "someone from the CPC," or, less commonly, particular members who serve on this commission, participants who did commonly explained that the CPC is the primary gatekeeper for development projects that need council approval, but that the commission's role is narrow, and does not extend to other types of decisions. Within that narrow role, the CPC hears proposals and requests related to new development and zoning changes throughout Dallas ${ }^{428}$, and its recommendations are passed to the City Council for a final decision. In practice, participants overwhelmingly considered each commissioner to be a proxy vote for the councilmember who appointed them; participants often suggested that this allows the city council to, as one participant put it, "outsource their fighting, because

${ }^{427}$ Dallas City Charter, 2015, p. 9; pp. 13-24; 75; 91

${ }^{428}$ Board of Adjustment Working Rules of Procedure, 2001, p. 3; Dallas City Charter, 2015, pp 51-53 
CPC meetings are rarely attended." When explaining why they included a member of the CPC on their decision-making team, one response well- summarized the general opinion:

Most decisions in Dallas deal with development, so it makes sense to have the CPC on board if you can get them. If the CPC likes your idea, and passes along a favorable recommendation, you've got a good shot at a rubber stamp from the city council.

Dallas' City Manager. Over 80\% of participants named City Manager A.C.

Gonzalez (by title or name) to their respective decision-making teams. In elaborating on why, participants pointed out that under Dallas' weak mayor system, tremendous decisionmaking power is vested in the office of its city manager. Variously, participants identified that Gonzalez' office is responsible for implementing the decisions of the mayor and city council, preparing the city's annual budget, coordinating city operations and programs, managing nearly all non-appointed city personnel, and enforcing municipal ordinances (including oversight of Dallas' police department), entering into financial agreements on behalf of the City of Dallas, and recommending how to use bonds and TIF revenue, among many other administrative responsibilities ${ }^{429}$. Participants also acknowledged that, like Mayor Rawlings, Gonzalez works closely with first-and second tier influentials, and that he has the broad support of organizations represented by citywide civic chairs; summarizing many of their comments:

Dallas' City managers have always been told to go out and bring economic development to the city. A.C. (Gonzales), like Mary (Suhm) before him, tries everything he can to keep Dallas business-friendly, whether that's TIF money, easing regulations, or just working with developers to find financing, navigate zoning and construction permits, or break logjams on the bureaucratic side of things.

Formal authorities, in summary. Within Dallas' citywide decision-making body, participants identified top-level elected leaders, political appointees, and its bureaucratic chief. United by their formal decision-making authority, derived from a combination of

\footnotetext{
${ }^{429}$ Dallas City Charter, 2015, pp. 25-27
} 
Dallas' city charter, various ordinances and bureaucratic policies, and professional deference, data suggest that these formal authorities are among Dallas' most powerful decision-makers.

Critically, however, no participant named an entire team of actors from this category, which suggests that for a decision to truly be accepted by Dallasites, there is room for actors who operate outside of the public sector.

First tier influentials. Table 4.11 shows summary statistics related to Dallas' citywide first tier influentials, named by eight or more participants to a hypothetical committee responsible for making a decision that would affect Dallas as a whole, and that would need to be supported by a majority of the city.

\begin{tabular}{|c|c|c|c|c|c|c|c|}
\hline \multirow[t]{2}{*}{ Name } & \multirow[t]{2}{*}{$\begin{array}{l}\text { Primary or Notable } \\
\text { Affiliation(s) }\end{array}$} & \multicolumn{2}{|c|}{$\begin{array}{c}\text { Decision-Making } \\
\text { Committee } \\
\text { Nominations }\end{array}$} & \multirow{2}{*}{$\begin{array}{l}\text { Mean } \\
\text { Power } \\
\text { Level } \\
(1-4)\end{array}$} & \multicolumn{2}{|c|}{$\begin{array}{c}\text { Recent Shared } \\
\text { Committee } \\
\text { Service }\end{array}$} & \multirow{2}{*}{$\begin{array}{c}\text { Mean } \\
\text { Familiarity } \\
\text { Level } \\
(1-4)\end{array}$} \\
\hline & & \# & $\%$ & & \# & $\%$ & \\
\hline Ray Hunt & Hunt Consolidated & 39 & $49 \%$ & 3.86 & 8 & $10 \%$ & 2.08 \\
\hline John Wiley Price & Dallas County Commissioner & 32 & $41 \%$ & 3.84 & 12 & $15 \%$ & 2.45 \\
\hline Harlan Crow & $\begin{array}{l}\text { Crow Holdings } \\
\text { Son of Trammel Crow }\end{array}$ & 21 & $27 \%$ & 3.74 & 30 & $38 \%$ & 2.09 \\
\hline Ross Perot Jr. & Hillwood & 17 & $22 \%$ & 3.66 & 14 & $18 \%$ & 2.09 \\
\hline $\begin{array}{l}\text { Kay Bailey } \\
\text { Hutchison }\end{array}$ & $\begin{array}{l}\text { U.S. Senate (former) } \\
\text { TX House of Rep. (former) TX } \\
\text { State Treasurer (former) }\end{array}$ & 14 & $18 \%$ & 3.59 & 8 & $10 \%$ & 2.12 \\
\hline Caroline Hunt & Rosewood Corp. & 13 & $16 \%$ & 3.38 & 12 & $16 \%$ & 2.38 \\
\hline T. Boone Pickens & BP Capital & 11 & $14 \%$ & 3.29 & 8 & $10 \%$ & 2.10 \\
\hline Ruth Collins Altshuler & Philanthropist & 11 & $14 \%$ & 3.13 & 14 & $18 \%$ & 2.09 \\
\hline Bobby Lyle & $\begin{array}{l}\text { Lyco Holdings } \\
\text { Southern Methodist University }\end{array}$ & 10 & $13 \%$ & 3.03 & 8 & $10 \%$ & 2.46 \\
\hline \multicolumn{2}{|c|}{$\begin{array}{l}\text { Mean Value (Actors in This Category) } \\
\text { Mean Value (Actors in All Categories) }\end{array}$} & $\begin{array}{l}19 \\
23\end{array}$ & $\begin{array}{l}24 \% \\
29 \%\end{array}$ & $\begin{array}{l}3.50 \\
3.11\end{array}$ & $\begin{array}{l}13 \\
20\end{array}$ & $\begin{array}{l}16 \% \\
26 \%\end{array}$ & $\begin{array}{l}2.21 \\
2.27\end{array}$ \\
\hline
\end{tabular}

Participants identified nearly every actor in this category as being part of Dallas' old guard, that is, a selective, enduring mix of civically-engaged actors who were born into the city's first families, or who have been "blessed" into this category through careers of service to Dallas. Compared to actors in other categories, category means for first tier influentials are above-average for mean power- and familiarity ratings, but not for recent shared committee service or nominations to decision-making committees. In the following paragraphs, this study will describe how these actors involve themselves in citywide decision-making, first broadly, and then for category standout John Wiley Price. 
In general, participants concurred that Dallas' citywide first tier influentials hold a tremendous degree of influence over the decision-making process, though close connections with each other, privileged access to several of Dallas' formal authorities and civic chairs, and tremendous reserves of social-, physical-, and financial capital. However, while many of these individuals are independently wealthy, participants regularly agreed that these actors intentionally curate strong social ties; summarizing many other comments, one participant said that:

These people are in all the same country clubs, they serve on all the same boards, they pray in all same churches; their kids go to the same exclusive private schools, (and) the same toplevel universities. They don't have to organize, because they already are - they're always forming new projects to fit into their vision of the city.

Participants regularly admitted that the purpose of these social ties is, in many cases, to "feel out" actors in other categories, and to identify partners who will allow these first tier influentials to remain influential in Dallas' decision-making process while keeping out of the public eye. Participants also opined that shared social network either creates, or was created by, what many called "shared vision” for Dallas, which many summarized as:

A city full of the most beautiful stadiums, the tallest skyscrapers, the largest convention centers, the most beautiful hotels and luxury condos, and the widest highways to connect all of it to the suburbs.

Category standout: John Wiley Price. Over $40 \%$ of participants nominated Dallas County Commissioner John Wiley Price to their decision-making committees, and he received an average power rating of 3.84, among the highest of all actors at the citywide level. In nominating Price to their decision-making teams, participants often referred to him as "the Black vote," noting that throughout his career, Price has, for decades, billed himself as "our man downtown," connecting his identity as an African-American to the largely African American district he represents, and that Dallas' formal authorities and other first tier influentials have relied on him to represent African-American interests in the decision-making 
process $^{430}$. Indeed, participants repeatedly conjected that he has become the "token" African-American in many of Dallas' policy- and developmental decisions.

For nearly as long as Price has been active in forwarding the interests of his constituents, he has been mired in scandals, including bribery, money laundering, and accusations of unethical behavior ${ }^{431}$. Participants, especially those with close relationships to Price, were unsurprised by the recent FBI investigations into Price's behavior, and suggested that his behavior is an “open secret” among Dallas' leaders; sentiments well-summarized by:

Price has been "our man downtown," the voice of the Black community in Dallas' all-white leadership for a long, long time, and lined his pockets by taking a cut of every deal he sent our way. Of course he's been on the take - he looks out for his own, and for himself. He's making $\$ 130,000$ as a commissioner, but owns multiple houses, multiple luxury cars, and wears suits that cost more than some of us make in a year.

For this reason, as well as the rising number of African-American political leaders and ranking bureaucrats, nearly two-thirds of participants suggested that, to varying degrees, his influence has declined rapidly, especially in the wake of federal bribery allegations that have been under investigation since 2014, and which include many of Price's staff, including himself. As one participant put it:

Price's star rose for many years, because he was the only [African American] running in an all-Black part of town. Now that better has come along, you're seeing him get what's been coming to him.

First tier influentials, in summary. Participants recognized that nearly every one of Dallas' first tier influentials has achieved a level of celebrity in the city, and many participants pointed out the biographies, newspaper features, civic awards, and allegations of scandal connected to each. Many called actors in this category "modern cowboys," evoking a romanticism that (arguably) pervades the Dallas myth ${ }^{432}$. Within Dallas' citywide decisionmaking process, participants agreed that this exclusive group of highly influential operatives

${ }^{430}$ Dallas County, 2012, p. 2; 2015

${ }^{431}$ Krause, 2016; Miller, 1991; Rogers, 2014; Schutze, 2008; 2011; Thompson, 2014

${ }^{432}$ Graff, 2008, pp. 81-90 
have historically exerted tremendous influence in Dallas' citywide decision-making process, and in spite of decaying membership, and that it continues to influence decisions in the city, either directly, or (more commonly) from behind more publicly-visible actors. Data seem to support these assertions, suggesting that within the citywide decision-making body, these actors are second only to citywide formal authorities in power ratings, but no one particular actor is seen on a large number of shared committees or boards.

Returning to a broad view of Dallas' citywide decision-making process, participants noted that this category of actors is exceptionally exclusive, and acknowledged that this exclusivity has resulted in a decline in this category's size, as aging members die - often without naming heirs - and that the second tier influentials who have been looked to as their replacements seem to have little interest in becoming "regents" in Dallas. As a result, participants regularly conceded that Dallas has historically been run by a small collection of elite influential operatives, and to some extent, remains as-such, but that the shrinking of this category of actors has created a power vacuum in the highest echelons of citywide decisionmaking, and the results of this vacuum, as participants noted, are two-fold: first, formal authorities have reclaimed significant decision-making authority, and second, there is more space for competing interests to enter into the decision-making structure, especially from more progressive formal authorities and ad-hoc collaborations involving second tier influentials.

Second Tier Influentials. Table 4.12 shows summary statistics related to Dallas' citywide second tier influentials, named by eight or more participants to their citywide, hypothetical decision-making teams. 
Table 4.12: Citywide Second Tier Influentials

\begin{tabular}{|c|c|c|c|c|c|c|c|}
\hline \multirow[t]{2}{*}{ Name } & \multirow[t]{2}{*}{$\begin{array}{l}\text { Primary or Notable } \\
\text { Affiliation(s) }\end{array}$} & \multicolumn{2}{|c|}{$\begin{array}{c}\text { Decision-Making } \\
\text { Committee } \\
\text { Nominations } \\
\end{array}$} & \multirow{2}{*}{$\begin{array}{c}\text { Mean } \\
\text { Power } \\
\text { Level } \\
(1-4) \\
\end{array}$} & \multicolumn{2}{|c|}{$\begin{array}{c}\text { Recent Shared } \\
\text { Committee Service }\end{array}$} & \multirow{2}{*}{$\begin{array}{c}\text { Mean } \\
\text { Familiarity } \\
\text { Level } \\
(1-4) \\
\end{array}$} \\
\hline & & $\#$ & $\%$ & & \# & $\%$ & \\
\hline Mary Suhm & City Manager (former) & 23 & $29 \%$ & 3.26 & 24 & $30 \%$ & 2.09 \\
\hline Clint McDonnough & Ernst \& Young, LLP & 15 & $19 \%$ & 3.04 & 27 & $34 \%$ & 2.49 \\
\hline John Scovell & Woodbine Development & 16 & $20 \%$ & 2.95 & 25 & $32 \%$ & 2.29 \\
\hline Robert Chereck & PlainsCapital & 16 & $20 \%$ & 2.95 & 18 & $23 \%$ & 2.13 \\
\hline Arcilia Acosta & CARCON Industries & 13 & $16 \%$ & 2.78 & 26 & $33 \%$ & 2.50 \\
\hline Michael Caffey & C.B. Richard Ellis (CBRE) & 14 & $18 \%$ & 2.71 & 25 & $32 \%$ & 2.01 \\
\hline Angela Hunt & Dallas City Council (former) & 12 & $15 \%$ & 2.64 & 19 & $24 \%$ & 2.36 \\
\hline Albert Black & $\begin{array}{l}\text { On-Target Supplies \& Logistics } \\
\text { Dallas Regional Chamber (former) }\end{array}$ & 11 & $14 \%$ & 2.45 & 18 & $23 \%$ & 2.36 \\
\hline Donna D. Halstead & $\begin{array}{l}\text { Dallas City Council (former) } \\
\text { Dallas Citizens Council (former) } \\
\end{array}$ & 8 & $10 \%$ & 2.39 & 18 & $23 \%$ & 2.04 \\
\hline Jeff Staubach & Jones Lang LaSalle & 8 & $10 \%$ & 2.38 & 25 & $32 \%$ & 2.38 \\
\hline Alan Walne & $\begin{array}{l}\text { Dallas City Council (former) } \\
\text { Texas State Fair Board }\end{array}$ & 9 & $11 \%$ & 2.32 & 21 & $27 \%$ & 2.49 \\
\hline Steve Everbach & Colliers International & 8 & $10 \%$ & 2.22 & 21 & $27 \%$ & 2.06 \\
\hline \multicolumn{2}{|c|}{$\begin{array}{l}\text { Mean Value (Actors in This Category) } \\
\text { Mean Value (Actors in All Categories) }\end{array}$} & $\begin{array}{l}13 \\
23\end{array}$ & $\begin{array}{l}16 \% \\
29 \%\end{array}$ & $\begin{array}{l}2.67 \\
3.11\end{array}$ & $\begin{array}{l}22 \\
20\end{array}$ & $\begin{array}{l}28 \% \\
26 \%\end{array}$ & $\begin{array}{l}2.27 \\
2.27\end{array}$ \\
\hline
\end{tabular}

This category features the largest number of actors out of any category at the citywide level, and is primarily composed of two groups: retired formal authorities, and members of Dallas' developer class. Data in table 4.12 suggest that these actors have, on average, an above-average number of nominations to decision-making committees, as well as (slightly) above-average recent shared committee membership. Data also suggest that these actors have a belowaverage power rating, and average ratings of familiarity. In the following sections, this study will use participant interview responses to elaborate upon these actors, first, Dallas' ex-formal authorities; second, the citywide developer class, and finally, category standout Mary Suhm.

Ex-formal authorities. Participants spoke to particularly active roles of a subset of Dallas' former city councilmembers and mayors, who after leaving office, have "retired into" prominent positions in real estate law-, investment-, and development firms, as well as on high-profile philanthropic boards. These actors are often hired into these positions specifically for their willingness utilize the connections they made while in office to garner council support for their new employers' projects, as well as regulatory and development assistance from city staff. Summarizing many comments, two participant (respectively) commented that: 
Some people never leave City Hall, even after they retire or get voted out. They land a job with a high-powered law firm, or with a developer, and then go right back down to City Hall to lobby their successor and former coworkers.

The experience of a top-level city employee, like a department head or elected official, is incredibly valuable to any business that interacts with those offices, so it's only reasonable that those employees would find their skills and contacts valuable in the private sector.

The developer class. Participants regularly nominated one (or more) of a handful of real estate developers, investors, financiers, and sales agents to their decision-making bodies, and frequently agreed that these actors share similar characteristics. First, each works for a company that operates in multiple cities throughout the United States, and most also have international presences as well. Second, each of these actors generally subscribes to a demand-based approach to development, and largely avoids speculative building in the hopes of attracting tenants, or building solely to elevate Dallas' civic profile. Finally, these individuals tend to be disinterested in serving on multiple high-profile civic boards and committees. As a result, these actors are more open to collaborating with a rotating cast of stakeholders (such as formal authorities, civic chairs, and anchor captains) on particular projects, but unlike their predecessors, do not form enduring coalitions; in describing this difference, participant comments are well-summarized by:

It's a different Dallas, now. Back in the day, Trammell Crow thought that Dallas needed a convention center and hotel to compete with other cities, so he went to City Hall and got a sack of money to help build a mid-sized convention space and hotel. Now, Dallas has a flagging convention center, so Jack Matthews built a hotel onto it - not because he believed Dallas needed it to compete, but because A.C Gonzales took half a billion city dollars and threw it at Matthews' company to build the [...] thing.

Category standout: Mary Suhm. Dallas' former city manager received the highest number of participant decision-making team nominations of any actor in this category (29\%), and also had the highest power rating of any actor in this category (3.26). In describing Suhm's role as a former city official, participants agreed that, even though she no longer draws a city paycheck, Suhm continues to remain a fixture in City Hall, negotiating city contracts with union employees, planning civic events, and working as an appointee to 
various boards and committees - often at the personal request of Mayor Rawlings. Speaking to this, participants commonly made statements similar to:

Mary (Suhm) never really left office. They don't pay her anymore, but she's always around, getting her hands into different projects. She retired under a cloud of suspicion, and a lot of bad blood with the city council, but she's got a proven history of getting things done, so it's hard to know what exactly to do with her. It seems like the plan is to keep her around as a volunteer until she moves on, one way or another.

Among participants who selected Suhm to serve on their hypothetical decision-making committees, common consensus was that the former city manager continues to have preferential access to Mayor Rawlings (and through him, the city council), top-level executives in the private sector, and many of Dallas' first tier influentials; as several allowed, "Having Mary (Suhm) on your team is almost like having A.C. (Gonzalez), most of the power, but none of the scrutiny that comes with being an official public employee."

Second tier influentials, in summary. Within Dallas' citywide decision-making process, participants identified a collection of actors, each of whom is only selectively involved in decision-making, but whose involvement is often a deciding factor in the success of a project or policy decision. Because of their numbers, as well as the lack of a common agenda, participants agreed that individual actors in this category tend to not be as individually influential as their first tier counterparts; however, many offered that, taken as a whole, these actors are still able to exert influence over the decisions of formal authorities at the citywide level.

Civic Chairs. Table 4.13 shows summary statistics related to Dallas' citywide civic chairs, named by eight or more participants to a hypothetical committee responsible for making a decision that would affect Dallas as a whole, and that would need to be supported by a majority of the city. 
Table 4.13: Citywide Civic Chairs

\begin{tabular}{|c|c|c|c|c|c|c|c|}
\hline \multirow[t]{2}{*}{ Name } & \multirow[t]{2}{*}{$\begin{array}{c}\text { Primary or Notable } \\
\text { Affiliation(s) }\end{array}$} & \multicolumn{2}{|c|}{$\begin{array}{c}\text { Decision-Making } \\
\text { Committee } \\
\text { Nominations }\end{array}$} & \multirow{2}{*}{$\begin{array}{l}\text { Mean } \\
\text { Power } \\
\text { Level } \\
(1-4)\end{array}$} & \multicolumn{2}{|c|}{$\begin{array}{l}\text { Recent Shared } \\
\text { Committee } \\
\text { Service }\end{array}$} & \multirow{2}{*}{$\begin{array}{c}\text { Mean } \\
\text { Familiarity } \\
\text { Level } \\
(1-4)\end{array}$} \\
\hline & & \# & $\%$ & & \# & $\%$ & \\
\hline Alice Murray & Dallas Citizens Council & 48 & $61 \%$ & 3.53 & 42 & $54 \%$ & 2.38 \\
\hline Mabrie Jackson & North Texas Commission & 28 & $35 \%$ & 3.14 & 22 & $28 \%$ & 2.47 \\
\hline Dale Petrosky & Dallas Regional Chamber & 20 & $25 \%$ & 2.97 & 23 & $29 \%$ & 2.12 \\
\hline \multicolumn{2}{|c|}{ Mean Value (Actors in This Category) } & 32 & $41 \%$ & 3.21 & 29 & $37 \%$ & 2.32 \\
\hline \multicolumn{2}{|c|}{ Mean Value (Actors in All Categories) } & 23 & $29 \%$ & 3.11 & 20 & $26 \%$ & 2.27 \\
\hline
\end{tabular}

This category consists of three leaders of civic organizations whose members include (and are often limited to) high-ranking business executives, city-, regional-, and statewide elected officials, and long-time civic philanthropists, in other words, the actors participants regularly referred to as the "ruling regents" of Dallas. In general, actors in this category received above-average nominations to decision-making teams, and the average scores for actors in this category are higher than averages from all categories combined in power, recent shared committee service, and familiarity. In the paragraphs that follow, this study will first describe the roles of Dallas' regional civic chairs, and then the role of category standout, Alice Murray.

Regional civic chairs. In explaining the inclusion of these actors to their hypothetical decision-making teams, participants acknowledged that these actors are able to act as go-betweens for Dallas' first tier and second tier influentials, and its formal authorities, and are able to garner support for a decision from Dallas' first tier and second tier influentials, and to marshal resources around making that those decisions into a reality. Many participants suggested that, while these actors are influential in their own right, their real presence in Dallas' decision-making body comes from preferential access to many of Dallas' formal authorities, and their ability- and willingness to assess and align the interests of their constituents, mobilize constituent physical- financial-, and social capital in service of those interests, identify- and support formal authorities who will be sympathetic, and use preferential access to those actors to push the agendas set forth by their organizations' members; as several participants agreed: 
Groups like the (Dallas) Citizens Council and the [North Texas Commission] are made up of Dallas' old guard, as well as big players from the northern suburbs. They've got direct lines into City Hall, but they represent interests from all over North Texas, so when they push an agenda for Dallas, who are they really serving - us, or the rich, white suburbs?

What used to be an oligarchy of Dallas' business elite is getting drowned out by people who have their eyes on the greater region, especially the northern suburbs.

Category standout: Alice Murray. Although participants concurred that each of these actors possesses access to tremendous resources and influence through their organizations' members, interviews made it clear that one leader, Alice Murray of the Dallas Citizens Council, possesses a degree of influence on a much higher order than other actors in this category. Selected by over $60 \%$ of participants for inclusion on their decision-making teams, and with a power score of 3.53, data suggest that the Citizens Council, and its leader, continue to possess an incredible influence over the city's decision-making process. Participant comments on Murray's role can be summarized by the comment:

\footnotetext{
Alice (Murray) is our unelected mayor. She doesn't have to necessarily approve of a project, but she and her people in the Citizens Council have to at least be neutral - you really can't get much done with them standing against you. They have the leaders of all the biggest banks, the construction companies, the nonprofits, the for-profits... anyone who is anyone is on the Citizens Council; they rule Dallas, and she basically rules them.
}

While participants conceded that Murray is a highly influential force, they regularly conjected that this influence is far weaker than it was in mid-to-late $20^{\text {th }}$ century Dallas, when the city's "ruling regents" enjoyed nearly limitless control over the decision-making process. This power started to fade in the 1970s, when Dallas moved to a mix of single-district and at-large councilmembers, and lost significant power in 1991, when Dallas moved to the "141" council system employed today ${ }^{433}$. Participants also noted that Dallas' Participants also suggested that, as members of the city's old guard die or retire from the politics of decisionmaking, the emerging leaders who appear likely to replace them are less active in supporting the Citizens Council, and that as Dallas continues to induce business migration within the 
city limits, there are more executives and top leaders; these leaders come into the city from all over the world, and bring with them a diverse range of ideas for the city. In describing this, participants' comments are well-summarized by:

The Dallas Citizens Council endorsed nearly every mayor in recent memory, and their members filled up campaign contributions lists going back to the last century - even on city council elections, but that's not as sure of a bet. A.C. (Gonzalez) is also one of their annointees, so when the Council wants something, they usually get it. Ordinary people have to make appointments to see their elected leaders, but Dallas' ruling oligarchs get direct lines.

Murray and her supporters don't rule the city like they used to. Just look at the City Council - she's lost seven seats since 2011, and as the current councilmembers hit their term limits, she stands to lose even more.

Civic chairs, in summary. Participants identified three leaders of Dallas' largest civic organizations as being particularly influential in the citywide decision-making process, citing their preferential access to formal authorities, and their ability- and willingness to combine this access with physical-, social-, and financial capital from many of Dallas' firstand second tier influentials, in service of goals supported by a majority of their members. As Chapter 2 detailed, historically, the organizations that these actors represent have had an outsized influence over Dallas' decision-making body, but external forces have significantly diminished this influence; as one participant put it:

Dallas tried hard to remain true to its big-business, big-building attitude, but the times, and the Supreme Court got in the way. Gone are the smoke-filled rooms where men would lay out plans for the city, but not everyone is ready to give up the past.

Even with their influence waning, though, participants agreed that actors in this category are highly influential in the citywide decision-making process, and will likely remain so for the foreseeable future.

Anchor Captains. Table 4.14 shows summary statistics related to Dallas' citywide anchor captains named by eight or more participants to their citywide, hypothetical decisionmaking committees. 
Table 4.14: Citywide Anchor Captains

\begin{tabular}{|c|c|c|c|c|c|c|c|}
\hline \multirow[t]{2}{*}{ Name } & \multirow[t]{2}{*}{$\begin{array}{l}\text { Primary or Notable } \\
\text { Affiliation(s) }\end{array}$} & \multicolumn{2}{|c|}{$\begin{array}{c}\text { Decision-Making } \\
\text { Committee } \\
\text { Nominations }\end{array}$} & \multirow{2}{*}{$\begin{array}{l}\text { Mean } \\
\text { Power } \\
\text { Level } \\
(1-4)\end{array}$} & \multicolumn{2}{|c|}{$\begin{array}{c}\text { Recent Shared } \\
\text { Committee Service }\end{array}$} & \multirow{2}{*}{$\begin{array}{c}\text { Mean } \\
\text { Familiarity } \\
\text { Level } \\
(1-4)\end{array}$} \\
\hline & & \# & $\%$ & & \# & $\%$ & \\
\hline Gerald Turner & Southern Methodist Univ. & 21 & $27 \%$ & 3.33 & 23 & $29 \%$ & 2.10 \\
\hline Joel Allison & Baylor, Scott, \& White & 20 & $25 \%$ & 2.71 & 19 & $24 \%$ & 2.27 \\
\hline David Daniel & $\begin{array}{l}\text { Univ. of TX at Dallas (former) } \\
\text { Univ. of TX System }\end{array}$ & 14 & $18 \%$ & 2.54 & 13 & $16 \%$ & 2.37 \\
\hline Lee Jackson & Univ. of North TX System & 12 & $15 \%$ & 2.47 & 24 & $30 \%$ & 2.24 \\
\hline \multicolumn{2}{|c|}{ Mean Value (Actors in This Category) } & 17 & $21 \%$ & 2.76 & 20 & $26 \%$ & 2.24 \\
\hline \multicolumn{2}{|c|}{ Mean Value (Actors in All Categories) } & 23 & $29 \%$ & 3.11 & 20 & $26 \%$ & 2.27 \\
\hline
\end{tabular}

At the citywide level, this category consists of four leaders connected to local hospitals and prominent universities. Compared to other categories, anchor captains, on average, received below-average committee nominations, power ratings, and ratings of mean familiarity levels. Overall, these actors also scored on-average for shared committee memberships. In the paragraphs that follow, this study will first describe the roles in citywide decision-making of anchor captains broadly, and then it will focus on category standout Gerald Turner.

Participants regularly noted that actors in this category have long-standing connections to Dallas, and as a result, have developed decades-long relationships with highranking formal authorities, as well as first tier influentials, several of whom have university- and hospital departments and facilities named after themselves, or their relatives. Participants also recognized that in the past, these organizations were used for little more than ensuring public support for somewhat questionable development projects, and that while this is still often the case, many asserted that this is beginning to change. Several participants asserted that anchor captains are still courted by Dallas' developer class to support development projects, so that these can qualify for state- and federal funding to offset construction costs, but that in exchange for that support, Dallas' anchor captains are starting to demand a greater role in projects with which they affiliate their institutions, paying more attention to these institutions' public images, and reputation in their communities. As several participants noted: 
Colleges and hospitals in Dallas, they don't have to work with you on a project, because they'll just work with the guy across the street who gives them a better deal. It's not just money, either - it's jobs for their students, or outpatient facilities that can do the biggest new scan. They know that you can't touch them on public opinion, so they're really starting to get into the driver's seat on projects, looking to expand opportunities and meet their own agendas, but it's all so new - maybe five or ten years, if that, so who knows whether it will last.

\section{Category standout: Gerald Turner. Over a quarter of participants nominated}

Gerald Turner, president of Southern Methodist University (SMU), a private, nonprofit university surrounded by some of the most expensive, prestigious neighborhoods in Dallas, to their decision-making teams, and his power rating (3.33) is markedly higher than the other anchor captains. When nominating Turner, participants often explained that his participation in Dallas' decision-making process is unique among similar leaders, in that SMU has long-been associated with power and influence in Dallas; several participants said that:

If you want to be someone in Dallas, and didn't go to a private school like Hockaday, Usuline, or Dallas International, then you want that SMU ring. The network is valuable, and everyone who matters knows it.

Indeed, in researching individuals named as influential operatives, this study found that a large number of participant-identified formal authorities and influential operatives have either graduated from the university, or serve (currently or formerly) on its board of directors, or within one of the university's departments. Participants regularly admitted that Turner himself, and several of the administrators under him, are deeply connected to Dallas' first tier influentials and civic chairs, and acknowledged that his support for a project can alleviate concerns among actors in these other categories, and that his support on a project is a viable alternative to direct support from actors in these other categories, and the "political baggage" that those actors often bring with them to projects. In describing this, participants regularly agreed that:

SMU has been associated with [Dallas'] rich and powerful for so long that it's almost a proxy for their approval, but the university has less negativity associated with its name than a group like the Dallas Citizens Council or the Dallas Petroleum Club, even though there's huge overlap in those circles. 
Anchor Captains, in summary. Participants identified four leaders of some of

Dallas' largest anchor institutions as being influential in the citywide decision-making process, citing connections with formal authorities, first tier influentials, and a subset of second tier influentials. Participants had difficulty explaining the role of these actors in decision-making, and usually suggested that the roles of these organizations are still evolving as Dallas' leaders learn how to work together with them, rather than relegating them to "ancillary" status. Summarizing many participant comments, one said that:

College presidents and hospital chiefs have always been part of the equation, at least when it got them a new building, but now they're not just working alone, happy with whatever scraps get thrown their way; they're being proactive, and that's a whole new ballgame. Talking about really running Dallas, though - that's a different thing completely. Who knows? Ask me again in five years.

Decision-makers in Dallas as a whole, in summary. This study asked participants knowledgeable about Dallas' decision-making process to identify- and describe actors who get involved in making citywide decisions, and to nominate 10 people to form a committee that would be responsible for making a decision that would affect the city as a whole. A total of 79 participants delivered a combined 790 nominations, and 726 of these went to the 32 individual- and group actors outlined in the previous section. These actors represent major public-, private-, and thirdsector organizations, but can largely be settled into support for one of two distinct agendas for Dallas: a neoliberal, growth machine past, and progressive, post-Fordist future. Before evaluating whether these actors, and the relationships among them, are suggestive of a structure within this decision-making process, this study will report its findings with respect to its two focus neighborhoods.

\section{Decision-makers in North Oak Cliff}

Recall that this study aims to extend previous studies of urban governance by also examining the structure of decision-making within neighborhoods. To understand the 
contemporary decision-making structure within North Oak Cliff, and whether (or to what extent) anchor institutions and CDCs have a primary role within it, this study asked participants knowledgeable about decision-making in North Oak Cliff to identify- and describe actors who get involved in making neighborhood-wide decisions, and to nominate 10 people to form a committee that would be responsible for making a decision that would affect the city as a whole.

A total of 40 (out of 79) participants were identified as being particularly cognizant of decision-making in North Oak Cliff; therefore, a maximum of 400 nominations were possible, and out of these, 86 votes, or $21.5 \%$ were cast for actors who did not garner enough votes (a minimum of 4 , or approximately $10 \%$ ) to be included in the tables throughout this section. In reporting on these actors, this study will first detail North Oak Cliff's formal authorities; next, it will introduce the city's its first tier influentials; third, its second tier influentials; fourth, its civic chairs; and finally, the neighborhood's anchor captains.

Formal authorities. Table 4.15 shows summary statistics related to North Oak Cliffs formal authorities, named by four or more participants to a hypothetical committee responsible for making a decision that would affect the neighborhood, and that would need to be supported by a majority of neighborhood's population.

Table 4.15: North Oak Cliff Formal Authorities

\begin{tabular}{|c|c|c|c|c|c|c|c|}
\hline \multirow[t]{2}{*}{ Name } & \multirow[t]{2}{*}{ Primary or Notable Affiliation(s) } & \multicolumn{2}{|c|}{$\begin{array}{c}\text { Decision-Making } \\
\text { Committee } \\
\text { Nominations }\end{array}$} & \multirow{2}{*}{$\begin{array}{c}\text { Mean } \\
\text { Power } \\
\text { Level } \\
(1-4)\end{array}$} & \multicolumn{2}{|c|}{$\begin{array}{c}\text { Recent Shared } \\
\text { Committee } \\
\text { Service }\end{array}$} & \multirow{2}{*}{$\begin{array}{c}\text { Mean } \\
\text { Familiarity } \\
\text { Level } \\
(1-4)\end{array}$} \\
\hline & & \# & $\%$ & & \# & $\%$ & \\
\hline Scott Griggs & Dallas City Council & 40 & $100 \%$ & 3.85 & 9 & $23 \%$ & 2.23 \\
\hline Michael Anglin & City Plan Commission (CPC) & 28 & $70 \%$ & 3.40 & 6 & $15 \%$ & 2.10 \\
\hline Scott Hounsel & Zoning Board of Adjustment (BOA) & 25 & $63 \%$ & 3.38 & 2 & $5 \%$ & 2.05 \\
\hline \multirow[t]{3}{*}{ Neva Dean } & Sust. Development \& Construction & 24 & $60 \%$ & 3.18 & 5 & $13 \%$ & 2.30 \\
\hline & an Value (Actors in This Category) & 29 & $73 \%$ & 3.45 & 6 & $14 \%$ & 2.17 \\
\hline & an Value (Actors in All Categories) & 21 & $52 \%$ & 2.96 & 4 & $10 \%$ & 2.25 \\
\hline
\end{tabular}

Actors in this category consist of the neighborhood's elected representative: Councilmember Scott Griggs, as well as two of his political appointees, and the interim 
planning director within the city's Sustainable Design \& Construction office, which handles issues related to zoning requests, variances, and exceptions, and development code amendments ${ }^{434}$. On average, actors in this category have the highest power rating of all categories, above-average decision-making committee nominations, above-average recent shared board or committee service, and below-average scores on familiarity. In the paragraphs that follow, this study will summarize participant responses regarding North Oak Cliff's formal authorities; first, the neighborhood's unelected leadership, i.e., its appointed CPC and BOA members, and city staff, and then, category standout Scott Griggs.

City staff and political appointees. In considering bureaucratic involvement in North Oak Cliff's decision-making structure, participants regularly discussed the role of its Neva Dean, the city's interim planning director, and (commonly in the same breath), the roles of Councilmember Griggs' appointees to the City Plan Commission (CPC) and Zoning Board of Adjustment (BOA). In some ways, city staff and political appointees serve similar functions as advisors to Councilmember Griggs, and as enforcers of his policy vision for the neighborhood, but a subset of participants proposed that city staff frequently advise as advocates of first tier- and second tier influentials, while CPC and BOA appointees reinforce Griggs' ideas.

Looking first at Interim Planning Director Neva Dean, whose office oversees permits and planning, and who works with city's Landmark Commission, overseeing which buildings receive landmark status and associated protections, participants agreed that her office is a recurrent battleground between second tier influentials and civic chairs who, respectively, propose and challenge plans for new development in the neighborhood. Participants frequently suggested that city staff tend to keep a pro-development agenda, and 
this bias is evident in Dean's office, where staff are often unhelpful in assisting residents find particular ordinances that are being violated, but generally will act once specific violations are documented; several commented that:

If a resident wants to complain about a project, they have to go to Planning and get a meeting, or know the codes and demand action through Scott (Griggs). It ends up being a fight down in Neva [Dean]'s office, or through public hearings, with her people taking the side of the developer.

In selecting Dean for their decision-making committees, participants identified her abilityand willingness to selectively enforce various development ordinances, especially when a project has the support of Councilmember Griggs, so long as those violations are relatively minor, and not safety-related. Many participants agreed that:

\begin{abstract}
Dean doesn't send inspectors out to deep-dive into every single project, because that's a waste of time and people she doesn't really have. If a proposal is good, and has [Griggs's] support, then those inspectors might elect to not go after you on minor zoning or permit violations, and they might not even show up as long as nobody complains.
\end{abstract}

In considering the roles of Griggs' political appointees in neighborhood decisionmaking, participants named Michael Anglin and Scott Hounsel (respectively, Griggs' appointees to the City Plan Commission (CPC) and Zoning Board of Adjustment (BOA)), as the councilmember's proxy votes during proposed zoning changes, battles over adding (or removing) historic district protections, and requested exceptions to extant zoning policies. To the extent that participants suggested pro-development bias in city staff, participants also identified an anti-development bias in these two actors, and recognized that these two, like Griggs himself, share a vision of a North Oak Cliff that respects its historical structures and density, rather than razing that history in favor of neoliberal renewal strategies.

Participants regularly drew parallels between Griggs' appointees and those of Councilmember Kingston (discussed in later sections), in that both sets of appointees are often in the minority when it comes to opposing particular developments, but participants agreed that Griggs' appointees are (generally) more successful in defeating controversial real- 
estate plans for two reasons: first, the developer class in North Oak Cliff is less enmeshed within the city than the analogous class in Downtown Dallas, and second, North Oak Cliff's civic chairs are actively involved in mobilizing neighborhood residents to oppose unpopular development, with a level of organization that does not exist in other neighborhoods. In drawing these distinctions, participants regularly called the neighborhood the "People's Republic of Oak Cliff," and commended the work of organizers; their comments are wellsummarized by:

Oak Cliff was neglected for so long that people had to work together to get anything out of City Hall, and there's a strong spirit of surviving even without Dallas' help. Different blocks come together in a way you just don't see anywhere else, and when you can get them all together, you get a voice that even the (City) Council can't ignore. They don't win every time, but they win more often than the developers would like.

\section{Category Standout: Councilmember Scott Griggs. Participants unanimously}

nominated Councilmember Scott Griggs to their neighborhood decision-making teams, and has the highest power rating (3.85) of all actors in North Oak Cliff. Often, participants would discuss the role of other neighborhood decision-makers in terms of how they work with the councilmember, and repeatedly said that other formal authorities serve primarily to inform- and implement Griggs' decisions, especially as those decisions relate to construction and development; as many agreed:

Scott (Griggs) is the chief executive of this district - a leader whose authority here is basically unquestionable. If he likes your project, then you'll get the permits and zoning taken care of quickly. If he doesn't, then suddenly you get hit with all of these obscure zoning laws and code violations, enough to delay your project for years, if not killing it outright. Enough money can get through that, but it's so expensive and time-consuming that most developers don't mess with it.

Participants also admitted that Griggs devotes much of his time to undoing the decisions of his predecessors, fighting to keep his district from becoming, as one participant put it, "a playground for the rich in North Dallas." Although Griggs opposes the commodification of the neighborhood, participants acknowledged that he is not totally anti-development, and 
has worked with locally-based developers, as well as developers with an interest in infill construction and low-rise, new-urbanist style development. Participants' regularly made comments similar to:

Back in the 90s, and even through the early 2000s, there was an attempt to revive North Oak Cliff by rezoning for suburban-style development, without respect to the layout or history of the area, which is tied up in streetcars and walking everywhere. Scott (Griggs) can only rezone so many places each year, so he's constantly fighting with developers to make sure they build with a sense of the scale and style of this place. We can't stay stagnant forever, but he tries to make sure that new development respects the feel of the community.

Formal authorities, in summary. When describing North Oak Cliff's decision-

making body, participants agreed that the neighborhood's city councilmember is the primary decision-maker. In addition to the unwritten policy of non-interference among councilmembers, participants acknowledged that within his district, Councilmember Griggs benefits from professional deference of the interim planning director, and from his involvement in working with his proxy votes appointed to the CPC and BOA. Summarizing many participant comments on this, one participant noted that:

Councilman Griggs is the central authority in this area. It's practically suicidal to fight him; sure, you can get permits and zoning approval without his okay, but he can bury you in regulations, historic district red tape, funding nightmares... he can either clear the way for your project, or have every city office stonewall and delay to the absolute legal limit.

First tier influentials. Table 4.16 shows summary statistics related to North Oak Cliffs first tier influentials, named by four or more participants to a hypothetical committee responsible for making a decision that would affect the neighborhood, and that would need to be supported by a majority of neighborhood's population.

\begin{tabular}{|c|c|c|c|c|c|c|c|}
\hline \multirow[t]{2}{*}{ Name } & \multirow[t]{2}{*}{$\begin{array}{l}\text { Primary or Notable } \\
\text { Affiliation(s) }\end{array}$} & \multicolumn{2}{|c|}{$\begin{array}{c}\text { Decision-Making } \\
\text { Committee } \\
\text { Nominations }\end{array}$} & \multirow{2}{*}{$\begin{array}{l}\text { Mean } \\
\text { Power } \\
\text { Level } \\
(1-4)\end{array}$} & \multicolumn{2}{|c|}{$\begin{array}{l}\text { Recent Shared } \\
\text { Committee Service }\end{array}$} & \multirow{2}{*}{$\begin{array}{c}\text { Mean } \\
\text { Familiarity } \\
\text { Level } \\
(1-4)\end{array}$} \\
\hline & & \# & $\%$ & & $\#$ & $\%$ & \\
\hline Jim Lake Jr. & Jim Lake Companies & 17 & $43 \%$ & 3.38 & 7 & $18 \%$ & 2.53 \\
\hline Joe McElroy & Square Foot Inc. & 16 & $40 \%$ & 2.88 & 0 & $0 \%$ & 2.10 \\
\hline Tom Prohaska & Texas Pro Properties, LLC & 10 & $25 \%$ & 2.78 & 0 & $0 \%$ & 2.08 \\
\hline \multirow{2}{*}{\multicolumn{2}{|c|}{$\begin{array}{l}\text { Mean Value (Actors in This Category) } \\
\text { Mean Value (Actors in All Categories) }\end{array}$}} & 14 & $36 \%$ & 3.01 & 2 & $6 \%$ & 2.24 \\
\hline & & 21 & $52 \%$ & 2.96 & 4 & $10 \%$ & 2.25 \\
\hline
\end{tabular}


Actors in this category consist of three locally-based rentiers who have built real estate empires on renting to residents with low- and moderate incomes, as well as leasing commercial space to area businesses. On average, actors in this category have fewer average nominations for inclusion in a decision-making committee than those in other categories, but have a slightly higher average power rating. Actors in this category are also lower, on average, on both shared committee service with participants and familiarity. In the paragraphs that follow, this study will examine the decision-making roles of North Oak Cliff's rentiers, particularly category standout Jim Lake, Jr.

Local rentiers. Participants largely agreed that actors in this subcategory are unified by their vast real estate holdings throughout North Oak Cliff (and southern Dallas in general), their long-standing involvement in area development decisions, especially in- and around development hotspots like the Bishop Arts District and the Oak Cliff Gateway, and their relative cooperation in partnering with the area's second tier influentials on real estate development, and joint efforts to lobby formal authorities at the neighborhood- and citywide level to relax ordinances (or, at least, enforcement) related to conditions in their rental properties.

While individually, no actor in this category received nominations from a majority of participants, many participants selected at least one of the three listed in table 4.16. In explaining why, participants often suggested that these actors usually opt to cooperate with-, rather than compete against one another, so gaining the support of one is usually enough to bring the others' support as well. Participants also agreed that this cooperation stems from the largely weak demand for development in the neighborhood, especially compared to the demand in nearby Downtown Dallas, so it is practically unheard of for these actors' interests to conflict. As many participants admitted: 
The guys who own the land around here have no reason to fight each other, so they work together to bundle up their various tracts and sell them to hungry developers. It's all quiet, and under the table, so the people - usually renters - living on that land usually don't know anything until the eviction notices start coming in, or they see bulldozers knocking something down.

Category standout: Jim Lake, Jr. A significant minority (43\%) of participants

nominated second-generation developer and Oak Cliff native Jim Lake, Jr., to their decisionmaking teams; indeed, participants rated Lake higher in power, shared committee membership, and familiarity than either of the other two actors in this category. Although participants uniformly respected Lake for his devotion to the neighborhood, a strong subset heavily criticized the effects of his development projects.

"When Jim Jr. started down here," one of Lake's advocates began, “everything was all boarded up. Now look out there - it's all alive. People shopping, eating... some even live here, who wouldn't have come through here without a platoon ten years ago." Participants frequently credited Jim Lake Jr. with successfully lobbying for the creation of a TIF district to induce development in both the Bishop Arts District and the Oak Cliff Gateway, but had divergent opinions of his motives. One group considered Lake a resource in fighting to preserve some of the neighborhood's architecture and character, and largely agreed that:

Jim (Lake) grew up here, and learned from his dad, Jim (Lake) Sr., that you don't always have to tear down a building to make something new.. They worked with local businesses to fill up old warehouses, and made community anchors where other people would just tear down and put some generic, brown building full of retail chains and companies that don't care about the neighborhood.

Not all participants were as positive, however, and their comments are well-summed with:

Jim (Lake) Jr. says that he cares about the neighborhood, but what he really cares about making money, and what makes money right now is saving old spaces. He's knocked down plenty of buildings, and kicked out plenty of family businesses here, back before it was hip to keep that stuff around.

First tier influentials, in summary. Within North Oak Cliff's decision-making process, participants agreed that a small group of landowners exert significant influence, 
although standout Jim Lake is notably more active than others in this category. Data seem to support these impressions, with Lake holding notably higher power, Committee Service, and familiarity scores than other actors in this category. Participants conceded that these actors work (to differing degrees) with area formal authorities, and with second tier influentials and anchor captains to further a broadly noncompetitive pro-development agenda. Increasingly, this cooperation is drawing the ire of residents who oppose what they consider "destructive gentrification," wherein local businesses and low-income renters are being displaced in favor of higher-income tenants imported from other parts of the city; this opposition, as well as attempts to mediate among different interests are being headed by area civic chairs.

Second tier influentials. Table 4.17 shows summary statistics related to North Oak Cliff's second tier influentials, named by four or more participants to a hypothetical committee responsible for making a decision that would affect the neighborhood, and that would need to be supported by a majority of neighborhood's population.

\begin{tabular}{|c|c|c|c|c|c|c|c|}
\hline \multirow[t]{2}{*}{ Name } & \multirow[t]{2}{*}{$\begin{array}{c}\text { Primary or Notable } \\
\text { Affiliation(s) }\end{array}$} & \multicolumn{2}{|c|}{$\begin{array}{c}\text { Decision- } \\
\text { Making } \\
\text { Committee } \\
\text { Nominations }\end{array}$} & \multirow[t]{2}{*}{$\begin{array}{l}\text { Mean } \\
\text { Power } \\
\text { Level } \\
(1-4)\end{array}$} & \multicolumn{2}{|c|}{$\begin{array}{c}\text { Recent Shared } \\
\text { Committee } \\
\text { Service }\end{array}$} & \multirow{2}{*}{$\begin{array}{c}\text { Mean } \\
\text { Familiarity } \\
\text { Level } \\
(1-4)\end{array}$} \\
\hline & & \# & $\%$ & & \# & $\%$ & \\
\hline Matt Segrest & Alamo Manhattan & 21 & $53 \%$ & 3.23 & 3 & $7 \%$ & 2.40 \\
\hline Farrokh \& Michael Nazerian & Exxir Capital & 19 & $48 \%$ & 2.85 & 0 & $0 \%$ & 2.35 \\
\hline David Eitches & Blackwood Developments, LLC & 15 & $38 \%$ & 2.70 & 0 & $0 \%$ & 2.03 \\
\hline David Spence & Good Space & 10 & $25 \%$ & 2.33 & 7 & $18 \%$ & 2.43 \\
\hline \multirow{2}{*}{\multicolumn{2}{|c|}{$\begin{array}{l}\text { Mean Value (Actors in This Category) } \\
\text { Mean Value (Actors in All Categories) }\end{array}$}} & 14 & $36 \%$ & 2.78 & 3 & $7 \%$ & 2.30 \\
\hline & & 21 & $52 \%$ & 2.96 & 4 & $10 \%$ & 2.25 \\
\hline
\end{tabular}

Actors in this category are all members of the developer class, and each is connected to multiple development projects in North Oak Cliff. Data suggest that, compared to actors in other categories, actors in this category are likely to be nominated to participants' decisionmaking committees, have below-average ratings of power and recent shared committee service, and above-average familiarity ratings. In the paragraphs that follow, this study will discuss the role of the local developer class in decision-making in North Oak Cliff broadly, and 
then it will draw out participant perceptions of category standout David Spence.

The developer class. When participants selected actors in this category for their hypothetical decision-making teams, they ofttimes acknowledged that these actors have forged strong relationships with neighborhood formal authorities, first tier influentials, and a subset of North Oak Cliff's civic chairs. Among participants more broadly, there was general agreement that these actors do not have similar agendas with respect to development; many commented that there are two types of actors in this new group: infill developers like David Spence, who focus on revitalizing blocks through remodeling single buildings, and larger builders like Matt Segrest of Alamo Manhattan, Farrokh and Michael Nazerian of Exxir Capital, and David Eitches of Blackwood Developments of whose projects involve significantly more demolition and reconstruction, commonly over multiple plots, if entire blocks at once. Nonetheless, participants drew a sharp contrast between developers active in North Oak Cliff and those revitalizing nearby Downtown Dallas, often saying that:
It's different here (in North Oak Cliff); larger developers like CBRE aren't as big of a presence, because they're focusing on projects in the hundreds of millions of dollars, whereas the biggest projects here are in the tens of millions.

Finally, participants opined that these actors ofttimes utilize their local knowledge to exploit historic divisions among neighborhood organizations, intentionally developing in places where multiple neighborhoods stand to benefit (or suffer) to varying extents. Many accused local landowners of using their knowledge of neighborhood mistrust to guide new developers into areas where inter-neighborhood distrust will act as a roadblock to a unified resistance to development, and as one participant put it:

Bishop Arts and the (Oak Cliff) Gateway are basically artificial - they're just lines on a map, and they cut across different neighborhoods in different ways. If the neighborhoods would work together, they could put up some opposition to development, but they won't, and these developers know that - they knew that when they bought the land where they did. 
Category standout: David Spence. Although David Spence, owner of Good

Space, had the lowest rating of power (2.33), and was the actor least nominated for inclusion on participants' decision-making teams (25\%), he scored higher than other actors in this category on both shared committee service and familiarity. In describing Spence's role in North Oak cliff, participants drew a distinction between him and other actors in this category; specifically, they noted that, whereas other actors in this category focus on larger developments, Spence's company repurposes existing, abandoned buildings. Participants regularly commented that:

In North Oak Cliff, everything used to be low-rise brick, laid out along trolley lines that were buried years ago. The big guys like Alamo Manhattan don't seem to get that we want to stay true to that, but David (Spence) does. For years now, he's been piecing together his developments, little by little, and with a lot of work himself.

While his projects lack the scope and magnitude of many others, participants often noted that he has much more community support, and that he has been integral in developing spaces for locally-owned businesses, and for fostering locally-oriented development in a neighborhood that is quickly being, as several conveyed, "parceled out" by larger developers. Finally, in their interviews, even participants who did not nominate Spence for their decision-making teams identified him as someone who is heavily involved in projects around the Bishop Arts District, and several conjected that his positive relationships with first tier influentials, formal authorities, and the general public would make him a formidable successor to Councilmember Griggs, once Griggs leaves office.

Second tier influentials, in summary. Comprised of real estate developers, North Oak Cliff's second tier influentials work closely with first tier influentials and formal authorities to reshape North Oak Cliff, particularly in the Bishop Arts District and Oak Cliff Gateway, both of which are covered by a TIF district. While participants did not commonly select any particular actor in this category for their decision-making teams, all participants selected at 
least one, agreeing that these actors are willing- and able to use their access to financial capital to bring much-needed development to the area, and that many are willing to utilize somewhat-questionable tactics in service of their agendas. However, participants noted exceptions to these blanket statements in David Spence of Good Space, whose practice of renovating existing structures has, in the eyes of many, saved many structures from demolition, and has been crucial in supporting the development of a local economy.

Civic chairs. Table 4.18 shows summary statistics related to North Oak Cliff's civic chairs, named by four or more participants to their hypothetical neighborhood decisionmaking committees.

\begin{tabular}{|c|c|c|c|c|c|c|c|}
\hline \multirow[t]{2}{*}{ Name } & \multirow[t]{2}{*}{ Primary or Notable Affiliation(s) } & \multicolumn{2}{|c|}{$\begin{array}{l}\text { Decision- } \\
\text { Making } \\
\text { Committee } \\
\text { Nominations }\end{array}$} & \multirow[t]{2}{*}{$\begin{array}{l}\text { Mean } \\
\text { Power } \\
\text { Level } \\
(1-4)\end{array}$} & \multicolumn{2}{|c|}{$\begin{array}{c}\text { Recent Shared } \\
\text { Committee Service }\end{array}$} & \multirow[t]{2}{*}{$\begin{array}{c}\text { Mean } \\
\text { Familiarity } \\
\text { Level } \\
(1-4)\end{array}$} \\
\hline & & $\#$ & $\%$ & & \# & $\%$ & \\
\hline Pam Conley & Kidd Springs Neighborhood Association & 27 & $68 \%$ & 2.85 & 5 & $13 \%$ & 2.25 \\
\hline Lisa Benskin & Old Oak Cliff Conservation League & 27 & $68 \%$ & 2.83 & 7 & $18 \%$ & 2.28 \\
\hline \multirow[t]{3}{*}{ Jason Roberts } & Better Block; Oak Cliff Transit Authority & 13 & $33 \%$ & 1.68 & 5 & $13 \%$ & 2.33 \\
\hline & Mean Value (Actors in This Category) & 22 & $56 \%$ & 2.45 & 6 & $14 \%$ & 2.28 \\
\hline & Mean Value (Actors in All Categories) & 21 & $52 \%$ & 2.96 & 4 & $10 \%$ & 2.25 \\
\hline
\end{tabular}

Actors in this category consist of two leaders of neighborhood associations and one neighborhood activist associated with a number of highly-acclaimed civic organizations active in North Oak Cliff. On average, these actors are slightly more likely than actors in general to be nominated to participants' decision-making committees, tend to serve on more shared boards and committees with participants, and are rated higher on familiarity. These actors also have a lower than average rating of power, compared to actors more broadly. While participants identified more similarities between Pam Conley and Lisa Benskin than between these two and Jason Roberts, participants had strong, unique opinions about each, and their respective roles in decision-making within North Oak Cliff. As a result, in the paragraphs that follow, this study will discuss each of these in turn. 
Category standout: Pam Conley. Over two-thirds of participants knowledgeable about North Oak Cliff named Pam Conley to their decision-making teams, and she holds the highest power rating (2.85) of any actor in the category. Conley is the president of the Kidd Springs Neighborhood Association, and is long-time resident of the area, although participants commented that she is most regularly found in city offices, meeting with Councilmember Griggs, or in public hearings regarding development - particularly regarding the Bishop Arts District, but also around the neighborhood broadly.

Participants - even those who did not nominate Conley for their decision-making committees - considered her to be a political force to be reckoned with, limited only by her propensity for irritating both her allies and her opponents. Participants regularly cited to her ability- and willingness to study zoning ordinances and building codes, work with local media (including the Dallas Morning News, Dallas Observer, and Oak Cliff Advocate) to keep media pressure on Councilmember Griggs, and most importantly, her ability to whip up resident opposition to development projects. Summarizing these points, participants acknowledged that:

\footnotetext{
"Pam Conley" is a name even Scott Griggs has to pay attention to, because she doesn't waste time. She knows codes and zoning regulations better than the departments do, and most importantly, she can- and will get voters to come out and raise a fuss.

She's done more to stop questionable development than anyone else. Two things balance her out: first, there are more developers with more projects than she has time to fight, and second, she pisses off just near as many people as she lines up as supporters.
}

Category standout: Lisa Benskin. As many participants selected Benskin as did Conley, and rated her nearly-identically on power (2.83). Participants described Benskin as less-polarizing than Conley, as well as more moderate when considering whether, or to what extent, to challenge new development in North Oak Cliff. In explaining why, participants pointed to the purpose of the organization she leads - the 34-neighborhood coalition called the Old Oak Cliff Conservation League (OOCCL). In practice, this means that its president, 
Lisa Benskin, is often looked to by Councilmember Griggs, city offices, and members of the media to speak on behalf of neighborhood residents, while also being looked to as a moderator among competing neighborhood interests. Participants recognized that Benskin often fosters close ties with first tier influentials and second tier influentials, and uses these connections to "nudge development along in ways that are less disruptive to the existing residents" and "preserve the spirit of the area, while addressing the results of long-time neglect and abandonment," rather than opposing all development outright. Participant thoughts can be summarized as follows:

In Dallas, development is a given - it's like breathing around here, you can't stop it forever. Under Lisa (Benskin), the [OOCCL] doesn't totally oppose development, and would rather work with developers than against them, because that leads to results that the neighborhoods might be able to live with.

Category standout: Jason Roberts. Out of North Oak Cliff's civic chairs, Jason Roberts had the fewest nominations (33\%) to decision-making committees, as well as the lowest rating of power (1.68). Although Roberts is not the head of a neighborhood association, he is affiliated with a number of civic organizations in North Oak Cliff, including the Better Block Project and Bike Friendly Oak Cliff, and is the founder of the North Oak Cliff Transit Authority, a nonprofit, nongovernmental organization responsible for successfully blending local-, state-, federal-, and private-sector funds, funneling these into designing and constructing a streetcar line connecting North Oak Cliff to Downtown Dallas $^{435}$. Participants who nominated Roberts to their decision-making teams (and several who did not) considered Roberts a "rising star" in the North Oak Cliff's decision-making process, but many criticized his forward-thinking advocacy as being "out of touch" with the needs of neighborhood's current residents, many of whom participants considered likely to 
be displaced as North Oak Cliff continues to gentrify. Summarizing participant comments, many suggested that:

Jason (Roberts) is going to get elected to high office someday, probably after millennials move south of the Trinity (River) and kick out the folks who live here now. Streetcars and bike lanes and urban gardens are nice, but we still can't even get enough decent grocery stores for the folks who don't have cars, or can't afford to use a lot of gas. He's the right man to solve problems that the neighborhood will have in ten years, after all the poor folks are pushed out.

Civic chairs, in summary. Actors in this category consist of two presidents of neighborhood associations and one neighborhood activist associated with a number of highly-acclaimed civic organizations active in North Oak Cliff. Participants agreed that each actor's approach to protecting and improving North Oak Cliff is unique, simultaneously appealing to- and distancing various constituent groups within the neighborhood.

Additionally, participants frequently that actors in this category spend tremendous amounts of their own time (often lacking financial resources to hire assistants) in service of their constituents, frequently to be met with more disappointments than successes. This is nearly the opposite of how participants described the experience of North Oak Cliff's sole anchor captain, to be discussed in the following subsection.

Anchor captains. Table 4.19 shows summary statistics related to North Oak Cliffs sole anchor captain named by four or more participants to a hypothetical committee responsible for making a decision that would affect the neighborhood, and that would need to be supported by a majority of neighborhood's population.

\begin{tabular}{|c|c|c|c|c|c|c|c|}
\hline \multirow[t]{2}{*}{ Name } & \multirow[t]{2}{*}{$\begin{array}{l}\text { Primary or Notable } \\
\text { Affiliation(s) }\end{array}$} & \multicolumn{2}{|c|}{$\begin{array}{c}\text { Decision-Making } \\
\text { Committee } \\
\text { Nominations }\end{array}$} & \multirow{2}{*}{$\begin{array}{c}\text { Mean } \\
\text { Power } \\
\text { Level } \\
(1-4)\end{array}$} & \multicolumn{2}{|c|}{$\begin{array}{c}\text { Recent Shared } \\
\text { Committee Service }\end{array}$} & \multirow{2}{*}{$\begin{array}{c}\text { Mean } \\
\text { Familiarity } \\
\text { Level } \\
(1-4)\end{array}$} \\
\hline & & \# & $\%$ & & \# & $\%$ & \\
\hline Martin Koonsman & Methodist Dallas Medical Center & 22 & $55 \%$ & 3.05 & 3 & $8 \%$ & 2.38 \\
\hline \multirow{2}{*}{\multicolumn{2}{|c|}{$\begin{array}{l}\text { Mean Value (Actors in This Category) } \\
\text { Mean Value (Actors in All Categories) }\end{array}$}} & 22 & $55 \%$ & 3.05 & 3 & $8 \%$ & 2.38 \\
\hline & & 21 & $52 \%$ & 2.96 & 4 & $10 \%$ & 2.25 \\
\hline
\end{tabular}


Martin Koonsman is the president of Methodist Dallas Medical Center (commonly referred to as Methodist Hospital), which has a significant amount of history with the neighborhood, tracing its roots in North Oak Cliff to $1924^{436}$. Compared to actors in other categories, Koonsman has an above-average number of nominations to decision-making committees, as well as an above-average score in both power and familiarity, but has recently served on fewer-than-average committees or boards with participants. In the paragraphs that follow, this study will discuss participant perspectives on Koonsman's role in neighborhood decision-making.

In reflecting on Koonsman's role as the president of the hospital, as well as the role of the hospital in decision-making, a strong subset of participants often accused Koonsman of using the hospital's history with North Oak Cliff, its presence as one of the few area medical facilities, and its status as a large employer to gain tremendous leeway with its expansion projects, to the point that many of these projects are able to proceed over objections of surrounding neighborhoods. As many agreed:

That hospital has been around for as long as anything else around here, and has hundreds, if not thousands of jobs connected to it. They get almost anything they want, because there's just nobody else that can soak up all those people if the hospital leaves.

Participants also often concurred that, outside of using its influence to ease restrictions on expansion, the hospital is generally uninvolved in neighborhood decision-making; in this way, the hospital behaves as "part time" member of the neighborhood's decision-making body. As several participants put it:

Martin Koonsman doesn't care about Oak Cliff, because none of his doctors or lead nurses live here, and he certainly doesn't either. None of those people wake up at $5 \mathrm{am}$ to the sound of supply trucks barreling down the street, but the people who live here have had to do that for months now. He wants to act like the hospital's a cornerstone of the neighborhood when it might get them some free money to build a new wing, but then his contractors will go and bulldoze a block of houses for the construction.

436 Methodist Health System, 2015 
It is important to note that not all participants had a negative appraisal of the role of Koonsman and the hospital in North Oak Cliff's decision-making process, or the effects of this involvement. Several considered the hospital to be an economic engine in an otherwisederelict part of the city, pointing to the thousands of jobs created by the hospital directly, as well as indirectly through its surrounding affiliated medical offices, its suppliers, and nearby businesses. One participant, echoing the thoughts of many others, said that:

Methodist Hospital has been an economic anchor south of the Trinity (River), even when everything else had abandoned the area. The commitment shown over the years, the jobs good, stable, well-paying jobs - created and maintained here can't be forgotten, even when it would have made more sense to move north with everyone else. The kinds of services that Methodist provides now couldn't have been dreamed of back in 1924, so if the hospital doesn't expand, it would have to move somewhere else.

Another, acknowledging the complicated relationship between the hospital and surrounding neighborhood, commented that:

[The hospital hasn't] always been a good neighbor. For a long time, [Methodist Hospital] ignored complaints, knowing that there wouldn't be repercussions. Those days have been gone for a long time, but under Dr. Koonsman, [the hospital has] really stepped up, to become a neighbor that isn't just an economic boon, but a real center for the community, working quickly to address neighborhood concerns in a meaningful way, and taking time to really listen to what people need from [the hospital].

Anchor captains, in summary. Participants often (but not always) held a negative view of the role of Martin Koonsman, and the hospital he represents, in North Oak Cliff's decision-making process. As a major employer and economic driver, participants agreed that it has a tremendous amount of clout with neighborhood formal authorities, and with its growing footprint, close relationships with first- and second tier influentials, but that it often only uses this clout to serve its own agenda, rather than becoming an advocate for the people who live in the community it serves.

Decision-makers in North Oak Cliff, in summary. This study asked participants knowledgeable about Dallas' decision-making process to identify- and describe actors who get involved in making citywide decisions, and to nominate 10 people to form a committee 
that would be responsible for making a decision that would affect the city as a whole. A total of 40 participants delivered a combined 400 nominations, and 314 of these went to the 15 individual- and group actors outlined in the previous section. These actors represent all three sectors, but also a deep division in North Oak Cliff, between use-value, represented by residents who seek to remain in their homes and locally-owned businesses, and exchangevalue, represented by the coalition of larger developers and landowners who are actively engaged in clearing older development in favor of higher-rent residences and retail outlets catering to the post-Fordist generation of young adults who are rapidly gentrifying the area. Before evaluating whether these actors, and the relationships among them are suggestive of a structure within this decision-making process, however, this study will report its findings with respect to Downtown Dallas.

\section{Decision-makers in Downtown Dallas}

To understand the contemporary decision-making structure within Downtown Dallas, and whether (or to what extent) anchor institutions and CDCs have a primary role within it, this study asked participants knowledgeable about decision-making in Downtown Dallas to identify- and describe actors who get involved in making neighborhood-wide decisions, and to nominate 10 people to form a committee that would be responsible for making a decision that would affect the city as a whole.

A total of 39 (out of 79) participants were identified as being particularly cognizant of decision-making in Downtown Dallas; therefore, a maximum of 390 nominations were possible, and out of these, 81 votes $(20.8 \%)$ were cast for actors who did not garner enough votes (a minimum of 4 , or $10 \%$ ) to be included in the tables throughout this section. In reporting on these actors, this study will first detail Downtown Dallas' formal authorities; next, it will introduce the city's its first tier influentials; third, its second tier influentials; and finally, its 
civic chairs. No anchor captains were nominated by enough participants to be included in this study's discussion of Downtown Dallas' decision-making process.

Formal authorities. Table 4.20 shows summary statistics related to Downtown Dallas' formal authorities, named by four or more participants to a hypothetical committee responsible for making a decision that would affect the neighborhood, and that would need to be supported by a majority of neighborhood's population.

\begin{tabular}{|c|c|c|c|c|c|c|c|}
\hline \multirow[t]{2}{*}{ Name } & \multirow{2}{*}{$\begin{array}{l}\text { Primary or Notable } \\
\text { Affiliation(s) }\end{array}$} & \multicolumn{2}{|c|}{$\begin{array}{l}\text { Decision-Making } \\
\text { Committee Votes }\end{array}$} & \multirow{2}{*}{$\begin{array}{c}\text { Mean } \\
\text { Power } \\
\text { Level } \\
(1-4)\end{array}$} & \multicolumn{2}{|c|}{$\begin{array}{l}\text { Recent Shared } \\
\text { Committee Service }\end{array}$} & \multirow{2}{*}{$\begin{array}{c}\text { Mean } \\
\text { Familiarity } \\
\text { Level } \\
(1-4)\end{array}$} \\
\hline & & \# & $\%$ & & \# & $\%$ & \\
\hline Philip Kingston & Dallas City Council & 39 & $100 \%$ & 3.97 & 9 & $23 \%$ & 2.23 \\
\hline A.C. Gonzalez & City Manager & 23 & $59 \%$ & 3.90 & 6 & $15 \%$ & 2.48 \\
\hline Karl Zavitkovsky & Office of Econ. Development & 13 & $33 \%$ & 3.77 & 5 & $13 \%$ & 2.43 \\
\hline Mark Rieves & Zoning Board of Adjustment & 15 & $38 \%$ & 3.26 & 0 & $0 \%$ & 1.95 \\
\hline Paul Ridley & City Plan Commission & 9 & $23 \%$ & 3.10 & 4 & $10 \%$ & 2.05 \\
\hline \multirow{2}{*}{\multicolumn{2}{|c|}{$\begin{array}{l}\text { Mean Value (Actors in This Category) } \\
\text { Mean Value (Actors in All Categories) }\end{array}$}} & 20 & $49 \%$ & 3.60 & 5 & $6 \%$ & 2.23 \\
\hline & & 17 & $44 \%$ & 3.29 & 11 & $28 \%$ & 2.31 \\
\hline
\end{tabular}

As in both Dallas citywide and North Oak Cliff, participants asserted that the primary agents of decision-making within Downtown Dallas. Actors in this category consist of the area's city councilmember, two of his political appointments, and two high-level city bureaucrats. On average, actors in this category have above-average numbers of nominations to decision-making committees and power ratings, and below-average recent shared committee service and familiarity. In describing the role of these actors in Downtown Dallas, this study will first introduce the role of city staff and appointed members of boards and commissions, and finally, category standout Philip Kingston.

City staff and political appointees. Looking first at the role of city staff in neighborhood decision-making, participants knowledgeable about Downtown Dallas' decision-making process regularly brought up the roles of ranking city staff, as well as Councilmember Kingston's appointees to the City Plan Commission (CPC) and Zoning 
Board of Adjustment (BOA). As in North Oak Cliff, participants concurred that city staff and political appointees serve similarly as advisors to Councilmember Kingston, and as the implementers of his vision for Downtown Dallas, but participants regularly submitted that city staff recurrently serve as mouthpieces of- and liaisons for first tier-and second tier influentials, while CPC and BOA appointees remain fiercely loyal to Kingston's wishes. Looking first at city staff, participants often nominated either (and not uncommonly both) City Manager A.C. Gonzalez, and Director of Economic Development Karl Zavitkovsky to their hypothetical decision-making teams. Looking first at City Manager Gonzalez, although his role in Downtown Dallas' decision-making body is similar to his role in citywide decision-making, participants conceded that he is generally only involved in the largest development projects, whose implications are likely to reverberate throughout the city; participants repeatedly cited examples of recent upgrades to the city's convention center, as well as rumors surrounding a plan to build a downtown baseball stadium, both with the enthusiastic support of area first tier influentials.

Gonzalez' economic development chief is Karl Zavitkovsky, whose office has authority over planning, permits and code compliance, as well day-to-day administration of the city's TIFs and PIDs), several of which several are contained within Downtown Dallas ${ }^{437}$. Participants agreed that Zavitkovsky's support for a project can, as several noted, "smooth the process" of project approval, particularly when there is no proposed change to land-use or zoning policies (which necessitate approval of Councilmember Kingston). Participants frequently admitted Zavitkovsky and Gonzalez work to both encourage- and enable development, rather than regulate developers, and many comments categorized development is an "outside proposal," wherein city departments are disinterested in project particulars,

${ }^{437}$ Dallas Office of Economic Development, 2015 
and are instead concerned with the amount of economic growth brought to Downtown

Dallas. In describing this, participants' comments are well-summarized by the following:

Karl and his boss are firm believers in the old-school "growth gospel" of Dallas, and Downtown is the jewel of the city's crown, so why wouldn't they push to bring as much development to the CBD as they can? They've completely subordinated regulations and planning policies to development, and any planner who wants to keep his job around here learns quickly to not concern himself with regulating proposals.

Looking at the role of Councilmember Kingston's appointees in neighborhood decision-making, participants acknowledged that Kingston's appointees to the CPC and BOA, like those of the other councilmembers, act as his proxy votes, deliberating and voting on proposals with his input, and assisting Kingston in countering the neoliberal tendencies found within Dallas' city hall. Participants recognized that, like Kingston, his appointees envision a Downtown Dallas open to more than just wealthy Dallasites and suburban visitors, but admitted that this remains a minority opinion, and one that opposes the position of ranking city staff. As a result, participants agreed that projects that do not have the approval of these appointees are not doomed to failure at the committee or council level, but that it is much easier to achieve positive outcomes with their support. Participant comments are well-summarized by the following:

Kingston gets one proxy on the CPC, and one on the (Zoning) Board of Adjustment. You've got his proxies, and the proxies of a few other councilmembers who share his progressive vision, but the majorities on both committees are still pro-development, and Downtown Dallas is the jewel of the city, so if you're going to see a dust-up over development, it's gonna (SIC) happen here. Egos run strong (SIC) here, so developers and their backers fight harder here than they might in other parts of town.

\section{Category standout: Councilmember Philip Kingston. All 39 participants}

nominated Councilmember Philip Kingston, who represents Downtown Dallas, to their decision-making teams, and his power score (3.97) is highest among both first tier influentials, and among all listed decision-makers in Downtown Dallas. Within Downtown Dallas, participants agreed that Councilmember Kingston commands functionally absolute authority 
over land-use decisions, and like his predecessor Angela Hunt, uses this authority in service of a vision for Downtown Dallas that embraces the post-Fordist tendencies of millennials who seek locations where work, home, and entertainment all exist in close proximity, while also advocating for historic preservation and incorporation of affordable housing within new development projects; describing this vision, participants consistently concurred that:

Philip (Kingston) is part of a newer wave of leaders in Dallas; they're not "antidevelopment," but they're against the kind of speculative, "build for building's sake" style that got Dallas in so much trouble in the 1980s. They want to develop, but they want to do it in a way that won't leave the city center vacant if this push to move back into Downtown turns out to just be a fad.

Participants admitted that Kingston's vision often puts the councilmember in opposition with City staff, as well as their backers found among Downtown Dallas' first tier influentials and civic chairs, many of whom continue to mobilize resources in ongoing attempts to remake Downtown Dallas around stadiums, convention centers, and high-end hotels, retail, and dining. Participants frequently conceded that Kingston, his staff, and his appointees to various boards and committees are able to challenge these projects, but are largely unable to completely halt them, primarily because of the close connections that persist between Dallas' public- and private sectors; many described this as a "David and Goliath" scenario, wherein, as one participant noted:

You have Philip (Kingston) and his people on one end, and then you've got A.C. (Gonzalez), (Mayor) Rawlings and the masters who control them on the other. In every development decision, Gonzalez and Rawlings come together and try to frame the issue in a way that makes every option one they like, but Kingston keeps coming back and pointing out alternatives, and finding holes in their proposals. He says the things people in City Hall don't want to hear, and that gets him a lot of popular support, but costs him the favor of Dallas' ruling elite. It's also not always effective, so sometimes he spends hours and hours on a plan that gets defeated in minutes.

Formal authorities, in summary. While participants acknowledged that these actors are among the most central in Dallas' decision-making process, interviews suggest that this category is less effective than it might otherwise be, due to frequent within-category infighting; participants regularly categorized a subset of the neighborhood's formal authorities 
as being in a degree of opposition with first tier and second tier influentials, some of whom are also considered highly influential in Dallas' citywide decision-making process, while other actors in this category enjoy a more collaborative set of relationships. Acting to mediate these tensions is the neighborhood's sole civic chair, although participants admitted that this actor's role in neighborhood decision-making is hardly neutral. In the sections that follow, these tensions, and the actors involved, will be explored.

First tier influentials. Table 4.21 shows summary statistics related to Downtown Dallas' first tier influentials, named by four or more participants to a hypothetical committee responsible for making a decision that would affect the neighborhood, and that would need to be supported by a majority of neighborhood's population.

\begin{tabular}{|c|c|c|c|c|c|c|c|}
\hline \multirow[t]{2}{*}{ Name } & \multirow{2}{*}{$\begin{array}{c}\text { Primary or Notable } \\
\text { Affiliation(s) }\end{array}$} & \multicolumn{2}{|c|}{$\begin{array}{l}\text { Decision-Making } \\
\text { Committee Votes }\end{array}$} & \multirow{2}{*}{$\begin{array}{c}\text { Mean } \\
\text { Power } \\
\text { Level } \\
(1-4)\end{array}$} & \multicolumn{2}{|c|}{$\begin{array}{c}\text { Recent Shared } \\
\text { Committee Service }\end{array}$} & \multirow{2}{*}{$\begin{array}{c}\text { Mean } \\
\text { Familiarity } \\
\text { Level } \\
(1-4)\end{array}$} \\
\hline & & \# & $\%$ & & \# & $\%$ & \\
\hline Ray Hunt & Hunt Consolidated & 21 & $54 \%$ & 3.92 & 5 & $13 \%$ & 2.54 \\
\hline Harlan Crow & Crow Holdings & 13 & $33 \%$ & 3.51 & 8 & $21 \%$ & 2.10 \\
\hline Ross Perot Jr. & Hillwood & 13 & $33 \%$ & 3.41 & 5 & $13 \%$ & 2.03 \\
\hline \multirow[t]{3}{*}{ Jody Grant } & Texas BankCap (Emeritus) & 9 & $23 \%$ & 2.90 & 4 & $10 \%$ & 2.48 \\
\hline & (Actors in This Category) & 14 & $36 \%$ & 3.44 & 6 & $14 \%$ & 2.29 \\
\hline & (Actors in All Categories) & 17 & $44 \%$ & 3.29 & 11 & $28 \%$ & 2.31 \\
\hline
\end{tabular}

Actors in this category consist of three particularly active members of Dallas' most influential families, and a financier who participants often credited with financing Downtown Dallas' revitalization following the Savings and Loan Crisis; participants considered each of these actors as part of the old guard in Dallas, and regularly made this known throughout their interviews. Compared to actors in other categories, Downtown Dallas' first tier influentials have above-average power ratings, and below-average nominations for decision-making teams, ratings of familiarity, and recent shared committee service with participants. In the following paragraphs, this study will outline participants' general thoughts on these old guard actors, and then their thoughts on category standout Ray Hunt. 
The old guard. Participants conceded that, while it is increasingly inaccurate to suggest that a small coalition of wealthy business executives, elite financiers, and civic leaders controls the priorities and politics of Dallas, a subset of the old guard's remnants remain exceptionally active in Downtown Dallas. Many of the comments about first tier influentials in Dallas' citywide decision-making structure overlap significantly with those made about first tier influentials in Downtown Dallas, which is unsurprising, given that three of the four actors listed in table 4.21 also appear in table 4.11, and the fourth (Jody Grant) was one vote shy of being included as well.

Participants were encouraged to consider whether, or to what extent, these first tier influentials had different roles in decision-making in Downtown Dallas, as compared to citywide decision-making. Participants agreed that, in Downtown Dallas as in the city as a whole, these actors utilize their access to physical-, financial-, and social capital to achieve a common, neoliberal agenda, but participants also suggested that there is a unique relationship between these actors and Downtown Dallas. Several commented that these actors, and their families, have been long-associated with large developments in Downtown Dallas, including skyscrapers and civic amenities that defined Dallas' skyline for decades. These participants also admitted that, increasingly, both the skyline itself and neighborhood surrounding it are transforming, with less and less input from the old guard, while the city council and bureaucracy is slowly transitioning away from dependence on their resources. As a result, those actors who do remain active focus their fading influence on Downtown Dallas, rather than spreading projects throughout the city. Well-summarizing many comments, one participant said that:

These men look back on their careers building Dallas, and the projects that their family names are connected to, and then they look at the new projects that they haven't been a part of. They see their works being crowded out by projects that belong the "new Dallas" that's starting to happen without them, and that doesn't sit right. Downtown Dallas is the heart of 
the city, so a lot of them are trying to get that one last, big project before they go, as a way of leaving the most visible mark on the city they can, by changing its skyline.

Category standout: Ray Hunt. Over half (54\%) of participants named billionaire

Ray Hunt to their decision-making teams, and his power score (3.92) is among the highest of all actors considered by this section. In explaining why, many participants admitted that the Hunt family has been intertwined with decision-making for decades, with several suggesting that: 'Dallas has 'first families,' like the Perots, Jones', Crows, and Bush's, but none of them have the pull of the Hunts." Describing Hunt, participants often agreed that:

Most of the "old guard" is gone, but Ray Hunt stuck around, and he's got enough land downtown and money in his pocket to keep things interesting. You won't see his names on as much these days, because he works through proxies to keep his name out of the newspaper. Hunt may be a dinosaur, but he outlasted all the others because he's smart, and he's probably going to keep pushing his old ideas for Downtown until he dies.

Participants frequently noted that Hunt prefers to keep his own name out of the public eye, and instead acts through proxies, such as citywide civic chair Alice Murray as well as formal authorities like Mike Rawlings and A.C. Gonzalez, in his efforts to develop his tremendous landholdings in Downtown Dallas into office buildings, luxury residential and retail properties, and perennial plans for urban sports arenas. Because Hunt develops primarily on land he already owns, uses a preferred development company, Woodbine Development, which is run by long-time business partner (and second tier influential) John Scovell, and works directly with aforementioned formal authorities and civic chairs to gain necessary permits, concessions, and support in final project approval by the City Council, participants conceded that he is well-equipped to sidestep the authority of Councilmember Kingston, who is ofttimes unable to meaningfully prevent Hunt's projects.

First tier influentials, in summary. Participants identified four actors that can be categorized as first tier influentials, and three among these were also identified as first tier influentials at the citywide level. At both levels, participants conjected that these actors use 
their resources and influence with civic chairs and a subset of formal authorities to forward a common vision for Downtown Dallas. Several participants conceded that the actors in this category represent what many called the "last breath" of mid-late $20^{\text {th }}$ century Dallas, and that while these actors' remain influential, their projects are not universally embraced by area formal authorities, which effectively limits what these actors are able to accomplish. About this, several participants' comments can by summarized by:

The big men all died off, retired out, or moved on; [Eugene] McDermott, [Trammell] Crow, Jack Evans, Bob Folsom - the men who built Dallas - so many just aren't around anymore. You still got (SIC) a few hanging on, but it's not like things used to be.

Second tier influentials. Table 4.22 shows summary statistics related to Downtown Dallas' second tier influentials, named by four or more participants to a hypothetical committee responsible for making a decision that would affect the neighborhood, and that would need to be supported by a majority of neighborhood's population.

Table 4.22: Downtown Dallas Second Tier Influentials

\begin{tabular}{|c|c|c|c|c|c|c|c|}
\hline \multirow[t]{2}{*}{ Name } & \multirow{2}{*}{$\begin{array}{c}\text { Primary or Notable } \\
\text { Affiliation(s) }\end{array}$} & \multicolumn{2}{|c|}{$\begin{array}{l}\text { Decision-Making } \\
\text { Committee Votes }\end{array}$} & \multirow{2}{*}{$\begin{array}{l}\text { Mean } \\
\text { Power } \\
\text { Level } \\
(1-4) \\
\end{array}$} & \multicolumn{2}{|c|}{$\begin{array}{c}\text { Recent Shared } \\
\text { Committee Service }\end{array}$} & \multirow{2}{*}{$\begin{array}{c}\text { Mean } \\
\text { Familiarity } \\
\text { Level } \\
(1-4)\end{array}$} \\
\hline & & \# & $\%$ & & $\#$ & $\%$ & \\
\hline Scott Krikorian & $\begin{array}{l}\text { Trammell Crow Co. } \\
\text { (subsidiary of CBRE) }\end{array}$ & 20 & $51 \%$ & 3.15 & 16 & $41 \%$ & 2.33 \\
\hline Jim Truitt & Forest City & 19 & $49 \%$ & 3.13 & 21 & $54 \%$ & 2.40 \\
\hline Michael Caffey & C.B. Richard Ellis (CBRE) & 18 & $46 \%$ & 3.08 & 12 & $31 \%$ & 2.53 \\
\hline $\begin{array}{l}\text { Vince } \\
\text { Ackerson }\end{array}$ & $\begin{array}{l}\text { Texas Capital Bank } \\
\text { (subsidiary of Texas BankCap) }\end{array}$ & 12 & $31 \%$ & 3.05 & 12 & $31 \%$ & 2.40 \\
\hline Jack Matthews & Matthews Southwest & 21 & $54 \%$ & 3.03 & 20 & $51 \%$ & 2.35 \\
\hline John Scovell & $\begin{array}{l}\text { Woodbine Development } \\
\text { Dallas Citizens Council }\end{array}$ & 11 & $28 \%$ & 2.85 & 16 & $41 \%$ & 2.25 \\
\hline Ted Hamilton & Hamilton Properties & 7 & $18 \%$ & 2.69 & 16 & $41 \%$ & 2.08 \\
\hline Brock Bailey & Bracewell \& Giuliani, LLP & 7 & $18 \%$ & 2.51 & 9 & $23 \%$ & 2.08 \\
\hline \multicolumn{2}{|c|}{$\begin{array}{l}\text { Mean Value (Actors in This Category) } \\
\text { Mean Value (Actors in All Categories) }\end{array}$} & $\begin{array}{l}14 \\
17\end{array}$ & $\begin{array}{l}36 \% \\
44 \%\end{array}$ & $\begin{array}{l}2.94 \\
3.29\end{array}$ & $\begin{array}{l}15 \\
11\end{array}$ & $\begin{array}{l}39 \% \\
28 \%\end{array}$ & $\begin{array}{l}2.30 \\
2.31\end{array}$ \\
\hline
\end{tabular}

Actors in this category consist of members of the developer class, including several executives within real estate development firms, one executive of a major real estate financial services provider (founded by first tier influential Jody Grant), and a senior partner in a large real estate law firm. Compared to actors in other categories, Downtown Dallas' second tier influentials received a below-average number of nominations to decision-making committees, below- 
average ratings of power and familiarity, but scored above-average on recent shared committee service with participants. In discussing the role of these actors in decision-making within Downtown Dallas, this study will outline the role of the neighborhood's developer class, particularly the role of category standout John Scovell.

Participants often said that Downtown Dallas' second tier influentials are generally uninvolved with the formation of new projects, and instead, are mobilized by first tier influentials and formal authorities for particular projects, primarily through shared membership within CBD's booster organization, Downtown Dallas Inc. Participants also admitted that that these newer developers, many of which located offices in Dallas after the Savings \& Loan Crisis, are less-likely to form enduring partnerships with one another, or with political leaders, because many are simply branch offices of national- or international firms. This is not to suggest, however, that second tier influentials are uninvolved in decision-making.

Participants frequently suggested that, once mobilized by first tier influentials and formal authorities to develop a project, that these actors exert tremendous control over the final product, as the ones primarily responsible for day-to-day project management. Participants also agreed that, although stiff opposition to a project is rare, when that happens, these actors rely on first tier influentials to collaborate with sympathetic formal authorities to gain regulatory concessions, or (if the opposition comes from Councilmember Kingston) a supportive vote from the City Council to overrule him, especially in parts of Downtown Dallas that are not in high-demand. As several put forward:

Dallas has a long history of working with the private sector, especially in Downtown, and historically, political leaders don't write Dallas' planning code - developers do. If someone in City Hall tries to stop a project that has the right backers, and those backers can't get it worked out, then you'll see someone pitch a fit about how they're going to have to "reconsider" development, and just like that, they get whatever they want out of the eight vote majority on the City Council. It's a script, and you'll see it over and over again, if you're around long enough. 
As a result, participants regularly considered these actors to be the "spiritual successors" to the men who build Dallas in the mid-to-late $20^{\text {th }}$ century, and that although their level of involvement in particularly large, high-visibility projects brings each a degree of celebrity, most resist joining any enduring coalitions; summarizing this, participants often commented along the lines of:

These new mega-builders are reshaping Dallas, and they're not asking permission from anyone to do it. They're like Trammel Crow was back in the ' 60 s and '70s, but once they finish a project, they just go home. They're not lobbying to change Dallas, and the old oligarchs don't know what to make of them.

Finally, participants repeatedly suggested that, as the recent development boom in Downtown Dallas continues to slow, these actors have been especially vocal in pressuring formal authorities for regulatory- and zoning concessions, as well as for additional public funding to complete particularly ambitious projects. Several participants agreed that:

In Downtown, most of the "easy" projects are done, so the projects now get complicated by unexpected surprises that crop up along the way - it happens with these older, abandoned buildings. The developers went in with plans, timelines, and financing, but backers pull out when plans change, and deadlines get missed. Some of these big builders are starting to go to City Hall, saying things like: "Hey, we did all this good work for you when you needed us, look at how great those are. If you want us to keep producing at that level, you need to work with us to make that happen, or we aren't going to finish and you'll be left with an eyesore that nobody can use."

Category standout: John Scovell. While only a minority of participants (28\%) nominated John Scovell to their decision-making teams, and his power rating (2.85) is among the lowest within Downtown Dallas' second tier influentials, participants often discussed Scovell's unique role in decision-making, as a director and chair for the Dallas Citizens Council, and as the CEO of his development company, co-founded with first tier influential Ray Hunt. Participants frequently referred to Scovell as either Ray Hunt's “proxy” or "gatekeeper," and proposed that this role sets him apart from other developers, while also not elevating him into the first tier influentials, because Scovell and his company most commonly develop properties with Hunt's advice- and consent, on Hunt-owned real estate, 
and on projects for which Hunt and other first tier influentials lobby formal authorities, particularly in Economic Development, to support. In describing this, participants often agreed that:

John (Scovell) is a firecracker, but he's content to do his job, make his money, and go home. He's not trying to build monuments to himself, but he'll build them for other people, because he doesn't have that thirst for immortality that you see in some of the other big names around here.

Second tier influentials, in summary. Participants identified eight individuals within Dallas' developer class as being particularly beneficial for decision-making in Downtown Dallas, and that these actors are particularly active in in pressuring formal authorities to support private development, albeit to a lesser extent than traditionally occurs in Dallas. Participants also identified one actor with an especially close tie to first tier influential Ray Hunt. Overall, participants agreed that these actors are willing to work on a wide variety of projects, beyond any particular vision for Downtown Dallas. The job of coordinating these various projects, and providing some broad guidance, falls to the only civic chair with enough nominations to be included in this study.

Civic chairs. Table 4.23 shows summary statistics related to John Crawford, the only civic chair in Downtown Dallas named by four or more participants to a hypothetical committee responsible for making a decision that would affect the neighborhood, and that would need to be supported by a majority of neighborhood's population.

Table 4.23: Downtown Dallas Civic Chairs

\begin{tabular}{|c|c|c|c|c|c|c|c|}
\hline \multirow[t]{2}{*}{ Name } & \multirow{2}{*}{$\begin{array}{l}\text { Primary or Notable } \\
\text { Affiliation(s) }\end{array}$} & \multicolumn{2}{|c|}{$\begin{array}{l}\text { Decision-Making } \\
\text { Committee Votes }\end{array}$} & \multirow{2}{*}{$\begin{array}{l}\text { Mean } \\
\text { Power } \\
\text { Level } \\
(1-4) \\
\end{array}$} & \multicolumn{2}{|c|}{$\begin{array}{c}\text { Recent Shared } \\
\text { Committee Service }\end{array}$} & \multirow{2}{*}{$\begin{array}{c}\text { Mean } \\
\text { Familiarity } \\
\text { Level } \\
(1-4)\end{array}$} \\
\hline & & $\#$ & $\%$ & & $\#$ & $\%$ & \\
\hline John Crawford & Downtown Dallas Inc. & 39 & $100 \%$ & 3.87 & 27 & $69 \%$ & 2.80 \\
\hline & Actors in This Category) & 39 & $100 \%$ & 3.87 & 27 & $69 \%$ & 2.80 \\
\hline & Actors in All Categories) & 17 & $44 \%$ & 3.29 & 11 & $28 \%$ & 2.31 \\
\hline
\end{tabular}

John Crawford, the CEO of Downtown Dallas Inc. (DDI), was nominated to serve on decision-making committees by all 39 participants with particular knowledge of 
Downtown Dallas' decision-making process making him the only unelected actor to be so frequently nominated in this neighborhood. Compared to actors in other categories, participants rated Crawford above-average on power and level of familiarity, and a majority of participants have served on a board or committee with him in the past five years, morethan double the average level of shared board or committee service. The following paragraphs will discuss Crawford's role in Downtown Dallas' decision-making process.

In their surveys and interviews, participants explained that Crawford leads Downtown Dallas Inc., a private nonprofit booster organization, which for the past halfcentury has dedicated itself to economic development and revitalization efforts in- and around Downtown Dallas ${ }^{438}$. The organization is funded through membership dues from firms whose interests generally involve the area in- and immediately surrounding Downtown, contracts with the City of Dallas ${ }^{439}$, as well as funds generated by the Downtown Improvement District, a PID wherein property owners are assessed an additional fee based on the value- and size of their property. Monies from this fee are reinvested within the district, often for "quality of life" improvements, infrastructure \& maintenance, and safety \& security initiatives $^{440}$. Participants regularly indicated that, practically speaking, DDI acts as a networking tool and facilitator for informal business transactions and development deals, and that this function continues even today, as the organization brings together high ranking private-, public-, and third-sector organizations as members, and through its board of directors ${ }^{441}$; summarizing participant comments, one emphatically noted:

Make no mistake, they (DDI) are not a nonprofit developer in the way that, say, Habitat for Humanity is a nonprofit developer. Downtown Dallas Inc. is, and always has been, a vehicle for big-time developers to get a piece of whatever public funds are out there, and to find the right people to come together for a project.

\footnotetext{
${ }^{438}$ Downtown Dallas Inc., 2015a; 2015b, p. B3

${ }^{439}$ Downtown Dallas Inc., 2015c, p. 1

${ }^{440}$ Dallas Office of Economic Development, 2015

${ }^{441}$ Downtown Dallas Inc., 2015d; 2015e
} 
Within the structure of neighborhood decision-making, DDI works with Dallas' city manager and OED to oversee- and implement Downtown Dallas 360, a master economic development- and revitalization plan that encompasses both the CBD and 14 surrounding "districts" that loosely map onto various neighborhoods surrounding the urban core. Participants concurred that DDI in general, and Crawford particularly, are able to shape development decisions by providing a less-formal space for public-private partnerships to form, and for project proposals to be developed before they officially reach the OED and City Council for support. Participant thoughts on this are well-summarized by two comments:

\footnotetext{
Look at who serves on DDI's board: you've got Economic Development, developers, law firms, mega real-estate, and city councilmembers - it's all politics and money. Deals that come out of that group (DDI) are approved before they're ever approved. If Crawford is willing to publicly support something, then all the people who need to agree to the idea are probably already on board, in one way or another, or they've at least already weighed in.

(John) Crawford has worked with developers and with City Hall for years - he's got the blessing of the "old guard" around town. He knows who to talk to, how to get things done; he knows when to lean on City Hall to bring more TIF money, and when a project isn't going anywhere.
}

In selecting Crawford for their decision-making teams, participants regularly noted that he has strong support from multiple stakeholders, including Dallas' old guard, many of its newer, more progressive leaders, area businesses, and much of the general public. However, participants also acknowledged that the organization's support is not universal, especially among residents who feel that DDI is only interested in new development, rather than in addressing the complaints and concerns of existing residents. This dissatisfaction, however, has not resulted in the formation of strong resident advocacy groups, and existing neighborhood associations are frequently supported by DDI, so their leaders are loathe to openly criticize the organization. In their description of the opposition to the tremendous authority of Downtown Dallas Inc., a vocal subset of participants said that: 
Downtown Dallas Inc. isn't in the business of development - it's in the business of the politics of development. John (Crawford) knows how to match investors with developers, and that gets you the form of a neighborhood, but not the substance. What gets built where has nothing to do with what residents want, or what the neighborhood needs if it's ever going to sustain itself after the building boom dies off. We have restaurants and museums and parks for block after block, but no grocery stores.

The residents of Downtown Dallas don't have the numbers to really coalesce around an activist neighborhood organization, or someone like Pam Conley in North Oak Cliff. The associations they have collect part of the money from the PID that supports DDI, but they use that on social events, not on lobbying down at City Hall.

Civic chairs, in summary. Participants summarized the role of Crawford and his organization as a unifying, networking organization that combines public- and private-sector ideas, as well as physical-, social-, and financial capital in service of a particular revitalization strategy for Downtown Dallas, and as a result, Crawford is a nexus of informal influence in Downtown Dallas' decision-making process, and that the approval of his organization, and its stakeholders, have been crucial the success of many projects in the area; as one participant explained it:

We have some amazing public-private partnerships in Downtown, and from those, we get parks, museums, and culture cornerstones that make people want to spend a little more time down here. We get people moving back to the inner city, where this place used to be $70 \%$ vacant, whereas, used to be, nobody came to Downtown unless they worked here. If some people had their way, that's all this area would ever be, but John (Crawford) and his team have pulled together something special down here.

Decision-makers in Downtown Dallas, in summary. This study asked participants knowledgeable about decision-making in Downtown Dallas to identifyand describe actors who get involved in making neighborhood-wide decisions, and to nominate 10 people to form a committee that would be responsible for making a decision that would affect the city as a whole. A total of 39 participants made 390 nominations, and out of those, 309 were cast for the 18 actors appearing on tables throughout this section.

Participant-identified actors represented four out of five broad categories used throughout this study's report of its qualitative findings, and participants identified several 
points of, respectively, collaboration and conflict among these actors. Throughout

participant interviews, a common thread was that in Downtown Dallas, much like in North

Oak Cliff and in the city as a whole, leaders can be divided into an old guard and a new guard, each with its own ideas for the future of the neighborhood; participant thoughts on this are well-summarized by the following:

Downtown Dallas is the jewel in the city's crown, and everyone who has a part in leading Dallas wants that area to be healthy again, and to thrive. Some people think that a healthy downtown looks like convention centers, hotels, and stadiums intermixed with high-end residential and retail, and others see a more inclusive Downtown that has a place for the whole spectrum of people - the rich, the poor, the middle-class, and everyone from millennials to the elderly.

\section{Qualitative Data Summary}

The previous reputational study of Dallas described three "classes" of leaders within the city's decision-making structure, and each class was comprised almost exclusively of business executives and wealthy elites ${ }^{442}$. To determine whether (or to what extent) the previous reputational analysis' results remain valid, and to expand on its findings, this study's 79 participants completed detailed surveys and interviews regarding the nature of decisionmaking in Dallas as a whole, as well as in two focus neighborhoods: North Oak Cliff and Downtown Dallas. Each participant provided information on decision-makers within Dallas as a whole, while 40 of these provided information on decision-makers in North Oak Cliff, and 39 provided similar information for Downtown Dallas.

Decision-makers were categorized thematically, and tables throughout this section reported data for those decision-makers who were nominated by at least $10 \%$ of participants knowledgeable about each geographic area of interest, including names, primary organizational affiliations, power ratings, recent shared board and committee service with participants, and participant ratings of familiarity. In addition to the five thematic categories

\footnotetext{
${ }^{442}$ Thometz, 1963, pp. 47-49
} 
of decision-makers, participants identified a theme of conflict between Dallas' development-

focused old guard and, and more progressive, often younger (or at least, less-experienced)

leaders. This conflict (to be revisited in Chapter 5) manifests uniquely in Dallas as a whole, as well as within both North Oak Cliff and Downtown Dallas, but is nonetheless a consistent source of tension.

\section{Chapter Summary}

This chapter aimed to report data collected using the methods introduced in Chapter 3 , in order to address this study's research questions and hypotheses. In the previous sections, this study reported quantitative data regarding select socioeconomic changes from 1980 to 2010, first for Dallas as a whole, then for the study's two focus neighborhoods:

North Oak Cliff and Downtown Dallas. Then, it detailed participant responses to surveys and interviews regarding decision-making in Dallas as a whole, North Oak Cliff, and Downtown Dallas.

ix Author's note: this study's operational definition of creative class employment is guided by Richard Florida's description, which includes careers in: "design, education, arts, music and entertainment, whose economic function is to create new ideas, new technology and/or creative content" (2002, p. 8), and this category is comprised of the following industries: information; finance and insurance, and real estate and rental and leasing; professional, scientific, and management, and administrative and waste management services; educational services, and health care and social assistance; and arts, entertainment, and recreation, and accommodation and food services.

x Author's note: this study's operationalization of "blue collar" is defined as class of employment wherein tasks usually involve manual labor, and often require work-specific clothing (dictionary.com, 2016), and is comprised of the following industries: agriculture, forestry, fishing, hunting, and mining; construction; manufacturing; transportation \& warehousing, and utilities.

xi Author's note: this study's operationalization of "service sector" is comprised of the following industries: wholesale trade; retail trade; and

"other services, except public administration."

xii Author's note: census data report public administration as an industry code unto itself, so it is reported by this study in order to ensure that the employment percentages across all industry categories add up to $100 \%$. 


\section{CHAPTER V}

\section{QUANTATIVE ANALYSIS AND DISCUSSION}

The purpose of this chapter is to analyze and evaluate the quantitative data reported in Chapter 4, in order to address this study's first three research questions - those related to the evolving context surrounding Dallas, as well as this study's two focus neighborhoods: North Oak Cliff and Downtown Dallas. In the chapter sections that follow, this study will first restate the relevant subset of its research questions and hypotheses. Next, it will review and synthesize quantitative data first presented in Chapter 4, before evaluating them with respect to urban literature regarding expected demographic- and economic shifts found in post-Fordist cities, as well as with respect to the effects of these shifts on creating a new normal in Dallas, compared to the old normals studied by Elkin and Thometz. Finally, this study will revisit limitations introduced in Chapter 3, before introducing additional limitations related specifically to these hypotheses.

\section{First Research Question and Context Hypotheses Revisited}

The purpose of this section is to outline the research questions that this study attempts to address, as well as its series of hypotheses to be tested. First, it will list the research questions that guide this study, and then, it will outline the hypotheses that this study's data will be used to evaluate.

\section{First Research Question Revisited}

As previous chapters have noted, this study aims to answer three primary research questions, but of particular concern to this chapter is the first of these: how have Dallas' 
demographics and economy evolved in the decades since the city was studied by previous urban scholars?

\section{Context Hypotheses Revisited}

In order to guide its attempts at addressing its first research question, this study forwards three (of six) primary hypotheses, relate to the changing socioeconomic context of Dallas as a whole, as well as the neighborhoods of North Oak Cliff and Downtown Dallas; these hypotheses are as-follows:

Hypothesis 1. First, and consistent with expectations of modern, economicallyprosperous cities in the globalized, post-Fordist paradigm and the chocolate cities, vanilla suburbs model, in the decades since the Elkin \& Thometz studies, Dallas' citywide socioeconomic context has changed in four primary ways:

- People identifying as "white alone" represent a smaller percentage of the population in 2010 (the most recent decennial census) than they did 1980 (the census immediately prior to the Elkin study).

- A smaller percentage of Dallas' workforce is employed in blue collar fields in 2010 than in 1980.

- A larger percentage of Dallas' workforce is employed in creative class fields in 2010 than in 1980.

- Dallas, as a whole, shows signs of greater economic polarization in 2010 than in 1980.

Hypothesis 2. Second, and consistent with expectations of literature surrounding gentrification of urban neighborhoods and the new donut model, within North Oak Cliff, recent urban redevelopment projects and neighborhood gentrification are associated with four primary changes in the neighborhood's respective socioeconomic context:

- People identifying as "white alone" represent a larger percentage of the neighborhood's population in 2010 than they did in 1980. 
- A smaller percentage of the neighborhood's workforce is employed in blue collar fields in 2010 than in 1980.

- A larger percentage of the neighborhood's workforce is employed in creative class fields in 2010 than in 1980.

- The neighborhood shows signs of greater economic polarization in 2010 than in 1980 .

Hypothesis 3. Third, and consistent with expectations of literature surrounding gentrification of urban neighborhoods and the new donut model, within Downtown Dallas, recent urban redevelopment projects and neighborhood gentrification are associated with four primary changes in the neighborhood's respective socioeconomic context:

- People identifying as "white alone" represent a larger percentage of the neighborhood's population in 2010 than they did in 1980.

- A smaller percentage of the neighborhood's workforce is employed in blue collar fields in 2010 than in 1980.

- A larger percentage of the neighborhood's workforce is employed in creative class fields in 2010 than in 1980.

- The neighborhood shows signs of greater economic polarization in 2010 than in 1980.

\section{Evaluation of Hypotheses}

The purpose of this section is to evaluate this study's first three research hypotheses. In the sections that follow, this study will first evaluate those hypotheses, which (as noted above) are related to the changing social- and economic contexts within Dallas as a whole, North Oak Cliff, and Downtown Dallas.

\section{Evaluation of Hypothesis 1}

The following paragraphs will utilize quantitative data first presented in Chapter 4 data in order to evaluate Hypothesis 1, regarding the socioeconomic profile of Dallas as an economically-prosperous city in the post-Fordist paradigm, and changes in that profile since 1980. In evaluating this hypotheses, this study will first evaluate the assumption that Dallas is 
indeed an economically-prosperous city. Then, this study will evaluate whether, in keeping with the chocolate cities, vanilla suburbs model, Dallas proper is noticeably "less white" than its surrounding suburbs, by comparing data from Dallas as a whole to data representing the suburban components of Dallas' surrounding MSA. Third, this study will concurrently evaluate whether Dallas' workers are less likely to be employed in blue collar fields in 2010 than they were in 1980, and whether those workers are more likely to be employed in creative class fields in 2010 than they were in 1980. Fourth, this study will evaluate whether Dallas' residents are, on the whole, more economically polarized in 2010 than Dallas' residents were in 1980. Finally, this study will evaluate these components holistically, to make a determination whether evidence supports (or fails to support) Hypothesis 1.

Evaluation of the assumption of Dallas as an economically-prosperous city. In evaluating whether Dallas could be considered an "economically prosperous" city, this study aims to define that term in a measurable way, supported by some subset of extant literature. To that end, a basic literature search for "economic prosperity" in scholarly publications resulted in roughly 141,000 scholarly articles ${ }^{443}$, and uncovered various approaches to measuring this concept, including measuring concepts as esoteric as light pollution ${ }^{444}$, degrees of religious freedom ${ }^{445}$, and birthplace diversity ${ }^{446}$. This study is not intended to be an exhaustive interrogation of the various facets of economic prosperity, so a narrower conceptualization is required, even if this narrower approach limits the study's findings.

To develop this narrow conceptualization, this study begins by defining the term "prosperity" as "the condition of being successful or thriving ${ }^{447}$." Expanding on the latter

\footnotetext{
${ }^{443}$ Google Scholar, 2016

444 cf. Henderson, Storeygard, \& Weil, 2011

445 cf. Alon \& Chase, 2005

${ }^{446} \mathrm{cf}$. Alesina, Harnoss, \& Rapoport, 2016

${ }^{447}$ merriam-webster.com, 2016a
} 
part of this definition yields that "to thrive" is defined in terms of successful development or growth $^{448}$. Thus, a useful (and measurable) alternative to measuring the broad concept of economic prosperity is to measure economic growth. Although competing measurement tools for analyzing economic growth exist, review of a variety of these methods suggested that, within the data already collected for this study, both population growth and unemployment rates are reliable measures of economic growth; more specifically, population growth is positively correlated with economic growth, and unemployment rate is negatively correlated with economic growth ${ }^{449}$. In operationalizing economic prosperity in terms of economic growth, this study is now able to test its assumptions about Dallas as an economically prosperous city, using data regarding citywide population totals and unemployment rates, which are restated from Chapter 4 in table 5.01.

Table 5.01: Citywide Population and Unemployment Rates, 1980 - 2010
\begin{tabular}{|l|l|l|l|l|}
\hline \multicolumn{1}{|c|}{ Year } & \multicolumn{1}{|c|}{$\mathbf{1 9 9 0}$} & \multicolumn{1}{c|}{$\mathbf{2 0 0 0}$} & \multicolumn{1}{|c|}{$\mathbf{2 0 1 0}$} \\
\hline Population & 904,078 & $1,006,877$ & $1,188,580$ & $1,197,816$ \\
\hline Unemployment & $7.4 \%$ & $12.2 \%$ & $4.3 \%$ & $4.6 \%$ \\
\hline
\end{tabular}

Looking first at population growth as a positive correlate of economic growth, a growing economy requires a growing population to increase both the number of available workers and the number of available customers ${ }^{450}$. Further, given the (relative) mobility of labor in the United States, migration patterns follow growth opportunities ${ }^{451}$. Put into simpler terms, growing economies require growing pools of workers and consumers, and worker-consumers move to growing economies where they can (presumably) find work. This in mind, table 5.01 shows, the city's population grew by nearly one-third from 1980 to 2010, though it should be noted that the rate of that growth peaked between 1990 and 2000 . Although a thorough interrogation of the reasons for this decline in growth rates from 2000

448 merriam-webster.com, 2016b

${ }^{449}$ Berry, 2014, pp. 2-3; Glaeser, Scheinkman, \& Shliefer, 1995, pp. 127-129; Jones, 2002, pp. 224-225; Skidelsky, 2009, pp. 121-126

${ }^{450}$ Berry, 2014, p. 1; Gamble. 2014, pp. 82-88

${ }^{451}$ Glaeser, Scheinkman, \& Shliefer, 1995, p. 127 
to 2010 is beyond the scope of this study, it is reasonable to suggest that causes may include the pressures of the Great Recession leading to less economic opportunity and an increased aversion to the risks of relocation among would-be residents, as well as increased competition for residents from Dallas' affluent, northern suburbs. Nonetheless, the unbroken, positive growth of Dallas' population suggests that the city's economy has grown over the period of 1980 to 2010.

In considering the relationship between unemployment and economic growth, cities with higher unemployment rates can be viewed as having a labor force that lacks (for whatever reason) the necessary training to be appealing to productive businesses in a given economic period ${ }^{452}$. Thus, a growing economy needs more than simply “enough" workers; instead, a growing economy needs enough adequately-trained workers. The relationship unemployment rates and Gross Domestic Product are connected by Okun’s Law, which suggests that a one-percentage point change in unemployment is negatively correlated with a (roughly) three-percentage point change in $\mathrm{GDP}^{453}$. While this ratio has historically proven stable for most Western economies, since the Great Recession (and its “jobless recovery”), some scholars have begun to question the specific numbers, while continuing to support the overall presence of a negative correlation between unemployment rates and economic growth $^{454}$. This relationship in mind, there are three critical trends to be found in Dallas' unemployment data. First, there are two periods - 1980 to 1990, and 2000 to 2010 - when unemployment grew from one census to the next, suggesting two downturns in the city's economic growth. These data fit with the economic history of the city, and bookend the two economic downturns related to, respectively, the combined S\&L Crisis and oil bust

\footnotetext{
452 Glaeser, Scheinkman, \& Shliefer, 1995, p. 131

453 Lee, 2000, p. 331

${ }^{454}$ cf. Ball, Leigh, \& Loungani, 2013; Cazes et al., 2011; Gordon, 2011; Meyer \& Tasci, 2012
} 
throughout the 1980s, as well as the Great Recession in the 2000s. Overall, though, it is important to note that Dallas' unemployment rate has declined from its peak in 1990, and in 2010 , is only $62.1 \%$ of what it was in 1980 . Therefore, it is reasonable to suggest that, based on Dallas' unemployment data (and setting aside economic downturns), the city's economy has grown from 1980 to 2010.

Certainly, these findings are limited, and in many ways they fail to adequately capture the many factors related to Dallas' economic growth. Nonetheless, when they are combined with, for example, the city's high concentration of headquarters' for Fortune 500 companies, its centralized location with respect to major highways and rail lines, its large, international airport, and the presence of municipal-, county-, and state incentives for development and business relocation to Dallas, a strong argument can be made in support of the overall assumption that Dallas is economically prosperous within the post-Fordist paradigm ${ }^{455}$.

Evaluation of Dallas as "less white." To evaluate whether Dallas as a whole has become "less white" between 1980 and 2010, this study collected data related to the city's racial profile for those census years; first presented in Chapter 4, these data are restated in table 5.02 .

Table 5.02: Citywide Population and Racial and Hispanic or Latino Status, 1980 - 2010

\begin{tabular}{|l|c|c|c|c|}
\hline & $\mathbf{1 9 8 0}$ & $\mathbf{1 9 9 0}$ & $\mathbf{2 0 0 0}$ & $\mathbf{2 0 1 0}$ \\
\hline Population & 904,078 & $1,006,877$ & $1,188,580$ & $1,197,816$ \\
\hline White Alone & $61.4 \%$ & $55.3 \%$ & $50.8 \%$ & $50.7 \%$ \\
\hline Nonwhite & $38.6 \%$ & $44.7 \%$ & $49.2 \%$ & $49.3 \%$ \\
\hline Hispanic or Latino (Any Race) & $12.2 \%$ & $20.9 \%$ & $35.6 \%$ & $42.4 \%$ \\
\hline
\end{tabular}

These data suggest that, even as Dallas' overall population has grown between 1980 and 2010, people in Dallas identifying as "white alone" have decreased as a percentage of the population at each census, with the sharpest declines occurring between 1980 and 1990. Returning to conceptualizations of race and urban geography, these data are consistent with

455 Bruns \& Rasmussen, 2016; Dallas Business Journal, 2015; Dallas Convention \& Visitors Bureau, 2015; Dallas Economic Development, 2016; Halkais, 2014 
the chocolate cities, vanilla suburbs model, which suggests that throughout the mid-late $29^{\text {th }}$ century, comparatively affluent whites abandoned central cities in favor of bedroom communities around the urban periphery, leading to majority-minority ("chocolate") cities surrounded by majority-white ("vanilla") suburbs. With respect to Dallas, although people identifying as Black or African-American make up the largest component of the city's nonwhite population, the most notable growth has been among Dallas' Hispanic and Latino population, which has more-than tripled from 1980 to 2010 - a growth rate that dwarfs those of any other racial- or cultural identifier. Indeed, when considering the overlap between this cultural identifier and racial identifiers, Dallas becomes majority-minority.

Although it is beyond the scope of this study to exhaustively study the causes of this growth, it is reasonable to suggest that a number of causes could explain (at least) some subset of this. These reasons include Dallas' location along major highway routes to the Mexican border, its relative proximity to the international border, the relatively low cost of housing - especially in the city's southern neighborhoods, its economic prosperity, and its proclivity for construction projects; in short, Dallas' economic prosperity drives demand for low-wage, often unskilled workers, its geography places it squarely in the migration path of these workers, and a portion of its housing is affordable enough to house them (examples of poor conditions notwithstanding).

While Dallas itself could be considered a "chocolate city," at least in the spirit of the term, can its suburbs be accurately considered "vanilla," for purposes of the model? To address this, data presented in table 5.03 show the relative percentages of the populations of 
Dallas and the suburban counties ${ }^{456}$ in the remainder of its MSA ${ }^{457}$ at the 2010 census $^{458}$.

Table 5.03: Race and Hispanic or Latino Status for Dallas and Surrounding Suburban MSA Counties, 2010

\begin{tabular}{|l|c|c|}
\hline & Dallas & Suburban MSA Counties \\
\hline Population & $1,197,816$ & $4,003,634$ \\
\hline White Alone & $50.7 \%$ & $73.1 \%$ \\
\hline Nonwhite & $49.3 \%$ & $26.9 \%$ \\
\hline Hispanic or Latino (Any Race) & $42.4 \%$ & $21.1 \%$ \\
\hline
\end{tabular}

Although these data are limited, they nonetheless suggest that the suburban counties in Dallas' MSA are indeed consistent with the expectations of the chocolate cities, vanilla suburbs model. Compared to its suburbs, people in Dallas do not identify as "white alone" at nearly twice the rate of people who live in the city's surrounding suburbs. In addition, over twice the percentage of Dallasites identify as Hispanic or Latino than residents of Dallas' surrounding suburban counties.

Certainly, the data used throughout this discussion suffer from a number of flaws, which will be expanded upon later in this study. Nonetheless, based on data presented in figures 5.02 and 5.03, this study supports its assertion that Dallas has become "less white" in 2010 than it was in 1980. Further, this study supports its assertion that the chocolate cities, vanilla suburbs model remains a valid conceptualization of the racial- and ethnic polarization in Dallas and its suburban counties.

\section{Evaluation of Dallas' workforce as less blue collar and more creative class.}

Recall that this study hypothesized that since 1980, Dallas' workforce has shifted to include a greater percentage of employees in creative class fields, as well as a smaller percentage of employees in blue collar fields - shifts that are basically consistent with what would be expected of the workforce of a thriving, post-Fordist economy.

\footnotetext{
${ }^{456}$ Author's note: Tarrant County was removed from the MSA, because it contains two large central cities: Arlington and Fort Worth. Therefore, this study only includes aggregated data from Collin, Delta, Denton, Ellis, Hunt, Johnson, Kaufman, Parker, Rockwall, and Wise counties.

457 United States Census Bureau, 2010a

458 Author's note: data are unavailable for previous censuses, due to changes in both census definitions for urban areas and changes in delineation (even when definitions remained consistent).
} 
To review how this study defines these terms, recall that the operational definition of creative class employment includes careers in: "design, education, arts, music and entertainment, whose economic function is to create new ideas, new technology and/or creative content" ${ }^{459}$; examples include careers in the FIRE sectors, as well as those in education and fine arts. Additionally, this study's operationalization of blue collar employment includes fields wherein tasks usually involve manual labor, and often require work-specific clothing ${ }^{460}$; examples include manufacturing and construction. Third, this study operationally defines service sector employment as a combination of the census categories of wholesale trade, retail trade, and "other services, except public administration." Finally, and primarily in order to ensure that category data add up to $100 \%$, this study also reports employment in public administration fields, which are reported as separate industry codes, and primarily include careers in government positions.

These operational definitions in mind, to evaluate whether the hypothesized workforce transition from employment in blue collar fields to creative class alternatives has occurred, this section revisits data related to employment by industry. There data were first introduced in Chapter 4, and are restated in table 5.04. As a reminder, data for 1980 and 1990 are based on Dallas' statistical area, while data for 2000 and 2010 come from census records based only on Dallas itself.

Table 5.04: Citywide Employment Percentages by Industry Cluster

\begin{tabular}{|l|c|c|c|c|}
\hline & $\mathbf{1 9 8 0}$ (Est.) & $\mathbf{1 9 9 0}$ (Est.) & $\mathbf{2 0 0 0}$ & $\mathbf{2 0 1 0}$ \\
\hline Creative Class & $36.6 \%$ & $53.2 \%$ & $51.6 \%$ & $52.7 \%$ \\
\hline Blue Collar & $34.0 \%$ & $26.1 \%$ & $25.7 \%$ & $25.7 \%$ \\
\hline Service Sector & $27.4 \%$ & $18.5 \%$ & $20.6 \%$ & $19.5 \%$ \\
\hline Public Administration & $2.0 \%$ & $2.2 \%$ & $2.1 \%$ & $2.1 \%$ \\
\hline
\end{tabular}

As Chapter 4 notes, data suggest that the largest transition in Dallas' employment profile occurs between 1980 and 1990, when the percentage of working Dallasites employed in

${ }^{459}$ Florida, 2002, p. 8

460 dictionary.com, 2016 
creative class fields grew by over 16 percentage points, with a similar percentage point loss spread over the service sector and blue collar clusters. Since 1990, the relative composition of Dallas' citywide employment in creative class-, blue collar-, service sector-, and public administration fields has held relatively steady, suggesting that the city may have reached a new equilibrium point with respect to the broad types of work that employees perform.

This new equilibrium point also coincides with the time in which Dallas' unemployment rate hit its highest point over the measurement period $(12.2 \%)$, as well as the height of economic tumult brought on by both the Savings \& Loan Crisis and oil bust. Prior to these crises, recall that Dallas was known as a regional manufacturing hub ${ }^{461}$, supplemented by a growing number of firms in real estate, banking, and finance ${ }^{462}$. If the data for 1980 and 1990 are indeed representative of Dallas itself (and not just the most representative of available data), then it would appear that, even though the CBD's brandnew skyscrapers saw unprecedented vacancy rates throughout the early 1990s, it was Dallas' blue collar firms that suffered the most, with employment losses between 1980 and 1990 that have not been seen since.

These data contain a number of unfortunate limitations (revisited later in this chapter); nonetheless, based on data in table 5.04, this study supports its hypothesis that, when comparing citywide employment data from 2010 to 1980, Dallas' employees are more likely to be employed in creative class fields, and less likely to be employed in blue collar fields. Still, it is critical to note that blue collar employment continues to make up a significant portion of the city's employment profile, and later sections of this chapter will suggest that there is significant intra-city variance with respect to where workers are employed.

${ }^{461}$ McKnight, 1956, pp. 167-169; 1957, pp. 39-43; Miller, 2013, p. 17; Payne, 1994, p. 274

${ }^{462}$ Thometz, 1963, pp. 10-11 
Evaluation of Dallas as more economically polarized. In evaluating whether Dallas is more economically polarized in 2010 than it was in 1980, first recall that this study operationally defines "greater economic polarization" as the presence of both higher median household income (MHI) and higher poverty rates. Chapter 4 presented data regarding both of these variables; these data are replicated in table 5.05. As a reminder, MHI is expressed in 2015 inflation-adjusted dollars, to better facilitate comparison among years.

Table 5.05: Citywide MHI and Poverty Rate, 1980 - 2010
\begin{tabular}{|l|c|c|c|c|}
\hline & $\mathbf{1 9 8 0}$ & $\mathbf{1 9 9 0}$ & $\mathbf{2 0 0 0}$ & $\mathbf{2 0 1 0}$ \\
\hline MHI (in 2015 inflation-adjusted dollars) & $\$ 79,611$ & $\$ 50,461$ & $\$ 52,146$ & $\$ 45,616$ \\
\hline Poverty Rate & $18.0 \%$ & $18.0 \%$ & $17.8 \%$ & $22.3 \%$ \\
\hline
\end{tabular}

For this study, greater economic polarization is operationalized in terms of both MHI and poverty rates; if both are higher in 2010 than in 1980, then the data would support greater economic polarization. Data suggest that, while MHI effectively decreased by over $40 \%$ between 1980 and 2010, the city's poverty rate increased by just under $24 \%$ over that same period.

Taking a long-term view of Dallas' economic profile, note that MHI seems to follow the health of the overall economy - recessions in the 1980s and early 2000s are accompanied by decreases in MHI, while the census betwixt these downturns suggests a (small) increase, as the economy started to recover. Additional data points would be needed to verify this speculation, but it fits with archival media accounts suggesting that, as early as the mid1970s, affluent Dallasites were migrating into the city's suburbs, following corporate migrations to expansive campuses in the city's suburbs, especially those in adjacent Collin County $^{463}$. This growth was acknowledged by Dallas' leaders as early as 1986, and was a primary motivator for the city's revised 1993 Thoroughfare Plan ${ }^{464}$, the construction of the

463 Allison, 2014; Kim, 2012; Schneider, 1992, pp. 33-37

${ }^{464}$ City of Dallas Department of Transportation, 1993, pp. 1-12 
DART light rail network, which runs along the city's major north-south highway, and major expansions to the regional interstate highway network ${ }^{465}$.

Additionally, data in table 5.05 suggest that Dallas' poverty rate remained stable from 1980 until 2000, upticking in 2010 following the Great Recession. Recall that Dallas' regional economy remained strong throughout the recession, which suggests that the increase in poverty rate, coupled with the 2010 losses in MHI that more-than erased gains seen at the 2000 census, it is reasonable to speculate that many high-income positions have moved beyond the city limits, while the positions that remain are filled by workers who utilize the aforementioned expansions in the regional transportation network to commute to urban jobs from suburban residences. For residents of Dallas with low incomes, a half-hour (or longer) drive to work may be unrealistic, if not impossible, so if these workers are limited to employment opportunities within the city (or even within the subset of Dallas served by mass transit). It is, therefore, likely that the trending decrease in $\mathrm{MHI}$ and recent increase in poverty rate both point to the same conclusion: economic opportunities in the growing regional economy may be increasingly out of reach for many Dallasites - a topic which will be revisited later in this chapter.

As has been noted throughout this chapter, data presented are far-from perfect. Flaws notwithstanding, the data in Table 5.05 fail to support the partial hypothesis that Dallas' economy has grown increasingly polarized between 1980 and 2010. Citywide, MHI has fallen significantly from 1980 levels, while unemployment has largely remained static. Finally, this study speculates that, while Dallas overall is not more economically polarized in 2010 than in 1980, it may be that the Dallas region is more polarized; people with low- and moderate incomes are concentrating within Dallas itself, while wealthier people are

465 Morris, 1997, pp. 3-8. 
distributed among the city's surrounding suburbs and exurbs - certainly, this trend can be seen in central cities across the nation, so it would be hardly surprising to see it in Dallas as well. Additionally, as future sections will suggest, data and trends at the citywide level mask some degree of neighborhood-level variance.

\section{Evaluation of Hypothesis 2}

The following paragraphs will utilize quantitative data first presented in Chapter 4 data in order to evaluate Hypothesis 2, regarding the socioeconomic profile of North Oak Cliff, a gentrifying central urban neighborhood characterized primarily by majority-nonwhite residents with low- to moderate incomes, and historically associated with decades of disinvestment, decline, and disconnection from the structures of citywide governance. In evaluating this hypotheses, this study will first evaluate whether, in keeping with the new donut model of urban demographic composition, North Oak Cliff is "more white" than it was in 1980. Then, this study will concurrently evaluate whether neighborhood workers are less likely to be employed in blue collar fields in 2010 than they were in 1980, and whether those workers are instead more likely to be employed in creative class fields. Third, this study will evaluate whether North Oak Cliff's residents are more economically polarized in 2010 than neighborhood residents were in 1980. Finally, this study will evaluate these components holistically, to make a determination whether (or to what extent) evidence supports this hypothesis.

Evaluation of North Oak Cliff as "more white." To evaluate whether North Oak Cliff has become "more white" between 1980 and 2010, this study collected data related to the neighborhood's racial profile for those census years; these data are restated in table 5.06.

\begin{tabular}{|c|c|c|c|c|}
\hline & 1980 & 1990 & 2000 & 2010 \\
\hline Population & 17,713 & 17,544 & 19,617 & 15,055 \\
\hline White Alone & $58.8 \%$ & $46.9 \%$ & $49.3 \%$ & $61.4 \%$ \\
\hline Nonwhite & $41.2 \%$ & $53.1 \%$ & $50.7 \%$ & $38.6 \%$ \\
\hline Hispanic or Latino (Any Race) & $31.2 \%$ & $48.8 \%$ & $65.0 \%$ & $59.9 \%$ \\
\hline
\end{tabular}


These data suggest that, while the neighborhood's population rapidly declined following the Great Recession, which itself was preceded by a significant population jump, the population of people identifying as "white alone" has been increasing from its 1990 nadir to a clear majority in 2010. To better understand what happened, table 5.07 shows the demographic numbers (rather than percentages) for North Oak Cliff.

Table 5.07: North Oak Cliff Population and Racial and Hispanic or Latino Status, Counts, 1980 - 2010

\begin{tabular}{|l|c|c|c|c|}
\hline & $\mathbf{1 9 8 0}$ & $\mathbf{1 9 9 0}$ & $\mathbf{2 0 0 0}$ & $\mathbf{2 0 1 0}$ \\
\hline Population & 17,713 & 17,544 & 19,617 & 15,055 \\
\hline White Alone & 10,408 & 8,229 & 9,679 & 9,239 \\
\hline Black or African American & 3,119 & 2,668 & 1,544 & 1,412 \\
\hline American Indian or Alaskan Native & 108 & 177 & 162 & 197 \\
\hline Asian American or Native Hawaiian & 173 & 82 & 71 & 149 \\
\hline Other or Mixed-Race & 3,905 & 6,388 & 8,161 & 4,058 \\
\hline Hispanic or Latino (Any Race) & 5,530 & 8,557 & 12,755 & 9,025 \\
\hline
\end{tabular}

These data suggest that much of the neighborhood's $2000-2010$ population loss is in is community of people who identify as "other or mixed-race," as well as in the neighborhood's community of people who identify as Hispanic or Latino; as a reminder, this latter category is independent of racial identification, so it is possible that there is overlap between these two groups. Nonetheless, these data suggest that, rather than there being a surge of people identifying as "white alone," the change in North Oak Cliffs demographic profile is best explained by population losses across several minority groups - losses also seen in the overall population figures for the neighborhood. Within the context of citywide growth in people identifying as nonwhite as a percentage of the population, these data suggest that there may be a migration of some minority groups away from North Oak Cliff.

Certainly, the chocolate cities, vanilla suburbs narrative describes the declining percentage (and counts) of people identifying as "white alone" in North Oak Cliff; this is also reflected in personal accounts of the neighborhood prior to $2000^{466}$. From the 2000 census forward, however, data in tables 5.06 and 5.07 support this study's assertion that a greater percentage 
of North Oak Cliff's population reports as "white alone" in 2010 than in 1980, consistent with the expectations of the new donut model. Later in this chapter, a similar analysis of Downtown Dallas' demographic trends will allow this study to evaluate whether this neighborhood is an outlier, or whether it is suggestive of a larger trend within Dallas.

\section{Evaluation of North Oak Cliff's workforce as less blue collar and more}

creative class. In evaluating whether North Oak Cliffs workforce (like that of Dallas as a whole) has shifted to include a greater percentage of employees in creative class fields, as well as a smaller percentage of employees in blue collar fields, Chapter 4 first introduced data regarding employment by industry cluster for North Oak Cliff. As a note, recall that these data, reproduced alongside citywide estimates in table 5.08, are limited to years 2000 and 2010.

Table 5.08: Citywide and North Oak Cliff Employment Percentages by Industry Cluster

\begin{tabular}{|c|c|c|c|c|c|c|c|c|}
\hline & \multicolumn{2}{|c|}{1980 (Est.) } & \multicolumn{2}{|c|}{1990 (Est.) } & \multicolumn{2}{|c|}{2000} & \multicolumn{2}{|c|}{2010} \\
\hline & Dallas & N. Oak Cliff & Dallas & N. Oak Cliff & Dallas & N. Oak Cliff & Dallas & N. Oak Cliff \\
\hline Creative Class & $36.6 \%$ & n.d. & $53.2 \%$ & n.d. & $51.6 \%$ & $44.7 \%$ & $52.7 \%$ & $65.3 \%$ \\
\hline Blue Collar & $34.0 \%$ & n.d. & $26.1 \%$ & n.d. & $25.7 \%$ & $34.9 \%$ & $25.7 \%$ & $14.3 \%$ \\
\hline Service Sector & $27.4 \%$ & n.d. & $18.5 \%$ & n.d. & $20.6 \%$ & $18.3 \%$ & $19.5 \%$ & $17.3 \%$ \\
\hline Public Administration & $2.0 \%$ & n.d. & $2.2 \%$ & n.d. & $2.1 \%$ & $2.1 \%$ & $2.1 \%$ & $1.8 \%$ \\
\hline
\end{tabular}

Between 2000 and 2010 the percentage of North Oak Cliff's resident workforce employed in creative class fields has grown at a much more rapid pace than that for Dallas as a whole, while the percentage of the neighborhood's workforce employed in blue collar fields has shrunk by a similarly extreme degree. As with Dallas as a whole, changes in the neighborhood's workforce employed in service sector and public administration fields are comparatively slight, suggesting greater stability in these fields.

Within the greater context of neighborhood depopulation between 2000 and 2010, it is reasonable to speculate about the possibility that blue collar employment is abandoning the workers of North Oak Cliff, and that employees of these firms are leaving as well, hoping to find work elsewhere. Alternatively, it may be that as employment opportunities in blue collar 
fields dry up, only households with workers in creative class, service sector, and public administration fields are able to afford to remain in the neighborhood. Whatever its cause, analysis of Downtown Dallas will begin to reveal whether the transitions in North Oak Cliff are outliers, or indicators of a greater story of displacement of people of color and blue collar workers within a revitalizing urban core.

Lacking data specific to North Oak Cliff for both 1980 and 1990, the "best guess" data for the makeup of its workforce employment profile would come from data representing Dallas' statistical area. However, this study argues that the scope of those areas is so large as to make them unusable; whereas Dallas itself represents a significant portion of its statistical area, North Oak Cliff is just one neighborhood out of hundreds within Dallas, so it would be inappropriate to substitute area-wide data for missing values within the neighborhood. As a result, while the rapid expansion of creative class employees and simultaneous decline of blue collar employees as percentages of North Oak Cliff's workforce suggests a trend in-line with literature regarding the gentrification of central urban neighborhoods, this study cannot reasonably support its assertion that, compared to its workforce in 1980, the neighborhood's workforce in 2010 can be characterized as "less blue collar and more creative class."

\section{Evaluation of North Oak Cliff as more economically polarized. Although}

Dallas as a whole did not exhibit signs of economic polarization, can the same be said for its gentrifying neighborhoods? Using data regarding median household income (MHI) and poverty rates, table 5.09 shows the changes in North Oak Cliff from 1980 to 2010.

Table 5.09: North Oak Cliff MHI and Poverty Rate, 1980 - 2010

\begin{tabular}{|l|c|c|c|c|}
\hline & $\mathbf{1 9 8 0}$ & $\mathbf{1 9 9 0}$ & $\mathbf{2 0 0 0}$ & $\mathbf{2 0 1 0}$ \\
\hline MHI (in 2015 inflation-adjusted dollars) & $\$ 28,861$ & $\$ 25,617$ & $\$ 51,915$ & $\$ 39,106$ \\
\hline Poverty Rate & $17.4 \%$ & $23.3 \%$ & $23.4 \%$ & $25.0 \%$ \\
\hline
\end{tabular}

Broadly speaking, these data suggest that inflation-adjusted MHI has increased from 1980 to 
2010, and additionally, that the neighborhood's poverty rate has also increased over that same period.

Of greater interest, however, is that while Dallas' MHI sunk dramatically between 1980 and 1990, likely resulting from the severe economic downturn in the mid-1980s, the MHI decrease in North Oak Cliff is comparative smaller; while the MHI for Dallas as a whole is more-than $\$ 50,000$ higher than that for the neighborhood $(\$ 79,611$ vs. $\$ 28,861)$ in 1980 , the difference shrinks to just under $\$ 25,000$ in 1990 (\$50,461 vs. \$25,617). Given the history of commercial and political neglect in this part of Dallas, it is reasonable to suspect that during this period, North Oak Cliff had already "bottomed out," that is, neighborhood median incomes were already so depressed that they simply had less room to fall. With median incomes so low at the 1990 census, it is reasonable to suspect that some amount of the growth seen at the 2000 census is merely regression toward a mean; however, this hardly seems adequate to explain a doubling of neighborhood MHI, when the citywide MHI only increased by roughly $\$ 1,500$. It is important to note that, at the 2000 census, the neighborhood- and citywide MHI figures are within $\$ 500$ of each other, although the significant decline at the 2010 census suggests that the groundswell of interest in North Oak Cliff had abated, likely as a result of the Great Recession.

For a neighborhood whose residents' median incomes are so depressed when compared to the citywide median, it should be unsurprising that, for three out of four censuses, poverty rates are significantly higher than those for Dallas citywide. That residents are able to remain in the neighborhood, even with such low incomes, also suggests that there is a significant amount of low-cost housing stock concentrated in the area - the kind of housing stock that is commonly targeted by both would-be gentrifiers and unscrupulous landlords. In the case of North Oak Cliff, archival searches suggest that both gentrifiers and 
slum lords are present, active, and at the heart of several, often-heated disagreements within the community ${ }^{467}$.

Certainly, the rising MHI between 1990 and 2000, as well as the documented interest in North Oak Cliff by developers throughout the mid-late $1990 \mathrm{~s}^{468}$ supports this speculation. In addition, the rapid increase in neighborhood MHI suggests some combination of an influx of people with higher incomes and an exodus of people with lower incomes occurred between 1990 and 2000, although the comparatively stable poverty rate suggests that the area attracted both people with high incomes (presumably to the gentrifying and middle-class neighborhoods) and people in lower income brackets (presumably to the derelict neighborhoods often adjacent to nicer ones). The growth in MHI and poverty rates between 1980 and 2000, but especially between 1990 and 2000 suggest that pockets of the neighborhood are gentrifying, while others continue to decline. Indeed, evidence of these block-by-block disparities in North Oak Cliff were visible even in the early $1980 \mathrm{~s}^{469}$, and the schizophrenic approach to neighborhood redevelopment since then has likely only exacerbated these differences.

Confounding this speculation, however, is the decrease in MHI found at the 2010 census; this may be a result of the Great Recession, or it may be a regression toward the mean. Although future study of this neighborhood will be required to fully address this issue, recall that the neighborhood's population declined by over $20 \%$ (or roughly 4,000 people) between 2000 and 2010, so it may be that people with higher incomes simply moved on, possibly as a result of the economic downturn, but perhaps also to seek opportunities in neighborhoods with access to better amenities (e.g. schools, newer housing stock, access to

\footnotetext{
${ }^{467}$ Brown, 2014; Griggs, 2016; Robberson, 2014; 2015; Schutze, 2001; 2015a; 2015b; Shine \& Ramirez, 2015; Stone, 2015a; 2015b; Wilonsky, 2015; 2016a;

${ }^{468}$ Elliott, Summey, \& Kokel, 2009, pp. 117-118; 2013, p. 59; Huang, 2014

${ }^{469}$ Freeman, 1982
} 
quality foods). While these data fail to capture some of the more nuanced, granular changes in the economic profile of North Oak Cliff, they nonetheless support the conclusion that the neighborhood has grown more economically polarized from 1980 to 2010, even in spite of citywide economic downturns.

Evaluation of Hypothesis 3. The following paragraphs will utilize quantitative data first presented in Chapter 4 data in order to evaluate Hypothesis 3, regarding the socioeconomic profile of Downtown Dallas, a mixed-use neighborhood being carved out of the repurposed "see-through skyscrapers" of Dallas' CBD. As with its previous discussion of North Oak Cliff, in evaluating Hypothesis 3, this study will first evaluate whether Downtown Dallas is "more white" than it was in 1980, in keeping with the prediction of the new donut model. Second, this study will evaluate whether neighborhood's employed workers are less likely to be employed in blue collar fields in 2010 than they were in 1980, and whether those workers are instead more likely to be employed in creative class fields. Third, this study will evaluate whether the neighborhood is more economically polarized in 2010 than it was 1980. Finally, this study will evaluate these components holistically, to make a determination whether (or to what extent) evidence supports this hypothesis.

Evaluation of Downtown Dallas as "more white." As it did with North Oak Cliff, to evaluate whether the percentage of Downtown Dallas' population identifying as "white alone" has, as-predicted by the new donut model, increased over the measurement period, this study examined census data related to the neighborhood's racial profile. These data, presented first in Chapter 4, are restated in table 5.10.

Table 5.10: Downtown Dallas Population and Racial and Hispanic or Latino Status, Percentages, 1980 - 2010

\begin{tabular}{|l|c|c|c|c|}
\hline & $\mathbf{1 9 8 0}$ & $\mathbf{1 9 9 0}$ & $\mathbf{2 0 0 0}$ & $\mathbf{2 0 1 0}$ \\
\hline Population & 2,900 & 3,444 & 2,198 & 9,262 \\
\hline White Alone & $50.3 \%$ & $36.6 \%$ & $69.0 \%$ & $64.6 \%$ \\
\hline Nonwhite & $49.7 \%$ & $63.4 \%$ & $31.0 \%$ & $35.4 \%$ \\
\hline Hispanic or Latino (Any Race) & $2.7 \%$ & $7.0 \%$ & $13.8 \%$ & $19.5 \%$ \\
\hline
\end{tabular}


These data suggest that, much like with North Oak Cliff, after a decline in the percentage of the population identifying as "white alone" between 1980 and 1990, the white population of Downtown Dallas has grown dramatically, spiking at the 2000 census before a slight decline (within the greater context of a significant increase in neighborhood population) found at the 2010 census. These data are consistent with this study's position that, prior to 1990 , Dallas is best described by the chocolate cities, vanilla suburbs mode, while after 1990, the new donut model appears more accurate, based on the demographic changes of these two central urban neighborhoods. It is also noteworthy that, although the percentage of the population identifying as Hispanic or Latino has also increased at each census, this group comprises a smaller percentage of Downtown Dallas' population than that of both Dallas as a whole and North Oak Cliff.

Digging deeper, table 5.11 shows, in greater detail, the demographic shifts found in Downtown Dallas between 1980 and 2010.

Table 5.11: Downtown Dallas Population and Racial and Hispanic or Latino Status, Counts, 1980 - 2010

\begin{tabular}{|c|c|c|c|c|}
\hline & 1980 & 1990 & 2000 & 2010 \\
\hline Population & 2,900 & 3,444 & 2,198 & 9,262 \\
\hline White Alone & 1,460 & 1,259 & 1,517 & 5,985 \\
\hline Black or African American & 1,269 & 2,089 & 466 & 2,156 \\
\hline American Indian or Alaskan Native & 30 & 25 & 17 & 67 \\
\hline Asian American or Native Hawaiian & 12 & 10 & 34 & 294 \\
\hline Other or Mixed-Race & 129 & 61 & 164 & 760 \\
\hline Hispanic or Latino (Any Race) & 78 & 242 & 304 & 1,804 \\
\hline
\end{tabular}

These data suggest that the neighborhood population loss between 1990 and 2000 is due primarily to a sharp decline in the number of residents who identify as Black or African American; however, given that this population returned to its 1990 level in 2010, this decline may simply be an error in the initial data collection. Local media report a different story, however - one of working-class majority-minority residential- and commercial corridors packed between- and around the skyline-defining monoliths being demolished to make way 
for upscale versions of themselves, as well as new commercial- and office spaces ${ }^{470}$. During this same time, efforts at the city level were made to remove the large concentration of homeless people from the neighborhood, primarily through pressuring food distribution centers to move operations elsewhere, using police officers to aggressively deter vagrants and panhandlers, and in some cases, actively rounding up and moving people into other $\operatorname{areas}^{471}$. Therefore, it is reasonable to speculate that, the loss of so many people identifying as Black or African American can be well-described by a combination of purges of the neighborhood's homeless population and gentrification of minority-majority communities.

This urban gentrification only expanded after the turn of the century, culminating in the Downtown Dallas 360 master revitalization plan introduced in Chapter 4, and which will be revisited in Chapter 6. Following the Great Recession, data in tables 5.10 and 5.11 suggest that the growth in Downtown Dallas' population is largely attracting people who identify as "white alone," although smaller gains can be seen in the percentages of the population identifying as, respectively, African American and Hispanic or Latino. To a lesser extent than in North Oak Cliff or Dallas citywide, there is evidence to support the pattern of "white flight" described by the chocolate cities, vanilla suburbs model between 1980 and 1990. Also as was found in North Oak Cliff, since 1990, and especially following the Great Recession, data in tables 5.10 and 5.11 instead support this study's assertion that a greater percentage of the neighborhood's population identifies as "white alone" in 2010 than in 1980, a finding that is wholly consistent with the new donut model.

\section{Evaluation of Downtown Dallas' workforce as less blue collar and more}

creative class. In evaluating whether Downtown Dallas' workforce (like that of both North

${ }^{470}$ Best \& Worst 1996, 1997; Schutze, 2000

${ }^{471}$ Nicholson, 2016; Schutze, 2002 
Oak Cliff and Dallas as a whole) has shifted to include a greater percentage of employees in creative class fields, as well as a smaller percentage of employees in blue collar fields, Chapter 4 first introduced data regarding employment by industry cluster for the neighborhood; as a note, recall that these neighborhood-level data are limited to 2000 and 2010. Neighborhood workforce data (where available), as well as comparative data for Dallas as a whole, are restated in table 5.12.

\begin{tabular}{|c|c|c|c|c|c|c|c|c|}
\hline & \multicolumn{2}{|c|}{1980} & \multicolumn{2}{|c|}{1990} & \multicolumn{2}{|c|}{2000} & \multicolumn{2}{|c|}{2010} \\
\hline & $\begin{array}{c}\text { Dallas } \\
\text { (Estimated) }\end{array}$ & $\begin{array}{l}\text { Downtown } \\
\text { Dallas }\end{array}$ & $\begin{array}{c}\text { Dallas } \\
\text { (Estimated) }\end{array}$ & $\begin{array}{l}\text { Downtown } \\
\text { Dallas }\end{array}$ & Dallas & $\begin{array}{l}\text { Downtown } \\
\text { Dallas }\end{array}$ & Dallas & $\begin{array}{l}\text { Downtown } \\
\text { Dallas }\end{array}$ \\
\hline Creative Class & $36.6 \%$ & n.d. & $53.2 \%$ & n.d. & $51.6 \%$ & $55.5 \%$ & $52.7 \%$ & $60.0 \%$ \\
\hline Blue Collar & $34.0 \%$ & n.d. & $26.1 \%$ & n.d. & $25.7 \%$ & $25.7 \%$ & $25.7 \%$ & $20.0 \%$ \\
\hline Service Sector & $27.4 \%$ & n.d. & $18.5 \%$ & n.d. & $20.6 \%$ & $16.6 \%$ & $19.5 \%$ & $18.2 \%$ \\
\hline Public Administration & $2.0 \%$ & n.d. & $2.2 \%$ & n.d. & $2.1 \%$ & $2.3 \%$ & $2.1 \%$ & $1.3 \%$ \\
\hline
\end{tabular}

These data suggest that, as with Dallas as a whole and North Oak Cliff, the percentage of Downtown Dallas' workforce employed in creative class fields is growing, while the percentage of the workforce employed in blue collar fields is on the decline. These shifts are not as dramatic as those found in North Oak Cliff, although they are larger than those found in Dallas as a whole. This should be unsurprising, however, as Downtown Dallas encompasses and surrounds the city's CBD, presenting an historical availability of jobs in creative class firms, while the city's industrial base has historically been centered closer to neighborhoods in the city's southern sector, although notable exceptions exist, such as the Del Monte Foods produce processing plant, and Kinki Sharyo International, which produces and maintains vehicles in the city's commuter light rail fleet. Further, as office towers in CBD increasingly become mixed-use centers, combining retail, residential, commercial, and hotel spaces, it is reasonable to speculate that, consistent with the post-Fordist "back to the city" movement described by the new donut model, the idea of a downtown apartment is attractive to the workers in downtown firms, a notion that has become part of the marketing strategy of the 
nonprofit development company Downtown Dallas, Inc. (DDI $)^{472}$.

As with North Oak Cliff, lacking data specific to Downtown Dallas for both 1980 and 1990, the "best guess" data for the makeup of the neighborhood's workforce employment profile would come from data representing Dallas' statistical area. However, this study continues to assert that the scope of those areas is so large as to make them unusable; whereas Dallas itself represents a significant portion of its statistical area, this neighborhood is just one neighborhood out of hundreds within Dallas, so it would be inappropriate to substitute area-wide data for missing values within the neighborhood. As a result, while the rapid expansion of creative class employees and simultaneous decline of blue collar employees as percentages of Downtown Dallas' workforce suggests a trend in-line with literature regarding the gentrification of central urban neighborhoods, this study cannot support its assertion that, compared to its workforce in 1980, the neighborhood's workforce in 2010 can be characterized as "less blue collar and more creative class."

Evaluation of Downtown Dallas as more economically polarized. Recall that, although evidence of increasing economic polarization was not found in Dallas as a whole, evidence was found for increasing economic polarization in the adjacent North Oak Cliff neighborhood.

Table 5.13: Downtown Dallas MHI and Poverty Rate, 1980 - 2010

\begin{tabular}{|l|c|c|c|c|}
\hline & $\mathbf{1 9 8 0}$ & $\mathbf{1 9 9 0}$ & $\mathbf{2 0 0 0}$ & $\mathbf{2 0 1 0}$ \\
\hline MHI (in 2015 inflation-adjusted dollars) & $\$ 38,324$ & $\$ 46,678$ & $\$ 78,897$ & $\$ 64,618$ \\
\hline Poverty Rate & $22.0 \%$ & $7.7 \%$ & $15.5 \%$ & $19.6 \%$ \\
\hline
\end{tabular}

These data suggest that, although MHI is over $\$ 25,000$ higher in 2010 than in 1980, even after adjusting for inflation, the poverty rate has decreased, which suggests a decline in economic polarization over the measurement period. However, when considering the

\footnotetext{
${ }^{472}$ Downtown Dallas Inc., 2015a
} 
positive trend in poverty rate growth since 1990, it is evident that polarization is on the rise within Downtown Dallas.

Of particular interest is the significant decline in the neighborhood poverty rate found at the 1990 census, followed by a sharp increase by 2000. It is reasonable to suspect that some portion of the decline is a result of the aforementioned efforts undertaken by City Hall to remove homeless people from the central city, but these efforts were at their greatest between 1990 and 2000, peaking in the months leading up to the city's hosting of the 1994 World Cup ${ }^{473}$. this study speculates that a larger portion of this decline can be explained by early attempts (especially in the mid-late 1990s) to revitalize residential portions of Downtown Dallas, which were characterized by the demolition of lower-income neighborhoods in favor of lower density, mixed-use, new urbanist developments that previous residents could ill-afford ${ }^{474}$. This early gentrification can be seen in the neighborhood depopulation illustrated in table 5.11, especially among people identifying as African American.

If the late $20^{\text {th }}$ century decline in poverty rate is attributable (at least in significant part) to homeless removal and gentrification in economically-marginalized residential pockets, how can the increases since the 1990 increase be explained? In part, these rises are attributable to a slight increase in the number of available housing units for people with low incomes; in 2005, 50 cottages were built for people with low incomes ${ }^{475}$. Additionally, in 2010, 200 apartment units were made available, although within three months, all units had been filled, and 300 people were waitlisted ${ }^{476}$. Third, media from that era reported that citywide efforts to force vagrants off of private property concentrated these individuals onto

473 Nicholson, 2016; Schutze, 2000; 2002

474 Best \& Worst 1996, 1997; Schutze 2000

475 Repko, 2005

476 Horner, 2010 
public land, much of which is concentrated in Downtown Dallas ${ }^{477}$. Finally, at the dawn of the $21^{\text {st }}$ century, new service providers had opened up, focusing on the homeless and people with low incomes ${ }^{478}$.

To speculate on additional causes of the growth in poverty rates and declining median household incomes, it is also possible that, in the older, less-pristine segments of the neighborhood that have not yet been redeveloped, landlords are taking advantage of the lack of affordable housing units in the area to rent units to large groups of people with low incomes, effectively creating shared-bedroom dormitories that "warehouse" the lowerincome workers who provide, for example, security- and janitorial services to the creative class firms throughout Downtown Dallas. Finally, in older neighborhoods with aging homeowners, it may be that several generations are living together, sharing costs to remain in the area when incomes are low, or during extended stretches of unemployment - a trend found to have grown dramatically in the wake of the Great Recession ${ }^{479}$.

Considering the trends in Downtown Dallas discussed so far, evidence supports this study's assertion that Downtown Dallas is more economically polarized in 2010 than it was in 1980. In addition, data presented so far support the speculation that as the city itself emerged from the economic malaise of the 1980s and early 1990s, Downtown Dallas began to transform itself into a neighborhood more fitting with the post-Fordist narrative of urban cores as centers of capital consumption, rather than centers of capital accumulation. The largely white, higher-income residents returning to Downtown Dallas, lured by the new amenities and development found in the Downtown Dallas 360 master plan, are putting a new

${ }^{479}$ Fry \& Passell, 2014, pp. 1-3 
face on the city center, but this "new face" hides a growing chasm between the neighborhood's "haves" and its "have-nots."

\section{Discussion of Context Hypotheses}

Throughout its evaluations of Dallas itself, as well as the neighborhoods of North Oak Cliff and Downtown Dallas, this study found evidence suggestive of a new normal in Dallas, following the city's economic collapse during the late 1980s and early 1990s. Broadly speaking, the residents of the post-collapse Dallas are less wealthy, and less-white than those of the pre-collapse Dallas, but when taking neighborhood-level data into account, it is clear that this broader trend contains notable exceptions. In the sections that follow, this study will first discuss the new normal at the citywide level, and then for the adjacent neighborhoods of Downtown Dallas and North Oak Cliff.

\section{Dallas as a Whole}

So what is the new normal in Dallas? As noted above, the residents of the contemporary city are a far cry from the Dallas depicted in its namesake television series. Much of Dallas is no longer majority-white, and a growing subset of the city's residents are growing increasingly poor, and increasingly economically segregated. In the wake of Dallas' white flight between 1980 and 1990, a growing population of people identifying as Hispanic or Latino is earning less and less, as-evidenced by the general decline in MHI from 1980 to 2010.

These trends have not gone unnoticed by Dallas' leaders'. A 2016 report by the Mayor's Task Force on Poverty reported that, since 1979, households earning more than $\$ 50,000$ annually have declined, while households earning less than $\$ 35,000$ have grown, and

over half of the households in Dallas earn less than $\$ 50,000$ per year ${ }^{480}$. Further, over $41 \%$ of

\footnotetext{
${ }^{480}$ Montoya, 2016, pp. 22-23
} 
Dallas' adult population lives below the poverty line, even while $70 \%$ of the city's "low income" workers are employed, and many hold full-time positions ${ }^{481}$.

Intersecting racial disparities with Dallas' position as a growing economy in the postFordist paradigm, minority workers often fill low-wage positions in creative class and service sector firms, such as data entry, entry-level finance, and healthcare, and many more are found in "producer services" fields like security, dining, janitorial- and facilities management services, and child care ${ }^{482}$. Further, as in other cities, members of Dallas' minority groups are disproportionately burdened by poverty; that same task force found that, in 2016, nearly one-third of nonwhites in Dallas live below the poverty line, and since 2000, the percentage of people who identify as Hispanic or Latino has expanded by just over $20 \%$, but the percentage of that population who live below the poverty line has increased by over $50 \%{ }^{483}$. As Dallas' economy expands, with job growth increasing by over 15\% between 2000 and 2014, and positive growth trajectories projected through $2023^{484}$, it is clear that people with low incomes are being increasingly left behind.

As the support workers underpinning Dallas' growth, these employees are indispensable, but with the lowest MHI of all major Texas cities, it is clear that they these workers are increasingly being paid at levels that suggest they are disposable. Not only is poverty in Dallas growing, data suggest that it is increasingly concentrated within particular neighborhoods, and even within these neighborhoods, within particular blocks - indeed, economic inequity is higher in Dallas than in any other city with a population over $250,000^{485}$. It is, therefore, reasonable to speculate that this intense, deepening economic

\footnotetext{
481 Montoya, 2016, p. 1

482 Shulman, 2015, pp. 75-89

${ }^{483}$ Montoya, 2016, pp. 1-3

484 2016, pp. 7-8

${ }^{485}$ p. 8
} 
segregation has its own effects on upward mobility, separating low-income workers (and their children) from opportunities to escape generational poverty ${ }^{486}$. The effects of widening economic (and often racial) segregation can be seen in the revitalization efforts found within two neighborhoods - North Oak Cliff and Downtown Dallas.

\section{North Oak Cliff}

If the 1990 census heralded a new normal in Dallas as a whole, this study speculates that a similar event has occurred in North Oak Cliff, albeit on a ten-year delay. In many ways, the new, upscale face of North Oak Cliff broadly embodies the ideal of urban revitalization. First, blue collar employment is dropping, and creative class employment is on the rise within the overall workforce. Second, new shops fill repurposed, original architecture, and the commercial corridors buzz with activity unseen in decades. Finally, instead of garnering attention from stories of violence and crime, the neighborhood is now garnering attention as a hip, young urban community for the post-Fordist millennials looking to live near, but not necessarily inside of, the central city ${ }^{487}$.

Economists often suggest that there is "no such thing as a free lunch," and in North Oak Cliff, the cost of the ongoing rebirth that has defined a new neighborhood trajectory is being paid by the displaced residents and businesses that once called the neighborhood "home." Far from the white flight that characterized this neighborhood at the close of the $20^{\text {th }}$ century, at the beginning of the $21^{\text {st }}$, whites have returned at a notable rate, leading to a number of media-documented battles between an ever-shrinking number of old residents, and an ever-growing number of new ones ${ }^{488}$. Thus, it is reasonable to suggest that, within this neighborhood, the new normal consists of a reality in which both wealthier and less-

\footnotetext{
${ }^{486}$ Montoya, 2016, pp. 4-5, 20-21

${ }^{487}$ Schutze, 2010a; 2015a

${ }^{488}$ Griggs, 2016; Laussade, 2016; McCarthy, 2015; Nicholson, 2015; Stone, 2015a; 2015b
} 
wealthy individuals are coexisting within adjacent, homogeneous enclaves. This speculation fits with media observations of the neighborhood ${ }^{489}$, and is not dissimilar to changes found in gentrifying neighborhoods in, for example, Paris since the late $1990 \mathrm{~s}^{490}$.

Further, even with workforce profile data limited to the $21^{\text {st }}$ century, it appears that as blue collar employment drops, so too does MHI, and in addition, data suggest that both unemployment and poverty rates are also rising in the neighborhood. From this, it is reasonable to suggest that, for all the articles lauding the redevelopment of an historicallydisinvested neighborhood, the reinvigoration found in North Oak Cliff is leaving some people behind; given the data collected, this study speculates that the shrinking availability of blue collar employment is pushing neighborhood residents - primarily nonwhites - to move elsewhere for employment, or to accept lower-paying positions within creative class industries. In other words, it appears that in this neighborhood, market forces and gentrification are overruling the "native" residents' right to place, resulting in some degree of dispersal. As one study participant, interviewed for their particular knowledge of North Oak Cliff described it:

There's a new neighborhood being built out of the old one [...]. Here, you had a community that was surviving, and just needed a little more attention from City Hall to fix the problems with the broken-down streets, the schools, and the crime. That's what we wanted, but what we got was this slap in the face - new buildings with shops selling nine-dollar slices of pie that we can't afford, new apartments we can't afford, and new people who don't want anything to do with the neighborhood they just moved into. We already had something, and it's like someone decided one day that it wasn't good enough, and that something else had to come in instead, and more and more of us are being pushed somewhere else.

To counter this trend, some residents have attempted to band together, but these efforts are often slow at best, and ineffective at worst. Built on a history of mistrust, the antiregime of North Oak Cliff's past continues to challenge efforts to unite the communities, and the internal debates within various alliance groups lead to inaction that can be capitalized upon by organized, resource-rich development firms, but also allow tremendous freedom for

489 Appleton, 2013a; Schutze, 2010; 2015a

${ }^{490}$ Clerval, 2006, pp. 6-9 
nontraditional actors, such as Jason Roberts and David Spence, both of whom were introduced in Chapter 4, to engage in smaller, interconnected development projects that unite area businesses, and strengthen the local economy in less-disruptive ways. These actors, and their efforts within the greater context of neighborhood disunity, will be revisited in both Chapters 5 and 6 .

\section{Downtown Dallas}

Dallas is a city that rewrites itself in response to setbacks, and this habit is most visible in Downtown; following the Kennedy assassination, the city spent roughly two decades replacing pre-war construction with massive office buildings, riding on the generosity of investors - both domestic and international - who used real estate development to evade taxes, while continuing to reap record-breaking profits. In the years following the economic implosion and IRS crackdown on investment properties as tax shelters, Downtown Dallas is once again rewriting itself - turning a former commercial hub into a mixed-use, post-Fordist utopia for the creative class, and utilizing a dizzying number public-private partnerships that arise from the Downtown Dallas 360 master development plan to achieve this makeover.

The effects of this makeover can be seen in the widening economic polarization in the neighborhood since 1990, even as median household incomes have dramatically increased over that same period, and unemployment between 2000 and 2010 has remained largely static; they can also be seen in the ever-growing population of people identifying as "white alone" since 1990. Given the broader connection between whiteness and wealth supported by the city's own research - it is reasonable to suggest that, like in North Oak Cliff, the new normal in Downtown Dallas is a neighborhood designed for- and populated by well-heeled, largely white employees of creative class firms. Meanwhile, a growing underclass of 
nonwhites eek out an existence in the shadows of this new growth - certainly

metaphorically, but also literally, in the parts of Downtown Dallas that lie between its skyscrapers, museums, public art displays, civic structures, and deck parks.

Whereas in North Oak Cliff, affluent whites are frequently displacing less-affluent people of color, in Downtown Dallas, the redevelopment of economically-marginalized spaces is a smaller story than the redevelopment of office buildings into mixed commercialresidential spaces. Thus, rather than (or, more accurately, in addition to) displacing marginalized populations, new neighborhood residents are instead creating new places where previously none existed. Therefore, the division between the "haves" and "have-nots" also takes on a geographic component - rather than gentrifying an existing low-income community, or creating a mixed-income alternative, the contemporary Downtown Dallas is a high-density, wealthy enclave being carved out of high-rises and office buildings, bringing a geographic component to division between the "haves" and the "have-nots." This geographic division, unsurprisingly, facilitates an attitudinal, "us versus them" mentality as well; indeed, when participants interviewed specifically for their knowledge of Downtown Dallas, the majority (34; 87.2\%) described the "new residents" of Downtown Dallas as being largely disinterested in the plight of the residents with lower incomes; one participant event went so far as to describe the situation as such:

The new people moving into the old office buildings, they may vote progressives into City Hall, but in the very next breath they're telling them (SIC) same people that the homeless are a nuisance to be eliminated, and to get the cops to crack down on panhandling and loitering, and to get the group homes either shut down or moved out into the poor Black neighborhood. They want bike lanes built, but then complain when poor people are riding bikes to get to work, slowing down traffic in the mornings. They want a DART (transit) bus that connects all the hot spots in- and around Downtown, but then they demand police to keep the homeless from riding when it's 100 degrees out here. They want the Disney version of Jane Jacobs - not a real community.

While in North Oak Cliff, there is a contingent of organizing, politically-active residents pushing back against the growing gentrification of their neighborhood, in Downtown Dallas, 
this does not appear to have happened. It is reasonable to suspect that some of this comes from the lack of population prior to redevelopment - in the former office buildings, for example, there were no previous residents to displace. In addition, the population that has been displaced - people who are homeless, as well as people living in now-gentrified neighborhoods - often have little (or no) voice in the political system, and are not wellequipped to mount resistance to redevelopment and displacement. Further, Downtown Dallas has traditionally been the epicenter of the city's redevelopment efforts, and is the area in which the city's power elite have historically held the most influence over political leaders. Finally, Downtown Dallas underwent the bulk of its modern-day redevelopment during a time when Dallas' city leaders were desperate to return to the untrammeled growth and development to which Dallasites were once accustomed. As a result, this study proposes that the pressure to redevelop, and the level of resources available to developers - in terms of both financial support and political support - simply overwhelmed the capacity of people who would have otherwise organized.

\section{The New Normal of Dallas Today vs. the Old Normals of Thometz and Elkin}

The Dallas of Thometz' early 1960s can be characterized by a deep optimism for the future, combining a desire to see the city move out from the shadow of the JFK assassination with an (at the time) boundless supply of private investment in urban redevelopment. The city was experiencing untrammeled growth on once-vacant land, as well as redevelopment where extant structures could no longer meet the needs of a budding metropolis, all guided by a tightly-knit pure entrepreneurial governing coalition. This

development was uneven, however, and focused primarily on the "white half" of the city, located to the north of the Trinity River. 
Roughly two decades later, this coalition had been so successful that city had built itself out of most of its developable land, at least in terms of land where developers were actively seeking to build. The city's southern neighborhoods continued to suffer from a dearth of development, as well as the loss of political ties as neighborhood whites fled across the river, leaving abandonment and decay in their wake. In the northern half of Dallas, as well as in the city's northern suburbs, commercial growth and residential relocation saw Dallas building itself out of developable land, and pitted the various interests in Dallas' governing coalition against one another, both over use value versus exchange value with respect to redeveloping existing land, and over public works projects, such as highway expansions and the construction of a commuter light rail service. As the men who built Thometz' Dallas retired or died, successors often failed to emerge, leaving the governing coalition fragmented and on the brink of collapse, but still broadly in control of what Elkin dubbed the complex entrepreneurial governing coalition.

Further complicating matters, recall that as Chapter 2 first discussed, shortly after Elkin's study, Dallas' economy completely collapsed. In the wake of this collapse, data from this chapter suggest a white exodus into Dallas' northern suburbs, while people identifying as Hispanic and Latino, and to a lesser extent, African American, moved out to fill the neighborhoods left behind. More recently, these data suggest a smaller-scale white rediscovery of the central city, through the gentrification of both North Oak Cliff and Downtown Dallas. In North Oak Cliff, this takes the appearance of long-time community residents and businesses being displaced in favor of both wealthier whites and the shops, restaurants, and entertainment venues that cater to them. Meanwhile in Downtown Dallas, the commercial hub of the city is being rebuilt into towering enclaves of wealthy whites, surrounded by an underclass of low-income minority groups; ironically, data suggest that 
many of these people likely work in the same creative class firms - possibly even in the same building, but while the whites enjoy positions of privilege, members of minority groups barely make ends meet.

As Dallas' economic- and demographic patterns change, so too must change its political boundaries - recall that the city's councilmembers are elected from districts that must maintain particular racial quotas in order to prevent voter disenfranchisement under a federal court order, so as populations migrate, council district borders will too. As these districts change, it is possible that long-time political leaders will find themselves representing new constituents (as occurred with Councilmember Scott Griggs, whose district was realigned in 2013), as well as new private-sector interests. As Dallas' minority population continues to grow, and as millennials return to the central city, it is reasonable to suspect that a more progressive set of political leaders are likely to be elected; to some extent, this is already happening, and the implications of this shift will be revisited in Chapter 6.

\section{Limitations, Revisited and Expanded}

As Chapter 3 notes, every study, no matter how well constructed, has limitations that shape the conclusions that can be drawn ${ }^{491}$. Understanding these limitations is critical for these findings to be properly evaluated, so in the paragraphs that follow, this study will revisit- and expand upon limitations first introduced in Chapter 3.

Looking first at this study's use of secondary-source data, any problems in the source data are inherited by this study, and this study is forced to rely on definitions and conceptualizations present in the source material. For example, participation rates for people identifying as Hispanic or Latino are questionable, presumably because people worry that census records will be used to identify them as undocumented immigrants, and they fear

\footnotetext{
${ }^{491}$ Schutt, 2009, p. 20
} 
deportation $^{492}$. As a result, recall that this study examined changes in poverty rates and median household income (MHI), as well as changes in demographics with respect to race and Hispanic or Latino status, which was complicated because MHI is available by race and Hispanic or Latino status at the tract level, but poverty rates by race and Hispanic or Latino status are not, therefore this study could only make broad inferences about the face of poverty in these two neighborhoods.

Additionally, in at least one case, data are unavailable because definitions used by the census bureau changed. One key example of this is that census definitions regarding employment industries changed dramatically between 1990 and 2000, so data comparing blue collar and creative class employment from 1980 and 1990 could not be reconciled with data from 2000 and 2010. Finally, recall that economic data span the decades from 1980 to 2010, inclusively, but during that time, Dallas experienced two large economic slowdowns - the Savings \& Loan Crisis, and the Great Recession - both of which likely affected the economic data, further weakening this study's quantitative findings. This particular limitation is not unique to this study; indeed, any case study would have similar complications.

Finally, this study relies on a somewhat "loose" conceptualization of economic prosperity, derived from a combination of dictionary definitions and a subset of past research. Using different definitions, a case could be built to suggest that Dallas is not actually economically prosperous, and that most of the prosperity associated with the city is actually attributable to the Dallas region, with the city itself in dire economic straits. This position, while an interesting thought experiment, fails to account for documented economic growth in the city, although as this chapter has noted throughout, this growth is not being felt by a significant subset of the city's population.

\footnotetext{
${ }^{492}$ Johnson et al., 2002, pp. 59-61
} 


\section{Chapter Summary}

The purpose of this chapter was to analyze and evaluate the data reported in Chapter 4 , in order to address this study's research questions. In the preceding chapter sections, this study first revisited its research questions and hypotheses. Next, it synthesized quantitative

data first presented in Chapter 4, before evaluating them with respect to urban literature regarding expected demographic- and economic transitions found in post-Fordist cities, as well as with respect to the effects of these transitions on Dallas' political landscape. Finally, this study revisited and expanded upon a subset of the limitations introduced in Chapter 3, before introducing additional limitations from data collection, reporting, and analysis. 


\section{CHAPTER VI}

\section{QUALITATIVE ANALYSIS AND DISCUSSION}

The purpose of this chapter is to analyze and evaluate the data reported in Chapter 4, in order to address this study's final two research questions - those related to the city's contemporary governing coalition. In the chapter sections that follow, this study will first revisit its second and third research questions, as well as its second set of hypotheses. Next, it will evaluate its qualitative findings in order to render an image of contemporary urban governance in Dallas, the relationship between the city's decision-making structures and entities involved in equitable economic development projects, and how these projects compare to efforts in a subset of other cities.

\section{Second and Third Research Questions and Coalition Hypotheses Revisited}

The purpose of this section is to outline the research questions that this study attempts to address, as well as its series of hypotheses to be tested. First, it will list the second and third research questions that guide this study, and then, it will outline the three hypotheses that this study's survey- and interview data will be used to evaluate.

\section{Second and Third Research Questions Revisited}

As previous chapters have noted, this study aims to answer three primary research questions. In Chapter 5, this study examined how Dallas' demographics and economy evolved in the decades since the city was studied by previous urban scholars. Now, this study will address the extent to which CDCs and anchor institutions are active participants in 
Dallas' governing coalition, and further, if they are active, what the effects of that involvement are on urban development and policymaking.

\section{Coalition Hypotheses Revisited}

In order to guide its attempts at addressing this second research question, this study revisits the final three of its primary hypotheses - those related to the decision-makers of Dallas as a whole, as well as the neighborhoods of North Oak Cliff and Downtown Dallas; these hypotheses are as-follows:

Hypothesis 4. In Dallas as a whole, representatives of anchor institutions and CDCs are primary (rather than ancillary) members of a citywide governing coalition, and this involvement portends a more equitable development paradigm than the value-neutral development seen in cities throughout the mid-late $20^{\text {th }}$ century.

Hypothesis 5. In North Oak Cliff, representatives of anchor institutions and CDCs in are primary (rather than ancillary) members, of a neighborhood governing coalition, and this involvement portends a more equitable development paradigm than the value-neutral development seen in cities throughout the mid-late $20^{\text {th }}$ century.

Hypothesis 6. In Downtown Dallas, representatives of anchor institutions and CDCs in are primary (rather than ancillary) members, of a neighborhood governing coalition, and this involvement portends a more equitable development paradigm than the value-neutral development seen in cities throughout the mid-late $20^{\text {th }}$ century.

\section{Evaluation of Coalition Hypotheses}

While Chapter 5 evaluated the relatively straightforward "context" hypotheses, the sections that follow will engage in evaluations of this study's three "coalition" hypotheses. In these sections, this study will first evaluate the presence and nature of decision-making structures in, respectively, Dallas citywide, North Oak Cliff, and Downtown Dallas, in order 
to understand whether, or to what extent, anchor institutions and CDCs are involved in contemporary decision-making. As a note of caution, throughout the sections that follow, this study will often make references to study participants; in the sections related to Hypothesis 4, the term "participants" will refer to all 79 participants in this study, while in those sections regarding Hypothesis 5 and Hypothesis 6, the term will refer only to those participants involved in discussions of those neighborhoods.

Evaluation of Hypothesis 4. The following paragraphs will utilize data first presented in Chapter 4 data in order to address Hypothesis 4, regarding the status of anchor institutions and CDCs in a governing coalition within Dallas as a whole. In the paragraphs that follow, this study will first seek to establish the presence- and nature of citywide decision-making power. Second, it will evaluate the relationship between power and nominations to decision-making committees. Third, it will evaluate the respective relationships between power and familiarity, and between power and recent shared board or committee service. Finally, it will relate these findings to the present hypothesis, in order to establish whether, to what extent, and to what end anchor institutions and CDCs are involved in contemporary citywide decision-making.

Citywide decision-makers. Of the study's 79 participants, only a subset admitted familiarity with Dallas' leadership in prior decades. Six participants $(7.6 \%)$ spoke to personal familiarity with the city's leaders and its decision-making processes in 1960s, while 26 $(32.9 \%)$ expressed familiarity with decision-makers and decision-making throughout the 1970s and 1980s. When asked to describe contemporary citywide decision-making, and the extent to which it differs from decision-making in the past, many of these more "tenured" participants made similar remarks, well-summarized by the following: 
There was a time when you had a basic group of two or three dozen men who would come together informally and fix problems, or address things as we needed to. Dallas was a lot smaller then, and people looked up to the men who made decisions like that. Things are a lot different now.... [Dallas] is so much bigger, and the world is so much faster, and I don't think we can ever go back to the old way of doing things, even if it was a lot easier.

Nonetheless, data first introduced in Chapter 4 suggest that, on some level, Dallas still has

people who have a reputation for being able to make decisions that affect the city as a whole.

Seventy-nine participants identified 32 individual- and group actors who have some

combination of formal decision-making authority and informal influence, and whose

presence on a citywide decision-making committee would help ensure that the decision

would be accepted by the community; table 6.01 revisits these decision-makers.

Table 6.01: Citywide Decision-Makers

\begin{tabular}{|c|c|c|}
\hline Category & Name & Most Notable Affiliation(s) \\
\hline \multirow{4}{*}{$\begin{array}{c}\text { Formal } \\
\text { Authorities }\end{array}$} & District-Based Councilmembers (14) & Dallas City Council \\
\hline & Mike Rawlings & Mayor \\
\hline & A.C. Gonzalez & City Manager \\
\hline & Appointed Commissioners (15) & City Plan Commission \\
\hline \multirow{9}{*}{$\begin{array}{l}\text { First Tier } \\
\text { Influentials }\end{array}$} & Ray Hunt & Hunt Consolidated \\
\hline & John Wiley Price & Dallas County Commissioner \\
\hline & Harlan Crow & Crow Holdings \\
\hline & Ross Perot Jr. & Hillwood \\
\hline & Kay Bailey Hutchison & U.S. Senate (former); TX House of Rep. (former); TX State Treasurer (former) \\
\hline & Caroline Hunt & Rosewood Corp. \\
\hline & T. Boone Pickens & BP Capital \\
\hline & Ruth Collins Altshuler & Philanthropist \\
\hline & Bobby Lyle & Lyco Holdings; Southern Methodist University \\
\hline \multirow{12}{*}{$\begin{array}{c}\text { Second } \\
\text { Tier } \\
\text { Influentials }\end{array}$} & Mary Suhm & City Manager (former) \\
\hline & Clint McDonnough & Ernst \& Young, LLP \\
\hline & John Scovell & Woodbine Development \\
\hline & Robert Chereck & PlainsCapital \\
\hline & Arcilia Acosta & CARCON Industries \\
\hline & Michael Caffey & C.B. Richard Ellis (CBRE) \\
\hline & Angela Hunt & Dallas City Council (former) \\
\hline & Albert Black & On-Target Supplies \& Logistics; Dallas Regional Chamber (former) \\
\hline & Donna D. Halstead & Dallas Citizens Council (former); Councilmember (former) \\
\hline & Jeff Staubach & Jones Lang LaSalle \\
\hline & Alan Walne & Dallas City Council (former) \\
\hline & Steve Everbach & Colliers International \\
\hline \multirow{3}{*}{$\begin{array}{l}\text { Civic } \\
\text { Chairs }\end{array}$} & Alice Murray & Dallas Citizens Council \\
\hline & Mabrie Jackson & North Texas Commission \\
\hline & Dale Petrosky & Dallas Regional Chamber \\
\hline \multirow{4}{*}{$\begin{array}{l}\text { Anchor } \\
\text { Captains }\end{array}$} & Gerald Turner & Southern Methodist University \\
\hline & Joel T. Allison & Baylor Healthcare \\
\hline & David Daniel & Univ. of Texas at Dallas (former); Univ. of Texas System \\
\hline & Lee Jackson & Univ. of North Texas System \\
\hline
\end{tabular}

Contemporary distribution of citywide decision-making power. The previous

reputational study of Dallas' leaders found that decision-makers in the early 1960s were

primarily composed of executives within commerce (including real estate, trade utilities, and 
communications), finance (including banking and insurance), manufacturing, and law, but also included a handful of leaders from education, government, organized labor, and religious institutions ${ }^{493}$. Even into the 1980 s, the dominance of business leaders - both directly, and through civic organizations - in Dallas' decision-making remained evident ${ }^{494}$.

This study proffers that that Dallas' contemporary governing coalition is no longer quite so narrow, though there continues to be a strong bias toward finance and real estate among the city's leaders, and the support of the old guard within Dallas' leadership can still advance or sustain a career in public leadership. To the extent that table 6.01 is an accurate representation of Dallas' citywide decision-makers, the data within suggest that Dallas' decision-makers are a collection of government officials (current and former), private-sector executives in local branches of multinational businesses, real estate offices, finance and investment firms, construction companies, and law firms, as well as heads of area anchor institutions and elite civic organizations. Additionally, unlike the Thometz study ${ }^{495}$, the decision-makers in table 6.01include both women and people of color.

Recall that Chapter 4 described five categories of decision-makers in Dallas: formal authorities, first tier influentials, second tier influentials, civic chairs, and anchor captains. As an added layer to these categories, in their interviews, all 79 participants agreed that some people in the city have more power than others. Table 6.02 extends survey data introduced Chapter 4, which listed mean power scores for each decision-maker, by including both total power scores and rank-order data.

\footnotetext{
493 Thometz, 1963, pp. 31-33

${ }^{494}$ Elkin, 1987a, pp. 67-71

495 Thometz, 1963, p. 31
} 
Table 6.02: Power Ratings of Citywide Decision-Makers

\begin{tabular}{|c|c|c|c|c|}
\hline $\begin{array}{l}\text { Rank } \\
\text { Order }\end{array}$ & Name & Category & Power Score & $\begin{array}{l}\text { Mean Power } \\
\text { Score }\end{array}$ \\
\hline 1 & District-Based Councilmembers (14) & Formal Authorities & 316 & 4.00 \\
\hline 2 & Ray Hunt & First Tier Influentials & 305 & 3.86 \\
\hline 3 & John Wiley Price & First Tier Influentials & 303 & 3.84 \\
\hline 4 & Mike Rawlings & Formal Authorities & 299 & 3.78 \\
\hline 4 & A.C. Gonzalez & Formal Authorities & 299 & 3.78 \\
\hline 6 & Harlan Crow & First Tier Influentials & 292 & 3.74 \\
\hline 7 & Ross Perot Jr. & First Tier Influentials & 289 & 3.66 \\
\hline 8 & Kay Bailey Hutchison & First Tier Influentials & 284 & 3.59 \\
\hline 9 & Alice Murray & Civic Chairs & 279 & 3.53 \\
\hline 10 & City Plan Commissioners (15) & Formal Authorities & 277 & 3.51 \\
\hline 11 & Caroline Hunt & First Tier Influentials & 267 & 3.38 \\
\hline 12 & Gerald Turner & Anchor Captains & 263 & 3.33 \\
\hline 13 & T. Boone Pickens & First Tier Influentials & 260 & 3.29 \\
\hline 14 & Mary Suhm & Second Tier Influentials & 254 & 3.26 \\
\hline 15 & Mabrie Jackson & Civic Chairs & 248 & 3.14 \\
\hline 16 & Ruth Collins Altshuler & First Tier Influentials & 247 & 3.13 \\
\hline 17 & Clint McDonnough & Second Tier Influentials & 240 & 3.04 \\
\hline 18 & Bobby Lyle & First Tier Influentials & 239 & 3.03 \\
\hline 19 & Dale Petrosky & Civic Chairs & 235 & 2.97 \\
\hline 20 & John Scovell & Second Tier Influentials & 233 & 2.95 \\
\hline 20 & Robert Chereck & Second Tier Influentials & 233 & 2.95 \\
\hline 22 & Arcilia Acosta & Second Tier Influentials & 220 & 2.78 \\
\hline 23 & Michael Caffey & Second Tier Influentials & 214 & 2.71 \\
\hline 23 & Joel T. Allison & Anchor Captains & 214 & 2.71 \\
\hline 25 & Angela Hunt & Second Tier Influentials & 206 & 2.64 \\
\hline 26 & David Daniel & Anchor Captains & 201 & 2.54 \\
\hline 27 & Lee Jackson & Anchor Captains & 195 & 2.47 \\
\hline 28 & Albert Black & Second Tier Influentials & 191 & 2.45 \\
\hline 29 & Donna D. Halstead & Second Tier Influentials & 189 & 2.39 \\
\hline 30 & Jeff Staubach & Second Tier Influentials & 188 & 2.38 \\
\hline 31 & Alan Walne & Second Tier Influentials & 183 & 2.32 \\
\hline 32 & Steve Everbach & Second Tier Influentials & 175 & 2.22 \\
\hline
\end{tabular}

Two findings from table 6.02 achieve statistical significance. First, power score and mean

power score share a perfect, positive correlation with one another ${ }^{496}$, which suggests that actors who received higher power scores also tended to receive higher ratings from each participant; additionally, when formal authorities, first tier influentials, second tier influentials, civic chairs, and anchor captains were coded, respectively, 0-4, the resulting moderate negative correlation ${ }^{497}$ between category and mean power score suggests that actors in some thematic categories (chiefly formal authorities and first tier influentials) tend to have higher mean power scores than actors in other categories (particularly second tier influentials and anchor captains).

These results suggest that there is a particular hierarchy among categories of actors in Dallas' decision-making structure; indeed, in describing the structure of citywide decision- 
making, 77 of 79 participants (97.5\%) used specific terms, e.g. "tiers," "echelons," or

"levels." To derive an empirically-supportable number of decision-making tiers, and

following the practice of a previous reputational study of Dallas ${ }^{498}$, this study utilizes

Duncan's New Multiple Range Test (DMRT) to measure the differences between each

power score and every other power score listed, in order to determine whether any gaps in

these scores are statistically significant, with significant gaps suggesting that scores are

clustered together; table 6.03 shows the results of this test for Dallas as a whole.

Table 6.03: Citywide Decision-Maker Levels of Power

\begin{tabular}{|c|c|c|c|c|c|}
\hline \multirow[b]{2}{*}{ Name } & \multirow[b]{2}{*}{ Thematic Category } & \multicolumn{4}{|c|}{ Subset for $\alpha=0.05$} \\
\hline & & $\begin{array}{l}\text { Low } \\
\text { Tier }\end{array}$ & $\begin{array}{c}\text { Low- } \\
\text { Middle } \\
\text { Tier }\end{array}$ & $\begin{array}{c}\text { High- } \\
\text { Middle } \\
\text { Tier }\end{array}$ & $\begin{array}{c}\text { High } \\
\text { Tier }\end{array}$ \\
\hline District-Based Councilmembers (14) & Formal Authorities & & & & 4.000 \\
\hline Ray Hunt & First Tier Influentials & & & 3.861 & \\
\hline John Wiley Price & First Tier Influentials & & & 3.835 & \\
\hline Mike Rawlings & Formal Authorities & & & 3.785 & \\
\hline A.C. Gonzalez & Formal Authorities & & & 3.785 & \\
\hline Harlan Crow & First Tier Influentials & & & 3.744 & \\
\hline Ross Perot Jr. & First Tier Influentials & & & 3.658 & \\
\hline Kay Bailey Hutchison & First Tier Influentials & & & 3.595 & \\
\hline Alice Murray & Civic Chairs & & & 3.532 & \\
\hline City Plan Commissioners (15) & Formal Authorities & & & 3.506 & \\
\hline Caroline Hunt & First Tier Influentials & & 3.380 & & \\
\hline Gerald Turner & Anchor Captains & & 3.329 & & \\
\hline T. Boone Pickens & First Tier Influentials & & 3.291 & & \\
\hline Mary Suhm & Second Tier Influentials & & 3.256 & & \\
\hline Mabrie Jackson & Civic Chairs & & 3.139 & & \\
\hline Ruth Collins Altshuler & First Tier Influentials & & 3.127 & & \\
\hline Clint McDonnough & Second Tier Influentials & & 3.038 & & \\
\hline Bobby Lyle & First Tier Influentials & & 3.025 & & \\
\hline Dale Petrosky & Civic Chairs & & 2.975 & & \\
\hline Robert Chereck & Second Tier Influentials & & 2.949 & & \\
\hline John Scovell & Second Tier Influentials & & 2.949 & & \\
\hline Arcilia Acosta & Second Tier Influentials & 2.785 & & & \\
\hline Joel T. Allison & Anchor Captains & 2.709 & & & \\
\hline Michael Caffey & Second Tier Influentials & 2.709 & & & \\
\hline Angela Hunt & Second Tier Influentials & 2.641 & & & \\
\hline David Daniel & Anchor Captains & 2.544 & & & \\
\hline Lee Jackson & Anchor Captains & 2.468 & & & \\
\hline Albert Black & Second Tier Influentials & 2.449 & & & \\
\hline Donna D. Halstead & Second Tier Influentials & 2.392 & & & \\
\hline Jeff Staubach & Second Tier Influentials & 2.380 & & & \\
\hline Alan Walne & $\begin{array}{l}\text { Second Tier Influentials } \\
\text { sel }\end{array}$ & 2.316 & & & \\
\hline Steve Everbach & Second Tier Influentials & 2.215 & & & \\
\hline
\end{tabular}

\footnotetext{
498 Thometz, 1963, pp. 44-46
} 
These data broadly support findings from table 6.02, and share superficial similarities to findings in the Thometz study ${ }^{499}$, in that they both suggest a series of statistically significant tiers within mean power scores for each of Dallas' citywide decision-makers. Figure 6.01 presents a visual representation of these tiers of citywide decision-making power.

Figure 6.01: The Structure of Citywide Decision-Making Power

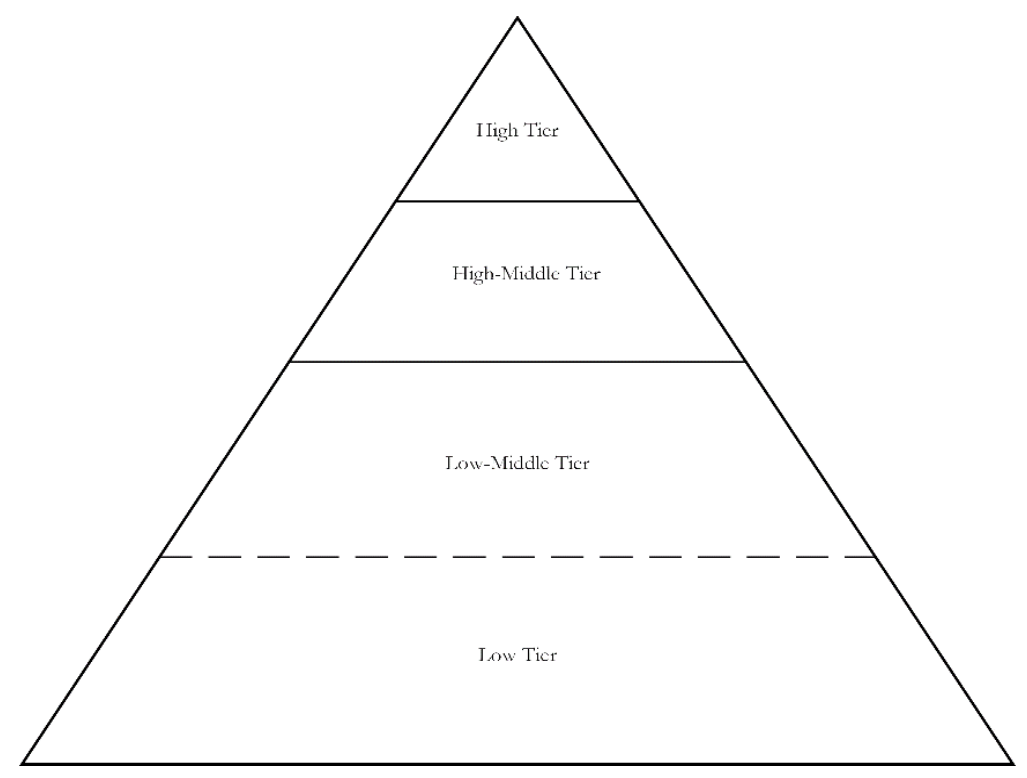

These findings take into account data in table 6.02 and table 6.03, as well as participant observations introduced in Chapter 4. In the paragraphs that follow, this study will broadly describe these findings with respect to previous studies, and then it will examine each of the four tiers.

Dallas' citymide decision-making structure, broadly. While Thometz found three tiers of power in mid-century Dallas (key leaders, top level, and second echelon), this study finds four: high tier, high-middle tier, low-middle tier, and low tier. Taken together, table 6.03 and figure 6.01 suggest a number of key findings that largely (but not wholly) agree with the previous reputational

$$
499 \text { 1963, p. } 45
$$


study of Dallas. In the paragraphs that follow, this study will outline key differences between its findings and those of its predecessors.

First, recall that the Thometz study described actors in Dallas' highest echelons of leadership as being involved in most aspects of decision-making, either themselves or through their representatives on various boards and committees, while lower echelons tended to be occupied by younger, less experienced leaders and older decision-makers who are retiring out of the politics of governing the city ${ }^{500}$. This study's findings largely agree with this; in describing actors found to be within the highest two tiers (respectively, high and highmiddle) participants generally described each as being deeply involved in most, if not all citywide decisions, while actors within lower tiers (low-middle and low), these actors are more likely to be described as only being involved in a subset of decision-making. In describing the difference, one participant commented that:

Here (in Dallas), we [have] always had "big men" who run most things, and smaller men who come around here and there with an opinion or who look to help. [...] It's still a little bit like that - some people are part of every decision that matters, and other people are closer to what you'd call an "expert" on a certain area - there's (SIC) go-to people for education, or schools, or whatever you want, and they don't have much say in anything else.

Second, the Thometz study found that Dallas' leaders were primarily members of the business community, most often finance and utilities, but also in manufacturing and trade $\mathrm{e}^{501}$. Two decades later, the Elkin study broadened the scope of city leadership to include government officials, citing the simultaneous weakening of Dallas' once-unified business coalitions and disruptive changes in the city's mayoral- and councilmember election systems, but conceded that the result was similar; in the entrepreneurial regime, Dallas' leaders continued to place development policies over redistribution ${ }^{502}$. Table 6.03 suggests that Dallas'

\footnotetext{
${ }^{500}$ Thometz, 1963, pp. 46-47

5011963 , p. 43

${ }^{502}$ Elkin, 1987b, pp. $42-44$
} 
leadership is still heavily dominated by business leaders - especially those in real estate development and construction - but that the seeds of transition away from the entrepreneurial regime may have already been planted; this will be revisited later in this study.

Finally, Thometz argued that, as actors in the higher tiers of Dallas' decision-making structure retired, they nominated actors in lower tiers to replace them ${ }^{503}$, though twenty years later, Elkin argued that this system had broken down, and new leaders were no longer being "brought up" to replace their predecessors ${ }^{504}$. In this study, 75 (94.9\%) of participants, including the 32 participants personally familiar with citywide leadership in the mid-late $20^{\text {th }}$ century, agreed that this system is largely a relic of history; as one put it:

[...] It used to be that the business leaders were the political leaders. The men at the top would give the younger men small tasks to handle, and if they did good (SIC), then they got put on bigger projects. [...] That changed when the Charter Association fell apart, though, and now it's a whole new world.

In considering the four-tier system conceptualized in figure 6.01 with respect to the five categories of decision-maker introduced in Chapter 4, the highest echelons of leadership are primarily occupied by actors in categories that are largely restricted. Note that the high tier is composed entirely of formal authorities; to join this category, an actor would need to either be elected to public office or be appointed to a high position in city bureaucracy. Further, the high-middle tier is made up of formal authorities and first tier influentials, as well as the civic chair in charge of the Dallas Citizens Council (itself composed largely of first tier influentials). Recall that, at the citywide level, first tier influentials are composed of key figures in Dallas' first families and a subset of outsiders with long careers serving the interests of these families; as an "invite only" category, membership is simply not open to a majority of actors involved in

${ }^{503}$ Thometz, 1963, pp. 70-76

${ }^{504}$ Elkin., 1987b, pp. 71-73 
citywide decision-making. This is conceptualized in figure 6.01 as a solid line between the bigh tier and high-middle tier, and another solid line between the high-middle tier and low-middle tier.

By contrast, lower echelons are more open to individuals - there can by any number of business leaders with an interest in the politics of development, or directors of nonprofit organizations with an interest in providing policy expertise. Indeed, actors in the low-middle tier and low tier are more varied, and analysis of participants' comments suggests that there are three broad categories of these actors, at least at the citywide level. First are actors whom 78 $(98.7 \%)$ of participants identified as being largely retired out of the politics of decisionmaking, but who retain strong connections to current city officials, and who can be relied upon to serve on boards or committees; summarizing this category, one participant noted that:

Nobody really retires out of City Hall. They might not have a formal, paying job, but there's always a committee that needs someone who knows how things work. Sometimes you'll see people down here more often after they're off the payroll than you did when they were on it.

Another participant described this phenomenon of post-retirement service asfollows:

It's hard to leave public service, even when you leave the public sector. Part of it is that everything in Dallas is politics, and it all takes forever to get done, but a bigger part of it is that, for a lot of us, service gets in your blood - you want to keep being involved, and it's easy to use your old connections to do that.

A second category was identified by $49(62.0 \%)$ of participants; in this category are the “policy experts," like leaders of nonprofit organizations, who have long-standing connections to Dallas' leaders, but are themselves only involved in subsets of decisionmaking, such as decisions related to educational policy or inter-governmental relations; One participant commented that these actors:

... usually end up married into one of the big names in Dallas, or they're a second or third son or daughter; their name is worth something to the big philanthropies in the area, but they aren't going to take over anyone's family business someday. They turn into experts on one particular issue, and they're the go-to folks whenever the mayor, or the council, or the city manager needs someone to help write a policy. 
A second participant said that:

City leaders don't have to be experts on anything, because they have a stable of "experts" to call up whenever they need to know something. Most of the councilmembers get real (SIC) bright people to advise them, usually from a related nonprofit, or from one of the local colleges, but others, not so much. Either way, those advisors start to get a reputation - their names end up in the newspaper, or on television. If they weren't an expert before, suddenly they become one, and they have an impact on policy for years.

A third category identified by a majority of participants (42 participants; $53.2 \%$ ) are younger executives, primarily involved in real estate development and construction firms. These actors have not yet been elevated into a higher tier, often because they have no interest in doing so. In describing this situation, one participant said that:

Years ago, you could always find someone willing to step into a bigger leadership role; it meant the chance to do something big in this great city, but it also meant promotions, raises, and the chance to rub elbows with famous Dallasites. That doesn't mean as much to a lot of people - they work for companies that have offices all over the world, and they're busy working on things in other cities... other counties... they don't have time for Dallas, beyond the occasional project here and there.

In differentiating low-middle tier and low tier actors, analysis of participant comments suggests that low-middle tier actors are most commonly people with at least ten years of history in citywide leadership positions, such as appointments to several civic boards or committees, having previously held elected office, participation in high-level fundraising for a civic project, or social connections to high-level leaders. While low-middle tier actors are involved in a wider array of decision-making, low tier actors tend to only be involved on particular projects or policy issues. This loose, fluid differentiation is represented in figure 6.01 as a dashed line between the low-middle tier and low tier, suggesting that actors could more easily shift between these tiers than between, for example, low-middle tier and high-middle tier. Key leaders, past and present. Thometz, in describing Dallas' leadership structure, identified seven key leaders of the city, who were involved in most citywide decisions, and whose opinions carried the most weight in the decision-making process ${ }^{505}$. These seven

\footnotetext{
505 Thometz, 1963, pp. 59-60
} 
leaders consisted of two banking and finance executives, two executives of utility companies, one manufacturing executive, and one trade executive ${ }^{506}$. This study argues that, in Dallas' contemporary decision-making structure, high tier leaders occupy this same central position; comprised entirely of the district-based city councilmembers, this tier is responsible for nearly all citywide decisions. In describing Dallas' city council, participants broadly agreed that the council supports a progressive social agenda for Dallas, but with respect to economic development - particularly when it comes to using publicly-funded inducement packages to lure new businesses and economic development - the council is divided into two camps: one that supports an untrammeled pro-development position, and another that supports a more limited development position, in which economic development is tied to, for example, provisions for affordable housing, or improvements to area infrastructure or schools. The presence of this division (and lack of "neutral" councilmembers) was unanimously agreed-upon, while the degree of nuance within it is reflected in table 6.04.

Table 6.04: Dallas City Council Divisions With Respect To Citywide Development

\begin{tabular}{|c|c|c|c|c|c|c|}
\hline \multirow{2}{*}{$\begin{array}{l}\text { Participant } \\
\text { Cluster }\end{array}$} & \multirow{2}{*}{$\begin{array}{l}\text { Participants } \\
\quad(\#)\end{array}$} & \multirow{2}{*}{$\begin{array}{l}\text { Participants } \\
\text { (\%) }\end{array}$} & \multicolumn{2}{|c|}{ Pro-Development } & \multicolumn{2}{|c|}{ Progressive-Development } \\
\hline & & & \multirow[t]{2}{*}{ Strong } & \multirow[t]{2}{*}{ Leaning } & \multirow[t]{2}{*}{ Leaning } & \multirow[t]{2}{*}{ Strong } \\
\hline \multicolumn{3}{|c|}{ Four-Category Participant Clusters } & & & & \\
\hline Cluster 1 & 8 & $10.1 \%$ & 6 & 3 & 3 & 3 \\
\hline Cluster 2 & 4 & $5.1 \%$ & 5 & 3 & 4 & 3 \\
\hline Cluster 3 & 5 & $6.3 \%$ & 4 & 5 & 2 & 4 \\
\hline Cluster 4 & 12 & $15.2 \%$ & 4 & 4 & 4 & 3 \\
\hline Cluster 5 & 14 & $17.7 \%$ & 4 & 4 & 3 & 4 \\
\hline \multicolumn{3}{|c|}{ Two-Category Participant Clusters } & \multicolumn{2}{|c|}{ Pro-Development } & \multicolumn{2}{|c|}{ Progressive-Developmen } \\
\hline Cluster 6 & 36 & $45.6 \%$ & \multicolumn{2}{|c|}{8} & \multicolumn{2}{|c|}{7} \\
\hline
\end{tabular}

These data suggest that a plurality of participants $(36 ; 45.6 \%)$ support a simple dichotomy on the city council between pro-development and progressive-development camps, and among these, there is agreement that a once-councilmember advantage is held by those who argue for policies in-line with those expected within an entrepreneurial governing coalition. Further, these data suggest that this $8-7$ split is agreed upon by an additional 26 participants $(32.9 \%)$

$$
5061963 \text {, p. } 43
$$


from clusters four and five, and all 79 participants (100\%) agreed that the pro-development alliance is larger than its progressive-development counterpart. Therefore, all participants agree on the presence- and nature of this council division, and 62 of these $(78.5 \%)$ agree on the sizes of the two alliances within the councilmembers themselves.

In elaborating on their respective positions, participants regularly cited ties between pro-development councilmembers and Dallas' neoliberal past, and admitted that these councilmembers benefit from the support of Dallas' first tier influentials and civic chairs, while the progressive-development councilmembers often experience challenges from these extragovernmental sources. Describing this scenario, one participant said that:

In parts of Dallas, especially in the rich neighborhoods to the north, you have people who have made a lot of money under the way we've always done things here, and they're going to support candidates who promise to keep things the same.

Another said that:

The men who built up Dallas in the 70s, and who sold it out to the suburbs in the 80 s and 90s had kids, and those kids are looking to come back now that Dallas is starting to look like dollar signs again. They're doing everything they can to keep an advantage on the (city) council, and to hamstring the younger councilmembers who want a different future in the city.

Nearly all participants $(63 ; 79.7 \%)$ qualified their observations by noting that, at nearly every council election since 2011, the "progressive development" contingent has grown, and that several of the pro-development councilmembers are rapidly approaching their term limits. Even participants who did not make such a qualification agreed that, if the progressive minority ever gains an additional council seat, such a change would dramatically affect the kinds of projects and policies undertaken by the highest echelons of Dallas' leadership. This situation will be revisited later in this study, although several comments regarding it are wellsummarized by the following:

The old Dallas - where businessmen made decisions on behalf of the city, and bringing new business was the only policy that mattered - that Dallas is going away. [...] Dallasites are getting tired of that old way, and you're seeing it in the council elections. Give it five, maybe ten more years, and you won't see that "old way" anymore. 
Top level leaders, past and present. Of the 55 top level leaders identified in the Thometz study, only one represented a government employee, while the remaining 54 were executives in banking and finance, insurance, utilities, manufacturing, local media, and trade. These leaders were often consulted on important decisions, and were only slightly less-involved than key leaders in decision-making. In addition, these actors often served to inform key leaders about issues about which critical decisions would need to be made ${ }^{507}$. This study finds that actors in the high-middle tier are loosely analogous to Thometz' top level. Actors in this tier are a combination of formal authorities, first tier influential and civic chair categories, and consist of highlevel political leaders (including the mayor and city manager), elite business leaders, civic philanthropists, leading members of Dallas' first families, and civic power brokers whose organizations have historically held strong influence in citywide decision-making.

With the exception of Mayor Rawlings, who has a vote on the city council, participants speaking broadly about actors who were categorized in the in the high-middle tier, described them as acting primarily in advisory capacity to high tier actors (or, less charitably, as "puppetmasters"), and participants reported that they have varying degrees of influence over particular councilmembers. Out of the 79 participants, $49(62.0 \%)$ spoke openly about deep ties between councilmembers representing districts in northern Dallas and particular private-sector high tier actors. Notably, $12(15.2 \%)$ were equally adamant about connections between councilmembers representing the city's southern districts and at least one privatesector actor found in the high tier category, and $6(7.6 \%)$ argued that all councilmembers have some connections with at least one private-sector actor found in the high tier, an additional 12 $(15.2 \%)$ participants declined to comment, even after reassurances of confidentiality; one participant, summing the thoughts of several others, said that "nearly everyone who gets up

\footnotetext{
507 Thometz, 1963, pp. 60-62
} 
high enough in Dallas politics has at least one friend who called in a favor or two to help them get there, or help them stay there." Recall that in Chapter 2, this study recounted the findings of the Elkin study of Dallas in the 1980s - primarily that Dallas' well-organized coalition of business leaders formed natural alliances with public officials, but were often at "arm's length" from the day-to-day running of the city ${ }^{508}$. Taken holistically, the participant observations noted above seem to suggest that, as Elkin found in 1987, the interests of the city's business community are well-represented in the highest levels of the city's formalized governance structure, even though this representation is primarily indirect; a representative description of this arrangement came from one participant, who said that:

\begin{abstract}
Mayors and councilmen used to get elected by the [Citizen's Charter Association] and the [Dallas Citizens Council]; those two groups controlled access to the ballot, and so their candidates were more-or-less the only choices. It was understood that the mayor and the council would include their benefactors on most decisions in the earliest stages; really, you could've turned the city over to the business community and not seen a difference, in those days. That's (SIC) been a lot of years, and the men who used to do that, the ones still alive, aren't so active anymore. They're more behind the scenes, sending one of their associates to meet over lunch, for example, and they aren't getting involved in every land deal or little detail in running the city.
\end{abstract}

Second echelon leaders, past and present. For Thometz, the second echelon category was

effectively a "catch-all" containing each decision-maker who did not fit into one of the previous categories. These leaders broadly fell into three categories: first, younger men who lacked the experience to move into a higher tier; second, older men retiring out of leadership; and third, men who had tremendous expertise or influence surrounding a particular topic or set of problems, but who lacked a generalized level of influence, and who were only invited to participant in particular decisions ${ }^{509}$. The present study finds that actors in Thometz' second echelon are loosely analogous to those found in the low-middle tier and low tier. This modern second echelon is broader than its historic counterpart, and contains

\footnotetext{
${ }^{508}$ Elkin, 1987a, pp. 76-77; 1987b, pp. $42-43$

${ }^{509}$ Thometz, 1963, pp. 56-57
} 
executives of national (and international) FIRE- and producer services firms, as well as retired (or term-limited) formal authorities who have elected to remain active in the decisionmaking process, anchor captains in charge of urban universities and hospitals, and civic chairs whose organizations comprise constituents from across Dallas’ MSA.

The present study also finds that this category no longer functions as a "farm league" from which actors in higher tiers draw their successors. As an aside, while only a minority of participants $(22 ; 27.8 \%)$ made reference to when this system broke down, the general consensus among participants links the breakdown of the city's structure of civic promotion to the time period between the late 1980s and mid-1990s; as one participant described it:

Back when the S\&L Crisis really gutted Dallas, I mean, really sent people packing for the suburbs, and ran a lot of the big companies out of business - that's when things got ugly with the "old guard." Men who would normally be looking for heirs to their empires were too busy trying to keep from going broke, and once people started moving out of Dallas for Richardson and Plano, they didn't so much care about what was going on in the big city.

Returning to the present second echelon, roughly two-thirds of participants $(52 ; 65.8 \%)$, including all 39 participants with primary expertise in Downtown Dallas, commented that the private-sector executives in this category are part of firms that operate in several states (or countries), and as such, have little interest in the politics of decision-making, while many of the former formal authorities seem to have little current interest in seeking new roles in city government, although a minority of participants (23, or $29.1 \%)$ speculated that this might change as the city's political landscape shifts; summarizing several other comments, one participant said that:

Thirty-, forty-, fifty years ago, young men "on their way up" got involved in what you might call "civic organizations," like the (Citizens) Charter Association or the (Dallas) Citizens Council. Now, young men and women "on their way up" in Dallas are part of global companies; even the big developers still headquartered in Dallas have offices all over the world. How can anyone spend their time working on improving this city, when they're working on projects in half-a-dozen (SIC) others?

Another, speculating about other reasons younger business executives avoid the politics of decision-making, suggested that: 
Everyone knows that the (city) council will be changing soon, as Dallas' voters wake up and realize what's happening with their tax money. Why get involved now, and maybe end up on the wrong side of the new city leaders? If you're going to be working in Dallas for a few years, it makes sense to wait and see how things shake out.

This study also finds that actors in the low-middle tier and low tier continue to lack significant generalized influence; all actors found in these tiers were described by at least one participant as being involved in particular projects, but not in a majority of citywide decisionmaking. Further, in describing the particular involvement of the anchor captains in these tiers, a slim majority $(41 ; 51.9 \%)$ of participants described them as filling "expertise gaps" for particular projects, particularly around those regarding higher education and healthcare. As one participant described it:

For the most part, if you don't run a business, your seat at the table only lasts as long as you can be the expert on a given topic being discussed. If you can do that long enough, and maybe make the right friends along the way, (then) that can change.

Decision-making power and nominations to decision-making committees. In addition to asking participants to give ratings of power for potential decision-makers in Dallas, the survey introduced in Chapter 3 asked participants to nominate 10 individuals to form a committee responsible for making a decision that would affect the entire city, and that needed to be broadly accepted by the city as a whole. As in the Thometz study ${ }^{510}$, several participants commented that 10 people would not be sufficient to ensure broad support, but many also noted that, among the 10 nominees, most would be able to "bring others in line" with the committee's decision. Participants who wanted to be able to nominate more than 10 people tended to be younger, with a median age of 39.1 (compared to the overall median age of 49.5), but there was no other discernable characteristic among them. In addition, some participants did not select the full 10 committee members; the lowest number of selected committee members was 6, and on average, participants

\footnotetext{
510 Thometz, 1963, pp. 47-48
} 
nominated 9.2 individuals to their hypothetical citywide decision-making team. The fact that some participants did not nominate a full 10 committee members negatively affects the validity of the results; nonetheless, table 6.05 shows the number of nominations that each decision-maker received, for all decision-makers receiving nominations from at least $10 \%$ (8) of the participants.

Table 6.05: Comparison between Citywide Decision-Making Committee Nominations and Decision-Maker Power Score

\begin{tabular}{|c|c|c|c|c|c|c|}
\hline \multirow{2}{*}{ Name } & \multirow{2}{*}{ Category } & \multirow{2}{*}{ Tier } & \multicolumn{2}{|c|}{$\begin{array}{c}\text { Committee } \\
\text { Nominations }\end{array}$} & \multicolumn{2}{|c|}{ Power } \\
\hline & & & Count & Rank & Score & Rank \\
\hline District-Based Councilmembers (14) & Formal Authorities & High Tier & 79 & 1 & 316 & 1 \\
\hline Mike Rawlings & Formal Authorities & High-Middle Tier & 73 & 2 & 299 & 4 \\
\hline A.C. Gonzalez & Formal Authorities & High-Middle Tier & 64 & 3 & 299 & 4 \\
\hline Alice Murray & Civic Chairs & High-Middle Tier & 48 & 4 & 279 & 9 \\
\hline Ray Hunt & First Tier Influentials & High-Middle Tier & 39 & 5 & 305 & 2 \\
\hline John Wiley Price & First Tier Influentials & High-Middle Tier & 32 & 6 & 303 & 3 \\
\hline Mabrie Jackson & Civic Chairs & Low-Middle Tier & 28 & 7 & 248 & 15 \\
\hline City Plan Commissioners (15) & Formal Authorities & High-Middle Tier & 26 & 8 & 277 & 10 \\
\hline Mary Suhm & Second Tier Influentials & Low-Middle Tier & 23 & 9 & 254 & 14 \\
\hline Harlan Crow & First Tier Influentials & High-Middle Tier & 21 & 10 & 292 & 6 \\
\hline Gerald Turner & Anchor Captains & Low-Middle Tier & 21 & 10 & 263 & 12 \\
\hline Dale Petrosky & Civic Chairs & Low-Middle Tier & 20 & 12 & 235 & 19 \\
\hline Joel T. Allison & Anchor Captains & Low Tier & 20 & 12 & 214 & 23 \\
\hline Ross Perot Jr. & First Tier Influentials & High-Middle Tier & 17 & 14 & 289 & 7 \\
\hline John Scovell & Second Tier Influentials & Low-Middle Tier & 16 & 15 & 233 & 20 \\
\hline Robert Chereck & Second Tier Influentials & Low-Middle Tier & 16 & 15 & 233 & 20 \\
\hline Clint McDonnough & Second Tier Influentials & Low-Middle Tier & 15 & 17 & 240 & 17 \\
\hline Kay Bailey Hutchison & First Tier Influentials & High-Middle Tier & 14 & 18 & 284 & 8 \\
\hline Michael Caffey & Second Tier Influentials & Low Tier & 14 & 18 & 214 & 23 \\
\hline David Daniel & Anchor Captains & Low Tier & 14 & 18 & 201 & 26 \\
\hline Caroline Hunt & First Tier Influentials & Low-Middle Tier & 13 & 21 & 267 & 11 \\
\hline Arcilia Acosta & Second Tier Influentials & Low Tier & 13 & 21 & 220 & 22 \\
\hline Angela Hunt & Second Tier Influentials & Low Tier & 12 & 23 & 206 & 25 \\
\hline Lee Jackson & Anchor Captains & Low Tier & 12 & 23 & 195 & 27 \\
\hline T. Boone Pickens & First Tier Influentials & Low-Middle Tier & 11 & 25 & 260 & 13 \\
\hline Ruth Collins Altshuler & First Tier Influentials & $\begin{array}{l}\text { Low-Middle Tier } \\
\end{array}$ & 11 & 25 & 247 & 16 \\
\hline Albert Black & Second Tier Influentials & Low Tier & 11 & 25 & 191 & 28 \\
\hline Bobby Lyle & First Tier Influentials & Low-Middle Tier & 10 & 28 & 239 & 18 \\
\hline Alan Walne & Second Tier Influentials & Low Tier & 9 & 29 & 183 & 31 \\
\hline Donna D. Halstead & Second Tier Influentials & Low Tier & 8 & 30 & 189 & 29 \\
\hline Jeff Staubach & Second Tier Influentials & Low Tier & 8 & 30 & 188 & 30 \\
\hline Steve Everbach & Second Tier Influentials & Low Tier & 8 & 30 & 175 & 32 \\
\hline
\end{tabular}

These data suggest that, broadly speaking, high tier and high-middle tier actors tended to receive the most nominations for citywide decision-making committees, while low-middle tier and low tier actors tended to receive the fewest nominations, although some exceptions do exist, and there is some overlap among these four tiers toward the middle of the table. What is clearer is that committee nominations and power are positively related; indeed, Spearman's $\varrho$ for these two variables is 0.793 , which is statistically significant at the $p<0.01$ level. While this is 
lower than the same calculation in the previous study of Dallas ${ }^{511}$, it is nonetheless a strong, positive indicator of the close relationship between a participant's perceptions of an actor's power, and their willingness to nominate that actor to make decisions at the citywide level. In effect, the question of committee selection is one of the practical application of power, therefore the strength of the correlation among these variables supports the use of a reputational analysis in studying the nature of power in Dallas.

In considering the role of power tiers within Dallas' decision-making structure, table 6.06 shows the total number of nominations to decision-making committees received by actors in each of the three tiers, and compares these to the hypothetical maximum number of nominations that could have been granted to these actors.

Table 6.06: Decision-Makers Selected to Serve on a Citywide Decision-Making Committee by Tier

\begin{tabular}{|l|c|c|c|c|}
\hline \multicolumn{1}{|c|}{ Tier } & Actors in Category & Total Nominations & $\begin{array}{c}\text { Total Possible } \\
\text { Nominations }\end{array}$ & $\begin{array}{c}\text { \% } \\
\text { High }\end{array}$ \\
\hline High-Middle & 1 & 79 & 79 & 711 \\
\hline Low-Middle & 11 & 334 & $46.00 \%$ \\
\hline Low & 11 & 184 & 790 \\
\hline
\end{tabular}

These data suggest that participants' nominations for citywide decision-making teams are skewed toward particularly powerful actors, with high tier being much more likely to be nominated for decision-making committees than high-middle tier actors, while actors in the lowmiddle tier and low tier were least likely to be nominated out of the four categories. As such, it is clear that participants would rely heavily on high tier and high middle tier actor for leadership on a citywide decision. The reliance on top-level leaders is in-line with findings from the previous reputational study of Dallas ${ }^{512}$, even though the contemporary makeup of top-level leadership is dramatically different from what it was over 50 years ago. These data continue to suggest the nature of decision-making at the citywide level; high tier and high-middle tier

511 Thometz, 1963, p. 49

512 1963, pp. 49-50 
actors are most likely to be strategically involved in a greater number of decisions, while lower-tier actors occupy less robust, though not unimportant roles.

Familiarity and shared committee service. How well do participants know the actors involved in Dallas' citywide decision-making process, and are these relationships related to participants' perceptions of citywide power? As part of their surveys, participants were asked to report on their level of familiarity with over 100 potential decision-makers in Dallas; possible responses included: "never heard of," "know slightly," "know well," and "personal friend or relative." These responses were recoded onto a scale of 1 to 4 , with “never heard of" corresponding to 1 , and the remaining scores coded to 2, 3, and 4, respectively. Table 6.07 shows the mean familiarity scores for each of the four tiers in Dallas' decision-making structure.

Table 6.07: Citywide Decision-Maker Mean Familiarity Score by Tier

\begin{tabular}{|l|c|}
\hline \multicolumn{1}{|c|}{ Tier } & Mean Familiarity Score \\
\hline High & 2.93 \\
\hline High-Middle & 2.20 \\
\hline Low-Middle & 2.25 \\
\hline Low & 2.28 \\
\hline
\end{tabular}

The previous reputational study of Dallas found that key leaders had the highest mean familiarity score, with top level actors having slightly lower mean familiarity scores, and second echelon actors having the lowest scores ${ }^{513}$. These data suggest that, while high tier actors have the highest mean familiarity scores, there is a notable decrease in mean familiarity with actors the high-middle tier, and an increase in mean familiarity as the tiers themselves decrease. These data also suggest that participants are most familiar with senior elected officials and lowertier decision-makers (some of whom are former elected leaders), while actors in the highest levels of informal influence are more distant. Finally, it should be noted that the differences

$$
5131963 \text {, p. } 53
$$


in mean familiarity among the four tiers are slight, and the overall correlation between mean familiarity and power score is not statistically significant ${ }^{514}$.

This study also asked participants to identify whether they had, in the past five years, served on a board or committee with each of the 101 potential citywide decision-makers, in addition to any individuals they wrote in. Table 6.08 shows the mean percentage of participants that actors in each thematic category and decision-making tier at the citywide level.

Table 6.08: Citywide Decision-Maker Mean Shared Board or Committee Service by Tier

\begin{tabular}{|l|c|}
\hline \multicolumn{1}{|c|}{ Tier } & Mean Shared Board or Committee Service \\
\hline High & $55.70 \%$ \\
\hline High-Middle & $23.55 \%$ \\
\hline Low-Middle & $23.51 \%$ \\
\hline Low & $26.35 \%$ \\
\hline
\end{tabular}

These data are similar to those in table 6.07, and suggest that that, on average, participants are most likely to have recently served on a board or committee with an actor in the high tier (i.e., a city councilmember), while actors in the high-middle tier and low-middle tier are least likely to have recent shared board or committee service. These findings are in-line with the previous reputational study of Dallas, which found that the city's elite private-sector leaders preferred to limit their committee involvement in order to keep out of the public eye, and reduce their likelihood of being involved in controversy ${ }^{515}$. Critically, the Spearman coefficient between shared committee service and power score, like with the correlation between familiarity and power score, is not statistically significant ${ }^{516}$. As a result, this study rejects the possibility that, in plain terms, participants merely nominated their friends, colleagues, or familiar-sounding names to serve on citywide decision-making teams, as well as the possibility that familiarity with any particular actors is linked to perceptions of power associated with that actor.

\footnotetext{
${ }^{514} \varrho=-.005, p>0.1$

515 Thometz, 1963, pp. 59-61

${ }^{516} \varrho=-0.168, p>0.1$
} 
Evaluation of Hypothesis 5. While Hypothesis 4 refreshes the image of Dallas' governing coalition, Hypothesis 5 refines this image, expanding upon urban scholarship regarding Dallas by focusing in on one of the city's central neighborhoods - North Oak Cliff. In the paragraphs that follow, this study will reframe data first presented in Chapter 4 in order to address the status of anchor institutions and CDCs within a neighborhood power structure. This study will first seek to establish the presence- and nature of organized neighborhood decision-making power. Then, as it did in the section regarding Hypothesis 4, this study will evaluate the relationship between power and nominations to decision-making committees. Third, it will evaluate the respective relationships between power and familiarity, and between power and recent shared board or committee service. Finally, it will relate these findings to the present hypothesis, in order to establish whether (and to what end) anchor institutions and CDCs are involved in neighborhood decision-making within North Oak Cliff.

North Oak Cliff's decision-makers. Out of this study's 79 participants, just over half (40) were able- and willing to answer survey items and interview questions regarding the decision-making process within North Oak Cliff, and the actors who have roles within it. As Chapter 4 details, these participants identified 16 individual- and group actors, who are particularly involved in neighborhood decision-making; these actors revisited in table 6.09.

\begin{tabular}{|c|l|l|}
\hline \multicolumn{2}{c|}{ Table 6.09: North Oak Cliff Decision-Makers } \\
\hline \multirow{4}{*}{ Category } & \multicolumn{1}{|c|}{ Name } & \multicolumn{1}{c|}{ Most Notable Affiliation(s) } \\
\hline \multirow{4}{*}{ Formal Authorities } & Scott Griggs & Dallas City Council \\
\cline { 2 - 3 } & Michael Anglin & City Plan Commission (CPC) \\
\cline { 2 - 3 } & Scott Hounsel & Zoning Board of Adjustment (BOA) \\
\cline { 2 - 3 } & Neva Dean & Sustainable Development \& Construction \\
\hline \multirow{3}{*}{ First Tier Influentials } & Jim Lake Jr. & Jim Lake Companies \\
\cline { 2 - 3 } & Joe McElroy & Real Estate Investor \\
\cline { 2 - 3 } & Tom Prohaska & Texas Pro Properties, LLC \\
\hline \multirow{3}{*}{$\begin{array}{c}\text { Second Tier } \\
\text { Influentials }\end{array}$} & Matt Segrest & Alamo Manhattan \\
\cline { 2 - 3 } & Farrokh \& Michael Nazerian & Exxir Capital \\
\cline { 2 - 3 } & David Eitches & Blackwood Developments, LLC \\
\cline { 2 - 3 } & David Spence & Good Space \\
\hline \multirow{2}{*}{ Civic Chairs } & Pam Conley & Old Springs Neighborhood Association \\
\cline { 2 - 3 } & Lisa Benskin & Better Block \\
\cline { 2 - 3 } & Jason Roberts & Methodist Dallas Medical Center \\
\hline Anchor Captains & Martin Koonsman &
\end{tabular}




\section{Contemporary distribution of neighborhood decision-making power. As}

Chapter 2 recounts, throughout the early-mid $20^{\text {th }}$ century, North Oak Cliff's strong (and exceptionally racist) business community wielded so much political influence that even city leaders dared not speak out against them publicly ${ }^{517}$, but by the late 1970 s, white flight, corporate abandonment, and the "us" versus "them" mentality dividing the city along the Trinity River left the neighborhood largely bereft of these resource-laden, politically connected actors. Racial and socioeconomic divisions split greater Oak Cliff into three camps - blue collar whites, African Americans moving into areas left behind by white flight, and a shrinking enclave of wealthy whites. Smaller ethnic- and socioeconomic groups agglomerated into particular blocks, and it was not uncommon for each block to be home to a different, independent community with its own set of leaders. As a result, there was not enough consensus for any particular leader to give the neighborhoods (including North Oak Cliff) a voice in Dallas politics ${ }^{518}$. As one participant put it:

For a long time, Dallas picked its leaders from at-large elections, which meant that the rich whites up in the north made all of the decisions. Down here, you had two dozen churches with pastors who all wanted to be the voice of the community, and every couple of blocks was a new neighborhood organization, and they all wanted to speak too. They were all too busy fighting each other for the scraps sent across the river by City Hall to ever mobilize, or to build the kind of civic clout you need to really make a difference. People could unite to fight off the things they didn't like, but couldn't come together to fight for things they really wanted, so the city stopped paying attention to us.

When participants were interviewed regarding how decisions in North Oak Cliff are made today, they described thematic categories of decision-makers, identical (in description, though not in individual membership) to those found in Dallas as a whole. Participants' comments in Chapter 4 described Councilmember Scott Griggs as being the center of neighborhood decision-making, with support from city staff and his hand-picked advisors. Data introduced in Chapter 4 also suggests the involvement of a number of long-tenured

${ }^{517}$ Hill, 1996, p. 169; Graff, 2008, p. 185

518 Merwin, 1977 
rentiers, real estate developers, neighborhood leaders, and the head of a local hospital in the decision-making process. Holistic examination of participants' comments suggests that while individuals may involve themselves in decision-making at the neighborhood level on particular projects, this involvement is often more informal than it is in Dallas as a whole. While at the citywide level, projects and policy priorities often necessitate the creation of formal task forces created by the mayor and city council, or the engagement of particular city departments, these formal structures are largely absent at the neighborhood level. Often, adhoc task forces are composed of long-standing leaders, who have a reputation for being able to gather and consolidate public interest around a project or policy, and accurately speak for their communities, but these kinds of leaders are in short supply in North Oak Cliff, primarily because so few people have been able to gather enough enduring support. In describing this situation, one participant said that:

The folks have all been fighting each other so long that, to be honest, they wouldn't know how to get along anymore, and everyone is so scared to lose out on what little they already have that they won't risk anyone else getting ahead enough to become a real leader.

To attempt to structure these various actors, and to serve as the basis for comparisons made in discussing the nature of neighborhood decision-making, table 6.10 extends survey data introduced Chapter 4, which listed mean power scores for each decision-maker, by including both total power scores and rank-order data. 
Table 6.10: Power Ratings of North Oak Cliff Decision-Makers

\begin{tabular}{|c|c|c|c|c|}
\hline $\begin{array}{l}\text { Rank } \\
\text { Order }\end{array}$ & Name & Category & Power Score & $\begin{array}{c}\text { Mean Power } \\
\text { Score }\end{array}$ \\
\hline 1 & Scott Griggs & Formal Authorities & 154 & 3.85 \\
\hline 2 & Michael Anglin & Formal Authorities & 136 & 3.40 \\
\hline 3 & Scott Hounsel & Formal Authorities & 135 & 3.38 \\
\hline 4 & Jim Lake Jr. & First Tier Influentials & 135 & 3.38 \\
\hline 5 & Matt Segrest & Second Tier Influentials & 129 & 3.23 \\
\hline 6 & Neva Dean & Formal Authorities & 127 & 3.18 \\
\hline 7 & Martin Koonsman & Anchor Captains & 122 & 3.05 \\
\hline 8 & Joe McElroy & First Tier Influentials & 115 & 2.88 \\
\hline 9 & Pam Conley & Civic Chairs & 114 & 2.85 \\
\hline 10 & Farrokh \& Michael Nazerian & Second Tier Influentials & 114 & 2.85 \\
\hline 11 & Lisa Benskin & Civic Chairs & 113 & 2.83 \\
\hline 12 & Tom Prohaska & First Tier Influentials & 111 & 2.78 \\
\hline 13 & David Eitches & Second Tier Influentials & 108 & 2.70 \\
\hline 14 & David Spence & Second Tier Influentials & 93 & 2.33 \\
\hline 15 & Jason Roberts & Civic Chairs & 67 & 1.68 \\
\hline
\end{tabular}

At the citywide level, power score and mean power score shared a strong, positive correlation with one another; for North Oak Cliff, these two share a perfect positive correlation $^{519}$, which suggests that actors with high power scores tended to receive more individual high scores (that is, more ratings of 3 and 4 on a four-point scale) than actors who received lower power scores. Additionally, when thematic categories are coded to a dummy variable, both total power score and mean power score are negatively correlated with thematic category ${ }^{520}$, suggesting that formal authorities and first tier influentials tend to have higher power scores than second tier influentials and civic chairs; anchor captains defy this trend, which is reflected in the relatively modest Spearman correlation coefficient ${ }^{521}$. Even with this more modest correlation (and obvious exception), these results suggest that there is a particular structure to decision-making in North Oak Cliff.

To test for the presence of tiers within the citywide decision-making structure, this study used Duncan's New Multiple Range Test (DMRT) to measure differences among mean power scores; the results of repeating this test for North Oak Cliff appear in table 6.11.

\footnotetext{
${ }^{519} \varrho=1.000, p<0.001$

520 Author's note: as with thematic categories in Dallas as a whole, formal authorities were coded with a 0 , first tier influentials were coded with a 1, second tier influentials were coded with a 2, civic chairs were coded with a 3, and anchor captains were coded with a 4.

${ }^{521} \varrho=-0.635, p<0.05$
} 
Table 6.11: North Oak Cliff Decision-Maker Levels of Power

\begin{tabular}{|c|c|c|c|c|}
\hline \multirow{2}{*}{ Name } & \multirow{2}{*}{ Thematic Category } & \multicolumn{3}{|c|}{ Subset for $\alpha=0.05$} \\
\hline & & Low Tier & Middle Tier & High Tier \\
\hline Scott Griggs & Formal Authorities & & & 3.85 \\
\hline Michael Anglin & Formal Authorities & & 3.40 & \\
\hline Scott Hounsel & Formal Authorities & & 3.38 & \\
\hline Jim Lake Jr. & First Tier Influentials & & 3.38 & \\
\hline Matt Segrest & Second Tier Influentials & & 3.23 & \\
\hline Neva Dean & Formal Authorities & & 3.18 & \\
\hline Martin Koonsman & Anchor Captains & & 3.05 & \\
\hline Joe McElroy & First Tier Influentials & & 2.88 & \\
\hline Pam Conley & Civic Chairs & & 2.85 & \\
\hline Farrokh \& Michael Nazerian & Second Tier Influentials & & 2.85 & \\
\hline Lisa Benskin & Civic Chairs & & 2.83 & \\
\hline Tom Prohaska & First Tier Influentials & & 2.78 & \\
\hline David Eitches & Second Tier Influentials & & 2.70 & \\
\hline David Spence & Second Tier Influentials & 2.33 & & \\
\hline Jason Roberts & Civic Chairs & 1.68 & & \\
\hline
\end{tabular}

In general, these data support the findings in table 6.10; formal authorities occupy higher

positions, and civic chairs tend to occupy lower positions, but there is also notable overlap,

especially throughout the middle tier, figure 6.02 presents a visual representation of these data.

Figure 6.02: The Structure of North Oak Cliff Decision-Making Power

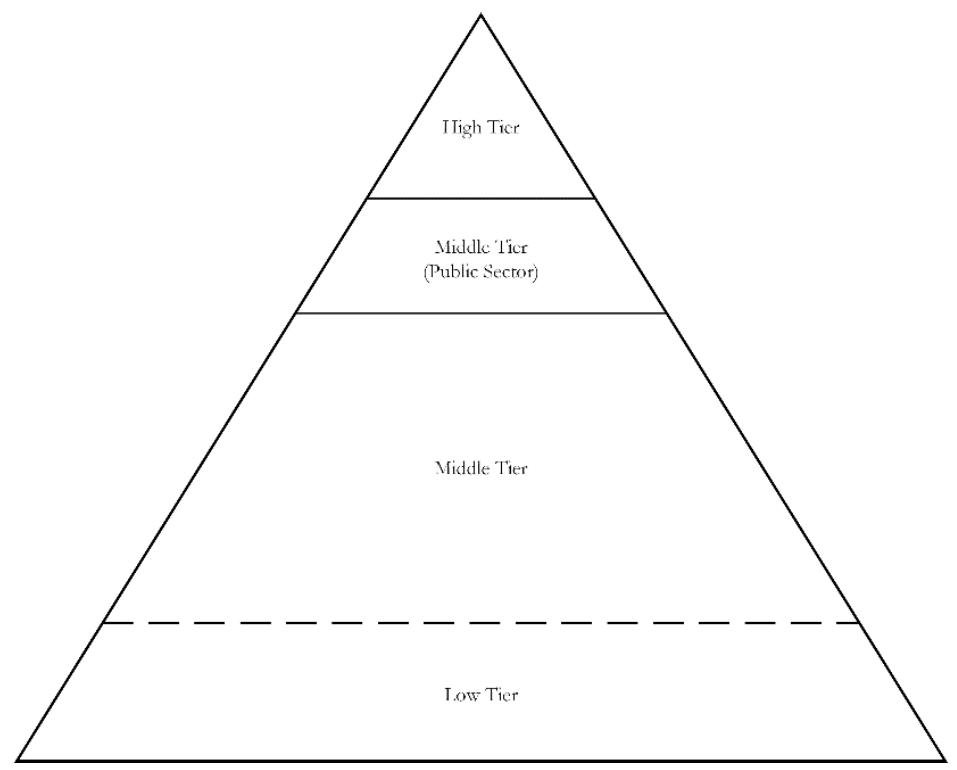

These findings take into account data in table 6.11, as well as participant observations first explored in Chapter 4. In the paragraphs that follow, this study will first discuss the North 
Oak Cliff decision-making structure broadly, and then it will individually examine each of this structure's three tiers.

North Oak Cliff's decision-making structure, broadly. At the citywide level, this study identified four tiers of decision-making power - high tier, high-middle tier, low-middle tier, and low tier, and evaluated them with respect to Thometz' three-tier model. In North Oak Cliff, this study identifies three tiers: high tier, middle tier, and low tier, and equates them with two of Thometz' three tiers - key leaders and second echelon. Though awkward, this is in-line with participant observations about decision-making in North Oak Cliff; primarily that formal decision-making is concentrated within the city councilmember's office, while other actors are limited to using their often-limited resources to influence his decisions one way or another. In the paragraphs that follow, this study will outline four key differences between the decision-making structures of North Oak Cliff and Dallas as a whole.

First, while North Oak Cliff (like Dallas as a whole) once operated under an entrepreneurial regime, commercial disinvestment, residential abandonment, and political disconnection flowing from white flight and suburbanization induced an antiregime. Briefly, recall that an antiregime is one possible result of a collapsed (or otherwise failed) governing coalition, composed of fragmented interest groups that fail to coalesce around a particular agenda, establish ties with the business community, or reconcile their various agendas with the political system ${ }^{522}$. An antiregime is successful at blocking unfavorable policies and development, but because it lacks the support of bureaucrats or organized institutions, it is unable to promote (or even passively allow) beneficial urban policies or development projects $^{523}$.

${ }^{522}$ DeLeon, 1992, p. 561

523 1992, pp. 561-562 
Returning to North Oak Cliff, historical evaluation of the neighborhood suggests that, during the neighborhood's decline through the 1970s and 1980s, would-be coalition members ${ }^{524}$ lacked the financial capital and connections to the Dallas political machine needed to create a successor coalition, and while some leaders emerged, none successfully pulled together competing interest groups into an enduring coalition with a shared agenda, and instead, were only successful in keeping out development, rather than selectively allowing particular development projects to breathe new life into an economicallymarginalized community ${ }^{525}$.

Second, when district-based council leadership returned to the neighborhood following the 1991 reorganization, there were no strong community institutions in place, and as a result, city councilmembers have been able to exert more influence here than in other districts. Recall that, in Chapter 4, participants praised the results of issue-based coalitions when they can successfully form; of the 40 participants highly knowledgeable about decision-making North Oak Cliff, all 40 mentioned that these coalitions largely fail to endure beyond individual issues; describing this, one participant said that:

There's 50 years of bad blood around here; racism, classism, (and) fights (that have) gone on so long, nobody remembers why they don't get along with the people across the street. You have rich living next to middle class, and "almost broke" living next to "dead broke," and so no one issue affects anyone the same as their neighbors. That's why nobody gets together, outside of a few.

Another commented that:

People south of the Trinity, they get riled up and unite about particular problems, like getting streets fixed, or stopping a specific development, but after that gets resolved, they all go their separate ways, and start all over again when something else comes up. Issues and problems can make a movement, but they can't make a community. It's (SIC) just not the same thing.

\footnotetext{
524 e.g. small business owners, neighborhood leaders, leaders of minority communities

525 Atkinson, 1975; Merwin, 1977
} 
Qualifying the above sentiments, 37 participants (92.5\%) made an exception to this for the

Old Oak Cliff Conservation League (OOCCL). Commenting directly about the OOCCL and its longevity, one participant said that:

\begin{abstract}
The [OOCCL] normally only takes a stand when a clear majority of its neighborhoods agree on something, and whatever they decide is usually some kind of compromise. They stay pretty neutral, supporting things like better schools, historic preservation districts, community service, (and) fixing roads, and they usually oppose things like widening a freeway, or building a big office building right next to houses. The only way that organization sticks together is if nobody rocks the boat too hard, and makes some neighborhood mad enough to want out. Individual neighborhoods might get more agitated, and take to the streets about something, but the whole group tends to let that happen, and remain overall pretty quiet.
\end{abstract}

Third, earlier in this chapter, this study found that at the citywide level, the highest echelons of leadership are involved in most aspects of decision-making, either individually or through proxies, while lower tiers tend to be occupied by less-active actors, who are generally only involved in particular projects. Now, this study finds a similar differentiation in North Oak Cliff, with the one high tier actor - Councilmember Scott Griggs - being involved in nearly every neighborhood-level decision, as noted in Chapter 4. At the same time, middle tier and low tier actors are generally only involved in particular projects - chiefly those involving real estate development. Of the 40 participants, $12(30.0 \%)$ clearly made this distinction by specifically mentioning economic development, while another 17 (42.5\%) spoke more broadly about concerns including area schools, police presence, strategic use of code enforcement (or "code crawls"), among others. Additionally, outside of the publicsector officials found in the middle-tier, there is tremendous disagreement among decisionmakers, often resulting from years of mistrust, primarily among racial- and ethnic groups, as well as between wealthier residents and their poorer neighbors. It should be noted, however, that 31 of the participants $(77.5 \%)$ mentioned that, to some extent, these overall divisions are softening, commonly stating that "things are better than they were." 
Fourth, recall that at the citywide level, higher decision-making tiers (bigh tier and highmiddle) were considered to be essentially closed to new membership; elected officials, appointees, and bureaucrats are largely replaced on a "one-for-one" basis, so these positions are effectively only available when there is a vacancy, while first tier influentials are created by virtue of family ties or invitation (i.e., "born in or blessed in"), and so this echelon is, in practical terms, only available to particular actors. Meanwhile, lower tiers (low-tier and lowmiddle tier) were considered more open to membership, with no fixed limits on size or qualifications. In North Oak Cliff, this study finds a similar combination of "restricted" and "unrestricted" tiers. In figure 6.02, this is conceptualized as a solid line between the high tier and the middle tier, and a dashed line between the middle tier and low tier. Figure 6.02 also shows a second, solid line dividing the middle tier, this represents the presence of particular actors within this tier - formal authorities - whose positions are effectively "locked" in place, and are only open to new actors as openings are created, most commonly as the result of a vacancy.

Note that, as with Dallas as a whole, North Oak Cliff's high tier, as well as the top positions in its middle tier are composed of public-sector officials who are replaced when vacancies exist; as a result, these positions are comparatively static, and participants unanimously agreed that actors in these positions tend to remain in them for years, and only leave office due to term limits, promotions, or retirement. By comparison, the remainder of the middle tier is more open; for example, another developer could attempt to develop property in North Oak Cliff, or a coalition of community members could form around a particular issue. Thus, taken holistically with participant observations about the overall decision-making structure of North Oak Cliff, the data in table 6.11 and figure 6.02 suggest that Councilmember Griggs, and to a slightly lesser extent, the public-sector employees of the middle-tier are the only constants found within neighborhood-wide decision-making, while 
other leaders generally only involve themselves on an ad-hoc bases, forming alliances with one another on one project, while simultaneously opposing each other on others. Describing the overall decision-making structure and process within North Oak Cliff, one participant said that:

\begin{abstract}
What's happening, especially in the Bishop Arts part of the neighborhood, is a lot like what happens in the rest of Dallas, but on a smaller scale, with Councilmember Griggs calling the shots, and delegating out to make things happen, while everyone else tries to influence his decisions on a project that affects them, either as residents, or as developers looking to make some money before the boom goes bust again.
\end{abstract}

Key leaders and top level, past and present. Recall that, prior to the 1991 city council restructure, North Oak Cliff was effectively 'cut off” from formal leadership, with no links to Dallas' political machine, no significant private-sector coalition, and an antiregime in which no single individual or organization held enough support to be widely accepted as a speaker for the community ${ }^{526}$. Following the restructure, the highest echelon of neighborhood leadership has been occupied by the neighborhood's city councilmember, who is the primary community decision-maker. Participants unanimously observed that Councilmember Griggs, in addition to effectively limitless authority over policy decisions and land-use within the community, also receives professional deference from members of the city's bureaucracy regarding code enforcement, infrastructure investment, and public safety matters, among many others. Fifteen participants $(37.5 \%)$ also considered the role of the historical dearth of investment in the neighborhood as a factor; with few competing economic interests taking up the councilmember's time, he has little need for additional support in decision-making beyond his current staff and advisors. As a result, many participants (38; 95\%) observed that there are few opportunities for other actors to meaningfully oppose a decision with which the councilmember agrees, suggesting in various (often colorful) terms: "There's Scott

\footnotetext{
${ }^{526}$ Merwin, 1977
} 
(Griggs), and then there's everyone else. He has the power to decide, and everyone else can only try to get him to change his mind."

Second echelon leaders, past and present. For Dallas' citywide decision-making structure, this study found that a high-middle tier of leaders, composed of highly influential business executives, civic philanthropists, and city staff had particularly high levels of influence over decisions made by bigh tier actors. This is not the case in North Oak Cliff; while table 6.15 shows formal authorities and first tier influentials occupying the highest three positions among the middle tier, 23 participants (57.5\%) agreed that these actors often do not exert any outsized degree of influence over Councilmember Griggs, when compared to other actors involved in neighborhood decision-making; instead, these participants often described Griggs as, as one participant put it, "working hard to not show favorites when he makes a decision." A minority of participants $(6 ; 15.0 \%)$ strongly disagreed, describing the councilmember as a "sellout" or "shill for gentrification," although of these, only 2 were able to point out a specific project to support their claim. Instead, nearly all $(39 ; 97.5 \%)$ of participants observed that the private- and third-sector actors found within the middle-tier 0often work together in ad-hoc partnerships as evidence of community support for a particular project or policy request, although these partnerships are fluid, and fail to result in the formation of enduring coalitions. One participant clearly summarized this scenario, describing it asfollows:

People around here get passionate about an issue, and they go out and find other people with that same passion, and they form these grand coalitions around it. The problem is that nobody really invests in team-building, or forming relationships among the different members, so these sorts of coalitions just don't last very long.

Further complicating the issue, all 40 participants variously identified competing agendas within North Oak Cliffs decision-making structure, supporting a three-agenda competition among pro-development, progressive-development, and anti-development constituencies; 
among active, engaged stakeholders in North Oak Cliff, participant observations suggest that there are no neutral parties, with respect to economic development.

Looking first at the pro-development agenda, table 6.12 shows the names most commonly associated with this perspective; this table also includes a summary entry for actors who did not receive enough participant nominations to be individually included for in-depth evaluation.

Table 6.12: North Oak Cliff Participant-Identified Pro-Development Agenda Supporters

\begin{tabular}{|l|c|c|}
\hline \multirow{2}{*}{\multicolumn{1}{|c|}{ Actor }} & Number & Participant Mentions \\
\cline { 2 - 3 } & 27 & Percentage \\
\hline Matt Segrest & 29 & $72.5 \%$ \\
\hline David Eitches & 17 & $42.5 \%$ \\
\hline Farrokh \& Michael Nazerian & 13 & $32.5 \%$ \\
\hline Martin Koonsman & 13 & $32.5 \%$ \\
\hline Tom Prohaska & 11 & $27.5 \%$ \\
\hline Joe McElroy & 9 & $22.5 \%$ \\
\hline Scott Griggs & 5 & $12.5 \%$ \\
\hline Jim Lake, Jr. & 3 & $7.5 \%$ \\
\hline David Spence & 2 & $5.0 \%$ \\
\hline Other Actor Not Listed & 9 & $22.5 \%$ \\
\hline
\end{tabular}

These data suggest that participants identified Matt Segrest, David Eitches, Tom Prohaska, and Farrokh \& Michael Nazerian most closely with an agenda described by one participant as a "mix of modern steel and glass high-rises that tower over gentrified, whitewashed historic properties that nobody who grew up here could afford to live in" and another called "the dream of millennials imposed on the reality of blue-collar neighborhoods." In more concrete terms, participants most commonly discussed attempts by these actors to lobby for relaxed development restrictions, especially regarding building height and density (21; $52.5 \%)$, reduced mandatory minimum parking allotments $(18 ; 45 \%)$, reduced (or eliminated) affordable housing minimums $(15 ; 37.5 \%)$, reduced (or eliminated) restrictions on the types of businesses allowed to occupy proposed developments $(13 ; 32.5 \%)$, and expanded limits to TIF support for development projects throughout the neighborhood $(13 ; 32.5 \%)$. This

527 Author's note: subcategory totals do not add up to, respectively, 40 or $100 \%$ 
agenda is largely market-based, and is fueled by migration of younger, wealthier whites back into North Oak Cliff. Describing this, one participant said that:

It's the market in Dallas, but you see it in all kinds of other big cities. People are moving back to these old neighborhoods because they like the vibe, but not all of them want a fixerupper house - they want to be surrounded by history without having to worry about old knob-and-tube (electrical wiring) or lead pipes. North Oak Cliff is unique, though, because so much of it is still here - most cities bulldozed these old buildings back in the fifties.

Opposing this agenda are progressive-development and anti-development advocates;

these actors (and the number of participants who identified them with a particular agenda)

are listed, respectively, in tables 6.13 and 6.14. As with table 6.12, these tables each also

include a summary entry for actors who did not receive enough participant nominations to

be individually included for in-depth evaluation.

Table 6.13: North Oak Cliff Participant-Identified Progressive Development Agenda Supporters

\begin{tabular}{|l|c|c|}
\hline \multirow{2}{*}{\multicolumn{1}{|c|}{ Actor }} & \multicolumn{2}{|c|}{ Participant Mentions 528} \\
\cline { 2 - 3 } & Number & Percentage \\
\hline Scott Griggs & 34 & $85.0 \%$ \\
\hline Jim Lake, Jr. & 29 & $72.5 \%$ \\
\hline Lisa Benskin & 24 & $60.0 \%$ \\
\hline Michael Anglin & 23 & $57.5 \%$ \\
\hline Scott Hounsel & 21 & $52.5 \%$ \\
\hline Neva Dean & 19 & $47.5 \%$ \\
\hline Jason Roberts & 13 & $32.5 \%$ \\
\hline David Spence & 12 & $30.0 \%$ \\
\hline Other Actor Not Listed & 15 & $37.5 \%$ \\
\hline
\end{tabular}

Table 6.14: North Oak Cliff Participant-Identified Anti-Development Agenda Supporters

\begin{tabular}{|l|c|c|}
\hline \multirow{2}{*}{ Actor } & \multicolumn{2}{|c|}{ Participant Mentions ${ }^{529}$} \\
\cline { 2 - 3 } & 40 & Percentage \\
\hline Pam Conley & 6 & $100.0 \%$ \\
\hline Other Actor Not Listed & \multicolumn{2}{|c|}{$15.0 \%$} \\
\hline
\end{tabular}

These data suggest that, overall, there is significant agreement among participants regarding

which actors are associated with a progressive position on development in North Oak Cliff.

Describing this positon, participants identified a number of characteristics, including

community involvement in new development projects, including public design charrettes as

part of the design process for new projects $(27 ; 67.5 \%)$, community needs assessments (22;

$55.0 \%)$, local ownership of businesses in new commercial spaces $(13 ; 32.5 \%)$, and

528 Author's note: subcategory totals do not add up to, respectively, 40 or $100 \%$

529 Author's note: subcategory totals do not add up to, respectively, 40 or $100 \%$ 
modifications to TIF eligibility requirements to ensure that, whenever possible, existing residents can afford rents in new housing units $(9 ; 22.5 \%)$.

Although participants' opinions differ on exactly what constitutes progressive development in North Oak Cliff, many appeared to, as the adage goes, "know it when they saw it." Citing specific examples of the work of actors supporting the progressivedevelopment agenda, 22 participants (55\%) referenced a recent development proposal by Matt Segrest's company, Alamo Manhattan, wherein community uproar over the design proposal led to a series of meetings between residents and the developer at Griggs' behest. These meetings eventually led to a series of significant design changes, accommodations for affordable housing units, and additional parking to address residents' concerns ${ }^{530}$.

For a smaller subset of decision-makers, the progressive-development agenda makes too many concessions, resulting in unnecessary displacement and what 5 participants $(12.5 \%)$ called "the neighborhood losing its soul." Participants unanimously named Pam Conley as the primary advocate for this position, which proffers heavy restrictions on newand infill development, including strict interpretations (and enforcement) of zoning ordinances $(19 ; 47.5 \%)$, limits on how many residential- and commercial tenants can be displaced by development $(15 ; 37.5 \%)$, and a moratorium on new development until existing codes and zoning can be updated to keep new development in-line with extant buildings (7; $17.5 \%$ ). Speaking of Conley's efforts specifically, participants commented on her fights to oppose the use of neighborhood streets for overflow parking $(32 ; 80 \%)$, density increases that result from tearing down existing structures in favor of new development $(16 ; 40.0 \%)$, and the creation of new restaurants with late hours in residential zones $(11 ; 27.5 \%)$.

\footnotetext{
${ }^{530}$ cf. Appleton, 2012a; 2012b; 2015b; 2015c; Chow, 2015; Griggs, 2016; R. Stone, 2015b
} 
Although participants often $(29 ; 72.5 \%)$ expressed frustration at Conley's hardline position with respect to development, most $(28 ; 70 \%)$ considered her an effective voice when Councilmember Griggs and other formal authorities are powerless. For example, 13 participants $(32.5 \%)$ mentioned that, as long as a development project is within the constraints of how a plot is zoned, and does not seek TIF funding, Councilmember Griggs is largely unable to prevent it, even if he disagrees with the development itself. In these cases, those participants admitted that Conley's knowledge of how to fight development and willingness to do so is often the only hope residents have to prevent disruptive development. While Conley is not always successful, a strong minority of participants $(14 ; 35.0 \%)$ noted that she often wins significant battles over zoning and new development against much larger, better-funded developers ${ }^{531}$. Describing this, one participant said that:

Pam (Conley) is a bulldozer, when it comes to protecting the quality of life for the poor folks living in the neighborhoods around here. Subtle, she ain't, but she's about the strongest, most effective change agent outside of the (city) council. If a fight can be won - and not all of them can - she stands the best chance of winning it.

While middle tier actors represent a majority of North Oak Cliff's contemporary second echelon, low tier actors David Spence and Jason Roberts tend to operate independently of other decision-makers, circumventing the larger decision-making process, albeit with the support of Councilmember Griggs. Looking first at second tier influential David Spence, whose company (Good Space) purchases vacant buildings, many of which are slated for demolition, renovates them, and rents them to local businesses and residents ${ }^{532}$. Many participants credited Spence for much of the initial revitalization of the Bishop Arts District within North Oak Cliff (23; 57.5\%), for saving commercial corridors throughout North Oak Cliff $(23 ; 57.5 \%)$, and for ensuring that, within his own projects, existing development is not

\footnotetext{
531 cf. Appleton, 2012a; 2012b; 2013d; Laussade, 2016; R. Stone, 2015a; Treviño, 2014

532 Appleton, 2013a; Best of Dallas, 2013; Mooney, 2014; Perez, 2015; Schutze, 2010; 2015; R. Stone, 2011
} 
displaced $(11 ; 27.5 \%)$. One participant described Spence as a "privateer developer - not part of the mainstream, but supported by City Hall for doing what the big developers can't do, which is keep the neighborhood fabric intact."

On a smaller scale, participants also identified civic chair Jason Roberts, who has been involved in two key projects within North Oak Cliff; first, the Oak Cliff Transit Authority, which wrote a successful application for 23 million dollars in federal TIGER funding to build a new streetcar line connecting the former "streetcar suburb" with Downtown Dallas ${ }^{533}$; and second, the Better Block Project, which collaborates with local residents, business owners, and artists to adapt intersections and vacant city blocks to include pop-up shops, improved pedestrian and bicycle infrastructure, and urban plazas using easilyremovable supplies like temporary paint, potted plants, and lightweight outdoor furniture ${ }^{534}$. Participants often commented that these projects draw attention to distressed areas within the neighborhood; as one put it:

People outside the area see Bishop Arts, and they think that Oak Cliff is doing alright now, and that maybe it's all turned around. That's just not true, though - you go three blocks away from that area and it's all still run down. Jason (Roberts) does a good job shining a light on places like that, showing what could happen in places that still need attention.

Some participants expressed concern over both Roberts' and Spence's efforts in North Oak

Cliff, accusing them of catering to the demands of newcomers to the neighborhood - the wealthier, white gentrifiers who are (slowly) displacing extant residents. As one put it:

You can't say that you're building for the neighborhood when you renovate a building to avoid having to build enough parking, and then bring in a tenant that charges $\$ 10$ for a slice of pie. People here don't even make $\$ 10$ an hour; at least, the people who were already here don't. People here don't have Saturdays off, so what good is an art project to them? How does a bike lane that cuts out a lane of traffic help someone get to work on time? For that matter, the streetcar doesn't even run when people need to get to work, so who really benefits?

${ }_{533}$ cf. Appleton, 2013b; 2015d; Austin, 2015; Crain, 2009

534 cf. Roberts, 2010; R. Ross, 2012; Team Better Block, 2016a 
Nonetheless, even their detractors hold Roberts and Spence in high regard for bringing positive attention to the neighborhood, even if the results (i.e. gentrification) are problematic. Many participants $(26 ; 65 \%)$ commented that, even when infill development brings additional parking headaches and traffic, the businesses are locally-owned, and hire local employees; one participant suggested that:

We don't like that the streets are packed with cars that don't live here, but at least the shops hire locally, and the owners live around here - if not in southern Dallas, then at least somewhere in the area. It's not like in other places, where the owner is a corporation out of some other state, who couldn't care less what happens here, or which neighbors get hurt by their businesses. When someone lives nearby, at least we have a chance to work with them and make things right.

Decision-making power and nominations to decision-making committees. In addition to asking participants to give ratings of power for potential decision-makers in North Oak Cliff, the survey introduced in Chapter 3 asked participants to nominate 10 individuals to form a committee responsible for making a decision that would affect the entire neighborhood, and that needed to be broadly accepted by the neighborhood as a whole. Much like in Dallas citywide, some participants did not select the full 10 committee members; the lowest number of selected committee members was 4, and on average, participants nominated 7.25 individuals to their hypothetical neighborhood decision-making team. The fact that some participants did not nominate a full 10 committee members negatively affects the validity of the results; nonetheless, table 6.17 shows the number of nominations that each decision-maker received, for all decision-makers receiving nominations from at least $10 \%$ (4) of the participants. 
Table 6.15: Comparison between North Oak Cliff Decision-Making Committee Nominations and Decision-Maker Power Score

\begin{tabular}{|c|c|c|c|c|c|c|}
\hline \multirow[t]{2}{*}{ Name } & \multirow[t]{2}{*}{ Category } & \multirow[t]{2}{*}{ Tier } & \multicolumn{2}{|c|}{$\begin{array}{c}\text { Committee } \\
\text { Nominations }\end{array}$} & \multicolumn{2}{|c|}{ Power } \\
\hline & & & Count & Rank & Score & Rank \\
\hline Scott Griggs & Formal Authorities & High Tier & 40 & 1 & 154 & 1 \\
\hline Michael Anglin & Formal Authorities & Middle Tier & 28 & 2 & 136 & 2 \\
\hline Pam Conley & Civic Chairs & Middle Tier & 27 & 3 & 114 & 9 \\
\hline Lisa Benskin & Civic Chairs & Middle Tier & 27 & 3 & 113 & 11 \\
\hline Scott Hounsel & Formal Authorities & Middle Tier & 25 & 5 & 135 & 3 \\
\hline Neva Dean & Formal Authorities & Middle Tier & 24 & 6 & 127 & 6 \\
\hline Martin Koonsman & Anchor Captains & Middle Tier & 22 & 7 & 122 & 7 \\
\hline Matt Segrest & Second Tier Influentials & Middle Tier & 21 & 8 & 129 & 5 \\
\hline Farrokh \& Michael Nazerian & Second Tier Influentials & Middle Tier & 19 & 9 & 114 & 9 \\
\hline Jim Lake Jr. & First Tier Influentials & Middle Tier & 17 & 10 & 135 & 3 \\
\hline Joe McElroy & First Tier Influentials & Middle Tier & 16 & 11 & 115 & 8 \\
\hline David Eitches & Second Tier Influentials & Middle Tier & 15 & 12 & 108 & 13 \\
\hline Jason Roberts & Civic Chairs & Low Tier & 13 & 13 & 67 & 15 \\
\hline Tom Prohaska & First Tier Influentials & Middle Tier & 10 & 14 & 111 & 12 \\
\hline David Spence & Second Tier Influentials & Low Tier & 10 & 14 & 93 & 14 \\
\hline
\end{tabular}

Data in table 6.15 suggest that, within North Oak Cliff, high tier actor Scott Griggs received the maximum possible nominations to decision-making committees. Much like in Dallas citywide, there is a visible degree of overlap among actors in the various thematic categories. Further echoing this study's findings at the citywide level, Spearman's $\varrho$ for these two variables is 0.702 , a finding that is statistically significant at the $p<0.01$ level. While this is lower than the same calculation at the citywide level, it is nonetheless a strong, positive indicator of the close relationship between a participant's perceptions of a given actor's power, and their willingness to nominate that actor to make decisions at the neighborhood level. In addition, these results help validate the use of a reputational analysis in studying the nature of power in North Oak Cliff.

In considering the role of power tiers within North Oak Cliffs decision-making structure, table 6.16 shows the total number of nominations to decision-making committees received by actors in each, and compares these to the hypothetical maximum number of nominations that could have been granted to these actors. 
Table 6.16: Decision-Makers Selected to Serve on a North Oak Cliff Decision-Making Committee by Tier

\begin{tabular}{|l|c|c|c|c|}
\hline \multicolumn{1}{|c|}{ Tier } & Number in Category & Total Nominations & $\begin{array}{c}\text { Total Possible } \\
\text { Nominations }\end{array}$ & $\%$ \\
\hline High Tier & 1 & 40 & 40 & $100 \%$ \\
\hline Middle Tier & 12 & 251 & 480 & $52.3 \%$ \\
\hline Low Tier & 2 & 23 & 80 & $28.8 \%$ \\
\hline
\end{tabular}

Taken with data from table 6.15, these data suggest that participants' nominations for neighborhood decision-making teams are skewed heavily in favor of Councilmember Griggs, evidenced his unanimous participant nominations for decision-making committees than other actors. Outside of Councilmember Griggs, these data show that middle tier actors are about half as likely to be nominated for neighborhood decision-making committees, but are nonetheless twice as likely as low tier actors to be selected. These data are in-line with aforementioned participant observations about the nature of decision-making in North Oak Cliff, particularly the centrality of Councilmember Griggs in decision-making, and the "outsider" status of low tier actors with respect to the politics of decision-making.

Familiarity and shared committee service. How well do participants know the actors involved in North Oak Cliffs decision-making process, and are these relationships related to participants' perceptions of neighborhood power? Table 6.17 shows the mean familiarity scores for each of the three tiers in North Oak Cliff's decision-making structure.

Table 6.17: North Oak Cliff Mean Familiarity Score by Category and Tier

\begin{tabular}{|l|c|}
\hline \multicolumn{1}{|c|}{ Tier } & Mean Familiarity Score \\
\hline High Tier & 2.23 \\
\hline Middle Tier & 2.24 \\
\hline Low Tier & 2.38 \\
\hline
\end{tabular}

At the citywide level, key leaders were found to have the highest familiarity score among the three decision-making tiers. Table 6.17 suggests that, for North Oak Cliff, these actors have the lowest mean familiarity scores, while low tier actors have the highest mean familiarity scores. However, as with data at the citywide level, these differences are slight. Additionally, 
as this study found for Dallas citywide, the Spearman coefficient between familiarity and participants' perceptions of power is not statistically significant ${ }^{535}$.

This study also asked participants to identify whether they had, in the past five years, served on a board or committee with each of the actors that they nominated to neighborhood decision-making committees; these data are reported in table 6.18.

Table 6.18: North Oak Cliff Mean Shared Committee Service by Tier

\begin{tabular}{|l|c|}
\hline \multicolumn{1}{|c|}{ Tier } & Mean Shared Board or Committee Service \\
\hline High Tier & $22.5 \%$ \\
\hline Middle Tier & $7.9 \%$ \\
\hline Low Tier & $15.0 \%$ \\
\hline
\end{tabular}

At the citywide level, participants were most likely to have recently served on a board or committee with high tier actors, followed by low tier actors. As the above data suggest, this pattern continues to hold for North Oak Cliff, although it should be noted that participants reported less shared board or committee service with these actors than their counterparts at the citywide level. In addition, it is critical to note that the correlation between shared committee service and perceptions of power is not statistically significant ${ }^{536}$. Therefore, as with Dallas as a whole, this study is able to reject the possibility that, in North Oak Cliff, participants' perceptions of power were skewed by proximity to various actors throughout the neighborhood.

Evaluation of Hypothesis 6. While Hypothesis 5 focuses on one of the city's central neighborhoods - North Oak Cliff, Hypothesis 6 examines the city's innermost neighborhood - Downtown Dallas. In the paragraphs that follow, this study will reframe data from Chapter 4 in order to address the status of anchor institutions and CDCs within a neighborhood power structure. First, this study will seek to establish the presence- and nature of organized neighborhood decision-making power. Then, it will evaluate the 
relationship between power and nominations to decision-making committees. Third, it will evaluate the respective relationships between power and familiarity, and between power and recent shared board or committee service. Finally, it will relate these findings to the present hypothesis, in order to establish whether (or to what end) anchor institutions and CDCs are involved in neighborhood decision-making within Downtown Dallas.

Downtown Dallas' decision-makers. Out of this study's 79 participants, just under half (39) were able- and willing to answer survey items and interview questions regarding the decision-making process within Downtown Dallas, and the actors who have roles within it. These participants identified 18 individual- and group actors, who are particularly involved in neighborhood decision-making; those actors are listed in table 6.19.

\begin{tabular}{|c|c|c|}
\hline Category & Name & Most Notable Affiliation(s) \\
\hline \multirow{5}{*}{ Formal Authorities } & Philip T. Kingston & Dallas City Council \\
\hline & A.C. Gonzalez & City Manager \\
\hline & Karl Zavitkovsky & Office of Economic Development \\
\hline & Mark Rieves & Zoning Board of Adjustment \\
\hline & Paul Ridley & City Plan Commission \\
\hline \multirow{4}{*}{ First Tier Influentials } & Ray Hunt & Hunt Consolidated \\
\hline & Harlan Crow & Crow Holdings \\
\hline & Ross Perot Jr. & Hillwood \\
\hline & Jody Grant & Texas BankCap \\
\hline \multirow{8}{*}{$\begin{array}{l}\text { Second Tier } \\
\text { Influentials }\end{array}$} & Scott Krikorian & Trammell Crow Co. (subsidiary of CBRE) \\
\hline & Jim Truitt & Forest City \\
\hline & Michael Caffey & C.B. Richard Ellis (CBRE) \\
\hline & Vince Ackerson & Texas Capital Bank (subsidiary of Texas BankCap) \\
\hline & Jack Matthews & Matthews Southwest \\
\hline & John Scovell & Woodbine Development \\
\hline & Ted Hamilton & Hamilton Properties \\
\hline & Brock Bailey & Bracewell \& Giuliani, LLP \\
\hline Civic Chairs & John Crawford & Downtown Dallas Inc. \\
\hline
\end{tabular}

Contemporary distribution of neighborhood decision-making power. For the

past half-century, much of Dallas' history has been baked into the bricks of its CBD.

Anxious to shake off the association with a slain president, Dallas' leaders invested significant sums of public dollars into razing depression-era offices and constructing modern skyscrapers - all within Downtown Dallas ${ }^{537}$. As the city's commercial hub, this

${ }^{537}$ Graff, 2008, pp. 220-221; Hill, 1996, pp. 160-169; Rice, 2007, pp. 220-221 
neighborhood had few residents throughout much of the late $20^{\text {th }}$ century, but was nonetheless at the center of Dallas' power structure. Of the 39 participants who answered questions regarding decision-making in Downtown Dallas, all of them spoke to this general theme in one way or another; one participant's comments stood out, however, and are asfollows:

The history of Dallas is the history of big men doing big things. A few of those men are still around, but even the ones who died years ago still watch over the city - their names are on the highways and skyscrapers and public places throughout the central business district. All of Downtown Dallas is basically a monument to the men who built it, and to the kind of leadership that allows that sort of thing to happen.

When participants were interviewed regarding the nature of decision-making in

Downtown Dallas today, they described thematic categories of decision-makers, which were substantively identical to those found in Dallas as a whole, and as later tables will suggest, there are several decision-makers found both at the citywide level and in Downtown Dallas. As occurred in North Oak Cliff, when describing the nature of decision-making in the neighborhood, participants speaking with respect to Downtown Dallas unanimously agreed that its councilmember, Philip Kingston, is a crucial member of the decision-making process. However, a majority $(28 ; 71.8 \%)$ also agreed that the councilmember shares many aspects of top-level neighborhood leadership, including city staff and long-standing business executives, as well as John Crawford, the developer-turned-director of the nonprofit development corporation and civic booster organization Downtown Dallas Inc. Of these 28 participants, ten referred to this as "co-leadership," with the councilmember acting more like a "first among equals" when it comes to Downtown Dallas specifically (as opposed to the remainder of his district). One participant summarized this, saying that:

When Dallas went 14-1 back in 1994, you had 13 districts where the councilmember got to rule however they saw fit, and nobody could really push back against that. District 14 is really two districts - Downtown Dallas and Lakewood/East Dallas. On the Lakewood side, you have a district mostly like any other on this side of the river, but in Downtown itself, you still have all the power players in Dallas. 
Outside of formal authorities and first tier influentials, Downtown Dallas' governing coalition is composed primarily of second tier influentials made up of actors within the city's developer class business executives in construction, real estate development, and related fields. To attempt to structure these various actors, and to serve as the basis for future comparisons, table 6.20 extends survey data introduced Chapter 4, which listed mean power scores for each decision-maker, by including both total power scores and rank-order data.

\begin{tabular}{|c|c|c|c|c|}
\hline $\begin{array}{l}\text { Rank } \\
\text { Order }\end{array}$ & Name & Category & Power Score & $\begin{array}{c}\text { Mean } \\
\text { Power Score }\end{array}$ \\
\hline 1 & Ray Hunt & First Tier Influentials & 153 & 3.92 \\
\hline 2 & A.C. Gonzalez & Formal Authorities & 152 & 3.90 \\
\hline 3 & John Crawford & Civic Chairs & 151 & 3.87 \\
\hline 4 & Philip T. Kingston & Formal Authorities & 150 & 3.97 \\
\hline 5 & Karl Zavitkovsky & Formal Authorities & 147 & 3.77 \\
\hline 6 & Harlan Crow & First Tier Influentials & 137 & 3.51 \\
\hline 7 & Ross Perot Jr. & First Tier Influentials & 133 & 3.41 \\
\hline 8 & Paul Ridley & Formal Authorities & 128 & 3.10 \\
\hline 9 & John Scovell & Second Tier Influentials & 123 & 2.85 \\
\hline 10 & Jim Truitt & Second Tier Influentials & 122 & 3.13 \\
\hline 11 & Mark Rieves & Formal Authorities & 121 & 3.26 \\
\hline 12 & Michael Caffey & Second Tier Influentials & 120 & 3.08 \\
\hline 12 & Ted Hamilton & Second Tier Influentials & 120 & 2.69 \\
\hline 14 & Jack Matthews & Second Tier Influentials & 119 & 3.03 \\
\hline 15 & Jody Grant & First Tier Influentials & 113 & 2.90 \\
\hline 16 & Scott Krikorian & Second Tier Influentials & 111 & 3.15 \\
\hline 17 & Brock Bailey & Second Tier Influentials & 105 & 2.51 \\
\hline 18 & Vince Ackerson & Second Tier Influentials & 98 & 3.05 \\
\hline
\end{tabular}

At the citywide level (and in North Oak Cliff), power score and mean power score shared a perfect, positive correlation with one another; for Downtown Dallas, this relationship is strong, but not perfect ${ }^{538}$, which suggests that actors with high power scores tended to receive more individual high scores (that is, more ratings of 3 and 4 on a four-point scale) than actors who received lower power scores, but this tendency is not as strong as in other geographies in this study. Additionally, when thematic categories are coded to a dummy variable, mean power score ${ }^{539}$ (but not total power score ${ }^{549}$ ) is negatively correlated with thematic category ${ }^{541}$. The relatively modest Spearman correlation coefficients describing

\footnotetext{
${ }^{538} \varrho=0.820, p<0.001$

${ }^{539} \varrho=-0.501, p<0.05$

${ }^{540} \varrho=-0.458, p=0.056$

541 Author's note: as with thematic categories in Dallas as a whole and North Oak Cliff, formal authorities were coded as 0, first tier influentials as 1 , second tier influentials as 2, and civic chairs as 3; no anchor captains received enough nominations for inclusion
} 
these relationships suggest that, while a connection exists, there are, as table 6.20 illustrates, multiple exceptions - most interestingly, that unlike in both Dallas citywide and North Oak Cliff, the highest raw power score is not held by the city councilmember representing the area. Nonetheless, these results suggest that there is a particular structure to decision-making in Downtown Dallas.

To test for the presence- and nature of such a structure, this study again utilized a Duncan's New Multiple Range Test to measure the significance of differences among mean power scores for decision-makers in Downtown Dallas; the results appear in table 6.21.

Table 6.21: Downtown Dallas Decision-Maker Levels of Power

\begin{tabular}{|c|c|c|c|c|}
\hline \multirow{2}{*}{ Name } & \multirow{2}{*}{ Thematic Category } & \multicolumn{3}{|c|}{ Subset for $\alpha=0.05$} \\
\hline & & Low Tier & Middle Tier & High Tier \\
\hline Philip Kingston & Formal Authorities & & & 3.97 \\
\hline Ray Hunt & First Tier Influentials & & & 3.92 \\
\hline A.C. Gonzalez & Formal Authorities & & & 3.90 \\
\hline John Crawford & Civic Chairs & & & 3.87 \\
\hline Karl Zavitkovsky & Formal Authorities & & & 3.77 \\
\hline Harlan Crow & First Tier Influentials & & 3.51 & \\
\hline Ross Perot Jr. & First Tier Influentials & & 3.41 & \\
\hline Mark Rieves & Formal Authorities & & 3.26 & \\
\hline Scott Krikorian & Second Tier Influentials & & 3.15 & \\
\hline Jim Truitt & Second Tier Influentials & & 3.13 & \\
\hline Paul Ridley & Formal Authorities & & 3.10 & \\
\hline Michael Caffey & Second Tier Influentials & & 3.08 & \\
\hline Vince Ackerson & Second Tier Influentials & & 3.05 & \\
\hline Jack Matthews & Second Tier Influentials & & 3.03 & \\
\hline Jody Grant & First Tier Influentials & 2.90 & & \\
\hline John Scovell & Second Tier Influentials & 2.85 & & \\
\hline Ted Hamilton & Second Tier Influentials & 2.69 & & \\
\hline Brock Bailey & Second Tier Influentials & 2.51 & & \\
\hline
\end{tabular}

Like its findings in North Oak Cliff, this study finds three tiers (bigh tier, middle tier, and low tier) in Downtown Dallas' decision-making structure, but uniquely, data in table 6.21 suggest that the highest of these tiers is not occupied solely by the neighborhood's city councilmember. These findings broadly support those found in table 6.20, as well as participant observations regarding a central conflict regarding decision-making in Downtown Dallas, which will be reconsidered later in this study. Finally, figure 6.03 illustrates the data in table 6.25, and shows the structure of decision-making at the neighborhood level. 


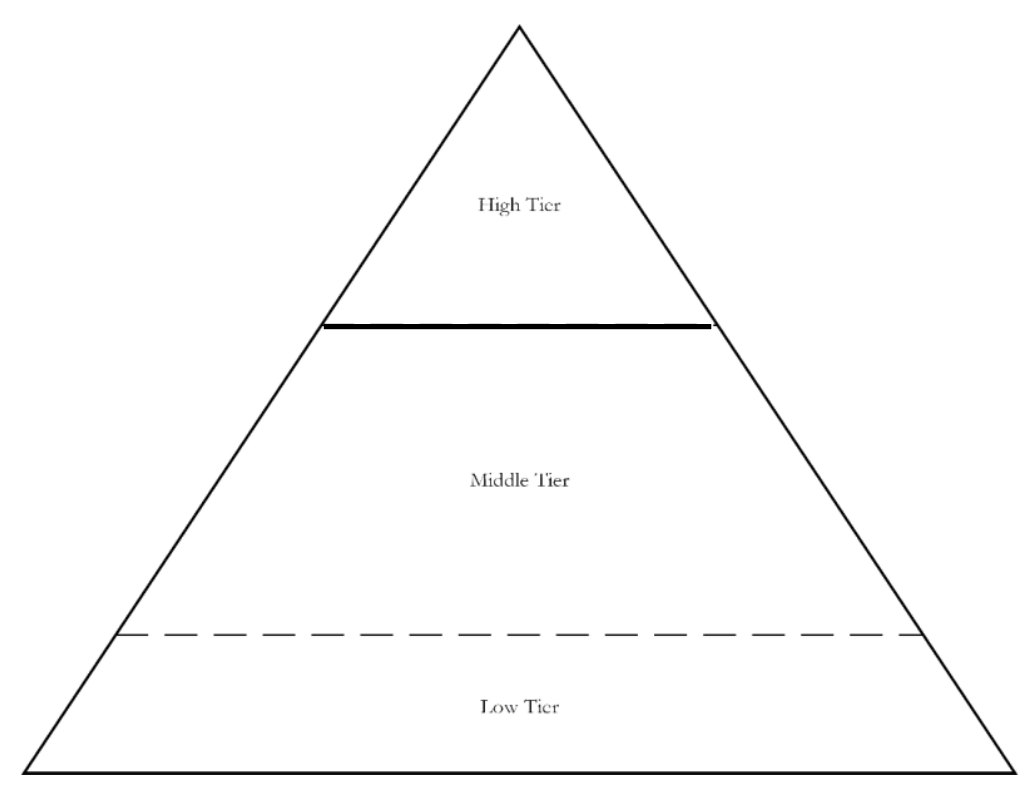

These findings take into account data in table 6.20 and 6.24 , as well as participant observations of the structure of power in Downtown Dallas. In the paragraphs that follow, this study will first discuss Downtown Dallas' decision-making structure broadly, and then it will individually examine each of this structure's three tiers.

Downtown Dallas' decision-making structure, broadly. At the citywide level, this study identified a decision-making structure composed of four tiers, with actors in the highest tiers sharing decision-making involvement, actors in the lowest tier tending to only be involved on particular decisions, and some gradient between the two. In North Oak Cliff, this study identified a decision-making structure in which a strong city councilmember consolidated decision-making authority, and a variety of lower-tier actors worked through ad-hoc alliances to influence his decisions. In Downtown Dallas, figure 6.03 conceptualizes a leadership structure that (like the one in North Oak Cliff) features three tiers, but that (like Dallas citywide) emphasizes a coalition of top-level actors who are involved in most neighborhoodlevel decisions and lower-tier actors whose involvement is limited to particular projects. 
Finally, as in Dallas citywide and North Oak Cliff, the highest echelons of decision-making in Downtown Dallas - the high tier occupied by formal authorities and first tier influentials - are particularly rigid in their membership. Echoing terms used for this category at the citywide level, 13 participants $(33.3 \%)$ used some version of "born in" or "blessed in" to describe how various actors in the first tier influentials category joined the highest echelons of leadership in Downtown Dallas. Nonetheless, because the barrier dividing high tier leaders is particularly rigid, while the low tier middle tier) is largely more open to membership, figure 6.03 depicts a solid line between high tier and middle tier, and a dashed line between the middle tier and low tier.

Key leaders and top level, past and present. While archival research uncovered a limited amount of literature regarding the decision-making structure (or lack thereof) in North Oak Cliff, archival research suggests that the history of Downtown Dallas' decision-making structure is indivisible from that of decision-making in Dallas as a whole; this is in-line with extant scholarly research, as well as participant descriptions of how decisions in the neighborhood were made in the past; these are well-summarized by the following:

Downtown (Dallas) has two things that come together to explain a lot about who runs the show. It's the jewel in the crown, so anyone who wants to build something big is going to want to build it right there, but also, only so many have the vision and resources to build a skyscraper or Reunion Tower. Egos run high in Dallas, and they don't run any higher than when there's a chance to change the skyline.

Therefore, this study argues that while North Oak Cliff suffered from a dearth of political leadership prior to the 1991 city council restructure, Downtown Dallas is the political heart of the city, where the city's wealthiest and most powerful press for ways to leave enduring marks on the city. As figure 6.03 illustrates, Downtown Dallas' high tier comprises a wider variety of actors than analogous tiers in Dallas citywide and North Oak Cliff, including government leaders, private-sector executives, and the head of a nonprofit development 
corporation. Supporting this high tier are middle tier actors, who a clear majority of participants (24; 61.5\%) agreed are effectively subservient to high tier actors, working to support (or oppose) various initiatives at the direction of their "superiors."

Corroborating data found in table 6.21, participants almost universally $(37 ; 94.9 \%)$ suggested that, while other councilmembers enjoy functionally limitless authority over development in their districts, Kingston is often challenged by Dallas' first tier influentials and their sympathizers on the Dallas City Council. In describing this situation, participants identified two primary factors: approaching term limits for "developer-friendly" city councilmembers (identified by 25 participants; 64.1\%), and the presence of an aging, though still powerful coalition of private sector leaders (35 participants; $89.7 \%$ ). As a result, participants often suggested that Kingston may (and does) lose a number of battles with developers in the short run, his fights garner him support from other progressive city leaders, as well as the voters in his district; as one participant put it:

It's the 1980 s and 90 s teaming up to fight the 00 s and $10 \mathrm{~s}$. What I mean is, men and women who succeeded in building Dallas in the 1970s, and rebuilding it in the 1990s are trying to do that again, but their ideas haven't changed any - it's all modern offices and luxury high-rises. The ideas are old, but there's a lot of money and (City) Council support behind them, because old, rich men like Ray Hunt all-but own half the councilmembers, the mayor, and the city manager. That's what Councilmember Kingston is fighting against, even though it's hard for him to break even, much less win.

Analysis of participant comments regarding actors in Downtown Dallas' decision-

making structure suggests strong agreement around two conflicting agendas: one supporting neoliberal, value-neutral development strategies in Dallas' urban core, and one with a more progressive outlook. Looking first at the pro-development agenda, table 6.22 shows the actors most commonly associated with this perspective by study participants; this table also includes a summary entry for actors who did not receive enough participant nominations to be individually included for in-depth evaluation. 
Table 6.22: Downtown Dallas Participant-Identified Pro-Development Agenda Supporters

\begin{tabular}{|l|c|c|}
\hline \multicolumn{1}{|c|}{ Actor } & \multicolumn{2}{c|}{ Participant Mentions } \\
\cline { 2 - 3 } & \multicolumn{2}{c|}{ Number } \\
\hline A.C. Gonzalez & 39 & Percentage \\
\hline Ray Hunt & 39 & $100.0 \%$ \\
\hline Karl Zavitkovsky & 33 & $100.0 \%$ \\
\hline Harlan Crow & 33 & $84.6 \%$ \\
\hline Scott Krikorian & 30 & $84.6 \%$ \\
\hline Vince Ackerson & 29 & $76.9 \%$ \\
\hline Jody Grant & 23 & $74.4 \%$ \\
\hline John Scovell & 21 & $59.0 \%$ \\
\hline John Crawford & 19 & $53.8 \%$ \\
\hline Ross Perot, Jr. & 19 & $48.7 \%$ \\
\hline Ted Hamilton & 17 & $48.7 \%$ \\
\hline Jim Truitt & 13 & $43.6 \%$ \\
\hline Michael Caffey & 8 & $33.3 \%$ \\
\hline Other Actor Not Listed & 18 & $20.5 \%$ \\
\hline
\end{tabular}

This agenda, unsurprisingly, advocates continuing the historical practice of using city funds to induce high-end, mixed-use development, new office space, urban stadiums, and further expansion of the downtown convention center ${ }^{543}$. Describing the actions of this agenda's adherents, participants specifically mentioned the use of TIF and BID districts (39; 100.0\%), and to a lesser extent, tax abatements $(20 ; 51.3 \%)$, earmarks within larger bond packages (8; $20.5 \%$, and preferential treatment during the contract bidding process $(7 ; 18.0 \%)$, which five participants called "sweetheart deals." In describing actors who adhere to this position on development, one participant said that:

You have to remember that before the real estate market went belly-up in the 80s, Dallas was putting up skyscrapers as fast as we could bring in the concrete and pig iron. We took money from the schools, from the police, (and) from the roads to build all (of) this, and when the market fell apart, what did we have to show for it? Now you have this group - the same ones from before, or their kids, or their proxies - coming to City Hall, hats in hand, trying to say that the only way to save Downtown is to repeat what we did before. Isn't that the definition of insanity - doing what you did before, and thinking things will be different?

A more charitable participant, representing the views of the majority (20 participants;

$51.28 \%$ ), characterized this agenda by suggesting that:

We have to keep Downtown Dallas growing, because if we don't grow here, then some other city will take those jobs out from under us. If it's not Dallas, it's Plano, Richardson, Irving, Arlington, or even suburbs further out - Allen, Fairview, McKinney, (and) Princeton.

\footnotetext{
542 Author's note: subcategory totals do not add up to, respectively, 39 or $100 \%$

543 Brown, 2016a; 2016b; Robinson-Jacobs, 2013; Schutze, 2016; Simek, 2015; 2016
} 
If it's not one of those, then maybe a different city in a different state. Point is, we either grow or we die, and Downtown is where growth happens.

As an alternative, participants unanimously identified a second, progressive-

development agenda, which seeks to bind public development incentives to more equitable economic development strategies and considerations for people who cannot afford upscale housing, dining, shopping, and entertainment ${ }^{544}$; table 6.23 shows which actors participants identified as being most closely associated with this perspective; as with table 6.22, this table includes a summary entry for actors who did not receive enough participant nominations to be individually included for in-depth evaluation..

Table 6.23: Downtown Dallas Participant-Identified Progressive Development Agenda Supporters

\begin{tabular}{|l|c|c|}
\hline \multirow{2}{*}{ Actor } & \multicolumn{2}{|c|}{ Participant Mentions } \\
\cline { 2 - 3 } & Number & Percentage \\
\hline Phillip Kingston & 39 & $100.0 \%$ \\
\hline Mark Rieves & 28 & $71.8 \%$ \\
\hline Paul Ridley & 26 & $66.7 \%$ \\
\hline John Crawford & 19 & $48.7 \%$ \\
\hline Other Actor Not Listed & 16 & $42.0 \%$ \\
\hline
\end{tabular}

As data in table 6.23 suggest, support for this agenda is largely found among formal authorities Phillip Kingston and two of his political appointees. These three actors hold within-district authority over zoning change proposals, land-use policies, and zoning exemptions to push for a number of progressive provisions added to development subsidies; participants variously identified examples such as: "middle class" retail and dining options (18 participants; 46.2\%), expanded affordable housing beyond legal requirements for TIF funding $(14 ; 35.9 \%)$, investment in local infrastructure improvements such as bike lanes $(12$; $30.8 \%)$, mid-block pedestrian crosswalks $(11 ; 28.2 \%)$, and traffic calming measures (11; $28.2 \%$ ), and requirements to bring in businesses like mid-range grocery stores, to support a growing population $(9 ; 23.1 \%)$.

${ }^{544}$ Celeste, 2014; Schutze, 2015b

545 Author's note: subcategory totals do not add up to, respectively, 39 or $100 \%$ 
In the fight over development projects in Downtown Dallas, participants unanimously identified one actor whose organization attempts (often successfully) to broker agreements between these disparate factions: civic chair John Crawford, who has become central in brokering what many participants $(31 ; 79.5 \%)$ considered to be "compromise deals" for development projects. It should be somewhat unsurprising, then, that tables 6.22 and 6.23 suggest that as many participants identify Crawford with the local pro-development agenda as identify him with the progressive-development alternative.

Recall that Crawford's organization, Downtown Dallas Inc. (DDI) has been part of Downtown Dallas' business community for over five decades. Traditionally, DDI has been a booster organization for the CBD, but since 2010, DDI has been at the center of fulfilling Downtown Dallas $360^{546}$, the master redevelopment plan for Downtown Dallas. Crawford himself has a decades-long career in real estate development in- and around Downtown Dallas, and most participants $(25 ; 64.1 \%)$ considered his professional- and social ties to be crucial in legitimizing him among first tier influentials, while the public oversight of DDI, through its board of directors, serves as a basis for the support of formal authorities both within the neighborhood and at the citywide level. While Crawford is not always successful in finding compromise between Kingston and his opponents, two-thirds of participants (26) agreed that Crawford is involved in nearly every development-related decision in the neighborhood, with many suggesting that Crawford's support among other key leaders places him as a de facto equal to Kingston himself, at least with respect to development decisions.

Second echelon leaders, past and present. Recall that, although the Thometz study did not specifically mention Downtown Dallas, literature regarding the city in the 1960s and 1970s

\footnotetext{
546 Downtown Dallas Inc., 2015, p. B3; Grimes, 2010
} 
suggests that decisions regarding the neighborhood were largely the purview of the business leaders and real estate developers who made decisions at the citywide level ${ }^{547}$; therefore, it is reasonable to assume that, if second echelon actors from the Thometz study took active roles in decision-making within Downtown Dallas, these actors (as a subset of all second echelon actors) were likely younger executives in real estate development, finance and investment, utilities, trade, and manufacturing. As figure 6.03 illustrates, this study finds that Downtown Dallas' contemporary second echelon is composed of its second tier influentials, which (as shown in table 6.21) notes are composed of executives in real estate development, finance and investment, and real estate law.

The vast majority of participants $(36 ; 92.3 \%)$ suggested that actors found in Downtown Dallas' contemporary second echelon are not individually involved in the early stages of neighborhood-level decisions, and their involvement tends to be project-specific. Where these actors differ from their likely predecessors is that, as participants often described it, they often intentionally avoid becoming key leaders in decision-making. All participants broadly agreed, however, that these actors are not tied to Dallas itself; their companies have offices across the United States (and in some cases, internationally), so their loyalties, if they exist at all, are primarily to their employers. Additionally, a minority of participants $(19 ; 48.7 \%$ ) also suggested that, because the future Downtown Dallas' leadership is uncertain, executives would normally transition into a more central role in decision-making are waiting to see what happens; as one participant suggested:

Dallas is in the middle of a power struggle, and it plays out here in Downtown because this is where the power players are the most invested, in terms of their reputations and their money. Progressive leaders like Philip (Kingston) are a seven-vote minority today, but they may not be in the minority forever, so the smart move, if you're an up-and-coming civic leader, is to wait a few years to see how it shakes out.

\footnotetext{
${ }^{547}$ Elkin, 1987b, pp. 38-41; Minora, 2013; Ruebens, 2011; Payne, 1994, pp. 369-378; 2010; Terranova, 2009, pp. 19-23; Wilonsky, 2008; 2011
} 
If these younger ones pick a side now, and that side ends up losing out in the end, then that hurts their business long-term.

Decision-making power and nominations to decision-making committees. In addition to asking participants to give ratings of power for potential decision-makers in Downtown Dallas, the survey introduced in Chapter 3 asked participants to nominate 10 individuals to form a committee responsible for making a decision that would affect the entire neighborhood, and that needed to be broadly accepted by the neighborhood as a whole. Much like in Dallas as a whole and North Oak Cliff, some participants did not select the full 10 committee members; the lowest number of selected committee members was 7 , and on average, participants nominated 9.18 individuals to their hypothetical neighborhood decision-making team. Once again, the fact that some participants did not nominate a full 10 committee members negatively affects the validity of the results, but nonetheless, table 6.24 shows the number of nominations that each decision-maker received, for all decision-makers receiving nominations from at least $10 \%$ (3.9, rounded up to 4$)$ of the participants.

Table 6.24: Comparison between Downtown Dallas Decision-Making Committee Nominations and Decision-Maker Power Score

\begin{tabular}{|c|c|c|c|c|c|c|}
\hline \multirow[t]{2}{*}{ Name } & \multirow[t]{2}{*}{ Category } & \multirow[t]{2}{*}{ Tier } & \multicolumn{2}{|c|}{$\begin{array}{c}\text { Committee } \\
\text { Nominations }\end{array}$} & \multicolumn{2}{|c|}{ Power } \\
\hline & & & Count & Rank & Score & Rank \\
\hline John Crawford & Civic Chairs & High Tier & 39 & 1 & 151 & 3 \\
\hline Philip Kingston & Formal Authorities & High Tier & 39 & 1 & 150 & 4 \\
\hline A.C. Gonzalez & Formal Authorities & High Tier & 23 & 3 & 152 & 2 \\
\hline Ray Hunt & First Tier Influentials & High Tier & 21 & 4 & 153 & 1 \\
\hline Jack Matthews & Second Tier Influentials & Middle Tier & 21 & 4 & 119 & 14 \\
\hline Scott Krikorian & Second Tier Influentials & Middle Tier & 20 & 6 & 111 & 16 \\
\hline Jim Truitt & Second Tier Influentials & Middle Tier & 19 & 7 & 122 & 10 \\
\hline Michael Caffey & Second Tier Influentials & Middle Tier & 18 & 8 & 120 & 12 \\
\hline Mark Rieves & Formal Authorities & Middle Tier & 15 & 9 & 121 & 11 \\
\hline Karl Zavitkovsky & Formal Authorities & High Tier & 13 & 10 & 147 & 5 \\
\hline Harlan Crow & First Tier Influentials & Middle Tier & 13 & 10 & 137 & 6 \\
\hline Ross Perot Jr. & First Tier Influentials & Middle Tier & 13 & 10 & 133 & 7 \\
\hline Vince Ackerson & Second Tier Influentials & Middle Tier & 12 & 13 & 98 & 18 \\
\hline John Scovell & Second Tier Influentials & Low Tier & 11 & 14 & 123 & 9 \\
\hline Paul Ridley & Formal Authorities & Middle Tier & 9 & 15 & 128 & 8 \\
\hline Jody Grant & First Tier Influentials & Low Tier & 9 & 15 & 113 & 15 \\
\hline Ted Hamilton & Second Tier Influentials & Low Tier & 7 & 17 & 120 & 12 \\
\hline Brock Bailey & Second Tier Influentials & Low Tier & 7 & 17 & 105 & 17 \\
\hline
\end{tabular}

The data in table 6.26 show that Downtown Dallas' decision-making structure broadly follows patterns seen in Dallas citywide and North Oak Cliff, with high tier actors generally 
having the most decision-making committee nominations, middle tier actors appearing in the middle of the list, and low tier actors receiving the fewest overall nominations, although (as in other geographies) exceptions to this exist. As was found in both North Oak Cliff and Dallas citywide, there is overlap among actors in each of the four thematic categories (no anchor captains were identified), but of particular interest is that civic chair John Crawford received as many nominations as the neighborhood's city councilmember; in this study, this is unique to Downtown Dallas. These results suggest that although Councilmember Kingston is the de jure primary decision-maker in Downtown Dallas, in practice, this position is shared (to varying extents) with civic chair John Crawford, formal authority A. C. Gonzalez, and first tier influential Ray Hunt.

This study also compares the correlation between decision-making committee nominations and power score. These variables, like their counterparts in North Oak Cliff and Dallas citywide, are positively correlated $^{548}$, but not to the same level of significance as measures for these other geographies. In short, while participants' perceptions of power are positively related to their willingness to nominate that actor to make decisions that would affect the neighborhood, in Downtown Dallas (moreso than in other geographies studied), additional factors are involved. This limitation in mind, the statistical significance of the relationship between committee nominations and power score nonetheless continues to validate the use of a reputational analysis in studying neighborhood-level power.

In considering the role of power tiers within Downtown Dallas' decision-making structure, table 6.25 shows the total number of nominations to decision-making committees received by actors in each tier, and compares these to the maximum number of nominations that could have been granted to these actors.

$$
{ }^{548} \varrho=0.529, p<0.05
$$


Table 6.25: Decision-Makers Selected to Serve on a Downtown Dallas Decision-Making Committee by Tier

\begin{tabular}{|l|c|c|c|c|}
\hline \multicolumn{1}{|c|}{ Tier } & Number in Category & Total Nominations & Total Possible Nominations & \% \\
\hline High Tier & 5 & 135 & $69.2 \%$ \\
\hline Middle Tier & 9 & 140 & 351 \\
\hline Low Tier & 4 & 34 & $39.9 \%$ \\
\hline
\end{tabular}

These data echo findings found in North Oak Cliff and Downtown Dallas, and suggest that high tier actors are more likely to be involved in neighborhood-level decision-making than middle tier actors, who are themselves more likely to be involved than low tier actors. This is in-line with participants' observations about decision-making, and is also consistent with expectations regarding the presence of a hierarchical structure in decision-making in Downtown Dallas.

Familiarity and shared committee service. How well do participants know the actors involved in Downtown Dallas' decision-making process, and are these relationships related to participants' perceptions of power? Table 6.26 shows the mean familiarity scores for each of the four thematic categories and two tiers in Downtown Dallas' decision-making structure.

Table 6.26: Downtown Dallas Decision-Maker Mean Familiarity Score by Tier

\begin{tabular}{|l|c|}
\hline \multicolumn{1}{|c|}{ Category or Tier } & Mean Familiarity Score \\
\hline High Tier & 2.50 \\
\hline Middle Tier & 2.24 \\
\hline Low Tier & 2.22 \\
\hline
\end{tabular}

At the citywide level, high tier actors were found to have the highest familiarity score among the three decision-making tiers, while in North Oak Cliff, these actors were found to have the lowest familiarity scores. Data in table 6.26 suggests that, like Dallas citywide, in Downtown Dallas, participants are most familiar with high tier actors, and comparatively less familiar with middle tier and low tier actors. These differences, though interesting, are nonetheless small, and as this study found in both North Oak Cliff and Dallas as a whole, 
the relationships between familiarity and participants' perceptions of power in Downtown Dallas is not statistically significant ${ }^{549}$.

This study also asked participants to identify whether they had, in the past five years, served on a board or committee with each of the actors that they nominated to neighborhood decision-making committees; these data are reported in table 6.27.

Table 6.27: Downtown Dallas Decision-Maker Mean Shared Committee Service by Tier

\begin{tabular}{|l|c|}
\hline \multicolumn{1}{|c|}{ Tier } & Mean Shared Committee Service \\
\hline High Tier & $26.7 \%$ \\
\hline Middle Tier & $27.9 \%$ \\
\hline Low Tier & $28.8 \%$ \\
\hline
\end{tabular}

These data suggest that, on average, participants are most likely to have recently served with low tier actors on a board or committee, with these percentages decreasing for middle tier and bigh tier actors. These findings are dissimilar to those found in Dallas as a whole and North Oak Cliff, but nonetheless, the relationship between shared committee service and participants' perceptions of decision-making power is not statistically significant ${ }^{550}$. Recall that this lack of significance also occurs when comparing familiarity with power; therefore, this study is able to reject the possibility that, in Downtown Dallas, participants' perceptions of power were skewed by proximity to various actors throughout the neighborhood.

\section{Discussion of Coalition Hypotheses}

In light of the changing demographic- and economic contexts of cities in the United States, and the growing roles of CDCs and anchor institutions in economic development and policymaking in cities like Cleveland ${ }^{551}$ and Philadelphia ${ }^{552}$, this study forwarded a need to revisit "big city politics." Building on a previous study of Dallas, this study systematically determined the relative decision-making power of individuals at the citywide level, as well as

\footnotetext{
${ }^{549} \varrho=0.245, p=0.328$

${ }^{550} \varrho=-0.196, p<0.05$

551 Alperovitz, 2013, pp. 5-6; Zuckerman et al., 2013, pp. 96-109

552 Dubb, McKinley, \& Howard, 2013, pp. 18-19
} 
in two neighborhoods uniquely impacted by aforementioned contextual changes. A major aim of this study was to provide data regarding the nature of contemporary urban governance, and the role (or lack thereof) of anchor institutions and CDCs in governing the modern commercial republic. In the paragraphs that follow, this study will first briefly summarize the methods used to address its coalition-centered hypotheses, as well as results of this study's qualitative data analysis. Then, it will compare real-world equitable economic development programs found in a subset of other cities to those found in Dallas.

\section{Dallas as a Whole}

In evaluating its second three hypotheses, this study began by updating knowledge of Dallas' citywide governing coalition. To summarize, during the summer and early fall of 2015, this study asked 79 participants to rate the levels of power for over 100 individuals active on various boards, committees, and civic projects, including business executives, political leaders, high-level bureaucrats, and directors of nonprofit organizations and local anchor institutions. This study, in repeating measures from previous work regarding Dallas, used Duncan's New Multiple Range Test to determine that the ranges of mean power ratings represented four distinct decision-making tiers at the citywide level. These tiers substantiate participant observations about the nature of decision-making at the citywide level, and suggest that high-ranking public sector officials have largely (but not entirely) supplanted business leaders at the highest echelons of decision-making.

Analysis methods used. Following in the footsteps of Hunter's 1953 analysis of Atlanta, and Thometz' 1963 analysis of Dallas, participants were asked to nominate ten actors to hypothetical decision-making committees, whose decisions would need to be accepted by the city as a whole. The number of nominations received were correlated with power scores, and were found to be positively related, suggesting that perceptions of power 
are a valid proxy for decision-making power, and validating the use of the reputational method in studying the nature of contemporary urban governance at the citywide level. Participants were also asked to indicate their amount of recent shared board- and committee service with these actors, and their level of familiarity with each. These results were correlated with power scores, but were not found to be statistically significant, which helps to negate the possibility that participants' perceptions of power were confounded by proximity to particular actors, while also helping to validate the reputational method itself.

CDC and anchor institution involvement in decision-making. A primary goal of this study was to find whether, or to what extent, CDCs and anchor institutions are part of Dallas' contemporary governing coalition, and to understand the effects of that involvement. With respect to the role of anchor institutions and CDCs in citywide decision-making, no CDC director achieved enough nominations to be included in this study's examination of citywide decision-making. However, four leaders of anchor institutions - three university presidents, and one hospital director - did receive enough nominations. This is a greater representation than was found in previous studies, but both qualitative and quantitative data suggest that the role of anchor institutions in citywide decision-making is limited; while these actors appear in the mid-range of power scores, data suggest that in general, they are only involved in decisions related to education and healthcare, or when a development project seeks to include facilities for their institutions.

Importantly, there is one exception to the above characterizations of the roles of anchor captains in decision-making - Gerald Turner, the president of Southern Methodist University. As detailed in Chapter 4, Turner and the university appear to be unique among Dallas' anchor institutions, in that have both long-been associated with power and influence in the city, as well as with several of Dallas' first tier influentials, who commonly use the 
university as a proxy supporter of various projects, allowing them to indirectly express approval without the "political baggage" associated with a direct endorsement.

The structure and nature of decision-making in Dallas as a whole. Based on its analysis of 79 participant surveys and interviews, this study affirms its suspicion that the strong, entrepreneurial governing coalition found in the Thometz study, which weakened and fragmented into the complex entrepreneurial governing coalition by Elkin's study, has continued to fragment and fade, although it would be inaccurate to suggest that this coalition has completely died. In the 1963 reputational study of Dallas, only two of 67 identified leaders were not then-current members of the business community ${ }^{553}$, but in this study, nine actors out of 32 are not directly affiliated with the city's business community; recall that this also contains two sets of actors (the city council and the CPC) who were considered jointly; were these separated, the number of "non-business actors" would more-than triple. A majority of these actors represent the public sector, especially at the highest levels of citywide decision-making, so while private sector elites and civic organizations remain highly influential, data strongly suggest that government officials have filled the "power vacuum" left behind by a fragmented business community. The sympathies of these formal authorities broadly still lie with the business- and real estate development communities, with a clear prodevelopment agenda being supported by a coalition containing the city manager, seven (out of fourteen) district-based councilmembers, and the mayor, and it is supported by an elite, wealthy, and older cohort of first tier influentials and the civic chairs whose organizations represent the old guard ideas of Dallas' past. However, an additional seven councilmembers support more progressive alternatives, and their ranks have been growing for several years, following the creation of the 14-1 election system.

\footnotetext{
553 Thometz, 1963, p. 48
} 


\section{North Oak Cliff}

This study also moved beyond previous research, by performing reputational analyses on two neighborhoods within the city - North Oak Cliff and Downtown Dallas. Looking first at North Oak Cliff, 40 of this study's 79 participants self-reported as being particularly knowledgeable about the decision-making process within this neighborhood, and through their surveys and interviews, it was clear that these actors had a thorough understanding of the history and current state of community-level leadership. Each participant was asked to nominate ten actors to hypothetical decision-making committees, whose decisions would need to be accepted by the neighborhood as a whole. Further, for each actor that they nominated, participants were asked to rate the power level of that individual, and to indicate any recent shared board- and committee service with that actor, and their level of familiarity.

Analysis methods used. Duncan's New Multiple Range Test was used to determine that the ranges of mean power ratings indicated three tiers of decision-making power. As with Dallas citywide, the number of nominations to decision-making committees that an actor received was found to be positively correlated with power scores, again suggesting that participant perceptions of power are a valid proxy for decision-making power in actuality. As with Dallas as a whole, neither recent shared committee service nor familiarity were found to be significantly correlated with participants' perceptions of decision-making power, which continues to validate the reputational method.

CDC and anchor institution involvement in decision-making. As with Dallas as a whole, a primary aim of this study was to find whether, or to what extent, CDCs and 
anchor institutions are part of North Oak Cliff's decision-making structure. Although one anchor captain, hospital director Martin Koonsman, was found to be influential in the neighborhood decision-making process, analysis of participant surveys and interviews suggests that Koonsman is only likely to involve himself in decisions that relate directly to the hospital, such as facilities expansion plans, or ongoing conflicts with the residents of households adjacent the hospital complex. Therefore, this study finds no particular evidence that anchor institutions or CDCs have become part of any governing coalition in North Oak Cliff, and no particular evidence to support the role of these institutions in equitable economic development programs.

The structure and nature of decision-making in North Oak Cliff. Based on its analysis of 40 participant surveys and interviews, this study finds that the antiregime of North Oak Cliff's past has been largely subsumed by the renewed presence of formal authorities in the neighborhood - particularly its city councilmember, Scott Griggs, who occupies the highest tier in the Duncan's test for North Oak Cliff, and whom participants considered to be the core actor in decision-making at the neighborhood level. Immediately below Griggs are his appointees to development-related boards and commissions, as well as pro-development city staff who (in most cases) defer to Griggs' wishes, but on matters of development, advocate on behalf of the developers. As participants unanimously agreed, other actors in the neighborhood are often forced to work together to sway Griggs' position on various policies and development projects. This leads to the ad-hoc formation of temporary alliances, and participants agreed that it is not uncommon for two leaders to work together on one issue while simultaneously opposing one another on a different one.

Participants agreed that, broadly speaking, new development and gentrification in this modest-income community are the catalysts for most debates among middle tier actors in 
North Oak Cliff. Participants also identified alliances among rentiers and developers - the first tier influentials and second tier influentials active in neighborhood decision-making. In characterizing these alliances, participants observed that the three largest neighborhood landowners work together with area developers in order to "bundle together" smaller parcels of land to be more suitable for larger development projects, often at the cost of displacing extant residents and businesses. Neighborhood leaders like Pam Conley and Lisa Benskin, while lacking in direct authority over land-use decisions, nonetheless work to educate and organize residents and business leaders who are at risk of displacement. Through mobilizing neighborhood residents, these two have been somewhat successful in changing development plans in ways that benefit their communities, and pressuring Councilmember Griggs to use his land-use powers to keep new projects small, and within the scale of existing structures.

While Conley and Benskin organize social capital in the neighborhood, two additional leaders - developer David Spence and "guerilla urban designer" Jason Roberts work to develop the physical capital in North Oak Cliff in ways that, while sometimes controversial, nonetheless attract positive press to the area and help to anchor locally-owned businesses into once-vacant commercial corridors. These two actors occupy the low tier of the neighborhood's decision-making structure, and often, participants characterized them as independent actors who generally circumvent the larger decision-making process, albeit with the support of Councilmember Griggs.

\section{Downtown Dallas}

In considering Downtown Dallas, 39 of this study's 79 participants self-reported as being particularly knowledgeable about the decision-making process within this neighborhood, and through their surveys and interviews, reports that were validated through survey data and interviews. As with participants responding to surveys and interview 
questions regarding North Oak Cliff, each of these 39 participants was asked to nominate ten actors to hypothetical decision-making committees, whose decisions would need to be accepted by the neighborhood as a whole. Further, for each actor that they nominated, participants were asked to rate the power level of that individual, and to indicate any recent shared board- and committee service with that actor, and their level of familiarity.

Analysis methods used. Duncan's New Multiple Range Test was used to determine that the ranges of mean power ratings indicated three tiers of decision-making power. As with Dallas citywide and North Oak Cliff, the number of nominations to decision-making committees that an actor received was found to be positively correlated with power scores, again suggesting that participant perceptions of power are a valid proxy for decision-making power in actuality. Additionally, neither recent shared committee service nor familiarity were found to be significantly correlated with participants' perceptions of decision-making power, which continues to validate the reputational method.

CDC and anchor institution involvement in decision-making. As with Dallas as a whole and North Oak Cliff, a primary aim of this study was to find whether, or to what extent, CDCs and anchor institutions are part of Downtown Dallas' decision-making structure. This study finds no particular evidence that anchor institutions or CDCs have become part of any governing coalition in Downtown Dallas and no particular evidence to support the role of these institutions in equitable economic development programs. However, as noted previously in this chapter, the private nonprofit development corporation Downtown Dallas Inc. (DDI), and its CEO John Crawford, have become integral to Downtown Dallas' decision-making process.

Recall that, for over half a century, DDI has acted as a booster organization for Downtown Dallas' business- and development interests, and has acted as a public face for a 
subset of like-minded formal authorities, first tier influentials, and second tier influentials, who combine public- and private resources to fulfill a common agenda: attracting economic development and improving the vitality of Downtown Dallas. In effect, the supporting members, directors, and senior leadership of DDI have created a neighborhood-level governing coalition within the larger structure of governance for Dallas as a whole, and prior to the transition to district-based councilmembers, many older participants referred to these actors as the "real power" in Dallas, with one going so far as to say that:

Up until maybe the mid-nineties, you had Downtown, and then you had the rest of the city. If any big idea came out of the "Big Men Downtown," no matter how crazy it was, it was probably going to happen. That's how we got most of the more imaginative projects you see through Downtown, from the underground mall to the top of (local landmark) Reunion Tower. The mayor and the council ran the rest of the city, but the Big Men - the Hunts, the Crows, the Coxes, the Perots, the Caruths - all of those families with museums and highways named after them - they ran Downtown like their own personal sandbox, and the truth is, for a long time it really was.

This coalition, as it existed before the current structure of the Dallas City Council, and before the city's economy collapsed, is likely part of the complex entrepreneurial governing coalition that Elkin identified - the one less interested in the day-to-day operations of Dallas' government, and more interested in a city government that facilitates "good development opportunities" ${ }^{554}$. Recall that Elkin already identified this coalition's weakening following the amendments to Dallas' charter in the 1980s, and from participant comments that, following the 1994 restructure of Dallas' elected leaders, this coalition seems to have largely evaporated outside of Downtown Dallas. Thus, what does the continued presence of a unified governing coalition mean for decision-making within the "mini-fiefdom" represented by Downtown Dallas' council district, and headed by its councilmember?

To answer this, consider that according to Miles's Law, actors are more likely to support policies that benefit their organizations over those that serve collective interests, or

\footnotetext{
${ }^{554}$ Elkin, 1987a, pp. $72-74$
} 
in other words, "where you stand depends on where you sit." While initially resulting from observations at the national level, survey and interview data from this survey suggest that this axiom applies to perspectives on Crawford and DDI as well. For example, a common theme among supporters of Crawford and DDI is that the organization's involvement has resulted in less infighting among competing interests, and a more unified vision of Downtown Dallas as part of DDI's involvement in the Downtown Dallas 360 development plan. Additionally, it is clear from participant comments that Crawford personally encourages more collaboration with City Staff and Councilmember Kingston than would have appeared in the past; comments representative of this position include:

DDI supports a lot of projects that end up controversial, but it won't support a bad project just because it's a big one - you really have to show how your idea fits with the bigger plan. Sometimes that means making concessions to folks like Kingston and his allies on City Council, and other times that means digging in for a long fight.

It's not like "The Godfather," where you go to John (Crawford) for approval on something, and if you don't get it, nothing happens. This is still Dallas, and if you really want to build something Downtown, there's always a way to get it built. It's just a lot easier when your vision aligns with his, since his team basically wrote Downtown Dallas 360 and he's got more sway with the banks and City Hall than near (SIC) anyone else.

Presenting an alternate viewpoint, the participants presented negative opinions of Crawford and DDI often suggested that the organization's support structure undermines the principles of a democratic society, by allowing private developers to circumvent the wishes of Councilmember Kingston in ways that are not possible on other districts; recall that one participant (whose comments were echoed by a number of others) said that: "What gets built where has nothing to do with what residents want, or what the neighborhood needs if it's ever going to sustain itself after the building boom dies off." Additionally, detractors suggested that Crawford and his organization are often used as a proxy for public input. As part of Downtown Dallas 360, DDI produces annual status reports on the state of Downtown Dallas, and also holds a number of events throughout the year to gauge public opinion on 
various projects. However, these events are often held on weekday evenings, frequently require reservations to be made in advance, and are all-but exclusively marketed through social media. As a result, people who work unstable schedules, or who are unable to find childcare, or simply cannot afford to take the time to attend these meetings are unable to effectively voice their opinions. Describing this situation, two participants said that:

There's (SIC) a lot of poor people living in Downtown, but you'd hardly know it by looking at the crowd in one of these big meetings. I don't even know if some of them would be let in the building, if they even knew to get an RSVP and could show up.

Decisions get made behind closed doors, in the closed sessions of directors' meetings, and over lunch and dinner meetings all over the city. When all that's done, and DDI wants it to look like there's neighborhood buy-in, they'll plan something in one of these gorgeous hotels around Downtown, but only at a time of day when folks with a regular 9-5 job can go, and they're all saying the same things about how they want more night life and how the poor folks and the homeless are all criminals to be locked up or removed. Those homeless folks, poor folks, (and) even the few parents with kids around here - they don't show up, but it wouldn't really matter if they did.

It should be noted that this sense of inevitability regarding projects that Crawford and DDI support (sometimes bordering on hopelessness or resignation) was a frequent theme among participants, appearing in $22(56.4 \%)$ of 39 the interviews.

While Councilmember Kingston's objections to value-neutral development in Downtown Dallas are often overridden by the city council's pro-development majority, it cannot be assumed that the councilmember is completely powerless with respect to economic development. Indeed, recall that individual councilmembers hold broad authority over TIF funding within their district, and this control is largely protected from the will of a council majority. As such, when a particular developer wants to access that funding within the large TIF districts in Downtown Dallas, they must negotiate with Councilmember Kingston.

Once again, this places Crawford and DDI in a position of being able to assemble a package of concessions and design revisions that are likely to be agreeable to the councilmember, and which already meet the requirements of Dallas' various construction and design codes; as one participant described the situation: 
[Crawford] knows what it's like to work with councilmembers who don't really agree with his vision for Downtown. He knew how to work with Angela (Hunt) before, and he knows how to work with Philip (Kingston) now, so when he tells you that you need to change something in a project to get that TIF money, then you'd be well-served by listening.

The structure and nature of decision-making in Downtown Dallas. Based on its analysis of 39 participant surveys and interviews, this study finds that the emerging rift between pro-development and progressive development leaders is writ largest in Downtown Dallas, the city's traditional epicenter of development. As noted previously, the majority of Downtown Dallas' decision-making structure (like that of Dallas as a whole) continues to strongly resemble the complex entrepreneurial governing coalition described in the Elkin study, even as such a coalition has largely faded throughout the remainder of Dallas. The purpose of this contemporary governing coalition, as it was during Elkin's study (and Thometz's before that) is to promote business- and real estate development interests, particularly those interests that, returning to extant urban theory, increase the exchange value of real estate in Dallas' urban core. This entrenched, pro-development agenda is composed of two clusters of actors - first, the first tier influentials who are personally able to access city-level formal authorities in order to find support for their projects, and second, the second tier influentials who are individually unlikely to secure an audience with citywide formal authorities. Therefore, while a subset of the most influential actors within the pro-development agenda can reliably count on support of actors like billionaire oilman-turned-developer Ray Hunt and City Manager A.C. Gonzalez, actors with less clout must rely on John Crawford and DDI to act as an intercessor and advisor for their projects, making Crawford a "swing vote" of sorts on development decisions. 
The success of Downtown Dallas' pro-development agenda lies in its ability to reliably sideline its opposition, while also silencing a disorganized (but growing) list of detractors, but how long can this success last? In the two decades since the start of district-based council elections, those councilmembers who continue to support the "Dallas Way" have seen their numbers decline, in favor of councilmembers (like Kingston) who favor a more progressive future. In addition, recall that younger business leaders and real estate developers frequently show little (if any) interest in getting involved in the politics of development, leaving few (if any) true successors to the "Big Men Downtown." Describing this transition, and what it portends for the future, participants' comments are well-represented by the following:

\footnotetext{
The main players in Downtown all see that the old way of building isn't going to last much longer. (Councilmember) Kingston and the folks who agree with him are the future. The developers who aren't too stubborn to change are finally embracing things like historic preservation and "complete streets," and there's even some serious talk about mixed-income housing in Downtown. They don't want to be on the wrong side of the future, so they're starting to change things now. Others, especially the younger ones, are just staying out of big projects for now, waiting to see what happens over the next couple of elections.
}

Equitable economic development in the commercial republic. At its outset, this study argued that, although CDCs and anchor institutions hold the potential to advance beyond "ancillary" status in the urban governing coalition, there is debate as to whether this occurs in actuality. While this study found no evidence supporting the role of these particular kinds of third-sector organizations in driving equitable urban economic development projects or policymaking within Dallas as a whole, or in either North Oak Cliff or Downtown Dallas, this is not the case in other cities. In the sections that follow, this study will briefly summarize efforts of anchor institutions and CDCs actively implementing these projects in two cities: Philadelphia and Cleveland. Then, it will speculate on why this kind of involvement was not found in Dallas. Finally, it will expand upon the efforts of two actors in North Oak Cliff - David Spence and Jason Roberts - in creating integrated 
networks of locally-owned, locally-oriented businesses within a community that, in many ways, is more similar to the aforementioned Rust Belt cities than it is to the rest of Dallas.

Equitable economic development in a subset of other cities. One example of third-sector involvement in urban economic development and policymaking is in Philadelphia, Pennsylvania. In this city, like in Dallas, political and business leaders exercise tremendous control over urban policy and economic development ${ }^{55}$. However, since (at least) the turn of the 21 st century, actors involved in Philadelphia's third-sector have begun injecting themselves into decisions regarding education ${ }^{556}$ and economic development ${ }^{557}$.

The results of this involvement can be seen in cross-sector partnerships within the city's economically-marginalized neighborhoods. For example, Drexel University, the William Penn Foundation, and the City of Philadelphia are leveraging over $\$ 575$ million in local- and federal Promise Zone funds, in order to support job creation, access to education, and spur economic development into low-income, majority-minority neighborhoods in West Philadelphia ${ }^{558}$. This involvement may also be part of a potential progressive shift in the city's governing coalition, with anchor institutions like the University of Pennsylvania providing public forums for progressive citizen engagement, and successfully pushing the city's development-focused governing coalition into retreat ${ }^{559}$.

A second example is in Cleveland, Ohio, which is also the traditional home of a tightly-knit pro-development governing coalition ${ }^{560}$. Here, the cross-sectoral involvement of CDCs in economic development stretching back (at least) to the Voinovich (1980-1988) and White (1989-2001) administrations ${ }^{561}$ have opened the door to a more progressive,

${ }_{555}$ Bulkley, 2007, pp. 168-169; McGovern, 2009, pp. 670-672

${ }^{556}$ Bulkley, 2007, pp. 169-171

557 Adams, 2014, ch. 2; pp. 123-125; McGovern, 2009, pp. 673-674

${ }^{558}$ City of Philadelphia, n.d.; Gammage, 2014; Giankaris, 2014; T. Ross, 2014, p. 19

${ }^{559}$ Lin, 2007; McGovern, 2009, pp. 674-685

${ }^{560}$ D. Keating, 2007, pp. 2-3, 12; McQuarrie, 2011, pp. 254-256

${ }^{561}$ D. Keating, 2009, pp. 3-4; McQuarrie, 2011, pp. 245-254; Vidal \& D. Keating, 2004, p. 133 
heterarchic governing coalition with a heavy emphasis on neighborhood redevelopment involving the public-, private-, and third sectors ${ }^{562}$; as a result, the city's growth-minded elites are more willing to accommodate neighborhood-level interests (even if only begrudgingly) ${ }^{563}$.

Following the mid-century collapse of its industrial base, Cleveland has suffered economically for decades, and its population is under half its 1950 level ${ }^{564}$, but continued cross-sector collaboration has created a sustainable, equitable economic development model that, while still small, suggests a new possibility for other, economically-challenged cities. Since 2008, the Evergreen Cooperative - a partnership between the Cleveland Foundation, Cleveland Clinic, University Hospitals, Case Western Reserve, and the city's municipal government - has leveraged over $\$ 35$ million in grants to create three worker-owned businesses in six of the city's most economically-marginalized neighborhoods ${ }^{565}$, providing hundreds of jobs and allowing workers to generate wealth through equity stakes in the companies themselves ${ }^{566}$.

So, with respect to the role of CDCs and anchor institutions in urban economic development and public policy, why Philadelphia and Cleveland, but not Dallas? To begin, governments must bargain over the conditions for inducing capital investment, in order to achieve the economic goals of dominant political interests. Further, the ability to bargain for capital investment is dependent upon the market position of a city, so an economically weak city like Cleveland or Philadelphia is less able to bargain with the private sector than an economically advantaged city like Dallas or Chicago ${ }^{567}$.

\footnotetext{
562 D. Keating, 2007, p. 6; McQuarrie, 2011, pp. 245-246

${ }_{563}$ McQuarrie, 2011, pp. 262-263

564 Alperovitz, Howard, \& Williamson, 2010; D. Keating, 2007, p. 7

565 Evergreen Cooperatives, 2016; Howard, Kuri, \& Lee, 2010, pp. 6-7; Tonnesen, 2012, p. 195

${ }^{566}$ Alperovitz \& Dubb, 2013, p. 6; Howard, Kuri, \& Lee, 2010, p. 7

${ }^{567}$ Kantor, Savitch, \& Haddock, 1997, pp. 349-353
} 
Building on this argument, this study suggests the possibility that there may be little (or no) private-sector capital investment available in cities with significant, decades-long patterns of commercial disinvestment - cities like both Philadelphia and Cleveland, which saw tremendous population- and economic losses during the Fordist crisis, and remain economically troubled decades later, even though signs point to some amount of recovery following the Great Recession ${ }^{568}$. Therefore, it may be that, in the absence of private-sector actors willing (or able) to invest capital into a particular city, even the most ardent prodevelopment leaders in Rust Belt cities like Philadelphia and Cleveland are simply more amenable to working with nontraditional organizations like CDCs and anchor institutions.

Returning to the Dallas example, recall that this study found no evidence supporting the role of CDCs or anchor institutions leveraging more equitable economic development in Dallas or either of the study's focus neighborhoods. Although Dallas is not dissimilar to Cleveland and Philadelphia with respect to urban poverty indicators, unlike both of these cities, it is a hotbed of private investment and real estate development. In 2015, commercial real estate investment was up by $45 \%$ over 2014 ; further, of the $\$ 129$ billion invested in 2015 , over half went to commercial real estate ( $\$ 33.5$ billion) and apartments ( $\$ 33$ billion), with over $\$ 22$ billion dollars in investment coming from foreign sources - primarily Asia and Canada ${ }^{569}$. In many respect, contemporary Dallas looks increasingly like the Dallas of the early 1980s, with tremendous investment in Downtown Dallas, as well as over 5 million square feet in mixed-use development located along previously-undeveloped tracts adjacent DART light rail stops since $2013^{570}$. With such a strong economy being fueled primarily by

\footnotetext{
568 Cleveland City Planning Commission, 2016; D. Keating, 2007, p. 2; Pew Charitable Trusts, 2016. pp. 1-2;

${ }^{569}$ Brown, 2015a; Perez, 2014a; 2014b; 2015

${ }^{570}$ Brown, 2015a; 2015b
} 
private investment, what need is there for public-sector leaders to enter into arrangements with third-sector dollars to induce cross-sectoral development?

Economic boom times aside, recall also the "Dallas Way," that is, the city's longstanding habit of using development to pave over the plight of the city's poor. Even if Dallas' economy lacked its current strength, it is unclear whether political leaders would consider these kinds of partnerships - certainly, these were not pursued during the economic downturn stretching from the mid-1980s to the mid-1990s. Then again, the city's political leadership was still dominated by pro-business interests, and while transition was underway, the complex entrepreneurial coalition was still headed by the "big men downtown," whose ideas for economic revitalization were still heavily anchored in the private sector, and the use of public incentives for private development. Would Dallas' current political leadership, with its (slim) pro-development majority be willing to entertain the idea of equitable alternative development strategies if the city's economy once again faltered? In Downtown Dallas, could Downtown Dallas Inc., its private nonprofit development corporation, address the issues of the poor (assuming it had the will to do so, which is certainly questionable).

Dallas, and scholars thereof, may not have to wait long to find out. Although real estate investment and economic growth are both still high in Dallas, especially in Downtown Dallas and its surrounding neighborhoods, commercial vacancy remains between $10 \%$ and $28 \%$ throughout the urban core, and new properties are sitting on the market longer, signaling an impending slowdown ${ }^{571}$. While Dallas' economy has greatly diversified itself after the Oil Boom went bust, if the bottom should fall out again, this study argues that Downtown Dallas Inc., which is funded by the real estate developers and businesses whose activities are focused primarily in- and around the CBD, would largely lack the financial

\footnotetext{
${ }^{571}$ Brown, 2016a
} 
resources to engage in equitable alternative development strategies, like those seen in Philadelphia and Cleveland. If Dallas "hot" real estate market cools, these private firms would likely shift their focus to other cities where they have significant operations, leaving (at best) token offices in the Dallas market, and these may be responsible for both the central city and its surrounding suburbs.

In its current economic context, Dallas is doing precious little to address the growing economic disparities between its "haves" and its "have-nots," and given its past, and the present state of the city's decision-making structure, it is unlikely that the city's current leadership would engage in partnerships with anchor institutions and CDCs to create equitable economic development opportunities if that economic context should cool. While the current pro-development leadership is - slowly - being replaced by a growing progressive development coalition, it is unclear when the "8-7 split" will fall in favor of leaders who favor new strategies, and further, it is also unclear when significant numbers of leading bureaucrats will follow suit. Within this somewhat-dismal outlook, however, there are two emerging leaders who, by finding ways to operate outside of the decision-making structure - albeit with the support of some of its members, are finding success at equitable alternative development strategies; these emerging leaders will be the focus of the next section.

\section{Equitable economic development, the Dallas way. While Philadelphia and}

Cleveland have suffered economically, Dallas' history since deindustrialization is largely characterized by economic growth, even without the inclusion (or, as some might see it, interference) of the third sector. As a result, it should be unsurprising that leaders of CDCs and anchor institutions are largely absent from the highest echelons of decision-making. Nonetheless, the continued preference for continuing neoliberal, corporate-centered development practices among a (shrinking) majority of Dallas' highest levels of leadership 
should not be taken to indicate that efforts to induce alternative, equitable economic development are not being undertaken, if not at the citywide level, then at least in (a subset of) Dallas' neighborhoods.

In Chapters 4 and 5, this study introduced the roles of local developer David Spence and "guerilla urban designer" Jason Roberts, and how each, on a (comparatively) small scale, is working to bring economic development into the North Oak Cliff neighborhood in ways that keep ownership within the neighborhood itself. Although their particular projects differ, what unites these two actors is that they have proven themselves willing to operate independently of other decision-makers, and circumvent the larger decision-making process in order to achieve their objectives. In the sections that follow, this study will briefly expand on how each of these actors works to improve economic equity within their neighborhood, using specific examples for each, and connecting them to extant urban theory.

David Spence. Jane Jacobs, in her seminal work, argued that neighborhoods devolve into slums in a cascading pattern, with small changes rapidly leading to decay; she also suggested that the reverse could also be true - small improvements in a neighborhood could lead to rapid improvements ${ }^{572}$; in Dallas, this "cascading effect" can be seen in the work of David Spence. Embodying Jacobs’ mixed-use, diverse, organic development mantra, Spence's most upscale projects are surrounded by taquerias, tire shops, and quinceanera boutiques that have been locally-owned for generations. Participants regularly credited Spence for his role in the ongoing revitalization of the Bishop Arts District, for saving commercial corridors throughout North Oak Cliff, and for his adaptive reuse of existing

\footnotetext{
${ }^{572}$ Jacobs, 1969, p. 279
} 
space has encouraged other local entrepreneurs to revive shuttered movie theaters, markets, and retail outlets ${ }^{573}$.

The key to Spence's success is more than simply redevelopment existing space; Spence also reaches out to area business owners looking to grow, and acts as a networking hub between his old clients and his new ones, helping to found- and expand collaborations among North Oak Cliffs locally-owned businesses. One of Spence's most successful collaborations has been with Shannon and Jenni Neffendorf, owners of Oak Cliff Coffee Roasters. In 2008, the Neffendorfs began roasting coffee in their garage, selling locally within the neighborhood ${ }^{574}$. Five years later, a partnership with Spence allowed them to open a storefront (Davis Street Espresso), and expand their clientele to include over two dozen restaurants and markets throughout North Oak Cliff and the Dallas area, while offering pastry options sourced from two neighborhood bakeries ${ }^{575}$. As their business has grown, their success has enabled the Neffendorfs to open a second shop next door to the original ${ }^{576}$.

Jason Roberts. Not everyone has the capital to invest in repurposing vacant and abandoned buildings, though. Jason Roberts became a public figure in 2005, when he helped found the Oak Cliff Transit Authority - a nonprofit organization that advocated for installing an electric streetcar to link North Oak Cliff (a former streetcar suburb) with Downtown Dallas. While some observers praised the five-year effort to connect these two growing neighborhoods, others describe the project as "by hipsters, for hipsters," and begrudged the $\$ 50$ million price tag, roughly half of which was covered by a federal TIGER grant $^{577}$. Opponents also criticized the limited number of stops and limited hours of

\footnotetext{
573 Appleton, 2013a; 2013b; McKenzie, 2010; R. Stone, 2015c

574 Goulding, 2016; Oak Cliff Coffee Roasters, 2012

575 Shelley, 2013

${ }^{576}$ Cadwalader, 2016

577 Appleton, 2013b; 2013c; 2015d; Austin, 2015; Crain, 2009; Simek, 2012; Young, 2016
} 
operation as unhelpful for residents with low incomes who reside in North Oak Cliff.

Although the line has proven controversial, with frequent service interruptions for maintenance issues since the 2015 inaugural run, it has already been successful enough that millions in additional city- and federal funding has been allocated to construct new stops throughout North Oak Cliff ${ }^{578}$.

As Chapters 4 and 5 note, Roberts - who also works as a full-time IT consultant ${ }^{579}-$ is more commonly known as a "guerilla urban designer," who sees blocks that have been "written off" as blighted, and envisions flower-lined, pedestrian- and bicycle-friendly streets, where empty lots are replaced with small, locally-owned shops selling locally-produced goods, and where people can see a place as something more than "that place" where "those people" live. His organization (a group of his friends with $\$ 1,000$ between them) called themselves Team Better Block, and identified an abandoned commercial corridor in North Oak Cliff that, while lined with abandoned storefronts, was zoned as light industrial, and (thanks to Dallas' draconian zoning laws) could not be easily rezoned.

Not satisfied with leaving this block to continue declining, Roberts and his team declared it a target for temporary, guerilla-style urban development. The team painted midblock pedestrian crosswalks, used potted plants to create protected bicycle lanes, installed (temporary) outdoor seating, and worked with local businesses and craftspeople to create pop-up shops and turning vacant storefronts into cafes that lined the street ${ }^{580}$. Strictly speaking, none of this was legal, but Roberts had the approval of the area's city councilmember, and the city's code enforcement team was notoriously absent from the area during the event ${ }^{581}$. The project was so successful that Roberts has repeated it in North Oak

578 Moto, 2015; Young, 2016

579 R. R. Ross, 2012

${ }^{580}$ R. R. Ross, 2012; Team Better Block, 2016b

${ }^{581}$ R. Stone, 2014 
Cliff, and now his team consults with other cities (most recently, Detroit) to engage in similar programs ${ }^{582}$. Importantly for the neighborhood, though, several of the businesses that participated in the Better Block's projects have remained in North Oak Cliff, hiring locally and forming a network of businesses that support one another ${ }^{583}$.

Good spaces and better blocks in building a local economy. Although the effects of projects undertaken by Spence and Roberts remain small compared to the size of the neighborhood and the magnitude of the need for equitable economic development, they are nonetheless crucial components of equitable economic development in North Oak Cliff in a number of different ways. In the paragraphs that follow, this study will connect these actors' real-world projects with extant urban theory regarding locally-owned, locally-oriented businesses. Then, it will consider the role of neighborhood context in the ability of projects like these to be successful, or even exist in the first place.

To begin, the businesses that work with Roberts and Spence often become part of North Oak Cliff's interconnected, organic network of locally-owned, locally-oriented businesses; this network serves a number of purposes. First, it strengthens the economic links between each business, allowing firms to more easily communicate their needs to one another. Second, it helps local businesses identify new opportunities for expansion into new markets. Finally, it helps local businesses match buyers and sellers ${ }^{584}$. Indeed, all of these benefits can be seen in the aforementioned example of Oak Cliff Coffee Roasters, which was able to move from being a (literal) garage industry to becoming an anchor business within the neighborhood and a regional exporter of goods, bringing dollars from all over the Dallas

${ }^{582}$ Roberts, 2010; Team Better Block, 2016a; 2016b; 2016d

583 Roberts, 2012

${ }^{584}$ Imbroscio, 2010, p. 122 
region back into an economically-marginalized neighborhood, thanks (at least in part) to the local business network found in the neighborhood.

Additionally, Roberts' and Spence's focus on supporting home-grown businesses through adaptive reuse of space preserves the "local flavor" of the neighborhood - that is, its culture, architecture, history, and art, when chain businesses would be more likely to bulldoze and rebuild ${ }^{585}$. Further, these businesses allow local dollars to be circulated repeatedly through North Oak Cliff, creating a local economic multiplier effect and increasing local tax revenues ${ }^{586}$. Finally, this interconnected dependence among local businesses makes it harder for any one of these to abandon the area ${ }^{587}$. For this reason, and because of the added variety found among these businesses, the entire local economy becomes more resilient in the face of economic shocks ${ }^{588}$. Looking toward North Oak Cliff's future, economic stability underpins enduring citizen engagement with politics and decisionmaking structures ${ }^{589}$ - something currently lacking among long-time neighborhood residents.

North Oak. Cliff: Philadelphia and Cleveland writ small. With respect to attempts at equitable economic development, why North Oak Cliff, but not Downtown Dallas or Dallas as a whole? This study argues that, when considering the respective contexts of these three geographies, North Oak Cliff is actually more similar to the previously-discussed cities of Cleveland and Philadelphia than it is to either Downtown Dallas or Dallas as a whole. Like those cities, North Oak Cliff has experienced decades of economic decline and residential abandonment, and its population - especially its people of color - generally earn low incomes, even as much of the northern half of Dallas continues to thrive. However, unlike

585 Shuman, 2006, pp. 57-58

${ }^{586}$ Imbroscio, 2010, p. 47, 122; Shuman, 2006, pp. 48-49

${ }^{587}$ Imbroscio, 2010, p. 48; Schragger, 2009, pp. 521-522; Shuman, 2006, p. 56, 62

588 Shuman, 2006, pp. 58-59

589 Alperovitz, 2011, pp. 47-49 
Cleveland and Philadelphia, as a single neighborhood, North Oak Cliff is unable to enter into cross-sectorial partnerships with anchor institutions and CDCs, and Dallas' city council has historically shown little interest in devoting significant resources to improving "those neighborhoods" occupied by "those people."

Dallas' contemporary governing coalition. To briefly review the state of Dallas' governing coalition in the years prior to this study, recall that as Chapter 2 first described, when Carol Thometz looked across Dallas in the early 1960s, and looked through the eyes of the city's leaders to understand how the Dallas was run, she found a structure composed of nearly 70 men from industries like finance, commerce, and manufacturing ${ }^{590}$. Among these, about $10 \%$ were centrally involved in nearly every aspect of decision-making, while a further $80 \%$ acted in many, but not all decisions, while the final 10\% were only involved tangentially as “technical experts" on particular issues ${ }^{591}$. At that time, Dallas' political leadership was selected by its strong, unified, and resource-laden business community, forming close professional- and personal ties among political and business leaders in what Elkin would refer to as a pure entrepreneurial governing coalition ${ }^{592}$; the at-large electoral system ensured that, with few exceptions, the wealthy, white voters of northern Dallas reliably supported the candidates forwarded by groups like the Dallas Citizens Council and the Citizens Charter Association, while the voices of minority groups in southern Dallas were largely silenced (or in later years, tokenized ${ }^{593}$.

This governing coalition would grow Dallas from a regional manufacturing hub into a global city, and would elect as mayors men like Bob Folsom and Starke Taylor, real-estate developers whose policies toward development would expand the city's footprint to well

${ }^{590}$ Thometz, 1963, p. 31

591 1963, pp. 43-45.

${ }^{592}$ Elkin 1987a, p. 62

${ }^{593}$ Morgan, 2004 pp. 102-113, 140-152; Phillips, 2010, pp. 102, 143-148 
over 300 square miles (of land that their companies largely owned), and would fill in that land with everything from skyscrapers to apartment complexes and acres of single-family housing, in a decade-long building boom that only ended when the local economy collapsed in the mid-1980s. In the years leading up to this collapse, Stephen Elkin looked across Dallas, and found that the city's untrammeled success in attracting globalized businesses, executives of which had little loyalty to Dallas itself, combined with the city's first attempt to modernize its election system, had left the city's governing coalition both depleted, and marred by infighting ${ }^{594}$. Gone were the days when Dallas' industrial titans played key roles in the day-to-day running of the city, and many of the aging leaders had found themselves without successors to carry on with the "Dallas Way." Even though the pure entrepreneurial coalition had given way to a complex entrepreneurial coalition, Elkin found that when business leaders and real estate developers wanted support for their projects from Dallas political leaders, support was nearly always found ${ }^{595}$.

This study does not challenge the notion that Dallas' decision-making structure was, at one time, an archetypical entrepreneurial governing coalition; it also does not challenge Elkin's differentiation between the pure entrepreneurial coalition of the 1960s and 1970s with the complex entrepreneurial coalition lasting from the 1980s until (at least) the mid-1990s. Instead, this study proffers that as Dallas emerged from economic ruin as a globalized economy composed largely of multinational firms with no particular loyalty to Dallas itself, and transitioned its political leadership to a district-based system that crippled the onceunstoppable political machine found in civic organizations like the Dallas Citizens Council

594 Elkin, 1987a, pp. 71-73

595 1987a, pp. 74-79; Payne, 1994, p. 388 
and (now-defunct) Citizens Charter Association, the seeds for structural transformation were sewn.

Also recall that the precursor elements that signal structural transformations among governing coalition typologies are poorly-studied, though the Elkin study notably includes a number of criteria that could divorce political leaders from the lure of economic elites - in effect, charting a hypothetical course that could transition entrepreneurial governing coalitions toward some (arguably) more progressive alternative. These conditions include a lowering of barriers to political dissent, reducing the eagerness and tenacity of business leaders with respect to public inducement packages, reducing the advantages that business leaders have when it comes to collecting and dispersing political funds, curbing the natural tendency of political leaders to facilitate inducements, and improving the grasp of public officials on the considerations of bowing to commercial interests at the expense of the principles of republican government ${ }^{596}$. Given the transitions since the Elkin study, are some subset of these criteria now satisfied?

This study argues that, in part, a subset of Elkin's conditions for transformation have been met. First, this study argues that barriers to political dissent were effectively reduced when the city switched from an at-large city council and mayor to its present hybrid of district-based councilmembers with an at-large mayor, 14 of 15 political leaders were suddenly held accountable primarily to their constituents. Councilmembers today are often seen in their communities, for example, to hold public hearings and gather public input, especially when the public is unhappy with a decision. To remain in the good graces of their constituents, councilmembers must approach decisions with an eye for the costs and benefits to their particular district, lest they be punished during re-election attempts. Second, 596 1987a, p. 146 
this study argues that district-based political leaders are somewhat less willing to pursue a pro-business agenda, especially when that agenda contains no considerations for their constituencies. Finally, without a unified business community, there is no longer a single "pro-business" agenda for political leaders to follow, and benefits to, for example, real estate developers seeking to repurpose occupied buildings must be weighed against the risk of harm to the residents and businesses that occupy them.

Thus, if political leaders are bound to the will of their constituents, and the business community is too disorganized to produce a unified agenda for those leaders to follow, Dallas' citywide decision-making structure seems to resist categorization using the existing typologies. If Dallas' decision-making structure has stumbled its way into a structure that no longer resembles the entrepreneurial governing coalition archetype, and if this divergence is too great for qualified descriptors (e.g. Elkin's complex entrepreneurial nomenclature), then how can Dallas' contemporary decision-making structure be most accurately described? In answering this question, first recall that this study recognizes seven broad types of governing coalitions; a summary of these, restated from Chapter 2, is provided in table 6.28.

Table 6.28: Typology of Governing Coalitions

\begin{tabular}{|c|c|}
\hline Coalition Type & Lead Actors \\
\hline Activist & $\begin{array}{l}\text { Minority-led electoral coalitions, engaged citizens, single-district councilmembers, neighborhood governments, } \\
\text { social justice or broker mayors, fiscal populists }\end{array}$ \\
\hline Caretaker & Caretaker mayors, anti-growth bureaucrats, fiscal populists, post-materialists \\
\hline Demand-Side & Neighborhood organizations, single-district councilmembers, minority mayors, post-materialists \\
\hline Entrepreneurial & Business-led coalitions, strong mayor, pro-growth bureaucrats \\
\hline Progressive & Minority-led electoral coalitions, single-district councilmembers, neighborhood governments, social justice mayors \\
\hline Stewardship & Group coalitions, engaged citizens, fiscal populists, "broker" mayors \\
\hline Antiregime & Temporary, issue-based coalitions; neighborhood organizations \\
\hline
\end{tabular}

These definitions in mind, figure 6.04 combines data previously introduced throughout this chapter, repackaging them into a comprehensive view of decision-making in Dallas as a whole, as well as in North Oak Cliff and Downtown Dallas. These data first illustrate the tiered decision-making structures found at the citywide level and in both focus neighborhoods, as well as the composition of each tier with respect to category of decision- 
maker. Further, the figure portrays the divisions within each separate structure with to the three development agendas found by this study - the pro-development and progressive development agendas found in all three geographies, and the anti-development agenda found in North Oak Cliff. Finally, the figure shows where these three separate decision-making structures are connected by actors with shared membership.

Figure 6.04: The Interconnected Decision-Making Structure in Dallas, North Oak Cliff, and Downtown Dallas

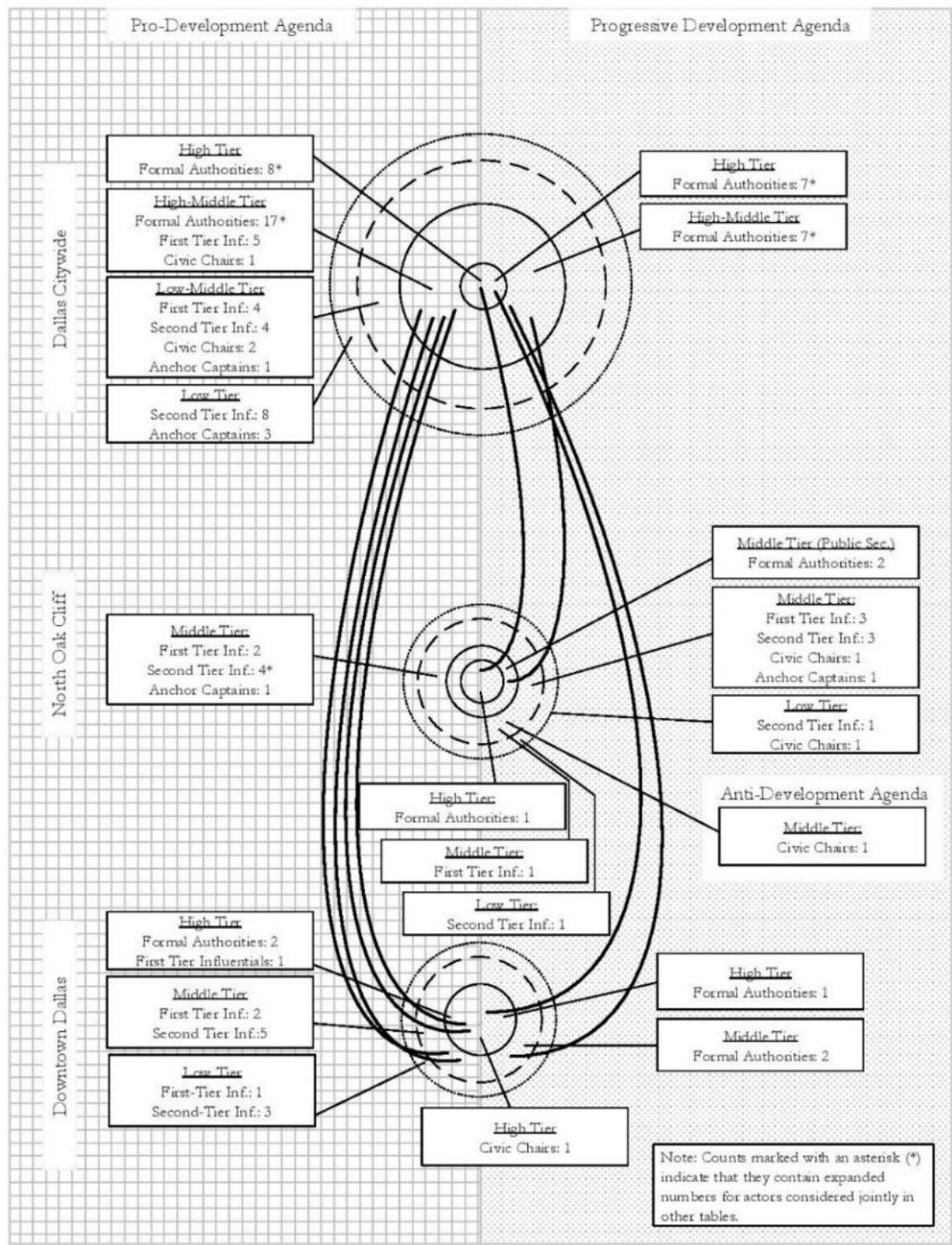


These data suggest a number of trends that connect contemporary decision-making structures in Dallas to those of the Elkin and Thometz studies. To begin, these data support the prior assertion that a majority of decision-makers in Dallas support a pro-development agenda, with roughly twice as many actors supporting this agenda than support alternatives. Additionally, these data suggest that a larger subset of leaders in Downtown Dallas is also active at the citywide level, when compared to leaders in North Oak Cliff. These findings are both telling and unsurprising, given the history of Dallas with respect to white flight and political disconnection of southern-sector neighborhoods, as well as the city's traditional penchant for using value-neutral economic development as a response to urban problems.

Data also suggest that that to whatever extent Elkin's complex entrepreneurial governing coalition persists, it is at its strongest within Dallas' central urban core. However, at the citywide level, whatever remains of that decision-making coalition has grown far more limited in 2016 than it was in either 1963 or 1987 . What remains is a pair of looselyorganized citywide agendas regarding economic development, and while adherents of the pro-development agenda currently holds a slim majority of decision-making power, their opponents continue to make gains at each election. As such, can Dallas' decision-making structure even be considered a governing coalition?

Dallas' decision-making structure as a nonregime. For a decision-making structure to be a governing coalition, several criteria must be met; these include:

- informal, stable groups of actors with access to resources;

- public- and private-sector members, allowing the coalition to cross the statemarket divide;

- cooperation across sectors

- distinct policy agendas; and

- a history of consensus and selective incentives to perpetuate it. ${ }^{597}$

${ }^{597}$ Reese \& Rosenfeld, 2002, p. 647 
Dallas' contemporary structure no longer features a stable, informal group of actors who can marshal enough resources to push a specific agenda (and it is unclear whether, except in the case of Downtown Dallas 360, such an agenda exists); instead, individual actors (and civic organizations) support particular projects, sometimes with the support of other actors, and sometimes in opposition to those same individuals. With lingering fragmentation among the city's business community precluding partnerships across business sectors, and a sharp divide among pro-development and progressive development councilmembers, there is also little enduring cooperation across the state-market divide outside of individual projects (again excepting Downtown Dallas 360). Finally, with a lack of a single policy agenda at the citywide level, this study found little evidence to suggest a pattern of selective incentives used to build consensus support for anything resembling a distinct policy agenda on the level of, for example, Stone's famous Atlanta case. Thus, this study considers Dallas to be a nonregime; but more than that - Dallas appears to be a collapsed entrepreneurial coalition with enough vestiges of the "old way" to prevent a "new way" from fully emerging, but not enough to revive the development-first agenda that once was. This divide creates a situation similar to that of New Orleans in the early $2000 s^{598}$, though for different reasons, and with different possible outcomes.

In the New Orleans example, this nonregime city lacks a stable of would-be political leaders within its business community, and this community also fails to provide monetary and non-monetary resources to the leaders that do emerge. Slow-growing, issue-based coalitions must negotiate (and re-negotiate) all policy decisions, and without stable ties among them, each new negotiation must start from square one ${ }^{599}$. Such coalitions may

\footnotetext{
598 cf. Burns \& Thomas, 2006; 2015

${ }^{599}$ Burns \& Thomas, 2006, pp. 519-520; 2015, pp. 13-16
} 
individually draw resources from private interests, but these resources are limited, and as a result, various actors only have enough resources to govern within particular interest areas, such as attracting a professional basketball team in 2002, or reducing the city's high crime and murder rates in the $1990 \mathrm{~s}^{600}$. In their initial assessment of the New Orleans nonregime, Scholars Burns and Thomas suggested that the city's amorphous decision-making nonstructure served well enough to avoid municipal bankruptcy or state takeover, but that was wholly inadequate during both the city's preparation for Hurricane Katrina, and during its reconstruction because it lacked the stability necessary to smoothly allocate resources and enact relevant policies in the lead-up to- and immediate aftermath of the disaster ${ }^{601}$. While this initial assessment raised concerns over whether an enduring governing coalition could form to address the city's ongoing needs ${ }^{602}$, a more recent assessment suggests that some amount of stability eventually returned to the city's leadership structure, and that an alliance between Uptown whites and the business community has emerged, albeit to the detriment of people of color and people with low incomes ${ }^{603}$.

Like New Orleans in the immediate aftermath of Hurricane Katrina, Dallas does not have a single, unified governing coalition, resulting from the collapse of the coalition that once existed. However, an important distinction must be made; while New Orleans in the early 2000s lacked any enduring decision-making structure, Dallas suffers from having too many. Consider that, at the citywide level, two sorts of governing coalitions exist, though with differential access to various resources. At the center of each of these coalitions is a subset of the city's mayor and city council - the 15 people with formal decision-making authority - as well as leading bureaucrats who are responsible for interpreting and

\footnotetext{
${ }^{600}$ Burns \& Thomas 2015, pp. 30, 127-130

${ }^{601} 2006$, pp. 520-523

${ }^{602}$ pp. 523-525

603 2015, pp. 60-61, 159-162
} 
implementing the decisions that are made. Each of the 14 district-based councilmembers is principally accountable to their district, rather than the city as a whole. Further, each of these councilmembers, the mayor, and those leading bureaucrats, holds a unique agenda, a unique set of preferences, unique loyalties, and a unique willingness to be influenced by particular actors. As a result, there are 15 different entry points into the decision-making process, and numerous entry points into the implementation of decisions, once they are made.

Further complicating the decision-making structure, consider that each council district is composed of perhaps innumerable neighborhood-level decision-making arrangements. Thus, city-level leadership is characterized by temporary arrangements between two semi-stable coalitions with differential access to private capital, and featuring political leaders who are themselves answerable solely to members of within-district issuebased associations that individually fail to possess the resources required to support permanent civic leaders aligned with a singular agenda. Thus, in considering the decisionmaking structure of Dallas, it may be more accurate to consider Dallas as a league of microcities with a "first among equals," at-large mayor, with decisions being framed in order to achieve an "eight-vote majority," rather than with an eye toward effectiveness and equity.

To differentiate Dallas' decision-making structure from what is found in New Orleans, and further, to differentiate the contemporary iteration of this structure from those of Dallas' own past, this study considers Dallas' current decision-making to be an unstable nonregime. What, however, does this mean? To begin, as an unstable decision-making structure, it is relatively amenable to change - consider that at the citywide level, the slim majority of pro-development agenda proponents is shrinking, while the minority of progressive development agenda proponents grows as political leaders reach their term limits; further, while progressive development agenda proponents seem to be replaced by like-minded successors (e.g. 
Councilmember Kingston and his predecessor, Councilmember Hunt), this is not always the case for pro-development actors (e.g. Councilmember Griggs and his predecessor, Councilmember Jasso).

Further, as a nonregime, citywide decision-making power is first fragmented among districts, and then divided among district-based political actors, their appointees, and various levels of bureaucrats who follow semi-stable agendas. Each of these agendas draws support (or at least non-opposition) from a variety of private- and (to a much lesser extent) thirdsector actors, who use their access to resources to influence various decisions, but who generally have no particular authority to make decisions on their own (with exceptions for organizations explicitly given authority, such as Downtown Dallas Inc.), and who most often act on their individual agendas, rather than "going along to get along" within a larger coalition. In addition, each council district studied seems to feature its own decision-making structure, independent of the kinds of structures found in other districts, although more research would be needed to verify whether this claim holds for all 14 districts. This study argues that, assuming that each of the 14 districts possesses a unique decision-making structure, if Dallas is to be moved toward a more equitable future with respect to economic development, changes must occur at the district level first, such that a majority of districts feature progressive, equitable economic development agendas, and leaders who support these agendas and provide necessary resources; this perspective (and implications thereof) will be revisited and expanded upon in Chapter 7.

Discussion of coalition hypotheses, in summary. This study's second three hypothesis are designed to address its second and third research questions, respectively: "To what extent (if any) are CDCs and anchor institutions active participants in Dallas' governing coalition?" and "If CDCs and anchor institutions are active participants in that coalition, 
what is the effect of their involvement on urban development and policymaking?” In the preceding sections, this study evaluated qualitative results of surveys and interviews from its 79 participants, in order to first uncover the nature of governing coalitions for Dallas as a whole, but also for two of its central urban neighborhoods: North Oak Cliff and Downtown Dallas.

Through its evaluation, this study found that, although there are signs of a growing progressive minority among Dallas' leaders, the city as a whole continues to embody an entrepreneurial governing coalition, focused on corporatist economic development strategies and maintaining a pro-business environment. Further, this study found speculative evidence suggesting that, as Dallas' old guard continues to fade, uncertainty about the future of Dallas' leadership may be preventing younger executives from joining in the politics of decisionmaking, out of concern for choosing the "losing" side. Additionally, although this study found no particular evidence to support the presence of anchor institutions and CDCs at the highest levels of decision-making, it did find that in North Oak Cliff, there are nonetheless efforts to engage in equitable economic development strategies, through the development of a network of locally-owned, locally-oriented businesses. Their results, while limited, offer real-world examples of the theoretical benefits of interconnected, locally-owned businesses, and do so with a flavor that respects the neighborhood "as it is," while offering a vision of what the neighborhood could be in the future. Finally, this study presented data supporting its conclusion that, at the citywide level, Dallas' decision-making structure is best conceptualized as an unstable nonregime, owing to a lack of cohesive, enduring, cross-sector support for a single developmental agenda. Because citywide decision-makers are divided (though unevenly) between two agendas (i.e. pro-development and progressive development), 
decision-making with respect to economic development is difficult, and coalitions tend to form around a patchwork of individual projects that generally lack any sort of overall vision.

\section{Chapter Summary}

The purpose of this chapter was to analyze and evaluate the data reported in Chapter 4, in order to address this study's research questions. In the preceding chapter sections, this study first revisited its research questions and hypotheses. Then, it evaluated its qualitative findings in order to render an image of contemporary urban governance in Dallas, the relationship between the city's decision-making structures and entities involved in equitable economic development projects, and how these projects compare to those in a subset of other cities. The implications of these relationships, as well as possibilities for Dallas' future, are the focus of the next (final) chapter. 


\section{CHAPTER VII}

\section{CONCLUSIONS, LIMITATIONS RE-REVISITED, AND NEW DIRECTIONS}

Conceptualizing urban decision-making structures based on theory is one thing; understanding those structures from the perspectives of the decision-makers themselves, and situating them within evolving socioeconomic- and historical contexts is an altogether different proposition. While decades of urban scholarship has focused on the former, there appears to be a relative dearth of recent studies in the vein of the latter, especially as cities muddle their way through the post-Fordist landscape. This is problematic, because historically, as cities have transitioned from one socioeconomic paradigm to the next, the theories that scholars consider reliable and accurate (notwithstanding all of the usual normative and empirical caveats about using these terms in the social sciences) have also transitioned, moving from community power studies of Fordist cities in the 1950s and 1960s to the crisis-era growth machines and urban regimes of the 1980s and 1990s. Now, cities have transitioned into yet another new socioeconomic paradigm (post-Fordism), but there appears to be no particularly new "grand" urban theory to match.

Thus, the purpose of this study is to reevaluate contemporary theories of urban governance in light of contemporary contexts of urban governance, utilizing the perspectives of both decision-makers themselves and persons knowledgeable about the urban decisionmaking process. In the sections that follow, this chapter will first summarize briefly those chapters that precede it. Then, it will summarize a number of particularly interesting findings, before engaging in a discussion about the future of urban governance in the Dallas 
case, considering that this case may contain lessons for other large, economically-vibrant cities in the United States. Following this, it will engage in a brief expansion of limitations first introduced in Chapter 3. Finally, it will suggest new directions for future scholarship, based on this work.

\section{The Present Study in Review}

Chapter 1 argued that, in the decades since scholars first examined United States cities using the urban political economy perspective, those cities have undergone both racialand economic transitions. To the former, while white flight allowed (some) residents to abandon central cities, a smaller, counter-migration of wealthier, highly educated whites moved back into gentrifying urban neighborhoods, at the cost of displacing people of color and people with lower incomes. To the latter, corporate disinvestment over that same period left many central cities all-but abandoned, and a subset of these central urban cores are transitioning into mixed-use hubs of capital accumulation, culture, and entertainment. Alongside these two transitions, CDCs and anchor institutions expanded into urban economic development projects and urban policymaking - roles previously assumed by actors in governing coalitions. From these, Chapter 1 suggested that it is possible that the entrepreneurial governing coalition archetype, characterized primarily by informal cooperation and resource-sharing among public- and private-sector actors is no longer an accurate representation of contemporary urban decision-making structures.

Anchoring Dallas's story in the greater context of United States cities following World War II, Chapter 2 explored the co-evolving histories of theories of urban governance; postwar socioeconomic paradigm shifts in the United States; and the growth, decline, and resurgence of Dallas through the intersecting lenses of urban governance and socioeconomics framed well by two previous qualitative studies of the city's governance 
structure. This chapter drew out summaries of contemporary urban theory, as well as a subset of particularly salient critiques, in order to more deeply establish the depth and breadth of the gap in extant literature that this study intended to fill, and introduced a new angle in the study of urban decision-making structures: the study of neighborhood-level decision-making structures, and an analysis of whether (or to what extent) actors, organizations, and institutions involved at one level interact with those at other levels, and the effects of that interaction. Owing to limited resources, Chapter 2 also established a focus on two neighborhoods: Downtown Dallas, which is composed of the as the city's rapidlyrevitalizing CBD and its immediate surroundings, and North Oak Cliff, a traditionally majority-minority, economically-marginalized neighborhood also undergoing revitalization, but that is experiencing internal turmoil regarding the displacement of long-time commercial- and residential occupants, and concerns over the potential loss of identity that may coincide with the influx of urban pioneers. Thus, Chapter 2 suggested that the structure of the story of Dallas is structurally similar to the story of the study of urban governance well-researched in the past, but lacking in contemporary follow-up, and that as a result, it would be valuable to revisit the city as the setting for a new study of who governs.

Chapter 3 outlined the setting of this study's data collection, and the methods used those data, arguing for the continued use of reputational crucial case analysis based on the resources available to the researcher, the benefits proffered by this method broadly, and the ability to compare the results of the present study to prior research. For its part, Chapter 4 described this study's quantitative data regarding select socioeconomic changes from 1980 to 2010, first for Dallas citywide, and then for the study's two focus neighborhoods. Then, Chapter 5 synthesized the aforementioned quantitative data, before evaluating them with respect to urban literature regarding expected demographic- and economic transitions found 
in post-Fordist cities, as well as with respect to the effects of these transitions on Dallas' political landscape. Finally, Chapter 6 synthesized this study's qualitative findings in order to render an image of contemporary urban governance in Dallas, the relationship between the city's decision-making structures and entities involved in equitable economic development projects, and how these projects compare to those in a subset of other cities.

\section{Summary of Findings}

The Dallas case allows for a number of findings into the nature of contemporary urban governance as it actually exists, which appears to deviate from the predictions of aging theories of urban governance. To begin, the Dallas case shines a light on the interconnected nature of contemporary decision-making the historical context of the city itself. Additionally, this case study reaffirms the importance of structures in decision-making, as well as the effect of those structures on the outcomes of the decision-making process. Third, this study suggests that CDCs and anchor institutions have a long way left to go, if they desire to become primary, rather than ancillary members of governing coalitions. Finally, this study suggests that under the right pressures, even the dominant decision-making archetype - the entrepreneurial governing coalition - can become something else, even if that transition is somewhat haphazard. In the sections that follow, each of these findings will be discussed inturn.

\section{Finding 1: the interconnected nature of real-world urban decision-making.}

This study argues that contemporary decision-making in Dallas is bound to the city's racial history. At the citywide level, first consider the landmark federal order for the city's election system to be reconstructed around racially-balanced districts, resulting from a federal lawsuit

filed using the Voting Rights Act wherein plaintiffs successfully arguing that the whitedominated northern neighborhoods were effectively silencing those political voices 
belonging to people of color. Additionally, as wealthy whites fled the city during the mid-late $20^{\text {th }}$ century, there was a similar exodus of corporate capital, with firms whose leaders often found themselves elected to high political office relocating to those suburbs. Thus, Dallas was left with fewer (and increasingly disinterested) leaders to act as successors. From these critical wounds, the city's traditional entrepreneurial governing coalition has all-but vanished. Certainly, signs of this collapse were visible during the Elkin study, when the damage was limited to the business side of the political-business alliance, but this study finds that by 2015, people with knowledge of the city's decision-makers openly considered that an alternative, more progressive coalition was poised to seize control - an arguably unthinkable proposition when the city's "old guard" was at the height of its power.

At the neighborhood level, the city's inability (or unwillingness) to equitably address the inequity in urban development is evident in the continued dearth of commercial- and political capital in the city's majority-minority southern neighborhoods, and can still be seen in the antiregime tendencies of the community organizations and neighborhood leaders within North Oak Cliff. The same legacy of northern-sector bias in development that stripped southern-sector neighborhoods of their economic vitality and political connectedness remains visible today, though the support among northern-sector councilmembers for development projects in Downtown Dallas over the objections of actors like Councilmember Kingston, even though otherwise, these leaders tend to defer to the wishes of individual councilmembers with respect to projects within their districts. As a result, the city's private-sector elites continue to enjoy significant (but waning) informal influence, even though this influence is largely limited to Downtown Dallas.

Finding 2: Structure still matters in urban decision-making. In his analysis of Broward County, Florida, Ronald Vogel noted that "communities that are decentralized in 
their decision-making structures face difficulties in pursuing policies designed to attract capital investment to the community" ${ }^{604}$. In Dallas, these difficulties are baked directly into its system of district-based political leadership. Recall that the "go along to get along" practices of councilmembers effectively splits the city into 14 mini-cities, each headed by a mini-mayor, or perhaps more cynically, 14 loosely-united fiefdoms headed by would-be feudal lords. This structure is self-reinforcing, because councilmembers are elected only by voters living within their districts, and as such, seek primarily seek benefits and resources for their own constituents, even at the cost of a more equitable distribution of resources, especially in districts or communities that have declined under decades of disinvestment. Thus, while individual council districts may gain short-term advantages or increases in prosperity, the city as a whole suffers ( $\grave{a}$ la the "tragedy of the commons").

As a result, this study finds it highly unlikely that Dallas will ever see a comprehensive development strategy, because such a strategy necessarily benefits some areas at the cost of others. Further, each councilmember is able to pursue a unique set of priorities, which challenges private- and third-sector actors to adapt their plans to suit each councilmember in whose district they seek to develop. In North Oak Cliff, for example, developers seeking the approval of Councilmember Griggs or his appointees often must hold neighborhood meetings, to ensure that the community is aware of (and broadly supports) new development projects, although there are some exceptions to this, based on zoning changes that were enacted prior to Griggs' involvement in city politics. By comparison, in Downtown Dallas, it is only necessary for a developer to gain the support of the first-and second tier influentials who are regularly willing to use their deep connections to the city's eight pro-development councilmembers (including the mayor) and to high-level city

$$
604 \text { 1992, p. } 124
$$


officials, in order to circumvent the disapproval of Councilmember Kingston.

Finding 3: CDCs and anchor institutions have a long way left to go. A critical finding in this study is that neither CDCs nor anchor institutions are particularly involved in the politics of decision-making in Dallas, and when they are involved, they tend to favor prodevelopment agenda items and self-serving policies. This is unfortunate, given that these organizations could be transformative in economically-marginalized communities, but also unsurprising, given that Dallas' public- and private-sector leaders are still able to combine political and economic capital in service of individual development projects, even when these projects fail to develop into enduring partnerships. Dallas is not unique in the noninvolvement of CDCs and anchor institutions in the decision-making process; certainly, while inclusive, community-based, cross-sectoral governing coalitions have been speculated about in the past ${ }^{605}$, like most progressive governing coalition typologies, they have only seen limited, short-lived instances in the real world (e.g. Chicago under Harold Washington, Philadelphia at the beginning of the $21^{\text {st }}$ century, San Francisco at the end of the $20^{\text {th }}$ century) ${ }^{606}$.

The Philadelphia case noted above is highly relevant to Dallas, because it features neighborhood-level mobilization combining the resources of anchor institutions with the involvement of hundreds of citizens and over a dozen community groups, which helped pave the way for the 2007 election of a progressive-minded mayor, causing speculation that the city's governing coalition could transition away from its elite-dominated, entrepreneurial governing coalition past ${ }^{607}$. Dallas, at a similar crossroads of its neoliberal past and an uncertain future, could benefit from the lessons found in Philadelphia - chiefly, that issue-

\footnotetext{
${ }^{605}$ Imbroscio, 1998, pp. 242-243

${ }^{606}$ DeLeon, 1992b, pp. 154-156; Imbroscio, 1998, p. 242; McGovern, 2009, pp. 682-689; Reese \& Rosenfeld, 2002, pp. 645-646

${ }^{607}$ McGovern, 2009, p. 666
} 
based alliances can lead to enduring coalitions, and can change how a city is governed. In this chapter's final substantive section, this study will revisit the Philadelphia case as a basis for discussing how Dallas' decision-making structure could become more progressive, even if the unstable nonregime persists.

\section{Finding 4: Under the right pressures, governing coalitions can transition.}

Following the dissolution of its business community, and a forced-restructure of its political leadership, Dallas' entrepreneurial governing coalition has been replaced by competing agendas and discord, found both among political leaders primarily interested in their own districts (over the city as a whole), and among private-sector leaders who are cautious about becoming too political, lest they be on the "wrong side" when the battle over Dallas' future as either a pro-development or a progressive development city is finally resolved. This study finds that, much like the San Francisco of the late 1980s, Dallas' has (at least, in substantive part) cast off its entrepreneurial governing coalition past, but has failed to supplant it with a unified alternative, resulting instead in the present unstable nonregime that is unable to pursue longterm development strategies, and is instead limited to reactionary policies and one-off, shortterm development plans.

Key to the return of a unified agenda is a necessary divorce of public-sector leaders from private-sector interests. While this has occurred in part, this study finds a continued series of deep connections between a subset formal authorities and various highly influential actors from the private- and third sectors. This in mind, encouraging news for progressive development advocates came in May 2016, when pro-development city manager A.C. Gonzalez announced his resignation, which became effective in early 2017 after only three years on the job, and amid suggestions of weakening support from city councilmembers ${ }^{608}$. Among the 
five candidates under consideration to replace Gonzalez were four from other cities as well as one internal candidate, widely assumed to be the "favorite" for the position, especially among pro-development advocates ${ }^{609}$, yet after a closed session in early December 2016, only one finalist was announced for a final city council vote. After three decades of city managers who made their careers within Dallas' city hall ${ }^{610}$, the city's incoming top bureaucrat - T.C. Broadnax - is a true "outsider," currently unaffiliated with the first tier and second tier influentials who, for so much of Dallas' history, have enjoyed preferred access to the levers of decision-making. This decision, confirmed by a majority council vote in mid-December, was lauded by progressive development councilmembers Kingston and Griggs ${ }^{611}$. With another key formal authority unencumbered by informal commitments to highly influential private actors, a progressive-minded future for economic development in Dallas becomes more plausible.

While this news is encouraging for advocates of a new, more progressive Dallas, it remains true that city-level decisions are still made by the "eight vote majority," which is currently tilted in favor of the pro-development agenda. While all councilmembers (excepting the mayor) will come up for re-election in May of 2017, for the first time in Dallas' history, no district-based councilmember is currently term-limited, so all 14 will benefit from incumbency. Because of the tremendous advantages this confers, this study finds it unlikely that a councilmember running for reelection would lose; however, as the recent presidential elections have reminded scholars and talking heads alike, there may not be such a thing as a "sure bet" in politics. Notably, and for the first time in recent memory, a sitting councilmember is actively campaigning against one of his colleagues; in early December

\footnotetext{
${ }^{609}$ Wilonsky, 2016c

${ }^{610}$ Celeste, 2016

${ }^{611}$ Hallman \& Wilonsky, 2016
} 
2016, Councilmember Kingston endorsed a progressive development challenger running for the seat of incumbent (and increasingly unpopular), pro-development councilmember (and Mayor Pro Tempore) Monica Alonzo ${ }^{612}$. Additionally, in northern Dallas, long-time realtor, real estate journalist, and "Dallas Way" critic Candy Evans is challenging pro-development advocate Lee Kleinman for his council seat, and she appears to have the support of several area real estate bodies $^{613}$. As the election draws closer, it is likely that additional challengers will emerge across the city, with some being supported by pro-development organizations and influential actors, and others being supported by progressive development advocates; thus, while it is possible that in this election, the "Dallas Way" may become functionally irrelevant, it is too early to tell whether this is likely to occur. Even with such unprecedented potential for upsets, however, this study argues that relying on upset votes in some districts, while hoping for progressive incumbents to retain their seats in others is, at best, a tenuous proposition for progressive development advocates.

\section{A Vision of Future Governance in the Commercial Republic}

With the aforementioned Philadelphia case in mind, this study argues that when community members (e.g. residents, business owners, leaders of community organizations and anchor institutions) are willing to assume key roles in designing their neighborhoods' revitalization, they gain the opportunity reclaim power that has historically been denied, and thus, develop a sense of ownership over their communities. From this, it follows that community-based governance can extend beyond simply involving community members in formal decision-making, and can also guide efforts to build the kinds of community capacity needed to address (a subset of) problems without the direct involvement of formal authorities. 
To be successful in Dallas, community-based governance requires councilmembers to be willing to share decision-making with community stakeholders, but at the same time, it is incumbent upon those stakeholders to find common ground, and to demonstrate a willingness and ability to make decisions together, cultivate leadership from within the communities themselves, and share knowledge and resources across sectoral boundaries, in spite of the presence of real (or perceived) slights ${ }^{614}$. Once organized behind a common, enduring agenda, this study suggests that community members will be able to demand a greater role in the formal decision-making process, either from incumbent political leadership, or by supporting challengers who are more open to shared governance. In the process of preparing community members to successfully assert roles in organized districtlevel decision-making, this study considers the roles of actors like David Spence (for business organization) and Jason Roberts (for community engagement).

In first speculating about Spence's role in the development of district-level, community-based governing coalitions, recall that - beyond repurposing and renovating existing structures, Spence's firm also works with local entrepreneurs to fill these buildings with locally-owned businesses, which are then interconnected with other firms in Spenceleased properties. Beyond the economic benefits that a network of interdependent, importsubstituting local firms provides for a community, Spence's network also allows business owners within a relatively compact commercial corridor to communicate with one another, share ideas, and potentially identify common concerns and develop a common agenda. Although Spence himself operates primarily in North Oak Cliff, this study argues that the model is both sustainable and transferable to other parts of the city, particularly in southernsector districts where Dallas' multinational real estate development firms have shown little

${ }^{614}$ McKieran, Kim, \& Lasker, 2000, pp. 23-29 
interest in investing. As tools for building a more inclusive decision-making structure, such networks could be mobilized in support of city councilmembers who value the protection and growth of locally-owned firms, and the kinds of development projects that allow more local businesses to form. In a progressive future for Dallas, these networks would aggregate their resources - both financial and social - to support progressive candidates and civic projects, and by connecting them financially, it becomes more reasonable for these actors to connect in support of political leaders as well.

While private-sector resources can help fund a candidate's campaign, as well as various projects throughout their term in office, councilmembers are (at least, ostensibly) responsible to the voters in their districts. This study argues that organized, engaged constituents are better able to hold a councilmember accountable than the disorganized collection of needs and demands found in, for example, North Oak Cliff. Thus, Dallas' progressive future relies on disparate interest groups coming together around a common vision for their development, which is where Jason Roberts enter the equation. Recall that Roberts' organization produces temporary urban revitalization projects in areas of deep disinvestment, engaging community members (e.g. residents, local business owners, and local community organizations) throughout the design- and implementation processes. Through this prolonged engagement, Roberts provides communities with best practices, training in community organization, and (non-financial) resources ${ }^{615}$. If these leaders and organizations can successfully work together after individual projects are completed, and are willing to move beyond past disagreements, then this study posits that they are likely to be wellpositioned to take ownership over neighborhood issues, and will have many of the necessary resources to be attractive partners for political leaders who are actively involved in the

\footnotetext{
615 Team Better Block, 2016c
} 
problem-solving process. In addition, this study argues that these coalitions will be better able to elucidate a cohesive set of demands for political leaders, as well as proposed solutions and resources that can be devoted toward these, all while representing significant numbers of voters who can alternatively reward or punish councilmembers during elections. In a progressive future Dallas, these neighborhood coalitions, working in concert with coalitions of locally-owned businesses, form the alternative support structures that councilmembers will need in order to fully divorce themselves from corporatist interests.

Although a Dallas run by progressive-minded political leaders who themselves are supported by (and accountable to) a series of district-level, community-based governing coalitions is an intriguing thought exercise, that it has not yet come to fruition is suggestive of the real-world challenges that this model faces - primarily, a lack of resources needed to scale up the initiatives of actors like Spence and Roberts. To begin, it is important to note that David Spence is not the primary (or arguably, even a significant) driver of the economic revitalization of North Oak Cliff, and even without his firm, North Oak Cliff would likely continue to be a focus for development. Spence's success is, to some extent, catalyzed by the unique confluence of factors that is bringing new life to North Oak Cliff (e.g. proximity to Downtown Dallas, TIF support, infrastructure investment), as well as the presence of larger, successful development projects. For his part, Roberts also shares a similar problem insufficient resources to increase scale. Because his organization relies on external funding and contracts with various cities to "reimagine" derelict spaces, Roberts is unable to focus on enduring projects, or on any single community. Thus, while his organization has found limited success in Dallas, as well as in other cities, it remains unclear whether small successes will translate into a larger movement. 
Without sufficient capacity to grow their existing projects, it seems unlikely that change-agents in southern Dallas will be able to convert these into a foundation for a more progressive future citywide. In other cities (e.g. Cleveland, Detroit, Philadelphia), funding for change-making initiatives came (at least, in part) from anchor institutions, but in Dallas, many of these institutions are often funded and lead by first tier and second tier influentials whose pro-development agenda built Dallas into the city it is today, and who would stand to benefit from continued pro-development policies. It stands to reason that, if these organizations had the desire (or ability) to involve themselves in programs like those being implemented by Spence and Roberts, they would have done so already.

Much like Dallas' new city manager, whose “outsider” status leaves him largely free of the tethers to Dallas' most highly-influential actors, there is one new anchor institution that has established itself in southern Dallas, and is also largely free of these tethers. As such, it is possible that this new institution - the first (and presently, only) public university within Dallas' city limits - can become the supporting organization that actors like Spence and Roberts need in order to "scale up" their efforts. The University of North Texas at Dallas, a “daughter" campus of the University of North Texas (located to the far northwest of Dallas), has taken up residence on over 250 acres of undeveloped land in the southern part of the city, and is rapidly expanding. While it remains small, this institution is already leveraging public- and private-sector support to improve its surrounding communities, both through capacity-building initiatives within disenfranchised neighborhoods and through involvement in economic development projects in derelict commercial centers ${ }^{616}$. Although these efforts are still relatively new, they could portend greater support for a more progressive Dallas in the future, regardless of the results of the next citywide election.

${ }^{616}$ University of North Texas at Dallas, 2016 


\section{Limitations, Re-Revisited and Expanded}

As Chapter 3 notes, every study, no matter how well constructed, has limitations that shape the conclusions that can be drawn ${ }^{617}$. Understanding these limitations is critical for these findings to be properly evaluated, so in the paragraphs that follow, this study will revisit- and expand upon limitations first introduced in Chapter 3.

Looking first at this study's use of secondary-source data, any problems in the source data are inherited by this study, and this study is forced to rely on definitions and conceptualizations present in the source material. For example, participation rates for people identifying as Hispanic or Latino are questionable, presumably because people worry that census records will be used to identify them as undocumented immigrants, and they fear deportation ${ }^{618}$. As a result, recall that this study examined changes in poverty rates and median household income (MHI), as well as changes in demographics with respect to race and Hispanic or Latino status, which was complicated because MHI is available by race and Hispanic or Latino status at the tract level, but poverty rates by race and Hispanic or Latino status are not, therefore this study could only make broad inferences about the face of poverty in these two neighborhoods.

Additionally, in at least one case, data are unavailable because definitions used by the census bureau changed. One key example of this is that census definitions regarding employment industries changed dramatically between 1990 and 2000, so data comparing blue collar and creative class employment from 1980 and 1990 could not be reconciled with data from 2000 and 2010. Finally, recall that economic data span the decades from 1980 to 2010, inclusively, but during that time, Dallas experienced two large economic slowdowns - the

${ }^{617}$ Schutt, 2009, p. 20

${ }^{618}$ Johnson et al., 2002, pp. 59-61 
Savings \& Loan Crisis, and the Great Recession - both of which likely affected the economic data, further weakening this study's quantitative findings. This particular limitation is not unique to this study; indeed, any case study would have similar complications.

In considering the collection of survey and interview data, additional limitations emerge. First, because surveys and interviews were collected in a natural (rather than laboratory) setting, it is extremely difficult for future scholars to replicate the study in other settings; moreover, the settings themselves may also have impacted the kinds of responses that participants were comfortable with giving. However, this may also be a benefit, as participants were allowed to select their interview and survey settings, and may have strategically selected locations where they could speak more freely. Even in these participantselected interview settings, however, there were occasions wherein participants were not comfortable addressing all aspects of each interview question.

In any case, responses were limited by the time constraint on the meetings; participants may have truncated responses in order to fit within the time allotted, reducing their overall quality. Related to this, because a number of survey items restricted the range of possible responses, the results are narrower than they may have been, were the questions written to be open-ended. A further limitation is that the nonrandom nature of snowball sampling introduces the possibility that the study sample is not actually representative of the (arguably unknowable) population; at best, it merely approximates the breadth of leaders involved in decision-making. This sampling was further limited because the researcher lacked the time or funds to interview every possible individual with knowledge of various decisionmaking structure, which denies this study the perspectives of un-interviewed individuals.

Related to the topic of participant perspectives, survey and interview results were based on participants' subjective opinions and knowledge, and as a result, contain an 
unknowable amount of error - participants could, for example, be misleading with their answers (intentionally or otherwise), be simply uninformed, may be biased in their responses and perceptions, or may be attempting to give the answers that they perceived to be desirable. This study's findings, then, may be skewed by the presence of actors whose positions in the leadership structure are artificially higher than they would normally be (a "man of the hour" effect), or artificially lower as a result of, for example, a local scandal. Some participants seemed, as a rule, to be reluctant to give low scores, but broadly speaking, this was not an issue in the vast majority of cases.

In addition, it must be noted that all data regarding the decision-makers described in Chapter 4, as well as the resulting analyses in this chapter, are temporally-locked in the summer and early fall of 2015, and may be less accurate as time passes, and circumstances change (e.g. death or retirement of a highly-nominated actor). The information gained from this study is, by its very nature, not as reliable as direct observation of the decision-making process, taken over several years, but such a study would be infeasible, given the lack of time or resources to perform it.

A final set of limitations come from the nature of this study's use of Dallas as a single-shot crucial case, rather than as part of a comparative study. To begin, Dallas was assumed to be an extreme outlier, with respect to the presence of anchor institutions and CDCs in governing coalitions; that no particular evidence was found to support their involvement is unsurprising, and while (as noted in Chapter 3) it does not preclude the possibility of anchor institutions and CDCs being deeply involved in the governing coalitions of other cities, it does limit the contributions that this study can make to the greater field. In addition, because of the lack of cross-case, comparative data, this study is unable to eliminate alternative explanations for its findings. Dallas may simply be too 
extreme an outlier, when compared to other cities. It should also be noted that both of this study's focus neighborhoods - North Oak Cliff and Downtown Dallas - represent areas undergoing various levels of gentrification. Dallas has as many as 355 neighborhoods ${ }^{619}$, spread over an area (approximately) eight times the size of San Francisco ${ }^{620}$, and it is unrealistic to assume that the results taken from these two are representative of those for other neighborhoods within Dallas.

\section{Recommendations for Future Research}

Because this study was conducted with a limited pool of resources, over an equallylimited amount of time, a number of concerns could not be addressed, and a number of new questions arose - questions that simply could not be answered in the interest of completing the work. Additionally, some of this study's limitations, especially those that resulted from a reliance on secondary-source data, are infeasible to eliminate without unrealistic budgets, but other limitations, such as those related to case studies more broadly, can be addressed by future scholars, especially those working in teams. With this study's unanswered questions and "addressable" limitations in mind, this section now offers avenues for future research.

To begin, recall this study was a single-shot case analysis, and as such, lacks a strong comparative element, both among Dallas' neighborhoods, and among Dallas and other, similar cities. Within the Dallas case, future scholarship should include additional neighborhoods from across the city's 14 districts, to determine whether Downtown Dallas and North Oak Cliff happen to be outliers, or whether, for example there are regional effects on leadership inside the city. Expanding to Dallas as one city among many, consider that it is yet-unknown whether (or to what extent) the city's contemporary decision-making structure

\footnotetext{
${ }^{619}$ Wilonsky, 2012

${ }^{620}$ United States Census Bureau, 2016a; 2016b
} 
(i.e. the unstable nonregime) is unique to Dallas. If several cities can be found to have a nonregime structure, even if this number is far-from a majority, then it may be time for scholarship to reconsider what the de facto urban governance model should be, even if the analysis of governing coalitions (or urban regimes) remains the preferred method for conceptualizing these structures. Additionally, by understanding the connections (to the extent that they exist) between neighborhood-level civic leadership and civic leadership citywide, new avenues may open for would-be progressive leaders to either forge new paths to equitable urban governance, or gain new insight into why efforts to-date have seen only limited success.

Returning to Dallas specifically, recall that this study's data collection and analysis concludes as Dallas enters a critical and highly uncertain election season. Whether or not the city's progressive development agenda manages to carry the day, a follow-up study in the weeks and months that follow could chronicle the transition of Dallas' decision-making structure as it marches toward one of three possibilities: first, a progressive-minded nonregime (unstable or otherwise), second, as a reformulated entrepreneurial governing coalition that must nonetheless reconcile its agenda with the visible success of progressive development initiatives, or as a continuation of the existing unstable nonregime. In each of these cases, the lessons learned are of immediate consequence to other cities facing what amount to "identity crises" with respect to how they will be run. Remember that a significant critique of contemporary urban theory is that it fails to identify the precursors of governing coalition transformation; in the Dallas case, this study argues that the restructuring of its city council and rise of progressive leaders from district-based elections, and the decline of its long-standing civic leaders with no apparent successors are two likely precursors of governing coalition shift, but the extent to which this is true will only be known once such a transition takes place, if it does at all. 
Further, in considering the New Orleans case, some results may take years to materialize.

Regardless of the outcome of this critical period, this study argues the lessons learned from a follow-up study of Dallas will be helpful for would-be progressive leaders in other cities, as well as for comparing the decision-making structures of "pre-crisis" and "post-crisis" Dallas.

Finally, in considering why Dallas' decision-making structure lacked the hypothesized involvement of CDCs and anchor institutions, this study considered that the city's relatively strong economy allowed decision-makers to pursue capital without the constraints of mission requirements (or put another way, capital without the constraints of conscience). This study now considers whether the willingness of governing coalitions to entertain alternative sources of capital for development projects exists on a spectrum, with "development-hungry" cities (e.g. Detroit, Cleveland) at one end, and "development-full" cities like Dallas on another. As an alternative to seeking out cities similar to the Dallas case, this path of future scholarship focuses on the relationship between the presence and outcomes of third-sector involvement in governing coalitions and the amount of urban development being undertaken through more traditional methods (inter alia public-private partnerships). Such a line of research could discover, for example, whether there is some kind of a "tipping point" or indicator that signals when (or whether) alternative development projects become acceptable within the traditional division of labor, and whether these projects indicate that third sector institutions have become equal (or at least "more equal") to public- and private sector institutions in governing coalitions.

\section{Chapter Summary}

As cities redefine themselves after decades of commercial abandonment, "urban renaissance" movements, white flight, and the gentrification of central urban neighborhoods, this study sought to determine whether cities still governed by the political-business 
coalitions conceptualized by urban regime theorists, or whether (or to what extent) new players had emerged. It suggested that, in the forty years since the dawn of the political economy paradigm, many cities looked nothing like they did when growth machine theory and urban regime analysis were first conceptualized, and that contemporary observations of central cities may, once again, yield new insight into their decision-making structures.

This study found that, at least in the Dallas case, the hypothesized "new players," that is, CDCs and anchor institutions, have failed to claim meaningful roles in the decisionmaking process, either at the citywide level, or within particular communities. However, and of (arguably) greater note, this study found that a city whose decision-making structure once epitomized the entrepreneurial governing coalition was now void of the unified agenda and resource-sharing that defines governing coalitions, and further, that the wounds were selfinflicted. As Dallas inches closer to deciding whether it will double-down on the prodevelopment agenda of its past, or whether a more progressive future is in order, individual progressive actors have found ways to operate successfully at the neighborhood level by working (for the most part) independently of Dallas' dysfunctional decision-makers, and as new institutions develop significant resource pools, the connections made between missiondriven capital and mission-driven actors may prove to be the final nail in the coffin for the "Dallas Way." In many ways, Dallas represents what many cities, especially those in the Rust Belt, might aspire to become; therefore, as the city's decision-making structure grapples with which future it wants to bring about, it remains poised to become either a shining example or a cautionary tale. 


\section{REFERENCES}

Abu-Laban, B. (1965). The reputational approach in the study of community power: a critical evaluation. Pacific Sociological Review, 35-42.

Adams, C. (2003). The meds and eds in urban economic development. Journal of Urban Affairs, 25(5), 571-588.

Adams, C. T. (2014). From the outside in: Suburban elites, third-sector organizations, and the reshaping of Philadelphia: Cornell University Press.

Adkisson, R. V., \& Zimmerman, L. (2004). Retail Trade on the U.S.-Mexico Border During the NAFTA Implementation Era. Growth and Change, 35(1), 77-89. doi:10.1111/j.0017-4815.2004.00239.x

Agger, R. E. (1956). Power attributions in the local community: theoretical and research considerations. Social Forces, 322-331.

Agger, R. E., \& Ostrom, V. (1956). The political structure of a small community. Public opinion quarterly, 81-89.

AIA Dallas. (2015). Profile: Jason Roberts. Retrieved from https://www.aiadallas.org/v/columns-detail/Profile-Jason-Roberts/m6/

Alesina, A., Harnoss, J., \& Rapoport, H. (2016). Birthplace diversity and economic prosperity. Journal of Economic Growth, 21(2), 101-138.

Alexander, C. H. (2002). A discussion of the quality of estimates from the American Community Survey for small population groups.

Alford, R. R., \& Friedland, R. (1985). Powers of theory: Capitalism, the state, and democracy: Cambridge University Press.

Allison, W. (2014). The rebirth of Dallas. D Magazine. Retrieved from http://www.dmagazine.com/publications/d-magazine/2014/september/rebirth-ofdallas/

Alon, I., \& Chase, G. (2005). Religious freedom and economic prosperity. Cato Journal, 25, 399.

Alperovitz, G. (2011). America beyond capitalism: Reclaiming our wealth, our liberty, and our democracy: Democracy Collaborative Pres. 
Alperovitz, G., \& Dubb, S. (2013). The new alliance: organizing for economic justice, building a new economy. Democracy Collective Working Paper. Democracy Colletive. Retrieved from http://www.garalperovitz.com/the-new-alliance-organizing-for-economic-justicebuilding-a-new-economy/

Alperovitz, G., Dubb, S., \& Howard, T. (2008). The next wave: Building university engagement for the 21 st century. The Good Society, 17(2), 69-75.

Alperovitz, G., Howard, T., \& Williamson, T. (2010). The Cleveland model. The Nation, 1, 21-24.

Amaro, H., \& Zambrana, R. E. (2000). Criollo, Mestizo, Mulato, LatiNegro, Indígena, white, or black? The US Hispanic/Latino population and multiple responses in the 2000 census. American journal of public health, 90(11), 1724.

Appleton, R. (2012a). Oak Cliff neighborhood group relishes 'huge victory' in zoning fight. The Dallas Morning News. Retrieved from The Dallas Morning News website: http://cityhallblog.dallasnews.com/2012/09/oak-cliff-neighborhood-group-relisheshuge-victory-in-zoning-fight.html/

Appleton, R. (2012b). Parking concerns grow with Oak Cliff's Bishop Arts District. The Dallas Morning News. Retrieved from The Dallas Morning News website: http://www.dallasnews.com/news/community-news/oakcliff/headlines/20120508-parking-concerns-grow-with-oak-cliffs-bishop-artsdistrict.ece

Appleton, R. (2013a). Oak Cliff's Tyler-Davis area gets change of scene from new businesses, property owner. The Dallas Morning News. Retrieved from The Dallas Morning News website: http://www.dallasnews.com/news/community-news/bestsouthwest/headlines/20130901-new-businesses-new-property-owner-bring-achange-of-scene-to-oak-cliff-neighborhood.ece

Appleton, R. (2013b). Year in review: In neighborhoods across Dallas area, projects changing landscape. The Dallas Morning News. Retrieved from http://www.dallasnews.com/news/community-news/bestsouthwest/headlines/20131214-new-coalition-of-neighborhood-groups-seeks-toboost-west-dallas-clout.ece

Appleton, R. (2013c). Praise be: the streetcar's coming, the streetcar's coming. The Dallas Morning News. Retrieved from The Dallas Morning News website: http://oakcliffblog.dallasnews.com/2013/05/praise-be-the-streetcars-coming-thestreetcars-coming.html/

Appleton, R. (2013d). New coalition of neighborhood groups seeks to boost West Dallas' clout. The Dallas Morning News. Retrieved from http:/ /www.dallasnews.com/news/community-news/bestsouthwest/headlines/20131214-new-coalition-of-neighborhood-groups-seeks-toboost-west-dallas-clout.ece 
Appleton, R. (2015a). Development would reshape entryway to Oak Cliff's Bishop Arts District. The Dallas Morning News. Retrieved from The Dallas Morning News website: http:// cityhallblog.dallasnews.com/2015/05/development-would-reshape-entrywayto-oak-cliffs-bishop-arts-district.html/

Appleton, R. (2015b). Bishop Arts project draws more fire; revised plan due Aug. 12. The Dallas Morning News. Retrieved from The Dallas Morning News website:

http://oakcliffblog.dallasnews.com/2015/06/bishop-arts-project-draws-more-firerevised-plan-due-aug-12.html/

Appleton, R. (2015c). Bishop Arts Gateway project center stage this evening at Texas Theatre. The Dallas Morning News. Retrieved from The Dallas Morning News website: http://oakcliffblog.dallasnews.com/2015/06/bishop-arts-gateway-project-centerstage-this-evening-at-texas-theatre.html/

Appleton, R. (2015d). Downtown-Oak Cliff streetcar debuts with speeches, curious riders. The Dallas Morning News. Retrieved from The Dallas Morning News website: http://www.dallasnews.com/news/community-news/bestsouthwest/headlines/20150413-downtown-oak-cliff-streetcar-debuts-with-speechescurious-riders.ece

Atkinson, A. B., \& Brandolini, A. (2001). Promise and pitfalls in the use of" secondary" datasets: Income inequality in OECD countries as a case study. Journal of economic literature, 771-799.

Atkinson, R. D. (1993). Defense Spending Cuts and Regional Economic Impact: An Overview. Economic Geography, 69(2), 107-122. doi:10.2307/143531

Audretsch, B. (1998). Agglomeration and the location of innovative activity. Oxford review of economic policy, 14(2), 18-29.

Austin, B. (2015). Oak Cliff welcomes back streetcars - after a nearly 60-year absence. KERA News. Retrieved from KERA News website: http://keranews.org/post/oak-cliffwelcomes-back-streetcars-after-nearly-60-year-absence

Azarian, R. (2011). Potentials and limitations of comparative method in social science. International Journal of Humanities and Social Science, 1(4), 113-125.

Bailey, M. J. (1959). Note on the Economics of Residential Zoning and Urban Renewal. Land Economics, 35(3), 288-292. doi:10.2307/3144825

Ball, L. M., Leigh, D., \& Loungani, P. (2013). Okun's law: fit at fifty? Retrieved from

Banfield, E. C. (1961). Political influence. Ann Arbor: The University of Michigan.

Barnes, J. A. (1972). Social networks. Reading, MA: Addison-Wesley Publishing Company.

Barth, E. A. T., \& Abu-Laban, B. (1959). Power structure and the Negro sub-community. American Sociological Review, 69-76. 
Bast, J. L. (1998). Sports Stadium Madness. The Heartland Institute, 85.

Baumgartner, F. R., \& Jones, B. D. (1993). Agendas and instability in American politics: University of Chicago Press.

Beauregard, R. A. (2010). The chaos and complexity of gentrification. In L. Lees, T. Slater, \& E. K. Wyly (Eds.), The gentrification reader (pp. 11-23). New York: Routledge.

Beekun, R. I., \& Glick, W. H. (2001). Organization structure from a loose coupling perspective: a multidimensional approach. Decision Sciences, 32(2), 227-250. doi:10.1111/j.1540-5915.2001.tb00959.x

Belknap, G., \& Smuckler, R. (1956). Political power relations in a Midwest city. Public opinion quarterly, 73-81.

Bennett, A., \& Elman, C. (2006). Complex causal relations and case study methods: the example of path dependence. Political Analysis, 14(3), 250-267.

Benning, T. (2014). City audit questions progress of South Dallas/Fair Park Trust Fund. The Dallas Morning News. Retrieved from http://www.dallasnews.com/news/communitynews/best-southwest/headlines/20141103-city-audit-questions-progress-of-southdallasfair-park-trust-fund.ece

Berry, C. (2014). The relationship between economic growth and population growth. Retrieved from Sheffield, UK:

Best of Dallas. (2013). The Dallas Observer. Retrieved from Best of Dallas website: http://www.dallasobserver.com/best-of/2013/shopping-and-services/bestdeveloper-6463671

Birch, E., Perry, D. C., \& Taylor Jr, H. L. (2013). Universities as Anchor Institutions. Journal of Higher Education Outreach and Engagement, 17(3), 7-16.

Blacks In Dallas. (2015). Dallas Black History. Retrieved from http://blacksindallas.com/dallasblackhistory/

Bluestone, B., \& Harrison, B. (1982). The deindustrialization of America: Plant closings, community abandonment, and the dismantling of basic industry: Basic books New York.

Bonjean, C. M. (1963). Community leadership: a case study and conceptual refinement. American Journal of Sociology, 672-681.

Bonjean, C. M., \& Olson, D. M. (1964). Community leadership: Directions of research. Administrative science quarterly, 278-300.

Borgatti, S. P., Mehra, A., Brass, D. J., \& Labianca, G. (2009). Network analysis in the social sciences. Science, 323(5916), 892-895. 
Borrus, M. (1997). Left for Dead: Asian Production Networks and the Revival of US Electronics.

Boustan, L. P., \& Margo, R. A. (2011). White Suburbanization and African-American Home Ownership, 1940-1980. Retrieved from

Boustan, L. P., \& Margo, R. A. (2013). A silver lining to white flight? White suburbanization and African-American homeownership, 1940-1980. Journal of Urban Economics, 78, 71-80. doi:http://dx.doi.org/10.1016/j.jue.2013.08.001

Brooks, G. (2014). Oak Cliff history: How our neighborhood came to be. Oak Cliff Advocate. Retrieved from Oak Cliff history: How our neighborhood came to be

Brown, S. (2014). Units near Mockingbird Station face obstacle. The Dallas Morning News. Retrieved from http://www.dallasnews.com/business/commercial-realestate/20140220-units-near-mockingbird-station-face-obstacle.ece

Brown, S. (2016a). Uptown Dallas office tower hits the market at expected record price. The Dallas Morning News. Retrieved from http://bizbeatblog.dallasnews.com/2016/04/uptown-dallas-office-tower-hits-themarket-at-expected-record-price.html/

Brown, S. (2016b). Dallas office developers may be overdoing it, new research report warns. The Dallas Morning News. Retrieved from http:/ / bizbeatblog.dallasnews.com/2016/03/dallas-office-developers-may-beoverdoing-it-new-research-report-warns.html/

Bruns, A., \& Rasmussen, P. (2016). Dare to be greater: These regions know how to connect the dots, bridge the gaps and cultivate talent. SiteSelection.

Bruyn, S. T. (1987). Beyond the market and the state. In S. T. Bruyn \& J. Meehan (Eds.), Beyond the market and the state: New directions in community development (pp. 3-27). Philadelphia: Temple University Press.

Bulkley, K. E. (2007). Bringing the private into the public changing the rules of the game and new regime politics in Philadelphia public education. Educational Policy, 21(1), 155184.

Burns, P., \& Thomas, M. O. (2006). The Failure of the Nonregime How Katrina Exposed New Orleans as a Regimeless City. Urban affairs review, 41(4), 517-527.

Burns, P. F., \& Thomas, M. O. (2015). Reforming New Orleans: The Contentious Politics of Change in the Big Easy: Cornell University Press.

Burt, R. S., \& Schott, T. (1989). Relational contents in multiple network systems. In L. C. Freeman, D. R. White, \& A. K. Romney (Eds.), Research methods in social network analysis (pp. 185-213). Fairfax, VA: George Mason University Press.

Byrne, J. P. (2002). Two cheers for gentrification. Howard Law Journal, 46, 405-426. 
Cadwalader, Z. (2016). Oak Cliff Coffee Goods: Shop happy in Dallas. Sprudge. Retrieved from http://sprudge.com/oak-cliff-coffee-93495.html

Cazes, S., Verick, S., \& Al Hussami, F. (2011). Diverging trends in unemployment in the United States and Europe: evidence from Okun's law and the global financial crisis. Retrieved from

Celeste, E. (2013). Can the Dallas Citizens Council reclaim its power? D Magazine. Retrieved from http://www.dmagazine.com/publications/d-magazine/1991/march/thehustler-john-wiley-price?single $=1$

Celeste, E. (2014). The Dallas affordable housing scandal. D Magazine. Retrieved from http://www.dmagazine.com/publications/d-magazine/2014/february/dallas-hudhousing-scandal

Celeste, E. (2016). Why Dallas City Manager A.C. Gonzalez must go. D Magazine. Retrieved from http:/ /www.dmagazine.com/publications/d-magazine/2016/march/dallascity-manager-ac-gonzalez-must-go/

Chow, K. (2015). Some skeptics pleased with revised Bishop Arts District development plan. KERA News. Retrieved from KERA News website: http://keranews.org/post/some-skeptics-pleased-revised-bishop-arts-developmentplan

Cisneros, H. G. (1996). The university and the urban challenge. Cityscape, 1-14.

City of Dallas Department of Susatainable Development and Construction. (2013). Strategic engagement 2013: Goals, objectives \& development strategies. Dallas, TX Retrieved from www.dallascityhall.com/forwardDallas/pdf/ES_121709.pdf.

City of Dallas. (2001). City of Dallas Board of Adjustment working rules of procedure. Dallas, TX.

City of Dallas. (2015). Charter of the city of Dallas, Texas. Dallas, TX.

City of Dallas. (2015). Sustainable development: Current planning. Retrieved from http://dallascityhall.com/departments/sustainabledevelopment/planning/Pages/def ault.aspx

City of Dallas Department of Transportation. (1993). Thoroughfare plan. Retrieved from http://dallascityhall.com/departments/pnv/transportationplanning/DCH\%20Documents/pdf/ThoroughfarePlan.pdf

City of Philadelphia. (n.d.). Promise Zone Philadelphia. Philadelphia Retrieved from http://www.phila.gov/Newsletters/PhilaPromiseZoneDoc3.pdf.

Clark, J. (1992). Democratising development: NGOs and the state. Development in Practice, 2(3), 151-162.

Clark, J. (2001). Six urban regime types: the effects of state laws and citizen participation on the development of alternative regimes. Public Administration Quarterly, 25(1), 3-48. 
Clark, T. N. (1967). Power and Community Structure: Who Governs, Where, and When?*. The Sociological Quarterly, 8(3), 291-300.

Clark, T. N. (1994). Race and class versus the New Political Culture. Urban innovation, 21-78.

Clark, T. N. (2002). Globalisation and transformations in political cultures. In R. Hambleton, H. V. Savitch, \& M. Stewart (Eds.), Globalism and local democracy (pp. 67-94). New York: Palgrave Macmillan.

Clark, T. N. (2004). The city as an entertainment machine (Vol. 9). Boston: Elsevier.

Clark, T. N., Bonjean, C., \& Lineberry, R. (1971). Community Politics: A Behavioral Approach: New York: The Free Press.

Clark, T. N., Lloyd, R., Wong, K. K., \& Jain, P. (2002). Amenities drive urban growth. Journal of Urban Affairs, 24(5), 493-515.

Clarke, S. E. (2002). Globalism and cities: a North American perspective. In R. Hambleton, H. V. Savitch, \& M. Stewart (Eds.), Globalism and local democracy (pp. 30-51). New York: Palgrave Macmillan.

Clavel, P., \& Deppe, M. (1999). Innovation in urban policy: movement and incorporation in city administration and community development. Policy Studies Journal, 27(1), 115-128.

Clavel, P., Pitt, J., \& Yin, J. (1997). The community option in urban policy. Urban affairs review, 32(4), 435-458.

Clerval, A. (2006). Gentrification, a frontier reshaping social division of urban space in the inner Paris. Paper presented at the 50th IFHP World Congress-Final report.

Cleveland City Planning Commission. (2016). Population trends. Retrieved from http://planning.city.cleveland.oh.us/cwp/pop_trend.php

Coates, D., \& Humphreys, B. R. (2000). Stadium Gambit and Local Economic Development, The. Regulation, 23, 15.

Coffey, B., \& Deirwechter, Y. (2005). The urban university as a vehicle for inner-city renewal: The University of Washington, Tacoma. In D. C. Perry \& W. Wiewel (Eds.), The University as Urban Developer (pp. 80-97). New York: ME Sharpe.

Cox, K. R. (1997). Governance, urban regime analysis, and the politics of local economic development. In M. Lauria (Ed.), Reconstructing urban regime theory: Regulating urban politics in a global economy (pp. 99-121). Thousand Oaks: SAGE Publications, Inc.

Cox, K. R., \& Mair, A. (1988). Locality and community in the politics of local economic development. Annals of the Association of American Geographers, 78(2), 307-325. 
Cox, K. R., \& Mair, A. (1989). Book review essay: Urban growth machines and the politics of local economic development. International Journal of Urban and Regional Research, 13(1), 137-146.

Coyer, S. M., \& Gallo, A. M. (2005). Secondary analysis of data. Journal of Pediatric Health Care, 19(1), 60-63. doi:http://dx.doi.org/10.1016/j.pedhc.2004.10.003

Crain, Z. (2009). Q\&A with Jason Roberts. D Magazine, (October 2009). Retrieved from http://www.dmagazine.com/publications/d-magazine/2009/october/q-a-withjason-roberts

Dahl, R. A. (1961). Who governs?: Democracy and power in an American city: Yale University Press.

Dallas Convention \& Visitor_Bureau. (2015). Stats \& fun facts. Retrieved from http://www.visitdallas.com/about/stats/

Dallas County Community College District. (2014). Poverty issues in Dallas County. Retrieved from http://www.dcccd.edu/AU/Chancellor/media/Pages/PovertyIssues.aspx\#.VKH7vAAA

Dallas County. (2012). Commissioners Court role. Dallas, TX. Retrieved from http://www.jisinformation.dallascounty.org/department/comcrt/

Dallas County. (2015). Commissioner John Wiley Price - District 3. Retrieved from http://www.dallascounty.org/department/comcrt/district3/bio.php

Dallas Economic Development. (2010). South Dallas / Fair Park Trust Fund. Dallas, TX Retrieved from http://dallascityhall.com/committee_briefings/briefings0210/ECO_SoDallasFairPa rkTrustFund_020110.pdf.

Dallas Economic Development. (2014a). Ferguson Road initiative. Retrieved from http://www.dallas-ecodev.org/redevelopment/neighborhood-initiatives/fergusonroad/

Dallas Economic Development. (2014b). Lancaster Corridor initiative. Retrieved from http://www.dallas-ecodev.org/redevelopment/neighborhood-initiatives/lancastercorridor/

Dallas Economic Development. (2014c). South Dallas / Fair Park initiatives. Retrieved from http://www.dallas-ecodev.org/redevelopment/neighborhood-initiatives/southdallas-fair-park/

Dallas Economic Development. (2014d). West Dallas / North Oak Cliff initiatives. Retrieved from http://www.dallas-ecodev.org/redevelopment/neighborhoodinitiatives/west-dallas-north-oak-cliff/

Dallas Economic Development. (2014e). Neighborhood initiatives. Retrieved from http://www.dallas-ecodev.org/redevelopment/neighborhood-initiatives 
Dallas Economic Development. (2015). TIFs \& PIDs. Retrieved from http://www.dallasecodev.org/incentives/tifs-pids/

D'Antonio, W. V., Ehrlich, H. J., \& Erickson, E. C. (1962). Further notes on the study of community power. American Sociological Review, 27(6), 848-854. doi:10.2307/2090414

D'Antonio, W. V., \& Erickson, E. C. (1962). The reputational technique as a measure of community power: an evaluation based on comparative and longitudinal studies. American Sociological Review, 362-376.

Danzger, M. H. (1964). Community power structure: Problems and continuities. American Sociological Review, 707-717.

Darling, C. (2012). Greetings from the new Oak Cliff. Retrieved from http:/ /www.dfw.com/2012/02/28/585005/dallas-oak-cliff-urban-restaurants.html

Davies, J. S. (2003). Partnerships versus regimes: why regime theory cannot explain urban coalitions in the UK. Journal of Urban Affairs, 25(3), 253-270.

Davis, K. (1965). The urbanization of the human population. Scientific American, 213, 41-53.

Davis, R. (1993). This time it's gonna be run by us. D Magazine, (March 1993). Retrieved from http://www.dmagazine.com/publications/d-magazine/1993/march/this-timeits-gonna-be-run-by-us/

D CEO Real Estate. (2014). A Dallas real estate family tree. D Magazine. Retrieved from http://www.dmagazine.com/publications/d-ceo/2014/real-estate-annual/dallasreal-estate-family-tree

de Socio, M. (2007). Business community structures and urban regimes: A comparative analysis. Journal of Urban Affairs, 29(4), 339-366.

de Vaus, D. A. (2001). Research design in social research. London: SAGE Publications Inc.

Deitrick, S., \& Soska, T. (2005). The University of Pittsburgh and the Oakland neighborhood: From conflict to cooperation or How the 800-Pound Gorilla learned to sit with-and not on-its neighbors The university as urban developer: Case studies and analysis. (pp. 25-44). New York: ME Sharpe.

Delaney, K. J., \& Eckstein, R. (2003). The devil is in the details: Neutralizing critical studies of publicly subsidized stadiums. Critical Sociology, 29(2), 189-210.

DeLeon, R. E. (1992a). The urban antiregime: Progressive politics in San Francisco. Urban affairs review, 27(4), 555-579.

DeLeon, R. E. (1992b). Left coast city: Progressive politics in San Francisco, 1975-1991: University Press of Kansas Lawrence, KS. 
Democracy Collaborative. (2014). Policies for community wealth building: Leveraging state and local resources. Retrieved from Takoma Park, MD:

Dick, H. R. (1960). A method for ranking community influentials. American Sociological Review, 395-399.

dictionary.com LLC. (2016). Blue Collar. Retrieved from http:/ / dictionary.reference.com/browse/blue-collar

Domhoff, G. W. (1978). Who really rules?: New Haven and community power reexamined (Vol. 65): Transaction Publishers.

Doreian, P. (1989). Models of network effects on social actors. In L. C. Freeman, D. R. White, \& A. K. Romney (Eds.), Research methods in social network analysis (pp. 295-317). Fairfax, VA: George Mason University Press.

Dowding, K., Dunleavy, P., King, D., \& Margetts, H. (1995). Rational Choice and Community Power Structures. Political studies, 43(2), 265-277.

Downtown Dallas Inc. (2015a). About us. Retrieved from http://www.downtowndallas.com/about/\#/mission

Downtown Dallas Inc. (2015a). Downtown Dallas. In DowntownDallasInc (Ed.). Dallas: Downtown Dallas Inc.

Downtown Dallas Inc. (2015b). Downtown Dallas. In DowntownDallasInc (Ed.). Dallas: Downtown Dallas Inc.

Downtown Dallas Inc. (2015c). Membership Dues2015(06/14). Retrieved from http://www.downtowndallas.com/files/DDIMmbrshpBrch2012_GrossFloor.pdf

Downtown Dallas Inc. (2015d). About us: Members. Retrieved from http://www.downtowndallas.com/about/\#/members

Downtown Dallas Inc. (2015e). About us: Board of directors. Retrieved from http://www.downtowndallas.com/about/\#/directors

Doyle, J. M., \& Kao, G. (2007). Are racial identities of multiracials stable? Changing selfidentification among single and multiple race individuals. Social psychology quarterly, $70(4), 405-423$.

Dreier, P. (1993). America's Urban Crisis: Symptoms, Causes, Solutions. North Carolina Law Review, 71.

Dreier, P., Mollenkopf, J., \& Swanstrom, T. (2004). Place matters: Metropolitics for the twenty-first century. Studies in government and public policy (Second ed.): Lawrence: University Press of Kansas. 
Dubb, S., \& Howard, T. (2012). Leveraging anchor institutions for local job creation and wealth building. Big Ideas for Job Creation, bttp:/ / community-wealth.org/_pdfs/news/ recentarticles/04-12/paper-dubb-boward. pdf.

Dubb, S. M., Sarah; Howard, Ted. (2013). The anchor dashboard: Aligning institutional practice to meet low-income community needs. Retrieved from Takoma Park, MD:

Eckstein, H. (1975). Case study and theory in political science. In F. I. Greenstein \& N. W. Polsby (Eds.), Handbook of political science (Vol. 7, pp. 79-137). Reading, MA: AddisonWesley.

Economics Research Associates. (2008). The economic and community impacts of the University of North Texas at Dallas. Retrieved from San Francisco, CA: http://www.cpupc.org/images/Economic_Impact_UNT_Dallas_2008.pdf

Editorial. (2014, 6/23). Editorial: New South Dallas housing formula, Editorial. The Dallas Morning News. Retrieved from http://www.dallasnews.com/opinion/editorials/20130623-editorial-new-southdallas-housing-formula.ece

Eisenhardt, K. M. (1989). Building theories from case study research. Academy of management review, 14(4), 532-550.

Eisinger, P. (2000). The politics of bread and circuses: Building the city for the visitor class. Urban affairs review, 35(3), 316-333. doi:10.1177/107808740003500302

Elkin, S. L. (1985). Twentieth century urban regimes. Journal of Urban Affairs, 7(2), 11-28.

Elkin, S. L. (1987a). City and regime in the American republic. University of Chicago Press.

Elkin, S. L. (1987b). State and market in city politics: Or, the 'real' Dallas. In C. N. Stone \& H. T. Sanders (Eds.), The politics of urban development (Vol. 1987, pp. 25-51). Lawrence, Kansas: University Press of Kansas.

Elliott, A. C., Summey, P. K., \& Kokel, G. B. (2009). Images of America: Oak Cliff. Charleston, SC: Arcadia.

Elliott, A. C., Summey, P. K., \& Kokel, G. B. (2013). Legendary Locals of Oak Cliff. Charleston, SC: Arcadia.

Elwood, S. Neighborhood revitalization through 'collaboration': Assessing the implications of neoliberal urban policy at the grassroots. GeoJournal, 58(2), 121-130.

doi:10.1023/B:GEJO.0000010831.73363.e3

Emirbayer, M., \& Goodwin, J. (1994). Network analysis, culture, and the problem of agency. American Journal of Sociology, 99(6), 1411-1454. doi:10.2307/2782580

Evergreen Cooperatives. (2016). About us. Retrieved from http://www.evgoh.com/aboutus/ 
Farley, R., \& Frey, W. H. (1992). Changes in the segregation of whites from blacks during the 1980s: small steps toward a more racially integrated society.

Farley, R., Schuman, H., Bianchi, S., Colasanto, D., \& Hatchett, S. (1978). "Chocolate city, vanilla suburbs:" Will the trend toward racially separate communities continue? Social Science Research, 7(4), 319-344.

Farley, R., Steeh, C., Jackson, T., Krysan, M., \& Reeves, K. (1993). Continued racial residential segregation in Detroit: 'Chocolate city, vanilla suburbs' revisited. Journal of Housing Research, 4(1), 1-38.

Fay, R. (2005). Model-assisted estimation for the American Community Survey. Paper presented at the Proceedings of the 2005 Joint Statistical Meetings on CD-ROM.

Federal Deposit Insurance Corporation. (1997). An examination of the banking crises of the 1980s and Early 1990s.

Ferguson, I. V., \& Crockett, C. W. (1980). Dallas-Fort Worth Labor Market Review. Austin, TX: Texas Employment Commission.

Ferman, B. (1996). Challenging the growth machine: Neighborhood politics in Chicago and Pittsburgh: Univ Pr of Kansas.

Florida, R. (2003). Cities and the creative class. City \& Community, 2(1), 3-19.

Florida, R. (2006). The flight of the creative class: the new clobal competition for talent. Liberal Education, 92(3), 22-29.

Florida, R. L. (2002). The rise of the creative class: and how it's transforming work, leisure, community and everyday life: Basic books.

Fortune. (2014). Fortune 500. Retrieved November 11, 2014 http:// fortune.com/fortune 500/

Fredericksen, P., \& London, R. (2002). Disconnect in the Hollow State: The Pivotal Role of Organizational Capacity in Community- Based Development Organizations. Public Administration Review, 60(3), 230-239.

Freeman, E. (1982). Hidden treasure: a closer look at Oak Cliff real estate. D Magazine, May 1982. Retrieved from http://www.dmagazine.com/publications/dmagazine/1982/may/hidden-treasure-a-doser-look-at-oak-cliff-real-estate/

Freeman, L. C., Fararo, T. J., Bloomberg Jr, W., \& Sunshine, M. H. (1963). Locating leaders in local communities: a comparison of some alternative approaches. American Sociological Review, 791-798.

French, R. M., \& Aiken, M. (1968). Community power in cornucopia: a replication in a small community of the Bonjean Technique of identifying community leaders. The Sociological Quarterly, 9(2), 261-270. doi:10.2307/4105046 
Frey, F. W. (1971). Comment: On issues and nonissues in the study of power. American Political Science Review, 65(04), 1081-1101.

Frisch, M., \& Servon, L. J. (2006). CDCs and the changing context for urban community development: A review of the field and the environment. Community Development, 37(4), 88-108.

Fry, R., \& Passel, J. S. (2014). In post-recession era, young adults drive continuing rise in multigenerational living. Retrieved from Washington, D.C.: http://www.pewsocialtrends.org/2014/07/17/in-post-recession-era-young-adultsdrive-continuing-rise-in-multi-generational-living/

Gamble, A. (2014). Crisis without end?: The unravelling of western prosperity: Palgrave Macmillan.

Gammage, J. (2014). "Promise Zone" designation brings hope in West Philadelphia. The Philadelphia Inquirer. Retrieved from

George, A. L., \& Bennett, A. (2005). Case studies and theory development in the social sciences: Mit Press.

Gerring, J. (2004). What is a case study and what is it good for? American Political Science Review, 98(02), 341-354.

Giankaris, N. (2014, 01/01/2014). Philadelphia designated as a Promise Zone, Drexel plays key role. Drexel Now: Campus \& Community. Retrieved from http://drexel.edu/now/archive/2014/january/philadelphia-as-a-promise-zone/

Giarratani, F., \& Houston, D. B. (1989). Structural change and economic policy in a declining metropolitan region: Implications of the Pittsburgh experience. Urban Studies, 26(6), 549-558.

Gilens, M., \& Page, B. I. (2014). Testing theories of American politics: Elites, interest groups, and average citizens. Perspectives on Politics.

Gittell, R., \& Wilder, M. (1999). Community development corporations: Critical factors that influence success. Journal of Urban Affairs, 21(3), 341-361.

Glaeser, E. L., Scheinkman, J. A., \& Shleifer, A. (1995). Economic growth in a cross-section of cities. Journal of Monetary Economics, 36(1), 117-143. doi:http:/ /dx.doi.org/10.1016/0304-3932(95)01206-2

Google. (2015). Google Maps. Retrieved from https://www.google.com/maps

Gordon, R. J. (2010). Okun's law and productivity innovations. The American Economic Review, 100(2), 11-15.

Goulding, L. (2016). The first family of Dallas Coffee. D Magazine. Retrieved from http://www.dmagazine.com/publications/d-magazine/2016/february/oak-cliffcoffee-roasters-davis-street-espresso-shannon-and-jenni-neffendorf 
Graff, H. J. (2008). The Dallas myth: The making and unmaking of an American city: U of Minnesota Press.

Grant, J. M. (1996). The great Texas banking crash: An insider's account. University of Texas Press.

Griggs, S. (2016). The Alamo Manhattan project: I'm on your side in making sure it looks like the Oak Cliff we love. Retrieved from http:/ / www.scottgriggsdallas.com/updates/the-alamo-manhattan-project-im-onyour-side

Grigsby, S. (2015). Does 'gentrification myth' distract from real poverty issues? The Dallas Morning News. Retrieved from http:// dallasmorningviewsblog.dallasnews.com/2015/01/does-gentrification-mythdistract-from-real-poverty-issues.html/

Grimes, A. (2010). Downtown Dallas 360, meet the community. The Dallas Observer. Retrieved from http://www.dallasobserver.com/news/downtown-dallas-360-meetthe-community-7104091

Gruben, W. (2006). NAFTA, trade diversion and Mexico's textiles and apparel boom and bust. Southwest Economy, 5, 11-13.

Haas, J. E., \& Drabek, T. E. (1973). Complex organizations: A sociological perspective: Prentice Hall.

Hackworth, J., \& Smith, N. (2001). The changing state of gentrification. Tijdschrift voor economische en sociale geografie, 92(4), 464-477.

Halkias, M. (2014). Texas dominates 2014 Fortune 500 list with 52 companies. The Dallas Morning News.

Hall, C. (2015). Pegasus stands watch over downtown Dallas' revitalization. The Dallas Morning News. Retrieved from http://www.dallasnews.com/business/columnists/cheryl-hall/20150609-pegasusstands-watch-over-downtown-revitalization.ece

Hallman, T. (2016). City Hall's top official, who brought Dallas Stars to town and nearly ran off Uber, to resign. The Dallas Morning News. Retrieved from The Dallas Morning News website: http://www.dallasnews.com/news/dallas-cityhall/2016/05/30/dallas-city-manager-a-c-gonzalez-announces-resignation

Hallman, T., \& Wilonsky, R. (2016). Dallas hires from the outside, names Tacoma city manager as new City Hall boss. The Dallas Morning News. Retrieved from http://www.dallasnews.com/news/dallas-city-hall/2016/12/09/dallas-hires-outsidenames-tacoma-city-manager-new-city-hall-boss

Hanson, R. (2003). Civic culture and urban change: Governing Dallas: Wayne State University Press. 
Hanson, R., Wolman, H., Connolly, D., Pearson, K., \& McManmon, R. (2010). Corporate citizenship and urban problem solving: The changing civic role of business leaders in American cities. Journal of Urban Affairs, 32(1), 1-23.

Harding, A. (1996). Is There a 'New Community Power'and Why Should We Need One?*. International Journal of Urban and Regional Research, 20(4), 637-655.

Harding, A. (1997). Urban Regimes in a Europe of the Cities? European urban and regional studies, 4(4), 291-314.

Harding, A. (1999). Review article: north urban political economy, urban theory and British research. British Journal of Political Science, 29(04), 673-698.

Harding, A. (2009). The history of community power. In J. S. Davies \& D. Imbroscio (Eds.), Theories of urban politics (2nd ed., pp. 27-39). Thousand Oaks, CA: SAGE Publications Inc.

Harding, A., \& Blokland, T. (2014). Urban theory: a critical introduction to power, cities and urbanism in the 21st century: SAGE Publications Inc.

Harkavy, I. (2009). Anchor institutions as partners in building successful communities and local economies. Retooling HUD for a Catalytic Federal Government: A Report to Secretary Shaun Donovan, Penn Institute for Urban Research, 147-168.

Harkavy, I., Birch, E., Alperovitz, G., Cantor, N., Clancy, G., Coletta, C., Weeks, J. (2009). Anchor institutions as partners in building successful communities and local economies. In P. C. G. Brophy, Rachel D. (Ed.), Retooling HUD for a catalytic federal government: a report to Secretary Shaun Donovan (pp. 147-168). Philadelphia: Penn Institute for Urban Research, University of Pennsylvania.

Hartman, C. (2002). City for sale: The transformation of San Francisco: Univ of California Press.

Harvey, D. (1989). The condition of postmodernity. Oxford: Blackwell.

Hatt, P. K. (1950). Stratification in the mass society. American Sociological Review, 216-222.

Henderson, V., Storeygard, A., \& Weil, D. N. (2011). A bright idea for measuring economic growth. The American Economic Review, 101(3), 194-199.

Hermann, M., \& Leuthold, H. (2002). The consequences of gentrification and Marginalisation on political behaviour. Paper presented at the Proceedings to the Conference «Upward Neighbourhood Trajectories.

Hill, P. E. (1996). Dallas: The Making of a Modern City: University of Texas Press.

Hill, R. C. (1986). Industrial restructuring, state intervention, and uneven development in the United States and Japan. In J. R. Logan \& T. Swanstrom (Eds.), Beyond the city limits: Urban policy and economic restructuring in comparative perspective (pp. 60-85). Philadelphia: Temple University Press. 
Horner, K. (2010). Downtown low-income apartments receive warm welcome. The Dallas Morning News, Mar 2010. Retrieved from Dallas News website: http://www.dallasnews.com/news/news/2010/03/25/20100324-Low-incomedevelopment-is-changing-minds-8374

Horner, K. (2010). Low-income development is changing minds in downtown Dallas. The Dallas Morning News, Mar 2010. Retrieved from Dallas News website: http://www.dallasnews.com/news/news/2010/03/25/20100324-Low-incomedevelopment-is-changing-minds- 8374

Howard, T., Kuri, L., \& Lee, I. P. (2010). The Evergreen Cooperative Initiative of Cleveland, Ohio. Paper presented at the White paper prepared for The Neighborhood Funders Group Annual Conference in Minneapolis, MN.

Huang, C. (2014). In Dallas, turning the page marked Nov. 22, 1963. The New York Times. Retrieved from http://www.nytimes.com/2014/08/10/travel/in-dallas-turning-thepage-marked-nov-22-1963.html?_r=2

Hunter, F. (1953). Community power structure: A study of decision makers: University of North Carolina Press Chapel Hill.

Hyde, J. (2008). Gentrification welcomed by Deep Ellum artists. Dallas Observer. Retrieved from http://www.dallasobserver.com/2008-01-17/news/gentrification-welcomedby-deep-ellum-artists/full/

Imbroscio, D. L. (1998). Reformulating urban regime theory: The division of labor between state and market reconsidered. Journal of Urban Affairs, 20(3), 233-248.

Imbroscio, D. L. (2003). Overcoming the neglect of economics in urban regime theory. Journal of Urban Affairs, 25(3), 271-284.

Imbroscio, D. L. (2004). Fighting Poverty with Mobility: A Normative Policy Analysis1. Review of Policy Research, 21(3), 447-461.

Imbroscio, D. L. (2010). Urban America reconsidered: Alternatives for governance and policy: JSTOR.

Jackson, K. T. (1985). Crabgrass frontier: the suburbanization of the United States. New York: Oxford University Press.

Jacobs, J. (1961). The death and life of great American cities: Random House Digital, Inc.

Jeffers, G. (2011). Dallas minorities persevered for years to gain 14-1 system of representation. The Dallas Morning News. Retrieved from http://www.dallasnews.com/section-archives/125thanniversary/headlines/20100724-dallas-minorities-persevered-for-years-to-gain-14-1system-of-representation.ece

Jessop, B. (1993). Towards a Schumpeterian Workfare State? Preliminary remarks on postFordist political economy. Studies in political economy, 40. 
Johnson, B., \& Turner, L. A. (2003). Data collection strategies in mixed methods research. In A. Tashakkori \& C. Teddlie (Eds.), Handbook of mixed methods in social and behavioral research (pp. 297-319). Thousand Oaks: SAGE Publications, Inc.

Johnson, T. P., O’Rourke, D., Burris, J., \& Owens, L. (2002). Culture and survey nonresponse. Survey nonresponse, 55-69.

Johnston, D. C. (2015). Divided: The perils of our growing inequality (Vol. 10): The New Press.

Jonas, A. E. G., \& Wilson, D. (Eds.). (1999). The urban growth machine: Critical perspectives two decades later. Albany, NY: State University of New York Press.

Jones, C. I. (2002). Sources of US economic growth in a world of ideas. American Economic Review, 220-239.

Joseph, L. B. (1981). Democratic revisionism revisited. American Journal of Political Science, 160187.

Juday, L. J. (2015). The Changing Shape of American Cities: Demographics Research Group.

Judd, D., \& Swanstrom, T. (2012). City politics: Pearson Higher Ed.

Judd, D. R. (2002). The infrastructure of play: building the tourist city: ME Sharpe.

Judd, D. R., \& Fainstein, S. S. (1999). The tourist city: Yale University Press.

Judd, D. R., \& Kopel, F. N. (1979). The politics of American cities: Private power and public policy: Little, Brown Boston.

Judd, D. R., \& Simpson, D. (2003). Reconstructing the local state: the role of external constituencies in building urban tourism. American Behavioral Scientist, 46(8), 10561069.

Judd, D. R., \& Swanstrom, T. (1998). City politics: Private power and public policy (Second ed.). New York City: HarperCollins College Publishers.

Kantor, P., Lefèvre, C., Saito, A., Savitch, H. V., \& Thornley, A. (2012). Struggling giants: Cityregion governance in London, New York, Paris, and Tokyo: University of Minnesota Press.

Kantor, P., \& Savitch, H. V. (2005). How to study comparative urban development politics: a research note. International Journal of Urban and Regional Research, 29(1), 135-151.

Kantor, P., Savitch, H. V., \& Haddock, S. V. (1997). The political economy of urban regimes: a comparative perspective. Urban affairs review, 32(3), 348-377.

Kaplan, M., \& Cuciti, P. L. (Eds.). (1986). The Great Society and its legacy: Twenty years of US social policy. Durham, NC: Duke University Press. 
Kaufman, H., \& Jones, V. (1954). The mystery of power. Public Administration Review, 14(3), 205-212.

Keating, D. (2007). Cleveland: A midwestern rustbelt city struggles to sur (re) vive. Paper presented at the Proceedings from Urban Futures Seminar. Durham University, United Kingdom.

Keating, M. (1991). Comparative urban politics: Power and the city in the United States, Canada, Britain, and France: Aldershot, England: E. Elgar.

Keating, R. J. (1999). Sports pork: The costly relationship between major league sports and government. Cato Institute Washington, DC.

Keating, W. D. (2009, September 2009). Redevelopment of vacant land in the blighted neighbourhoods of Cleveland, Obio, resulting from the housing foreclosure crisis. Paper presented at the ISA RC 43 Conference-"Housing Assets, Housing People", Glasgow, Scotland.

Kemper, R. V. (2005). Dallas-Fort Worth: Toward new models of urbanization, community transformation, and immigration. Urban Anthropology and Studies of Cultural Systems and World Economic Development, 125-149.

Kennedy, M. M. (1979). Generalizing from single case studies. Evaluation Review, 3(4), 661678.

Kettl, D. F. (2000). Public administration at the millennium: The state of the field. Journal of Public Administration Research and Theory, 10(1), 7-34.

Kettl, D. F. (2000). The transformation of governance: Globalization, devolution, and the role of government. Public Administration Review, 60(6), 488-497.

Kilburn, H. W. (2004). Explaining U.S. urban regimes: a qualitative comparative analysis. Urban affairs review, 39(5), 633-651.

Kim, T. (2012, 02/04/2012). North Texas sprawl came from pro-growth policies. The Dallas Morning News. Retrieved from http://www.dallasnews.com/news/localnews/20120204-north-texas-sprawl-sprang-from-pro-growth-policies.ece

Korinek, A., Mistiaen, J. A., \& Ravallion, M. (2006). Survey nonresponse and the distribution of income. The Journal of Economic Inequality, 4(1), 33-55.

Krause, K. (2016). Federal trial linked to John Wiley Price corruption case reveals aggressive lobbying efforts. The Dallas Morning News. Retrieved from http:/ / crimeblog.dallasnews.com/2016/01 / federal-trial-linked-to-john-wiley-pricecorruption-case-reveals-aggressive-lobbying-efforts.html/

Laumann, E. O. (1979). Network analysis in large social systems: Some theoretical and methodological problems. In P. W. Holland \& S. Leinhardt (Eds.), Perspectives on social network research (pp. 379-402). New York: Academic Press Inc. 
Laumann, E. O., Galaskiewicz, J., \& Marsden, P. V. (1978). Community structure as interorganizational linkages. Annual review of sociology, 455-484.

Laumann, E. O., Marsden, P. V., \& Prensky, D. (1989). The boundary specification problem in network analysis. In L. C. Freeman, D. R. White, \& A. K. Romney (Eds.), Research methods in social network analysis (Vol. 61, pp. 61-87). Fairfax, VA: George Mason University Press.

Lauria, M. (1982). Selective urban redevelopment: a political economic perspective. Urban geography, 3(3), 224-239.

Lauria, M. (Ed.) (1997). Reconstructing urban regime theory: Regulating urban politics in a global economy. Thousand Oaks: SAGE Publications, Inc.

Laussade, A. (2016). Breaking: Zoli's Pizzeria closing on Valentine's Day. The Dallas Observer. Retrieved from Dallas Observer website: http://www.dallasobserver.com/restaurants/breaking-zolis-pizzeria-closing-onvalentines-day-8013349

Lee, J. (2000). The robustness of Okun's law: Evidence from OECD countries. Journal of macroeconomics, 22(2), 331-356.

Lees, L. (2000). A reappraisal of gentrification: towards a 'geography of gentrification'. Progress in Human Geography, 24(3), 389-408. doi:10.1191/030913200701540483

Lewis, C. H., \& Stockton, J. R. (2016). Manufacturing industries. The Handbook of Texas Online. Retrieved from https://tshaonline.org/handbook/online/articles/dzm01

Ley, D. (1994). Gentrification and the politics of the new middle class. Environment and Planning D: Society and Space, 12(1), 53-74.

Lijphart, A. (1971). Comparative politics and the comparative method. The American Political Science Review, 682-693.

Lin, J. (2007). Influx of newcomers fueling Phila. activism: Newcomer perspective fuels civic activism. The Philadelphia Inquirer. Retrieved from articles.philly.com/2007-0826/news/25230020_1_civic-groups-urban-planner-center-city-district

Logan, J. R., \& Molotch, H. L. (2007). Urban fortunes: The political economy of place (20th anniversary edition with a new preface). Berkeley, CA: University of California Press.

Logan, J. R., Whaley, R. B., \& Crowder, K. (1997). The Character and Consequences of Growth Regimes An Assessment of 20 Years of Research. Urban affairs review, 32(5), 603-630.

Lupsha, P. A. (1987). Structural Change and Innovation: Elites and Albuquerque Politics in the 1980s. In C. N. Stone \& H. T. Sanders (Eds.), The politics of urban development (pp. 230-243). Lawrence, KS: University Press of Kansas. 
MacLeod, G. (2011). Urban Politics Reconsidered Growth Machine to Post-democratic City? Urban Studies, 48(12), 2629-2660.

MacLeod, G., \& Goodwin, M. (1999). Reconstructing an urban and regional political economy: on the state, politics, scale, and explanation. Political Geography, 18(6), 697730 .

Manley, J. F. (1983). Neo-Pluralism: A Class Analysis of Pluralism I and Pluralism II. The American Political Science Review, 77(2), 368-383. doi:10.2307/1958922

Markusen, A. (1992). Dismantling the Cold War Economy. World Policy Journal, 9(3), 389-399.

Martinez- Fernandez, C., Audirac, I., Fol, S., \& Cunningham- Sabot, E. (2012). Shrinking cities: Urban challenges of globalization. International Journal of Urban and Regional Research, 36(2), 213-225.

Mays, V. M., Ponce, N. A., Washington, D. L., \& Cochran, S. D. (2003). Classification of race and ethnicity: implications for public health. Annual review of public health, 24, 83.

McCarthy, A. (2015). Zoli's plans to close Bishop Arts location next year, might open in Houston. The Dallas Observer. Retrieved from http://www.dallasobserver.com/restaurants/zoli-s-plans-to-close-bishop-artslocation-next-year-might-open-in-houston-7637925

McElhaney, J., \& Hazel, M. V. (2015). Dallas, TX. Handbook of Texas Online. Retrieved from https://www.tshaonline.org/handbook/online/articles/hdd01

McGovern, S. J. (2009). Mobilization on the Waterfront: The Ideological/Cultural Roots of Potential Regime Change in Philadelphia. Urban affairs review, 44(5), 663-694. doi:10.1177/1078087408323943

McKenzie, W. (2010). N. Oak Cliff's Unusual Transformation. The Dallas Morning News. Retrieved from http://www.dallasnews.com/opinion/columnists/williammckenzie/20101022-William-McKenzie-N-Oak-9796.ece

McKieran, L., Kim, S., \& Lasker, R. (2000). Collaboration: learning the basics of community governance. Community, 3, 23-29.

McKnight, T. L. (1956). Manufacturing in Dallas: a study of effects: Bureau of Business Research, University of Texas.

McKnight, T. L. (1957). Aircraft Manufacturing in Texas. The Southwestern Social Science Quarterly, 38(1), 39-50.

McQuarrie, M. (2011). Nonprofits and the Reconstruction of Urban Governance: Housing Production and Community Development in Cleveland, 1975-2005: University of Chicago Press. 
Merten, S. (2009). Dallas' homeless turn to The Bridge for food, shelter, and a new start. The Dallas Observer. Retrieved from http://www.dallasobserver.com/news/dallashomeless-turn-to-the-bridge-for-food-shelter-and-a-new-start-6406120

Merwin, J. (1977). What you don't know about Oak Cliff (and should). D Magazine.

Methodis tHealth System. (2015). History. Retrieved from http://www.methodisthealthsystem.org/History

Meyer, B., \& Tasci, M. (2012). An unstable Okun's Law, not the best rule of thumb. Economic Commentary (June).

Meyers, J. (2009). Housing for homeless to open in long-vacant downtown Dallas high-rise. The Dallas Morning News, Dec 2009. Retrieved from Dallas News website: http://www.dallasnews.com/news/news/2010/03/25/20100324-Low-incomedevelopment-is-changing-minds- 8374

Miles, M. B. (1979). Qualitative data as an attractive nuisance: The problem of analysis. Administrative science quarterly, 590-601.

Miller, E. H. (2015). Nut Country: Right-wing Dallas and the Birth of the Southern Strategy: University of Chicago Press.

Miller, L. (1991). The hustler: John Wiley Price. D Magazine. Retrieved from http:/ /www.dmagazine.com/publications/d-magazine/1991/march/the-hustlerjohn-wiley-price? single $=1$

Mills, C. W. (1956). The power elite. New York: Oxford University Press.

Milward, H. B., \& Provan, K. G. (2000). Governing the hollow state. Journal of Public Administration Research and Theory, 10(2), 359-380.

Minora, L. (2013). Downtown Dallas tunnel system forgotten but not dead. The Dallas Morning News. Retrieved from http:/ /www.dallasnews.com/news/communitynews/downtown-dallas/headlines/20130216-downtown-dallas-tunnel-systemforgotten-but-not-dead.ece

Misra, T. (2014). How achor institutions like hospitals and universities can help cities. Retrieved from http://www.citylab.com/cityfixer/2014/11/universities-andhospitals-are-the-new-anchor-institutions-for-cities/382110/

Mitchell, J. (2015). Dallas is worst in the nation for neighborhood inequality. The Dallas Morning News. Retrieved from Opinion Blog website:

http://dallasmorningviewsblog.dallasnews.com/2015/07/dallas-is-worst-in-thenation-for-neighborhood-inequality.html/

Mitchell, J. C. (1969). The concept and use of social networks: Indianapolis: Bobbs-Merrill.

Mitchell, J. C. (1974). Social networks. Annual review of anthropology, 3, 279-299. 
Mizruchi, M. S. (1994). Social Network Analysis: Recent Achievements and Current Controversies. Acta Sociologica, 37(4), 329-343. doi:10.2307/4200918

Molotch, H. (1976). The city as a growth machine: Toward a political economy of place. American Journal of Sociology, 82(2), 309-332.

Molotch, H. (1993). The political economy of growth machines. Journal of Urban Affairs, 15(1), 29-53. doi:10.1111/j.1467-9906.1993.tb00301.x

Montoya, R. (2016a). Poverty in Dallas: the drivers and reasons behind the alarming increase in poverty in Dallas. Retrieved from Dallas:

Montoya, R. (2016b). Reducing the epidemic of poverty and ending the opportunity gap. Retrieved from Dallas:

http://dallascityhall.com/government/Council\%20Meeting\%20Documents/b_redu cing-the-epidemic-of-poverty-and-ending-the-opportunitygap_combined_090716.pdf

Mooney, M. J. (2014). Lunch with: David Spence. D CEO, (April 2014). Retrieved from http://www.dmagazine.com/publications/d-ceo/2014/april/lunch-with-davidspence-of-good-space

Morgan, R. P. (2004). Governance by decree: The impact of the Voting Rights Act in Dallas: Univ Pr of Kansas.

Mossberger, K. (2009). Urban regime analysis. In J. S. Davies \& D. Imbroscio (Eds.), Theories of urban politics (2nd ed., pp. 40-54). Thousand Oaks, CA: SAGE Publications Inc.

Mossberger, K., \& Stoker, G. (2001). The evolution of urban regime theory: the challenge of conceptualization. Urban affairs review, 36(6), 810-835.

Moto, M. (2015). After half a century the streetcar is back. Retrieved from http:/ /www.gooakcliff.org/2015/04/after-half-a-century-the-streetcar-is-back/

Myers, D. (2016). Peak Millenials. Paper presented at the City Forum, Austin, TX.

Najam, A. (2000). The four c's of government: Third sector- government relations. Nonprofit Management and Leadership, 10(4), 375-396.

National Bureau of Economic Research. (2010). US business cycle expansions and contractions. Cambridge, MA Retrieved from http://www.nber.org/cycles/sept2010.pdf.

Nicholson, E. (2015). There goes the neighborhood: the ups and downs of gentrification in Dallas. The Dallas Observer. Retrieved from http://www.dallasobserver.com/news/there-goes-the-neighborhood-the-ups-anddowns-of-gentrification-in-dallas-7723959 
Nicholson, E. (2016). Dallas Farmers Market is a battleground in the war over how to address the city's homelessness problem. The Dallas Observer. Retrieved from http://www.dallasobserver.com/news/dallas-farmers-market-is-a-battleground-inthe-war-over-how-to-address-the-citys-homelessness-problem-8033657

Nyden, P. W., \& Wiewel, W. (1991). Challenging uneven development: an urban agenda for the 1990s: Rutgers University Press.

Oak Cliff Coffee Roasters. (2012). About us. Retrieved from http://www.oakcliffcoffee.com/about-us

Okner, B. A. (1974). Subsidies of stadiums and arenas. Paper presented at the Government and the sport business, Washington, DC.

Pagano, M. A., \& Bowman, A. O. M. (1995). The state of American federalism, 1994-1995. Publius: The Journal of Federalism, 25(3), 1-21.

Payne, D. (1994). Big D: Triumphs and troubles of an American supercity in the 20th century: Three Forks Press.

Payne, D. (2010). Dallas Citizens Council wields a mighty influence even today. The Dallas Morning News. Retrieved from http:/ /www.dallasnews.com/section-archives/125thanniversary/headlines/20100618-dallas-citizens-council-wields-a-mighty-influenceeven-today.ece

Peet, R., \& Watts, M. (1993). Introduction: Development Theory and Environment in an Age of Market Triumphalism. Economic Geography, 69(3), 227-253. doi: $10.2307 / 143449$

Perez, C. (2014a). Why investors are flocking to downtown Dallas. D CEO, (September). Retrieved from http://www.dmagazine.com/publications/dceo/2014/september/why-investors-are-flocking-to-downtown-dallas

Perez, C. (2014b). Building the City: Mike Ablon, David Spence, and Scott Rohrman. D Magazine. Retrieved from D Magazine Real Estate website: http:/ / realestate.dmagazine.com/2015/01/building-the-city-mike-ablon-davidspence-and-scott-rohrman/

Perez, C. (2015). Why the Dallas real estate market is hot. D CEO. Retrieved from D CEO website: http://www.dmagazine.com/publications/d-ceo/2015/real-estateannual/hottest-dallas-real-estate-market-in-decades/

Peters, B. G. (1998). Comparative politics: Theory and methods: NYU Press.

Peterson, P. E. (1981). City limits: University of Chicago Press.

Pew Charitable Trusts. (2016). Philadelphia: the state of the city. Retrieved from Philadelphia: http://www.pewtrusts.org/en/research-and-analysis/reports/2016/03/philadelphiathe-state-of-the-city-a-2016-update 
Pfautz, H. W. (1962). The power structure of the Negro sub-community: a case study and a comparative view. Phylon (1960-), 23(2), 156-166.

Phillips, M. (2010). White metropolis: race, ethnicity, and religion in Dallas, 1841-2001: University of Texas Press.

Pierre, J. (2005). Comparative urban governance: uncovering complex causalities. Urban affairs review, 40(4), 446-462.

Polsby, N. W. (1959). Three problems in the analysis of community power. American Sociological Review, 796-803.

Polsby, N. W. (1960). How to study community power: the pluralist alternative. The Journal of Politics, 474-484.

Polsby, N. W. (1980). Community power and political theory: Yale University Press.

Préteceille, E. (1990). Political paradoxes of urban restructuring: Globalization of the economy and localization of politics. In J. R. Logan \& T. Swanstrom (Eds.), Beyond the city limits (pp. 27-59). Philadelphia: Temple University Press.

Pugalis, L., \& Townsend, A. R. (2014). The emergence of 'new'spatial coalitions in the pursuit of functional regions of governance. Regional Science Policy \& Practice, 6(1), 4967.

Pulido, L. (2000). Rethinking Environmental Racism: White Privilege and Urban Development in Southern California. Annals of the Association of American Geographers, 90(1), 12-40. doi:10.1111/0004-5608.00182

Reed, I. W. (1989). The life and death of UDAG: An assessment based on eight projects in five New Jersey cities. Publius: The Journal of Federalism, 19(3), 93-109.

Reese, L. A., \& Rosenfeld, R. A. (2002). Reconsidering Private Sector Power: Business Input and Local Development Policy. Urban affairs review, 37(5), 642-674. doi:10.1177/107808740203700502

Reitz, S. (2015). Carnival Barker's is open in Oak Cliff. Dallas Observer. Retrieved from http://www.dallasobserver.com/restaurants/carnival-barkers-is-open-in-oak-cliff7289240

Repko, M. (2012, 08/17/2015). North Texas sprawl came from pro-growth policies. The Dallas Morning News. Retrieved from http://www.dallasnews.com/news/news/2015/08/17/cottages-for-the-chronicallyhomeless-take-shape-in-south-dallas

Rew, L., Koniak-Griffin, D., Lewis, M. A., Miles, M., \& O'Sullivan, A. (2000). Secondary data analysis: new perspective for adolescent research. Nursing Outlook, 48(5), 223229. 
Ricci, D. M. (1984). The tragedy of political science: politics, scholarship, and democracy. New Haven, CT: Yale University Press.

Rice, M. (2007). Downtown Dallas: Romantic past, modern renaissance. Dallas, Texas: Brown Books.

Rich, M. J. (1992). UDAG, economic development, and the death and life of American cities. Economic development quarterly, 6(2).

Rives, N. W. J., \& Serow, W. J. (1988). Introduction to applied demography: Data sources and estimation techniques. Thousand Oaks: SAGE Publications Inc.

Roberts, J. (2010). Oak Cliff Better Block 2: 1300 West Davis Street. Retrieved from http://betterblock.org/blog/2010/10/19/oak-cliff-better-block-2-1300-west-davisstreet/

Roberts, J. (2012). Becoming the Change. Retrieved from https://www.whitehouse.gov/blog/2012/07/30/becoming-change

Robinson, T. (1996). Inner-city innovator: The non-profit community development corporation. Urban Studies, 33(9), 1647-1670. doi:Doi 10.1080/0042098966547

Robinson-Jacobs, K. (2015). Push is on in Dallas for expansion of convention center. The Dallas Morning News. Retrieved from http://www.dallasnews.com/business/headlines/20131025-push-is-on-in-dallas-forexpansion-of-convention-center.ece

Rodgers, S. (Producer). (2009). Urban growth machine. The International Encylopedia of Human Geography.

Rogers, T. (2014). Jim Schutze was right — six years ago — about John Wiley Price. D Magazine. Retrieved from http:/ frontburner.dmagazine.com/2014/07/28/jimschutze-was-right-six-years-ago-about-john-wiley-price/

Rogers, T. (2017). Candy Evans files to run against Lee Kleinman. D Magąine. Retrieved from https://www.dmagazine.com/frontburner/2017/01/candy-evans-files-to-runagainst-lee-kleinman/

Romzek, B. S., LeRoux, K., \& Blackmar, J. M. (2012). A preliminary theory of informal accountability among network organizational actors. Public Administration Review, 72(3), 442-453.

Rosenbaum, A. (1967). Community power and political theory: a case of misperception. Berkeley Journal of Sociology, 91-116.

Ross, R. (2012). Building a better block in Oak Cliff. Texas Observer. Retrieved from The Texas Observer website: https://www.texasobserver.org/building-a-better-block-inoak-cliff/ 
Ross, T. (2014). Eds, meds, and the feds: how the federal government can foster the role of anchor institutions in community revitalization. Retrieved from https://cdn.americanprogress.org/wp-content/uploads/2014/10/EdsMedsFedsOct.pdf

Rowthorn, R., \& Coutts, K. (2004). De-industrialisation and the balance of payments in advanced economies. Cambridge Journal of Economics, 28(5), 767-790.

Rubin, H. J. (1993). Understanding the ethos of community-based development: Ethnographic description for public administrators. Public Administration Review, 428437.

Ruebens, L. (2011). System of downtown Dallas tunnels, sky bridges could close under plan studied by city task force. The Dallas Morning News. Retrieved from http:/ / www.dallasnews.com/news/community-news/downtowndallas/headlines/20110820-system-of-downtown-dallas-tunnels-sky-bridges-couldclose-under-plan-studied-by-city-task-force.ece

Rundquist, B., Lee, J.-H., \& Rhee, J. (1996). The Distributive Politics of Cold War Defense Spending: Some State Level Evidence. Legislative Studies Quarterly, 21(2), 265-281. doi: $10.2307 / 440183$

Sachdev, J. C. (1976). Disinvestment: A corporate failure or a strategic success. International Studies of Management \& Organization, 6(1/2), 112-130.

Saito, L., \& Truong, J. (2015). The L.A. Live Community Benefits Agreement: Evaluating the agreement results and shifting political power in the city. Urban affairs review, 51(2), 263-289. doi:10.1177/1078087414527064

Sassen, S. (2000). Cities in a world economy (Second ed.). Thousand Oaks, CA: Pine Forge Press.

Savitch, H. V. (1988). Post-industrial cities: Politics and planning in New York, Paris, and London: Princeton University Press Princeton, NJ.

Savitch, H. V., \& Thomas, J. C. (Eds.). (1991). Big city politics in transition. Newbury Park, Calif.: SAGE Publications, Inc.

Schattschneider, E. E. (1960). The Semi-Sovereign People: A Realist's View of Democracy in America. Chicago: Holt, Rinehart, \& Winston.

Schill, M. H. (1996). Assessing the Role of Community Development Corporations in Inner City Economic Development. NYU Rev. L. \& Soc. Change, 22, 753.

Schmidt, E. (2012). Know your neighborhood. Retrieved 05/05/2015, from BC Workshop http://www.bcworkshop.org/posts/dallas-neighborhood-map

Schneider, W. (1992). The suburban century begins. The Atlantic Monthly, 270(1), 33-44. Retrieved from http://www.theatlantic.com/past/politics/ecbig/schnsub.htm 
Schnurman, M. (2014). Texas is a leader in income inequality, too. The Dallas Morning News. Retrieved from http://www.dallasnews.com/news/community-news/bestsouthwest/headlines/20131214-new-coalition-of-neighborhood-groups-seeks-toboost-west-dallas-clout.ece

Schragger, R. C. (2009). Mobile capital, local economic regulation, and the democratic city. University of Virginia Legal Working Paper Series, 115.

Schulze, R. O., \& Blumberg, L. U. (1957). The determination of local power elites. American Journal of Sociology, 290-296.

Schumpeter, J. A. (1950). Capitalism, Socialism, and Democracy (3rd ed.): New York, Harper.

Schutt, R. (2009). Investigating the social world (Sixth ed.). Washington DC: Pine Forge Press.

Schutze, J. (2001). Absentee minded. The Dallas Observer. Retrieved from http://www.dallasobserver.com/news/absentee-minded-6391500

Schutze, J. (2001). Le grand pissoir. The Dallas Observer. Retrieved from http://www.dallasobserver.com/news/le-grand-pissoir-6390011

Schutze, J. (2001). You can go home again. The Dallas Observer. Retrieved from http://www.dallasobserver.com/news/you-can-go-home-again-6395647

Schutze, J. (2004). Boxcar Miller. The Dallas Observer. Retrieved from http://www.dallasobserver.com/news/boxcar-miller-6384481

Schutze, J. (2008). Congresswoman calls out John Wiley Price for shaking down development deal. The Dallas Observer. Retrieved from http:/ / www.dallasobserver.com/news/congresswoman-calls-out-john-wiley-pricefor-shaking-down-development-deal-6373054

Schutze, J. (2009). That's the Dallas Way! Schutze is Live Blogging From the City Hall Corruption Trial. The Dallas Observer. Retrieved from http://www.dallasobserver.com/news/thats-the-dallas-way-schutze-is-live-bloggingfrom-the-city-hall-corruption-trial-7116608

Schutze, J. (2010a). Oak Cliff becomes cool embracing what other parts of Dallas have fought: Builders, bikes and immigrants. The Dallas Observer. Retrieved from Dallas Observer website: http://www.dallasobserver.com/news/oak-cliff-becomes-coolembracing-what-other-parts-of-dallas-have-fought-builders-bikes-and-immigrants6407711

Schutze, J. (2011). John Wiley Price? Problem? What problem? Nothing to see here, folks. The Dallas Observer. Retrieved from http://www.dallasobserver.com/news/johnwiley-price-problem-what-problem-nothing-to-see-here-folks-7109958 
Schutze, J. (2014). The money pit: Dollars go AWOL at the South Dallas/Fair Park Trust Fund. The Dallas Observer. Retrieved from http://www.dallasobserver.com/2014-11$13 /$ news/south-dallas-fair-park-trust-fund/full/

Schutze, J. (2015a). Mexicans saved Oak Cliff while they saved American Cities. Bikos came later. The Dallas Observer. Retrieved from Dallas Observer website: http://www.dallasobserver.com/news/mexicans-saved-oak-cliff-while-they-savedamerican-cities-bikos-came-later- 7126267

Schutze, J. (2015b). Developer throws tantrum, daily newspaper calls for Lollipops. The Dallas Observer. Retrieved from Dallas Observer website: http://www.dallasobserver.com/news/developer-throws-tantrum-daily-newspapercalls-for-lollipops-7482084

Schutze, J. (2016). Pssst. Listen. City Hall says they can't find files for $\$ 29.9$ million? No accident. The Dallas Observer. Retrieved from Dallas Observer website: http://www.dallasobserver.com/news/pssst-listen-city-hall-says-they-cant-find-filesfor-299-million-no-accident-8148628

Seawright, J., \& Gerring, J. (2008). Case selection techniques in case study research a menu of qualitative and quantitative options. Political Research Quarterly, 61(2), 294-308.

Sheets, R. G., Smith, R. L., \& Voytek, K. P. (1985). Corporate disinvestment and metropolitan manufacturing job loss. Social science quarterly, 66(1), 218.

Shelley, M. (2013). Into Shelley's belly: Davis Street Espresso in Oak Cliff. D Magazine. Retrieved from http://sidedish.dmagazine.com/2013/09/03/into-shelleys-bellydavis-street-espresso-in-oak-cliff/

Shulman, B. (2015). In the heart of our economy and our lives. In D. C. Johnston (Ed.), Divided: The perils of our growing inequality (Vol. 10): The New Press.

Shuman, M. H. (2006). The Small-Mart Revolution: How local businesses are beating the global competition: Berrett-Koehler Publishers.

Simek, P. (2012). Why the Oak Cliff streetcar is a $\$ 50$ million waste. D Magazine. Retrieved from http://www.dmagazine.com/publications/d-magazine/2012/january/why-theoak-cliff-streetcar-is-a-50-million-dollar-waste

Simek, P. (2014). Finance panel: Southern Dallas just needs more George Baileys. D Magazine. Retrieved from 10/31/2014 website: frontburner.dmagazine.com/2014/10/31/finance-panel-southern-dallas-just-needsmore-george-baileys/

Simek, P. (2015). Would a Downtown Dallas Rangers Stadium just be another boondoggle? D Magazine. Retrieved from http:/ / frontburner.dmagazine.com/2015/09/30/woulda-downtown-dallas-rangers-stadium-just-be-another-boondoggle/ 
Simek, P. (2016). Are "Dallas Office Developers" building too many buildings? D Magazine. Retrieved from http:/ / frontburner.dmagazine.com/2016/03/16/are-dallas-officedevelopers-building-too-many-new-buildings/

Skidelsky, R. J. A. (2010). Keynes: the return of the master. New York: PublicAffairs.

Smith, A. S. (1998). The American Community Survey and intercensal population estimates: Where are the crossroads? Washington, D.C. Retrieved from http://www.census.gov/population/www/documentation/twps0031/twps0031.ht $\mathrm{ml}$.

Smith, E. (2008). Pitfalls and promises: The use of secondary data analysis in educational research. British Journal of Educational Studies, 56(3), 323-339.

Smith, J. M. (2010). "Re-stating" theories of urban development: the politics of authority creation and intervoernmental triads in postindustrial Chicago. Journal of Urban Affairs, 32(4), 425-448.

Snow, R. E., Hutcheson, J. D., \& Prather, J. E. (1981). Using reputational sampling to identify residential clusters of minorities dispersed in a large urban region: Hispanics in Atlanta, Georgia. Proceedings, Section on Survey Research Methods $\sim$ American Statistical Association, 101-106.

Sobel, R. (1989). Trammell Crow, master builder: the story of America's largest real estate empire: John Wiley \& Sons.

Solnit, R., \& Schwartzenberg, S. (2002). Hollow city: The siege of San Francisco and the crisis of American urbanism: Verso.

Stake, R. E. (1995). The art of case study research: SAGE Publications Inc.

Stake, R. E. (2005). Qualiative case studies. In N. K. Denzin \& Y. S. Lincoln (Eds.), The $S A G E$ bandbook of qualitative research (3 ed., pp. 443-466). Thousand Oaks, CA: SAGE PUBLICATIONS INC.

Sternlieb, G. (1971). The city as sandbox. The Public Interest(25), 14.

Stoecker, R. (1997). The CDC model of urban redevelopment: A critique and an alternative. Journal of Urban Affairs, 19(1), 1-22.

Stoker, G., \& Mossberger, K. (1994). Urban regime theory in comparative perspective. Environment and Planning C: Government and Policy, 12(2), 195-212.

Stone, C. N. (1989). Regime politics: Governing Atlanta, 1946-1988. Lawrence, KS: University Press of Kansas.

Stone, C. N. (1993). Urban regimes and the capacity to govern: a political economy approach. Journal of Urban Affairs, 15(1), 1-28. doi:10.1111/j.14679906.1993.tb00300.x 
Stone, C. N., Orr, M. E., \& Imbroscio, D. (1991). The reshaping of urban leadership in US cities: A regime analysis. Urban life in transition, 222-239.

Stone, C. N., \& Sanders, H. T. (1987). Reexamining a classic case of developmental politics: New Haven, Connecticut. In C. N. Stone \& H. T. Sanders (Eds.), The politics of urban development (pp. 159-181). Lawrence, KS: University Press of Kansas.

Stone, R. (2011). David Spence wins conservation achievement award. Oak Cliff Advocate. Retrieved from Oak Cliff Advocate website:

oakcliff.advocatemag.com/2011/11/david-spence-wins-conservation-achievementaward/

Stone, R. (2014). Better Block returns to Tyler Street April 27. Oak Cliff Advocate. Retrieved from Oak Cliff Advocate website: http://oakcliff.advocatemag.com/2014/04/better-block-returns-tyler-street-april$27 /$

Stone, R. (2015a). Here is the revised Alamo Manhattan design for Bishop Arts. Oak Cliff Advocate. Retrieved from Oak Cliff Advocate website: http://oakcliff.advocatemag.com/2015/09/here-is-the-revised-alamo-manhattandesign-for-bishop-arts/

Stone, R. (2015b). This map shows property owners in the proposed Alamo Manhattan project. Oak Cliff Advocate. Retrieved from Oak Cliff Advocate website: http:/ / oakcliff.advocatemag.com/2015/06/this-map-shows-property-owners-in-theproposed-alamo-manhattan-project/

Stone, R. (2015c). Where is Oak Cliff? The geographic boundaries are debatable. Oak Cliff Advocate. Retrieved from Oak Cliff Advocate website: http:/ / oakcliff.advocatemag.com/2015/02/where-is-oak-cliff-the-geographicboundaries-are-debatable/

Storper, M. (1997). The city: centre of economic reflexivity. Service Industries Journal, 17(1), 1 27.

Storper, M. (1997). The regional world: territorial development in a global economy: Guilford Press.

Stradling, D., \& Stradling, R. (2008). Perceptions of the burning river: Deindustrialization and Cleveland's Cuyahoga River. Environmental History, 13(3), 515-535.

Strom, E. (2008). Rethinking the politics of downtown development. Journal of Urban Affairs, 30(1), 37-61. doi:10.1111/j.1467-9906.2007.00373.x

Sumka, H. J. (2010). Neighborhood revitalization and displacement: a review of the evidence. In L. Lees, T. Slater, \& E. K. Wyly (Eds.), The gentrification reader (pp. 324332). New York: Routledge.

Swyngedouw, E. (2011). Interrogating post-democratization: Reclaiming egalitarian political spaces. Political Geography, 30(7), 370-380. 
Team Better Block. (2016a). How to Build a Better Block. Retrieved from http://betterblock.org/how-to-build-a-better-block/

Team Better Block. (2016b). Better Block Project Map. Retrieved from http://betterblock.org/better-block-projects-map/

Team Better Block. (2016c). About Us. Retrieved from http://teambetterblock.com/\#about

Team Better Block. (2016d). Jason Roberts. Retrieved from http:/ / teambetterblock.com/jason-roberts/

Terranova, C. N. (2009). Ultramodern underground Dallas: Vincent Ponte's pedestrian-way as systematic solution to the declining downtown. Urban History Review/Revue d'bistoire urbaine, 18-29.

Texas Employment Commission. (1990). Dallas-Fort Worth Labor Market Review. Austin, TX: Texas Employment Commission.

Thomas, G. (2011). A typology for the case study in social science following a review of definition, discourse, and structure. Qualitative inquiry, 17(6), 511-521.

Thomas, J. C., \& Savitch, H. V. (1991). Introduction: Big city politics, then and now. In J. C. Thomas \& H. V. Savitch (Eds.), Big city politics in transition (pp. 1-13). Newbury Park, Calif.: SAGE Publications, Inc.

Thometz, C. E. (1963). The decision-makers: the power structure of Dallas (Vol. 31): Southern Methodist University Press.

Thompson, S. (2012, 03/28). Dallas City council unanimously supports $\$ 4.7$ million for Sylvan Thirty. The Dallas Morning News. Retrieved from http:/ / cityhallblog.dallasnews.com/2012/03/dallas-city-council-unanimousl-1.html/

Thompson, S. (2014). Perot firm Hillwood apparently caught up in John Wiley Price scandal. The Dallas Morning News. Retrieved from http://www.dallasnews.com/news/crime/headlines/20140726-perot-firm-hillwoodapparently-caught-up-in-john-wiley-price-scandal.ece

Tichy, N. M., Tushman, M. L., \& Fombrun, C. (1979). Social Network Analysis for Organizations. The Academy of Management Review, 4(4), 507-519. doi:10.2307/257851

Tonnesen, S. (2012). Stronger Together: Worker Cooperatives as a Community Economic Development Strategy. Georgetown Journal on Poverty Law \& Policy, 20, 187.

Trahan, J. (2010). Former Dallas mayor pro tem, 2 others to receive corruption sentences. The Dallas Morning News. Retrieved from http://www.dallasnews.com/news/community-news/dallas/headlines/20100225Former-Dallas-mayor-pro-tem-9656.ece 
Treviño, J. (2015). Development at site of Mission Hotel to bring apartments, retail space. The Dallas Morning News. Retrieved from The Dallas Morning News website: http://www.dallasnews.com/news/community-news/bestsouthwest/headlines/20150206-development-at-site-of-mission-hotel-to-bringapartments-retail-space.ece

Troutman, P. (2004). A growth machine's Plan B: Legitimating development when the valuefree growth ideology is under fire. Journal of Urban Affairs, 26(5), 611-622.

Turner, R. S. (2002). The politics of design and development in the postmodern downtown. Journal of Urban Affairs, 24(5), 533-548.

Twelvetrees, A. (1989). Organizing for neighbourhood development. Brookfield, VT: Avebury.

United States Congress Office of Technology Assessment (1992). After the cold war : living with lower defense spending. Washington, DC: Congress of the U.S., Office of Technology Assessment.

United States Census Bureau (Cartographer). (1980a). 80T48113_001

United States Census Bureau (Cartographer). (1980b). 80T48113_002

United States Census Bureau (Cartographer). (1990a). 90T48113_001

United States Census Bureau (Cartographer). (1990b). 90T48113_002

United States Census Bureau (Cartographer). (2000a). CT41883_001

United States Census Bureau (Cartographer). (2000b). CT41883_002

United States Census Bureau (Cartographer). (2010a). DC10CT_C48113_001

United States Census Bureau (Cartographer). (2010b). DC10CT_C48113_002

United States Census Bureau. (2010c). QT-P3: Race and Hispanic or Latino Orginin: 2010. 2010 Census Summary File 1. Retrieved from factfinder.census.gov/faces/tableservices/jsf/pages/productview.xhtml?pid=DEC_ 10_SF1_QTP3\&prodType=table

United States Census Bureau. (2010d). B11001A: Household type (including living alone) (White alone). 2006-2010 American Community Survey 5-Year Estimates. Retrieved from http://factfinder.census.gov/faces/tableservices/jsf/pages/productview.xhtml?fpt= table

United States Census Bureau. (2010e). B11001: Household type (including living alone). 2006-2010 American Community Survey 5-Year Estimates. Retrieved from http:// factfinder.census.gov/faces/tableservices/jsf/pages/productview.xhtml?fpt= table 
United States Census Bureau. (2010f). B11001B: Household type (including living alone) (Black or African American alone). 2006-2010 American Community Survey 5-Year Estimates. Retrieved from http://factfinder.census.gov/faces/tableservices/jsf/pages/productview.xhtml?fpt= table

United States Census Bureau. (2010g). B11001C: Household type (including living alone) (American Indian or Alaskan Native). 2006-2010 American Community Survey 5-Year Estimates. Retrieved from

http://factfinder.census.gov/faces/tableservices/jsf/pages/productview.xhtml?fpt= table

United States Census Bureau. (2010h). B11001D: Household type (including living alone) (Asian Alone). 2006-2010 American Community Survey 5-Year Estimates. Retrieved from http://factfinder.census.gov/faces/tableservices/jsf/pages/productview.xhtml?fpt= table

United States Census Bureau. (2010i). B11001E: Household type (including living alone) (Native Hawaiian and Other Pacific Islander Alone). 2006-2010 American Community Survey 5-Year Estimates. Retrieved from http:// factfinder.census.gov/faces/tableservices/jsf/pages/productview.xhtml?fpt= table

United States Census Bureau. (2010j). B11001F: Household type (including living alone) (Some Other Race Alone). 2006-2010 American Community Survey 5-Year Estimates. Retrieved from http://factfinder.census.gov/faces/tableservices/jsf/pages/productview.xhtml?fpt= table

United States Census Bureau. (2010k). B11001G: Household type (including living alone) (Two or More Races). 2006-2010 American Community Survey 5-Year Estimates. Retrieved from http:// factfinder.census.gov/faces/tableservices/jsf/pages/productview.xhtml?fpt= table

United States Census Bureau. (20101). B11001I: Household type (including living alone) (Hispanic or Latino). 2006-2010 American Community Survey 5-Year Estimates. Retrieved from

http:/ factfinder.census.gov/faces/tableservices/jsf/pages/productview.xhtml?fpt= table

United States Census Bureau. (2010m). B19013: Median household income in the past 12 months (in 2010 inflation-adjusted dollars). 2006-2010 American Community Survey 5 Year Estimates. Retrieved from http:// factfinder.census.gov/faces/tableservices/jsf/pages/productview.xhtml?pid= ACS_10_5YR_B19013\&prodType $=$ table 
United States Census Bureau. (2010n). B19013A: Median household income in the past 12 months (in 2010 inflation-adjusted dollars) (white alone householder). 2006-2010 American Community Survey 5-Year Estimates. Retrieved from www.bls.gov/data/inflation_calculator.htm

United States Census Bureau. (2010o). B19013B: Median household income in the past 12 months (in 2010 inflation-adjusted dollars) (Black or African American alone householder). 2006-2010 American Community Survey 5-Year Estimates. Retrieved from http:// factfinder.census.gov/faces/tableservices/jsf/pages/productview.xhtml?pid= ACS_10_5YR_B19013\&prodType=table

United States Census Bureau. (2010p). B19013C: Median household income in the past 12 months (in 2010 inflation-adjusted dollars) (American Indian or Alaskan Native alone householder). 2006-2010 American Community Survey 5-Year Estimates. Retrieved from http:/ / factfinder.census.gov/faces/tableservices/jsf/pages/productview.xhtml?pid= ACS_10_5YR_B19013\&prodType=table

United States Census Bureau. (2010q). B19013D: Median household income in the past 12 months (in 2010 inflation-adjusted dollars) (Asian alone householder). 2006-2010 American Community Survey 5-Year Estimates. Retrieved from http:/ / factfinder.census.gov/faces/tableservices/jsf/pages/productview.xhtml?pid= ACS_10_5YR_B19013\&prodType=table

United States Census Bureau. (2010r). B19013E: Median household income in the past 12 months (in 2010 inflation-adjusted dollars) (Native Hawaiian and Other Pacific Islander alone householder). 2006-2010 American Community Survey 5-Year Estimates. Retrieved from http:/ / factfinder.census.gov/faces/tableservices/jsf/pages/productview.xhtml?pid= ACS_10_5YR_B19013\&prodType $=$ table

United States Census Bureau. (2010s). B19013F: Median household income in the past 12 months (in 2010 inflation-adjusted dollars) (Some Other Race alone householder). 2006-2010 American Community Survey 5-Year Estimates. Retrieved from http://factfinder.census.gov/faces/tableservices/jsf/pages/productview.xhtml?pid= ACS_10_5YR_B19013\&prodType $=$ table

United States Census Bureau. (2010t). B19013G: Median household income in the past 12 months (in 2010 inflation-adjusted dollars) (Two or More Races householder). 20062010 American Community Survey 5-Year Estimates. Retrieved from http:/ / factfinder.census.gov/faces/tableservices/jsf/pages/productview.xhtml?pid= ACS_10_5YR_B19013\&prodType=table

United States Census Bureau. (2012). Top 20 cities: Highest ranking cities, 1790 to 2010. Retrieved from https://www.census.gov/dataviz/visualizations/007/508.php

United States Census Bureau. (2012a). Top 20 cities. Retrieved from http://www.census.gov/dataviz/visualizations/007/508.php 
United States Census Bureau. (2012b). Source and accuracy. Retrieved from http://www.census.gov/did/www/sahie/methods/source.html

United States Census Bureau. (2015). How we count America: the census numbers tell us who we are and what we need. Retrieved from http://www.census.gov/2010census/about/how-we-count.php

United States Census Bureau. (2016a). QuickFacts: Dallas city, Texas. Retrieved from http:/ /www.census.gov/quickfacts/table/PST045215/4819000,0667000

United States Census Bureau. (2016b). QuickFacts: San Francisco city, California. Retrieved from www.census.gov/quickfacts/table/PST045215/0667000

University Of North Texas at Dallas. (2016). SERCH. Retrieved from http://www.untdallas.edu/serch

Usborne, D. (1996). Obituary: Jerry Junkins. The Independent. Retrieved from http://www.independent.co.uk/news/people/obituary-jerry-junkins-1335539.html

Valler, D. (1996). Locality, local economic strategy and private sector involvement: case studies in Norwich and Cardiff. Political Geography, 15(5), 383-403.

Vidal, A. C. (1992). Rebuilding communities: A national study of urban community development corporations: Community Development Research Center, Graduate School of Management and Urban Policy, New School for Social Research.

Vidal, A. C., \& Keating, D. (2004). Community development: Current issues and emerging challenges. Journal of Urban Affairs, 26(2), 125-137.

Vidich, A. J., \& Bensman, J. (1968). Small town in mass society: Class, power, and religion in a rural community: University of Illinois Press.

Vogel, R. K. (1992). Urban political economy: Broward County, Florida: Univ Pr of Florida.

Walcott, S. M. (1999). Bustbelt to boomtown: Regime succession and the transformation of downtown Indianapolis. Urban geography, 20(7), 648-666.

Walker, J. L. (1966). A critique of the elitist theory of democracy. The American Political Science Review, 285-295.

Wallace, S. L. (1999). Social entrepreneurship: The role of social purpose enterprises in facilitating community economic development. Journal of developmental entrepreneurship, $4(2), 153$.

Walton, J. (1966). Substance and artifact: the current status of research on community power structure. American Journal of Sociology, 430-438. 
Whelan, R. K. (1987). New Orleans: Mayoral politics and economic-development policies in the postwar years, 1945-1986. In C. N. Stone \& H. T. Sanders (Eds.), The politics of urban development (pp. 216-229). Lawrence, KS: University Press of Kansas.

Whelan, R. K., Young, A. H., \& Lauria, M. (1994). Urban regimes and racial politics in New Orleans. Journal of Urban Affairs, 16(1), 1-21.

Wilonsky, R. (2008). Forty years ago, a man had a plan for Downtown Dallas ... The Dallas Observer. Retrieved from http://www.dallasobserver.com/news/forty-years-ago-aman-had-a-plan-for-downtown-dallas-7127397

Wilonsky, R. (2011). Into Downtown's tunnels, a horror story. The Dallas Observer. Retrieved from http:/ / www.dallasobserver.com/news/into-downtowns-tunnels-a-horrorstory-7109098

Wilonsky, R. (2012). The definition of your Dallas neighborhood is about to get very specific. The Dallas Morning News. Retrieved from http:/ / www.dallasnews.com/news/community-news/dallas/headlines/20120904the-definition-of-your-dallas-neighborhood-is-about-to-get-very-specific.ece

Wilonsky, R. (2015). If Dallas can seal the deal, there will be four affordable units in Klyde Warren Park high-rise. The Dallas Morning News. Retrieved from http:/ / cityhallblog.dallasnews.com/2015/08/if-dallas-can-seal-the-deal-there-willbe-four-affordable-units-in-klyde-warren-park-high-rise.html/

Wilonsky, R. (2016a). How can a city as rich as dallas be so poor? The Dallas Morning News. Retrieved from http://www.dallasnews.com/opinion/commentary/2016/09/08/can-city-richdallas-poor

Wilonsky, R. (2016b). Dallas' city manager candidates made a good first impression. So why not wait for a second? The Dallas Morning News. Retrieved from http://www.dallasnews.com/news/dallas-city-council/2016/12/08/dallas-citymanager-candidates-made-good-first-impression-wait-second

Wilson, D., \& Wouters, J. (2003). Spatiality and growth discourse: the restructuring of America's rust belt cities. Journal of Urban Affairs, 25(2), 123-138.

Windle, P. E. (2010). Secondary data analysis: is it useful and valid? Journal of PeriAnesthesia Nursing, 25(5), 322-324. doi:http://dx.doi.org/10.1016/j.jopan.2010.07.005

Wolch, J. R., \& Geiger, R. K. (1986). Urban restructuring and the not-for-profit sector. Economic Geography, 3-18.

Wolfinger, R. E. (1960). Reputation and reality in the study of "community power". American Sociological Review, 636-644.

Wolfinger, R. E. (1971). Nondecisions and the study of local politics. American Political Science Review, 65(04), 1063-1080. 
Wolfinger, R. E. (1973). The politics of progress. Upper Saddle River, NJ: Prentice-Hall.

Wyly, E. K. (2014). Community power. Retrieved from http://ibis.geog.ubc.ca/ ewyly/u200/power.pdf

Yin, J. S. (1998). The community development industry system: A case study of politics and institutions in Cleveland, 1967-1997. Journal of Urban Affairs, 20(2), 137-157.

Yin, R. K. (1981). The case study crisis: Some answers. Administrative science quarterly, 26(1), 58-65. doi:10.2307/2392599

Yin, R. K. (2013). Case study research: Design and methods: SAGE Publications Inc..

Young, S. (2014). New York Times can't help itself, strains to tie Oak Cliff rejuvenation to JFK murder. Dallas Observer. Retrieved from www.dallasobserver.com/news/newyork-times-cant-help-itself-strains-to-tie-oak-cliff-rejuvenation-to-jfk-murder7120991

Young, S. (2016). Kingston breaks with tradition and makes endorsement of council challenger. The Dallas Observer. Retrieved from http:/ / www.dallasobserver.com/news/kingston-breaks-with-tradition-and-makesendorsement-of-council-challenger-9001227

Zaretsky, A. M. (2001). Should cities pay for sports facilities? Regional Economist. Retrieved from http:/ / www.stlouisfed.org/publications/re/articles/?id=468

Zdenek, R. (1987). Community development corporations. In S. T. Bruyn \& J. Meehan (Eds.), Beyond the market and the state: New directions in community development (pp. 112127). Philadelphia: Temple University Press.

Zielenbach, S. (2000). The art of revitalization: Improving conditions in distressed inner-city neighborhoods (Vol. 12): Routledge.

Zimmerman, J. (2008). From brew town to cool town: Neoliberalism and the creative city development strategy in Milwaukee. Cities, 25(4), 230-242. doi:http://dx.doi.org/10.1016/j.cities.2008.04.006

Zuckerman, D. S., Holly Jo; Dubb, Steve; Howard, Ted. (2013). Hospitals building healthier communities. Retrieved from College Park, MD:

Zukin, S. (1987). Gentrification: Culture and Capital in the Urban Core. Annual review of sociology, 13, 129-147. 


\section{APPENDICES}

\section{Appendix 1}

\begin{tabular}{|c|c|c|}
\hline \multicolumn{3}{|c|}{ Quantitative Data Source Tables, 1980} \\
\hline Variable Description & $\begin{array}{c}\text { Source Table } \\
\text { (City of Dallas) }\end{array}$ & $\begin{array}{c}\text { Source Table } \\
\text { (CBD \& Oak Cliff Tracts) }\end{array}$ \\
\hline Population (all) & Table P1: General Characteristics of Persons & Table P1: General Characteristics of Persons \\
\hline Population (white) & Table P1: General Characteristics of Persons & Table P1: General Characteristics of Persons \\
\hline $\begin{array}{l}\text { Population (black or African } \\
\text { American) }\end{array}$ & Table P1: General Characteristics of Persons & Table P1: General Characteristics of Persons \\
\hline $\begin{array}{l}\text { Population (American Indian or } \\
\text { Alaskan native) }\end{array}$ & Table P1: General Characteristics of Persons & Table P1: General Characteristics of Persons \\
\hline $\begin{array}{l}\text { Population (Asian American, } \\
\text { Pacific Islander, or native } \\
\text { Hawaiian) }\end{array}$ & Table P1: General Characteristics of Persons & Table P1: General Characteristics of Persons \\
\hline Population (other / mixed) & Table P1: General Characteristics of Persons & Table P1: General Characteristics of Persons \\
\hline Population (nonwhite) & Table P1: General Characteristics of Persons & Table P1: General Characteristics of Persons \\
\hline Population (Hispanic) & Table P7: Race \& Spanish Origin & Table P7: Race \& Spanish Origin \\
\hline Median Household Income & $\begin{array}{l}\text { Table 3: Summary of Occupation, Income, } \\
\text { and Poverty Characteristics }\end{array}$ & $\begin{array}{l}\text { Table P10: Labor Force and Disability } \\
\text { Characteristics of Persons }\end{array}$ \\
\hline Poverty Rate & Table P11: Income \& Poverty Status in 1979 & Table P11: Income \& Poverty Status in 1979 \\
\hline Unemployment Rate & $\begin{array}{l}\text { Table P10: Labor Force and Disability } \\
\text { Characteristics of Persons }\end{array}$ & $\begin{array}{l}\text { Table P10: Labor Force and Disability } \\
\text { Characteristics of Persons }\end{array}$ \\
\hline $\begin{array}{l}\text { Employment: Agriculture, forestry, } \\
\text { fishing and hunting, and mining }\end{array}$ & N.D. & N.D. \\
\hline Employment: Construction & N.D. & N.D. \\
\hline Employment: Manufacturing & $\begin{array}{l}\text { Table 2: Summary of Labor Force and } \\
\text { Commuting Characteristics }\end{array}$ & $\begin{array}{l}\text { Table 2: Summary of Labor Force and } \\
\text { Commuting Characteristics }\end{array}$ \\
\hline Employment: Wholesale trade & N.D. & N.D. \\
\hline Employment: Retail trade & N.D. & N.D. \\
\hline $\begin{array}{l}\text { Employment: Transportation and } \\
\text { warehousing, and utilities }\end{array}$ & N.D. & N.D. \\
\hline Employment: Information & N.D. & N.D. \\
\hline $\begin{array}{l}\text { Employment: Finance and } \\
\text { insurance, and real estate and } \\
\text { rental and leasing }\end{array}$ & N.D. & N.D. \\
\hline $\begin{array}{l}\text { Employment: Professional, } \\
\text { scientific, and management, and } \\
\text { administrative and waste } \\
\text { management services }\end{array}$ & N.D. & N.D. \\
\hline $\begin{array}{l}\text { Employment: Educational } \\
\text { services, and health care and social } \\
\text { assistance }\end{array}$ & N.D. & N.D. \\
\hline $\begin{array}{l}\text { Employment: Arts, entertainment, } \\
\text { and recreation, and } \\
\text { accommodation and food services }\end{array}$ & N.D. & N.D. \\
\hline $\begin{array}{l}\text { Employment: Other services, } \\
\text { except public administration }\end{array}$ & N.D. & N.D. \\
\hline $\begin{array}{l}\text { Employment: Public } \\
\text { administration }\end{array}$ & N.D. & N.D. \\
\hline
\end{tabular}




\section{Appendix 2}

Quantitative Data Source Tables, 1990

\begin{tabular}{|c|c|c|}
\hline Variable Description & $\begin{array}{l}\text { Source Table } \\
\text { (City of Dallas) }\end{array}$ & $\begin{array}{c}\text { Source Table } \\
\text { (CBD \& Oak Cliff Tracts) }\end{array}$ \\
\hline Population (all) & Table 1: General Characteristics of Persons & Table 8: Race \& Hispanic Origin \\
\hline Population (white) & Table 1: General Characteristics of Persons & Table 8: Race \& Hispanic Origin \\
\hline $\begin{array}{l}\text { Population (black or African } \\
\text { American) }\end{array}$ & Table 1: General Characteristics of Persons & Table 8: Race \& Hispanic Origin \\
\hline $\begin{array}{l}\text { Population (American Indian or } \\
\text { Alaskan native) }\end{array}$ & Table 1: General Characteristics of Persons & Table 8: Race \& Hispanic Origin \\
\hline $\begin{array}{l}\text { Population (Asian American, } \\
\text { Pacific Islander, or native } \\
\text { Hawaiian) }\end{array}$ & Table 1: General Characteristics of Persons & Table 8: Race \& Hispanic Origin \\
\hline Population (other / mixed) & Table 1: General Characteristics of Persons & Table 8: Race \& Hispanic Origin \\
\hline Population (nonwhite) & Table 1: General Characteristics of Persons & Table 8: Race \& Hispanic Origin \\
\hline Population (Hispanic) & Table 1: General Characteristics of Persons & Table 8: Race \& Hispanic Origin \\
\hline Median Household Income & Table 19: Income and Poverty Status in 1989 & Table 19: Income and Poverty Status in 1989 \\
\hline Poverty Rate & Table 19: Income and Poverty Status in 1989 & Table 19: Income and Poverty Status in 1989 \\
\hline Unemployment Rate & $\begin{array}{l}\text { Table 18: Labor Force and Disability } \\
\text { Characteristics of Persons }\end{array}$ & $\begin{array}{l}\text { Table 18: Labor Force and Disability } \\
\text { Characteristics of Persons }\end{array}$ \\
\hline $\begin{array}{l}\text { Employment: Agriculture, forestry, } \\
\text { fishing and hunting, and mining }\end{array}$ & N.D. & N.D. \\
\hline Employment: Construction & N.D. & N.D. \\
\hline Employment: Manufacturing & $\begin{array}{l}\text { Table 18: Labor Force and Disability } \\
\text { Characteristics of Persons }\end{array}$ & $\begin{array}{l}\text { Table 18: Labor Force and Disability } \\
\text { Characteristics of Persons }\end{array}$ \\
\hline Employment: Wholesale trade & N.D. & N.D. \\
\hline Employment: Retail trade & N.D. & N.D. \\
\hline $\begin{array}{l}\text { Employment: Transportation and } \\
\text { warehousing, and utilities }\end{array}$ & N.D. & N.D. \\
\hline Employment: Information & N.D. & N.D. \\
\hline $\begin{array}{l}\text { Employment: Finance and } \\
\text { insurance, and real estate and } \\
\text { rental and leasing }\end{array}$ & $\begin{array}{l}\text { Table 18: Labor Force and Disability } \\
\text { Characteristics of Persons }\end{array}$ & $\begin{array}{l}\text { Table 18: Labor Force and Disability } \\
\text { Characteristics of Persons }\end{array}$ \\
\hline $\begin{array}{l}\text { Employment: Professional, } \\
\text { scientific, and management, and } \\
\text { administrative and waste } \\
\text { management services }\end{array}$ & N.D. & N.D. \\
\hline $\begin{array}{l}\text { Employment: Educational } \\
\text { services, and health care and social } \\
\text { assistance }\end{array}$ & N.D. & N.D. \\
\hline $\begin{array}{l}\text { Employment: Arts, entertainment, } \\
\text { and recreation, and } \\
\text { accommodation and food services }\end{array}$ & N.D. & N.D. \\
\hline $\begin{array}{l}\text { Employment: Other services, } \\
\text { except public administration }\end{array}$ & N.D. & N.D. \\
\hline $\begin{array}{l}\text { Employment: Public } \\
\text { administration }\end{array}$ & N.D. & N.D. \\
\hline
\end{tabular}




\section{Appendix 3}

Quantitative Data Source Tables, 2000

\begin{tabular}{|c|c|c|}
\hline Variable Description & $\begin{array}{c}\text { Source Table } \\
\text { (City of Dallas) }\end{array}$ & $\begin{array}{c}\text { Source Table } \\
\text { (CBD \& Oak Cliff Tracts) }\end{array}$ \\
\hline Population (all) & $\begin{array}{l}\text { Table DP-1: Profile of General Demographic } \\
\text { Characteristics }\end{array}$ & $\begin{array}{l}\text { Table DP-1: Profile of General Demographic } \\
\text { Characteristics }\end{array}$ \\
\hline Population (white) & $\begin{array}{l}\text { Table DP-1: Profile of General Demographic } \\
\text { Characteristics }\end{array}$ & $\begin{array}{l}\text { Table DP-1: Profile of General Demographic } \\
\text { Characteristics }\end{array}$ \\
\hline $\begin{array}{l}\text { Population (black or African } \\
\text { American) }\end{array}$ & $\begin{array}{l}\text { Table DP-1: Profile of General Demographic } \\
\text { Characteristics }\end{array}$ & $\begin{array}{l}\text { Table DP-1: Profile of General Demographic } \\
\text { Characteristics }\end{array}$ \\
\hline $\begin{array}{l}\text { Population (American Indian or } \\
\text { Alaskan native) }\end{array}$ & $\begin{array}{l}\text { Table DP-1: Profile of General Demographic } \\
\text { Characteristics }\end{array}$ & $\begin{array}{l}\text { Table DP-1: Profile of General Demographic } \\
\text { Characteristics }\end{array}$ \\
\hline $\begin{array}{l}\text { Population (Asian American, } \\
\text { Pacific Islander, or native } \\
\text { Hawaiian) }\end{array}$ & $\begin{array}{l}\text { Table DP-1: Profile of General Demographic } \\
\text { Characteristics }\end{array}$ & $\begin{array}{l}\text { Table DP-1: Profile of General Demographic } \\
\text { Characteristics }\end{array}$ \\
\hline Population (other / mixed) & $\begin{array}{l}\text { Table DP-1: Profile of General Demographic } \\
\text { Characteristics }\end{array}$ & $\begin{array}{l}\text { Table DP-1: Profile of General Demographic } \\
\text { Characteristics }\end{array}$ \\
\hline Population (nonwhite) & $\begin{array}{l}\text { Table DP-1: Profile of General Demographic } \\
\text { Characteristics }\end{array}$ & $\begin{array}{l}\text { Table DP-1: Profile of General Demographic } \\
\text { Characteristics }\end{array}$ \\
\hline Population (Hispanic) & $\begin{array}{l}\text { Table DP-1: Profile of General Demographic } \\
\text { Characteristics }\end{array}$ & $\begin{array}{l}\text { Table DP-1: Profile of General Demographic } \\
\text { Characteristics }\end{array}$ \\
\hline Median Household Income & $\begin{array}{l}\text { Table DP-3: Profile of Selected Economic } \\
\text { Characteristics }\end{array}$ & $\begin{array}{l}\text { Table DP-3: Profile of Selected Economic } \\
\text { Characteristics }\end{array}$ \\
\hline Poverty Rate & $\begin{array}{l}\text { Table DP-3: Profile of Selected Economic } \\
\text { Characteristics }\end{array}$ & $\begin{array}{l}\text { Table DP-3: Profile of Selected Economic } \\
\text { Characteristics }\end{array}$ \\
\hline Unemployment Rate & $\begin{array}{l}\text { Table DP-3: Profile of Selected Economic } \\
\text { Characteristics }\end{array}$ & $\begin{array}{l}\text { Table DP-3: Profile of Selected Economic } \\
\text { Characteristics }\end{array}$ \\
\hline $\begin{array}{l}\text { Employment: Agriculture, forestry, } \\
\text { fishing and hunting, and mining }\end{array}$ & $\begin{array}{l}\text { Table DP-3: Profile of Selected Economic } \\
\text { Characteristics }\end{array}$ & $\begin{array}{l}\text { Table DP-3: Profile of Selected Economic } \\
\text { Characteristics }\end{array}$ \\
\hline Employment: Construction & $\begin{array}{l}\text { Table DP-3: Profile of Selected Economic } \\
\text { Characteristics }\end{array}$ & $\begin{array}{l}\text { Table DP-3: Profile of Selected Economic } \\
\text { Characteristics }\end{array}$ \\
\hline Employment: Manufacturing & $\begin{array}{l}\text { Table DP-3: Profile of Selected Economic } \\
\text { Characteristics }\end{array}$ & $\begin{array}{l}\text { Table DP-3: Profile of Selected Economic } \\
\text { Characteristics }\end{array}$ \\
\hline Employment: Wholesale trade & $\begin{array}{l}\text { Table DP-3: Profile of Selected Economic } \\
\text { Characteristics }\end{array}$ & $\begin{array}{l}\text { Table DP-3: Profile of Selected Economic } \\
\text { Characteristics }\end{array}$ \\
\hline Employment: Retail trade & $\begin{array}{l}\text { Table DP-3: Profile of Selected Economic } \\
\text { Characteristics }\end{array}$ & $\begin{array}{l}\text { Table DP-3: Profile of Selected Economic } \\
\text { Characteristics }\end{array}$ \\
\hline $\begin{array}{l}\text { Employment: Transportation and } \\
\text { warehousing, and utilities }\end{array}$ & $\begin{array}{l}\text { Table DP-3: Profile of Selected Economic } \\
\text { Characteristics }\end{array}$ & $\begin{array}{l}\text { Table DP-3: Profile of Selected Economic } \\
\text { Characteristics }\end{array}$ \\
\hline Employment: Information & $\begin{array}{l}\text { Table DP-3: Profile of Selected Economic } \\
\text { Characteristics }\end{array}$ & $\begin{array}{l}\text { Table DP-3: Profile of Selected Economic } \\
\text { Characteristics }\end{array}$ \\
\hline $\begin{array}{l}\text { Employment: Finance and } \\
\text { insurance, and real estate and } \\
\text { rental and leasing }\end{array}$ & $\begin{array}{l}\text { Table DP-3: Profile of Selected Economic } \\
\text { Characteristics }\end{array}$ & $\begin{array}{l}\text { Table DP-3: Profile of Selected Economic } \\
\text { Characteristics }\end{array}$ \\
\hline $\begin{array}{l}\text { Employment: Professional, } \\
\text { scientific, and management, and } \\
\text { administrative and waste } \\
\text { management services }\end{array}$ & $\begin{array}{l}\text { Table DP-3: Profile of Selected Economic } \\
\text { Characteristics }\end{array}$ & $\begin{array}{l}\text { Table DP-3: Profile of Selected Economic } \\
\text { Characteristics }\end{array}$ \\
\hline $\begin{array}{l}\text { Employment: Educational } \\
\text { services, and health care and social } \\
\text { assistance }\end{array}$ & $\begin{array}{l}\text { Table DP-3: Profile of Selected Economic } \\
\text { Characteristics }\end{array}$ & $\begin{array}{l}\text { Table DP-3: Profile of Selected Economic } \\
\text { Characteristics }\end{array}$ \\
\hline $\begin{array}{l}\text { Employment: Arts, entertainment, } \\
\text { and recreation, and } \\
\text { accommodation and food services }\end{array}$ & $\begin{array}{l}\text { Table DP-3: Profile of Selected Economic } \\
\text { Characteristics }\end{array}$ & $\begin{array}{l}\text { Table DP-3: Profile of Selected Economic } \\
\text { Characteristics }\end{array}$ \\
\hline $\begin{array}{l}\text { Employment: Other services, } \\
\text { except public administration }\end{array}$ & $\begin{array}{l}\text { Table DP-3: Profile of Selected Economic } \\
\text { Characteristics }\end{array}$ & $\begin{array}{l}\text { Table DP-3: Profile of Selected Economic } \\
\text { Characteristics }\end{array}$ \\
\hline $\begin{array}{l}\text { Employment: Public } \\
\text { administration }\end{array}$ & $\begin{array}{l}\text { Table DP-3: Profile of Selected Economic } \\
\text { Characteristics }\end{array}$ & $\begin{array}{l}\text { Table DP-3: Profile of Selected Economic } \\
\text { Characteristics }\end{array}$ \\
\hline
\end{tabular}




\section{Appendix 4}

Quantitative Data Source Tables, 2010

\begin{tabular}{|c|c|c|}
\hline Variable Description & $\begin{array}{l}\text { Source Table } \\
\text { (City of Dallas) }\end{array}$ & $\begin{array}{c}\text { Source Table } \\
\text { (CBD \& Oak Cliff Tracts) }\end{array}$ \\
\hline Population (all) & $\begin{array}{l}\text { Table QT-P3: Race and Hispanic or Latino } \\
\text { Origin: } 2010\end{array}$ & $\begin{array}{l}\text { Table QT-P3: Race and Hispanic or Latino } \\
\text { Origin: } 2010\end{array}$ \\
\hline Population (white) & $\begin{array}{l}\text { Table QT-P3: Race and Hispanic or Latino } \\
\text { Origin: } 2010\end{array}$ & $\begin{array}{l}\text { Table QT-P3: Race and Hispanic or Latino } \\
\text { Origin: } 2010\end{array}$ \\
\hline $\begin{array}{l}\text { Population (black or African } \\
\text { American) }\end{array}$ & $\begin{array}{l}\text { Table QT-P3: Race and Hispanic or Latino } \\
\text { Origin: } 2010\end{array}$ & $\begin{array}{l}\text { Table QT-P3: Race and Hispanic or Latino } \\
\text { Origin: } 2010\end{array}$ \\
\hline $\begin{array}{l}\text { Population (American Indian or } \\
\text { Alaskan native) }\end{array}$ & $\begin{array}{l}\text { Table QT-P3: Race and Hispanic or Latino } \\
\text { Origin: } 2010\end{array}$ & $\begin{array}{l}\text { Table QT-P3: Race and Hispanic or Latino } \\
\text { Origin: } 2010\end{array}$ \\
\hline $\begin{array}{l}\text { Population (Asian American, } \\
\text { Pacific Islander, or native } \\
\text { Hawaiian) }\end{array}$ & $\begin{array}{l}\text { Table QT-P3: Race and Hispanic or Latino } \\
\text { Origin: } 2010\end{array}$ & $\begin{array}{l}\text { Table QT-P3: Race and Hispanic or Latino } \\
\text { Origin: } 2010\end{array}$ \\
\hline Population (other / mixed) & $\begin{array}{l}\text { Table QT-P3: Race and Hispanic or Latino } \\
\text { Origin: } 2010\end{array}$ & $\begin{array}{l}\text { Table QT-P3: Race and Hispanic or Latino } \\
\text { Origin: } 2010\end{array}$ \\
\hline Population (nonwhite) & $\begin{array}{l}\text { Table QT-P3: Race and Hispanic or Latino } \\
\text { Origin: } 2010\end{array}$ & $\begin{array}{l}\text { Table QT-P3: Race and Hispanic or Latino } \\
\text { Origin: } 2010\end{array}$ \\
\hline Population (Hispanic) & $\begin{array}{l}\text { Table QT-P3: Race and Hispanic or Latino } \\
\text { Origin: } 2010\end{array}$ & $\begin{array}{l}\text { Table QT-P3: Race and Hispanic or Latino } \\
\text { Origin: } 2010\end{array}$ \\
\hline Median Household Income & $\begin{array}{l}\text { ACS Table B19013: Median Household } \\
\text { Income in the Past } 12 \text { Months (in } 2010 \\
\text { Inflation-Adjusted Dollars) }\end{array}$ & $\begin{array}{l}\text { ACS Table B19013: Median Household } \\
\text { Income in the Past } 12 \text { Months (in } 2010 \\
\text { Inflation-Adjusted Dollars) }\end{array}$ \\
\hline Poverty Rate & $\begin{array}{l}\text { ACS Table S1701: Poverty Status in the Past } \\
12 \text { Months }\end{array}$ & $\begin{array}{l}\text { ACS Table S1701: Poverty Status in the Past } \\
12 \text { Months }\end{array}$ \\
\hline Unemployment Rate & $\begin{array}{l}\text { ACS Table DP03: Selected Economic } \\
\text { Characteristics }\end{array}$ & $\begin{array}{l}\text { ACS Table DP03: Selected Economic } \\
\text { Characteristics }\end{array}$ \\
\hline $\begin{array}{l}\text { Employment: Agriculture, forestry, } \\
\text { fishing and hunting, and mining }\end{array}$ & $\begin{array}{l}\text { ACS Table DP03: Selected Economic } \\
\text { Characteristics }\end{array}$ & $\begin{array}{l}\text { ACS Table DP03: Selected Economic } \\
\text { Characteristics }\end{array}$ \\
\hline Employment: Construction & $\begin{array}{l}\text { ACS Table DP03: Selected Economic } \\
\text { Characteristics }\end{array}$ & $\begin{array}{l}\text { ACS Table DP03: Selected Economic } \\
\text { Characteristics }\end{array}$ \\
\hline Employment: Manufacturing & $\begin{array}{l}\text { ACS Table DP03: Selected Economic } \\
\text { Characteristics }\end{array}$ & $\begin{array}{l}\text { ACS Table DP03: Selected Economic } \\
\text { Characteristics }\end{array}$ \\
\hline Employment: Wholesale trade & $\begin{array}{l}\text { ACS Table DP03: Selected Economic } \\
\text { Characteristics }\end{array}$ & $\begin{array}{l}\text { ACS Table DP03: Selected Economic } \\
\text { Characteristics }\end{array}$ \\
\hline Employment: Retail trade & $\begin{array}{l}\text { ACS Table DP03: Selected Economic } \\
\text { Characteristics }\end{array}$ & $\begin{array}{l}\text { ACS Table DP03: Selected Economic } \\
\text { Characteristics }\end{array}$ \\
\hline $\begin{array}{l}\text { Employment: Transportation and } \\
\text { warehousing, and utilities }\end{array}$ & $\begin{array}{l}\text { ACS Table DP03: Selected Economic } \\
\text { Characteristics }\end{array}$ & $\begin{array}{l}\text { ACS Table DP03: Selected Economic } \\
\text { Characteristics }\end{array}$ \\
\hline Employment: Information & $\begin{array}{l}\text { ACS Table DP03: Selected Economic } \\
\text { Characteristics }\end{array}$ & $\begin{array}{l}\text { ACS Table DP03: Selected Economic } \\
\text { Characteristics }\end{array}$ \\
\hline $\begin{array}{l}\text { Employment: Finance and } \\
\text { insurance, and real estate and } \\
\text { rental and leasing }\end{array}$ & $\begin{array}{l}\text { ACS Table DP03: Selected Economic } \\
\text { Characteristics }\end{array}$ & $\begin{array}{l}\text { ACS Table DP03: Selected Economic } \\
\text { Characteristics }\end{array}$ \\
\hline $\begin{array}{l}\text { Employment: Professional, } \\
\text { scientific, and management, and } \\
\text { administrative and waste } \\
\text { management services }\end{array}$ & $\begin{array}{l}\text { ACS Table DP03: Selected Economic } \\
\text { Characteristics }\end{array}$ & $\begin{array}{l}\text { ACS Table DP03: Selected Economic } \\
\text { Characteristics }\end{array}$ \\
\hline $\begin{array}{l}\text { Employment: Educational } \\
\text { services, and health care and social } \\
\text { assistance }\end{array}$ & $\begin{array}{l}\text { ACS Table DP03: Selected Economic } \\
\text { Characteristics }\end{array}$ & $\begin{array}{l}\text { ACS Table DP03: Selected Economic } \\
\text { Characteristics }\end{array}$ \\
\hline $\begin{array}{l}\text { Employment: Arts, entertainment, } \\
\text { and recreation, and } \\
\text { accommodation and food services }\end{array}$ & $\begin{array}{l}\text { ACS Table DP03: Selected Economic } \\
\text { Characteristics }\end{array}$ & $\begin{array}{l}\text { ACS Table DP03: Selected Economic } \\
\text { Characteristics }\end{array}$ \\
\hline $\begin{array}{l}\text { Employment: Other services, } \\
\text { except public administration }\end{array}$ & $\begin{array}{l}\text { ACS Table DP03: Selected Economic } \\
\text { Characteristics }\end{array}$ & $\begin{array}{l}\text { ACS Table DP03: Selected Economic } \\
\text { Characteristics }\end{array}$ \\
\hline $\begin{array}{l}\text { Employment: Public } \\
\text { administration }\end{array}$ & $\begin{array}{l}\text { ACS Table DP03: Selected Economic } \\
\text { Characteristics }\end{array}$ & $\begin{array}{l}\text { ACS Table DP03: Selected Economic } \\
\text { Characteristics }\end{array}$ \\
\hline
\end{tabular}




\section{Appendix 5}

\section{Dear [Participant Name]:}

My name is Benjamin Leamon, and I am a doctoral candidate at the University of Louisville. As part of my dissertation, I am conducting research on the general decision-making process in Dallas. Because of your involvement in [Name of Organization], I would like to request your participation in a brief survey and interview to help me better understand how projects that affect large parts of the city are implemented. Your answers will be completely confidential. In addition, the results of the survey will be reported in summary format, so your particular responses cannot be linked back to you.

To participate in the study, please contact me by email at benjamin.leamon@louisville.edu, or by phone at 502-554-6126.

Thank you for your time and consideration. If you have any questions about the survey, please feel free to contact me, at the email address or phone number provided above.

Sincerely, Benjamin Leamon

Urban \& Public Affairs, The University of Louisville 


\section{Appendix 6}

\begin{tabular}{|c|c|c|c|}
\hline \multicolumn{1}{|c|}{ Census Tract Boundary Changes, 1980-2010 } & Tract ID \\
Tract ID & Tract ID & Tract ID \\
$\mathbf{( 1 9 8 0 )}$ & $(\mathbf{1 9 9 0 )}$ & & Me10) \\
& & Census Tract 32.01 & Sped into 204 \\
\hline Census Tract 32.01 & Census Tract 32.01 & Split into 42.01 \& 42.02 & \\
\hline Census Tract 42 & Census Tract 42 & & Census Tract 204 \\
\hline
\end{tabular}




\section{Appendix 7}

All Census Tracts Used in this Study

\begin{tabular}{|l|l|l|}
\hline Tracts Used to Approximate Downtown Dallas & Census Tract 31.01 & Census Tract 204 \\
\hline Census Tract 17.01 & Census Tract 32.01 & \\
\hline Census Tract 21 & Census Tract 42.01 & Census Tract 42.02 \\
\hline Tracts Used to Approximate North Oak Cliff & & \\
\hline Census Tract 20 & \\
\hline Census Tract 44 &
\end{tabular}


Appendix 8

[THIS PAGE INTENTIONALLY LEFT BLANK] 


\section{Informed Consent Agreement}

PLEASE READ THIS DOCUMENT CAREFULLY. YOUR SIGNATURE IS REQUIRED FOR PARTICPATION. YOU MUST BE AT LEAST 18 YEARS OF AGE TO GIVE YOUR CONSENT TO PARTICIPATE IN RESEARCH. IF YOU DESIRE A COPY OF THIS CONSENT FORM, YOU MAY REQUEST ONE AND WE WILL PROVIDE IT.

\section{Description of the Study:}

This is a one-session study of the nature of Dallas' decision-making process.

\section{Nature of Participation:}

If you consent to participate, you will be asked to participate in one session, during which you will be asked to complete the attached survey.

\section{Purpose of the Study:}

The goal of the survey is to understand how community-wide decisions are made in Dallas, as well as understanding the relationships among the people who are most active in this process. We are primarily interested in your personal evaluation of how influential different people are in this city, based on your own experience.

\section{Possible Risks:}

When filling out the survey, you may feel uncomfortable rating the influence of particular individuals. In addition, you may feel that you do not have enough information to answer each question.

\section{Possible Benefits:}

When your participation is complete, you will be given an opportunity to learn about this research.

\section{Confidentiality:}

All of your answers will be anonymous, and no identifying markers will be used. In addition, completed surveys will be stored within a controlled-access office, inside of a locked cabinet only accessible to the researcher. The results of the survey will only be reported in aggregate, and no direct quotations will be used. Finally, please remember that no particular person's responses interest us; we are interested in the general decision-making process in Dallas.

\section{Opportunities to Question:}

Please direct questions about this research to: Benjamin Leamon, at (502) 554-6126, or benjamin.leamon@louisville.edu.

\section{Statement of Voluntary Participation:}

Your participation in this study is entirely voluntary. If you decide not to participate, there will not be any negative consequences. In addition, if you decide to participate, you may stop participating at any time, also with no negative consequences. By signing the supplied form, you are attesting that you understand this information, and that you freely give your consent to participate in this survey. 
[THIS PAGE INTENTIONALLY LEFT BLANK] 


\section{Survey Introduction}

Thank you for participating in this survey of Dallas' decision-making process. This survey is part of a research project that will help fulfill the requirements for a doctoral dissertation at the University of Louisville. The goal of the survey is to understand how community-wide decisions are made in Dallas, as well as understanding the relationships among the people who are most active in this process. For each question, please answer based on your experience and opinions, even if doing so may mean that you cannot answer a question in its entirety. While a more complete survey will be more helpful for the project than a less-complete one, all answers and responses will benefit the research, and even a partiallycompleted survey is tremendously appreciated. 


\section{Section 1: City-Wide Leadership}

Many people would suggest that there is a group of leaders within the city, whose members are highly active in making most of the important decisions, especially regarding public policy or urban development.

On the following pages are a series of lists of influential people in Dallas. For each person on the list, please complete the table that follows to the best of your knowledge and ability, using the following information as a guide:

\section{Rating of Influence- 1 (low) to 4 (high):}

a. In this blank, please indicate how influential this person is with respect to policy decisions or development in Dallas, ranging from 1 (not very influential) to 4 (highly influential).

\section{Reasoning for Rating:}

a. In this blank, please discuss why you gave this person the rating you did. Again, please be aware that these answers will be kept strictly confidential, and will not be reproduced in any way.

\section{Committee or Project in the Past 5 Years (circle yes or no):}

a. In this blank, please indicate (yes/no) whether you have worked on a committee with this person in the past five years.

\section{Relationship (circle one):}

a. In this blank, please circle the item which best describes your relationship to the person

At the bottom of the list are several blank spaces. In those spaces, please list any names you feel should be on the list, but who are not currently listed.

As a reminder: all of your responses are confidential, and no direct quotations will be used without your permission 


\begin{tabular}{|c|c|c|c|c|}
\hline Name & $\begin{array}{c}\text { Rating of } \\
\text { Influence } \\
1 \text { (low) to } \\
4 \text { (high) }\end{array}$ & Reasoning for Rating & $\begin{array}{l}\text { Committee } \\
\text { or Project in } \\
\text { Past } 5 \text { Years }\end{array}$ & $\begin{array}{c}\text { Your Relationship to } \\
\text { This Person }\end{array}$ \\
\hline Elaine Agather & \begin{tabular}{lr}
1 & 2 \\
3 & 4 \\
\multicolumn{2}{c}{ Don't } \\
Know or \\
Not Sure
\end{tabular} & & $\begin{array}{l}\text { Yes } \\
\text { No }\end{array}$ & $\begin{array}{l}\text { Never heard of } \\
\text { Know slightly } \\
\text { Know well } \\
\text { Personal friend or } \\
\text { relative }\end{array}$ \\
\hline $\begin{array}{l}\text { Thomas M. } \\
\text { "Tom" Dunning }\end{array}$ & \begin{tabular}{lr}
1 & 2 \\
3 & 4 \\
\multicolumn{2}{c}{ Don't } \\
Know or \\
Kot Sure
\end{tabular} & & $\begin{array}{l}\text { Yes } \\
\text { No }\end{array}$ & $\begin{array}{c}\text { Never heard of } \\
\text { Know slightly } \\
\text { Know well } \\
\text { Personal friend or } \\
\text { relative }\end{array}$ \\
\hline $\begin{array}{l}\text { Christopher J. } \\
\text { Durovich }\end{array}$ & \begin{tabular}{lr}
1 & 2 \\
3 & 4 \\
\multicolumn{2}{c}{ Don't } \\
Know or \\
Not Sure
\end{tabular} & & $\begin{array}{l}\text { Yes } \\
\text { No }\end{array}$ & $\begin{array}{l}\text { Never heard of } \\
\text { Know slightly } \\
\text { Know well } \\
\text { Personal friend or } \\
\text { relative }\end{array}$ \\
\hline $\begin{array}{l}\text { Matthew K. } \\
\text { Rose }\end{array}$ & \begin{tabular}{lr}
1 & 2 \\
3 & 4 \\
\multicolumn{2}{c}{ Don't } \\
Know or \\
Kot Sure
\end{tabular} & & $\begin{array}{l}\text { Yes } \\
\text { No }\end{array}$ & $\begin{array}{c}\text { Never heard of } \\
\text { Know slightly } \\
\text { Know well } \\
\text { Personal friend or } \\
\text { relative }\end{array}$ \\
\hline $\begin{array}{l}\text { John Field } \\
\text { Scovell }\end{array}$ & \begin{tabular}{lr}
1 & 2 \\
3 & 4 \\
\multicolumn{2}{r}{ Don't } \\
Know or \\
Kot Sure
\end{tabular} & & $\begin{array}{l}\text { Yes } \\
\text { No }\end{array}$ & $\begin{array}{l}\text { Never heard of } \\
\text { Know slightly } \\
\text { Know well } \\
\text { Personal friend or } \\
\text { relative }\end{array}$ \\
\hline
\end{tabular}




\begin{tabular}{|c|c|c|c|c|}
\hline Name & $\begin{array}{c}\text { Rating of } \\
\text { Influence } \\
1 \text { (low) to } \\
4 \text { (high) }\end{array}$ & Reasoning for Rating & $\begin{array}{l}\text { Committee } \\
\text { or Project in } \\
\text { Past } 5 \text { Years }\end{array}$ & $\begin{array}{c}\text { Your Relationship to } \\
\text { This Person }\end{array}$ \\
\hline $\begin{array}{l}\text { Richard K. } \\
\text { "Rich" } \\
\text { Templeton }\end{array}$ & \begin{tabular}{lr}
1 & 2 \\
3 & 4 \\
\multicolumn{2}{l}{ Don't } \\
Know or \\
Kot Sure
\end{tabular} & & $\begin{array}{l}\text { Yes } \\
\text { No }\end{array}$ & $\begin{array}{l}\text { Never heard of } \\
\text { Know slightly } \\
\text { Know well } \\
\text { Personal friend or } \\
\text { relative }\end{array}$ \\
\hline $\begin{array}{l}\text { Kneeland C. } \\
\text { Youngblood }\end{array}$ & \begin{tabular}{lr}
1 & 2 \\
3 & 4 \\
\multicolumn{2}{c}{ Don't } \\
\multicolumn{2}{c}{ Know or } \\
\multicolumn{2}{r}{ Not Sure }
\end{tabular} & & $\begin{array}{l}\text { Yes } \\
\text { No }\end{array}$ & $\begin{array}{l}\text { Never heard of } \\
\text { Know slightly } \\
\text { Know well } \\
\text { Personal friend or } \\
\text { relative }\end{array}$ \\
\hline $\begin{array}{c}\text { Arcilia C. } \\
\text { Acosta }\end{array}$ & \begin{tabular}{lr}
1 & 2 \\
3 & 4 \\
\multicolumn{2}{c}{ Don't } \\
Know or \\
Not Sure
\end{tabular} & & $\begin{array}{l}\text { Yes } \\
\text { No }\end{array}$ & $\begin{array}{l}\text { Never heard of } \\
\text { Know slightly } \\
\text { Know well } \\
\text { Personal friend or } \\
\text { relative }\end{array}$ \\
\hline $\begin{array}{c}\text { Rafael M. } \\
\text { Anchia }\end{array}$ & \begin{tabular}{lr}
1 & 2 \\
3 & 4 \\
\multicolumn{2}{c}{ Don't } \\
Know or \\
Not Sure
\end{tabular} & & $\begin{array}{l}\text { Yes } \\
\text { No }\end{array}$ & $\begin{array}{l}\text { Never heard of } \\
\text { Know slightly } \\
\text { Know well } \\
\text { Personal friend or } \\
\text { relative }\end{array}$ \\
\hline $\begin{array}{l}\text { Barry G. } \\
\text { Andrews }\end{array}$ & \begin{tabular}{lr}
1 & 2 \\
3 & 4 \\
\multicolumn{2}{c}{ Don't } \\
Know or \\
Not Sure
\end{tabular} & & $\begin{array}{l}\text { Yes } \\
\text { No }\end{array}$ & $\begin{array}{l}\text { Never heard of } \\
\text { Know slightly } \\
\text { Know well } \\
\text { Personal friend or } \\
\text { relative }\end{array}$ \\
\hline $\begin{array}{c}\text { Ralph W. Babb } \\
\text { Jr. }\end{array}$ & \begin{tabular}{lr}
1 & 2 \\
3 & 4 \\
\multicolumn{2}{c}{ Don't } \\
Know or \\
Not Sure
\end{tabular} & & $\begin{array}{l}\text { Yes } \\
\text { No }\end{array}$ & $\begin{array}{l}\text { Never heard of } \\
\text { Know slightly } \\
\text { Know well } \\
\text { Personal friend or } \\
\text { relative }\end{array}$ \\
\hline
\end{tabular}




\begin{tabular}{|c|c|c|c|c|}
\hline Name & $\begin{array}{c}\text { Rating of } \\
\text { Influence } \\
1 \text { (low) to } \\
4 \text { (high) }\end{array}$ & Reasoning for Rating & $\begin{array}{l}\text { Committee } \\
\text { or Project in } \\
\text { Past } 5 \text { Years }\end{array}$ & $\begin{array}{c}\text { Your Relationship to } \\
\text { This Person }\end{array}$ \\
\hline Brock K. Bailey & \begin{tabular}{lr}
1 & 2 \\
3 & 4 \\
\multicolumn{2}{l}{ Don't } \\
\multicolumn{2}{c}{ Know or } \\
\multicolumn{2}{r}{ Not Sure }
\end{tabular} & & $\begin{array}{l}\text { Yes } \\
\text { No }\end{array}$ & $\begin{array}{l}\text { Never heard of } \\
\text { Know slightly } \\
\text { Know well } \\
\text { Personal friend or } \\
\text { relative }\end{array}$ \\
\hline $\begin{array}{c}\text { Barclay E. } \\
\text { Berdan }\end{array}$ & \begin{tabular}{lr}
1 & 2 \\
3 & 4 \\
\multicolumn{2}{c}{ Don't } \\
\multicolumn{2}{c}{ Know or } \\
\multicolumn{2}{r}{ Not Sure }
\end{tabular} & & $\begin{array}{l}\text { Yes } \\
\text { No }\end{array}$ & $\begin{array}{l}\text { Never heard of } \\
\text { Know slightly } \\
\text { Know well } \\
\text { Personal friend or } \\
\text { relative }\end{array}$ \\
\hline $\begin{array}{l}\text { David W. } \\
\text { Biegler }\end{array}$ & \begin{tabular}{lr}
1 & 2 \\
3 & 4 \\
\multicolumn{2}{c}{ Don't } \\
Know or \\
Not Sure
\end{tabular} & & $\begin{array}{l}\text { Yes } \\
\text { No }\end{array}$ & $\begin{array}{l}\text { Never heard of } \\
\text { Know slightly } \\
\text { Know well } \\
\text { Personal friend or } \\
\text { relative }\end{array}$ \\
\hline Gene H. Bishop & \begin{tabular}{lr}
1 & 2 \\
3 & 4 \\
\multicolumn{2}{c}{ Don't } \\
Know or \\
Not Sure
\end{tabular} & & $\begin{array}{l}\text { Yes } \\
\text { No }\end{array}$ & $\begin{array}{l}\text { Never heard of } \\
\text { Know slightly } \\
\text { Know well } \\
\text { Personal friend or } \\
\text { relative }\end{array}$ \\
\hline Kim R. Cocklin & \begin{tabular}{lr}
1 & 2 \\
3 & 4 \\
\multicolumn{2}{c}{ Don't } \\
Know or \\
Not Sure
\end{tabular} & & $\begin{array}{l}\text { Yes } \\
\text { No }\end{array}$ & $\begin{array}{l}\text { Never heard of } \\
\text { Know slightly } \\
\text { Know well } \\
\text { Personal friend or } \\
\text { relative }\end{array}$ \\
\hline $\begin{array}{l}\text { Thomas W. } \\
\text { Codd Jr. }\end{array}$ & \begin{tabular}{lr}
1 & 2 \\
3 & 4 \\
\multicolumn{2}{c}{ Don't } \\
Know or \\
Not Sure
\end{tabular} & & $\begin{array}{l}\text { Yes } \\
\text { No }\end{array}$ & $\begin{array}{l}\text { Never heard of } \\
\text { Know slightly } \\
\text { Know well } \\
\text { Personal friend or } \\
\text { relative }\end{array}$ \\
\hline
\end{tabular}




\begin{tabular}{|c|c|c|c|c|}
\hline Name & $\begin{array}{c}\text { Rating of } \\
\text { Influence } \\
1 \text { (low) to } \\
4 \text { (high) }\end{array}$ & Reasoning for Rating & $\begin{array}{l}\text { Committee } \\
\text { or Project in } \\
\text { Past } 5 \text { Years }\end{array}$ & $\begin{array}{c}\text { Your Relationship to } \\
\text { This Person }\end{array}$ \\
\hline David E. Daniel & \begin{tabular}{lr}
1 & 2 \\
3 & 4 \\
\multicolumn{2}{l}{ Don't } \\
\multicolumn{2}{c}{ Know or } \\
\multicolumn{2}{r}{ Not Sure }
\end{tabular} & & $\begin{array}{l}\text { Yes } \\
\text { No }\end{array}$ & $\begin{array}{l}\text { Never heard of } \\
\text { Know slightly } \\
\text { Know well } \\
\text { Personal friend or } \\
\text { relative }\end{array}$ \\
\hline $\begin{array}{l}\text { Joseph M. } \\
\text { DePinto }\end{array}$ & \begin{tabular}{lr}
1 & 2 \\
3 & 4 \\
\multicolumn{2}{c}{ Don't } \\
\multicolumn{2}{c}{ Know or } \\
\multicolumn{2}{r}{ Not Sure }
\end{tabular} & & $\begin{array}{l}\text { Yes } \\
\text { No }\end{array}$ & $\begin{array}{l}\text { Never heard of } \\
\text { Know slightly } \\
\text { Know well } \\
\text { Personal friend or } \\
\text { relative }\end{array}$ \\
\hline Sean Donohue & \begin{tabular}{lr}
1 & 2 \\
3 & 4 \\
\multicolumn{2}{c}{ Don't } \\
Know or \\
Not Sure
\end{tabular} & & $\begin{array}{l}\text { Yes } \\
\text { No }\end{array}$ & $\begin{array}{l}\text { Never heard of } \\
\text { Know slightly } \\
\text { Know well } \\
\text { Personal friend or } \\
\text { relative }\end{array}$ \\
\hline Kent Eastman & \begin{tabular}{lr}
1 & 2 \\
3 & 4 \\
\multicolumn{2}{c}{ Don't } \\
Know or \\
Not Sure
\end{tabular} & & $\begin{array}{l}\text { Yes } \\
\text { No }\end{array}$ & $\begin{array}{l}\text { Never heard of } \\
\text { Know slightly } \\
\text { Know well } \\
\text { Personal friend or } \\
\text { relative }\end{array}$ \\
\hline $\begin{array}{l}\text { Ruben E. } \\
\text { Esquivel }\end{array}$ & \begin{tabular}{lr}
1 & 2 \\
3 & 4 \\
\multicolumn{2}{c}{ Don't } \\
Know or \\
Not Sure
\end{tabular} & & $\begin{array}{l}\text { Yes } \\
\text { No }\end{array}$ & $\begin{array}{l}\text { Never heard of } \\
\text { Know slightly } \\
\text { Know well } \\
\text { Personal friend or } \\
\text { relative }\end{array}$ \\
\hline $\begin{array}{l}\text { Wright L. } \\
\text { Lassiter Jr. }\end{array}$ & \begin{tabular}{lr}
1 & 2 \\
3 & 4 \\
\multicolumn{2}{c}{ Don't } \\
Know or \\
Not Sure
\end{tabular} & & $\begin{array}{l}\text { Yes } \\
\text { No }\end{array}$ & $\begin{array}{l}\text { Never heard of } \\
\text { Know slightly } \\
\text { Know well } \\
\text { Personal friend or } \\
\text { relative }\end{array}$ \\
\hline
\end{tabular}




\begin{tabular}{|c|c|c|c|c|}
\hline Name & $\begin{array}{c}\text { Rating of } \\
\text { Influence } \\
1 \text { (low) to } \\
4 \text { (high) }\end{array}$ & Reasoning for Rating & $\begin{array}{l}\text { Committee } \\
\text { or Project in } \\
\text { Past } 5 \text { Years }\end{array}$ & $\begin{array}{c}\text { Your Relationship to } \\
\text { This Person }\end{array}$ \\
\hline $\begin{array}{l}\text { Pauline } \\
\text { Medrano }\end{array}$ & \begin{tabular}{lr}
1 & 2 \\
3 & 4 \\
\multicolumn{2}{c}{ Don't } \\
Know or \\
Not Sure
\end{tabular} & & $\begin{array}{l}\text { Yes } \\
\text { No }\end{array}$ & $\begin{array}{l}\text { Never heard of } \\
\text { Know slightly } \\
\text { Know well } \\
\text { Personal friend or } \\
\text { relative }\end{array}$ \\
\hline David B. Miller & \begin{tabular}{lr}
1 & 2 \\
3 & 4 \\
\multicolumn{2}{c}{ Don't } \\
Know or \\
Not Sure
\end{tabular} & & $\begin{array}{l}\text { Yes } \\
\text { No }\end{array}$ & $\begin{array}{l}\text { Never heard of } \\
\text { Know slightly } \\
\text { Know well } \\
\text { Personal friend or } \\
\text { relative }\end{array}$ \\
\hline $\begin{array}{c}\text { Anne B. } \\
\text { Motsenbocker }\end{array}$ & \begin{tabular}{lr}
1 & 2 \\
3 & 4 \\
\multicolumn{2}{c}{ Don't } \\
Know or \\
Not Sure
\end{tabular} & & $\begin{array}{l}\text { Yes } \\
\text { No }\end{array}$ & $\begin{array}{l}\text { Never heard of } \\
\text { Know slightly } \\
\text { Know well } \\
\text { Personal friend or } \\
\text { relative }\end{array}$ \\
\hline $\begin{array}{l}\text { Daniel K. } \\
\text { Podolsky }\end{array}$ & \begin{tabular}{lr}
1 & 2 \\
3 & 4 \\
\multicolumn{2}{c}{ Don't } \\
\multicolumn{2}{c}{ Know or } \\
\multicolumn{2}{r}{ Not Sure }
\end{tabular} & & $\begin{array}{l}\text { Yes } \\
\text { No }\end{array}$ & $\begin{array}{l}\text { Never heard of } \\
\text { Know slightly } \\
\text { Know well } \\
\text { Personal friend or } \\
\text { relative }\end{array}$ \\
\hline Cindy Schamp & \begin{tabular}{lr}
1 & 2 \\
3 & 4 \\
\multicolumn{2}{c}{ Don't } \\
Know or \\
\multicolumn{2}{r}{ Not Sure }
\end{tabular} & & $\begin{array}{l}\text { Yes } \\
\text { No }\end{array}$ & $\begin{array}{l}\text { Never heard of } \\
\text { Know slightly } \\
\text { Know well } \\
\text { Personal friend or } \\
\text { relative }\end{array}$ \\
\hline Pete Schenkel & \begin{tabular}{lr}
1 & 2 \\
3 & 4 \\
\multicolumn{2}{c}{ Don't } \\
Know or \\
\multicolumn{2}{r}{ Not Sure }
\end{tabular} & & $\begin{array}{l}\text { Yes } \\
\text { No }\end{array}$ & $\begin{array}{l}\text { Never heard of } \\
\text { Know slightly } \\
\text { Know well } \\
\text { Personal friend or } \\
\text { relative }\end{array}$ \\
\hline
\end{tabular}




\begin{tabular}{|c|c|c|c|c|}
\hline Name & $\begin{array}{c}\text { Rating of } \\
\text { Influence } \\
1 \text { (low) to } \\
4 \text { (high) }\end{array}$ & Reasoning for Rating & $\begin{array}{l}\text { Committee } \\
\text { or Project in } \\
\text { Past } 5 \text { Years }\end{array}$ & $\begin{array}{c}\text { Your Relationship to } \\
\text { This Person }\end{array}$ \\
\hline $\begin{array}{l}\text { Jere W. } \\
\text { Thompson, Jr. }\end{array}$ & \begin{tabular}{lr}
1 & 2 \\
3 & 4 \\
\multicolumn{2}{c}{ Don't } \\
Know or \\
Not Sure
\end{tabular} & & $\begin{array}{l}\text { Yes } \\
\text { No }\end{array}$ & $\begin{array}{l}\text { Never heard of } \\
\text { Know slightly } \\
\text { Know well } \\
\text { Personal friend or } \\
\text { relative }\end{array}$ \\
\hline $\begin{array}{l}\text { Jack C. } \\
\text { Vaughn, Jr. }\end{array}$ & \begin{tabular}{lr}
1 & 2 \\
3 & 4 \\
\multicolumn{2}{c}{ Don't } \\
Know or \\
Not Sure
\end{tabular} & & $\begin{array}{l}\text { Yes } \\
\text { No }\end{array}$ & $\begin{array}{l}\text { Never heard of } \\
\text { Know slightly } \\
\text { Know well } \\
\text { Personal friend or } \\
\text { relative }\end{array}$ \\
\hline John Warner & \begin{tabular}{lr}
1 & 2 \\
3 & 4 \\
\multicolumn{2}{c}{ Don't } \\
Know or \\
Not Sure
\end{tabular} & & $\begin{array}{l}\text { Yes } \\
\text { No }\end{array}$ & $\begin{array}{l}\text { Never heard of } \\
\text { Know slightly } \\
\text { Know well } \\
\text { Personal friend or } \\
\text { relative }\end{array}$ \\
\hline $\begin{array}{l}\text { J. Patrick } \\
\text { Faubion }\end{array}$ & \begin{tabular}{lr}
1 & 2 \\
3 & 4 \\
\multicolumn{2}{c}{ Don't } \\
\multicolumn{2}{c}{ Know or } \\
\multicolumn{2}{r}{ Not Sure }
\end{tabular} & & $\begin{array}{l}\text { Yes } \\
\text { No }\end{array}$ & $\begin{array}{l}\text { Never heard of } \\
\text { Know slightly } \\
\text { Know well } \\
\text { Personal friend or } \\
\text { relative }\end{array}$ \\
\hline $\begin{array}{l}\text { Robert Stephen } \\
\text { Folsom }\end{array}$ & \begin{tabular}{lr}
1 & 2 \\
3 & 4 \\
\multicolumn{2}{c}{ Don't } \\
Know or \\
\multicolumn{2}{r}{ Not Sure }
\end{tabular} & & $\begin{array}{l}\text { Yes } \\
\text { No }\end{array}$ & $\begin{array}{l}\text { Never heard of } \\
\text { Know slightly } \\
\text { Know well } \\
\text { Personal friend or } \\
\text { relative }\end{array}$ \\
\hline Henry Gilchrist & \begin{tabular}{lr}
1 & 2 \\
3 & 4 \\
\multicolumn{2}{c}{ Don't } \\
Know or \\
\multicolumn{2}{r}{ Not Sure }
\end{tabular} & & $\begin{array}{l}\text { Yes } \\
\text { No }\end{array}$ & $\begin{array}{l}\text { Never heard of } \\
\text { Know slightly } \\
\text { Know well } \\
\text { Personal friend or } \\
\text { relative }\end{array}$ \\
\hline
\end{tabular}




\begin{tabular}{|c|c|c|c|c|}
\hline Name & $\begin{array}{c}\text { Rating of } \\
\text { Influence } \\
1 \text { (low) to } \\
4 \text { (high) }\end{array}$ & Reasoning for Rating & $\begin{array}{l}\text { Committee } \\
\text { or Project in } \\
\text { Past } 5 \text { Years }\end{array}$ & $\begin{array}{c}\text { Your Relationship to } \\
\text { This Person }\end{array}$ \\
\hline Wanda Granier & \begin{tabular}{lr}
1 & 2 \\
3 & 4 \\
\multicolumn{2}{l}{ Don't } \\
\multicolumn{2}{c}{ Know or } \\
\multicolumn{2}{r}{ Not Sure }
\end{tabular} & & $\begin{array}{l}\text { Yes } \\
\text { No }\end{array}$ & $\begin{array}{l}\text { Never heard of } \\
\text { Know slightly } \\
\text { Know well } \\
\text { Personal friend or } \\
\text { relative }\end{array}$ \\
\hline Howard Hallam & \begin{tabular}{lr}
1 & 2 \\
3 & 4 \\
\multicolumn{2}{c}{ Don't } \\
\multicolumn{2}{c}{ Know or } \\
\multicolumn{2}{r}{ Not Sure }
\end{tabular} & & $\begin{array}{l}\text { Yes } \\
\text { No }\end{array}$ & $\begin{array}{l}\text { Never heard of } \\
\text { Know slightly } \\
\text { Know well } \\
\text { Personal friend or } \\
\text { relative }\end{array}$ \\
\hline Linda W. Hart & \begin{tabular}{lr}
1 & 2 \\
3 & 4 \\
\multicolumn{2}{c}{ Don't } \\
Know or \\
Not Sure
\end{tabular} & & $\begin{array}{l}\text { Yes } \\
\text { No }\end{array}$ & $\begin{array}{l}\text { Never heard of } \\
\text { Know slightly } \\
\text { Know well } \\
\text { Personal friend or } \\
\text { relative }\end{array}$ \\
\hline $\begin{array}{l}\text { Thomas O. } \\
\text { "Tom" Hicks }\end{array}$ & \begin{tabular}{lr}
1 & 2 \\
3 & 4 \\
\multicolumn{2}{c}{ Don't } \\
Know or \\
Not Sure
\end{tabular} & & $\begin{array}{l}\text { Yes } \\
\text { No }\end{array}$ & $\begin{array}{l}\text { Never heard of } \\
\text { Know slightly } \\
\text { Know well } \\
\text { Personal friend or } \\
\text { relative }\end{array}$ \\
\hline David B. Holl & \begin{tabular}{lr}
1 & 2 \\
3 & 4 \\
\multicolumn{2}{c}{ Don't } \\
Know or \\
\multicolumn{2}{r}{ Not Sure }
\end{tabular} & & $\begin{array}{l}\text { Yes } \\
\text { No }\end{array}$ & $\begin{array}{l}\text { Never heard of } \\
\text { Know slightly } \\
\text { Know well } \\
\text { Personal friend or } \\
\text { relative }\end{array}$ \\
\hline $\begin{array}{l}\text { Matthew "Matt" } \\
\text { Houston }\end{array}$ & \begin{tabular}{lr}
1 & 2 \\
3 & 4 \\
\multicolumn{2}{c}{ Don't } \\
Know or \\
Not Sure
\end{tabular} & & $\begin{array}{l}\text { Yes } \\
\text { No }\end{array}$ & $\begin{array}{l}\text { Never heard of } \\
\text { Know slightly } \\
\text { Know well } \\
\text { Personal friend or } \\
\text { relative }\end{array}$ \\
\hline
\end{tabular}




\begin{tabular}{|c|c|c|c|c|}
\hline Name & $\begin{array}{c}\text { Rating of } \\
\text { Influence } \\
1 \text { (low) to } \\
4 \text { (high) }\end{array}$ & Reasoning for Rating & $\begin{array}{l}\text { Committee } \\
\text { or Project in } \\
\text { Past } 5 \text { Years }\end{array}$ & $\begin{array}{c}\text { Your Relationship to } \\
\text { This Person }\end{array}$ \\
\hline $\begin{array}{l}\text { James R. } \\
\text { Huffines }\end{array}$ & \begin{tabular}{lr}
1 & 2 \\
3 & 4 \\
\multicolumn{2}{c}{ Don't } \\
Know or \\
Not Sure
\end{tabular} & & $\begin{array}{l}\text { Yes } \\
\text { No }\end{array}$ & $\begin{array}{l}\text { Never heard of } \\
\text { Know slightly } \\
\text { Know well } \\
\text { Personal friend or } \\
\text { relative }\end{array}$ \\
\hline Hunter L. Hunt & \begin{tabular}{lr}
1 & 2 \\
3 & 4 \\
\multicolumn{2}{c}{ Don't } \\
Know or \\
Kot Sure
\end{tabular} & & $\begin{array}{l}\text { Yes } \\
\text { No }\end{array}$ & $\begin{array}{l}\text { Never heard of } \\
\text { Know slightly } \\
\text { Know well } \\
\text { Personal friend or } \\
\text { relative }\end{array}$ \\
\hline Ray L. Hunt & \begin{tabular}{lr}
1 & 2 \\
3 & 4 \\
\multicolumn{2}{c}{ Don't } \\
Know or \\
Not Sure
\end{tabular} & & $\begin{array}{l}\text { Yes } \\
\text { No }\end{array}$ & $\begin{array}{l}\text { Never heard of } \\
\text { Know slightly } \\
\text { Know well } \\
\text { Personal friend or } \\
\text { relative }\end{array}$ \\
\hline $\begin{array}{l}\text { Kay Bailey } \\
\text { Hutchison }\end{array}$ & \begin{tabular}{lr}
1 & 2 \\
3 & 4 \\
\multicolumn{2}{c}{ Don't } \\
\multicolumn{2}{c}{ Know or } \\
\multicolumn{2}{r}{ Not Sure }
\end{tabular} & & $\begin{array}{l}\text { Yes } \\
\text { No }\end{array}$ & $\begin{array}{l}\text { Never heard of } \\
\text { Know slightly } \\
\text { Know well } \\
\text { Personal friend or } \\
\text { relative }\end{array}$ \\
\hline Lee F. Jackson & \begin{tabular}{lr}
1 & 2 \\
3 & 4 \\
\multicolumn{2}{c}{ Don't } \\
\multicolumn{2}{c}{ Know or } \\
\multicolumn{2}{r}{ Not Sure }
\end{tabular} & & $\begin{array}{l}\text { Yes } \\
\text { No }\end{array}$ & $\begin{array}{l}\text { Never heard of } \\
\text { Know slightly } \\
\text { Know well } \\
\text { Personal friend or } \\
\text { relative }\end{array}$ \\
\hline Eric Johnson & \begin{tabular}{lr}
1 & 2 \\
3 & 4 \\
\multicolumn{2}{c}{ Don't } \\
Know or \\
\multicolumn{2}{r}{ Not Sure }
\end{tabular} & & $\begin{array}{l}\text { Yes } \\
\text { No }\end{array}$ & $\begin{array}{l}\text { Never heard of } \\
\text { Know slightly } \\
\text { Know well } \\
\text { Personal friend or } \\
\text { relative }\end{array}$ \\
\hline
\end{tabular}




\begin{tabular}{|c|c|c|c|c|}
\hline \multirow[t]{2}{*}{$\begin{array}{c}\text { Name } \\
\text { (Write-In; } \\
\text { Optional) }\end{array}$} & $\begin{array}{c}\text { Rating of } \\
\text { Influence } \\
1 \text { (low) to } \\
4 \text { (high) }\end{array}$ & Reasoning for Rating & $\begin{array}{l}\text { Committee } \\
\text { or Project in } \\
\text { Past } 5 \text { Years }\end{array}$ & $\begin{array}{c}\text { Your Relationship to } \\
\text { This Person }\end{array}$ \\
\hline & \begin{tabular}{lr}
1 & 2 \\
3 & 4 \\
\multicolumn{2}{c}{ Don't } \\
Know or \\
Not Sure
\end{tabular} & & $\begin{array}{l}\text { Yes } \\
\text { No }\end{array}$ & $\begin{array}{c}\text { Never heard of } \\
\text { Know slightly } \\
\text { Know well } \\
\begin{array}{c}\text { Personal friend or } \\
\text { relative }\end{array}\end{array}$ \\
\hline & \begin{tabular}{lr}
1 & 2 \\
3 & 4 \\
\multicolumn{2}{c}{ Don't } \\
Know or \\
Not Sure
\end{tabular} & & $\begin{array}{l}\text { Yes } \\
\text { No }\end{array}$ & $\begin{array}{c}\text { Never heard of } \\
\text { Know slightly } \\
\text { Know well } \\
\begin{array}{c}\text { Personal friend or } \\
\text { relative }\end{array} \\
\end{array}$ \\
\hline & \begin{tabular}{lr}
1 & 2 \\
3 & 4 \\
\multicolumn{2}{c}{ Don't } \\
Know or \\
Not Sure
\end{tabular} & & $\begin{array}{l}\text { Yes } \\
\text { No }\end{array}$ & $\begin{array}{c}\text { Never heard of } \\
\text { Know slightly } \\
\text { Know well } \\
\begin{array}{c}\text { Personal friend or } \\
\text { relative }\end{array}\end{array}$ \\
\hline & \begin{tabular}{lr}
1 & 2 \\
3 & 4 \\
\multicolumn{2}{c}{ Don't } \\
Know or \\
\multicolumn{2}{c}{ Not Sure }
\end{tabular} & & $\begin{array}{l}\text { Yes } \\
\text { No }\end{array}$ & $\begin{array}{c}\text { Never heard of } \\
\text { Know slightly } \\
\text { Know well } \\
\begin{array}{c}\text { Personal friend or } \\
\text { relative }\end{array} \\
\end{array}$ \\
\hline & \begin{tabular}{lr}
1 & 2 \\
3 & 4 \\
\multicolumn{2}{c}{ Don't } \\
Know or \\
Not Sure
\end{tabular} & & $\begin{array}{l}\text { Yes } \\
\text { No }\end{array}$ & $\begin{array}{c}\text { Never heard of } \\
\text { Know slightly } \\
\text { Know well } \\
\begin{array}{c}\text { Personal friend or } \\
\text { relative }\end{array}\end{array}$ \\
\hline & \begin{tabular}{lr}
1 & 2 \\
3 & 4 \\
\multicolumn{2}{c}{ Don't } \\
Know or \\
Not Sure
\end{tabular} & & $\begin{array}{l}\text { Yes } \\
\text { No }\end{array}$ & $\begin{array}{c}\text { Never heard of } \\
\text { Know slightly } \\
\text { Know well } \\
\begin{array}{c}\text { Personal friend or } \\
\text { relative }\end{array} \\
\end{array}$ \\
\hline & \begin{tabular}{lr}
1 & 2 \\
3 & 4 \\
\multicolumn{2}{c}{ Don't } \\
Know or \\
Not Sure
\end{tabular} & & $\begin{array}{l}\text { Yes } \\
\text { No }\end{array}$ & $\begin{array}{c}\text { Never heard of } \\
\text { Know slightly } \\
\text { Know well } \\
\begin{array}{c}\text { Personal friend or } \\
\text { relative }\end{array}\end{array}$ \\
\hline
\end{tabular}


[THIS PAGE INTENTIONALLY LEFT BLANK] 


\section{Section 2: City-Wide Project Committee}

For this section, which begins on the next page, imagine that you are responsible for a project that will have an impact felt throughout the city, and that this project will require a decision made by a group of leaders - leaders whose opinions nearly everyone would accept. Using the lists from the previous section, as well as your own knowledge of Dallas' leaders, which ten leaders would you choose, and why?

As a reminder: all of your responses are confidential, and no direct quotations will be used without your permission.

\begin{tabular}{|c|c|c|c|c|}
\hline \multirow[t]{5}{*}{$\begin{array}{l}\text { Name } \\
\text { (Write-In) }\end{array}$} & Reasoning for Adding to Your Team & \multicolumn{2}{|c|}{$\begin{array}{c}\text { Committee or Project in } \\
\text { Past } 5 \text { Years }\end{array}$} & $\begin{array}{l}\text { Your Relationship to } \\
\text { This Person }\end{array}$ \\
\hline & & Yes & No & $\begin{array}{l}\text { Never heard of } \\
\text { Know slightly } \\
\text { Know well } \\
\text { Personal friend or } \\
\text { relative }\end{array}$ \\
\hline & & Yes & No & $\begin{array}{l}\text { Never heard of } \\
\text { Know slightly } \\
\text { Know well } \\
\text { Personal friend or } \\
\text { relative }\end{array}$ \\
\hline & & Yes & No & $\begin{array}{l}\text { Never heard of } \\
\text { Know slightly } \\
\text { Know well } \\
\text { Personal friend or } \\
\text { relative }\end{array}$ \\
\hline & & Yes & No & $\begin{array}{l}\text { Never heard of } \\
\text { Know slightly } \\
\text { Know well } \\
\text { Personal friend or } \\
\text { relative }\end{array}$ \\
\hline
\end{tabular}




\begin{tabular}{|c|c|c|c|c|}
\hline \multirow[t]{7}{*}{$\begin{array}{c}\text { Name } \\
\text { (Write-In) }\end{array}$} & \multirow[t]{2}{*}{ Reasoning for Adding to Your Team } & \multicolumn{2}{|c|}{$\begin{array}{c}\text { Committee or Project in } \\
\text { Past } 5 \text { Years }\end{array}$} & $\begin{array}{l}\text { Your Relationship to } \\
\text { This Person }\end{array}$ \\
\hline & & Yes & No & $\begin{array}{l}\text { Never heard of } \\
\text { Know slightly } \\
\text { Know well } \\
\text { Personal friend or } \\
\text { relative }\end{array}$ \\
\hline & & Yes & No & $\begin{array}{l}\text { Never heard of } \\
\text { Know slightly } \\
\text { Know well } \\
\text { Personal friend or } \\
\text { relative }\end{array}$ \\
\hline & & Yes & No & $\begin{array}{l}\text { Never heard of } \\
\text { Know slightly } \\
\text { Know well } \\
\text { Personal friend or } \\
\text { relative }\end{array}$ \\
\hline & & Yes & No & $\begin{array}{l}\text { Never heard of } \\
\text { Know slightly } \\
\text { Know well } \\
\text { Personal friend or } \\
\text { relative }\end{array}$ \\
\hline & & Yes & No & $\begin{array}{l}\text { Never heard of } \\
\text { Know slightly } \\
\text { Know well } \\
\text { Personal friend or } \\
\text { relative }\end{array}$ \\
\hline & & Yes & No & $\begin{array}{l}\text { Never heard of } \\
\text { Know slightly } \\
\text { Know well } \\
\text { Personal friend or } \\
\text { relative }\end{array}$ \\
\hline
\end{tabular}




\section{Section 3: Development in Downtown Dallas}

In recent years, there has been a tremendous revitalization effort within downtown Dallas, with construction of new properties, as well as revitalization of existing ones. For this section, which begins on the next page, imagine that you are responsible for a new project in downtown Dallas, which (like in the previous section) will require a decision to be made by a group of leaders, whose opinions nearly everyone would accept. Using the lists from the previous section, as well as your own knowledge of neighborhood leaders, which ten leaders would you choose to help with this project, and why?

As a reminder: all of your responses are confidential, and no direct quotations will be used without your permission. 


\begin{tabular}{|c|c|c|c|c|}
\hline \multirow[t]{2}{*}{$\begin{array}{c}\text { Name } \\
\text { (Write-In) }\end{array}$} & \multirow[t]{2}{*}{ Reasoning for Adding to Your Team } & \multicolumn{2}{|c|}{$\begin{array}{c}\text { Committee or Project in } \\
\text { Past } 5 \text { Years }\end{array}$} & $\begin{array}{c}\text { Your Relationship to } \\
\text { This Person }\end{array}$ \\
\hline & & Yes & No & $\begin{array}{l}\text { Never heard of } \\
\text { Know slightly } \\
\text { Know well } \\
\text { Personal friend or } \\
\text { relative }\end{array}$ \\
\hline & & Yes & No & $\begin{array}{l}\text { Never heard of } \\
\text { Know slightly } \\
\text { Know well } \\
\text { Personal friend or } \\
\text { relative }\end{array}$ \\
\hline & & Yes & No & $\begin{array}{l}\text { Never heard of } \\
\text { Know slightly } \\
\text { Know well } \\
\text { Personal friend or } \\
\text { relative }\end{array}$ \\
\hline & & Yes & No & $\begin{array}{l}\text { Never heard of } \\
\text { Know slightly } \\
\text { Know well } \\
\text { Personal friend or } \\
\text { relative }\end{array}$ \\
\hline & & Yes & No & $\begin{array}{l}\text { Never heard of } \\
\text { Know slightly } \\
\text { Know well } \\
\text { Personal friend or } \\
\text { relative }\end{array}$ \\
\hline & & Yes & No & $\begin{array}{l}\text { Never heard of } \\
\text { Know slightly } \\
\text { Know well } \\
\text { Personal friend or } \\
\text { relative }\end{array}$ \\
\hline & & Yes & No & $\begin{array}{l}\text { Never heard of } \\
\text { Know slightly } \\
\text { Know well } \\
\text { Personal friend or } \\
\text { relative }\end{array}$ \\
\hline
\end{tabular}




\begin{tabular}{|c|c|c|c|c|}
\hline $\begin{array}{c}\text { Name } \\
\text { (Write-In) }\end{array}$ & Reasoning for Adding to Your Team & $\begin{array}{c}\text { Committee or Project in } \\
\text { Past 5 Years }\end{array}$ & $\begin{array}{c}\text { Your Relationship to } \\
\text { This Person }\end{array}$ \\
\hline & & & No & $\begin{array}{c}\text { Never heard of } \\
\text { Know slightly } \\
\text { Know well } \\
\text { Personal friend or } \\
\text { relative }\end{array}$ \\
\hline & & Yes & No & $\begin{array}{c}\text { Never heard of } \\
\text { Know slightly } \\
\text { Know well } \\
\text { Personal friend or } \\
\text { relative }\end{array}$ \\
& & & Yes & Never heard of \\
& & & & Know slightly \\
& & & Know well \\
& & & & Personal friend or \\
& & & & relative \\
\hline
\end{tabular}




\section{Section 4: Development in North Oak Cliff}

In recent years, there has been significant interest in the redevelopment of North Oak Cliff, with many organizations and leaders involved in a number of projects throughout the neighborhood. For this section, which begins on the next page, imagine that you are responsible for a project in North Oak Cliff. Similar to the previous sections, this project will require a decision made by a group of leaders - leaders whose opinions nearly everyone would accept. Using the lists from the first section, as well as your own knowledge of neighborhood leaders, which ten leaders would you choose, and why?

As a reminder: all of your responses are confidential, and no direct quotations will be used without your permission.

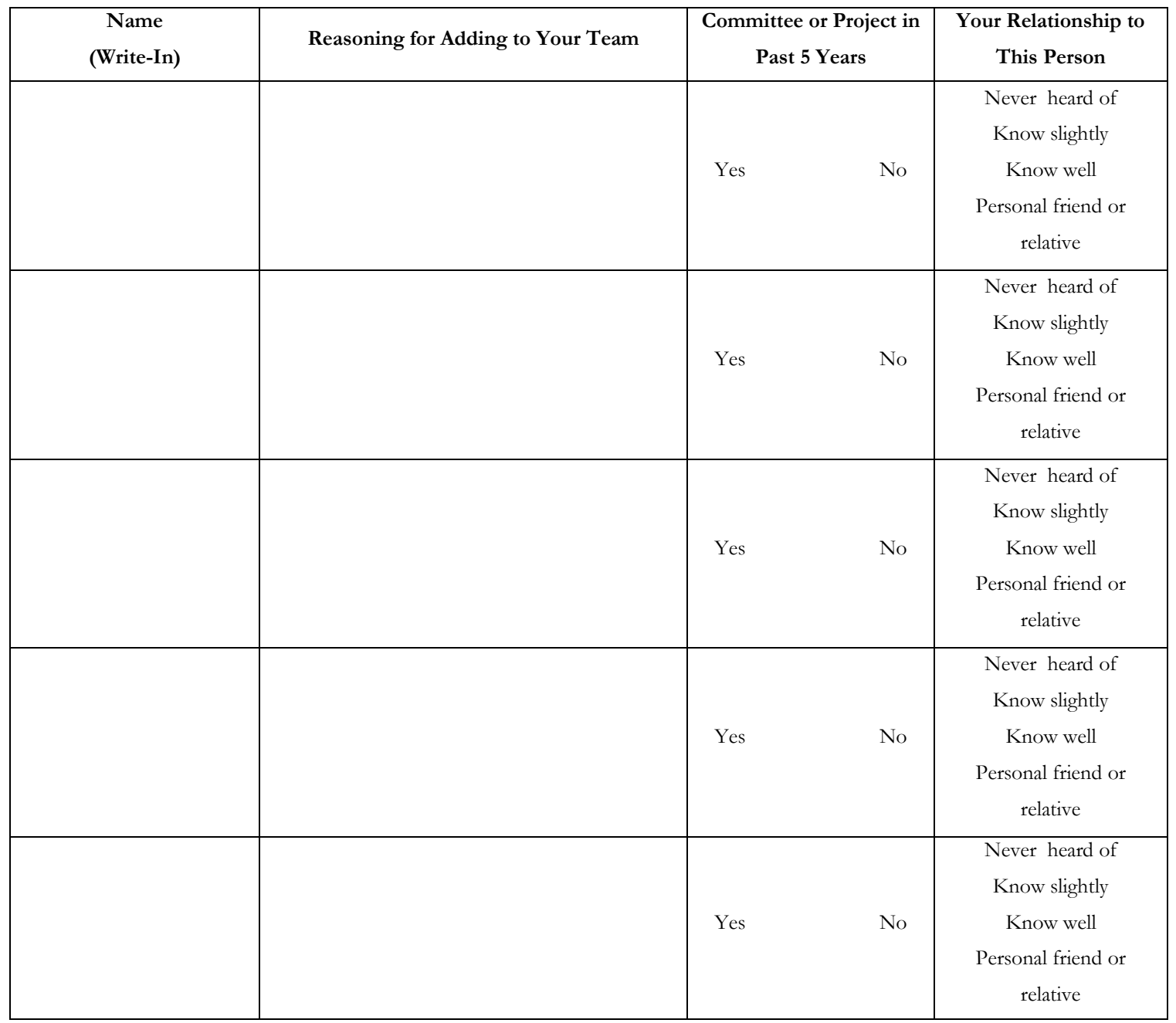




\begin{tabular}{|c|c|c|c|c|}
\hline \multirow[t]{2}{*}{$\begin{array}{l}\text { Name } \\
\text { (Write-In) }\end{array}$} & \multirow[t]{2}{*}{ Reasoning for Adding to Your Team } & \multicolumn{2}{|c|}{$\begin{array}{c}\text { Committee or Project in } \\
\text { Past } 5 \text { Years }\end{array}$} & $\begin{array}{l}\text { Your Relationship to } \\
\text { This Person }\end{array}$ \\
\hline & & Yes & No & $\begin{array}{l}\text { Never heard of } \\
\text { Know slightly } \\
\text { Know well } \\
\text { Personal friend or } \\
\text { relative }\end{array}$ \\
\hline & & Yes & No & $\begin{array}{l}\text { Never heard of } \\
\text { Know slightly } \\
\text { Know well } \\
\text { Personal friend or } \\
\text { relative }\end{array}$ \\
\hline & & Yes & No & $\begin{array}{l}\text { Never heard of } \\
\text { Know slightly } \\
\text { Know well } \\
\text { Personal friend or } \\
\text { relative }\end{array}$ \\
\hline & & Yes & No & $\begin{array}{l}\text { Never heard of } \\
\text { Know slightly } \\
\text { Know well } \\
\text { Personal friend or } \\
\text { relative }\end{array}$ \\
\hline & & Yes & No & $\begin{array}{l}\text { Never heard of } \\
\text { Know slightly } \\
\text { Know well } \\
\text { Personal friend or } \\
\text { relative }\end{array}$ \\
\hline
\end{tabular}




\section{Section 5: Free Response on Leadership in Dallas}

In this final section, please record any concluding thoughts on the nature of decisionmaking in Dallas, such as your thoughts on how decisions are made, who makes them, or the types of people who get most heavily involved in Dallas' decision-making body, either for the city as a whole, or for projects in particular neighborhoods. Please also list any other names of people who might be willing to provide additional information that may be helpful for this study.

As a reminder: all of your responses are confidential, and no direct quotations will be used without your permission. 


\section{Appendix 9}

1. What can you tell me about projects and development in Dallas; specifically - who gets involved?

2. Thinking about how development can differ based on the area, how does development in South Dallas and Oak Cliff - like what's going on with the Bishop Arts District and Oak Cliff Gateway - differ from projects in Downtown, like Downtown Dallas 360?

3. You mentioned that $<$ Organization(s) or Person(s) $>$ was involved in $<$ Development Plan $>$ - could you tell me more about that?

4. Could you tell me a bit about how you are involved, or where you stand on some of these developments? 


\section{CURRICULUM VITA}

\section{Benjamin C. Leamon}

Urban \& Public Affairs, The University of Louisville, Louisville KY 40292 | (502) 554-6126 | benjamin.leamon@louisville.edu

\section{Education}

Doctor of Philosophy, Urban \& Public Affairs - The University of Louisville,

Louisville KY

Dissertation Title: Urban governance reconsidered: Assessing the roles of publicprivate- and third-sector leaders in governing the modern city. Anticipated graduation: May 2017

Master of Science, Social Work - The University of Louisville, Louisville KY

Bachelor of Science, Psychology — The University of Texas at Dallas, Richardson

$2005-2010$

TX

\section{Courses Taught}

Urban Political Economy — The University of Louisville

This introductory course enables and encourages students to interrogate the nature of contemporary urban governance, examining urban problems, solutions, and their implications from a variety of perspectives. Students collaborate in diverse teams to understand what it means to govern a city in a time of tremendous global changes.

\section{University Service}

Director of Finance — University of Louisville Student Activities Board, Louisville KY

Chief financial officer, project manager, and administrative coordinator of a seven-committee board comprised of students, faculty, staff, and community members dedicated to student enrichment and programming at a campus of over 22,500 students. Primarily responsible for monthly financial auditing and reporting, management of an approximately $\$ 500,000$ annual operating- and payroll budget, purchasing and vendor relations, contract management in conjunction with university legal- and financial staff, and post-event evaluation. Also responsible for collaborating with marketing director and university marketing team to develop-and implement multi-channel marketing campaigns for student events. 
Data analyst and assistant for sustainability initiatives, responsible for collaborating with community partners, university faculty and staff, and public-sector leaders on various projects to reduce the University of Louisville's carbon footprint and encourage behavior change among students, faculty, and staff. Also worked with students, faculty, and staff to develop innovating programming and leadership opportunities for students and sustainability initiatives.

Appropriations Chair — University of Louisville Student Government Association, Louisville KY

Committee director responsible for drafting- and managing the $\$ 1.195$ million operating budget for the university's SGA. Chief activities include managing a team of student leaders in the evaluation of funding requests for student programming, student organizations, and student travel for both undergraduate and graduate students, ensuring best practices with respect to financial record-keeping on behalf of student leaders for 12 colleges and schools, with budgets ranging from $\$ 1,000$ to approximately $\$ 45,000$, and assisting university staff with training on university financial accountability practices and policies.

Director of Green Initiatives — University of Louisville Engage Lead Serve Board, Louisville KY

Project manager for sustainability-related student programming and service opportunities. Primarily responsible for monthly financial audits, management of a $\$ 15,000$ project budget, stakeholder surveys, supervising student- and community-member volunteers on project sites, and regular project evaluations. Also assisted senior leadership to update and streamline governing documents, policies, and board procedures.

Liaison to Student Activities Board - University of Louisville Student Government Association, Louisville KY

Chief liaison between student programming leaders and student government leaders, responsible for facilitating open communication among these stakeholders, and partnering with university staff to ensure that that programming volunteers operated within SGA guidelines and university policies and procedures, assisting students with event programming and volunteer coordination, and assisted programming staff with streamlining and updating policies and procedures.

\section{Recent Publications \& Presentations}

Governing Dallas: the nature of governance in the post-industrial commercial republic An analysis of the economic- and demographic changes in Dallas, Texas since the 1980s, including an assessment of the city's formal- and informal governance structures, based on interviews with 80 of the city's public-, private-, and third-sector leaders, as well as community leadership structures based on interviews with community leaders in North Oak Cliff and Downtown Dallas. (UAA National Conference, 2016)

Weaving sustainability into curricula across disciplines: Challenges and successes from the Green Threads faculty workshop

An evaluation of the effectiveness of a multi-year, multidisciplinary faculty workshop, designed to integrate tenets of sustainability into course design throughout the university. (AASHE National Conference, 2015) 
The medicine doesn't heal: Differential effects of economic revitalization on social equity within low-income communities

A study of the connections between social equity and economic revitalization in low-income majority-white and low-income majority-nonwhite neighborhoods in Louisville, KY, using publiclyavailable quantitative indices. (UAA National Conference, 2015).

\section{Community Service}

Dallas GrowSouth AmeriCorps VISTA — Office of Mayor Michael S. Rawlings, Dallas, TX 2016 - Present Facilitated development of neighborhood goals and objectives, and completion of grant-funded community improvement projects using public-, private-, and third-sector resources. Engaged university students in neighborhood-identified community service projects throughout southern Dallas, and developed these "one-off" projects into a recurring service day, coupled with ongoing lines of communication between University of North Texas at Dallas staff and local community leaders, so that student volunteers can be connected with community projects. Developed a research agenda and implementation strategy for Community Court Advisory Boards with all Dallas Community Courts. Partnered with City Staff, community leaders, student leaders, and area stakeholders to develop- and pilot community-driven solutions to the notable problem of stray animals in southern Dallas.

Data Analyst Intern, Community Impact - Metro United Way, Louisville KY

Assisted with constructing needs assessments for communities of people with low incomes, and partnered with marketing team to develop "neighborhood snapshot" reports for partner organizations and public access. Assisted with financial audits and organizational vitality studies of partner organizations as part of a comprehensive funding restructure. Completed a comprehensive analysis of public elementary- middle- and high school feeder patterns to maximize the effectiveness of out-of-school time (OST) programs to support federal grant applications in partnership with city officials.

\section{Awards \& Certificates}

Collaboration of the Year, The University of Louisville Office of Student Involvement 